\title{
Écriture et transmission des savoirs de l'Antiquité à nos jours
}

Dominique Briquel (dir.)

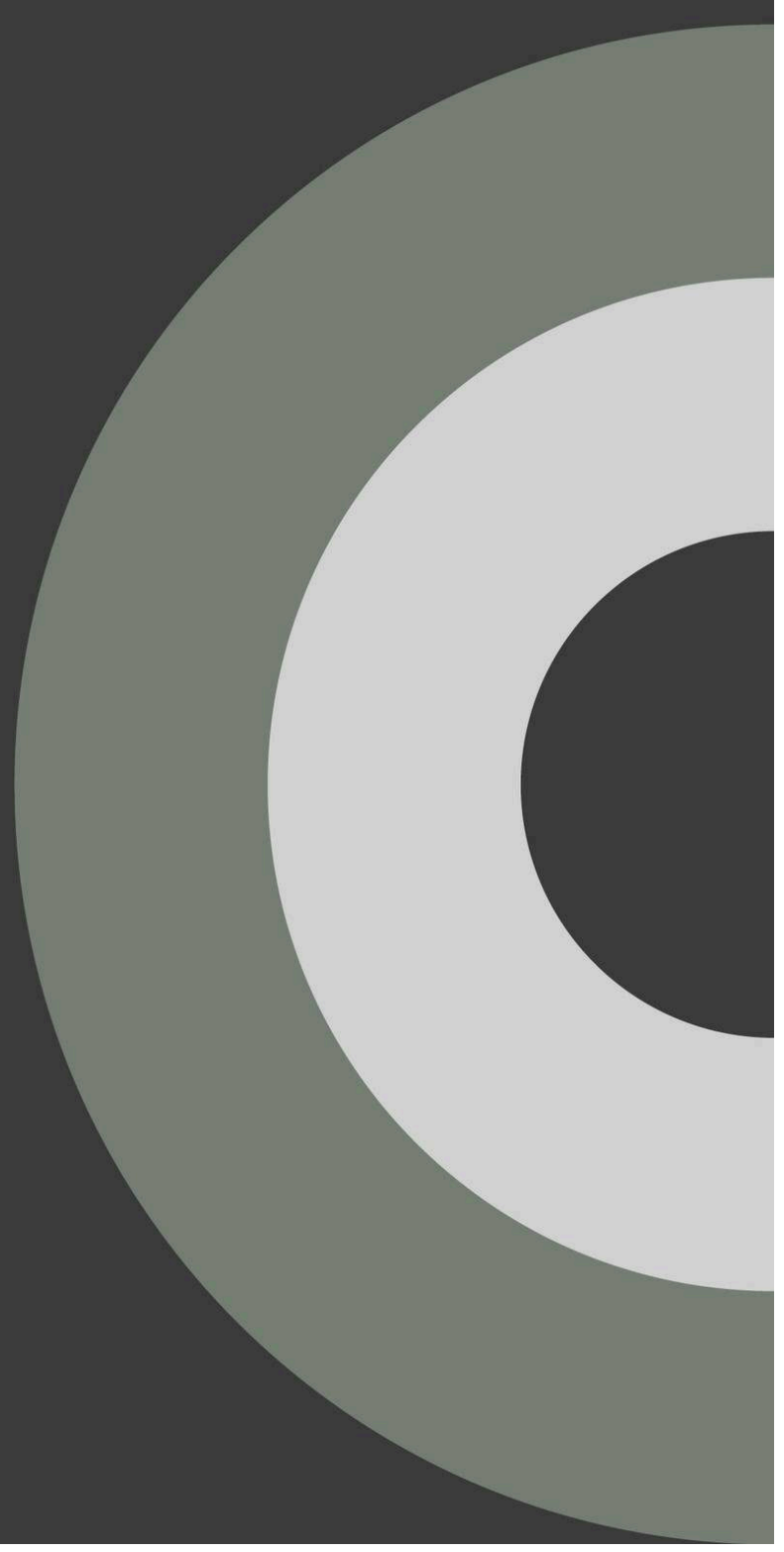




\section{Écriture et transmission des savoirs de l'Antiquité à nos jours}

Dominique Briquel (dir.)

DOI : $10.4000 /$ books.cths. 8121

Éditeur : Éditions du Comité des travaux historiques et scientifiques Année d'édition : 2020

Date de mise en ligne : 21 janvier 2020

Collection : Actes des congrès nationaux des sociétés historiques et scientifiques

ISBN électronique : 9782735508969

\section{QboOoks}

http://books.openedition.org

\section{Référence électronique}

BRIQUEL, Dominique (dir.). Écriture et transmission des savoirs de l'Antiquité à nos jours. Nouvelle édition [en ligne]. Paris : Éditions du Comité des travaux historiques et scientifiques, 2020 (généré le 21 décembre 2020). Disponible sur Internet : <http://books.openedition.org/cths/8121>. ISBN : 9782735508969. DOI : https://doi.org/10.4000/books.cths.8121.

Ce document a été généré automatiquement le 21 décembre 2020.

(C) Éditions du Comité des travaux historiques et scientifiques, 2020 Conditions d'utilisation :

http://www.openedition.org/6540 
Pendant longtemps, la transmission des savoirs s'est faite directement, du maître à l'élève, de l'artisan à l'apprenti, par un enseignement oral que venait compléter la démonstration des gestes de la pratique. L'apparition de l'écriture, et plus encore la diffusion de la literacy ont fait que des méthodes de transmission indirectes ont pu se faire jour et que l'acquisition d'un savoir, quel qu'il soit, a pu se faire sans contact immédiat avec le détenteur de ce savoir, mais par le truchement d'un livre ou d'une autre forme d'écrit. Il s'est ensuivi une capacité de diffusion des savoirs quasiment illimitée, des plus techniques et spécialisés aux plus abstraits et généralistes. C'est cette explosion de la transmission des savoirs que les vingt auteurs des contributions ici réunies ont cherché à explorer en mettant en lumière différentes facettes, à travers une série d'exemples, allant de l'Antiquité à l'époque contemporaine.

Le Congrès national des sociétés historiques et scientifiques rassemble chaque année universitaires, membres de sociétés savantes et jeunes chercheurs. Ce recueil est issu de travaux présentés lors $\mathrm{du} 143^{\mathrm{e}}$ Congrès sur le thème « La transmission des savoirs ».

\section{DOMINIQUE BRIQUEL}

Membre émérite du CTHS, professeur émérite de latin à l'université Paris IV - ParisSorbonne, directeur d'études émérite à l'École pratique des hautes études (EPHE) 
SOMMAIRE

Introduction

Du texte à la carte et de la carte au texte : un rapport réciproque dans la transmission du savoir géographique à la fin de l'Antiquité

Delphine Acolat

Voir ce que l'on entend ou décrire ce que l'on voit : sphaera, pinax, orbis depictus : l'attestation de l'usage de la carte dans la pédagogie antique

Le dessin cartographique comme prolongement et éclairage indispensable du texte, inséré dans le manuscrit

Transmission, réappropriation et réutilisation d'un savoir « antique » à l'époque médiévale (XII $-X V^{e}$ siècles) : le cas des Variæ de Cassiodore

Nicolas Michel

Poésie et enseignement de la courtoisie dans le duché d'Aquitaine aux XII et XIII siècles :

examen de quatre ensenhamens

Sébastien-Abel Laurent

Les cours d'Aquitaine à la fin du XII ${ }^{\mathrm{e}}$ siècle

La courtoisie constituée comme savoir

Les manières de transmettre la courtoisie

La transmission de l'histoire antique et sa mise en images dans les États latins d'Orient : les manuscrits de l'Histoire Ancienne jusqu'à César, Saint Jean d'Acre (1260-1291)

Émilie Maraszak

La production de manuscrits enluminés dans les États latins d'Orient

Le récit de l'Histoire Ancienne jusqu'à César et sa copie en Terre sainte

La transformation des images de l'histoire antique en Terre sainte

Les héros antiques célébrés par les images levantines

La «transmission du savoir » d'Athènes à Paris : variations autour d'un topos dans trois chroniques médiévales françaises

Judith Förstel

Du « puits de philosophie » athénien à la « fontaine de savoir » parisienne : la translatio studii comme introduction à l'histoire du royaume dans les Grandes chroniques de France

L'intervention de saint Denis et l'emblème de la fleur de lis chez Guillaume de Nangis

Une traduction française adaptée aux circonstances politiques

Le « savoir-être " noble : étude sur les facteurs et les modalités de transmission d'un savoir valorisé de part et d'autre des Alpes au Moyen Âge

Florentin Briffaz

L'horizon nobiliaire : pour un panorama des noblesses savoyardes

Des écrits vecteurs d'un savoir-être noble

Réalités ou chimères au miroir du train de vie : le « savoir-vivre » noble, autre versant du « savoir-

être » noble

Les Enseignements d'Anne de France à sa fille Suzanne de Bourbon : questions et mises en perspective

Marie-Geneviève Grossel

Mise en perspective : specula et enseignements

Définir le propos et son écriture

De la Fleur de lis en medecine à la Fleur de cyrurgie : une stratégie éditoriale?

Adeline Sanchez

Un large corpus aux variables de transmission importantes

Infléchissement des ambitions du discours médical au service des chirurgiens 
La dynastie des Saugrain: huit générations au service du livre et d'un art Arnaud Berthonnet

Jean Saugrain (v. 1518-1586), le libraire réformé

Sept générations de libraires-imprimeurs parisiens

Les enfants d'Antoine-Claude Saugrain, $7^{\mathrm{e}}$ génération, et de Marie Brunet : des destins exceptionnels

Les maîtres écrivains : acteurs méconnus de la transmission des savoirs Célia Cabane

La corporation des maîtres écrivains : des praticiens entre deux monopoles

Manuels et méthodes d'écriture

Quelles sources pour faire l'histoire des maîtres écrivains?

Être maître écrivain, est-ce être enseignant ou artisan?

Les livres d'ingénieurs au XVIII siècle : le cas emblématique de Bélidor

Bernard Delaunay

Un anachronisme assumé

Un personnage emblématique : Bélidor

Quels livres? quelle nouveauté?

Pour conclure

Le projet épigraphique de Jean-François Séguier : fondements, réalisation, portée (1703-1784)

Michel Christol

Un savoir régional : le Dictionnaire de la Provence du docteur Claude-François Achard (1785-1788)

Régis Bertrand

Un médecin aux curiosités encyclopédiques

Les quatre premiers volumes

Les volumes biographiques

La Description de la Provence (ou Géographie)

Postérité du Dictionnaire de la Provence

Du Magasin pittoresque à la Bibliothèque des Merveilles : les défis encyclopédiques d'Édouard Charton

Annie Lagarde-Fouquet

Rappels biographiques

Le rêve encyclopédique au service du plus grand nombre

Le Magasin pittoresque

La Bibliothèque des Merveilles

Littérature de jeunesse et métier des armes : la formation de l'esprit militaire chez

Alexandre de Saillet, maitre de pension et pédagogue (1812-1866)

Louis Bergès

Un homme de tradition militaire marginal

Une œuvre pédagogique originale

Une vision ouverte à la modernité

Les missionnaires traducteurs et la transmission des savoirs occidentaux en Chine au XIX siècle : étude du cas de Timothy Richard

Yi Zhang

Une étude de cas : Timothy Richard

Traduire l'histoire du monde

Les «chroniques » dans les revues archéologiques : exploration d'un espace de diffusion des savoirs de 1873 à 1914

Sandra Péré-Noguès

Le corpus étudié

La fabrication d'une rubrique nouvelle

Une forme originale

La circulation des informations 
Savoir-vivre et savoir être dans les romans de T. Trilby : éléments d'une stratégie éducative Mathilde Hallot-Charmasson

Les formes traditionnelles de la littérature éducative pour modèles

La littérature, élément d'une éducation morale

La transmission des savoir vivre et savoir être de la bourgeoisie catholique conservatrice

Lire et relire Trilby

Les Instructions $d u$ CTHS pour la Recherche des antiquités dans le nord de l'Afrique (1890) et l'histoire de l'archéologie du Maghreb

Roger Hanoune

Une réalisation du CTHS

Les auteurs et leurs textes

Une tradition de littérature pratique

L'intérêt des Instructions

La presse écrite généraliste contemporaine française : vecteur de transmission de savoirs nouveaux et pas encore fixés?

Annick Batard

Des innovations techniques auxquelles la presse fait un large écho

Le vocabulaire et la langue

De nouvelles pratiques et leurs termes entrés dans les usages 
NOTE DE L'ÉDITEUR

Les articles de cet ouvrage ont été validés par le comité de lecture des Éditions du Comité des travaux historiques et scientifiques dans le cadre de la publication des actes du $143^{e}$ Congrès national des sociétés historiques et scientifiques tenu à Paris en 2018. 


\title{
Introduction
}

\author{
Dominique Briquel
}

1 Pendant longtemps, la transmission des savoirs s'est faite directement, du maître à l'élève, de l'artisan à l'apprenti, par un enseignement oral que venait compléter la démonstration des gestes de la pratique. L'apparition de l'écriture, et plus encore la diffusion de la literacy, ont fait que des méthodes de transmission indirectes ont pu se faire jour et que l'acquisition d'un savoir, quel qu'il soit, a pu se faire sans contact immédiat avec le détenteur de ce savoir, mais par le truchement d'un livre ou d'une autre forme d'écrit. Il s'est ensuivi une capacité de diffusion des savoirs quasiment illimitée, des plus techniques et spécialisés aux plus abstraits et généralistes. C'est cette explosion de la transmission des savoirs que les vingt auteurs des communications ici réunies ont cherché à explorer en mettant en lumière différentes facettes, à travers une série d'exemples, allant de l'Antiquité à l'époque contemporaine. Bien sûr, les conditions matérielles de la réalisation des vecteurs de la transmission ont changé au cours de cette longue suite de siècles: l'humanité est passée de l'âge des manuscrits (évoqué pour la transmission des lettres de Cassiodore par N. Michel), à celui de l'imprimerie (étudié par A. Berthonnet pour les huit générations d'éditeurs lyonnais puis parisiens que furent les Saugrain, qui mirent en œuvre l'invention de Gutenberg, depuis sa naissance à l'époque de la Réforme et des controverses religieuses dont elle fut un instrument privilégié jusqu'à la transformation des processus de fabrication et de diffusion au XIX ${ }^{\mathrm{e}}$ siècle qui marqua la fin de la longue tradition familiale), avant que, tout récemment, de nouveaux modes de diffusion fussent permis par l'émergence de l'informatique (question abordée par A. Batard, qui souligne l'enthousiasme qu'ils suscitèrent dans la presse française des années 1990, de Libération au Figaro). En même temps, plusieurs auteurs soulignent à juste titre le fait que l'écrit ne se suffit pas vraiment à lui-même et doit fréquemment être accompagné d'images qui le rendent compréhensible ou au moins en facilitent ou agrémentent l'usage (ainsi D. Acolat pour les traités de géographie des auteurs antiques, É. Maraszak pour les illustrations de manuscrits de Saint-Jean d'Acre sur l'histoire de l'Antiquité). C'est d'ailleurs un des caractères du volume que d'être accompagné d'une riche iconographie, qui montre excellemment cette combinaison entre texte et image que permet la diffusion par l'écrit, et que facilitent encore les procédés informatiques. 
2 Le volume traite de la longue durée, puisque si les deux premières contributions traitent d'auteurs antiques, ou au moins relevant encore - avec Cassiodore - de ce qu'on peut considérer comme l'Antiquité tardive, les quatre suivantes traitent de la période proprement médiévale, $\mathrm{du} \mathrm{XII}^{\mathrm{e}}$ au $\mathrm{Xv}^{\mathrm{e}}$ siècle, puis deux abordent des ouvrages de la Renaissance, cinq des $\mathrm{XVII}^{\mathrm{e}}$-XVIII ${ }^{\mathrm{e}}$ siècles, les sept dernières abordant des réalisations plus proches de notre temps, depuis la première moitié du xix siècle jusqu'au tournant des $\mathrm{xx}^{\mathrm{e}}$ et $\mathrm{xxI}^{\mathrm{e}}$ siècles. Mais un tel classement chronologique donnerait une fausse idée de la problématique, puisqu'un des privilèges de la transmission écrite est de transcender les époques; aussi un aspect remarquable du volume est qu'une série d'études s'attache à la manière dont des connaissances remontant à l'Antiquité ont été transmises à des périodes plus tardives - permanence de l'œuvre de Cassiodore, qui vivait au $\mathrm{VI}^{\mathrm{e}}$ siècle, aux XII $-\mathrm{XV}^{\mathrm{e}}$ siècles (N. Michel), de l'histoire ancienne, depuis Alexandre, à travers l'Histoire ancienne jusqu'à César, dans les États croisés (É. Maraszak), la redécouverte des inscriptions antiques et les premiers essais de leur collation systématique au $\mathrm{XVIII}^{\mathrm{e}}$ siècle, avec le Nîmois J.-F. Séguier (M. Christol), l'information sous forme de chroniques des découvertes dans la littérature scientifique dans la période 1873-1914 (S. Péré-Noguès) et, question abordée par R. Hanoune, l'organisation de la diffusion, y compris par des non spécialistes, de la documentation nouvelle à laquelle donna lieu la conquête de l'Algérie puis le protectorat sur la Tunisie, qui fut une des grandes tâches du CTHS dès sa création en 1834 (concrétisée par la rédaction, due à R. Cagnat, des Instructions pour la recherche des antiquités du nord de l'Afrique, publiées en 1890). Cet intérêt pour l'Antiquité peut au reste aller de pair avec une orgueilleuse conscience du progrès accompli depuis par l'humanité : on le voit avec la contribution de J. Förstel sur ce topos de la littérature du Moyen Âge que Paris avait désormais remplacé Athènes comme centre de la culture et des arts.

3 Les savoirs transmis par l'écrit peuvent être très spécialisés. B. Delaunay étudie ainsi le cas de Bélidor, ingénieur du XVIII ${ }^{e}$ siècle qui rédigea des ouvrages tels que La Science des ingénieurs, Le Bombardier français, L'Architecture hydraulique. Ils peuvent aussi être le fait de groupes spécifiques, qui affichent ainsi leur maitrise de savoirs particuliers, éventuellement en concurrence avec d'autres. C'est le cas des chirurgiens (voire chirurgiens-barbiers) auxquels est consacrée la contribution de A. Sanchez qui, au XVI ${ }^{\mathrm{e}}$ siècle, diffusent les principes de leur art, réputé inférieur à celui des médecins, dans des ouvrages en français au lieu du latin auquel avaient recours les médecins proprement dits. C'est le cas également des maittres-écrivains, étudiés par C. Cabane, corporation peu connue du Paris des $\mathrm{XVII}^{\mathrm{e}}$-XVIII ${ }^{\mathrm{e}}$ siècles, coincée entre un rôle technique de spécialistes de la calligraphie et des fonctions d'enseignants qui empiétaient sur celle des maîtres des petites écoles laïcs ou des religieux qui avaient des charges d'éducation. Dans un autre genre, l'écrit vise parfois à conforter l'identité d'un groupe beaucoup plus large, notamment sur une base régionale : c'est le sens du Dictionnaire de la Provence rédigé par le docteur C.-F. Achard entre 1785 et 1788, étudié par R. Bertrand, qui se voulait une somme des savoirs sur la région, aussi bien d'un point de vue historique, géographique que pour ce qui est de la langue (avec le premier dictionnaire du provençal).

4 Mais la formation à laquelle vise la transmission écrite des savoirs peut aller jusqu'à l'ambition de réformer la société en l'ouvrant sur de nouvelles connaissances. L'article de Y. Zhang traite d'une ambition de ce genre dans le cas particulier de la Chine du XIX ${ }^{\mathrm{e}}$ 
siècle, confrontée à ce qui était ressenti comme un retard désastreux par rapport à l'Occident: un missionnaire baptiste écossais, Timothy Richard, entreprit alors une vaste œuvre de traduction en chinois d'ouvrages anglais afin de favoriser l'émergence d'une classe de lettrés ouverte aux idées occidentales. Dans la France de ce même XIX ${ }^{\mathrm{e}}$ siècle, comme le rappelle A. Lagarde-Fouquet, l'ancien saint-simonien Édouard Charton (1807-1890) cherchait à diffuser auprès des masses, sous une forme agréable, un savoir encyclopédique à travers les séries successives des petits ouvrages du Magasin pittoresque et de la Bibliothèque des merveilles : parmi les plus de quatre cents auteurs auxquels il fit appel et qui contribuèrent à l'entreprise, on trouve des noms aussi illustres, dans des genres différents, que George Sand, le naturaliste Geoffroy-Saint Hilaire ou l'archéologue et directeur de l'École des Chartes Jules Quicherat.

5 À une époque antérieure et dans une perspective tout autre, l'écrit peut viser à renforcer la cohésion et conforter la position sociale d'un groupe restreint en lui inculquant ses valeurs. Ce fut le cas pour la noblesse du Moyen Âge et du début de la Renaissance, à travers les cas, étudiés respectivement par S.-A. Laurent, F. Briffaz et M.G. Grossel, de la poésie dite d'enseignement (les ensenhamens) dans le duché d'Aquitaine aux XII ${ }^{\mathrm{e}}$-XIII ${ }^{\mathrm{e}}$ siècles, de l'affirmation, en particulier à travers des aménagements prévus pour leur demeure, pour l'aristocratie savoyarde de l'époque médiévale et des instructions données par Anne de France à sa fille Suzanne de Bourbon, dans un ouvrage qu'elle lui offrit comme étrennes en 1504-1505. Dans tous ces écrits, c'est la conscience d'appartenir à une élite qui est mise en avant, ce qui ne va pas au reste sans le rappel qu'il lui faut respecter les devoirs qui sont les siens, avec le sens de l'honneur qui doit la caractériser.

6 Les Enseignements d'Anne de France avaient été composés pour une jeune fille. Ils sont représentatifs d'une littérature destinée à la jeunesse, à finalité formatrice. Ce genre d'ouvrages a existé à toutes les époques et a souvent pris la forme de récits attrayants, loin de toute pesanteur didactique. Deux exemples, des $\mathrm{XIX}^{\mathrm{e}}$ et $\mathrm{xx}^{\mathrm{e}}$ siècles, font l'objet d'études dans cet ouvrage : celui, traité par L. Bergès, d'Alexandre de Saillet (1812-1866) dont les productions, dans des genres divers (portraits d'enfants, présentations de loisirs utiles, contes, romans historiques), ont pour but de conforter les saines valeurs chez leurs jeunes lecteurs et notamment préparer les adolescents au métier des armes, et celui, qui fait l'objet de la communication de $\mathrm{M}$. Hallot-Chamasson, de Marie-Thérèse de Marnyphac (1875-1962), alias « T. Trilby ", qui signa une abondante série de romans pour la jeunesse, répondant à une stratégie éducative visant à promouvoir non tant les connaissances que les règles d'un comportement répondant aux principes catholiques (ce qui ne va pas d'ailleurs sans une mise en avant, à laquelle on ne se serait sans doute pas attendu, de figures de femmes fortes et actives).

7 La question des vecteurs de la transmission écrite des savoirs est immense. Il est bien évident que les vingt contributions réunies dans ce volume ne pouvaient que l'effleurer. À tout le moins donnent-elles une bonne idée de sa richesse et de sa diversité, dans un panorama qui nous mène de l'Antiquité à l'époque actuelle, des manuscrits copiés par les scribes dans les monastères du Moyen Âge aux ordinateurs qui garnissent aujourd'hui nos bureaux, de spécialistes s'adressant à un public limité et très «pointu » à des vulgarisateurs ou des romanciers visant une large audience, 
d'auteurs sans prétention littéraire à des poètes conscients de la valeur de leur art comme ceux qui chantèrent la fin'amor. On ne peut qu'être reconnaissant à ceux qui ont présenté ces communications lors du Congrès des Sociétés Savantes de Paris en 2018 de nous avoir fait entrevoir l'étendue de cet immense continent sur lequel il reste tant à explorer.

\section{AUTEUR}

\section{DOMINIQUE BRIQUEL}

Membre émérite du CTHS, professeur émérite de latin à l'université Paris IV - Paris-Sorbonne, directeur d'études émérite à l'École pratique des hautes études (EPHE) 


\title{
Du texte à la carte et de la carte au
} texte : un rapport réciproque dans la transmission du savoir géographique à la fin de l'Antiquité

\author{
Delphine Acolat
}

\begin{abstract}
Peut-on prouver l'utilisation pédagogique de dessins, de diagrammes, voire de cartes dans l'Antiquité, si aucune source figurée ne nous est parvenue? La question de la transmission du savoir géographique pose la question du rapport entre le texte et la mise en carte. Dans les manuscrits médiévaux, nous avons quelques exemples de « mise en carte» de textes géographiques, qui sont sans doute un héritage direct de représentations antiques ${ }^{1}$. Bien que ce ne soit en aucun cas ce que nous appelons aujourd'hui une carte (pas d'échelle, pas de convention graphique), mais plutôt un schéma ou un diagramme, où l'on plaçait les toponymes, et parfois des formes, elle semble avoir joué un rôle certain dans l'apprentissage des savoirs. Quel rapport de réciprocité s'est établi entre le texte et la figure pour la connaissance et la maîtrise du monde? L'auctoritas dont bénéficièrent certains auteurs nous a permis d'étudier comment les toponymes antiques et les méthodes d'apprentissage via le dessin furent transmis à partir de l'Antiquité tardive, jusqu'aux manuscrits médiévaux qui nous sont parvenus.
\end{abstract}

\section{Voir ce que l'on entend ou décrire ce que l'on voit : sphaera, pinax, orbis depictus : l'attestation de l'usage de la carte dans la pédagogie antique}

Dans les manuscrits antiques, l'inventaire des éléments constitutifs du monde (montagnes, fleuves, mers, cités, peuples) était-il accompagné de schémas? Dans la démarche pédagogique, le dessin précédait-il le texte explicatif ou l'inverse? La forme cartographique, quelle qu'elle soit, peut avoir suscité la présentation écrite des 
données, puisque, par essence, elle permet l'utilisation combinée d'informations et produit de l'ordre dans des données ${ }^{2}$.

3 L'usage de schémas cartographiques est attesté dans un but pédagogique dans trois textes tardo-antiques ${ }^{3}$. Le rhéteur Eumène, dans un discours prononcé en 297, recommande l'utilisation conjointe de la carte et du texte, quand il décrit un orbis depictus représenté sur les portiques de l'école d'Autun, où la jeunesse pouvait localiser les conquêtes impériales :

«Car là, ainsi que vous avez pu, je crois, le vérifier par vous-même, pour faciliter l'instruction de la jeunesse, et partant de ce principe que des choses difficiles à saisir par l'enseignement oral sont plus clairement expliquées au regard, on a représenté la situation des lieux avec leurs noms, leur étendue, leurs distances, la source et l'embouchure de tous les fleuves, les sinuosités des rivages et les circuits de l'Océan qui embrasse les continents, et ses mouvements impétueux. ${ }^{4}$ "

L'expression utilisée est claire : le regard sur la carte permet de voir plus clairement et de mieux comprendre ce que l'on a pu expliquer par un enseignement oral (manifestius oculis). Le second exemple date de 435 . Un poème situé à la fin d'une énumération toponymique de provinces, la Diuisio orbis terrarum ${ }^{5}$, atteste de l'existence d'une carte commandée par l'empereur Théodose II et réalisée par deux serviteurs, suivant des modèles textuels ou figurés plus anciens, qu'ils améliorent et corrigent, «l'un écrivant et l'autre peignant » (dum scribit, pingit et alter) : la double expression laisse penser que la carte comportait des inscriptions ou était accompagnée d'un texte pour en faciliter la lecture, ou, à l'inverse, qu'elle servait d'illustration au texte. La relation entre le texte et ce que nous assimilons à une carte, parce qu'elle était sans doute le plus souvent picta et objet du regard ${ }^{6}$, quelle que soit sa forme ${ }^{7}$, est attestée par les mots specimen terrae quam oecumenen appellamus, et semble donc essentielle dès l'Antiquité. Le schéma compile et rend plus "visible", donc plus clairs et intelligibles, les savoirs énoncés dans un texte ou énumérés à un élève.

5 Enfin, entre 540 et 572, Cassiodore associe le texte et la carte dans ses conseils pédagogiques aux moines de Vivarium: il recommande de lire une description du monde, puis de regarder et d'apprendre le contenu d'un pinax, « carte » faite d'après le texte de la Périégèse de Denys d'Alexandrie, dont les vers devenus célèbres ont décrit le monde connu au $\mathrm{II}^{\mathrm{e}}$ siècle; Cassiodore lie le texte et la carte, puisque celle-ci va permettre « de voir presque comme par le regard ce que l'on a entendu» :

"Qu'il vous soit aussi nécessaire de connaître la cosmographie, c'est à juste titre que je vous le conseille, car vous devez savoir avec évidence en quelle partie du monde est situé chacun des lieux que vous lisez dans les livres saints. Ce qui se produira parfaitement si vous vous hâtez de lire avec application le petit livre de Julius Orator que je vous ai laissé. Les mers, les îles, les montagnes fameuses, les provinces, les cités, les peuples y sont rassemblés selon une quadruple division, en sorte qu'il ne manque à ce livre presque rien de ce que l'on sait qui touche à la connaissance de la cosmographie. [...] Ensuite, apprenez la carte (pinax) de Denys qui, ramassée en un bref espace, vous permettra de voir presque comme par le regard ce que vous aurez entendu de vos oreilles dans le livre précédent. Alors, si le noble souci de la connaissance vous a enflammés, vous avez le codex de Ptolémée ; rendant visibles les moindres lieux, l'auteur vous semblera presque avoir habité toutes les régions du monde et il vous permettra, à vous qui, comme il convient à des moines, devez demeurer en un seul endroit, de parcourir en esprit les espaces que d'autres n'ont embrassés que par de pénibles pérégrinations. ${ }^{8}$ "

6 Le « petit livre de Julius Orator » est la Cosmographia de Julius Honorius, qui établit un inventaire du monde ordonné en quatre parties d'après une carte ${ }^{9}$, qui date sans doute 
$\mathrm{du} \mathrm{IV}^{\mathrm{e}}$, au plus tard $\mathrm{du} \mathrm{VI}^{\mathrm{e}}$ siècle ${ }^{10}$. D'après une phrase du prologue selon une des versions manuscrites ${ }^{11}$, c'est une suite de notes prises à l'écoute d'un maître (magister) qui commentait (commentarium) une carte du monde (sphaera) en faisant une liste de noms de lieux selon la catégorie géographique à laquelle ils appartiennent ${ }^{12}$. Le texte ne devait pas être séparé de la carte, selon les intentions du maître ${ }^{13}$. Quatre " océans ", eux-mêmes déterminés par les points cardinaux, ordonnent un classement, en quatre parties du monde, de toponymes plus ou moins mis à jour à son époque ${ }^{14}$, qui devaient figurer sur la carte circulaire du monde commentée à l'élève. L'œuvre de Julius Honorius a été très diffusée dans l'Occident médiéval ${ }^{15}$, mais hélas aucune carte qui l'aurait accompagnée ne nous est parvenue.

7 Ainsi, si l'on ne peut affirmer que cette pratique, avec des schémas cartographiques illustrant systématiquement un texte ou l'inverse, ait été générale, l'association texte/ carte semble encouragée pour la transmission du savoir géographique scolaire tardoantique, païen puis chrétien ${ }^{16}$. Dans tous les exemples précédemment cités, le recours à l'observation d'une représentation cartographique, nécessairement synthétique et clairement organisée, est essentiel dans le processus intellectuel d'acquisition efficace du savoir géographique et à sa transmission.

\section{Le dessin cartographique comme prolongement et éclairage indispensable du texte, inséré dans le manuscrit}

\section{Du dessin en marge du texte aux « cartes textuelles »}

8 La phrase de Cassiodore énonçait que le texte de la description du monde de Denys d'Alexandrie était accompagné d'une carte, voire remplacé par celle-ci. Mais la mise en carte remonte-t-elle à la rédaction par Denys ou est-elle élaborée ensuite pour servir la pédagogie des maîtres devant leurs élèves ? Le problème se pose à partir du moment où un schéma correspondant au texte est en position marginale dans le manuscrit. On a des scholies antérieures au v $v^{e}$ siècle sous forme de schémas mis en marge ${ }^{17}$; il ne s'agit pas de carte générale du monde habité : pour l'île de Délos, on a un schéma avec deux cercles concentriques avec le nom au milieu, entourés de onze petits cercles qui symbolisent les îles des Cyclades environnantes (fig. 1), et sur un autre feuillet, un petit schéma de l'Asie sous forme de carré légendé sur les côtés (fig. 2) ${ }^{18}$. Pour autant, rien ne prouve que l'auteur de la Périégèse ait voulu insérer de tels schémas dès le $\mathrm{II}^{\mathrm{e}}$ siècle, puisque ce sont les scholiastes qui les citent, en renvoyant à une comparaison avec une carte à consulter avec le texte, qui est critiquée comme étant insuffisamment précise ou incomplète, mais dont on ignore l'origine et la datation. Tout au plus pouvons-nous en déduire que dès l'Antiquité tardive (dès avant le $\mathrm{v}^{\mathrm{e}}$ siècle), la pratique de l'illustration explicative par des schémas «cartographiques» est avérée dans la transmission des savoirs. 
Fig. 1. - Schéma des îles Cyclades dans la Périégèse de Denys d'Alexandrie.

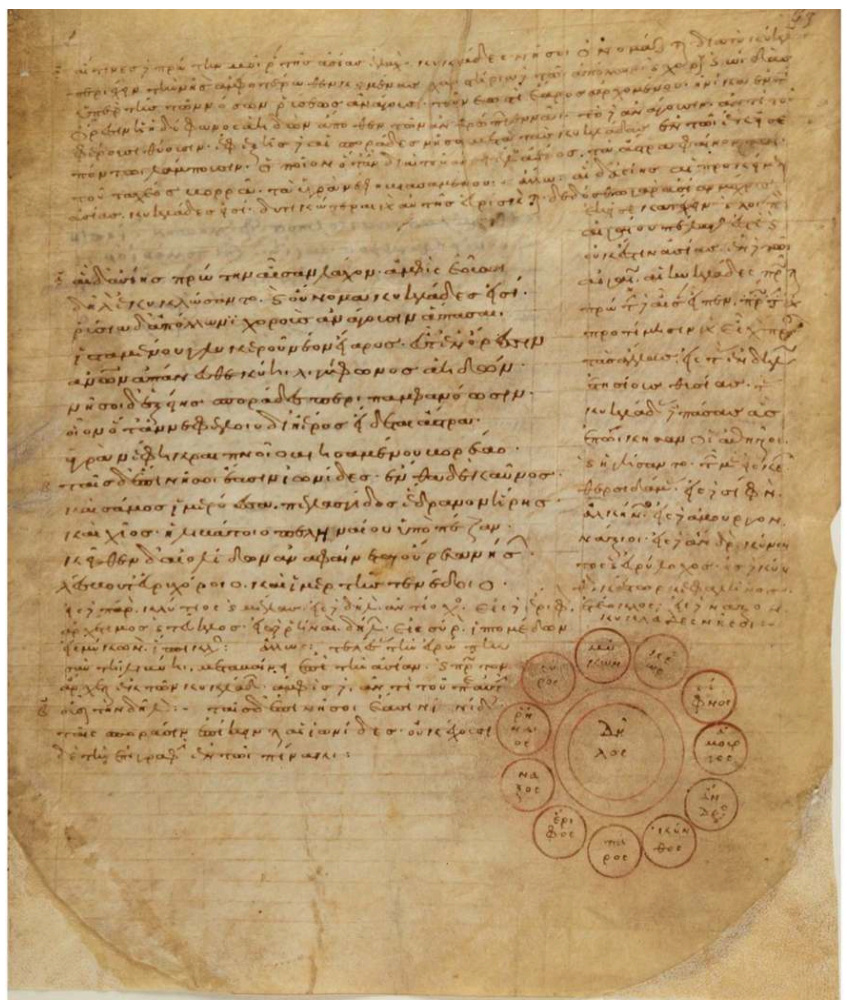

Paris, BnF, Parisianus graecus Ms. 2771, fol. 63r. (ve siècle).

Fig. 2. - Schéma de l'Asie dans la Périégèse de Denys d'Alexandrie.

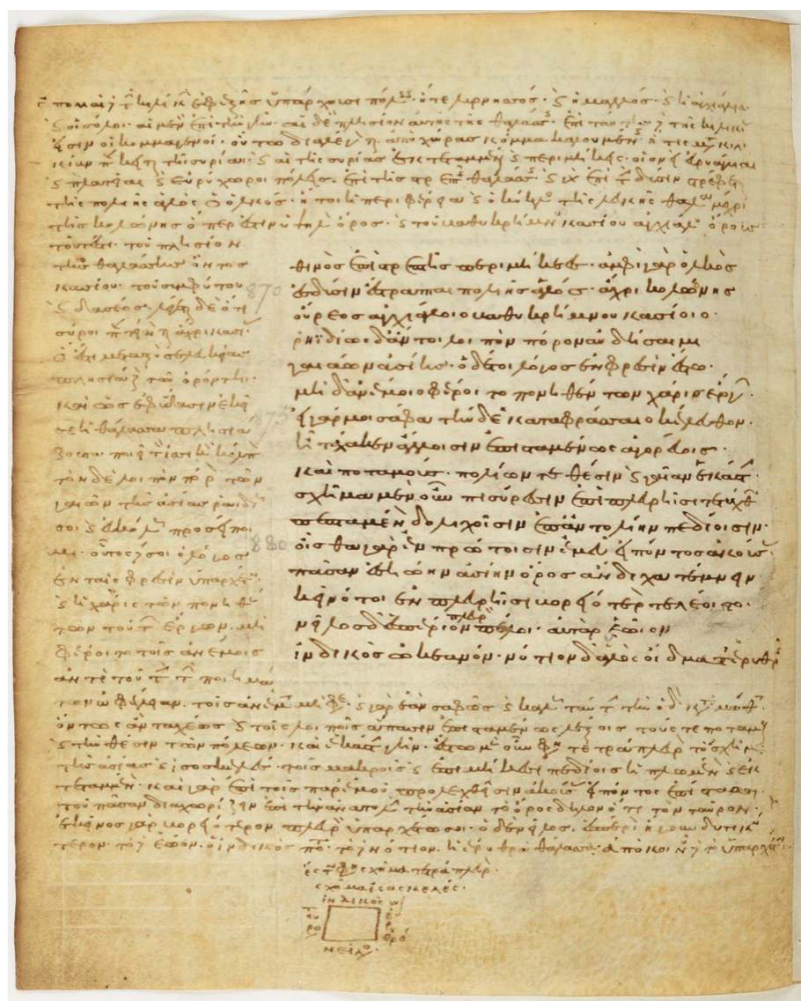

Paris, BnF, Parisianus graecus Ms. 2771, fol. 73v. (ve siècle). 
Les manuscrits de Salluste et de Lucain, correspondant aux passages du Bellum Iugurthinum (17.3 et 19) et de la Pharsale (9.411 sq.), où sont discutées la structure de l' orbis terrarum et la répartition des peuples et lieux de l'Afrique, ont des schémas tripartites de l'œcoumène en $\mathrm{T}-\mathrm{O}^{19}$ dans leurs marges ${ }^{20}$, à titre de gloses. Si l'on ne peut les faire remonter avec certitude à un archétype de l'Antiquité, puisque les manuscrits les plus anciens datent du IX ${ }^{\mathrm{e}}$ siècle, d'après P. Gautier Dalché, les schémas des textes de Salluste et de Lucain sont probablement issus de commentaires scolaires antiques de grammatici $^{21}$, tout comme, vraisemblablement, ceux qui accompagnent le texte d'Isidore de Séville ${ }^{22}$. Les trois parties du monde habité sont conformes à la tradition antique, et dans la sphère répartie en trois zones, des listes de noms sont organisées selon deux types : dans le premier, les mots sont les uns à la suite des autres, ligne après ligne, sous un titre par continent ${ }^{23}$ (fig. 3) : In Asia sunt prouinciae XV [...], In Europa sunt prouinciae XIII [...], In Africa sunt XII prouinciae [...]. Dans un second type, plus riche en toponymes, les noms de lieux sont présentés en colonnes, qui tentent de respecter un regroupement topographique (fig. 4) ${ }^{24}$, selon leurs positions respectives dans l'orbis terrarum. Ce procédé classe visuellement et topographiquement les éléments décrits dans le texte : le schéma résume et fixe les localisations par secteurs, il permet d'avoir une vision simultanée des éléments listés, de leur importance numérique par régions à l'intérieur de chaque continent. Ainsi, la carte peut remplacer un texte ${ }^{25}$ : on peut alors évoquer le terme de "cartes textuelles", sans symboles ni dessins, où l'aspect schématique aide à mémoriser la répartition des toponymes.

Fig. 3. - Schéma en T-O (diamètre $19 \mathrm{~cm}$ ), manuscrit d'Isidore de Séville, De natura rerum.

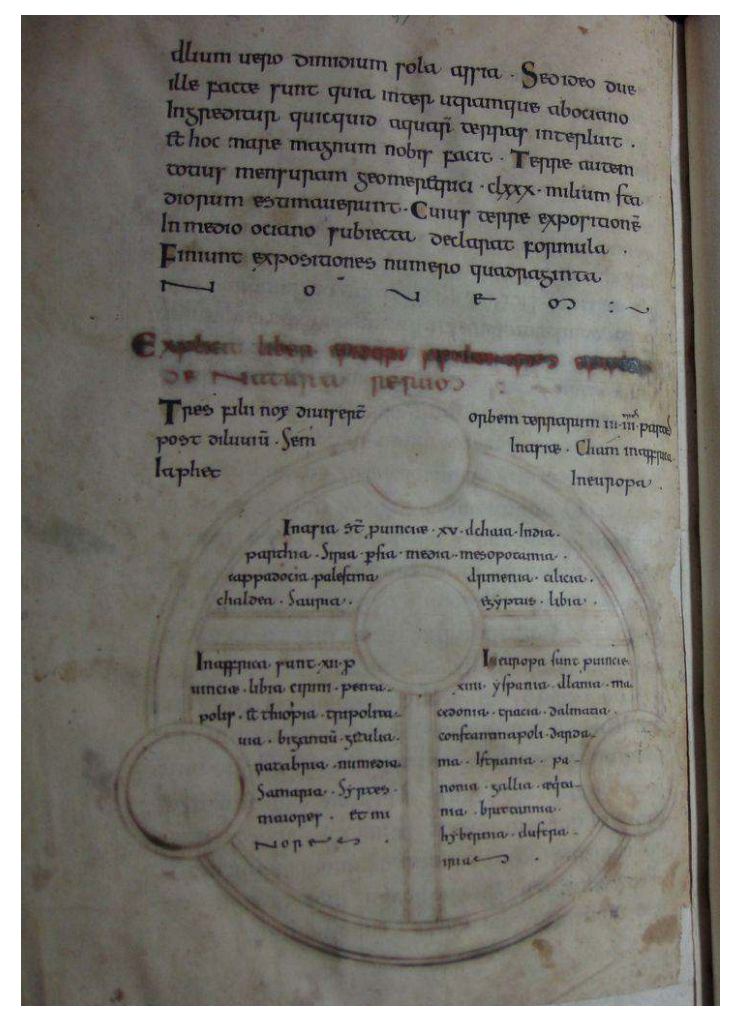

Cathedral Library of Exeter, Ms 3507, fol. 67r (x॥e siècle). D'après Harley 1987, vol 2, 347. 
Fig. 4. - Schéma de type T-O, avec listes de lieux, Arnstein Bible, vers 1172.

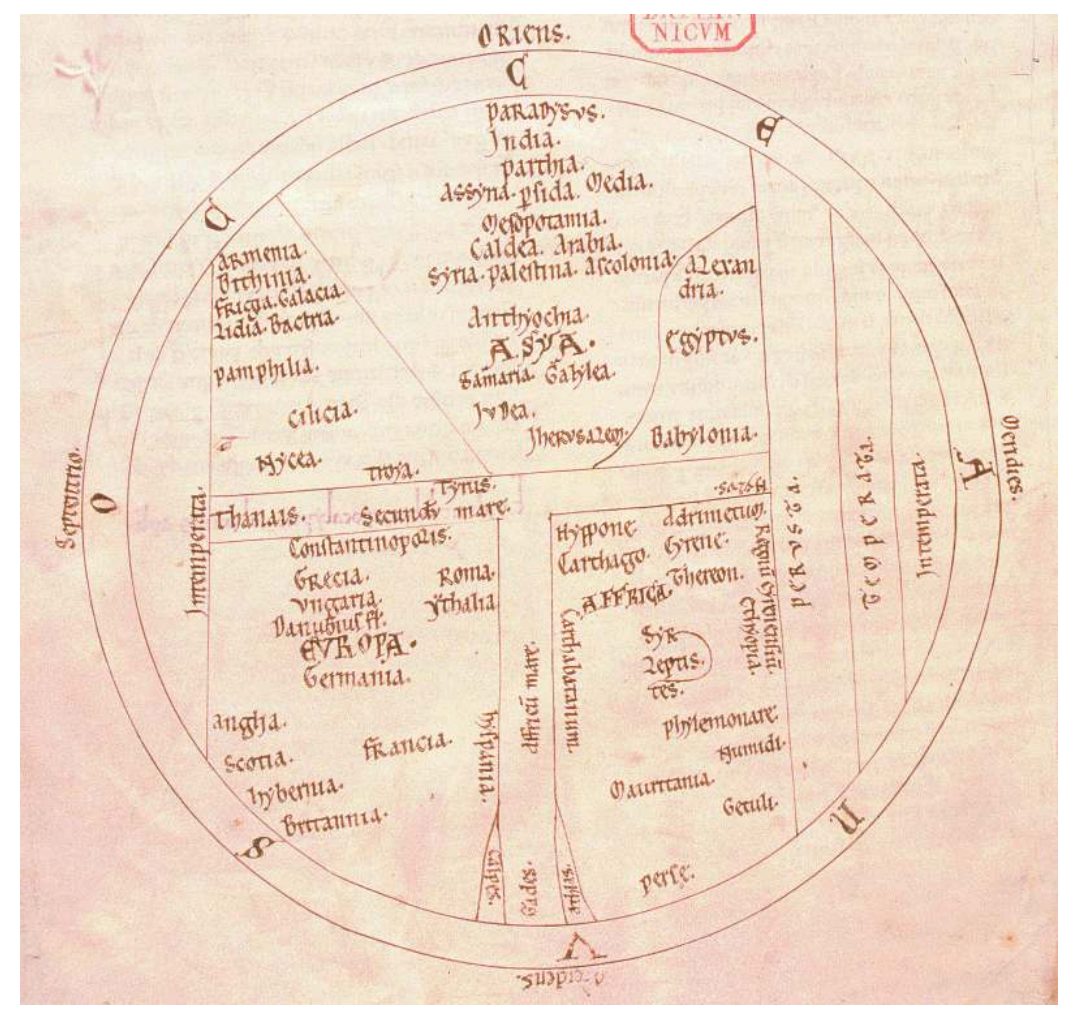

British Library, Ms. Harley. 2799, fol. 241v. D’après Gautier Dalché, 1994b.

10 Le schéma du Ms. Harley 2799 (fig. 4) occupe plus de la moitié inférieure du feuillet, et la sphère s'inscrit dans les trois dernières lignes du texte au-dessus. Il n'est pas ajouté en marge. Même si la «mise en carte » ne peut être datée avec certitude de l'écriture du texte par Isidore de Séville, la réalité géographique romaine datant de l'époque impériale est la base des connaissances, à laquelle s'ajoute la mise à jour médiévale des informations; le conservatisme est un élément important pour comprendre les choix qui sont faits dans la transmission des savoirs depuis l'Antiquité. L'œcoumène tripartite (avec une Asie plus grande que l'Europe et l'Afrique ${ }^{26}$, comporte des listes de noms, mêlant régions/provinces (noms romains avec quelques ajouts médiévaux), villes, fleuves, peuples, répartis par secteurs géographiques ${ }^{27}$, c'est-à-dire agencés selon un ordre topographique ${ }^{28}$.

La nette majorité des noms est antique : les toponymes africains et le terme Affricum mare sont issus du texte de Salluste ${ }^{29}$, auquel sont ajoutés des noms antiques ancrés dans la tradition géographique gréco-romaine, remontant à la période hellénistique, par exemple Calpe, Atlas, Tanais, Nilus. De plus, l'actualisation des noms est faible : seuls Anglia, Francia et Ungaria et quelques références et transformations bibliques attendues (entre autres exemples, Paradysus, Hyppone - siège épiscopal - au lieu de Hippo Regius, Hherusalem et un développement lexical conséquent sur sa région avec Samaria, Galilea, Iudea) ont été ajoutés par un copiste. On a donc une synthèse de connaissances antiques que le copiste a faiblement mise à jour. 


\section{Le schéma dessiné indissociable du texte}

12 Le Commentaire sur le Songe de Scipion, de Macrobe, écrit au v siècle et très diffusé jusqu'à la fin du Moyen Âge, comporte dans le texte même des manuscrits la citation et l'appel à un dessin cartographique ou schéma diagrammatique ${ }^{30}$, témoin irréfutable du fait que la carte était considérée comme un complément indispensable à la lecture du texte dès l'écriture de l'ouvrage. Le texte même du livre II mentionne, et ce, à plusieurs reprises, des figures explicatives. Dans sa description géographique de la Terre, une phrase énonce qu'il met «devant les yeux [du lecteur]» une descriptio ${ }^{31}$. A priori la descriptio pourrait être tout autant un texte qu'un schéma explicatif des zones climatiques sur le globe : mais la mention de ante oculos et l'opposition entre descriptio (que nous traduirons par "figure ») et sermo (" ce qui est énoncé ») un peu plus tôt nous semble explicite et révélatrice de la présence d'un dessin : "L'esprit pourra concevoir le raisonnement plus facilement par la figure que par le discours ${ }^{32}$ ». Dans le livre I, il faut noter que Macrobe a déjà précisé que «la description que l'on met devant les yeux » permet de "comprendre plus facilement » ce dont on parle ${ }^{33}$, et il a utilisé le même champ lexical. Au paragraphe 6 du livre II, il écrit même que « le lecteur nous entendra sans peine, s'il a sous les yeux la description de la sphère terrestre, donnée au chapitre précédent : au moyen de la figure jointe à cette description, il lui sera aisé de nous suivre » $(2.6,1)$. Le contenu géographique est ainsi énoncé à la fois dans le texte et dans le schéma adjacent, qui en est une forme résumée, alternative au texte, mais insérée dans le texte, comme une évidente condition à la compréhension, et non comme un élément subsidiaire.

13 Les plus anciens manuscrits retrouvés prouvent ce rapport entre le texte et le schéma géographique : celui-ci, inséré dans la phrase située au-dessus et en dessous (2.5,13-17), représente la Terre divisée en zones, sans légende explicite, avec seulement des lettres autour du cercle figurant le globe ${ }^{34}$ (fig. 5). Dans la démarche méthodologique de Macrobe, le texte semble venir en second, pour compléter le diagramme, comme une explication orale lors d'un cours, où le maître montre une carte et en explique les parties. En effet, après l'énoncé des lettres "écrites » (adscripta) autour du cercle à tracer figurant la Terre, Macrobe définit les zones entre les lignes tracées à partir des lettres, sur le schéma :

«Soit le globe terrestre A, B, C, D; soient les droites G, I et E, F, limites des deux zones glaciales ; soient $\mathrm{M}, \mathrm{N}$ et $\mathrm{K}, \mathrm{L}$, limites des deux zones tempérées ; soit enfin $\mathrm{A}$, $B$, la ligne équinoxiale ou la zone torride. L'espace compris entre G, C, I, ou la zone glaciale boréale, et celui compris entre $\mathrm{E}, \mathrm{D}, \mathrm{F}$, ou la zone glaciale australe, sont couverts d'éternels frimas ; les lieux situés entre $\mathrm{M}, \mathrm{B}, \mathrm{K}$ et $\mathrm{N}, \mathrm{A}, \mathrm{L}$, sont sous la zone torride : il suit de là que l'espace renfermé entre $\mathrm{G}, \mathrm{M}$ et $\mathrm{I}, \mathrm{N}$, et celui entre KE et FL, doivent jouir d'une température moyenne entre l'excès du chaud et l'excès du froid des zones qui les bornent [...] Des deux zones tempérées où les dieux ont placé les malheureux mortels, il n'en est qu'une qui soit habitée par des hommes de notre espèce, Romains, Grecs ou Barbares ; c'est la zone tempérée boréale qui occupe l'espace GI, MN. »

14 Quelques paragraphes plus loin se trouve le cinquième diagramme présent dans l'œuvre, qui est celui dont la transmission pose le plus de problèmes. Il découle de celui précédemment cité, avec ses zones expliquées grâce aux lettres, car il s'agit ici «à partir d'une figure insérée » (descriptio substituta) que Macrobe regarde (ante oculos), que le lecteur "découvre" (invenies) l'emprise des mers par rapport aux terres, l'encerclement par le grand Océan, la forme générale de la terre habitée de 
l'hémisphère nord, «telle une chlamyde » (chlamydi similem ${ }^{35}$ ) et les connexions entre la mer Rouge, l'océan Indien, la mer Caspienne, la Méditerranée et l'Océan ${ }^{36}$. Après que le texte a annoncé la "figure insérée » et décrit son contenu, dans la plupart des manuscrits, le dessin est donc placé logiquement entre la fin de la phrase concernée (incognitus perseuerat) $(2.9,7)$ et le début de la suivante annoncée par un mot de liaison (Quod autem) $(2.9,8)$ (fig. 6 et 7) ${ }^{37}$. Hormis quelques rares cas de manuscrits du $\mathrm{IX}^{\mathrm{e}}$ et $\mathrm{x}^{\mathrm{e}}$ siècles ${ }^{38}$ qui se sont vus ajouter une figure tardive de la Terre qui, de fait, va se retrouver en marge ou sur un feuillet ajouté (fig. 8) ${ }^{39}$, ce qui est frappant, c'est la place laissée par le copiste dans le feuillet, pour le dessin, au milieu du texte, voire en haut du feuillet : il joue donc un rôle didactique, annoncé comme tel par l'auteur tardo-antique, et est assumé comme un élément indispensable et indissociable du chapitre sur l'organisation spatiale de la Terre.

Fig. 5. - Schéma zonal de la Terre avec des lettres commentées dans le texte de Macrobe.

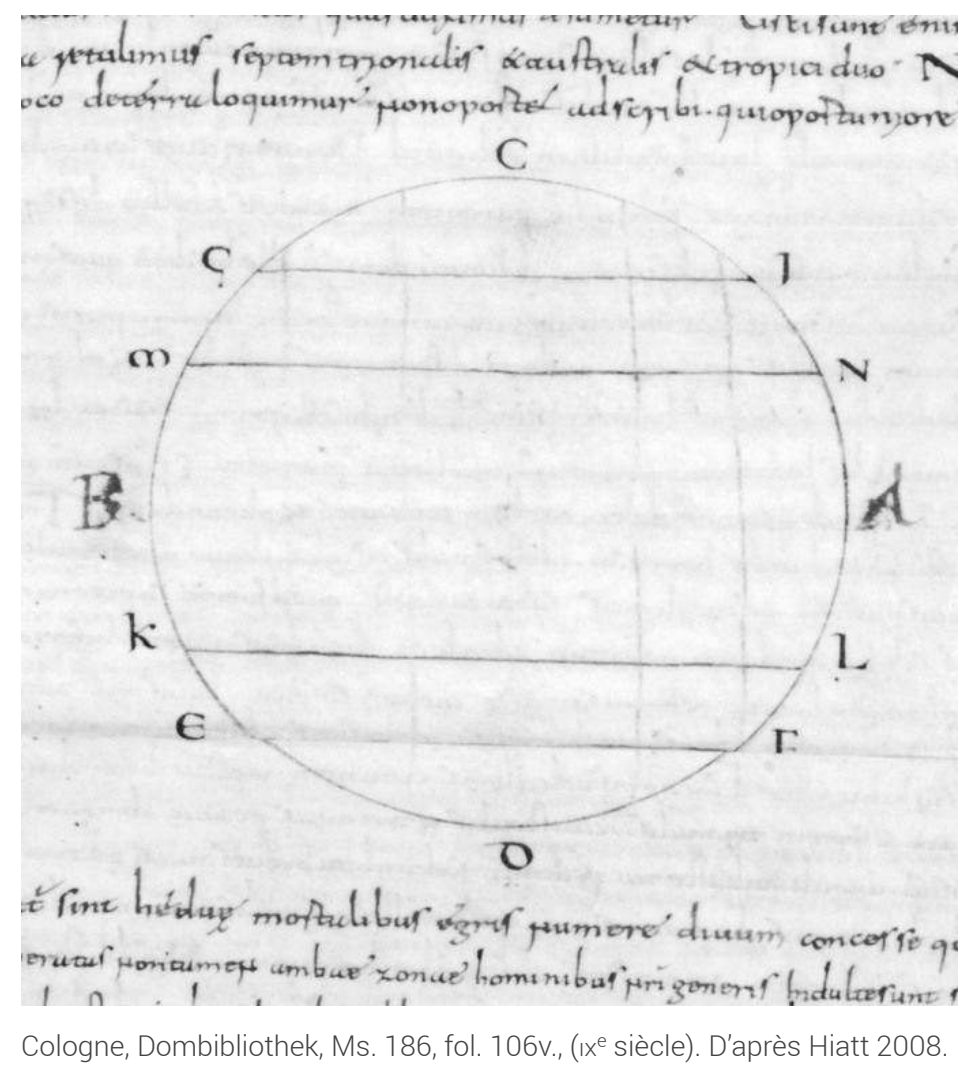


Fig. 6. - Schéma zonal de la Terre avec légendes des mers, dans le texte du Macrobe.

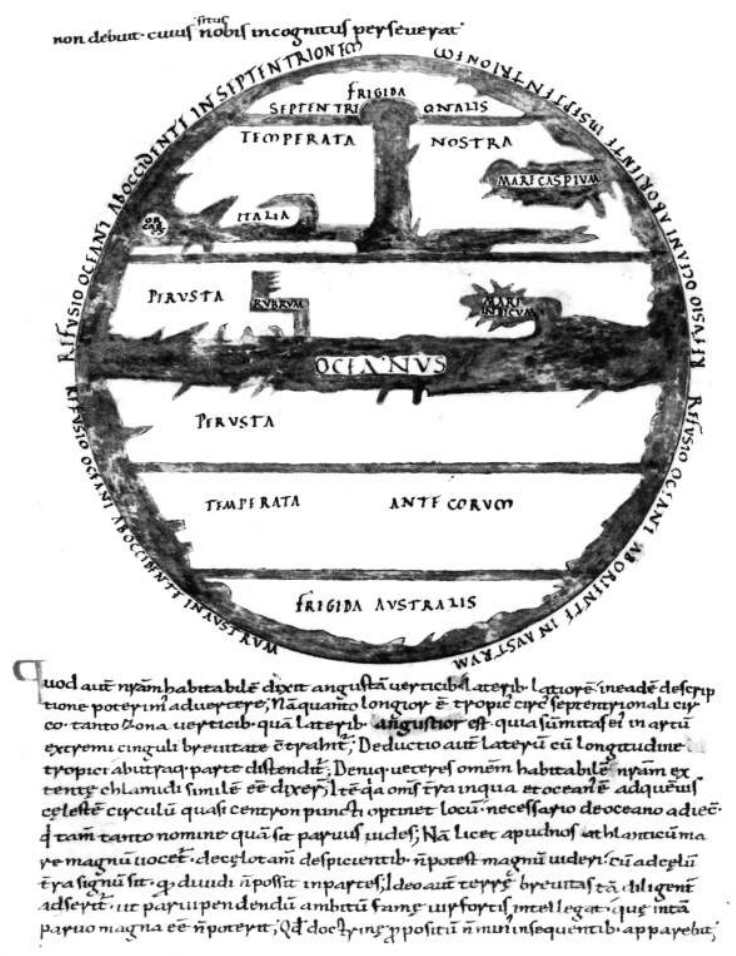

Rome, Bibliotheca Apostolica Vaticana, Ms. Palat. lat.1341, fol. 86v., (Lorsch, $x^{e}$ siècle). D'après Hiatt, 2008.

15 S'il est impossible de recomposer exactement ce diagramme tel qu'il était probablement inséré dans l'archétype $\mathrm{du} \mathrm{v}^{\mathrm{e}}$ siècle, on peut examiner les manuscrits les plus anciens qui nous sont parvenus ( $\mathrm{IX}^{\mathrm{e}}-\mathrm{X}^{\mathrm{e}}$ siècles) $)^{40}$; de rares noms propres, cités dans le texte adjacent ${ }^{41}$, servent de repères dans des formes schématiques : " mer Rouge ", «mer Indienne », " mer Caspienne », « Océan ${ }^{42}$. Quelques manuscrits ajoutent l'Italie (Italia), et les "Orcades» (les îles Orkney) dans un cercle évoquant leur caractère insulaire. Les zones climatiques sont légendées : frigida septentrionalis, temperata nostra, perusta (deux fois), temperata antecorum, frigida australis (fig. 6) ${ }^{43}$. Le manuscrit de Bruxelles $^{44}$ (fig. 7) présente les mêmes toponymes mais sous forme de liste énumérative, sans que l'on puisse parler de dessin des formes littorales. Sous l'inscription du nom des trois mers précitées, des traits forment des vaguelettes, sans marquer la connexion avec l'anneau océanique; l'Italie est dans une étiquette rectangulaire ; seul le cercle entourant le nom " Orcades» peut figurer l'insularité. Sur certains manuscrits, il y a en plus "Syene » (Assouan), et «Meroe », cité et île à la fois, qui sert de borne repère pour séparer la zone torride de la zone tempérée ${ }^{45}$, noms présents également à plusieurs reprises dans le texte de Macrobe $^{46}$. Méroé est la ville d'Éthiopie antique de référence pour la limite méridionale du monde africain civilisé aux yeux des Romains dans la littérature encyclopédique ${ }^{47}$, qui permet aussi de tracer le méridien jusqu’à Alexandrie depuis Ératosthène ${ }^{48}$. 
Fig. 7. - Schéma zonal de la Terre dans Macrobe.

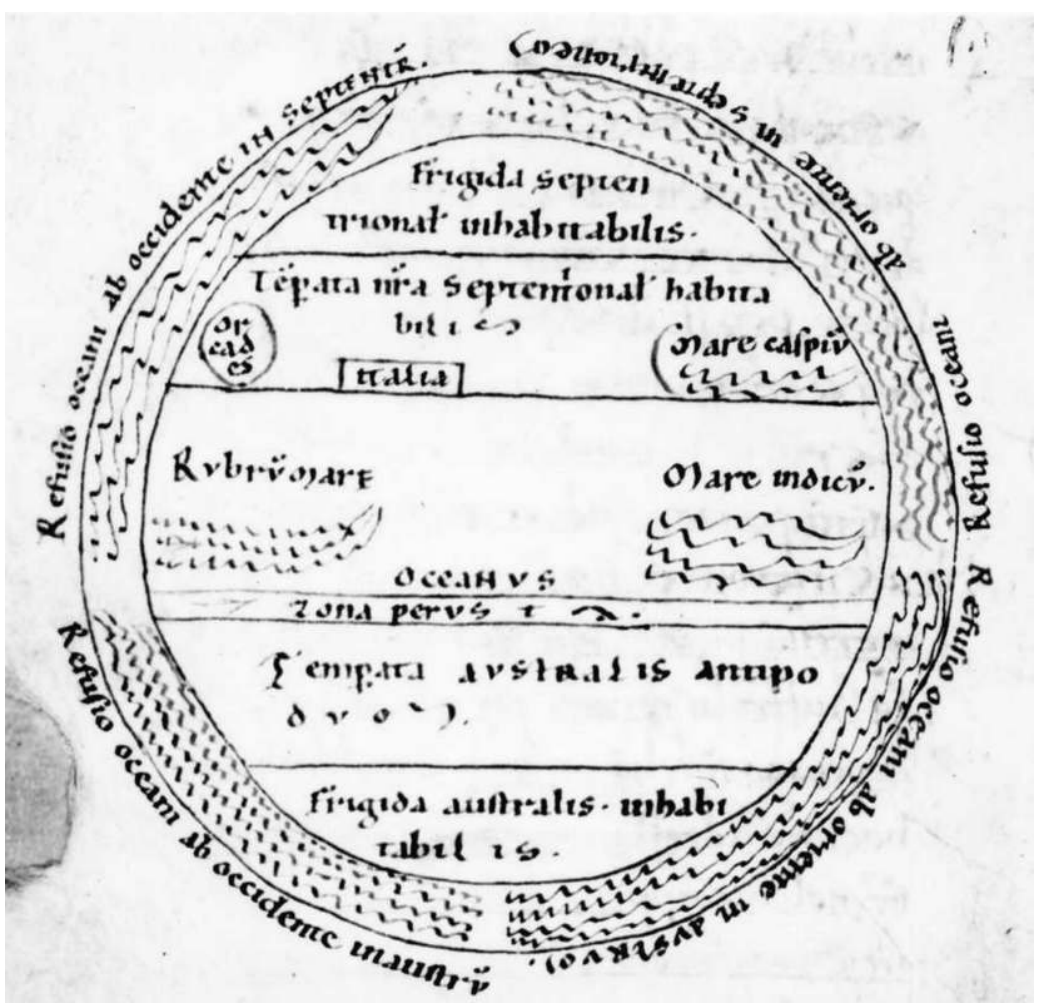

Bruxelles, Bibliothèque royale, Ms. 10146, fol. 109v. (Ix-xe siècle). D'après Hiatt, 2008.

Fig. 8. - Schéma de la Terre avec l'Océan central, ajouté à un premier état du texte de Macrobe au IX $\mathrm{e}^{\mathrm{e}}$ siècle, et schéma zonal de la Terre ajouté au XII siècle.

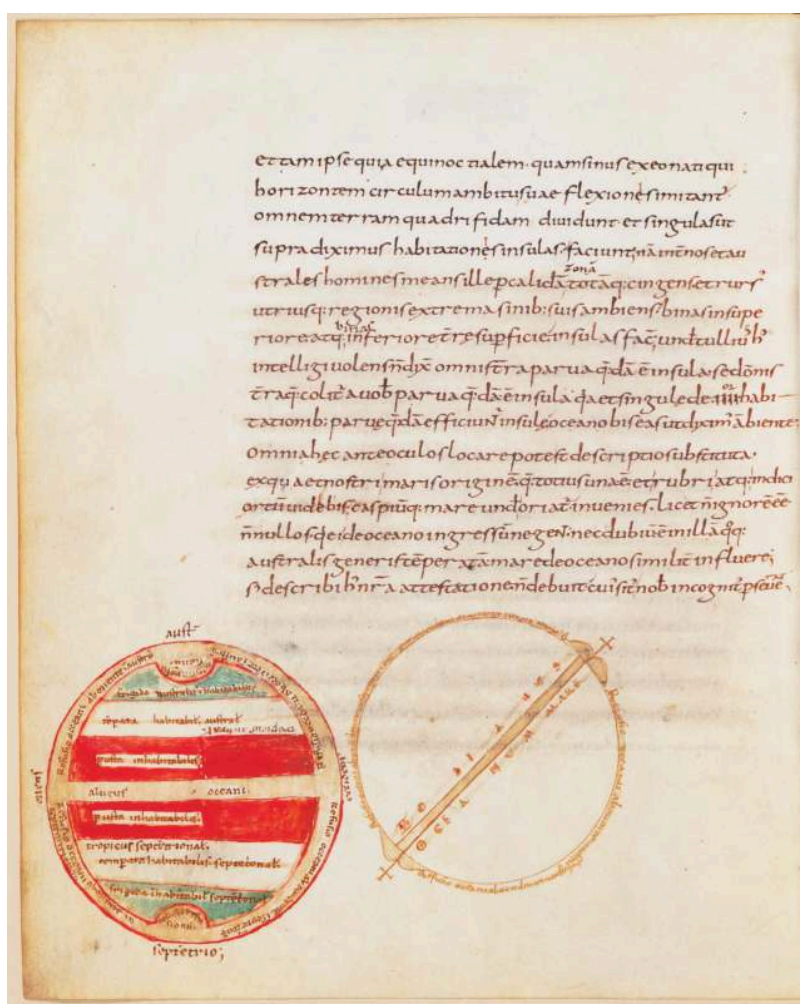

Paris, BnF Ms. lat. 6370, fol. 89v. (Ix siècle). D'après Hiatt, 2008. 
Le problème est que la transmission cartographique n'est pas évidente : d'après A. Hiatt $(2008,154)$, sur 6 manuscrits du IX ${ }^{\mathrm{e}}$ siècle qui contiennent le passage $2.9,7-8$, où l'auteur cite la carte, deux manuscrits révèlent les difficultés qui se posaient aux lecteurs et aux copistes quand la carte manquait. Dans un des cas, datant de 820 , à Tours ${ }^{49}$, Lupus de Ferrières, à la fin du IX $\mathrm{x}^{\mathrm{e}}$ siècle, a fait gratter et effacer 17 lignes de texte qu'on a ensuite resserré pour gagner de la place en bas de feuillet, et on y a ajouté une simple sphère avec l'Océan (Oceanum mare), puis au XII ${ }^{\mathrm{e}}$ siècle, un copiste a dessiné la carte zonale de la Terre à gauche (fig. 8). Dans l'autre cas, un blanc avait été laissé dans la page à l'endroit du texte, et au $\mathrm{XI}^{\mathrm{e}}$ siècle, finalement, on a commencé à ajouter la carte, jamais terminée, sur un nouveau feuillet à l'écart ${ }^{50}$. Après cette première phase de transmission difficile de la partie cartographique illustrant le texte, A. Hiatt avance l'hypothèse d'une deuxième phase de transmission de l'œuvre, avec toutes ses figures, à partir du $\mathrm{X}^{\mathrm{e}}-\mathrm{XI}^{\mathrm{e}}$ siècle, et notamment dans le sud de la Germanie, avec soit la copie d'un exemplaire manuscrit qui avait gardé trace de la carte depuis l'archétype, soit la reconstruction de son contenu.

17 Par la suite, à partir de la fin du XI ${ }^{\mathrm{e}}$ siècle, on augmente le contenu toponymique des schémas avec des noms qui ne sont pas issus du texte de Macrobe mais ajoutés d'après d'autres listes à vocation pédagogique ou des références bibliques.

Ainsi, la transmission des savoirs passe pour la majorité des cas des manuscrits de Macrobe $^{51}$ par la complexification d'un schéma archétype très épuré remontant probablement au $\mathrm{v}^{\mathrm{e}}$ siècle, mais en mêlant peu à peu des références existant dans d'autres textes géographiques antiques païens ${ }^{52}$ puis dans des textes médiévaux chrétiens, voire en orientant les figures à l'Est. Dans tous les cas, au fil des transmissions manuscrites, l'hémisphère sud reste bien présent, et vierge de toute annotation de repère géographique (sauf le nom zonal: temperata et inhabitabilis), conformément aux instructions de Macrobe qui avance, selon les thèses datant de la période hellénistique et de Cratès de Mallos, l'hypothèse d'une symétrie.

Les figures de Macrobe, présentées par lui-même comme une alternative au texte, et très diffusées dans l'enseignement de la géographie de la Terre à partir du XII ${ }^{\mathrm{e}}$ siècle $^{53}$, ont certainement eu une influence sur d'autres mappemondes qui circulent à partir du $\mathrm{XI}-\mathrm{XII}{ }^{\mathrm{e}}$ siècle. La meilleure preuve du succès de la longue transmission de ses écrits et cartes depuis le $\mathrm{v}^{\mathrm{e}}$ siècle est sa diffusion sous forme manuscrite, puis imprimée, jusqu'en 1560.

Dans la géographie romaine, par tradition, l'inventaire du monde est fait à travers des catégories qui restent toujours les mêmes : à la géographie physique (cours d'eau, mers, îles, montagnes) s'ajoute éventuellement la géographie humaine, avec les peuples, les villes et les provinces. Le mode de pensée de l'espace n'a pas vraiment évolué au cours de l'Antiquité tardive, et dans un but didactique, l'exposé des connaissances géographiques s'est concentré et simplifié en listes où le découpage des régions était immédiatement compréhensible et intégrable dans des schémas, qui facilitaient l'appréhension des éléments composant le monde, leur compréhension, leur mémorisation. Les copistes médiévaux ont conservé ces noms, qui ne correspondaient 
plus à des réalités contemporaines, auxquels ils ont ajouté éventuellement des références récentes.

Le dessin et le texte ont été établis dès l'Antiquité tardive dans un rapport de réciprocité étroit, visant à l'efficacité de la transmission des savoirs. On affichait, montrait, commentait les «cartes» dans un but pédagogique ${ }^{54}$. Malgré des changements somme toute relatifs, la connaissance géographique qui est transmise par le schéma cartographique jusqu'au milieu du Moyen Âge reste donc longtemps celle d'éléments célèbres structurant l'espace du monde connu antique autour du Bassin méditerranéen, pour représenter un orbis terrarum aux traits résolument romains.

\section{BIBLIOGRAPHIE}

ARGOUD, G. \& GUILLAUMIN, J., éd. (2003) : Sciences exactes et sciences appliquées à Alexandrie (III ${ }^{\mathrm{e}}$ siècle av. J.-C.-- ${ }^{\text {er }}$ siècle apr. J.-C.) : Actes du Colloque International de Saint-Étienne (6-8 juin 1996), Saint-Étienne.

ARNAUD, P. (1990a) : La cartographie à Rome, thèse de doctorat, Université Paris IV.

ARnAUD, P. (1990b) : «Plurima Orbis Imago. Lectures conventionnelles des cartes au Moyen Âge », Médiévales, 18, 33-51.

ARNAUD, P. (2009) : « Texte et carte d'Agrippa. Historiographie et données textuelles », GeogrAnt, p. 57-110.

BLOCK FRIEDMAN, J. \& MOSSLER FIGG, K. (2000) : Trade, Travel, and Exploration : An Encyclopedia, Routledge.

DAN, A. (2017) : « La mappemonde d'Albi - un pinax chôrographikos. Notes sur les origines antiques de la carte et du texte du ms Albi 29 fol. 57v-58r ", Cartes \& Géomatique, 234, p. 13-44.

DERENZINI, G. (1995) : « I disegni nei manoscritti delle Opere e i giorni di Esiodo : problemi della tradizione iconografica e testuale », ans IACOBINI A. et ZANINI E., Arte profana e arte sacra a Bisanzio, Roma, Argos, p. 450-451.

DESTOMBES, M. (1964) : Mappemondes A. D. 1200-1500. Catalogue préparé par la commission des cartes anciennes de l'Union Géographique Internationale, Amsterdam.

EDSON, E. (1997) : Mapping time and space: How Medieval Mapmakers viewed their World, Londres.

GAUTIER DALCHÉ, P. (1988) : La « Descriptio mappe mundi » de Hugues de Saint-Victor, texte inédit avec introduction et commentaire, Paris.

GAUTIER DALCHÉ, P. (1994) : « Notes sur la "carte de Théodose II" et sur la "mappemonde de Théodulf d'Orléans" », GeogrAnt, 3, p. 91-108.

GAUTIER DALCHÉ, P. (1994b) : « De la glose à la contemplation. Place et fonction de la carte dans les manuscrits du haut Moyen Âge ", dans Testo e immagine nell'alto medioevo, Settimane di studio del Centro italiano di studi sull'alto medioevo, XLI, 2, Spolète, p. 693-771. 
GAUTIER DALCHÉ, P. (2002) : «Les diagrammes topographiques dans les manuscrits des classiques latins (Lucain, Solin, Salluste) », dans LARDET P. : La tradition vive. Mélanges d'histoire des textes en l'honneur de Louis Holtz, Paris, p. 291-306.

GAUTIER DALCHÉ, P. (2005) : «Tradition et renouvellement dans la représentation de l'espace géographique au IX ${ }^{e}$ siècle ", dans Géographie et culture, la représentation de l'espace $d u \mathrm{VI}^{e}$ au XII siècle, Aldershot, p. 121-165.

GAUTIER DALCHÉ, P. (2006) : « Maps in words : the descriptive logic of medieval geography, from the eighth to the twefth century ", dans HARVEY, éd. 2006, p. 223-242.

GAUTIER DALCHÉ, P. (2008) : «L'héritage antique de la cartographie médiévale : les problèmes et les acquis », dans TALBERT \& UNGER, éd. 2008, p. 29-66.

GAUTIER DALCHÉ, P. (2013) : La Terre. Connaissance, représentations, mesure au Moyen Âge, Turnhout.

GAUTIER DALCHÉ, P. (2014) : «L'enseignement de la géographie dans l'Antiquité tardive », Klio, 96, 1, p. $144-182$.

GAUTIER DAlChÉ, P., NIColet, C. (1987) : « Les "quatre sages" de Jules César et la "mesure du monde" selon Julius Honorius. II : la tradition médiévale », Journal des Savants, p. 184-209.

HARLEY, J. B. \& WOODWARD, D. (1987) : History of Cartography. I Cartography in Prehistoric, Ancient, and Medieval Europe and the Mediterranean, Chicago.

HIATT, A. (2008) : « The Map of Macrobius before 1100 », Imago Mundi, 59 (2007), p. 149-176.

HOOGVLIET, M. (2007) : Pictura et Scriptura. Textes, images et herméneutique des Mappae mundi (XIII ${ }^{e}-\mathrm{XVI}{ }^{e}$ siècles), Turnhout.

JACOB, C. (2003) : « La bibliothèque, la carte et le traité : les formes de l'accumulation du savoir à

Alexandrie ", dans ARGOUD \& GUILLAUMIN, p. 19-37.

LILLEY, K. D., éd. (2013) : Mapping Medieval Geographies : geographical encounters in the Latin West and beyond, Cambridge.

LOZOVSKY, N. (2008) : « Maps and panegyrics : Roman geo-ethnographical rhetoric in late Antiquity and the Middle Ages ", dans TALBERT \& UNGER, éd. 2008, p. 169-188.

MODÉRAN, Y. (2003) : « De Julius Honorius à Corippus : la réapparition des Maures au Maghreb oriental », CRAI, 147, 1, p. 257-285.

TALBERT, R. \& UNGER, R. W., éd. (2008) : Cartography in Antiquity and the Middle Ages : fresh perspectives, new methods, Leyde.

\section{NOTES}

1. Pour la mappa d'Albi (Albi, Ms 29 f. $57 \mathrm{v}$. http:// archivesnumeriques.mediatheques.grand-albigeois.fr/_images/OEB/RES_MS029/ index.htm.), $96 \%$ des noms (50 en tout) sont cités chez Orose ou Isidore de Séville. La plupart des noms ne sont pas des références bibliques. Face à la carte du monde (f. 57v), qui est aujourd'hui la plus ancienne conservée (seconde moitié du viII ${ }^{\mathrm{e}}$ siècle), et qui elle-même présente les lieux sous forme de listes, se trouve une liste de 24 mers et 12 vents avec pour titre Indeculum quod maria uel uenti sunt ( Index des mers et des vents ", f. 58r). Après les deux feuillets se trouve le texte géographique d'Orose (f. $58 \mathrm{v}$ à 
61v). Voir Dan 2017, 13-44. Mais la carte, avec 50 noms inscrits, ne reflète pas uniquement le texte d'Orose, et n'est pas liée étroitement au texte. C'est dans cette mesure que nous l'écarterons de notre propos.

2. Jacob 2003, 28, écrit qu'elle crée « un ensemble de relations abstraites entre des lieux que rien ne permettrait de rapprocher autrement ».

3. Gautier Dalché 2008, 39.

4. Eum., Pan. Lat., Pro scholis restaurandis, 20.2, t. I, Les Belles Lettres, Paris, 1949 : « Siquidem illic, ut ipse uidisti, credo, instruendae pueritiae causa, quo manifestius oculis discernuntur quae difficilius percipiuntur auditu, omnium cum nominibus suis locorum situs spatia interualla descripta sunt, quidquid ubique fluminum oritur et conditur, quacumque se litorum sinus flectunt, qua uel ambitu cingit orbem uel impetus inrumpit Oceanus ". Voir Lozovsky 2008, 98 et 169-172: « Thus both the map itself, which seems to have existed as a physical object, and its description by Eumenius were meant to serve as vehicles for imperial propaganda $"$.

5. Dans les manuscrits Vatican, Vat. Lat. 642, XII ${ }^{\mathrm{e}}$ siècle; Leyde, Bibl. der Rijksuniv. Scaliger 39. Voir Gautier Dalché 1994a. Le poème, qui eut une large diffusion au Moyen âge, fut repris par Dicuil.

6. Le concept n'est pas nouveau. Arnaud 2009, 55, rappelle que, d'après Pline l'Ancien (3.17 : Cum orbem orbi spectandum propositus esset [...]), au $\mathrm{I}^{\mathrm{er}}$ siècle le but d'Agrippa était " de donner à voir le monde », quand il fit réaliser une carte affichée sans doute sur un portique à Rome.

7. Depuis la fameuse «carte d'Agrippa », perdue, dont la forme est toujours l'objet de vifs débats, jusqu'aux grandes mappae mundi médiévales héritées de l'Antiquité (voir Hoogvliet 2007), en passant par les formae des arpenteurs, les pinakes, ou l'archétype antique de la Tabula Peutingeriana, sous forme d'itinéraire, la question de la forme prise par la mise en images des informations géographiques et ethnographiques (schéma aux lignes géométriques, diagramme, mappemonde ou "carte locale ou régionale " avec des informations multiples, au sens moderne) reste largement posée et non résolue, faute de sources conservées et d'informations. Pour une tentative de typologie des cartes anciennes, voir Arnaud 1990, 187-208.

8. Cassiod., Inst., 1.25 : Cosmographiae quoque notitiam uobis percurrendam esse non immerito suademus, ut loca singula, quae in libris sanctis legitis, in qua parte mundi sint posita euidenter cognoscere debeatis. Quod uobis proueniet absolute, si libellum Iulii oratoris, quem uobis reliqui, studiose legere festinetis, qui maria, insulas, montes famosos, prouincias, ciuitates, flumina, gentes ita quadrifaria distinctione complexus est, ut paene nihil libro ipsi desit, quod ad cosmographiae notitiam cognoscitur pertinere. [...] Deinde penacem Dionisii discite breuiter comprehensum, ut quod auribus in supradicto libro percipitis, paene oculis intuentibus uidere possitis. Tum si uos notitiae nobilis cura flammauerit, abeti Prolomei codicem, qui sic omnia loca euidenter expressi, ut eum cunctarum regionum paene incolam fuisse iudicetis, eoque fiat ut uno loco positi, sicut monachos decet animo percurratis quod aliquorum peregrinatio plurimo labore collegit. (Édition Mynors 1937, 66. Traduction de Gautier Dalché 2009, 64).

9. Modéran 2003, 265-268; Kubitschek : « Julius Honorius », RE

(t.X, 1919, col. 614-628) ; Gautier Dalché 1987.

10. Un seul manuscrit est actuellement divisé entre le Paris. Lat. 2769, f. 23v et le Paris. Lat. 4808 , f. 53 r-65r. 
11. Paris BnF, lat. 4808, f. 53r-65r (A), datable par son écriture onciale du vie siècle. Il a pour particularité de donner le titre : excerpta eius sphaera uel continentia.

12. Julius Honorius, Cosmographia : «Et ut haec ad compendia ipsa deducta in nullum errorem cadat, sicut a magistro dictum est, hic liber excerptorum ab sphaera ne separetur. Sequuntur enim compendia, quae infra scripta uidebis. Quattuor (ut iterum dicam) oceanorum ratio non praetermittenda. Sunt enim per orbem totum terrae cosmographiae maria XXV, insulae LI, montes famosi XXX, prouinciae LV, oppida CCXVIII, flumina LV, gentes XC. Haec omnia in descriptione recta orthographiae transtulit publicae rei consulens Iulius Honorius magister peritus atque sine aliqua dubitatione doctissimus : illo nolente ac subterfugiente nostra partita protulit, diuulgauit et rei publicae scientiae obtulit " (éd. Riese A., 1878: Geographi Latini minores, Heilbronn, 55).

13. Julius Honorius, Cosmographia : «Propter aliquos anfractus ne intellectum forte legentis perturbet et uitio nobis acrostichis esset, hic excerpendam esse curauimus [...] Et ut haec ratio ad conpendia ista deducta in nullum errorem cadat, sicut a magistro dictum est, hic liber exceptorum ab sphaera ne separetur » (éd. Riese 1878, 24 et 55).

14. Riese 1878, 21-55. Voir la prudence adoptée, pour l'Afrique du Nord, par Modéran 2003,40 .

15. Gautier Dalché 1997, 187.

16. Gautier Dalché 2008, 39 et Gautier Dalché 1994b. Il note que le manuscrit de la recension A de Julius Honorius témoigne de l'eruditio de ses lecteurs.

17. Derenzini 1995, 450-451.

18. BnF, Parisianus graecus Ms. 2771, f. 63r ; f. 73v.

19. Sur la carte T-O, tournée vers l'Orient, les trois continents connus, l'Asie, l'Europe et l'Afrique, sont placés de part et d'autre de barres verticale et horizontale, formant un $\mathrm{T}$, qui représentent le tracé des fleuves (Tanaïs, Nil) et de la mer (Méditerranée), éléments structurants de l'orbis terrarum. En haut de la barre horizontale se trouve l'Asie, et de part et d'autre de la verticale (Méditerranée), l'Europe et l'Afrique. Voir figures 7, 8 et 9.

20. Plus de 60 exemples dans les manuscrits de Salluste ont été répertoriés par Destombes 1964, 66-73. Voir Block Friedman 2000, 534-535. Parmi les 12 manuscrits les plus anciens $\mathrm{du} \mathrm{IX}^{\mathrm{e}}$ au $\mathrm{X}^{\mathrm{e}}$ siècle, 5 sont illustrés de schémas cartographiques. Destombes en a distingué deux sortes : les unes ont une vingtaine ou trentaine de noms, les autres une cinquantaine. Pour Salluste, on peut voir l'exemple du BnF, Ms. Lat.6253, f. 52v, orienté à l'ouest : les noms sont répartis dans des cases au cœur du schéma tripartite, beaucoup plus détaillé pour l'Afrique (partie gauche). Autre exemple, la carte de la Bibliotheca Medicea Laurenziana de Florence (Plut. 16.18, f. 63v), datant du XIII ${ }^{\mathrm{e}}$ siècle. Voir les illustrations dans Harley 1987, 344.

21. Gautier Dalché 1994, 707 et Gautier Dalché 2008, 37-38.

22. Cela concerne le livre 13 des Etymologiae qui énonce la forme de la Terre, les océans, mers, rivières, vents.

23. Manuscrit d'Isidore de Séville, De natura rerum, vers 960-980, Cathedral Library of Exeter, Ms. 3507, f. 67r.

24. British Library, Ms. Harley 2799, f. 241v. Voir Gautier Dalché 1994, 724.

25. Voir Gautier Dalché 2005, 136. Gautier Dalché 2014, 167. Voir aussi Lilley 2013, 8, citant Gautier Dalché 2006a. 
26. La Méditerranée est appelée Affricum mare, et sépare l'Europe de l'Africa. Les fleuves Thanais and Nylus séparent chacun respectivement l'Asie de l'Europe, et l'Afrique de l'Europe. Tout autour se trouve un double cercle : Occeanus.

27. En Asie, on lit par colonne, de gauche à droite : Armenia, Bithinia, Frigia, Galacia, Lidia, Bactria, Pamphilia, Cilicia, Nycea et Troya, puis, sous Paradysus : India, Parthia, Assyria, Persida, Media, Mesopotamia, C(h)aldea, Arabia, Syria, Palestina, Ascolonia, Anthyochia. Sous le nom ASYA (qui est centré), Samaria, Galylea, Iudea, Hherusalem. Dans le $3^{\mathrm{e}}$ secteur, Alexandria, Egyptus, Babylonia. Pour l'Europe, quatre zones structurent la présentation en liste : à droite, Roma, Ythalia (sic), au centre Constantinopolis, Grecia, Ungaria, Danubius fl(uuius), Germania. Francia est décalé et isolé vers la droite. Hyspania est écrit en perpendiculaire, hors de toute colonne. À gauche, Anglia, Scotia, Hybernia, Britannia. Enfin, l'Afrique (Affrica) : Hyppone, Carthago, Adrimetum, Cyrene, Syrtes (séparé en deux syllabes), Thereon, Leptis, Phylemonare, Numidi, Mauretania, Getuli, Perse. En transversale perpendiculaire à droite : Regnum Cyrenensium, Ethyopia.

28. C'est le même principe d'organisation de la liste par zones géographiques dans une carte d'un manuscrit de Solin datant du XII ${ }^{\mathrm{e}}$ siècle.

29. Cathabatanum est par exemple le mont Cathabatmos de Salluste déformé, qui est un plateau à l'ouest du Nil marquant la limite de l'égypte. Voir Gautier Dalché 2002.

30. Gautier Dalché 2005 préfère le $2^{\mathrm{e}}$ terme et nous considérons également que c'est le plus adapté. Le schéma diagrammatique ne comprend pas nécessairement de formes dessinées ou symboliques, et est fondé sur des formes géométriques simples et des découpages zonaux de l'œcoumène, avec des légendes inscrites et des regroupements de noms. Arnaud 1990b, 51, parle même d'idéogrammes. On a pu répertorier au moins 100 mappemondes dans les manuscrits de Macrobe, dont 63 antérieures au xIII ${ }^{\mathrm{e}}$ siècle.

31. Macrobe, 2.9.7: « omnia haec ante oculos locare potest descriptio substituta ».

32. Macrobe, 2.5, 13 : « animo facilius inlabitur concepta ratio descriptione quam sermone ».

33. Macrobe, 1.21, 3 : « quia facilior ad intellectum per oculos uia est, id quod sermo descripsit uisus adsignet ».

34. Cologne, Dombibliothek, Ms. 186, f. 106v.

35. Macrobe, 2.9,8.

36. Macrobe, 2.9,7 : "omnia haec ante oculos locare potest descriptio substituta, ex qua et nostri maris originem, quae totius una est, et Rubri atque Indici ortum videbis, Caspiumque mare unde oriatur invenies ".

37. Voir Gautier Dalché 2008, 36. L'image du globe illustre d'abord les manuscrits de Macrobe, puis ceux d'Isidore de Séville ; Gautier Dalché 1994, 798, exclut que les cartes soient d'Isidore et parle d'abus de langage pour " cartes isidoriennes ».

38. 6 manuscrits, parfois incomplets, datent du Ix siècle et présentent un schéma de la Terre : BnF, Ms. lat.6370 ; Cologne Dombibliothek Ms. 186 ; Bern, Burgerbibliothek, Ms. 347 ; BnF, Ms. nal.454; Bibliotheca Apostolica Vaticana, Reg. Lat. 1669 et 1762.

39. Le manuscrit de la BnF, Ms. Lat. 6379 , f. $89 \mathrm{v}$ présente un schéma zonal, mis en marge en bas de feuille à gauche, qui date du XII siècle et qui a été ajouté à un manuscrit du IX $X^{e}$ siècle, puisqu'on a effacé 17 lignes de la première version écrite sans illustration, pour faire de la place au schéma en resserrant le texte plus haut. Dans un autre cas, une carte qui n'a pas été finie a été ajoutée au XI ${ }^{\mathrm{e}}$ siècle en pleine page, mais à la fin du Commentaire de Macrobe (Cologne, Dombibliothek, Ms. 186, f. 74v). D'après 
A. Hiatt, 2008, 154-155, ces ajouts postérieurs dans un manuscrit sont révélateurs des difficultés rencontrées par les copistes et les lecteurs face à l'éventuelle absence de carte, que l'on va pallier ensuite.

40. 35 manuscrits de Macrobe datent d'avant 1100.Voir Hiatt, 2008, 153-154.

41. Macrobe, 2.9,7.

42. " mare rubrum, mare indicum, mare caspium, oceanus ».

43. Bibliotheca Apostolica Vaticana, Ms. 1341, f. 86 (Abbaye de Lorsch). Ce sont les mêmes noms sur plusieurs manuscrits, parmi lesquels Oxford, Bodleian Library, Ms. D’Orville 77, f. 100r.

44. Bruxelles, Bibliothèque royale, Ms. 10146, f. 109v.

45. 5 manuscrits sur les 35 plus anciens évoquent ces cités.

46. Macrobe, 2.7 et 2.8,3. P. Gautier Dalché pense que ces noms ont été ajoutés à la carte originale $(1994 b, 717)$; on ne peut pas prouver le contraire, mais le fait est que Macrobe explique la position importante de ces deux cités, l'un (Syène) étant sur le tropique nord du Cancer, l'autre (Méroé) à la limite de la zone torride.

47. Entre autres, Pline l'Ancien, Histoire naturelle, 6.181-183. Au-delà de Méroé, explique-t-il, se trouvent des races monstrueuses.

48. Strabon, Géographie, 1.4 ; 1-2. Ptolémée, Géographie, 4.7.7.

49. Paris, BnF, Ms. lat. 6370 , f. $89 \mathrm{v}$.

50. Cologne, Dombibliothek, Ms. 186, f. $74 \mathrm{v}$.

51. Le manuscrit Munich, Bayerische Staatsbibliothek, Clm 14436, f. 58r est un contreexemple de la fin $\mathrm{x}^{\mathrm{e}}$-début $\mathrm{XI}^{\mathrm{e}}$ siècle : il est une simplification du dessin et une diminution des références géographiques.

52. Par exemple, le manuscrit de Munich, Bayerische Staatsbibliothek, Clm 6362, f. 74r, et de la British Library, Egerton Ms. 2976, f. 62v, du début du XII siècle où les toponymes hispania, alpes, gades, balearia, sardinia, Sicilia, egiptus,asia apparaissent, alors qu'ils ne figurent pas dans les manuscrits les plus anciens. On trouve aussi indiqués le Tanais et le Palus Maeotis.

53. M. Destombes, 1964, a trouvé plus de 150 manuscrits entre le XIII siècle et le XVI siècle.

54. Gautier Dalché 2005, 152.

\section{RÉSUMÉS}

Les descriptions du monde sous forme de listes de toponymes antiques sont une des formes d'écrit géographique qui perdurent dans l'Antiquité tardive, et qui sont reprises et compilées au haut Moyen Âge. Plusieurs exemples d'œuvres littéraires transmises par des manuscrits, et des sources épigraphiques de l'apprentissage scolaire, tels que tablettes et papyri, nous montrent que la connaissance du monde figurait parmi les objectifs de l'éducation et de l'érudition. Les traités de géographie permettent de suivre l'évolution de la culture du monde antique, des méthodes 
d'apprentissage, et la circulation du savoir. Y avait-il un modèle commun, une base de la connaissance, et sur quoi était-elle fondée ? Progresse-t-elle au fur et à mesure d'expéditions de découverte? Nous tenterons de déterminer quel a pu être l'usage de cartes ou de schémas cartographiques dans un contexte scolaire de transmission du savoir géographique.

\section{AUTEUR}

DELPHINE ACOLAT

Maître de conférences en histoire romaine, Université de Bretagne Occidentale, Laboratoire Centre François d'épistémologie et d'histoire des sciences et des techniques 


\title{
Transmission, réappropriation et réutilisation d'un savoir " antique » à l'époque médiévale $\left(\mathrm{XII}^{\mathrm{e}}-\mathrm{XV}^{\mathrm{e}}\right.$ siècles) : le cas des Varioe de Cassiodore
}

\author{
Nicolas Michel
}

\begin{abstract}
«Further study of manuscripts of the Varice is needed. Doing so would require reconstructing the readership of the Varice on a case-by-case basis, but might reveal patterns useful for understanding how the Varice contributed to the active reconstruction of the memory of the later Roman Empire for medieval audiences. ${ }^{1}$ "
\end{abstract}

1 Flavius Magnus Aurelius Cassiodorus «Senator ", dit Cassiodore, homme de confiance des derniers représentants de la dynastie des Amales dans l'Italie ostrogothique, s'impose comme l'une des figures majeures de la littérature médiévale, entendue au sens large du terme. Parmi une production intellectuelle foisonnante, qu'elle soit politique, spirituelle, pédagogique ou littéraire, la collection épistolaire connue sous le nom de Varice a depuis longtemps bénéficié d'un intérêt tout particulier de la part des chercheurs qui y voyaient une source de première main pour la connaissance de l'Antiquité tardive. Pourtant, malgré le potentiel analytique exceptionnel de l'œuvre sur le plan diachronique, ces différentes études demeurent majoritairement centrées sur des analyses internes, stylistiques ou historiques, délaissant ainsi l'histoire de la postérité des Varice ${ }^{2}$. C'est pourquoi notre projet de thèse ${ }^{3}$, loin de chercher à reprendre le dossier philologico-historique de l'œuvre, se propose d'interroger les Varice sous l'angle de l'histoire des pratiques culturelles et sociales de l'écrit, répondant ainsi au souhait émis par Shane Bjornlie qui déplorait le peu d'attention accordée à la réception concrète de la collection épistolaire de Cassiodore. Car c'est bien de transmission, de réception et, bien évidemment, d'usage dont il est ici question. La focale de notre recherche, à savoir les $\mathrm{XII}^{\mathrm{e}}-\mathrm{XV}^{\mathrm{e}}$ siècles, se situe donc en aval, près de six siècles après la rédaction des Varioe. 
2 Pourquoi cependant se restreindre aux derniers siècles du Moyen Âge, lorsqu'on sait que Cassiodore mit la touche finale à sa collection épistolaire dans les années 537-538 à Ravenne? Voilà justement où se situe la première, et non des moindres, pierre d'achoppement de l'enquête. En effet, si bon nombre d'auteurs du Haut Moyen Âge, essentiellement pour la période carolingienne, puisèrent abondamment dans le corpus cassiodorien, les Varice demeurent pourtant absentes du paysage littéraire médiéval avant le début $\mathrm{du} \mathrm{XI}^{\mathrm{e}}$ siècle, époque qui vit la production des premiers manuscrits des Varice parvenus jusqu'à nous. Notre contribution tentera donc dans un premier temps d'expliquer le vide apparent constaté pour la période qui s'échelonne entre la date d'achèvement de l'œuvre et le $\mathrm{xl}^{\mathrm{e}}$ siècle, pour ensuite se concentrer sur l'explosion de manuscrits, correspondant selon toute vraisemblance à une « redécouverte » des Varice, observée au cours de la seconde moitié du xII ${ }^{\mathrm{e}}$ siècle.

3 Avant toute chose, il convient de rappeler quelques éléments biographiques sur le personnage. Né vers 485 dans une famille aristocratique de Calabre, Cassiodore exerça d'abord une série de fonctions politiques de haut niveau: d'abord comme conseiller de son père, alors préfet du prétoire; puis comme membre de l'entourage des rois ostrogoths, auprès desquels il exerça la charge de questeur, maître des offices (poste qui fut auparavant entre les mains de Boèce, dont il fut le contemporain) et préfet du prétoire. Peu de temps après la compilation des Varice, Cassiodore partit pour Constantinople, départ causé par la prise de Ravenne par Bélisaire en 540. Il y demeura jusqu'en 555 environ avant de revenir en Calabre sur les terres familiales pour y fonder le célèbre monastère de Vivarium, lequel joua au travers de son scriptorium et de sa bibliothèque un rôle essentiel dans la sauvegarde d'une bonne partie de la culture classique, notamment grecque, grâce aux nombreuses traductions qui y furent réalisées ${ }^{4}$.

4 Les Variae, compilées nous l'avons dit vers 537-538 à Ravenne, appartiennent à l'activité politique de l'auteur. Il s'agit d'une collection épistolaire, organisée en douze livres pour un total de 468 lettres, où sont rassemblés les actes rédigés par Cassiodore en tant que questeur (I-IV), maître des offices (V, VIII-IX) et préfet du prétoire (X-XII), les livres VI-VII reprenant des formules types de nomination de fonctionnaires destinées à servir de modèles (tabl. 1).

Tab. 1. - Organisation de la collection des Variae

\begin{tabular}{|c|c|c|c|}
\hline Livres & Autorité & Cassiodore & Dates \\
\hline I-IV & Théodoric & Questeur & 506-511 \\
\hline $\mathrm{V}$ & Théodoric & Maître des Offices & $523-526$ \\
\hline VI-VII & / & $\begin{array}{l}\text { Formules } \\
\text { nomination }\end{array}$ & / \\
\hline $\begin{array}{l}\text { VIII- } \\
\text { IX }\end{array}$ & Athalaric & Maître des Offices & $\begin{array}{lll}526-527 & \text { (VIII); } 526-527 & \text { et } \\
533-534 & & \end{array}$ \\
\hline $\mathrm{X}$ & $\begin{array}{l}\text { Amalasonte, Théodat et } \\
\text { Vitigès }\end{array}$ & Préfet du Prétoire & $534-537$ \\
\hline XI-XII & Cassiodore & Préfet du Prétoire & $533-537$ \\
\hline
\end{tabular}


Au-delà de l'intérêt évident de la collection pour l'étude de l'Italie ostrogothique de la première moitié $\mathrm{du} \mathrm{VI}^{\mathrm{e}}$ siècle, l'œuvre occupe une place décisive dans l'histoire de la littérature latine, puisqu'il s'agit de la première véritable collection épistolaire organisée comme telle - les lettres de Symmaque et de Sidoine Apollinaire n'ayant pas la même finalité -, marquée par un projet textuel évident puisque réunie par l'auteur de son vivant - Cassiodore a en effet développé à Vivarium la pratique de réunir différents textes dans un seul et même volume, la Bible par exemple, appelé pandecte, ou son Historia tripartita, in unum collectce - avec une ferme intention de pérennité. Dans le prologue, Cassiodore exprima d'ailleurs clairement le souhait de voir sa collection utilisée par les générations futures, dans une optique utilitaire, pragmatique ${ }^{5}$. Ce souhait semble avoir été réalisé au regard de l'incroyable diffusion manuscrite qu'a connue la collection. Dans son édition de 1894, qui est du reste un véritable modèle de scientificité pour l'époque, Theodor Mommsen établit une liste de 118 manuscrits, liste que nous avons réussi à augmenter d'une soixante de témoins pour parvenir actuellement à un total de 184 exemplaires conservés.

6 Jusqu'ici la tâche semble assez aisée : il suffit de mettre à jour la liste de Mommsen (exercice néanmoins délicat au vu de l'évolution de certains fonds, comme pour les anciens manuscrits de la collection Phillipps) tout en la complétant grâce aux nouveaux catalogues et outils informatiques disponibles. Cette étape achevée, il suffirait d'effectuer une série d'analyses codicologiques et historiques (caractéristiques matérielles des volumes, environnement textuel, annotations et marques de lecture, provenance, etc.) pour pouvoir répondre à nos interrogations de départ. Malheureusement, cet idéal se transforme rapidement en utopie par le simple fait que la collection épistolaire de Cassiodore n'a pas connu une diffusion aussi constante et organisée que nous le souhaiterions.

7 En effet, l'écrasante majorité des manuscrits ne transmettent qu'une partie de la collection, ce qui conduisit Mommsen à établir six familles textuelles, en fonction des différents livres contenus dans chaque codex : classe I = I-IV, 39 ; classe II = I-VII, 41 ; classe III = VI-VIII, 10 ; classe IV = VII, 41-XII ou VIII-XII ; classe V = extraits des livres VIII-XII ; classe VI = collection complète (mais texte corrompu, où sont mixés des manuscrits de plusieurs classes, dont aucun n'est antérieur au XIV siècle). Ce constat pose de nombreuses difficultés d'analyse : comment interpréter chaque classe? Quel rôle assigner au texte de Cassiodore, en particulier dans les manuscrits (assez nombreux) qui ne transmettent que quelques feuillets extraits de la collection? La fragmentation de l'œuvre répond-elle à un choix, effectué en fonction du contenu de chaque livre, ou bien celle-ci dépend-elle simplement du « hasard» de la transmission textuelle?

8 À cette difficulté philologique vient s'ajouter, comme annoncé précédemment, l'absence quasi absolue de la moindre trace des Varice avant le $\mathrm{xI}^{\mathrm{e}}$ siècle. Comment expliquer une telle disparition? Pour tenter de répondre à cette question, ou à tout le moins lancer quelques pistes de réponses possibles, nous nous sommes intéressé à la tradition textuelle et manuscrite d'autres œuvres du Senator, dans l'espoir d'y trouver quelques éléments de comparaison avec notre propre texte.

9 Pour commencer, il nous faut nous pencher sur le destin de la bibliothèque de Vivarium: on sait qu'il existait sur place deux bibliothèques, la première, celle de Cassiodore, fut rapidement intégrée dans la seconde, à savoir celle des moines. Après la mort de son fondateur, le monastère connut un déclin assez rapide, de telle sorte que la 
bibliothèque monastique fut transférée au cours $\mathrm{du} \mathrm{VII}^{\mathrm{e}}$ siècle dans la bibliothèque pontificale du Latran à Rome. Qu'en est-il dès lors de la survie de l'œuvre cassiodorienne? Si l'on observe l'histoire de la transmission de textes tels que l' Expositio Psalmorum, le De Orthographia ou encore les Institutiones, on peut établir le parcours suivant: après avoir été transférées à Rome, les œuvres de Cassiodore demeurèrent soit dans les bibliothèques monastiques de l'Italie centro-méridionale (telle celle du Mont-Cassin), ces manuscrits ayant par la suite donné naissance à une tradition germanique particulièrement féconde, soit ils partirent en Grande-Bretagne avec les moines évangélisateurs au $\mathrm{VII}^{\mathrm{e}}$ siècle, où ils donnèrent lieu à plusieurs copies insulaires en Northumbrie, avant de revenir sur le continent au siècle suivant, notamment par le biais d'Alcuin, ancien maître de l'école de York. C'est alors que l'on vit la floraison de copies dans plusieurs centres d'écriture du royaume franc, ainsi que dans certaines fondations insulaires situées en Allemagne (Saint-Gall, Lorsch, Reichenau, Saint-Emmeran, Echternach) ou en Italie (en particulier Bobbio et Vercelli). En dehors des indices laissés par les manuscrits ou catalogues de bibliothèques, d'autres éléments attestent de la circulation du corpus cassiodorien, en particulier les œuvres d'Isidore de Séville, de Bède le Vénérable et bien évidemment d'Alcuin, trois auteurs qui utilisèrent abondamment les œuvres du Senator ${ }^{6}$.

Qu'en est-il des Varice? Dans l'état actuel de nos connaissances, aucune trace directe ou indirecte de l'œuvre n'a pu être décelée avant le IX siècle. Nous avons bien évidemment tenté de regarder du côté du De anima, œuvre composée peu de temps après les Varice et qui est explicitement définie par son auteur comme le treizième livre de la collection ${ }^{7}$. L'œuvre, pour laquelle on conserve des manuscrits dès le $\mathrm{IX}^{\mathrm{e}}$ siècle, est utilisée par Hincmar de Reims ou encore Raban Maur et fut vraisemblablement envoyée en GrandeBretagne à l'instar d'autres textes de Cassiodore ${ }^{8}$. Malgré l'union théorique prévue par le Senator entre les deux textes, les Varice sont une fois de plus absentes des premiers temps de l'histoire du De anima. Il faut donc en conclure que cette œuvre, si elle faisait initialement partie des Varice en tant que treizième livre de la collection, connut rapidement une diffusion indépendante, sans doute en raison de la nature même de son contenu, assez éloigné du caractère administratif des douze premiers livres.

11 Venons-en à la première trace laissée par les Varice de Cassiodore. C'est dans le catalogue de la prestigieuse abbaye bénédictine de Lorsch, fondée à la limite du land de Hesse (centre-ouest de l'Allemagne) en 764, rédigé en plusieurs phases au cours de la première moitié $\mathrm{du} \mathrm{IX}^{\mathrm{e}}$ siècle, que l'on trouve, juste avant les lettres de Sidoine Appolinaire, la mention suivante : libri epistolarum senatoris diaconi, postea presbyteri, ad diversos numero XVII in uno codice ${ }^{9}$. Nous savons que la bibliothèque contenait à la même époque un exemplaire du De anima, dont descendent les manuscrits de la seconde famille telle que définie par James W. Halporn dans son édition. Il est probable que le manuscrit mentionné dans l'inventaire contenait initialement la collection complète des Varice, avant que celle-ci ne soit amputée du De anima ${ }^{10}$. L'abbaye de Lorsch ayant des liens étroits avec la cour impériale carolingienne, il n'est pas impossible d'y voir une origine pour le texte des Varice. Samuel Barnish, dans son ouvrage de 1992, avait déjà émis l'hypothèse d'une influence possible de l'école palatine d'Aix concernant certains manuscrits du De anima, en posant la question de l'éventuelle connaissance des Varice par les membres de la chancellerie carolingienne ${ }^{11}$. Il conviendra dans nos recherches futures d'investiguer plus avant cette hypothèse. Faute d'éléments tangibles pour les périodes précédentes, nous souhaiterions à présent nous intéresser aux 
premiers témoins conservés de la collection épistolaire du Senator, en tentant de mieux saisir ce regain d'intérêt si soudain observé à partir du XII ${ }^{\mathrm{e}}$ siècle.

Comme nous l'avons dit précédemment, aucun exemplaire des Varice n'a pu être retrouvé pour la période antérieure au $\mathrm{XI}^{\mathrm{e}}$ siècle. Ce n'est qu'à ce moment qu'apparaissent les premiers témoins de la collection: il s'agit de deux fragments, le premier conservé à Halle-Wittenberg, qui contient des extraits du livre IX, le second, autrefois possédé par l'historien allemand Karl Koppmann (connu sous le nom de fragment Koppmannianum) et décrit par Adolf Hofmeister, contient une partie du livre VIII (lettres 1, 2, 3, 10 et 11$)^{12}$.

Toutefois, ces deux fragments, restreints à l'aire germanique, apparaissent comme une exception, certes notable, au regard de la véritable explosion manuscrite qui s'opère à partir de la seconde moitié du $\mathrm{XII}^{\mathrm{e}}$ siècle, période qui marque véritablement la renaissance des Varice. De cette époque, on ne dénombre pas moins d'une quinzaine de manuscrits, provenant de France (principalement la France du Nord), du centre et de l'ouest de l'Allemagne, et pour deux manuscrits d'Angleterre ${ }^{13}$. L'essentiel des codices ont été copiés dans des scriptoria d'abbayes bénédictines ${ }^{14}$, bien qu'on recense déjà un manuscrit cistercien, copié à la fin du XII ${ }^{\mathrm{e}}$ siècle à Clairvaux ${ }^{15}$.

Nous avons vu que les abbayes bénédictines allemandes possédaient déjà le texte des Varice, milieu d'où proviennent vraisemblablement les deux fragments du $\mathrm{xl}^{\mathrm{e}}$ siècle. Mais comment expliquer la soudaine production française et anglaise? L'une des tentatives de réponse, certes non exhaustive, réside dans le séjour concomitant du pape Alexandre III et de l'archevêque de Cantorbéry Thomas Becket en France entre 1163 et 1165. On pourrait en effet supposer qu'Alexandre III, qui séjourna du côté de Sens accompagné d'une importante cour, a pu apporter des exemplaires des Varice restés dans les monastères bénédictins d'Italie méridionale. Ces manuscrits auraient alors servi de modèles pour la copie d'exemplaires français, d'où serait par exemple issue la copie de Clairvaux. Quant à Thomas Becket, ce dernier aurait alors joué le rôle de passeur pour la tradition anglaise, rapportant avec lui en Angleterre une ou plusieurs copies des Varice. Nous en voulons pour preuve le manuscrit 166 de la Magdalena College Libray (Oxford), copié dans la seconde moitié du XII ${ }^{\mathrm{e}}$ siècle dans le nord de la France et légué à la cathédrale de Christ Church avec le reste de la collection de Thomas Becket au moment de sa mort à la fin de l'année $1170^{16}$. La possession du manuscrit par l'archevêque est confirmée par le catalogue médiéval de la bibliothèque de Christ Church, établi au XIV siècle et édité par James Montague Rhodes, où l'on trouve, au numéro 835, le titre "Epistole regis Atheniensium $»^{17}$. L'erreur de titulature s'explique vraisemblablement par la confusion du copiste qui a inscrit en tête du premier feuillet le titre erroné, repris ensuite par le catalogueur sans vérification du contenu. La cote, «.D. ij. Ga. v. .sa.», inscrite dans le coin supérieur droit, permet de lever toute hésitation puisqu'il s'agit bel et bien du système de cotation propre à Christ Church. On peut donc en conclure que Thomas Becket acquit, lors de son séjour en France, l'exemplaire des Varice, qui fut ensuite rapporté en Angleterre avec le reste de sa bibliothèque. Il nous faudra voir, par la comparaison entre les différents manuscrits, si ce dernier est à l'origine des deux autres exemplaires anglais produits à la même époque, en particulier le manuscrit 0.7.13 du Trinity College à Cambridge, qui fut légué à l'abbaye de St-Albans par l'abbé Simon, ami de Thomas Becket.

Au-delà des concours de circonstances qui peuvent expliquer cette recrudescence dans la production manuscrite des Varice, c'est d'abord et avant tout le contexte culturel 
général qui explique, selon nous, ce regain d'intérêt pour la collection épistolaire de Cassiodore. Peu de temps auparavant, vers la fin du XI ${ }^{\mathrm{e}}$ siècle, apparaît au Mont-Cassin, dans le Latium italien, un nouveau genre stylistique et littéraire, l'ars dictaminis. Cet art de la rédaction se présente comme une actualisation proprement médiévale des techniques stylistiques héritées de la rhétorique antique. Intrinsèquement lié à la composition épistolaire, mode de communication par excellence à l'époque, largement employée dans les milieux notariaux et dans les chancelleries, en particulier papale et impériale, l'ars engendra une production littéraire abondante durant les derniers siècles de la période médiévale. Au-delà des pratiques administratives, la discipline connut un essor majeur au sein du milieu universitaire - au départ depuis Pavie et Bologne, puis progressivement en France à partir d'Orléans -, dans le cadre plus général de l'enseignement de la rhétorique et des techniques de composition en prose latine. Loin d'être cantonnée à un groupe restreint d'utilisateurs, l'ars dictaminis devint rapidement la technique scripturaire par excellence d'un point de vue stylistique ${ }^{18}$. En tant que collection épistolaire, les Varice se trouvèrent inévitablement liées à ce mouvement culturel majeur : plusieurs études ${ }^{19}$ et témoignages médiévaux ${ }^{20}$ attestent des rapports entretenus avec l'ars dictaminis. Cette liaison s'explique notamment par le statut dont jouissait Cassiodore à l'époque, considéré par certains, tel ce professeur de médecine et ami de Pétrarque, Tommaso del Garbo, comme le "père de l'éloquence ", au détriment de Cicéron ${ }^{21}$. La nature même de l'œuvre, dont le titre, Variæe, fait directement référence aux différents styles utilisés par Cassiodore pour rédiger ses lettres, en fonction de leur destinataire, entrait en parfaite adéquation avec les exigences stylistiques défendues par l'ars dictaminis ${ }^{22}$.

Bien entendu, l'intérêt des médiévaux pour l'œuvre du Senator ne se cantonne pas au domaine épistolographique. Les Vario, de par leur caractère encyclopédique, où les digressions architecturales, culturelles ou scientifiques abondent ${ }^{23}$, servirent de source à nombre d'auteurs médiévaux, en particulier pour la rédaction de florilèges, comme le célèbre Florilegium Gallicum (xII ${ }^{\mathrm{e}}$ siècle), qui rassemble des extraits d'une quarantaine d'auteurs, majoritairement classiques, et dans lequel les Varice occupent une place importante ${ }^{24}$.

On le voit, la tâche à accomplir est vaste et les questions nombreuses : Comment évolue la production manuscrite des Varice, dans le temps et dans l'espace? Peut-on déceler des traces laissées par les Varice avant le XII ${ }^{e}$ siècle, moment qui vit la production des premiers manuscrits conservés de l'œuvre? Dans quels milieux retrouve-t-on l'œuvre de Cassiodore? Peut-on déceler des foyers spécifiques de diffusion de l'œuvre, et, si tel est le cas, en quoi sont-ils représentatifs de la réception des Varice? Est-il possible d'établir une typologie des possesseurs? Existe-t-il une corrélation entre les possesseurs des Varice et les milieux de diffusion des traités d'ars dictaminis? Au-delà du cas précis de l'œuvre de Cassiodore, notre thèse permettra de mieux comprendre les mécanismes de transmission textuelle sur le long terme. Comment les médiévaux des $\mathrm{XII}^{\mathrm{e}}-\mathrm{XV}^{\mathrm{e}}$ siècles mobilisent-ils des matériaux créés plus de cinq siècles avant eux ? Observe-t-on une forme de réactualisation de ces textes, en fonction du contexte historique de réception? En cherchant à saisir la vie d'une œuvre à partir de son utilisation concrète par un lectorat des $\mathrm{XII}^{\mathrm{e}}-\mathrm{XV}^{\mathrm{e}}$ siècles, tout en inscrivant le codex au cœur de l'enquête et en l'envisageant à la fois comme un objet matériel, un vecteur de culture et le révélateur des milieux qui l'ont produit et utilisé, notre thèse placera l'accent sur la question du statut du texte durant les derniers siècles du Moyen Âge. 


\section{BIBLIOGRAPHIE}

BARNISH Samuel J. B., The Variæ of Magnus Aurelius Cassiodorus Senator, Liverpool, Liverpool University Press, 1992.

BARRET Sébastien et GRÉVIN Benoît, Regalis excellentia : les préambules des actes des rois de France au XIV siècle (1300-1380), Paris, École nationale des chartes, 2014.

BECKER Gustav, Catalogi Bibliothecarum antiqui, Bonn, Éditions Cohen, 1885.

BJORNLIE Shane, «The Letter Collection of Cassiodorus ", dans sogno Christiana, sToRIN Bradley et WATTS Edward (éd.), A Critical Introduction and Reference Guide to Late Antique Letter Collections, Berkeley, University of California Press, 2016, p. 433-438.

Cassiodore, De anima, éd. par James W. HALPORN, Turnhout, Brepols (Corpus christianorum, series latina XCVI), 1973.

Cassiodore, Expositio psalmorum LXXI-CL, éd. par Marc ADRIAEN, Turnhout, Brepols (Corpus christianorum, series latina XCVIII), 1958.

Cassiodore, Varice, éd. par Theodor MOMMSEN, Berlin, Berolini (Monumenta Germaniae Historica. Auctores antiquissimi, 12), 1894.

CHANDELIER Joël, « Quand le disciple aimerait dépasser le maître : Gentile da Foligno, Tommaso del Garbo et Pétrarque entre scolastique et humanisme », dans Cédric GIRAUD et Dominique POIREL (éd.), La rigueur et la passion. Mélanges en l'honneur de Pascale Bourgain, Turnhout, Brepols, 2016 (Instrumenta Patristica et Mediaevalia, 71), p. 693-707.

CHRIST Karl, Die Bibliothek des Klosters Fulda im 16. Jahrhundert : Die Handschriften-Verzeichnisse, Leipzig, Zentralblatt für Bibliothekswesen, Beiheft 64, 1933.

COURCELLE Pierre, Les Lettres grecques en Occident : de Macrobe à Cassiodore, Paris, Éditions de Boccard, 1948.

GATTI Paolo et STOPPACCI Patrizia, « Cassiodorus Senator », dans CHIESA Paolo et CASTALDI Lucia (dir.), La trasmissione dei testi latini del Medioevo, IV, Firenze, SISMEL - Edizioni del Galluzzo (Millennio Medievale, 94), 2012, p. 82-142.

GRÉVIN Benoît, Rhétorique du pouvoir médiéval. Les lettres de Pierre de la Vigne et la formation du langage politique européen (XIII ${ }^{e}-X V^{e}$ siècle), Rome, École française de Rome, 2008.

GRÉVIN Benoît et TURCAN-VERKERK Anne-Marie (éd.), Le dictamen dans tous ses états. Perspectives de recherche sur la théorie et la pratique de l'ars dictaminis ( $\mathrm{XI}^{e}-\mathrm{XV} V^{e}$ siècles), Turnhout, Brepols, 2015.

FAUVINET-RANSON Valérie, "La réception variée des Variæe de Cassiodore au Moyen Âge ", dans AMADIEU Jean-Baptiste, JOUBERT Jean-Marc, PLOTON Nicollet François et VARTEJANU-JOUBERT Mădălina (éd.), Les Sources au cour de l'épistémologie historique et littéraire, Paris, École nationale des chartes, 2016, p. 35-47.

HELLER Emmy (éd.), Die Ars dictandi des Thomas von Capua : Kritisch erläuterte Edition, Heidelberg, Sitzungsberichte der Heidelberger Akademie der Wissenschaften, 1929.

HOFMEISTER Adolf, « Zur Überlieferung von Cassiodors Variæ », Historische Vierteljahrschrift, vol. 26, 1931, p. 13-46. 
JONES Leslie W., « Further Notes concerning Cassiodorus' Influence on Mediæval Culture », Speculum, vol. 22, 1947, p. 254-256.

JONES Leslie W., « The Influence of Cassiodorus on Mediæval Culture », Speculum, vol. 20, 1945, p. 433-442.

MANITUS Max, Geschichte der lateinischen Literatur des Mittelalters, III, München, Beck, 1931.

MONTAGUE RHODES James, The Ancient Libraries of Canterbury and Dover : the Catalogues of the Libraries of Christ Church Priory and St. Augustine's Abbey at Canterbury and of St. Martin's Priory at Dover, Cambridge, Cambridge University Press, 1903.

ROBERTSON James C. (éd.), Materials for the history of Thomas Becket, archbishop of Canterbury, III, London, Éditions Longman, 1877.

ROUSE Richard H., « Florilegia and Latin Classical Authors in Twelfth-and Thirteenth-Century Orléans », Viator, vol. 10, 1979, p. 131-160.

SCHALLER Hans Martin, Handschriftenverzeichnis zur Briefsammlung des Petrus de Vinea, Hannover, Hahn (Monumenta Germaniae historica. Hilfsmittel 18), 2002.

\section{NOTES}

1. S. Bjornlie, « The Letter Collection of Cassiodorus », p. 445.

2. Citons à titre d'exception l'étude récente de V. Fauvinet-Ranson, "La réception variée des Varice de Cassiodore au Moyen Âge », p. 35-47.

3. Les Variæ de Cassiodore, une collection épistolaire à l'épreuve du temps: étude de la diffusion, réception et de l'usage de l'œuvre (XII ${ }^{e}-\mathrm{XV}^{e}$ siècles), thèse préparée sous la direction conjointe de Xavier Hermand (Université de Namur) et de Paul Bertrand (Université Catholique de Louvain) à l'Université de Namur, en partenariat avec le Centre des Pratiques Médiévales de l'Écrit (PraME).

4. Sur toutes ces questions, on se réfèrera à l'ouvrage classique de P. Courcelle, Les Lettres grecques en Occident : de Macrobe à Cassiodore.

5. Cassiodore, Varice, éd. par T. Mommsen, p. 4, § 9-10.

6. Sur la tradition textuelle et manuscrite des œuvres de Cassiodore, on consultera en premier lieu la notice rédigée par P. Gatti et P. Stoppacci, "Cassiodorus Senator ", p. 82-142. On lira également l'article de L. W. Jones, «The Influence of Cassiodorus on Mediaeval Culture», p. 433-442, à compléter avec «Further Notes concerning Cassiodorus' Influence on Mediaeval Culture », p. 254-256.

7. Cassiodore, Expositio psalmorum LXXI-CL, éd. M. Adriaen, CXLV, 2 : in libro Animæe, qui in Variarum opere tertius decimus continetur.

8. Sur ce texte, voir l'introduction à l'édition de l'œuvre par J. W. Halporn, p. 503-532.

9. Bibliotheca Apostolica Vaticana, Pal. Lat. 1877, f. $29 \mathrm{v}^{\circ}$. En dehors du fait que la biographie de Cassiodore ne fait nullement mention d'une quelconque charge de doyen ou de son accession à la prêtrise, le chiffre «XVII " pose problème. Il est probable que le copiste se soit trompé dans la rédaction de la notice, dans laquelle il aurait dû inscrire le chiffre «XIII » et non «XVII ». Si l'on part du principe que le manuscrit en question contenait également le De anima, soit la collection complète, on arrive bel et bien au nombre de treize livres. 
10. En plus de cet exemplaire carolingien, l'abbaye de Lorsch semble avoir possédé deux autres manuscrits de la collection épistolaire. Le premier, aujourd'hui conservé à la Bibliotheca Apostolica Vaticana sous la cote Pal. lat. 273, fut copié à la fin du XII siècle et transmet les sept premiers livres de l'œuvre. Le second, aujourd'hui disparu, est mentionné par l'évêque de Worms en 1502 comme contenant uniquement les cinq derniers livres, voir K. Christ, Die Bibliothek des Klosters Fulda im 16. Jahrhundert : Die Handschriften-Verzeichnisse, p. 191.

11. S. J. B. Barnish, The Variæ of Magnus Aurelius Cassiodorus Senator.

12. Ce fragment - une double page d'un quaternion, ayant servi de couverture avant d'être découvert par Karl Koppman, bibliothécaire à Rostock - d'origine allemande semble avoir été copié à partir de l'archétype perdu de Lorsch. Voir A. Hofmeister, «Zur Überlieferung von Cassiodors Varice», p. 13-46.

13. Les manuscrits appartiennent majoritairement aux classes I et II établies par Mommsen. Pour l'espace français, il convient de signaler deux exemplaires, aujourd'hui disparus, légués par l'évêque de Bayeux Philippe d'Harcourt à l'abbaye normande du Bec (1142-1163), voir G. Becker, Catalogi Bibliothecarum antiqui, p. 201, notice $38: \mathrm{n}^{\text {os }} 58$ et 91.

14. Parmi ceux-ci, il convient de mentionner le cas du ms. Leiden, Universiteit Bibliothek, Vulcanius 46, copié à l'abbaye de Fulda pour l'abbé Rugger II (1176-1177). Le codex fut décrit par les différents éditeurs de la collection comme transmettant la meilleure version du texte pour cette période.

15. Montpelier, Bibliothèque de l'école de médecine, H 294 (1180-1200).

16. Cette bibliothèque, riche d'une septantaine de volumes, fut constituée lors de son séjour en France grâce à un important réseau de relations disséminé à travers tout le royaume. James C. Robertson (éd.), Materials for the history of Thomas Becket, archbishop of Canterbury, p. $76:[. .$.$] post missarum celebrationem et divinarum contemplationem, etiam$ studio litterarum et maxime divinae paginae, operam dabat, libris etiam conscribendis et perquirendis a domino papa privilegiis, selon le témoignage de son secrétaire particulier, Herbert de Bosham, voir aussi p. 359 et 379.

17. James Montague Rhodes, The Ancient Libraries of Canterbury and Dover : the Catalogues of the Libraries of Christ Church Priory and St. Augustine's Abbey at Canterbury and of St. Martin's Priory at Dover, p. 84.

18. Sur l'ars dictaminis, on consultera en premier lieu l'ouvrage collectif publié par B. Grévin et A.-M. Turcan-Verkerk (éd.), Le dictamen dans tous ses états. Perspectives de recherche sur la théorie et la pratique de l'ars dictaminis ( $\mathrm{XI}^{e}-\mathrm{XV}^{e}$ siècles), en particulier la riche bibliographie qui fait aujourd'hui référence aux p. 543-595.

19. H.M. Schaller, Handschriftenverzeichnis zur Briefsammlung des Petrus de Vinea; B. Grévin, Rhétorique du pouvoir médiéval. Les lettres de Pierre de la Vigne et la formation du langage politique européen (XIII $-\mathrm{XV}{ }^{e}$ siècle); S. Barret et B. Grévin, Regalis excellentia : les préambules des actes des rois de France au XIV siècle (1300-1380).

20. Citons par exemple la célèbre Summa dictaminis du cardinal Thomas de Capoue (mort vers 1235), dans laquelle Cassiodore est élevé au rang de modèle pour la technique du dictamen en prose: Dictaminum vero genera tria sunt, a veteribus definita: prosaicum scilicet, metricum et rhythmicum ; prosaicum ut Cassiodori, metricum ut Virgilii, rhythmicum ut Primatis, éd. E. Heller, Die Ars dictandi des Thomas von Capua: Kritisch erläuterte Edition, p. 13. 
21. J. Chandelier, «Quand le disciple aimerait dépasser le maître : Gentile da Foligno, Tommaso del Garbo et Pétrarque entre scolastique et humanisme », p. 701.

22. Cassiodore, Varice, éd. par T. Mommsen, p. 5, § 15 : Librorum vero titulum, operis indicem, causarum praeconem, totius orationis brevissimam vocem, variarum nomine praenotavi, quia necesse nobis fuit stilum non unum sumere, qui personas varias suscepimus ammonere.

23. Voir notamment les exemples présentés par V. Fauvinet-Ranson, "La réception variée des Varice de Cassiodore au Moyen Âge ", p. 45-47. Plusieurs auteurs de la fin du $\mathrm{XII}^{\mathrm{e}}$ siècle mobilisent des passages des Varice dans leurs propres œuvres: Ralph de Diceto dans ses Abbreviationes chronicorum; Gérard de Cambrai pour sa Topographia Hibernica; enfin le De naturis rerum d'Alexander Neckam. Sur ces emprunts, voir M. Manitus, Geschichte der lateinischen Literatur des Mittelalters, p. 625-26, 638, 786-87.

24. Sur ce document, voir l'article de R. H. Rouse, «Florilegia and Latin Classical Authors in Twelfth-and Thirteenth-Century Orléans », p. 131-160.

\section{RÉSUMÉS}

CEuvre majeure pour la connaissance historique de l'Italie ostrogothique, les Varice constituent une source de première main pour l'historien de l'Antiquité tardive. Ce recueil de 468 lettres, articulées en douze livres, apparaît du reste comme l'une des premières collections épistolaires organisées. Loin de chercher à questionner à nouveau les Varice en tant que source historique, nous souhaitons nous intéresser à la réception de celles-ci près de six siècles après leur rédaction par Cassiodore. Avec près de 180 manuscrits recensés, les Varice constituent l'une des collections épistolaires les plus diffusées et les plus utilisées durant tout le Moyen Âge. Notre communication, issue d'une thèse de doctorat en cours, visera à mettre en lumière les mécanismes de transmission, de réappropriation et de réutilisation d'une œuvre, dans une perspective résolument diachronique.

\section{AUTEUR}

NICOLAS MICHEL

Aspirant F.R.S.-FNRS, Université de Namur-Centre des Pratiques Médiévales de l'Écrit (PraME) 


\title{
Poésie et enseignement de la courtoisie dans le duché d'Aquitaine aux XII ${ }^{\mathrm{e}}$ et XIII ${ }^{\mathrm{e}}$ siècles : examen de quatre ensenhamens
}

\author{
Sébastien-Abel Laurent
}

1 L'amour courtois est réputé être apparu au XII siècle grâce aux troubadours, ces « inventeurs » de l'amour. Les descriptions qu'en ont données Alfred Jeanroy, Martin de Riquer et Michel Zink, pour ne citer que quelques auteurs parmi les plus marquants, permettent d'en définir précisément les contours ${ }^{1}$. Quelques mots s'avèrent cependant indispensables afin de préciser le cadre de cet article.

2 L'amour courtois ${ }^{2}$ - fin'amor en occitan - fait tout d'abord référence à une relation amoureuse entre un homme et une femme, ou plutôt une dame - domna en occitan. L'homme déclare son amour pour cette dame au travers de chansons, tout en se soumettant par avance à l'idée d'attendre son consentement. De manière paradoxale, cette attente finit par devenir un objet de plaisir en soi, car plus le soupirant attend et plus il doute, plus il anticipe la joie qu'il obtiendra de la satisfaction de son désiri3.

3 La fin'amor contient donc intrinsèquement une dimension pédagogique. Tant que la dame se refuse au troubadour, elle l'incite à trouver de nouvelles manières poétiques de lui exprimer son amour. Le poète en tire une satisfaction littéraire nouvelle, tout en permettant aux autres troubadours de mesurer ses progrès dans la maitrise de son art.

4 Les relations courtoises ne se limitent pas en effet pas au duo formé par le soupirant et sa dame. Elles prennent place dans un milieu confiné, celui de la cour, qui détermine largement l'avenir de la liaison amoureuse évoquée par le troubadour. Ce dernier doit tenir compte de la présence des proches de la dame - souvent des hommes : le père, les frères, encore plus fréquemment le mari. Il doit également se garder de fauter face à ses concurrents, symbolisés par la figure omniprésente du lauzengier, courtisan médisant et avide de percer les secrets de chacun pour en user de manière malveillante. 
C'est dans ce contexte qu'apparaît, dans les dernières décennies du XII ${ }^{\mathrm{e}}$ siècle, un genre nouveau de poèmes: les ensenhamens. Ces textes ont fait l'objet de nombreuses études qui ont permis d'en définir les contours. Malgré l'absence de définition dans la littérature didactique provençale du Moyen Âge, les travaux de François Pirot puis de Don Alfred Monson ont mis en avant l'existence d'un corpus d'une vingtaine de textes, datés entre la fin $d u x{ }^{e}$ siècle et la première moitié $d u x{ }^{e}$ siècle et couvrant l'ensemble de l'ère occitane ${ }^{4}$.

6 François Pirot classe les ensenhamens en trois catégories: les "ensenhamens de courtoisie ", dont l'objet est de préciser les règles à suivre par un courtisan ou une courtisane en fonction de son statut social; les "ensenhamens moraux", qui édictent des principes de vie généraux, sans précision de leur destinataire; enfin les «sirventes ensenhamens ", sous-genre spécifique s'apparentant au sirventes joglaresc, à savoir un poème destiné à se moquer des faibles connaissances ou de la piètre apparence d'un jongleur ${ }^{5}$. En revanche, Don Alfred Monson, qui insiste sur ce qu'il appelle le "didactisme courtois » et le climat de bienveillance général pour définir le genre de l' ensenhamen, agrège un nombre inférieur de poèmes sous l'étiquette des "ensenhamens » en excluant notamment les sirventes ensenhamens.

7 Ce travail se plaçant dans une perspective strictement historique, nous avons privilégié la définition de François Pirot, dans la mesure où nous ne cherchons à revenir sur la définition du genre en lui-même et où nous préférons de ce fait considérer les sources disponibles de la manière la plus large possible. Toutefois, pour des raisons de cohérence géographique, nous n'avons retenu que les poèmes rédigés par des troubadours aquitains aux $\mathrm{XII}^{\mathrm{e}}$ et $\mathrm{XIII}^{\mathrm{e}}$ siècles. Ainsi, cette étude se limite à quatre ensenhamens:

- Qui comte vol apendre d'Arnaut-Guilhem de Marsan (rédigé à la fin du XII e siècle)

- Razos es e mezura d'Arnaut de Mareuil (rédigé sensiblement à la même époque) ${ }^{7}$;

- Fadet joglar de Guiraut de Calanson (écrit à la fin du XII ou au début du XIII ${ }^{e}$ siècle en réponse au sirventes-ensenhamen Cabra joglar du troubadour catalan Guerau de Cabrera) ${ }^{8}$;

- Guordo, ieus fas un sol sirventes l'an de Bertrand de Paris de Rouergue (composé à la fin du XIII siècle) ${ }^{9}$.

Cette liste, en dehors de l'incertitude qui continue de subsister quant aux origines réelles de Guiraut de Calanson, qualifié de gascon par sa biographie médiévale (vida) sans que l'on sache si elle dit vrai ${ }^{10}$, fait ressortir le rôle majeur des troubadours aquitains dans l'éclosion du genre de l'ensenhamen, puisqu'ils sont présents dès l'éclosion du genre. On peut donc émettre l'hypothèse que les conclusions que l'on peut tirer des ensenhamens rédigés par des troubadours aquitains soient valables pour l'ensemble de l'espace occitan médiéval.

9 L'idée, suggérée par Georges Duby, que la fin'amor fut une réponse culturelle à la mise en place des États médiévaux nous servira ici de guide ${ }^{11}$. Selon cet historien, la fin'amor, en offrant aux plus jeunes des courtisans le «leurre » de la dame à aimer, servait en réalité des intérêts des seigneurs dominant les cours. Il en concluait que l'on pouvait imaginer que l'art lyrique des troubadours dans son ensemble, avait servi finalement les intérêts des États médiévaux, dont le renouveau est sensible à partir du milieu du XII ${ }^{\mathrm{e}}$ siècle.

10 Afin d'explorer cette hypothèse, nous adopterons une démarche en trois temps. Nous nous interrogerons d'abord sur la configuration du monde curial en Aquitaine à la fin 
$\mathrm{du} \mathrm{XII}^{\mathrm{e}}$ siècle, lorsque débute l'histoire qui nous intéresse. Nous chercherons ensuite à comprendre, à partir des quatre textes que nous avons examinés, comment la courtoisie s'est progressivement constituée, à l'intérieur de ce milieu, en tant que savoir. Nous terminerons enfin sur les manières de transmettre la courtoisie dont témoignent ces textes.

\section{Les cours d'Aquitaine à la fin du XII ${ }^{\mathrm{e}}$ siècle}

11 Le duché d'Aquitaine a connu un destin politique mouvementé au cours de notre période. À la fin du XII ${ }^{\mathrm{e}}$ siècle, il était intégré à l'Empire Plantagenêt. Mais tout change après 1204 et le rattachement de la quasi-totalité du duché à la couronne de France, en dehors du Bordelais. Ces changements n'ont toutefois pas affecté l'aspect général du monde curial aquitain, marqué par l'éclatement et l'absence d'une cour dominant clairement les autres. Avant 1137 et la mort du dernier duc guillelmide en ligne directe, Guillaume X, Poitiers apparaissait véritablement comme la principale cour d'Aquitaine. Mais la cité ducale fut dépassée par des cours basées dans les résidences aristocratiques des seigneurs de Ventadour, de Turenne ou encore, avec le fameux Bertran de Born, de Hautefort. De fréquents échanges reliaient ces lieux entre eux, comme l'attestent les trajets, nombreux et redondants, des troubadours d'une cour à l'autre. En somme, tout se passe comme si les courtisans, et singulièrement les troubadours, vivaient constamment entre plusieurs cours, si bien que l'ensemble de celles-ci formaient à l'échelle du duché, un peu comme un archipel.

12 À l'époque des Plantagenêt, on retrouve nombre de troubadours dans l'entourage ducal ; par exemple Bernart de Ventadour suivit Aliénor d'Aquitaine en Angleterre, comme il l'évoque directement dans sa chanson Lancan vei per mei landa. On ne doit toutefois pas surestimer l'importance du mécénat Plantagenêt auprès des troubadours, car le roi d'Angleterre lui-même, Henri II Plantagenêt, s'est montré relativement indifférent à leurs œuvres. C'est ainsi que Bernart de Ventadour, dans la chanson précédemment citée, exprimait sans détour son souhait de revenir dans son Limousin natal après un malheureux épisode anglais :

«Bien que je sois éloigné de ma dame [restée en Limousin], elle m’attire vers elle comme un aimant, la belle que Dieu veut protéger. Si le roi anglais et duc normand le veut, je la verrai avant que l'hiver nous surprenne. Par la volonté du roi je suis Anglais et Normand, et n'était-ce pour Mon-Aimant, je resterais ici jusqu'après Noël. ${ }^{12}$ »

13 En réalité, seuls Geoffroy de Bretagne et surtout son frère Richard Cœur de Lion apparaissent au sein de la famille Plantagenêt, comme de véritables protecteurs des troubadours ${ }^{13}$. Mais la cour de Richard ne logeait pas constamment à Poitiers, comme avant l'extinction de la lignée directe des Guillelmides en 1137, avec la mort de son grand-père Guillaume X. Richard préférait nettement Bordeaux, au point que deux troubadours parmi les plus célèbres, Bertran de Born et Guiraut de Borneil, finirent par l'appeler « seigneur de Bordeaux ${ }^{14}$ ».

14 C'est précisément dans la région de Bordeaux que fut écrit le premier ensenhamen conservé, celui d'Arnaut-Guilhem de Marsan ${ }^{15}$. Ce troubadour est d'autant plus remarquable qu'il apparait à plusieurs reprises dans la suite de Richard, lorsque celui-ci se trouvait dans la région, dans les années 1170 à 1190. La vida du modeste jongleur Peire de Valeira le cite également comme le seigneur qui lui avait permis de débuter sa 
carrière $^{16}$. En somme, l'auteur du premier ensenhamen connu était un fidèle du duc d'Aquitaine et sa petite cour rayonnait, au sud de Bordeaux, sur la partie inférieure de la vallée de la Garonne.

Notons cependant qu'Arnaut-Guilhem de Marsan représente une exception dans l'ensemble des quatre auteurs qui nous retiennent. Deux d'entre eux, Arnaut de Mareuil et Guiraut de Calanson, étaient aimantés par la brillante cour de Barcelone et la Catalogne. Quant à Bertrand de Paris de Rouergue, il évoluait loin de Poitiers ou de Bordeaux, à la cour de Rodez ${ }^{17}$. En fait, tout se passe comme si le relatif désintérêt des Plantagenêt pour les troubadours, en dehors de Geoffroy et de Richard Cœur de Lion, puis celui des Capétiens, avait poussé les troubadours aquitains auteurs d'ensenhamens à éditer leurs préceptes pour des courtisans ne vivant pas dans le duché. Ce faisant, ils diffusaient hors d'Aquitaine ce qu'ils y avaient appris.

\section{La courtoisie constituée comme savoir}

En ce qui concerne les contenus des ensenhamens, à présent, le panel de textes choisis nous met au contact des trois types d'ensenhamens distingués par François Pirot. Le poème d'Arnaut-Guilhem de Marsan Qui conte vol apendre, tout d'abord, appartient clairement au registre des ensenhamens de courtoisie. Il se présente en effet au départ comme le récit d'une rencontre inattendue : alors qu'il se trouve avec quelques-uns de ses proches, Arnaut-Guilhem de Marsan reçoit la visite d'un chevalier inconnu, qui vient solliciter auprès de lui quelques conseils sur la façon de se comporter à la cour :

«Seigneur, au nom de Dieu, je vous prie d'avoir pitié de moi : c'est d'un pays très éloigné que je suis directement venu vous trouver pour vous demander conseil, car vous avez de la sagesse et du mérite : je veux que vous m'aidiez par vos conseils à me former en matière d'amour. ${ }^{18}$ "

Arnaut-Guilhem de Marsan accepte bien volontiers de dispenser ses conseils. Ce poème, à bien des égards, est précurseur des autres ensenhamens de courtoisie, notamment les passages sur les soins du corps et la parure. Un siècle plus tard, on voit encore le troubadour catalan Amanieu de Sescars rédiger deux ensenhamens, l'un pour un jeune homme, l'autre pour une jeune femme, dans lesquels de tels conseils trouvent leur place $^{19}$.

Le poème Razos es e mezura d'Arnaut de Mareuil appartient, lui, au sous-genre des ensenhamens moraux. Le troubadour y développement longuement les qualités morales qui doivent être celles d'un courtisan - le mérite (pretz), la prouesse (proeza), la connaissance (conoissensa), le savoir (sabers), l'esprit (sens), la largesse (largueza) et le pouvoir (poders). Élément intéressant: à la fin de son poème Arnaut de Mareuil rapporte qu'il a pu dresser ce portrait en observant longuement la dame qu'il aime, ce dont il la remercie :

«[...] Dame preuse et savante, si j'ai quelque connaissance, votre souvenir, qui me pourfend par son tourment, me la donne et me l'affermit ; c'est pourquoi je vous rends louange et merci de tous les biens que je possède et je vous en rends grâce, car vous êtes proche de mon cœur, ma dame $[. . .]^{20}$ »

Ce passage, typiquement dans la veine de la fin'amor, suggère que c'est en revenant inlassablement à l'image de sa dame, en cherchant un moyen de la séduire, qu'Arnaut Daniel a pu acquérir les connaissances nécessaires à comprendre l'idéal courtois, pensé de manière universelle. 
20 Arnaut-Guilhem de Marsan comme Arnaut de Mareuil placent finalement leurs ensenhamens sous le registre de l'utilité. Ils cherchent à rendre service à ceux qui, contrairement à eux, sont moins avancés dans la connaissance de la fin'amor. C'est d'ailleurs ainsi que débute Qui comte vol apendre :

«Si quelqu'un est capable de bien comprendre un conte et veut l'apprendre, je vais vous en dire un qui peut en valoir beaucoup d'autres, je sens que les autres ont du sens, mais voici celui qui a le plus de valeur et il traite d'un sujet tel qu'il sera toujours utile $[. . .]^{21} »$

21 Les deux sirventes ensenhamens que sont Fadet joglar et Guordo, ie us fos un sol sirventes l'an se placent en revanche sur le registre de l'inutilité. Destinés à des jongleurs, c'est-à-dire à des individus que leur statut place en dehors du monde courtisan tout en leur permettant de le fréquenter, ces textes assez violents, voire cruels, sont l'occasion pour leurs auteurs d'en remontrer à leurs interlocuteurs. On devine que ces derniers sont venus solliciter une chanson ou une recommandation. En échange, ils reçoivent ce qu'il faut bien qualifier de bordées de moqueries :

(Fadet joglar, version du chansonnier R) :

"Jongleur Fadet, comment peux-tu solliciter ce qui est difficile à exécuter? Que je te donne sur-le-champ un bon sirventes tel qu'on ne le puisse démentir ! [... ${ }^{22}$ »

(Guordo, ie us fas un sol sirventes l'an) :

«Guordon, je vous compose un seul sirventes l'an, et selon mes possibilités, je vous l'avais composé bon et beau; mais je vois maintenant que c'est peine perdue et je veux désormais que vous cherchiez un autre patron. Jamais vous n'avez su chanson, ni sirventes, vers ou descort que je vous fis réciter en cour. Comme l'ignorance vous perd et vous confond, souvent vous dîtes en haut ce qui est en bas [... ${ }^{23}$ ”

En somme, ce qui permet aux troubadours de constituer la courtoisie comme un savoir transmissible renvoie à une vision hiérarchisée de la société, car une distinction s'opère en fonction des destinataires. S'ils sont parfaitement intégrés au monde de la cour ou ont vocation à l'être, notamment par la naissance, il est utile de les initier. S'ils ne peuvent espérer intégrer le monde curial, tout effort est déclaré d'avance inutile. En ce sens, les ensenhamens témoignent d'une certaine fermeture de la noblesse entre la fin $\mathrm{du} \mathrm{XII}^{\mathrm{e}}$ siècle et le début $\mathrm{du} \mathrm{XIII}^{\mathrm{e}}$ siècle, comme on a pu l'observer dans d'autres domaines de la vie aristocratique à la même époque ${ }^{24}$. Les difficultés évoquées par Raimbaut de Vaqueiras pour obtenir son adoubement dans ses épitres à Boniface IV de Montferrat rentrent dans une perspective similaire. Sur ce point, le duché d'Aquitaine n'apparaît pas isolé.

\section{Les manières de transmettre la courtoisie}

Dernier point à aborder, la mise en scène de l'acte de transmission du savoir, telle qu'on la dégage de notre corpus, s'avère tout aussi révélatrice des évolutions profondes de la société aquitaine médiévale.

La forme dialoguée, tout d'abord, est privilégiée. Seule Razos es e mezura ne se présente pas comme le récit d'une rencontre entre deux personnes, encore que la dimension de dialogue n'y soit pas à proprement parler absente. Ensuite, la rencontre met en scène une relation clairement inégalitaire entre l'enseignant et l'enseigné. Dans Qui comte vol apprendre, on l'a vu, la trame narrative est basée sur une demande de conseil. Il s'agit en fait d'un ressort couramment utilisé par les troubadours, qui imitent en cela une 
pratique féodale. Il y aurait d'ailleurs matière à mener une étude exhaustive sur l'utilisation du motif du conseil dans l'art des troubadours, car elle peut prendre deux sens opposés - lorsque le seigneur demande conseil auprès des vassaux ou lorsqu'un individu de rang inférieur sollicite l'avis d'un seigneur. Dans le cas qui nous occupe, la mise en scène de la demande de conseil par un jeune chevalier inconnu peut par exemple évoquer un passage d'une chanson de Guiraut de Borneil, No puesc sofrir c'a la dolor. Après avoir rêvé qu'un épervier sauvage se soit posé sur le poing, le troubadour a ainsi ces paroles :

"Je racontais le songe à mon seigneur, car on doit le dire à son ami..$^{25}$ "

Comme dans l'ensenhamen d'Arnaut-Guilhem de Marsan, rédigé sensiblement à la même époque, la relation hiérarchique se double d'une intention amicale qui vient en atténuer la rudesse. Arnaut-Guilhem de Marsan poursuit dans la même veine quand il déclare aux proches qui l'accompagnent qu'il désire s'entretenir seul avec son solliciteur. Un peu plus loin dans le poème, il rapporte qu'ils quittent ensemble le château d'Arnaut-Guilhem pour trouver refuge dans un verger :

«[...] Pour moi, je me levai et emmenai mon ami, cet homme dont je vous parle; nous quittâmes la salle ensemble et descendîmes l'escalier, lui et moi seulement : il n'y avait que nous deux. Nous entrâmes dans un verger où je le fis asseoir face à moi à côté d'un laurier et je commençai à lui parler $[. . .]^{26}$ "

Dans la poésie des troubadours, le verger ou le jardin est un espace d'intimité, au sein duquel on peut fuir un instant la pression du regard des autres courtisans massés dans la grande salle du château, l'aula. Dans l'extrait que nous venons de citer, ArnautGuilhem de Marsan fait très clairement à son solliciteur la grâce de ne pas dévoiler en public son ignorance des règles de la vie à la cour, afin de ne pas lui faire perdre la face.

Il en va tout autrement des deux sirventes ensenhamens. Les deux jongleurs qui subissent les railleries de leurs maîtres doivent les écouter en public, sans pouvoir fuir la honte de se voir ainsi rabroués. La volonté d'humilier est d'autant plus cruelle qu'elle portait sur leur connaissance des chansons et des jeux à la mode, chose qu'ils auraient dû mieux connaître que leurs seigneurs. Quelques extraits, parmi de nombreux autres, pourront nous en convaincre :

« Si tu ne veux pas abandonner ta manière de faire des sottises quand tu voudras aller à sa cour [à la cour du Roi d'Aragon], (tu ne dois) assurément pas te plaindre de t'en aller si par malheur tu ne te fais pas bien recevoir. ${ }^{27}$ " (Fadet Joglar)

«[...] Et vous ne savez d'Agamemnon le Grand, ni de Feton la folle prière qu'il fit, ni d'Achille je ne pense que vous sachiez quelque chose $[. . .]^{28} »$ (Guordo, ie us fas un sol sirventes l'an )

Les sirventes ensenhamens prennent en fait le contre-pied de l'ensenhamen de courtoisie en ce qui concerne leur mise en scène. La relation de domination y est beaucoup plus brutale, le dialogue se fait face à la cour. Ces textes en réalité ne sont pas isolés. On voit ainsi Bertran de Born se moquer avec hauteur d'un jongleur venu le solliciter dans le sirventes intitulé Maillolin joglar malastruc:

«Maillolin, malheureux jongleur, puisqu'on m'a parlé de vous et que vous me demandez des chansons, je souhaite vous aider en cela. En effet, vous êtes vil sous des airs d'honnête homme; mieux vaudrait vous louer pour des combats judiciaires que de vivre des rebuts des autres. Votre entretien m'a paru si ennuyeux qu'un autre homme serait irrité ; vous êtes plus sot qu'un mouton et le chant de la corneille est plus pur que le vôtre. Mieux écouter un porc ladre ou un blessé quand on l'opère plutôt que vous $[. . .]^{29}$ " 

considération ne viennent que partiellement valider l'hypothèse de Georges Duby concernant l'utilité socio-politique de l'art lyrique occitan. Certes, entre le $\mathrm{xII}^{\mathrm{e}}$ siècle et le XIII ${ }^{e}$ siècle, l'autorité du pouvoir des successeurs des ducs s'est considérablement renforcée, car aussi bien les Plantagenêt que les Capétiens ont cherché à développer des administrations efficaces pour contrôler l'espace aquitain. Mais, à l'exception des cas de Richard Cœur de Lion et de Geoffroy de Bretagne, les souverains de l'Aquitaine n'ont pas véritablement cherché à utiliser les services des troubadours pour relayer leur pouvoir. Dès la seconde moitié du XII ${ }^{\mathrm{e}}$ siècle, il est notable que les troubadours aquitains cherchent des " patrons » hors du duché, en Toulousain, en Catalogne ou en Italie du Nord. Il est d'ailleurs significatif que ce soit dans ces régions que la littérature didactique occitane ait vue le jour, comme si on y avait compris l'intérêt de faire vivre l'héritage des troubadours aquitains.

Pour autant, on ne peut pas nier que les ensenhamens aquitains témoignent, à leur manière, des changements profonds de la société médiévale liés à la mutation des États. Face à la pression d'administrations de plus en plus compétentes, une frange non négligeable de l'aristocratie aquitaine n'eut de cesse, particulièrement au $\mathrm{XII}^{\mathrm{e}}$ siècle, d'ériger des barrières de plus en plus hautes entre elle et les non-nobles. C'est ce dont témoignent les sirventes ensenhamens de Guiraut de Calanson et de Bertrand de Paris de Rouergue.

En définitive, l'étude de ces ensenhamens aquitains des $\mathrm{XII}^{\mathrm{e}}$ et $\mathrm{XIII}{ }^{\mathrm{e}}$ siècles révèle l'importance des connexions entre littérature et politique. À ce titre, des études portant sur des thèmes croisant ces deux champs de connaissance pourront s'avérer utiles à l'avenir, en prenant soin de distinguer le plus nettement possible les positions relatives de chaque personne identifiée dans les échanges poétiques des troubadours.

\section{BIBLIOGRAPHIE}

AURELL Martin, La Noblesse en Occident ( $V^{e}-X V^{e}$ siècle), Paris, Colin, 1996.

BEC Pierre, « La douleur et son univers poétique dans la poésie de Bernard de Ventadour », Cahiers de civilisation médiévale, vol. XI, n 44, 1968, p. 454-571. 
BOUTIÈRE Jean, Biographie des troubadours. Textes provençaux des XIII et XIV siècles, Paris, Nizet, 1964. CORBELLARI Alain, « Retour sur l'amour courtois », Cahiers de recherches médiévales et humanistes, $\mathrm{n}^{\circ}$ 17, 2009, p. 375-385.

DE CAUNA Jacques, L'Ensenhamen ou Code du parfait chevalier du troubadour Arnaut-Guilhem de Marsan (traduction de l'ancien occitan par Gérard GOUIRAN), Cressé, Éditions des régionalismes, 2017.

DE RIQUER Martin, Los trovadores. Historia literaria y textos, $3^{\mathrm{e}}$ éd., Barcelone, Ariel, 1992.

DUBY Georges, « À propos de l'amour que l'on dit courtois », dans Mâle Moyen Âge, Paris, Flammarion (Champs), 1988, p. 74-82.

EUSEBI Mario, «L'Ensenhamen di Arnaut di Mareuil », Romania, t. 90, n² 257, 1969, p. 14-30.

GOUIRAN Gérard, L'amour et la guerre. L'œuvre de Bertran de Born, Aix-en-Provence, Publications de l'Université de Provence, 1985, (2 tomes).

GIUSEPPE E., Sansone, Testi didattico-cortesi di Provenza, Bari, Adriatica Editrice, 1977.

JEANRoy Alfred, La Poésie lyrique des troubadours, Toulouse-Paris, Privat-Didier, 1934.

MENEGALDO Silvère, «La recommandation paradoxale, ou le jongleur cible de la satire. Nouvel essai de définition du sirventes joglaresc dans la lyrique occitane des XII $^{\mathrm{e}}$ et $\mathrm{XIII}^{\mathrm{e}}$ siècles (avec en annexe une traduction commentée) ", Cahiers de recherches médiévales et humanistes, $n^{\circ} 22,2011$, p. 537-586.

MONSON Don Alfred, Les « ensenhamens » occitans. Essai de définition et de délimitation du genre, Paris, Klincksieck, 1981.

PIROT François, Recherches sur les connaissances littéraires des troubadours occitans et catalans des XII et XIII ${ }^{e}$ siècles. Les « sirventes-ensenhamens » de Guerau de Cabrera, Guiraut de Calanson et Bertran de Paris, Barcelone, Real Academia de Buenas Letras, 1972.

ZINK Michel, Les Troubadours. Une histoire poétique, Paris, Perrin, 2013.

\section{NOTES}

1. A. Jeanroy, La Poésie lyrique des troubadours, t. 2, p. 62 sqq. ; M. de Riquer, Los trovadores, t. 1, p.9-102; M.Zink, Les Troubadours, p.9-16. D'autres références seront données au fil du texte.

2. L'expression a été forgée par Gaston Paris à la fin du XIX siècle. Voir A. Corbellari, « Retour sur l'amour courtois », p. 375.

3. P. Bec, «La douleur et son univers poétique dans la poésie de Bernard de Ventadour », p. 545-546.

4. F. Pirot, Recherches sur les connaissances littéraires des troubadours, p. 19-73, et

D. A. Monson, Les « ensenhamens » occitans, p. 15-29.

5. S. Menegaldo, « La recommandation paradoxale », p. 547-552.

6. BEdT 29a.I. G. E. Sansone, Testi didattico-cortesi di Provenza, p. 109-180. Voir également J. de Cauna et G. Gouiran, L'ensenhamen ou Code du parfait chevalier, p. 78-107.

7. BEdT 30.VI. M. Eusebi, « L'Ensenhamen di Arnaut di Mareuil », p. 17-24. 
8. BEdT 243.7a. F. Pirot, Recherches sur les connaissances littéraires des troubadours, p. 563-595. L'ensenhamen Cabra joglar (BEdT 242a.1) a été édité dans le même ouvrage, p. 545-562.

9. BEdT 85.1. F. Pirot, Recherches..., p. 596-614.

10. J. Boutière, Biographies des troubadours, p. 217.

11. G. Duby, «À propos de l'amour que l'on dit courtois », p. 82.

12. "[...] Sil reis engles e.l ducs normans/o vol, eu la veirai abans/que l'iverns nos sobreprenda.//Pel rei sui engles e normans,/e si no fos Mos Azimans,/restera tro part calenda ». BEdT 70.26, v. 43-48. Texte et traduction M. Lazar, Bernard de Ventadour. Chansons d'amour, p. 174.

13. Nous remercions au passage Gérard Gouiran de nous avoir rappelé l'importance de Geoffroy en tant que protecteur de Bertran de Born, que nous avions omis de citer au cours de notre présentation.

14. Guiraut de Borneil le dénomme ainsi dans la chanson Qan lo freitz el glatz e la neus, BEdT 242.60, v. 14-26. R. V. Sharman, The Cansos and Sirventes of the Troubadour Giraut de Borneil, p. 93. Il recommence dans la chanson Lo doutz chanz d'un auzel, BEdT 242.46, v. 46-60. R. V. Sharman. The Cansos..., p. 379. Bertran de Born appelle également Richard Cœur de Lion "le seigneur de Bordeaux" à deux reprises dans deux versions différentes de la chanson Molt m'es dissendre car col (BEdT 80.28) : une première fois au vers 9 , dans la rédaction commune à l'ensemble des chansonniers, et une seconde fois dans la seule version du chansonnier $\mathrm{a}^{2}$, au vers 42 . Voir G. Gouiran, L'amour et la guerre, t. II, p. 510-515.

15. J. De Cauna et G. Gouiran, L'ensenhamen ou Code du parfait chevalier, p. 11-22.

16. J. Boutière, Biographies des troubadours, p. 14-15.

17. F. Pirot, Recherches sur les connaissances littéraires des troubadours, p. 298 sqq.

18. "[...] Senher, per Dieu merci/te prec aias de mi,/car de mot lo(n)ga terra/soi sai per cosselh querra/tot dreitamen a vos,/car es savis e pros, e quem cocelh/com d'amors m'aparelh [...] ». BEdT 29a.I, v. 59-66. J. de Cauna et G. Gouiran, L'ensenhamen ou Code du parfait chevalier, p. 80-81.

19. L'ensenhamen au chevalier est intitulé El temps de nadalor (BEdT 21a.III), celui à la demoiselle En aquel mes de mai (BEdT 21a.IV). G. Sansone, Testi didattico-cortesi di Provenza, p. 181-289.

20. "[...] Pros dona e valens,/corteza et conoissens,/s'en ren ai conoissensa,/la vostra sovinensa/que m'es d'enuei escrima,/lam dona e la m'aprima :/per qu'eu de totz mos bes/vos ren laus e merces/e us o grazisc ades,/car m'es del cor pus pres,/dona ». BEdT 30.VI, v. 337-347. Texte établi par M. Eusebi, «L'Ensenhamen di Arnaut di Mareuil», p. 24. Traduction de l'auteur.

21. "Qui comte vol apendre,/e be lo sap entendre,/ie us en dirai un tal/que motz d'autres en val;/e sen ben d'autres sen,/mas ve us lo pus valen,/e mou de tal razo/que tostemps sera bo [...] ». BEdT 29a.I, v. 1-8.

22. " Fadet ioglar/co potz pe(n)sar/so q(e) es greu p(er) eyssarnir/cades te do./Sirventes bo/ co(m) nol te puesca d(e)sm(en)tir [...]». BEdT 243.7a, v.1-6. F. Pirot, Recherches sur les connaissances littéraires des troubadours, p. 564.

23. «Guordo, ie.us fas un sol sirventes l'an,/e, si pogues, fera vos bon e bel;/mas eras vey que n'ay perdut l'afan/e vuelh hueymays queiratz autre capdel./Anc no saupes chanson ni 
sirventes,/vers ni descort qu'en cort a dir fezes./que no's sabers vos marris e us cofon,/soven dizetz so qu'es d'aval d'amon [...]». BEdT 85.1, v. 1-8. F. Pirot, Recherches sur les connaissances littéraires des troubadours, p. 600.

24. M. Aurell, La noblesse en Occident, p. 95-99.

25. «[...] El songe comtei mon senhor,/c'a son amic lo deu hom dir [...]». BEdT 242.51, v. 21-22. R. V. Sharman, p. 217. Traduction de l'auteur.

26. «[...] E yeu levey en pes,/prezi lo mieu amic/(seluy que yeu vos dic),/laissem a totz la sala/e dissendem l'escala,/solamen mi e luy,/car enaisi fom duy./Intrem en un verdier/e deves un laurier/fil denan mi assire,/e comenseyll a dire [...] ». BEdT 29a.I, v. 158-168. J. de Cauna et G. Gouiran, L'ensenhamen ou Code du parfait chevalier, p. 84-85.

27. «[...] Si.l fadeiar/no vols laissar,/can volras en sa cort venir,/non querelhar/ja del anar,/ s'a(l) melhor non te fas grazir ». BEdT 243.7a, v. 235-240.

28. "[...] Ni no sabetz d'Agamenon lo gran;/ni de Feton lo fol orat que fe ;/ni d'Achilles no cug sapiatz re [...] ». BEdT 85.1, v. 49-51. F. Pirot, Recherches sur les connaissances littéraires des troubadours, p. 603.

29. "Maillolin, joglar malastruc,/pos acoindat m'a hom de vos/e mi venes qerre chansos,/en talent ai q'ie us e vailha./Qar iest avols e semblas bos,/mieills fors foses campios/qe viure d'autrui curailha./Aital solatz m'aves faissuc/qu'autr'om en seria enuios;/ez es plus nescis qe montos,/e canta plus clar li grailha./Porc q'om regarda millargos/fai meilhor escoutar qe vos,/o nafrat qan hom lo tailha [...] ». BEdT 80.24, v. 1-14. G. Gouiran, L'amour et la guerre, t. II, p. $780-781$.

\section{RÉSUMÉS}

Le duché d'Aquitaine a vu naître l'art lyrique occitan aux $\mathrm{XII}^{\mathrm{e}}$ et $\mathrm{XIII}^{\mathrm{e}}$ siècles. Cette poésie comporte un volet didactique qui a contribué à son succès, grâce au genre des ensenhamens. Dans ce cadre s'ébaucha un modèle laïc de comportement en contrepoint des efforts de l'Église catholique pour domestiquer l'aristocratie. Le but de notre communication est donc d'explorer pourquoi et comment cette pédagogie de la courtoisie, observée au travers des quatre ensenhamens rédigés à cette époque et dans cet espace, est apparue. Il s'agit tout d'abord de remettre en perspective ses contenus. Il faut ensuite en préciser les moyens. Enfin, la question des acteurs - émetteurs et récepteurs - doit être posée. Cette étude permet au final de percevoir les déterminants des attitudes de chaque membre des cours d'Aquitaine aux XII ${ }^{\mathrm{e}}$ et XIII ${ }^{\mathrm{e}}$ siècles, en mettant notamment l'accent sur les effets de la distance sociale entre les partenaires des échanges poétiques.

\section{AUTEUR}

\section{SÉBASTIEN-ABEL LAURENT}

Chercheur associé au CESCM, Université de Poitiers (UMR 7302), associé au CRULH, Université de Lorraine 


\title{
La transmission de l'histoire antique et sa mise en images dans les États latins d'Orient : les manuscrits de l' Histoire Ancienne jusqu'à César, Saint Jean d'Acre (1260-1291)
}

\author{
Émilie Maraszak
}

\begin{abstract}
Nés des croisades et des conquêtes latines en Terre sainte, les États latins d'Orient voient s'établir des Occidentaux en Orient aux XII et XIII ${ }^{\mathrm{e}}$ siècles. En quelques années, ces États deviennent des intermédiaires des échanges de savoirs scientifiques, culturels et artistiques entre l'Occident latin, le monde byzantin et le monde arabo-musulman. Pendant près de deux siècles, de 1098, date des conquêtes de la Première Croisade, à 1291, date de la chute de Saint Jean d'Acre, la société latine établie en Terre sainte encourage des projets artistiques au carrefour des mondes latin, byzantin et arabe. Ces œuvres d'art syncrétiques et multiculturelles, qu'elles concernent l'architecture militaire, l'architecture religieuse, ou encore les arts figurés (mosaïques, peintures murales, icônes ou manuscrits enluminés), ont, pour la plupart d'entre elles, la particularité de conserver un héritage occidental en Orient tout en s'inspirant des mondes qui les entourent et en adoptant des motifs orientaux.
\end{abstract}

\section{La production de manuscrits enluminés dans les États latins d'Orient}

2 En ce qui concerne les manuscrits plus particulièrement, recensés pour la première fois par Hugo Buchthal en $1957^{1}$, la production s'étend, elle aussi, sur près de deux siècles. $\mathrm{Au} \mathrm{XII}$ e siècle et jusqu'à la prise de Jérusalem par Saladin en 1187, nous n'avons connaissance que d'un atelier de production, le scriptorium du Saint Sépulcre à Jérusalem, dont l'organisation générale reflète celle des ateliers d'Occident. Cette 
première période voit donc la production de livres entièrement confiée à un atelier monastique, ou plutôt canonial, à l'image de ce qui existe dans les abbayes et monastères occidentaux depuis les premiers siècles de l'histoire du livre. En toute logique, ce scriptorium se consacre presque exclusivement à la production de manuscrits liturgiques destinés au service divin dans les différentes églises et communautés religieuses fondées ou transformées par les Francs au XII siècle. Il demeure le seul dont l'existence soit prouvée, même si des villes telles Tripoli ou Antioche ont également pu accueillir des ateliers en leurs murs. Quelques années seulement après l'implantation franque en Orient, le scriptorium du Saint-Sépulcre est en mesure de reprendre les traditions de décoration venant d'Occident, tout en y insérant des éléments byzantins grâce à la formation des artistes de l'atelier au contact des maîtres grecs et des manuscrits d'origine byzantine. Cette maitrise de l'art de l'enluminure suppose la venue en Orient d'artistes confirmés qui se sont ensuite instruits au contact des artistes orientaux. Elle suppose aussi la formation d'une nouvelle génération d'enlumineurs qui font la synthèse des influences occidentales et orientales pour former la tradition de l'enluminure croisée. Ces artistes produisent des livres à la demande des églises et monastères latins. Mais ils sont aussi capables de répondre ponctuellement, et de manière remarquable, à une commande personnelle comme c'est le cas avec le Psautier de la reine Mélisende ${ }^{2}$, un manuscrit de dévotion privée qui demeure l'exemple le plus connu, copié par les chanoines du Saint-Sépulcre.

3 Après les événements de 1187 et la prise de Jérusalem par Saladin, à l'image de l'histoire des États latins qui doivent se reconstruire, nous observons un certain temps avant la reprise de l'activité. Et c'est après le séjour de Louis IX en Terre sainte, entre 1250 et 1254, que la production de manuscrits connaît un véritable renouveau artistique et d'importants changements. À travers les exemples de cadeaux diplomatiques commandés à l'occasion des missions qu'il envoie auprès des khans mongols ${ }^{3}$ et la restauration des défenses du Royaume latin de Jérusalem, Louis IX s'engage en faveur des arts croisés. Il encourage la production artistique locale à son propre compte. Sa contribution la plus importante est sans aucun doute tournée vers les livres, avec des commandes beaucoup plus personnalisées qui amènent un nouveau dynamisme aux ateliers de Terre sainte. Même si aucune source ne s'en fait l'écho, il est sans doute possible que Louis IX ou un membre de son entourage ait emporté avec lui en Orient quelques livres de sa bibliothèque. En effet, nous connaissons l'exemple de Guillaume de Rubrouck qui, en partant pour l'orient, emmène une partie de sa bibliothèque, des bibles enluminées, des livres liturgiques, un bréviaire et un psautier comme il le raconte dans ses lettres au roi ${ }^{4}$. Il apparaît que le roi de France aurait pu emporter avec lui quelques copies de Bibles moralisées. Daniel Weiss ${ }^{5}$ avance même l'idée que la Bible moralisée conservée à la Bobleian Library d'Oxford ${ }^{6}$, terminée autour de l'année 1245, aurait pu être du voyage pour influencer ensuite la production des ateliers levantins. Avant de regagner la France en 1254, il semble que le roi soit à l'origine de la fondation d'un ou plusieurs ateliers de production de manuscrits enluminés à Saint Jean d'Acre. Il leur apporte les toutes dernières influences parisiennes qui, dans la tradition croisée, vont désormais être associées aux influences orientales. Un manuscrit lui est personnellement associé et ce codex richement décoré est considéré comme l'élément fondateur de cette dernière période de la production levantine. Louis IX serait en effet à l'origine de la commande de la Bible de Saint Jean d'Acre ${ }^{7}$, apparaissant également sous le nom de Bible de l'Arsenal, en référence à son lieu 
de conservation dépendant aujourd'hui de la Bibliothèque Nationale de France, un manuscrit étudié dans le cadre de sa thèse par Daniel Weiss ${ }^{8}$.

4 La seconde moitié du XIII ${ }^{\mathrm{e}}$ siècle voit la délocalisation de la production de Jérusalem à Saint Jean d'Acre, nouvelle capitale croisée, et surtout un changement dans le contenu même de ces ouvrages. Puisque des livres religieux, la production se tourne désormais vers des récits historiques qui sont les manuscrits les plus copiés, témoignant du goût des commanditaires pour ce type de littérature. Pendant les dernières années d'existence du Royaume latin de Jérusalem, entre 1250 et 1291, deux récits connaissent un succès certain : l'Histoire d'Outremer de Guillaume de Tyr ${ }^{9}$ et l'Histoire Ancienne jusqu'à César, sur laquelle nous nous concentrerons pour la suite de cet article.

\section{Le récit de l'Histoire Ancienne jusqu'à César et sa copie en Terre sainte}

5 Trois manuscrits enluminés en Terre sainte ont été conservés pour ce récit: le plus ancien à la Bibliothèque municipale de $\operatorname{Dijon}^{10}$, que nous utiliserons tout particulièrement pour illustrer notre propos, un deuxième à la Bibliothèque Royale de Belgique $^{11}$ très proche du premier et enfin le plus somptueux du point de vue de sa décoration conservé à la British Library de Londres ${ }^{12}$. Le récit de l'Histoire Ancienne jusqu'à César a, lui, été compilé en Occident, en Flandre plus précisément entre 1208 et 1230 , pour ensuite voyager en Orient dès le milieu du XIII ${ }^{e}$ siècle. Paul Meyer est le premier à identifier le récit en $1885^{13}$ et lui donne son titre d'Histoire Ancienne jusqu'à César, en fonction des bornes chronologiques que recouvre cette compilation. On parle aussi d'Histoire Universelle pour ce texte car l'Histoire Ancienne jusqu'à César, comme son nom l'indique, recouvre l'histoire du monde depuis sa création jusqu'aux premières campagnes de Jules César en Gaule selon des sections qui apparaissent au fil des chapitres du récit, identiques dans les trois manuscrits, de même que les sources employées par le compilateur pour créer la trame de son récit. Nous pouvons organiser la succession de ces récits et de leurs sources (tabl. 1).

Tabl. 1. - Organisation des récits de L'Histoire Ancienne jusqu'à César et leurs sources.

\begin{tabular}{|l|l|}
\hline Sections & Sources \\
\hline La Genèse & Ancien Testament Historia Scolastica de Pierre le Mangeur \\
\hline L'histoire de l'Assyrie (Ninus/Sémiramis) & Orose, Historiae adversus paganos \\
\hline L'histoire de Thèbes & Roman de Thèbes \\
\hline $\begin{array}{l}\text { L'histoire de la Grèce : Athéniens et } \\
\text { Crétois, les Amazones et Hercule }\end{array}$ & Orose, Historiae adversus paganos \\
\hline La guerre de Troie & Darès le Phrygien, Dictys le Crétois Roman de Troie \\
\hline L'épopée d'Énée & Roman d'Eneas \\
\hline Les premiers temps de Rome & Orose, Historiae adversus paganos \\
\hline L'histoire des Perses, de Judith et d'Esther & $\begin{array}{l}\text { Orose, Historiae adversus paganos Ancien Testament } \\
\text { (Judith et Esther) }\end{array}$ \\
\hline Alexandre le Grand & Roman d'Alexandre \\
\hline
\end{tabular}


Suite de l'histoire de Rome (jusqu'à Jules César)

a. Claudius est en réalité Claudius Quadrigarius. Avec Valerius Antias, ils sont connus de l'auteur de la compilation par l'intermédiaire d'Orose qui les cite comme sources.

\section{(c) É. Maraszak.}

6 L'Histoire Ancienne jusqu'à César est la plus ancienne histoire universelle rédigée en langue vernaculaire, une compilation qui s'inscrit dans un mouvement initié au XII siècle développant les récits en prose et langue vernaculaire pour un public laïque et lettré. Rappelons notamment la création des quatre romans antiques au XII ${ }^{\mathrm{e}}$ siècle, le Roman de Thèbes ${ }^{14}$, le Roman de Troie ${ }^{15}$, le Roman d'Enéas ${ }^{16}$ ou Énée, et le Roman d'Alexandre ${ }^{17}$, des récits que l'auteur de l'Histoire Ancienne jusqu'à César reprend dans sa compilation pour les sections concernées. En plus de ces sources presque contemporaines, l'auteur a fait le choix d'autres textes qui impliquent une connaissance de sources bibliques comme les livres de l'Ancien Testament pour l'histoire des patriarches, de sources anciennes comme les auteurs de l'histoire romaine qui lui sont connus par l'intermédiaire d'une référence incontournable des historiens médiévaux, Orose ${ }^{18}$ et ses Histoires contre les Païens ${ }^{19}$ dont il tire de nombreux passages. Il construit donc un vaste quadrillage du temps qui implique la mise au point d'une chronologie associant histoire biblique d'après le texte de la Genèse et son commentaire par Pierre le Mangeur ${ }^{20}$ et histoire païenne. La réussite de l'auteur, demeuré anonyme, est d'avoir su recréer un enchaînement du temps et des civilisations.

7 Cette compilation trouve donc ses origines dans les cours princières du nord de la France, mais, très rapidement, probablement au moment de la septième croisade menée par Louis IX entre 1248 et 1254, le récit traverse la Méditerranée et rencontre son public dans les États latins d'Orient d'après le nombre de manuscrits copiés. Au sein de ce récit, l'histoire antique occupe une place prépondérante et demeure identique aux copies occidentales. Les images associées à ce cycle de l'Antiquité ont connu des changements par rapport à celles occidentales. Car, à partir d'un cycle iconographique venu d'Occident au milieu du XIII ${ }^{\mathrm{e}}$ siècle, les nobles francs de Terre sainte et les enlumineurs à leur service créent un cycle de miniatures qui, non seulement, s'inscrit totalement dans la tradition multiculturelle croisée, mais permet aussi à la société latine d'outre-mer d'affirmer son identité sociale et de véhiculer un message politique.

\section{La transformation des images de l'histoire antique en Terre sainte}

Les Francs souhaitent ainsi maintenir leur identité dans un environnement oriental et cette affirmation passe d'abord par la conservation de leur héritage occidental que nous retrouvons dans le choix d'un texte en langue française, une langue minoritaire au Proche-Orient où l'arabe, le syriaque et le grec sont les langues les plus parlées. Les premières influences occidentales reposent aussi sur les thèmes des miniatures à travers le répertoire des personnages et des gestes inspirés d'un manuscrit probablement originaire du nord de la France. Héritées de la tradition occidentale, les images de l'histoire antique transmises dans les manuscrits se caractérisent en premier 
lieu par un anachronisme qui gomme les distances spatio-temporelles et qui vise à souligner le caractère universel du comportement humain. Cet anachronisme passe par le décor, les usages, la religion, les institutions, le vêtement. Il est évident, surtout dans les images, avec l'exemple des scènes de combat singulier ou de batailles dans lesquelles les armes et les armures sont celles de chevaliers du xiII ${ }^{\mathrm{e}}$ siècle et non de l'Antiquité (fig. 1). Les images mettent en lumière l'équipement du chevalier tel qu'il aurait pu être au XIII siècle, au moment des croisades : le heaume, l'armure, la lance, le bouclier, la bannière, le cheval et son propre équipement, et notamment son caparaçon. Notons également l'utilisation de l'héraldique. Les partitions et les meubles apparaissant sur les images des trois manuscrits sont trop généralistes pour être associés à des familles de Terre sainte, car ces meubles ne sont autres que des lions, des aigles, la croix fleurdelisée, des besants, des annelets et des billettes. De même, les partitions sont loin d'être complexes : les fasces, les bandes (diagonales), le trescheur ou l'écusson...

Fig. 1. - Premier combat des Amazones, Histoire Ancienne jusqu'à César.

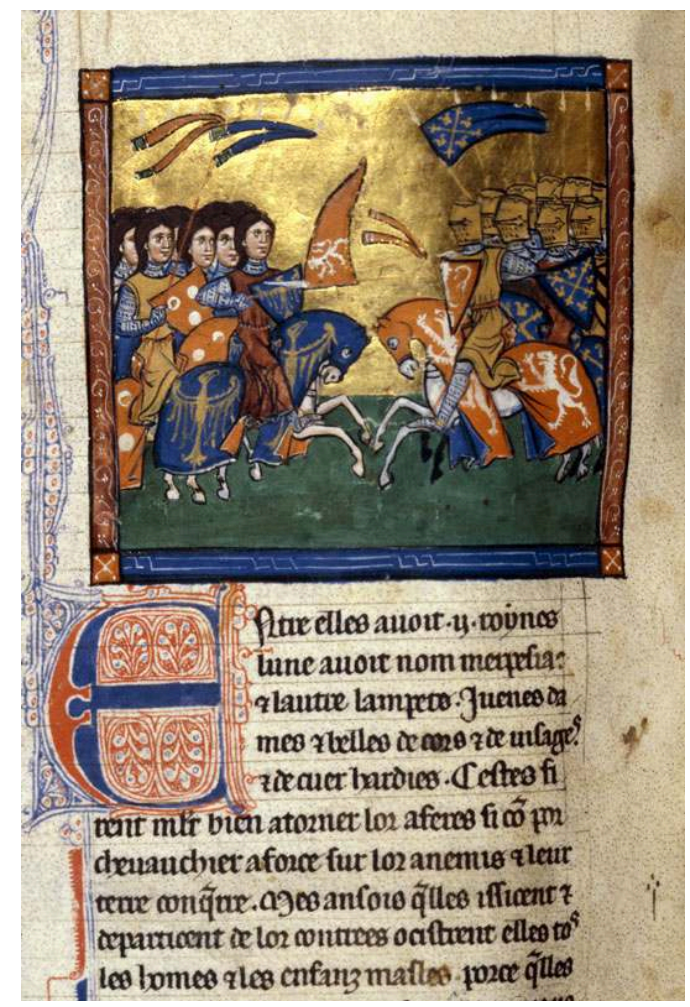

Dijon, Bibliothèque municipale, MS. 562, Saint Jean d'Acre, 1260-1270, F. 86 verso.

9 Nous relevons néanmoins un véritable travail de la part des enlumineurs de l'Histoire Ancienne de Dijon et de Londres pour développer une certaine cohérence dans ces motifs héraldiques. En effet, à l'occasion des batailles, l'écu, le caparaçon et la bannière $\mathrm{du}$ chevalier sont tous assortis aux mêmes armes. Une première correspondance qui apparait sur la miniature d'Ædipe (fig. 2) mais que nous relevons encore davantage sur la scène du combat singulier opposant Tydée et Polynice devant Adraste (fig. 3). Sur cette image, qui pourrait très bien représenter également une scène de tournoi, les adversaires sont pourvus d'un détail absent sur les autres miniatures, celle du panache ornant le heaume. Les armes arborées par les duellistes sont nettement définies: les 
armes de gueules à l'aigle d'argent opposées à celles d'azur au lion d'or pour le manuscrit de Dijon. Un autre exemple du soin apporté à l'héraldique se développe dans le cycle d'Alexandre de l'Histoire Ancienne de Dijon où le roi de Macédoine est figuré avec les mêmes armoiries dans toutes les miniatures qui lui sont consacrées: de gueules au lion d'argent. Des motifs qui apparaissent sur les bannières qui l'accompagnent (fig. 4) mais aussi sur le caparaçon de Bucéphale et son écu au moment de la bataille contre Porus (fig. 5). Une cohérence qui est absente des manuscrits de Londres et de Bruxelles.

Fig. 2. - Edipe affrontant la Sphinge, Histoire Ancienne jusqu'à César.

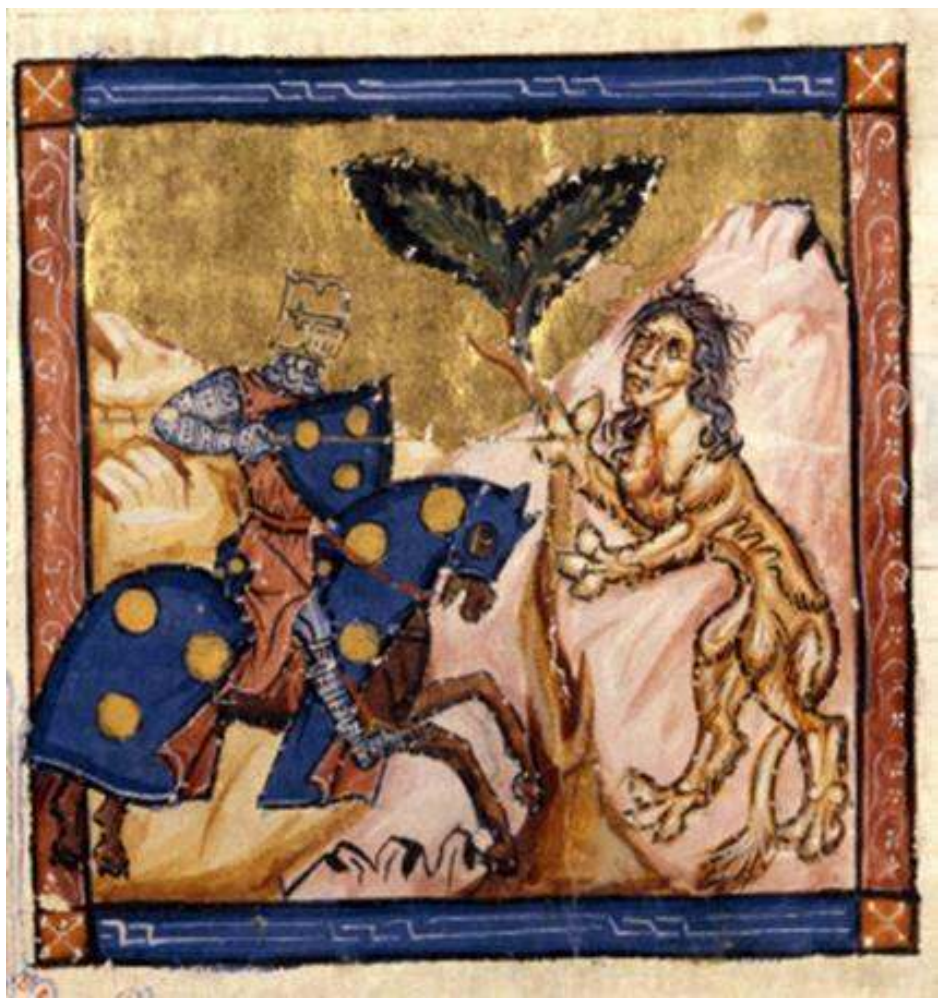

Dijon, Bibliothèque municipale, MS. 562, Saint Jean d'Acre, 1260-1270, F. 67 verso. 
Fig. 3. - Combat de Tydée et Polynice devant Adraste, Histoire Ancienne jusqu'à César.

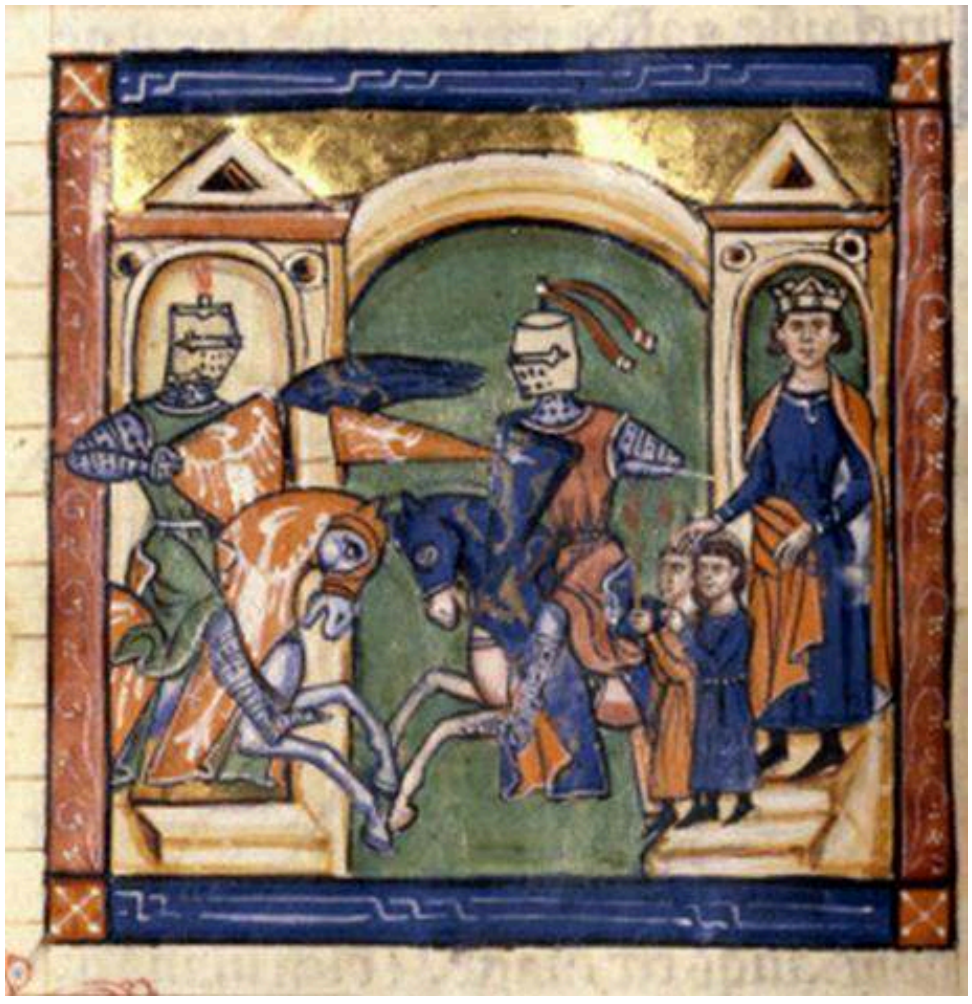

Dijon, Bibliothèque municipale, MS. 562, Saint Jean d'Acre, 1260-1270, F. 70 verso.

Fig. 4. - Alexandre agenouillé devant le grand prêtre de Jérusalem, Histoire Ancienne jusqu'à César.

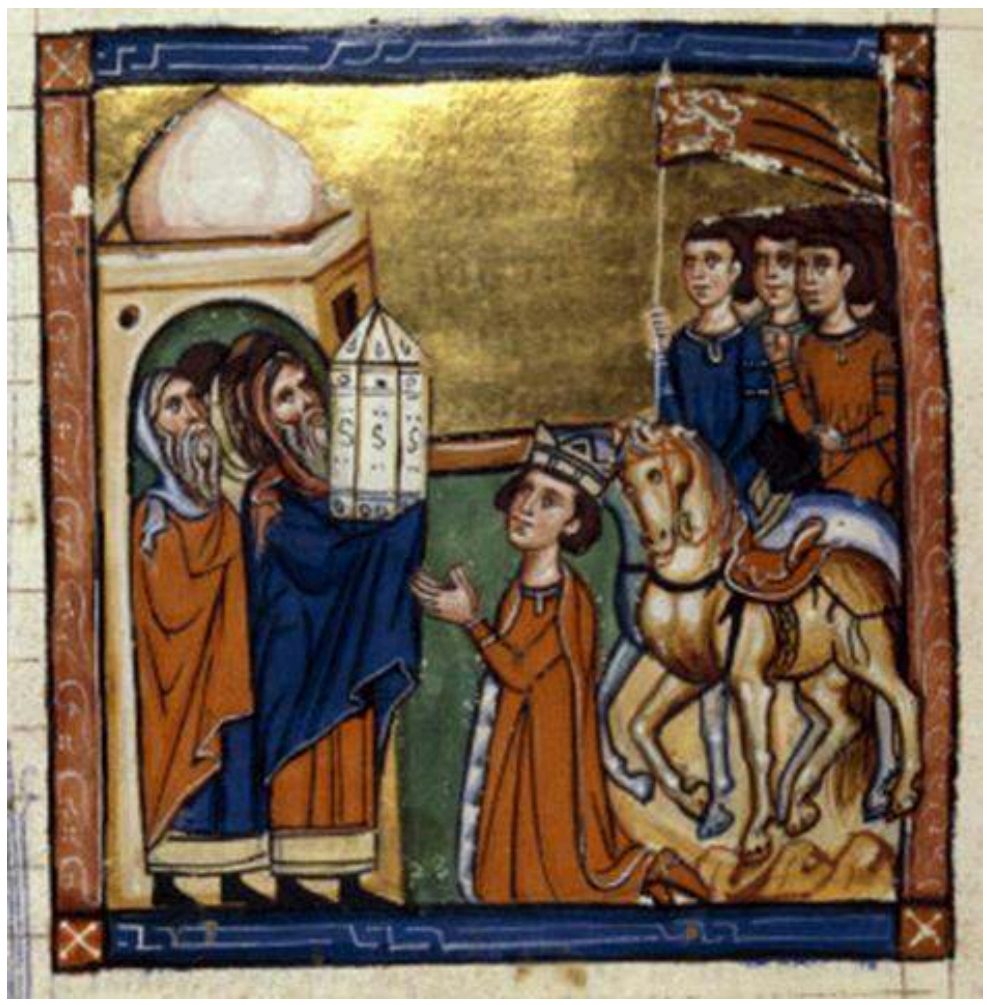

Dijon, Bibliothèque municipale, MS. 562, Saint Jean d'Acre, 1260-1270, F. 170 verso. 
Fig. 5. - La bataille de l'Hydaspes (Alexandre contre Porus), Histoire Ancienne jusqu'à César.

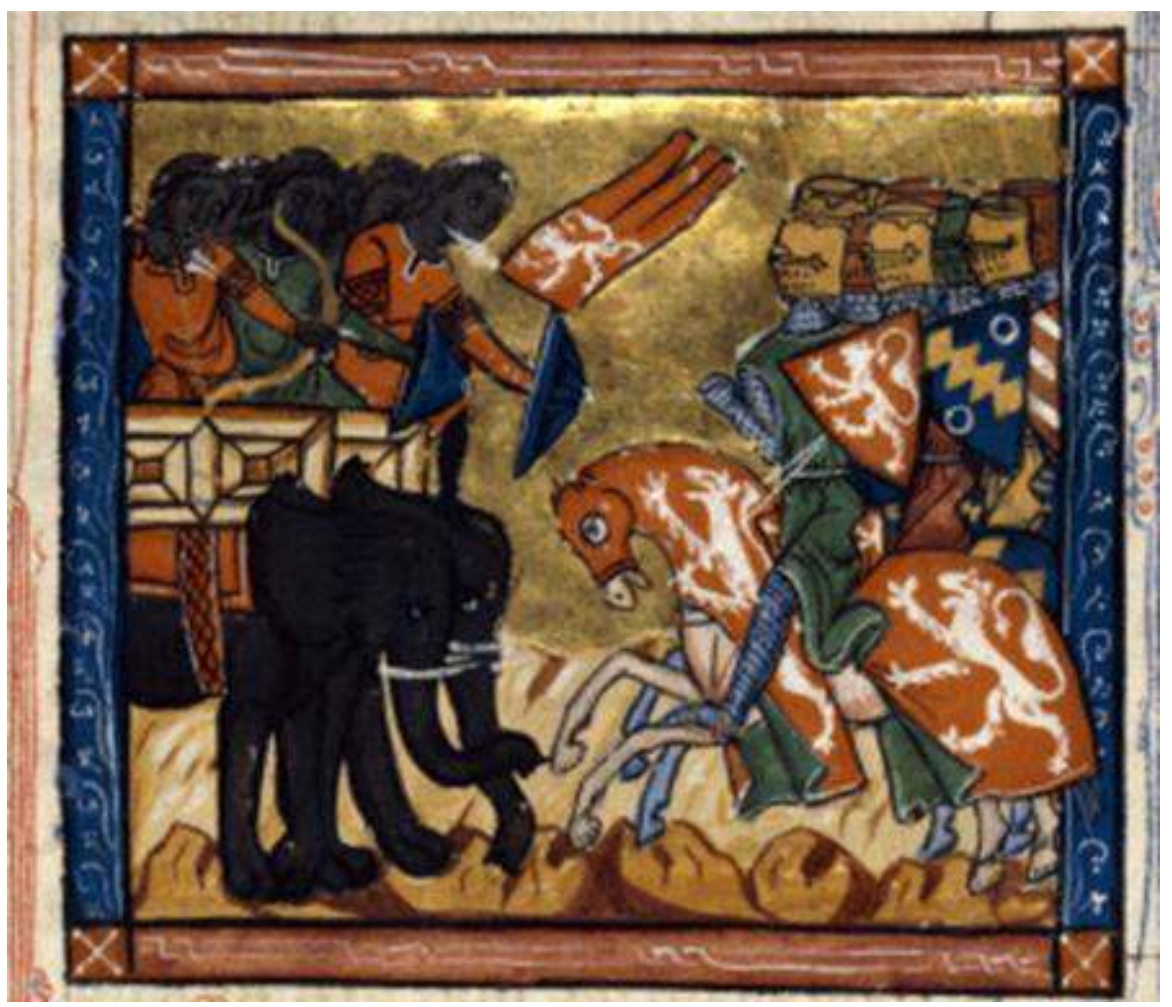

Dijon, Bibliothèque municipale, MS. 562, Saint Jean d'Acre, 1260-1270, F. 172 verso.

Tout l'art des enlumineurs de Terre sainte, depuis le XII ${ }^{e}$ siècle et tout particulièrement en cette seconde moitié $\mathrm{du}$ XIII ${ }^{\mathrm{e}}$ siècle, est d'avoir su associer ces références occidentales, parfois contemporaines, à des influences orientales de diverses origines. Une insertion de motifs, de traits orientaux, apportée avec subtilité par ces artistes totalement imprégnés d'un savoir-faire misant sur ce parti-pris depuis l'établissement $\mathrm{du}$ scriptorium du Saint-Sépulcre dans les années 1110. Plusieurs influences orientales sont présentes dans tous les manuscrits, la plus importante étant byzantine, dans les miniatures de la Genèse en particulier, une section dont le personnage principal demeure le patriarche, sous les traits d'un vieil homme barbu portant un vêtement aux draperies tubulaires (fig. 6). Toutes les figures patriarcales sont représentées sous le même motif, que le personnage soit Noé, Abraham, Loth, Isaac et enfin Jacob. Mais des influences arabo-musulmanes sont aussi ponctuellement présentes avec certains motifs comme la présence de turbans pour les ennemis d'Alexandre lors de la bataille de l'Hydaspes des manuscrits de Londres (folio 204) et Bruxelles (folio 218 verso) ou les toits en dôme pour la représentation de Jérusalem dans le manuscrit de Dijon (fig. 4). La mise en image de l'histoire antique est donc largement inspirée de motifs occidentaux mais, ponctuellement, elle peut aussi faire l'objet d'une transformation subtile de la part des enlumineurs pour les inscrire dans la tradition levantine. 
Fig. 6. - L'hospitalité d'Abraham à Mambré, Histoire Ancienne jusqu'à César.

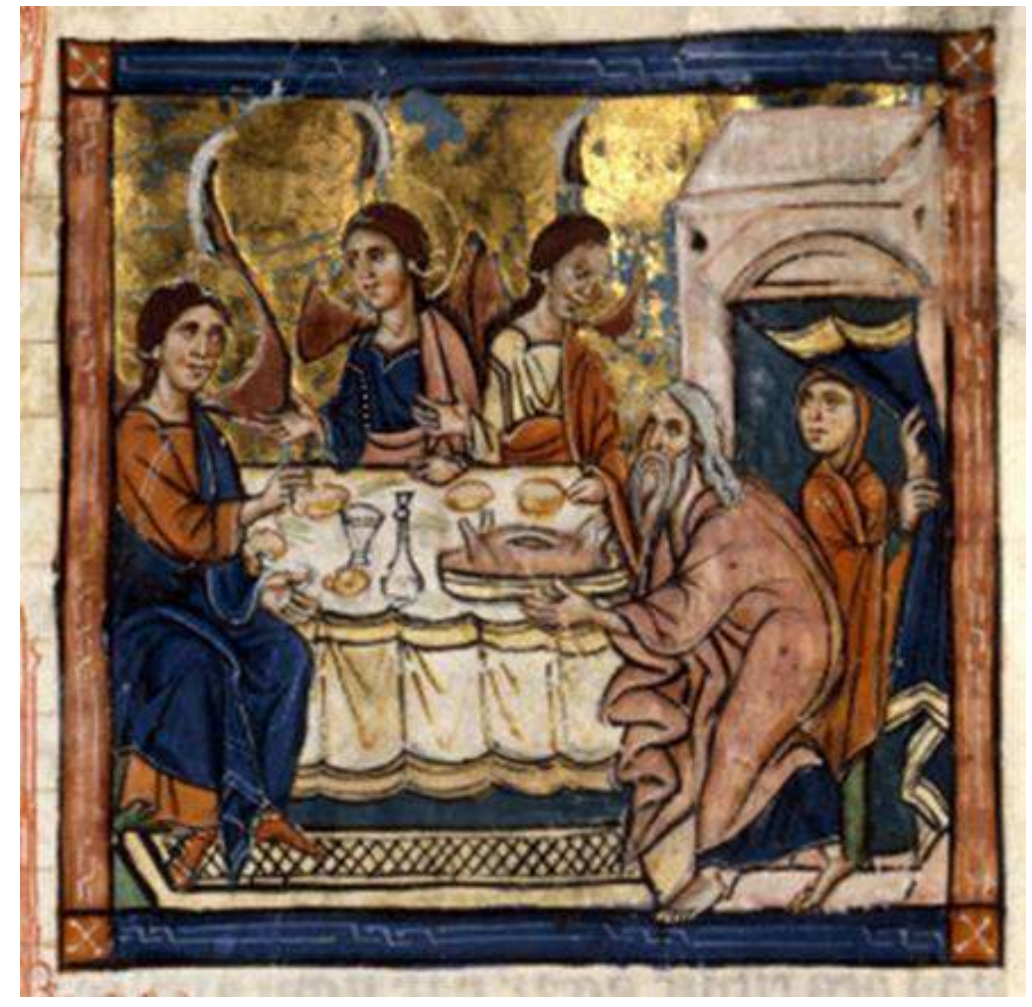

Dijon, Bibliothèque municipale, MS. 562, Saint Jean d'Acre, 1260-1270, F. 21 verso.

\section{Les héros antiques célébrés par les images levantines}

11 Ces enlumineurs levantins au service de nobles francs de Terre sainte font aussi le choix de mettre en avant des personnages. Certains héros connaissent des destins remarquables dont les manuscrits se font l'écho en leur consacrant des miniatures : ce sont les Patriarches pour la Genèse. Pour la mythologie et l'histoire antique, ce sont avant tout des héros civilisateurs ou fondateurs comme les Amazones (fig. 1), Énée et Alexandre (fig. 4 et 5). Le succès d'une histoire universelle en Orient auprès du public franc s'explique en partie par le fait que les Francs y trouvent des histoires particulières qui font écho à leur expérience, car certains héros ont vécu en Terre sainte, ou plus largement au Proche-Orient. Certains ont même remporté sur place de grandes victoires qu'ils leur envient: Alexandre le Grand et ses victoires à Tyr et à Gaza, Pompée pour ses conquêtes en Judée, représenté lors de son triomphe à son retour (fig. 7). Ces récits réunis et les héros mis en avant favorisent la réflexion politique qu'ils mènent alors au sein de leur communauté sur les fondements, le juste exercice et les limites de leur pouvoir. 
Fig. 7. - Le triomphe de Pompée, Histoire Ancienne jusqu'à César.

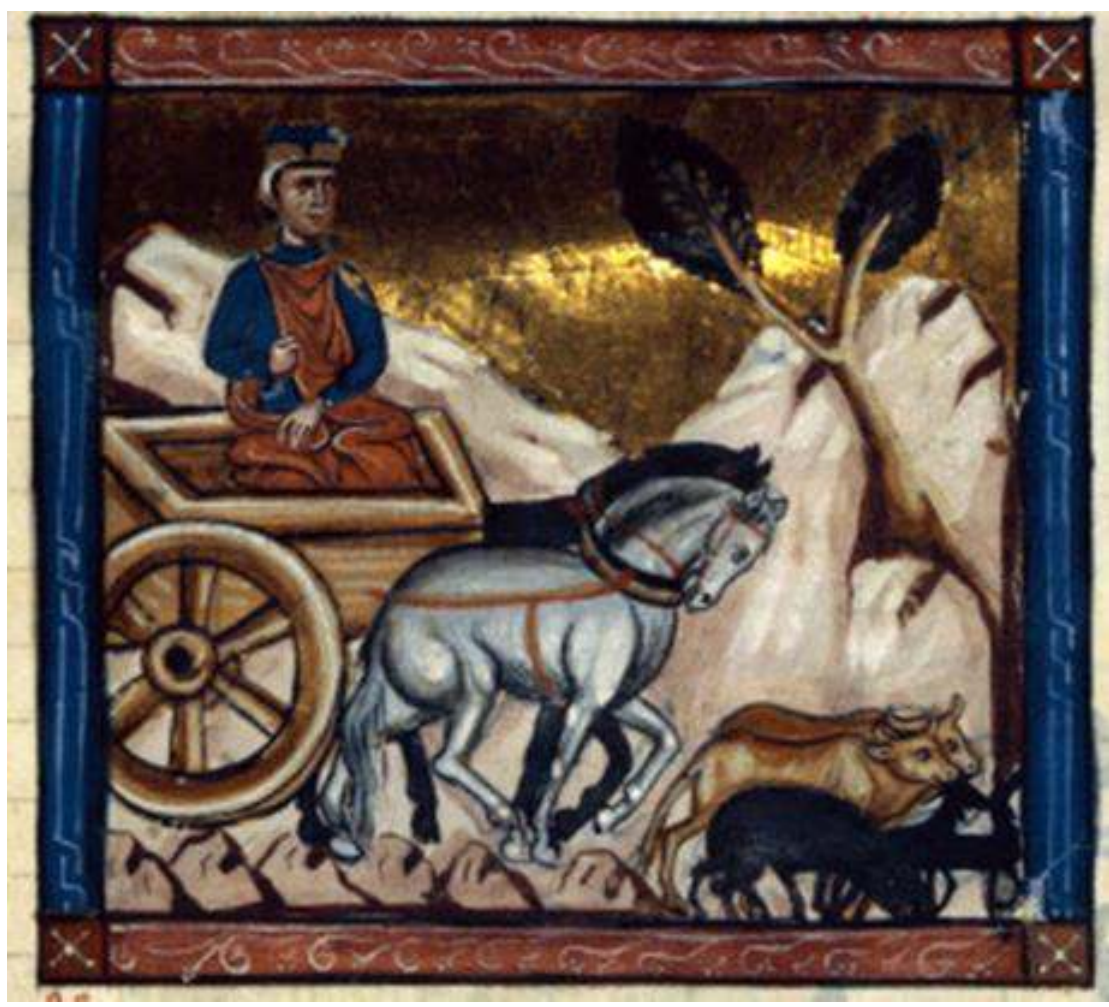

Dijon, Bibliothèque municipale, MS. 562, Saint Jean d'Acre, 1260-1270, F. 270.

12 Les manuscrits de Terre sainte de l'Histoire Ancienne jusqu'à César accordent par exemple une place particulière aux Amazones qui apparaissent dans six miniatures du manuscrit de Dijon ${ }^{21}$, quatre dans celui de Bruxelles ${ }^{22}$ et six à nouveau dans la copie de Londres $^{23}$. Tant dans le texte que dans les images, les Amazones ne transgressent plus les lois de leur sexe en prenant les armes, elles défendent des causes justes: la vengeance de leurs maris tués en Égypte (fig. 1) ou l'aide apportée aux Troyens (fig. 8). Cette indulgence quant à leur action et le jugement positif dont elles font l'objet pourraient s'expliquer non seulement par l'influence des femmes sur la demande d'un tel récit, mais aussi par leur participation à la croisade, à l'image d'Aliénor d'Aquitaine au moment de la deuxième croisade assimilée à la reine Penthésilée. Les trois copies de Terre sainte traduisent donc un véritable intérêt pour ces femmes guerrières, dont les qualités militaires et le courage sont reconnus dans le contexte de la croisade et des États latins d'Orient. Malgré le cours des événements qui voit finalement leur défaite, elles ne sont jamais présentées en position de faiblesse mais bien sur un pied d'égalité avec leurs adversaires au moment des combats. Les Amazones sont aussi considérées comme un peuple ayant vécu dans cette région de l'Orient, que ce soit en Libye chez certains auteurs comme Diodore de Sicile, ou plus vraisemblablement dans la région du Pont-Euxin, sur la rive sud de la Mer Noire. Et nous retrouvons ce concept chez plusieurs auteurs en lien avec la Terre sainte, en plus du Roman de Troie qui développe l'histoire de la reine Penthésilée et de ses femmes originaires de Féménie: Guillaume de Tyr, la lettre du Prêtre Jean ${ }^{24}$ ou dans l'Historia Orientalis de Jacques de Vitry ${ }^{25}$ (évêque d'Acre de 1216 à 1228). Ainsi, comme elles ont porté secours aux Troyens, les Amazones apparaissent pour les Francs comme un secours légendaire qui pourrait retourner la situation à leur avantage alors qu'ils font face aux avancées mameloukes. 
Fig. 8. - La reine Penthésilée et les Amazones devant Troie, Histoire Ancienne jusqu'à César

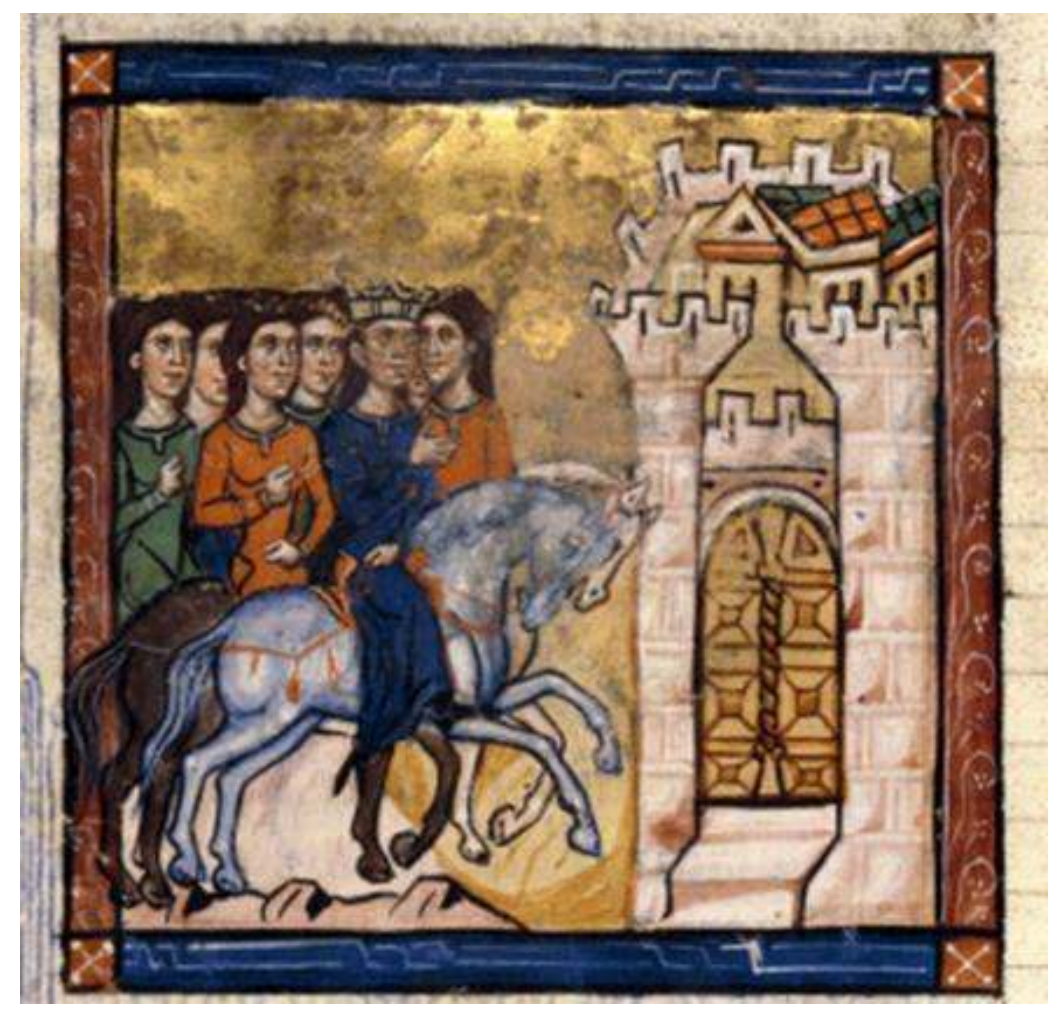

Dijon, Bibliothèque municipale, MS. 562, Saint Jean d'Acre, 1260-1270, F. 102 verso.

13 La commande d'un manuscrit de l'Histoire Ancienne a aussi pour but de servir la gloire du lignage des nobles de Terre sainte, s'inscrivant ponctuellement au sein d'une autre forme de littérature, la littérature généalogique. Avec la section consacrée à la guerre de Troie, la propagande des Francs en Orient rappelle leurs origines troyennes, comme le montre une des rubriques présente dans les trois copies : Coment Friga frere Eneas fu la premiere semence des Francois (Dijon, folio 108; Bruxelles, folio 144 ; Londres, folio 129). Ce mythe de l'origine troyenne des Francs reprend le modèle de la légende antique qui attribue la fondation de Rome à Énée, mais aussi les récits du Pseudo-Frédégaire et la Gesta Historiae Francorum. Le compilateur de l'Histoire Ancienne s'inspire enfin de la littérature généalogique créée à la cour des Plantagenêt dans l'Historia Regum Britanniae rédigée entre 1135 et 1138 par le gallois Geoffroy de Monmouth, relayée en français dans le Roman de Brut de Wace achevé vers 1155. Raconter cette histoire troyenne revient, pour les demandeurs nobles levantins, à rechercher un âge d'or dans une ville légendaire. C'est aussi justifier une nouvelle translation de leur pouvoir de l'occident vers l'Orient. Ce lien avec les Troyens apparaît notamment sur la miniature de la mort d'Hector (fig. 9) dans les trois manuscrits. Le fils de Priam est tué par Achille dans un combat déloyal: Achille, le héros grec, le transperce de sa lance alors qu'Hector lui tourne le dos, tout occupé à s'emparer du heaume d'un de ses adversaires tué au combat. 
Fig. 9. - Achille tuant Hector de sa lance, Histoire Ancienne jusqu'à César.

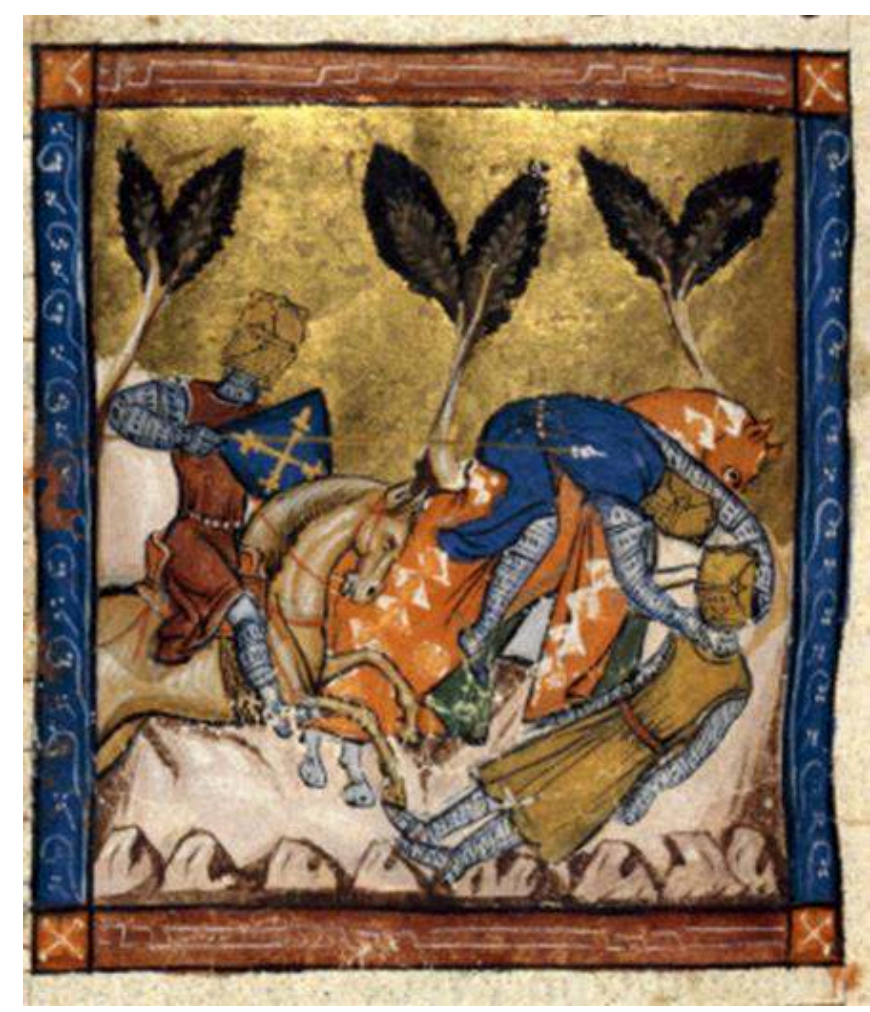

Dijon, Bibliothèque municipale, MS. 562, Saint Jean d'Acre, 1260-1270, F. 96 verso.

Enfin, dernière grande figure présente dans les trois cycles de miniatures, il s'agit d'Alexandre le Grand qui exerce une certaine fascination sur les sociétés aristocratiques de par l'ambiguïté de son destin. Ce héros de l'Antiquité est formé comme un souverain exemplaire, savant et érudit puisque éduqué par le philosophe Aristote, et doué de songe prophétique. Son histoire est aussi une sorte de préfiguration à l'histoire des croisades par l'itinéraire de son expédition mais surtout avec son entrée à Jérusalem. Cet épisode permet aux historiens du Moyen Âge de donner un caractère chrétien à Alexandre lors de son passage à Jérusalem et de sa prosternation devant le prêtre du Temple (fig. 4). Ces deux images présentes dans les manuscrits de Dijon et Bruxelles (au folio 216 verso) relient donc directement Alexandre à l'histoire de Terre sainte et peuvent être interprétées comme des représentations du roi exemplaire venu faire ses dévotions à Jérusalem. Modèle de comportement pour les Francs du Royaume latin de Jérusalem, Alexandre représente à lui seul des vertus royales et chevaleresques qui en font un exemple tout en apportant la fascination pour les contrées orientales. Mais il est aussi le souverain de l'hybris, de la démesure lorsqu'il tente de mener une conquête qui l'amène jusqu'en Inde et quand il souhaite soumettre le monde entier à son autorité. Car, en dépassant les limites du monde connu, il fait passer son profit personnel et son goût de la conquête avant l'intérêt général, une attitude qui va le conduire à sa perte et qui apparaît dans les trois manuscrits dans sa rencontre avec des monstres: un monstre tricorne et un monstre bicéphale (fig. 10). 
Fig. 10. - Monstres tricorne et bicéphale rencontrés par Alexandre le Grand, Histoire Ancienne jusqu'à César.
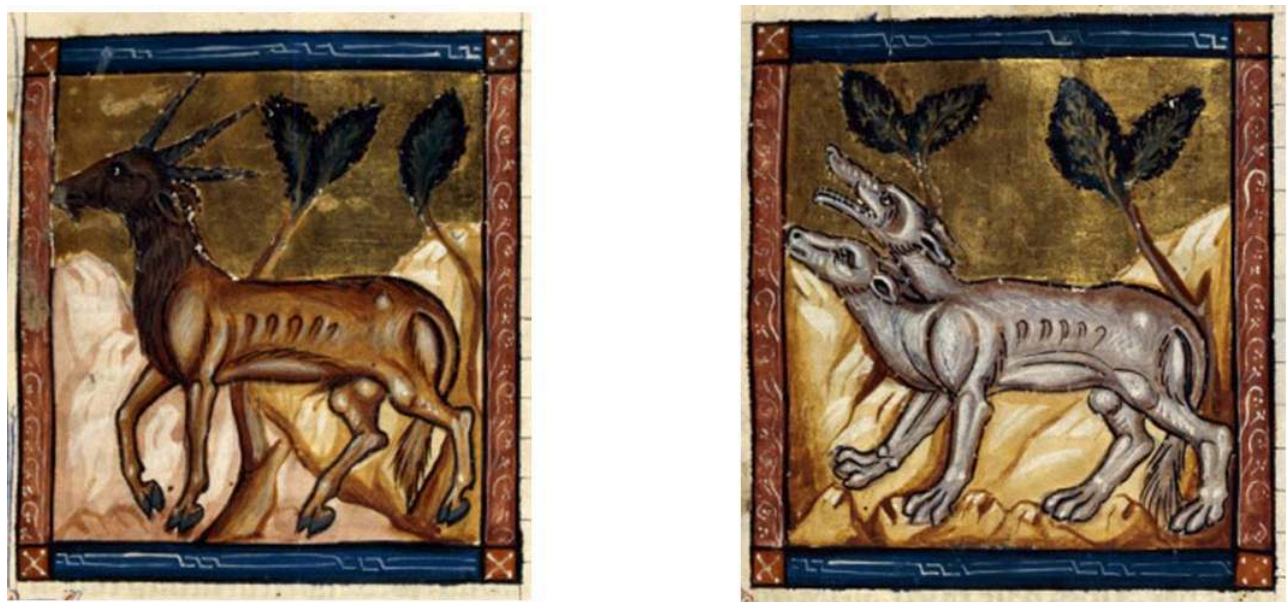

Dijon, Bibliothèque municipale, MS. 562, Saint Jean d'Acre, 1260-1270, F. 176 et 178.

rois manuscrits de l'Histoire Ancienne jusqu'à César enluminés à Saint Jean d'Acre nous montrent la transmission de l'histoire antique au sein d'une histoire universelle durant les dernières décennies du Royaume latin de Jérusalem. Il apparaît que le délai entre sa compilation en Flandre et son voyage en Terre sainte est très court, à peine une vingtaine d'années. Sur place, si le récit n'a subi aucune modification, les images ont été transformées pour correspondre aux attentes des demandeurs francs de Terre sainte. Entre héritages occidentaux et ajouts d'éléments orientaux, la mise en image de l'histoire antique doit permettre de servir un message culturel et politique des nobles levantins qui retrouvent dans les héros de l'Antiquité des modèles universels qu'ils rattachent à leur tradition levantine. Une manière pour eux de légitimer leur présence en Orient en cette période de déclin. Commanditaires et artistes ont ainsi souhaité affirmer certains aspects de leur culture levantine dans ces images et incarner un transfert des motifs et des techniques artistiques dans cette région qui favorise les échanges entre les civilisations.

\section{BIBLIOGRAPHIE}

BEJCZY Istvan, La Lettre de Prêtre Jean. Une utopie médiévale, Paris, Imago, 2001.

BUCHTHAL Hugo, Miniature paintings in the Latin Kingdom of Jerusalem, Oxford, Clarendon Press, 1957.

Le Roman de Thèbes, publié par Guy Raynaud de Lage, Paris, H. Champion, 2002.

Le Roman d'Éneas, publié par Aimé Petit, Paris, Librairie générale française, Lettres Gothiques, 1997. 
Le Roman d'Alexandre, traduction de Laurence Harf-Lancner, Paris, Livre de Poche, collection Lettres gothiques, 1994.

Histoire des Croisades par Jacques de Vitry, Collection des Mémoires relatifs à l'Histoire de France, sous la direction de M. Guizot, Paris, J.-L.-J. Brière, 1825.

MEYER Paul, « Les premières compilations françaises d'histoire ancienne », Romania, XIV, Paris, 1885.

Orose, Histoire contre les païens, Tome I, Livres I-III, texte établi et traduit par Marie-Pierre Arnaud-Lindet, Paris, Les Belles Lettres, 1990.

Orose, Histoire contre les païens, Tome II, Livres IV-VI, texte établi et traduit par Marie-Pierre Arnaud-Lindet, Paris, Les Belles Lettres, 1991.

Orose, Histoire contre les païens, Tome III, Livre VII, texte établi et traduit par Marie-Pierre ArnaudLindet, Paris, Les Belles Lettres, 1991.

Pierre le Mangeur, Petri Comestoris Scolastica Historia, Liber Genesis, Turnhout, Brepols, 2005.

RUBROUCK Guillaume de, Voyage dans l'empire mongol : 1253-1255, Traduction de Claude-Claire et René Kapler, Paris, Imprimerie nationale, 1993.

SAINT-MAURE Benoît de, Le Roman de Troie, traduction d'Emmanuèle Baumgartner, Paris, 10/18, Série Bibliothèque médiévale dirigée par P. Zumthor, 1987.

WEISS Daniel, The pictorial language of the Arsenal Old Testament: Gothic and Byzantine contributions and the meaning of crusader art (Paris, Bibliothèque de l'Arsenal, MS. 5211), Baltimore, Johns Hopkins University, 1993.

WEISS Daniel, Art and crusade in the age of saint Louis, New York, Cambridge University Press, 1998.

\section{NOTES}

1. H. Buchthal, Miniature paintings in the Latin Kingdom of Jerusalem.

2. Londres, British Library, Egerton, Psautier de la reine Mélisende, 1139, Jérusalem, SaintSépulcre, 1131-1143.

3. Le dominicain André de Longjumeau, envoyé une première fois en 1245 par le pape Innocent IV, est à nouveau chargé d'une ambassade auprès des Mongols par Louis IX en 1249. Depuis Chypre et accompagné de son frère Guillaume, de Jean de Carcassonne, il gagne Mossoul puis le lac Balkach où il rencontre la veuve de Güyük et lui remet les cadeaux du roi : une tente-chapelle écarlate décorée de panneaux retraçant la vie du Christ et une relique de la Vraie Croix. Quelques années plus tard, en 1253, le franciscain Guillaume de Rubrouck se verra confier une nouvelle mission auprès des Mongols accompagné de Barthélémy de Crémone et de nouveaux présents: une chapelle (sans doute une tente à nouveau) équipée des ornements nécessaires à l'office ainsi que des livres, parmi lesquels une Bible commandée par le roi et un psautier offert par la reine Marguerite de Provence.

4. G. de Rubrouck, Voyage dans l'empire mongol : 1253-1255.

5. D. Weiss, Art and crusade in the age of saint Louis.

6. Oxford, Bodleian Library, ms. 270b, Bible Moralisée, Paris, vers 1245. 
7. Paris, BnF, Bibliothèque de l'Arsenal, ms. 5211, Bible de Saint Jean d'Acre, Acre, 1250-1254.

8. D. Weiss, The pictorial language of the Arsenal Old Testament: Gothic and Byzantine contributions and the meaning of crusader art (Paris, Bibliothèque de l'Arsenal, ms. 5211).

9. L'Histoire d'Outremer de Guillaume de Tyr, est un récit créé au XII siècle par un "Poulain », c'est-à-dire un natif de Terre sainte issu de la première génération de croisés qui ont décidé de s'installer en Orient. Après avoir étudié à Paris pendant une vingtaine d'années, Guillaume de Tyr rentre en Terre sainte pour devenir archidiacre, puis archevêque de Tyr en 1175, d'où le nom que nous lui attribuons aujourd'hui. Il est connu pour sa chronique en latin intitulée Historia Rerum in Partibus Transmarinis Gestarum qui raconte l'histoire du Royaume latin de Jérusalem et des États francs jusqu'en 1184. C'est donc l'une des sources les plus importantes pour l'histoire des États latins de Terre sainte depuis leur fondation, car le récit a été créé sur place. Il a ensuite été continué à plusieurs reprises pour couvrir davantage l'histoire des Latins en Terre sainte et c'est en français que l'ouvrage se répand avec succès en Terre sainte à partir du milieu du XIII ${ }^{\mathrm{e}}$ siècle. La chronique est en effet traduite entre 1220 et 1223, elle prend alors le titre d'Histoire d'Outremer et les continuations qui suivent sont toutes en français. Élaborées en plusieurs étapes, ces suites vont parfois jusqu'en 1277 et certaines d'entre elles, comme la Chronique d'Ernoul allant de 1184 à 1197, ont également vu le jour en Terre sainte. Ernoul est en effet un serviteur de Balian d'Ibelin, seigneur de Terre sainte qui avait tenté de défendre Jérusalem face à Saladin en 1187. L'Histoire d'Outremer est donc un récit historique, une histoire de la fondation des États latins et des croisades racontée par un natif de Terre sainte qui, grâce à son éducation et à sa connaissance des courants littéraires occidentaux, reproduit une chronique qui s'avère être une véritable histoire officielle de la société latine d'outre-mer. Ce sont également des Francs de Terre sainte comme Ernoul qui traduisent et poursuivent le récit au XIII ${ }^{\mathrm{e}}$ siècle.

10. Dijon, bibliothèque municipale, ms. 562, Histoire Ancienne jusqu'à César, Acre, 1260-1270.

11. Bruxelles, Bibliothèque Royale de Belgique, ms. 10 175, Histoire Ancienne jusqu'à César, Acre, 1275-1280.

12. Londres, British Library, Add. 15 268, Histoire Ancienne jusqu'à César, Acre, vers 1285.

13. P. Meyer, «Les premières compilations françaises d'histoire ancienne ».

14. Le Roman de Thèbes, publié par Guy Raynaud de Lage.

15. B. de Saint-Maure, Le Roman de Troie.

16. Le Roman d'Éneas, publié par Aimé Petit.

17. Le Roman d'Alexandre, traduction de Laurence Harf-Lancner.

18. Orose : historien $d u v^{e}$ siècle qui prit part au synode de Jérusalem en 415 contre Pélage, et qui, à la demande de saint Augustin, rédigea ses Histoires pour trouver des arguments historiques à l'encontre des Goths qui ont pillé Rome en 410.

19. Orose, Histoire contre les païens, Tome I, Livres I-III ; Tome II, Livres IV-VI ; Tome III, Livre VII.

20. Pierre le Mangeur, Petri Comestoris Scolastica Historia, Liber Genesis.

21. Dans le manuscrit de l'Histoire Ancienne de Dijon : le premier combat des Amazones (f. 86v), La chevauchée des Amazones (f. 87), Ménalippè et Hippolytè combattant 
Hercule et Thésée (f. 88), La reine Penthésilée conduisant ses Amazones devant Troie (f. 102v), Armée de Penthésilée face aux Grecs de Pyrrhus (f. 103), Camille et ses Amazones face à Énée (125v).

22. Dans le manuscrit de l'Histoire Ancienne de Bruxelles: Le premier combat des Amazones (f. 117v), Ménalippè et Hippolytè combattant Hercule et Thésée (f. 119), Armée de Penthésilée face aux Grecs de Pyrrhus (f. 138), Camille et ses Amazones face à Énée (165v).

23. Dans le manuscrit de l'Histoire Ancienne de Londres: Le premier combat des Amazones (f. 101v), Ménalippè et Hippolytè combattant Hercule et Thésée (f. 103), La reine Penthésilée et ses Amazones devant Troie (f. 122), Armée de Penthésilée face aux Grecs de Pyrrhus (f. 123), Rencontre entre Camille et Turnus (f. 149).

24. Au milieu du XII siècle, un mythe circule en Orient puis en Occident à propos d'un mystérieux royaume chrétien, celui que Prêtre Jean décrit dans sa lettre légendaire adressée à différents monarques occidentaux. La première mention de ce prêtre apparaît au milieu du XII siècle dans la chronique d'Otton de Freising, avant même que la lettre circule, adressée en premier à l'empereur Manuel Ier Comnène. (Bejczy, Istvan, La Lettre de Prêtre Jean. Une utopie médiévale, Paris, Imago, 2001).

25. Histoire des Croisades par Jacques de Vitry, Collection des Mémoires relatifs à l'Histoire de France.

\section{RÉSUMÉS}

Les États latins d'Orient voient s'établir des Occidentaux en Orient aux $\mathrm{XII}^{\mathrm{e}}$ et $\mathrm{XIII}^{\mathrm{e}}$ siècles. Ils deviennent des intermédiaires des échanges de savoirs scientifiques, culturels et artistiques entre l'Occident latin, le monde byzantin et le monde arabo-musulman. Pendant près de deux siècles, la société latine établie en Terre sainte encourage des projets artistiques multiculturels qui ont la particularité de conserver un héritage occidental en Orient tout en s'adaptant à leur environnement de Terre sainte et en adoptant des motifs orientaux. À travers trois manuscrits de l'Histoire Ancienne jusqu'à César enluminés à Saint Jean d'Acre entre 1260 et 1291, nous observons la transmission de l'histoire antique, sa diffusion en Orient latin et les modifications apportées au cycle iconographique pour répondre aux projets politiques et culturels des nobles levantins.

\section{AUTEUR}

\section{ÉMILIE MARASZAK}

Université de Bourgogne, membre associée de l'UMR ARTEHIS 6298 


\title{
La «transmission du savoir »
} d'Athènes à Paris : variations autour d'un topos dans trois chroniques médiévales françaises

\author{
Judith Förstel
}

1 Le thème choisi par le CTHS pour son Congrès de 2018 entre en résonance avec un topos cher aux auteurs du Moyen Âge : celui de la «translatio studii », grand mouvement de transmission du savoir depuis l'Orient jusque vers l'Occident ${ }^{1}$. Pour les lettrés médiévaux, la sagesse était en effet née à l'est : en Égypte, comme le disait déjà Platon, ou chez les Hébreux, comme le voulait l'héritage judéo-chrétien, et bien sûr en Grèce, en laquelle on reconnaissait, au Moyen Âge comme aujourd'hui, la mère de la philosophie. Et de ces contrées lointaines, la sagesse était venue en Occident : d'abord à Rome, puis dans le royaume des Francs. Cette idée, déjà présente à l'époque carolingienne ${ }^{2}$, s'est beaucoup développée au XIII e siècle, avec l'essor de la prestigieuse université de Paris, encouragé par le roi et par le pape. L'université parisienne est alors une toute jeune institution: cette communauté de maitres et d'étudiants a vu ses privilèges reconnus par Philippe Auguste en 1200 , et a reçu ses statuts du légat pontifical Robert de Courson en $1215^{3}$. Mais déjà, elle jouit d'une image très forte de " fontaine de sagesse ", en raison de son enseignement théologique, réputé dans tout l'Occident. C'est ainsi que la décrit, par exemple, un traité encyclopédique très diffusé à cette époque, l'Image du monde, écrit par Gossuin de Metz vers 1246 :

«Tout autresi vous pui je dire que Paris est la fontainne ou l'en peut plus puisier

science que en autre lieu, qui avoir i peut demourance. ${ }^{4}$ "

Et ce, parce que Paris abrite la sagesse venue d'Athènes et de Rome :

«Clergie regne orendroit a Paris, si comme ele fist a Athenes, une cité de grant noblesce. ${ }^{5} »$

Cette image de Paris comme nouvelle Athènes a été abondamment reprise par les chroniqueurs contemporains. Or, si l'on observe de plus près les textes, on s'aperçoit que ce thème de la «transmission du savoir » est loin d'être neutre : il est utilisé pour 
promouvoir le pouvoir royal, mais aussi d'autres institutions plus ou moins directement liées à celui-ci. Nous nous proposons de le démontrer au travers de trois textes écrits dans la seconde moitié $d u$ XIII ${ }^{e}$ siècle et au tout début du XIV siècle : les Grandes chroniques de France de Primat, la Vie de Louis IX écrite en latin par Guillaume de Nangis et sa traduction française. Bien que ces trois ouvrages entretiennent entre eux une évidente filiation, ils n'en développent pas moins trois interprétations particulières du même topos, mis au service de projets différents.

\section{Du « puits de philosophie » athénien à la « fontaine de savoir » parisienne : la translatio studii comme introduction à l'histoire du royaume dans les Grandes chroniques de France}

$4 \quad$ Le premier de ces textes se trouve dans les Grandes chroniques de France, monumentale histoire de la monarchie française, mise en œuvre à Saint-Denis sous le règne de Saint Louis. L'ouvrage, qui court depuis les origines franques jusqu'à la fin du règne de Philippe Auguste, fut solennellement offert par l'abbé de Saint-Denis au roi de France, Philippe III, vers 1275. On connaît l'importance de ces Grandes chroniques de France - qui ne portaient pas encore ce titre, mais plutôt celui de « roman des rois »-, appelées à être poursuivies jusqu'au $\mathrm{xv}^{\mathrm{e}}$ siècle, au sein de l'abbaye mais aussi dans l'entourage royal ${ }^{6}$.

5 Or, le prologue de ce jalon fondamental dans la mise en écrit de l'histoire de France s'achève justement sur une référence à la transmission du savoir, depuis Athènes vers Paris :

« [...] la fonteine de clergie, par cui sainte Eglise est soustenue et enluminee, florist à Paris. Si com aucun veulent dire, clergie et chevalerie sont touz jors si d'un acort, que l'une ne puet sanz l'autre; touz jors se sont ensemble tenues, et encores, Dieu merci, ne se departent eles mie. En III regions ont habité en divers tens : en Grece regnerent premierement, car en la cité d'Athenes fut jadis le puis de philosophie et en Grece la flors de chevalerie. De Grece vindrent puis à Rome. De Rome sont en France venues. Diex par sa grace vuelle que longuement i soient maintenues à la loenge et à la gloire de son non, qui vit et regne par touz les siecles des siecles. Amen. ${ }^{7}$ »

Primat, l'auteur de ce texte, présente ainsi la France comme l'héritière des traditions de l'Antiquité gréco-romaine, à la fois en matière de «clergie », c'est-à-dire de savoir et de connaissance, et de "chevalerie», autrement dit de puissance militaire. Il n'est pas l'inventeur de cette association, que l'on trouve déjà dans le Cligès de Chrétien de Troyes (vers 1176) : dans le début de ce roman courtois, la France est en effet décrite comme la terre d'accueil de la «clergie » et de la « chevalerie » venues de Grèce ${ }^{8}$. Mais Primat applique plus spécifiquement cette transmission du savoir à l'université de Paris, «fontaine de sagesse, par laquelle sainte Église est soutenue et éclairée ». Cette métaphore combine les deux images le plus souvent associées à l'université de Paris au $\mathrm{XIII}^{\mathrm{e}}$ siècle, notamment dans les bulles pontificales: celle de la source, du fleuve qui abreuve les écoliers assoiffés de sagesse, et celle de l'astre, de la lumière qui illumine la Chrétienté.

7 Alors que la majeure partie du prologue des Grandes chroniques de France est un décalque d'ouvrages antérieurs, empruntant au Ménestrel d'Alphonse de Poitiers ou à Aimoin de 
Fleury, sa conclusion, en revanche, semble bien être une création originale? ${ }^{9}$ En choisissant d'achever ce préambule sur le thème de la transmission du savoir, Primat exalte à la fois l'université de Paris et la capitale du royaume dont il s'apprête à retracer l'histoire. L'importance qu'il donne ainsi à Paris se retrouve dans la suite de son récit: par exemple, lorsqu'il se penche sur les temps mérovingiens, époque où le partage égalitaire du « royaume des Francs » entre les différents fils du roi défunt était la règle, Primat explique qu'il ne donne le titre de « roi de France » qu'aux souverains qui ont régné sur Paris.

8 La transmission de la sagesse antique à Paris a donc un arrière-plan politique : le royaume de France s'affirme ainsi comme dépositaire d'un héritage culturel qui brille d'un éclat tout particulier dans sa capitale. Le lien établi entre le prestige intellectuel de la ville et son statut de "tête du royaume " s'inscrit dans la lignée des textes de Guillaume Le Breton, le chapelain de Philippe Auguste, qui exaltait déjà Paris comme " caput regni » et comme « doctrix (...) totius orbis » dans la Philippide ${ }^{10}$.

\section{L'intervention de saint Denis et l'emblème de la fleur de lis chez Guillaume de Nangis}

9 Le texte fondateur de Primat a fortement influencé d'autres chroniqueurs du xiII siècle, à commencer par ceux qui ont poursuivi son effort au sein de l'abbaye de Saint-Denis. Celle-ci s'est en effet affirmée, aux $\mathrm{xII}^{\mathrm{e}}$ et $\mathrm{xIII}^{\mathrm{e}}$ siècles, comme le principal atelier d'écriture de l'histoire de France, et la plume tombée des mains de Primat, qui est sans doute mort vers 1277, a aussitôt été reprise par un autre moine de l'abbaye, Guillaume de Nangis, qui fut archiviste de Saint-Denis jusqu'à sa mort vers 1300. Guillaume de Nangis a écrit plusieurs ouvrages d'histoire, notamment une longue chronique universelle, et un récit en latin du règne de Saint Louis ${ }^{11}$. Cette Vie de Louis IX, antérieure à sa canonisation en 1297, a été, comme le "roman des rois » de Primat, offerte au roi Philippe III. Guillaume de Nangis y reprend le thème de la translatio studii, dans un chapitre consacré à la grande grève universitaire de 1229-1230.

Pendant deux ans, l'université de Paris est en effet restée fermée, les maîtres et les étudiants s'opposant au pouvoir royal alors assumé en titre par le jeune roi Louis IX, mais dans les faits par la régente, sa mère Blanche de Castille. À la source de cette contestation, une banale histoire de violence urbaine : une rixe avec des étudiants, au faubourg Saint-Marcel, violemment réprimée par les sergents du guet. Les privilèges de l'université ayant été bafoués, ses membres se mirent en grève. Il fallut de longs mois, et l'intervention du pape, pour aboutir enfin à un compromis qui permît à l'université de Paris de rouvrir ses portes, non sans avoir perdu quelques-uns de ses maîtres, définitivement partis à Toulouse ou à Oxford.

11 Le récit de cet épisode est l'occasion, pour le moine de Saint-Denis, d'un long développement sur l'université, qu'il présente comme l'un des piliers du royaume de France. De ce texte, qui a fait l'objet d'une analyse détaillée de Jacques Le Goff ${ }^{12}$, nous extrayons le passage consacré à la translatio studii :

«Duplex enim par flos lilii sapientiam et militiam significat, quce duo sequentes de Grcecia in Galliam Dionysium Aeropagitam cum fide, quam ibidem Dei gratia seminavit, tertium florem lilii facientem custodiunt et defendunt. Nam fides gubernatur et regitur sapientia, ac demum militia defensatur. Quamdiu enim prcedicta tria fuerint in regno Francice pariter et 
ordinate sibi invicta cohorentia, stabit regnum. Si autem de eodem separata fuerint, vel

avulsa, omne illud in seipsum desolabitur atque cadet. ${ }^{13}$ " bénéficiait d'une primauté à la fois spirituelle et matérielle, et il l'a appliquée à un emblème de ce royaume : la fleur de lis. Il identifie les trois fleurons du lis comme une triade science-foi-chevalerie, le tout ayant été, selon lui, amené en France depuis Athènes par saint Denis l'Aréopagite. Paris bénéficie ainsi d'une double transmission: celle du message chrétien, saint Denis ayant été l'évangélisateur de la ville, mais aussi celle de la sagesse antique, que Denis avait acquise à Athènes avant de se convertir en écoutant saint Paul, ainsi que le rapportent les Actes des Apôtres. Guillaume de Nangis combine cette tradition, cultivée dans son abbaye depuis l'époque d'Hilduin au $\mathrm{Ix}^{\mathrm{e}}$ siècle, avec le thème de la translatio studii et aboutit à une synthèse originale. L'association de saint Denis à la translatio studii n'était du reste pas sans fondements, dans la mesure où l'abbaye éponyme constituait l'un des rares foyers de culture grecque au sein du royaume de France : on y célébrait la missa greca et on y conservait plusieurs manuscrits grecs ${ }^{14}$.

Cette association entre le lis royal et saint Denis n'est pas restée cantonnée au seul milieu dionysien, puisqu'elle a été reprise au XIV ${ }^{\mathrm{e}}$ siècle par Philippe de Vitry dans le Chapel des fleurs de lis (écrit entre 1332 et 1335) ${ }^{15}$. Elle est cependant caractéristique des méthodes employées par les historiens de Saint-Denis pour lier la fortune de leur abbaye à celle des rois de France, dans la lignée de Suger. Il est très significatif, à cet égard, que Guillaume de Nangis ait employé l'expression "caput regni » à propos de Saint-Denis dans un autre passage de sa Vie de Louis IX, où il rapporte la perte du Saint $\mathrm{Clou}^{16}$. À ses yeux, l'abbaye constitue le pôle spirituel de la capitale du royaume de France, de par la protection assurée à la monarchie par saint Denis. En associant ce dernier à la translatio studii, Guillaume de Nangis place son abbaye au centre de la promotion du royaume de France.

\section{Une traduction française adaptée aux circonstances politiques}

La Vie de Louis IX de Guillaume de Nangis a été traduite en français, et cette version française, avec quelques ajouts, a été intégrée aux Grandes chroniques de France vers le début du XIV siècle. À propos de la grève de 1229, l'auteur a suivi dans ses grandes lignes le texte de Guillaume de Nangis, mais il y a porté quelques modifications qui ne sont pas sans intérêt. Voici donc sa propre interprétation des faits, qui reprend le thème de la translatio studii mais en modifie quelque peu la teneur :

" Jadiz, en ancien temps, clergie demoura à Athenes et chevalerie en Grece. Après, d'iluec s'en parti et s'en ala à Romme, et tantost chevalerie après. Par l'orguel des Rommainz, se parti le clergié de Romme et s'en vint en France et tantost chevalerie après. Et de ce nous senefie la fleur de liz qui est escripte es armes au roy de France, car il y a III fueilles. La fueille qui est ou mileu nous segnefie la foy crestienne, et les autres II du costé senefient le clergié et la chevalerie qui doivent estre touz jourz apareillié de deffendre la foy crestienne. Et tant comme ces III demorront en France, foy, clergié et chevalerie, le reanme de France sera fort et ferme et plain de richece et d'onneur. ${ }^{17}$ "

La chronique en français a repris l'association de la translatio studii et de la fleur de lis, proposée par Guillaume de Nangis, mais la figure tutélaire de saint Denis a été évacuée. 
Ce n'est d'ailleurs pas le seul passage de la Vie de Saint Louis qui élude ainsi le saint ou son abbaye, ce qui semble indiquer que la traduction n'a pas été effectuée au sein de l'atelier dionysien, mais plutôt dans l'entourage royal ${ }^{18}$.

Par ailleurs, l'auteur a transformé un thème désormais rangé parmi les lieux communs, celui de la transmission du savoir et de la puissance de l'Orient vers l'Occident, en une réflexion très actuelle sur l'Église : celle-ci, nous dit-il, a dû quitter Rome pour échapper à l'outrecuidance de ses habitants. Cette incise fait probablement référence au départ de la papauté, qui a abandonné Rome pour la France avec l'élection de Clément $\mathrm{V}$, en 1305 - déplacement qui allait conduire à l'installation des papes en Avignon.

17 Ce glissement inattendu du topos de la translatio studii s'opère à partir d'un jeu sur les deux sens du mot "clergie", qui peut renvoyer soit au savoir, soit à l'état clérical : l'auteur part du premier sens, mais dérive ensuite sur le second, ainsi que l'explicite le passage du féminin au masculin. Ainsi, ce n'est plus simplement le savoir qui vient de Grèce et de Rome, et qui constitue l'un des fleurons du lys de France ; c'est désormais l'Église.

18 La fin du texte nous décrit la fleur de lis, comme chez Guillaume de Nangis, mais avec un message politique un peu différent: le royaume s'appuie sur les trois fleurons que sont le clergé, la foi et la chevalerie. Cette interprétation de l'emblème de la monarchie française s'accorde avec la titulature de Philippe le Bel, le «roi très chrétien " ${ }^{19}$. L'Église, qui est l'une des composantes du royaume de France, ne saurait donc lui être supérieure : l'auteur se situe ici, sans surprise, dans le camp des juristes de Philippe le Bel, contre les prétentions théocratiques de Boniface VIII ${ }^{20}$.

À la fin du premier exemplaire de cette Vie de Saint Louis, copiée à la suite du « roman des rois" de Primat (Paris, Bibliothèque Sainte-Geneviève, ms 782), figure une mappemonde probablement contemporaine qui renforce le message politique attaché à la translatio studii ${ }^{21}$ (fig. 1). Sur la carte, quatre icones représentent les principales villes de l'Europe: Athènes, Constantinople, Rome et Paris (fig. 2). Si la trilogie AthènesRome-Paris constitue l'illustration du prologue des Grandes chroniques de France et de l'extrait de la Vie de Saint Louis que nous venons de citer, l'adjonction de Constantinople superpose au thème de la translatio studii celui de la translatio imperii, selon un processus que Mireille Chazan a également mis en lumière dans la Chronique universelle de Guillaume de Nangis ${ }^{22}$. Là encore, cette évolution peut être rapprochée des formules des juristes de Philippe le Bel, « imperator in suo regno ». 
Fig. 1. - Mappemonde dessinée sur le folio 374 verso du manuscrit 782 de la Bibliothèque SainteGeneviève (Grandes chroniques de France) : vue d'ensemble.

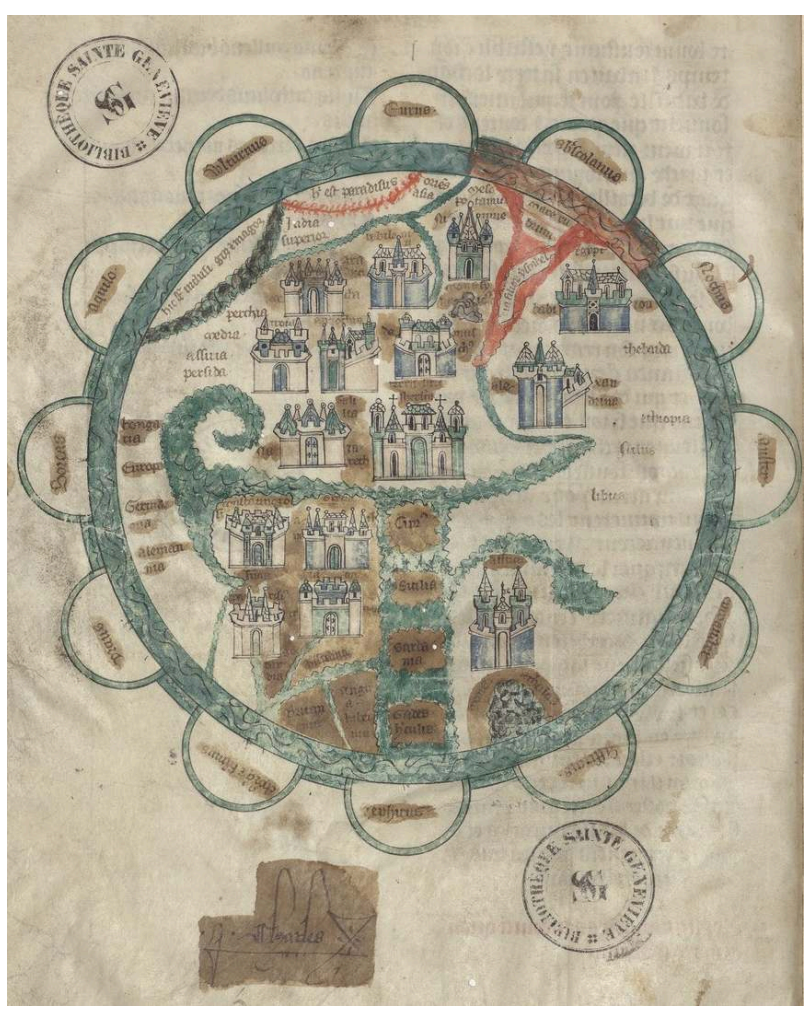

BnF. Département des Manuscrits Français 2813.

Fig. 2. - Détail de l'Europe.

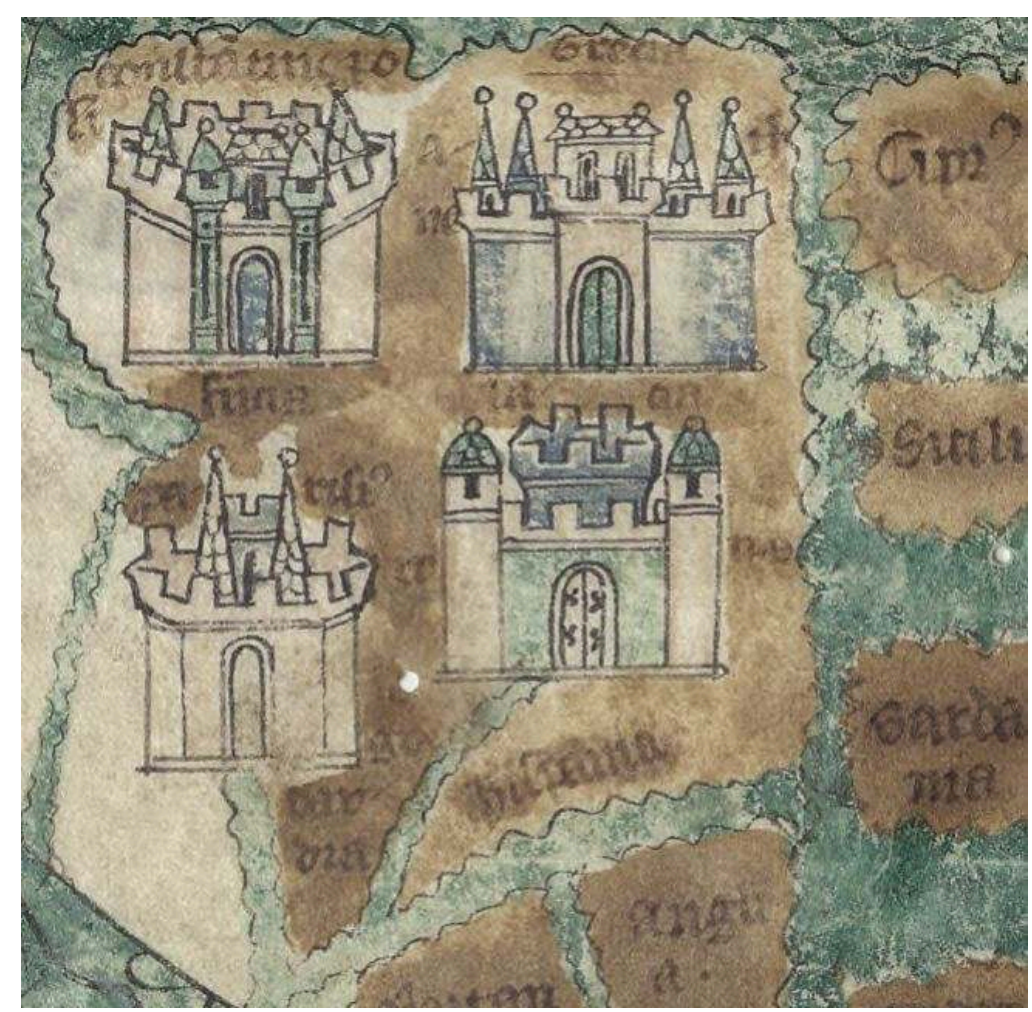

BnF. Département des Manuscrits Français 2813. 
En somme, à travers ces trois exemples, on voit que le thème de la «transmission du savoir » est chargé de connotations qui varient suivant le contexte de rédaction. Nous en avons cité trois témoins pris chez les chroniqueurs français du XIII ${ }^{\mathrm{e}}$ et du début du $\mathrm{XIV}^{\mathrm{e}}$ siècle, tout à l'honneur de Paris; mais les Anglais ne sont pas en reste, et font continuer le mouvement de translation de l'Orient vers l'Occident, jusqu'à l'université d'Oxford: c'est ce qu'avance par exemple le théologien anglais Jean de Galles (John Waleys) dans son Compendiloquium ${ }^{23}$.

21 La transmission du savoir est donc ressentie comme un enjeu éminemment politique par les écrivains du Moyen Âge. Mais le topos n'est pas univoque et se prête à des usages divers. Si l'exaltation du royaume de France est un thème partagé par les trois chroniqueurs ici retenus, chacun d'eux l'infléchit en fonction de ses propres intérêts. L'introduction ou au contraire l'omission de la figure de saint Denis dans le schéma de la «transmission du savoir » d'Athènes à Paris est représentative de ces inflexions. Au-delà du Moyen Âge, le thème de la translatio studii avait bien sûr tout pour séduire les écrivains français de la Renaissance. Preuve de sa vitalité, il a été adopté au début du $\mathrm{XIV}^{\mathrm{e}}$ siècle pour promouvoir Lyon, devenu à l'occasion des guerres d'Italie le «second œil de France »: on imagine alors qu'une "catherve et compaignie de philosophes » athéniens se serait installée près de la confluence du Rhône et de la Saône, au temps où Minos régnait en Crète ${ }^{24}$. La "transmission du savoir » apparaît donc toujours comme l'un des éléments qui fondent le prestige d'une ville. Mais la remise en cause de l'aréopagitisme de saint Denis allait peu à peu ruiner les savantes constructions du XIII siècle en faveur de Paris - même si l'on en trouve encore l'écho dans certains ouvrages tardifs, comme la Galliade de Le Fèvre de La Boderie, en $1582^{25}$.

\section{BIBLIOGRAPHIE}

BEAUNE Colette, Naissance de la nation France, Paris, Gallimard (Folio Histoire, 56), 1993.

BERSCHIN Walter, Griechisch-lateinisches Mittelalter : von Hieronymus zu Nikolaus von Kues, BerneMunich, A. Francke, 1980.

BRINCKEN Anna-Dorothee Von Den, “Fines Terrae”. Die Enden der Erde und der vierte Kontinent auf mittelalterlichen Weltkarten, Hannover, Hahnsche Buchhandlung (« Monumenta Germaniæ Historica. Schriften », vol. 36), 1992.

CHAZAN Mireille, « Guillaume de Nangis et la translation de l'Empire aux rois de France », dans AUTRAND Françoise, GAUVARD Claude et MOEGLIN Jean-Marie (dir.), Saint-Denis et la royauté. Études offertes à Bernard Guenée, membre de l'Institut, Paris, Publications de la Sorbonne, 1999, p. 463-480.

Chrétien de Troyes, Cligès, éd. Charles Méla, traduction et notes par Charles Méla et Olivier Collet, Paris, Le Livre de poche (Lettres gothiques), 1994 (rééd. 2008).

DELABORDE Henri-François, « Notes sur Guillaume de Nangis », BEC, T. XLIV, 1883, p. 192-201. 
DELISLE Léopold, Mémoire sur les ouvrages de Guillaume de Nangis (extrait de : Mémoires de l'Académie des inscriptions et belles-lettres, tome XXVII, $2^{\mathrm{e}}$ partie), Paris, Imprimerie nationale, 1873.

DESTOMBES Marcel, Mappemondes A.D. 1200-1500. Catalogue préparé pour la Commission des cartes anciennes de l'Union géographique internationale, Amsterdam, N. Israël, 1964.

Dit de la fleur de lis de Guillaume de Digulleville, éd. Frédéric Duval, Paris, École des chartes (Mémoires et documents de l'École des chartes, 95), 2014.

GILSON Étienne, Les idées et les lettres, Paris, J. Vrin, 1932.

GOROCHOV Nathalie, Naissance de l'université : les écoles de Paris, d'Innocent III à Thomas d'Aquin, v. 1200v. 1245, Paris, H. Champion (Études d'histoire médiévale, 14), 2012.

Gossuin de Metz, L'image du monde de maitre Gossouin : texte du manuscrit de la Bibliothèque nationale, fonds français $n^{\circ}$ 574, éd. O.H. Prior, Lausanne, Imprimeries réunies, 1913.

GUENÉE Bernard, « Les Grandes chroniques de France. Le Roman aux roys (1274-1518) », dans NORA Pierre (dir.), Les Lieux de mémoire, partie II : La Nation, tome I, Paris, Gallimard, NRF (Bibliothèque illustrée des histoires), 1986, p. 189-214.

GUENÉE Bernard, Comment on écrit l'histoire au XIII siècle. Primat et le "Roman des roys ", Paris, CNRS éditions, 2016 (édition établie par Jean-Marie Moeglin).

Guillaume de Nangis, Gesta sanctæe memorice Ludovici regis Franciœ, éd. Daunou et Naudet, Recueil des Historiens des Gaules et de la France, tome XX, Paris, Imprimerie royale, 1840, p. 309-461.

GUYOT-BACHY Isabelle, « La Chronique abrégée des rois de France de Guillaume de Nangis : trois étapes de l'histoire d'un texte ", dans CASSAGNES-BRouQuet Sophie, CHAUou Amaury, Рichot Daniel et RousseLot Lionel (dir.), Religion et mentalités au Moyen Âge. Mélanges en l'honneur d'Hervé Martin, Rennes, Presses Universitaires de Rennes, 2003, p. 39-46.

HEDEMAN Anne D., « Le pouvoir des images saintes dans les Grandes chroniques de France. Le cas de Saint Louis », dans COLLARD Franck, LACHAUD Frédérique et SCORDIA Lydwine (dir.), Images, pouvoirs et normes. Exégèse visuelle de la fin du Moyen Âge (XIII -XVe siècle), Paris, Classiques Garnier, 2017, p. 237-265.

Jean de Galles (John Waleys), Compendiloquium de vitis illustrium philosophorum, éd. Luke Wadding, Florilegium de vita et dictis illustrium philosophorum et Breviloquium de sapientia sanctorum, Rome, $\mathrm{N}$.

A. Tinassium, 1655.

JEAUNEAU Edouard, Translatio studii. The Transmission of Learning. A Gilsonian Theme, The Etienne Gilson series 18, Toronto, Pontifical Institute of Mediaeval Studies, 1995.

JONGKEES Adrian Gerard, «Translatio studii : les avatars d'un thème médiéval », dans Miscellanea Medicevalia in memoriam Jan Frederick Niermeyer, Groningen, 1967, p. 41-51.

KRYNEN Jacques, L'Empire du roi. Idées et croyances politiques en France, XIII ${ }^{e}-\mathrm{XV}^{e}$ siècle, Paris, Gallimard (collection «Bibliothèque des Histoires »), 1993.

LECOQ Danielle, « Éléments pour une lecture d'une mappemonde médiévale », Mappemonde, T. 88, 2007, p. 13-17.

LE GALL Jean-Marie, Le Mythe de saint Denis, entre Renaissance et Révolution, Seyssel, Champ Vallon, 2007.

LE GOFF Jacques, Saint Louis, Paris, Gallimard (Bibliothèque des Histoires), 1996. 
Les Grandes chroniques de France, éd. Jules Viard, Paris, H. Champion (Société de l'Histoire de France), 1920-1953, (10 vol.).

LUSIGNAN Serge, «L'Université de Paris comme composante de l'identité du royaume de France : étude sur le thème de la translatio studii », dans BABEL Rainer et MOEGLIN Jean-Marie (dir.), Identité régionale et conscience nationale en France et en Allemagne du Moyen Âge à l'époque moderne, actes du colloque organisé par l'université Paris XII, l'Institut universitaire de France et l'Institut historique allemand à l'université Paris XII et à la Fondation Singer-Polignac, 6-8 octobre 1993, Sigmaringen, Thorbecke (Beihefte der Francia, 39), 1997, p. 59-72.

LUSIGNAN Serge, "Vérité garde le roy ». La construction d'une identité universitaire en France (XIIl ${ }^{e}-\mathrm{XV}^{e}$ siècle), Paris, Publications de la Sorbonne, 1999.

Notker le Bègue, Gesta Karoli Magni imperatoris, éd. H.F. Haefele (MGH Scriptores rerum germanicarum N.S., T. 12), Berlin, 1959.

PATSCHOVSкy Alexander, « Der heilige Dionysius, die Universität Paris und der französische Staat », Innsbrucker historische Studien, T. I, 1978, p. 9-31.

Philippe de Vitry, Le Chapel des fleurs de lis, éd. Arthur Piaget, Romania, T. 27, 1898, p. 55-92.

RAMÈZE Guillaume, L'Origine et antiquité de la cité de Lyon et l'Histoire de Palanus, édition du ms. Paris, Arsenal, 5111, éd. Giovanni Palumbo, Paris, Classiques Garnier, 2011.

SPIEGEL Gabrielle M., The Chronicle Tradition of Saint-Denis : A Survey, Brookline (Mass.)-Leiden, Classical folia, 1978.

STONES Alison, Gothics Manuscripts 1260-1320, Part I, Londres, Harvey Miller, 2013.

TYL-LABORY Gillette, « Guillaume de Nangis », Dictionnaire des lettres françaises, tome I : Le Moyen

Âge, Paris, Fayard, 1992, p. 636-637

VERGER Jacques, «L'Université de Paris au Moyen Âge (XIII ${ }^{\mathrm{e}}-\mathrm{XV}^{\mathrm{e}}$ siècle) », dans BovE Boris et GAUVARD Claude (dir.), Le Paris du Moyen Âge, Paris, Belin, 2014, p. 173-192.

\section{NOTES}

1. Le thème de la translatio studii a suscité de nombreuses études, notamment : E. Gilson, Les idées et les lettres, p. 182-186; A.G. Jongkees, «Translatio studii: les avatars d'un thème médiéval»; A. Patschovsky, «Der heilige Dionysius, die Universität Paris und der französische Staat»; C. Beaune, Naissance de la nation France, p. 300-303; E. Jeauneau, "Translatio studii», the Transmission of Learning. A Gilsonian Theme; S. Lusignan, «L'Université de Paris comme composante de l'identité du royaume de France : étude sur le thème de la translatio studii »; S. Lusignan, "Vérité garde le roy». La construction d'une identité universitaire en France, p. 225-277; B. Guenée, Comment on écrit l'histoire au XIII' siècle, p. 58-60.

2. Voir notamment Notker le Bègue, Gesta Karoli Magni imperatoris, p. 731-732; dans cette œuvre, rédigée vers 884-887, Notker souligne le soutien apporté par Charlemagne aux savants tels qu'Alcuin, grâce à qui les Francs peuvent se comparer aux Romains et aux Athéniens de l'Antiquité («Moderni Galli sive Franci antiquis Romanis et Atheniensibus cequarentur»). 
3. Sur les débuts de l'université de Paris, voir notamment: N. Gorochov, Naissance de l'université: les écoles de Paris, d'Innocent III à Thomas d'Aquin, v. 1200-v. 1245 ; J. Verger, "L'Université de Paris au Moyen Âge (xIII $-\mathrm{Xv}^{\mathrm{e}}$ siècle) ».

4. L'Image du monde de maître Gossouin, chap. VI: «Des trois manieres de gens, et comment clergie vint en France», p. 78. Traduction en français moderne : «Ainsi, je puis vous dire que Paris est, de tous les lieux où l'on peut demeurer, la fontaine où l'on peut le mieux s'abreuver de science. »

5. Ibidem, p. 77 : «Le savoir règne aujourd'hui à Paris, comme il le fit jadis à Athènes, une cité de grande noblesse. »

6. B. Guenée, "Les Grandes chroniques de France. Le Roman aux roys (1274-1518)»;

B. Guenée, Comment on écrit l'histoire au XIII siècle. Primat et le "Roman des roys"; G.M. Spiegel, The Chronicle Tradition of Saint-Denis : A Survey.

7. Grandes chroniques de France, éd. Jules Viard, t. I, p. 5-6. « [...] la fontaine de savoir, par laquelle sainte Église est soutenue et éclairée, jaillit à Paris. Et comme certains le disent, savoir et vaillance s'accordent toujours, et l'un ne peut aller sans l'autre; ils se sont toujours tenus ensemble, et de nos jours encore, Dieu merci, ils ne se séparent point. Ils ont séjourné en trois régions, au fil du temps : d'abord en Grèce, car c'est en la cité d'Athènes que fut jadis puisée la philosophie, et en Grèce que fleurissait alors la vaillance. De Grèce, elles passèrent dans Rome. De Rome, elles sont venues en France. Dieu, par sa Grâce, veuille-t-il les y maintenir longtemps, à la louange et à la gloire de Son nom, qui vit et règne par les siècles des siècles. Amen. »

8. Cligès, vers 30-44. Bernard Guenée a souligné le parallèle entre les deux textes, signe de l'intérêt de Primat pour la littérature de langue française (B. Guenée, Comment on écrit l'histoire au XIII' siècle..., p. 60).

9. B. Guenée, Comment on écrit l'histoire au XIII siècle, p. 49.

10. Guillaume le Breton, Philippide, chant I, vers 97-101, p.11: "At jam Sequanio surgebat littore cunctis/Urbibus urbs speciosa magis, bona cujus ad unguem/Commendare mihi sensus brevitate negatur,/Que caput est regni, que grandia germina regum/Educat, et doctrix existit totius orbis». Traduction: "Mais déjà s'élevait sur les rives de la Seine une ville plus belle que toutes les autres villes, dont les avantages ne peuvent être parfaitement mis en valeur par la faible étendue de mon esprit, qui est la capitale du royaume, qui fait croître de grandes gerbes de rois, et qui enseigne à tout l'univers. »

11. L. Delisle, «Mémoire sur les ouvrages de Guillaume de Nangis »; H.-F. Delaborde, "Notes sur Guillaume de Nangis"; J. Viard, édition des Grandes chroniques de France, tome VII, p. III-IV ; G. Spiegel, The Chronicle Tradition of Saint Denis, p. 101-102 ; J. Le Goff, Saint Louis, p. 349-350 (et sur les Gesta, p. 357-362); notice de G. Tyl-Labory dans le Dictionnaire des lettres françaises, Le Moyen Âge, p. 636-637 ; I. Guyot-Bachy, « La Chronique abrégée des rois de France de Guillaume de Nangis : trois étapes de l'histoire d'un texte ».

12. J. Le Goff, Saint Louis, p. 354-356. Cette analyse porte sur le texte de la chronique universelle, qui reprend presque mot pour mot le passage de la Vie de Louis IX. Le texte de Guillaume de Nangis a également été étudié par Alexander Patschovsky, «Der heilige Dionysius, die Universität Paris und der französische Staat », p. 23.

13. Guillaume de Nangis, Gesta sanctæe memorice Ludovici regis Francioe, p.318-320. Traduction: « ... les deux fleurons symétriques de ce lys représentent la sagesse et la chevalerie, qui toutes deux, venues de Grèce en Gaule en suivant Denis l'Aréopagite, avec la foi que la grâce de Dieu y a répandue, gardent et défendent le fleuron central de 
la fleur de lys. Car la foi est gouvernée et régie par la sagesse, et défendue par la chevalerie. Aussi longtemps que ces trois vertus seront présentes dans le royaume de France, indissolublement liées ensemble, le royaume sera stable. Mais si elles en étaient séparées ou arrachées, il serait tout entier désolé et s'effondrerait. »

14. W. Berschin, Griechisch-lateinisches Mittelalter, p. 164-167.

15. Philippe de Vitry, «Le Chapel des fleurs de lis de Philippe de Vitry », p. 90, strophes 156-158. Voir Fr. Duval, introduction de son édition du Dit de la fleur de lis de Guillaume de Digulleville, p. 59-60 ; A. Patschovsky, "Der heilige Dionysius, die Universität Paris und der französische Staat », p. 24.

16. Guillaume de Nangis, Gesta sanctee memoriæe Ludovici regis Franciæe, p. 322.

17. Grandes chroniques de France, t. VII, §13, p.60-61. "Jadis, aux temps anciens, le savoir se trouvait à Athènes et la chevalerie en Grèce. Après, il en est parti pour aller à Rome, entrainnant aussitôt la chevalerie à sa suite. L'orgueil des Romains poussa le clergé à quitter Rome pour la France, et avec lui, la chevalerie. Et c'est ce que nous marque la fleur de lis qui figure sur les armes du roi de France, car elle a trois feuilles : celle du milieu représente la foi chrétienne, et les deux autres, sur les côtés, le clergé et la chevalerie qui doivent se tenir toujours prêts à défendre la foi chrétienne. Et tant que ces trois-là demeureront en France, la foi, le clergé et la chevalerie, le royaume de France sera fort et ferme et plein de richesse et d'honneur. »

18. Comme le souligne Jules Viard dans l'introduction du tome VII des Grandes chroniques de France.

19. Je remercie Olivier Mattéoni pour cette remarque, formulée au cours des échanges pendant le Congrès.

20. J. Krynen, L'Empire du roi, p. 85-109.

21. D. Lecoq, "Éléments pour une lecture d'une mappemonde médiévale ». La date habituellement retenue pour cette image est relativement tardive: vers 1364-1372 (M. Destombes, Mappemondes, 50.19, p. 177 ; A.-D. von den Brincken, Fines Terrae, p. 136), mais on a récemment proposé une datation plus précoce: la carte aurait alors été dessinée au moment de l'adjonction de la Vie de Saint Louis, dans le premier quart du $\mathrm{XIV}^{\mathrm{e}}$ siècle (A. Stones, Gothics Manuscripts 1260-1320, Part I, vol. 2, notice I-21, p. 42-45); A. D. Hedeman, «Le pouvoir des images saintes dans les Grandes chroniques de France. Le cas de Saint Louis ", p. 242-245.

22. M. Chazan, « Guillaume de Nangis et la translation de l'Empire aux rois de France ».

23. Jean de Galles (John Waleys), Compendiloquium de vitis illustrium philosophorum, chap. IX, p. 424.

24. O. Ramèze, L'Origine et antiquité de la cité de Lyon, p. 82, § 12.

25. J.-M. Le Gall, Le mythe de saint Denis, p. 52-53. 


\section{RÉSUMÉS}

Le thème de la "translatio studii », ou transmission du savoir et de la sagesse depuis l'Orient vers l'Occident, est un topos récurrent de la littérature médiévale. Primat l'a utilisé à la louange du royaume de France dans le prologue de son "roman des rois", vaste compilation historique offerte à Philippe III vers 1274, que l'on connaît aujourd'hui sous le nom de «Grandes chroniques de France ». S'inspirant de ce texte, Guillaume de Nangis a ensuite repris la même image à propos de la grande grève universitaire de 1229-1230, dans sa Vie de Louis IX. Cette fois, la «translatio studii " se voit convoquée pour rendre hommage non seulement au royaume, mais aussi à saint Denis et à l'université de Paris. Enfin, le continuateur de Primat s'est à son tour emparé du thème, mais en revenant à l'interprétation initiale. L'article se propose donc de montrer, à travers ces trois textes, comment la «transmission du savoir » peut constituer un sujet politique et servir à promouvoir le pouvoir royal, mais aussi d'autres institutions plus ou moins directement liées à celui-ci.

\section{AUTEUR}

\section{JUDITH FÖRSTEL}

Conservateur du patrimoine au service Patrimoines et Inventaire de la région Île-de-France 


\title{
Le « savoir-être » noble : étude sur
} les facteurs et les modalités de transmission d'un savoir valorisé de part et d'autre des Alpes au Moyen Âge

\author{
Florentin Briffaz
}

1 La scène se déroule en 1361 à la cour du comte de Savoie. Un scribe doit mettre au propre un compte de châtellenie. Chemin faisant, recopiant les différents items, il en vient à la rubrique de la dîme de Saint-Gervais. Il commence par transcrire soigneusement le texte expliquant que ladite ferme a été perçue pour les années 1358, 1359 et 1360 par le châtelain de Montjoie en personne, Jean de Fillinges, et renvoie ainsi au compte de cet autre officier. Mais, parti trop vite en besogne, le scribe a oublié de préciser plus en avant la qualité sociale de Jean de Fillinges, pourtant déjà titulaire de l'avant-nom de dominus. Il insère alors dans le texte, entre le nom de l'officier et le détail de sa fonction (castellanus montisgaudii) le qualificatif de miles, parure éminemment nobiliaire ${ }^{1}$.

2 S'il faut bien entendu ne pas surinterpréter le souci de détail de ce scribe et si les qualificatifs nobiliaires sont parfois précisés au cours du texte, l'épisode est cependant révélateur d'un certain état d'esprit et d'une forme de valorisation d'une condition nobiliaire, et ce, même dans les actes de la pratique (ici la comptabilité), documents que l'on aurait pu croire assez neutres en la matière. C'est de toute évidence une forme de « savoir-être » noble dont ces textes cherchent à louer les vertus.

En effet, à l'occasion du $143^{\mathrm{e}}$ congrès du CTHS, l'accent a été mis sur la transmission des savoirs, par-delà leur grande diversité, et particulièrement sur les différents agents de diffusion mais également sur les références qui peuvent sous-tendre ces processus. Or, cet article a pour but d'identifier les conditions et les éléments de transmission de ce que l'on peut appréhender comme étant un véritable « savoir-être noble » en prenant en particulier pour cadre d'étude la principauté médiévale savoyarde, vaste entité 
politique établie de part et d'autre des Alpes. De fait, la noblesse est un champ de recherches à la fois fécond et complexe, ne serait-ce que parce qu'elle intègre des catégories très diverses qui sont à certains moments unies par l'émulation dans le service au prince. Le «savoir-être » noble, à différentes échelles, devient un objet d'imitation et le prince lui-même, noble prééminent, devient un modèle par sa conduite.

De surcroît, il convient de se départir d'une lecture trop déterministe et téléologique. Cependant, le corpus savoyard est riche d'une myriade de documents issus de la comptabilité domaniale. Or, cette matière pragmatique, au détour de quelques formules administratives, peut révéler un certain discours valorisant l'état nobiliaire. Le « savoir-être » noble, que l'on retrouve plus ou moins fortement pensé, théorisé, codifié dans d'autres sources comme les chroniques de cour ou certains actes normatifs émanant de la chancellerie princière, devient alors un savoir culturel et politique de préséance sociale. Ainsi, la réflexion proposée ici vise à repérer ces références et ces canaux de diffusion par une approche plurielle et multiscalaire. Des processus d'imitation peuvent d'ailleurs être repérés à différents niveaux, tant sur le plan des comportements sociaux que des choix architecturaux et l'on peut de fait identifier une forme de "savoir-vivre » noble qui est intimement associée au «savoir-être » noble comme les travaux des archéologues ont pu le montrer.

Notre étude s'organisera en trois temps. Dans un premier temps, nous tenterons de brosser un panorama des noblesses savoyardes. Nous insisterons sur le fait que la noblesse puise en réalité à différentes sources et que les trajectoires sociales, politiques et économiques des lignages sont variées. Dans un deuxième temps, nous nous intéresserons à la documentation écrite savoyarde en montrant comment celle-ci est en réalité un passeur d'un véritable «savoir-être » noble. Nous prendrons pour champ de recherches aussi bien les chroniques savoyardes médiévales, véritables vectrices d'un idéal nobiliaire, à l'image de la chronique de Cabaret $^{2}$, que les sources issues de la comptabilité dont les travaux pionniers de Christian Guilleré ou de Jean-Louis Gaulin ${ }^{3}$ ont mis en évidence toute la richesse. Dans un dernier temps, nous étudierons la question du "savoir-vivre » noble, sorte de double du « savoir-être noble » au prisme d'une réflexion portant sur les constructions architecturales comme support de l'expression nobiliaire, réelle ou espérée, mais également sur la tenue de l'hôtel seigneurial et sur les processus polymorphes d'imitation princière, mis en évidence en particulier par les travaux d'Élisabeth Sirot.

\section{L'horizon nobiliaire : pour un panorama des noblesses savoyardes}

\section{Les nobles et le territoire savoyard}

Précisons tout d'abord brièvement le cadre de l'étude. La principauté médiévale savoyarde s'étend de part et d'autre des Alpes. Elle comprend des espaces variés gagnés par mariage et héritage, comme la Bresse en 1272, par achat (le comté de Genève en 1401) ou par conquête (la terre de Gex par exemple en 1353). À son apogée, elle s'étire ainsi de la Saône à la plaine du Pô et de Fribourg à Nice. La politique de contrôle des principaux cols (en particulier le Grand Saint-Bernard et le Mont-Cenis), axes de passage de nombreux flux commerciaux, est une constante chez les Savoie, véritables 
«portiers des Alpes». D'après les estimations de Bernard Demotz, en 1416, date de l'érection de la Savoie en duché pour Amédée VIII, véritable moment d'apogée, la principauté s'étend sur quelque $45000 \mathrm{~km}^{2}$ et le domaine direct comprend 175 châtellenies ${ }^{4}$. Dans l'arc alpin occidental, la Savoie n'est pourtant pas la seule entité qui entre en jeu. Il faut signaler ici notamment la rivalité historique avec une autre principauté, à savoir le Dauphiné

7 Pour beaucoup d'entre eux, les nobles savoyards sont confrontés à un environnement montagnard. La montagne est à la fois un horizon culturel et un territoire particulier pensé comme tel dont la toponymie s'empare. De nobles lignages peuvent ainsi être établis en de moyennes et hautes vallées ou tout simplement en des cols, à l'instar de la famille noble de Bénévix, au col des Gets, point de contact entre le Faucigny et le Chablais. La pente et la verticalité apparaissent alors comme un horizon quotidien et le fruit des alpages demeure l'un des enjeux essentiels ${ }^{6}$.

8 L'espace traversé quotidiennement et parcouru mentalement par les noblesses savoyardes est somme toute largement rural. Néanmoins, plusieurs lignages évoluent dans un contexte spécifiquement urbain, même s'il n'est de réseau urbain fortement développé en Savoie. Au milieu du Xve siècle, Chambéry, qui devient progressivement la capitale de l'État savoyard, ne compte elle-même que 4000 à 5000 habitants mais peut drainer quelques individus souhaitant s'attirer les bonnes grâces d'un prince qui y réside de temps en temps. Toutefois, ce dernier, sorte de primus inter pares, demeure itinérant et les nobles attachés à son service se doivent de le suivre dans son nomadisme châtelain ou dans ses campagnes militaires.

\section{Des sources plurielles de noblesse}

9 Comment alors saisir ces noblesses savoyardes? La réalité est fort complexe. La noblesse est d'abord une réputation, une reconnaissance sociale. Est noble celui qui est reconnu comme tel ${ }^{7}$. Point de lettre de noblesse avant que l'obtention de la dignité ducale en $1416^{8}$ ne vienne institutionnaliser un fait, une prééminence sociale. Dans la documentation savoyarde, on observe toute une série de dispositifs langagiers visant à mettre en évidence différents marqueurs relevant de la noblesse et de ses différents visages: miles (chevalier), domicellus (damoiseau), scutiffer (écuyer), nobilis vir (noble homme) émaillent notamment les textes tout en recoupant des réalités fort diverses suivant le contexte documentaire. Au XIV ${ }^{e}$ siècle, si l'on songe au principat d'Amédée VI dit le Comte Vert, célèbre pour sa croisade contre les Turcs en 1366-1367, les vertus chevaleresques sont toujours autant valorisées comme étant partie intégrante du savoir-être noble. Et la création d'un ordre de chevalerie comme l'ordre du Collier, réactivé en 1383 , s'inscrit dans cette logique9.

10 Il faut de même rappeler que la particule ne fait bien entendu pas le noble au Moyen Âge. L'association avec un lieu éponyme n'est pas non plus systématique, car toute noblesse n'est pas d'origine seigneuriale et ne doit pas son nom par exemple à la détention ancestrale d'un château. L'exemple de la famille noble des Martin à Sallanches, dans le moyen Faucigny est explicite. Ici, point de possession castrale dont elle ait tiré son nom. Les Martin se distinguent uniquement dans les textes par des qualificatifs renvoyant à une condition nobiliaire. De façon plus décisive et plus coutumière, ils occupent une forme de préséance à Sallanches, avec d'autres familles nobles, en vertu de certains droits détenus depuis un temps ancien (antiquitus) et jadis 
en alleu, comme pour la ferme des fours de Sallanches ${ }^{10}$. On les retrouve fortement ancrés dans le mandement, et ce, bien avant que le Faucigny ne devienne savoyard en 1355. Au Xve siècle, ils tiennent toujours le haut du pavé et contribuent à l'émulation entre lignages aristocratiques lors des donations à la collégiale ou lors des banquets funéraires ${ }^{11}$.

\section{Un patchwork de lignages}

En définitive, il ressort du tableau des noblesses savoyardes plusieurs contrastes: certains lignages demeurent de faible envergure tandis que d'autres ont de solides assises territoriales et politiques. Des familles peuvent constituer un véritable réseau de fidélités, avant même l'arrivée des Savoie. Par exemple, la famille de Lucinge, branche des anciens sires de Faucigny, ramifiés à l'envi, est solidement implantée dans le Faucigny. Quand le comte de Savoie prend possession de la région, non sans difficultés, il doit compter avec le prestige des Lucinge. La nomination de plusieurs d'entre eux à des postes de châtelains dans la région, comme Humbert de Lucinge à Bonneville dès le 2 juin $1361^{12}$, s'inscrit dans cette logique de maintien des potentats locaux, nécessaire à l'acceptation du prince dans la région.

Le service princier est de fait l'occasion pour certains grands lignages de se placer au plus près du prince, en se faisant les chantres de la fidélité au seigneur éminent tout en gardant de solides assises territoriales. Les Challant par exemple, véritables maitres du Val d'Aoste, ne serait-ce que par la densité du réseau castral qu'ils ont bâti dans la région et par l'accumulation de charges, n'hésitent pas à jouer les premiers rôles à la cour de Savoie. L'étude de la comptabilité domaniale des années 1350-1370, fait souvent état de la présence à Chambéry d'Aymon de Challant, seigneur de Fénis et d'Aymaville qui, paré de tous ses titres seigneuriaux et nobiliaires, travaille comme auditeur des comptes ${ }^{13}$.

Le service princier est alors une occasion réelle de mise en avant pour certains lignages importants, à la fois pour les chefs de famille (parfois créditeurs du prince, ils sont alors remboursés en étant nommés châtelains ou en obtenant l'inféodation d'une châtellenie) et pour les nombreux cadets qui peuvent trouver en l'espèce une échappatoire. Les trajectoires nobiliaires sont donc variées. Le service princier peut être le vecteur d'une ascension sociale pour de petits lignages qui sont vus comme d'autant moins dangereux par le comte de Savoie. Gardons-nous d'avoir une vision univoque du groupe nobiliaire savoyard. Certains sont certes nobles, mais ne possèdent qu'une petite demeure se distinguant mal du paysage environnant et que quelques droits éminents sur certaines productions, certains produits d'alpages.

\section{Des écrits vecteurs d'un savoir-être noble}

\section{Les chroniques savoyardes, passeurs d'un idéal nobiliaire}

Il convient de faire une place toute particulière à la chronique dite de Cabaret, véritable matrice de toutes les chroniques princières savoyardes. Celle-ci fut rédigée vers 1419, à la demande du duc de Savoie Amédée VIII, par Jean d'Orville, dit Cabaret, un spécialiste de l'écrit que l'on voit œuvrer dix ans plus tard pour Louis II de Bourbon. La chronique de Cabaret est de fait un miroir fort intéressant des préoccupations du prince et de sa 
cour. Ainsi, Amédée VIII, tout juste élevé au rang de duc, commande à Cabaret la geste de sa famille, selon une logique discursive et narrative qui tient de la chronologie dynastique depuis le mythique ancêtre Bérold le Saxon, neveu de l'empereur Otton III. Assurément, c'est un véritable "savoir-être " noble idéalisé que met en scène le chroniqueur, que ce soit dans le récit grandiloquent de la marche du prince (quitte à travestir quelque peu la vérité historique ou à passer sous silence quelques épisodes moins glorieux ${ }^{14}$ ) ou dans la narration des faits et gestes des nobles luttant aux côtés des comtes de Savoie successifs.

En réalité, le chroniqueur s'intéresse essentiellement aux batailles. C'est là un idéal princier et nobiliaire marqué par la valeur guerrière et, plus encore, chevaleresque. $\mathrm{Si}$ Azincourt constitue en 1415 le linceul de «la fine fleur de la chevalerie française », la Savoie d'Amédée VIII et de Cabaret reste bercée à la même époque par les exploits militaires des ancêtres du nouveau duc. En somme, le chroniqueur livre une histoire faite de bruits et de fureurs à un prince qui n'est pourtant que peu versé dans le métier des armes. Les faits racontés, certes, sont antérieurs au principat d'Amédée VIII, mais c'est bien la veine chevaleresque qui est valorisée. Il suffit de lire les quelques lignes consacrées au Comte Rouge, le nouvel Hannibal, lors de la traversée des montagnes (le col du Galibier tout spécialement) pour rapidement rejoindre Nice en $1388^{15}$.

Plus encore, le savoir-être noble transmis dans cette chronique est celui d'une forme d'obéissance au prince et de hiérarchie féodale (certains nobles combattants peuvent lever bannière). Cabaret insiste sur le devoir du vassal noble de participer aux campagnes de son seigneur en venant avec le plus de gens d'armes possible. À l'instar de la campagne contre les Visconti de 1372-1375, le chroniqueur insiste sur le mandement du comte comme étant un moment clé de l'éthique nobiliaire, à la fois parce que c'est une revue d'effectifs, une mise en ordre de bataille et surtout une mise en scène d'une noblesse attentive au service armé qu'elle doit, sinon à son seigneur direct pour certains, du moins à son seigneur princier éminent pour la majorité ${ }^{16}$.

Ensuite, les chroniques peuvent émaner certes du pouvoir princier, mais également de lignages aristocratiques inférieurs soucieux de suivre l'exemple du suzerain et de cultiver un état nobiliaire. Dans l'espace savoyard médiéval, il n'existe, en l'état actuel des connaissances, qu'une chronique de ce type qui relève d'un milieu non princier, à savoir la chronique de la Maison de Challant, scrupuleusement étudiée et commentée par Guido Castelnuovo ${ }^{17}$.

18 Le mode de narration propre à ces chroniques de cour devient véritablement un mode de transmission des valeurs nobiliaires particulièrement prisé qui influence d'une certaine façon certains actes de la pratique. Par exemple, l'incipit d'un cartulaire du sire de Thoire-Villars commencé en 1373 (et copié vers 1423-1428 pour le duc de Savoie) révèle l'horizon culturel nobiliaire. Il se présente sous la forme d'un prologue narrant les grands faits de l'année de début de rédaction du cartulaire, de manière à situer le principat d'Humbert VII de Thoire-Villars. Or, le scribe présente un seigneur noble dans son époque, mais en empruntant à la matière des chroniques leurs préoccupations et leur rythme de narration. Il y a là une certaine part de grandiloquence qui n'est pas sans rappeler les batailles de la guerre de Cent ans que conte Froissart. L'incipit du cartulaire mentionne notamment les chevauchées de Du Guesclin en Gascogne comme faisant partie, à côté des références classiques de datation (année de pontificat, de règne, de principat) des grands événements d'actualité qu'il convient de transcrire et qui font partie de l'arrière-plan culturel des Thoire-Villars ${ }^{18}$. 


\section{La comptabilité savoyarde, support de la préséance sociale nobiliaire?}

19 Les actes de la pratique, spécialement la comptabilité, sont à première vue des sources relativement neutres. Pourtant, ce sont également des sources vectrices d'une certaine forme d'idéologie nobiliaire. À la façon des listes de souscription, les qualités nobiliaires dans toute leur mouvance sont précisées dans les différentes rubriques ou dans les actes recopiés en guise de justificatifs. Bien entendu, il convient de prendre en compte le contexte de production et de ne pas avoir une lecture trop déterministe. De fait, c'est le prince, noble prééminent par excellence, qui est le destinataire en dernier lieu de toute cette littérature administrative. La noblesse demeure l'horizon de référence. Mais en même temps, le monde des officiers qui sert le prince et qui produit cette foison de documents n'est pas uniquement nobiliaire. Une pesée générale indique une forte présence de nobles parmi les officiers savoyards, à commencer par les châtelains. Pour une vision d'ensemble, à partir du XIII ${ }^{\mathrm{e}}$ siècle, Bernard Demotz donne une fourchette entre 70 et $90 \%$, et ce, pour les châtelains comme pour les baillis ${ }^{19}$.

20 Ainsi, mettre en évidence la qualité nobiliaire de certains officiers ou de certains personnages n'est pas anodin, surtout quand l'on sait que certains officiers ne le sont pas. Le rang nobiliaire est un leitmotiv dans le discours de la comptabilité. Les scribes, mettant au net les documents, essaient d'indiquer cette forme de prééminence sociale. Car le noble est celui qui se distingue, ici par un avant-nom prestigieux, un titre également qu'il peut porter en vertu de l'hérédité, d'une alliance fructueuse ou de l'acquisition d'un fief. Les officiers eux-mêmes, à commencer par les châtelains, sont confrontés à l'horizon nobiliaire. Dans la Savoie médiévale, le châtelain détient une fonction militaire, judiciaire et financière. Au sein de cette triade grossièrement brossée, l'aspect bellique n'est pas un des moindres. Le châtelain se doit de faire la guerre pour le seigneur et de rassembler des hommes pour, d'abord défendre la place dont il a la garde, puis suivre le seigneur dans des campagnes parfois fort lointaines. Or, la guerre est une prérogative typiquement nobiliaire et les grands feudataires bannerets comme de petits nobles châtelains issus de lignages obscurs se doivent de répondre à l'appel du comte. C'est ainsi qu'un Jean de Fillinges, noble sans grande envergure occupant la fonction de châtelain de Montjoie de 1358 à 1363 participe à la croisade du Comte Vert.

Mais cette distinction à laquelle semble souscrire le discours comptable est à double tranchant. D'un côté, être noble implique un savoir être qui, de façon plus ou moins implicite, est à la base d'une notabilité et d'une forme de préséance. D'un autre côté, il est des risques d'avilissement et de dérogation qui guettent le noble. Quand, dans la rubrique des peines (banna concordata ou banna condempnata) infligées par le châtelain en vertu de l'exercice de la justice, au milieu d'une longue liste de vilains perpétrant quelque forfait mineur, on retrouve des nobles, bien identifiés comme tels, attirant l'attention sur eux en étant impliqués dans des rixes de village ${ }^{20}$, il n'est pas sûr que l'état social de l'impétrant en sorte grandi. De fait, la comptabilité met en évidence la qualité sociale du condamné, en vue certes d'un appel éventuel, mais également en vertu sans doute de cette forme de pénétration du discours nobiliaire ambiant. 


\section{Réalités ou chimères au miroir du train de vie : le " savoir-vivre » noble, autre versant du « savoir-être » noble}

\section{Inscrire son rang dans la pierre : la demeure comme matrice de l'expression nobiliaire}

D'autres élements du « savoir-vivre nnoble sont à appréhender, à commencer par la décoration murale des demeures ${ }^{22}$. Dans la Combe de Savoie, la maison forte de Cruet est un exemple célèbre et a donné lieu à toute une série d'études passionnantes ${ }^{23}$. Elle conserve un cycle de peintures murales, daté de l'aube du XIV siècle et consacré au roman de chevalerie Girart de Vienne, œuvre rédigée vers 1180 et mettant en scène la lutte entre Charlemagne et son vassal Girart. La frise, établie de part et d'autre de la cheminée de la grande salle (aula), représente ainsi plusieurs épisodes caractéristiques des goûts aristocratiques de l'époque et de la permanence de l'éthique courtoise et de l'idéal chevaleresque vers 1300 : on y voit les pratiques cynégétiques (l'empereur à la chasse), la cérémonie de l'adoubement (Girart est adoubé par l'empereur), la cour du prince (les courtisans assistent au coucher nuptial de Charlemagne), les batailles et luttes armées ou encore le duel judiciaire.

On saisit bien ainsi la référence chevaleresque en cette charnière des $\mathrm{XIII}^{\mathrm{e}}-\mathrm{XIV}^{\mathrm{e}}$ siècles qui mâtine encore largement l'horizon culturel des occupants. Un même idéal nobiliaire louant les valeurs du noble miles se comparant aux héros des chansons de geste se retrouve à Theys dans le Grésivaudan où un décor peint de la fin du XIII siècle transpose en partie le fameux roman de Chrétien de Troyes, Le conte du Graal ou Le roman de Perceval. Les médaillons, insérés dans un décor géométrique, retracent la jeunesse du héros et ornent à nouveau la salle d'apparat sous le regard central de la cheminée qui polarise l'espace. 


\section{Savoir tenir l'hôtel seigneurial}

26 Le « savoir-vivre » noble passe également par la tenue d'un hôtel soigné. Tout ceci est fonction des ressources et de la position sociale des individus et des lignages. L'hôtel nécessite un ensemble de serviteurs qui suivent le maître dans son itinérance. Vivre noblement, c'est, par le biais d'un réseau dense de familiers, pouvoir notamment s'approvisionner en vêtements luxueux, en mets raffinés, recevoir et tenir une cour animée où les festins sont égayés par la présence de musiciens. Chez les Thoire-Villars par exemple, le vêtir de toute la famille est une préoccupation de tous les jours et on voit dans leur comptabilité l'achat de vêtements provenant des grandes régions drapantes d'Europe, par des circuits commerciaux pas toujours spécifiés, mais sans doute via l'intermédiaire de la plaque tournante lyonnaise. L'hôtel du sire de ThoireVillars semble relativement important, avec, à noter, une spécialisation pour les ménétriers. Le seigneur n'hésite pas à acheter pour ses propres musiciens des tambours (beudons) et à les envoyer à la cour d'autres potentats comme en Savoie. En définitive, c'est là une façon de cultiver l'appartenance au groupe nobiliaire que de vouloir mener grand train. Et si les finances ne peuvent pas toujours suivre, ce sont les intentions qui comptent.

Vivre noblement, c'est plus encore défendre la part noble, une sanior pars qui se voit et qui s'incarne également dans le choix des aliments et de certains gibiers à valeur ajoutée et à fort capital symbolique. Ainsi, quand, le 26 mai 1382, Humbert VII de Thoire-Villars octroie le droit de chasse aux habitants d'Arbent dans la châtellenie afférente et dans la baronnie de Thoire, il se réserve les parties nobles du gibier, à savoir les quatre pattes de l'ours, la hure du sanglier et le sommier du cerf ${ }^{24}$. Il faut également pouvoir recevoir le prince quand celui-ci est en déplacement. Humbert VI de Thoire-Villars par exemple reçoit à manger le Comte Vert, courant 1368 ou début 1369 et fait venir notamment des anguilles fraîches et salées pour régaler les convives ${ }^{25}$.

\section{Des processus d'imitation princière}

28 On repère ainsi, à différentes échelles, une véritable tendance à l'imitatio principis en matière de savoir-vivre noble. Élisabeth Sirot a relevé plusieurs marqueurs architecturaux chez la petite aristocratie dans les comtés de Genève et de Savoie ${ }^{26}$. Elle met en évidence plusieurs modèles, comme l'aula du château comtal de Ripaille. Des éléments aristocratiques et seigneuriaux tels que les plafonds, la chapelle privée ou la cheminée se retrouvent aussi bien dans les résidences princières (château des comtes de Genève à Annecy par exemple) que dans des constructions plus modestes de l'aristocratie des comtés. Le réseau castral peut ainsi être la partie émergée de ce discours d'affirmation seigneuriale et nobiliaire. Chez les Thoire-Villars, maîtres d'une large partie de la Dombes et du Bugey, on observe un programme architectural très développé, illustré par l'octogone du donjon de Trévoux qui renvoie à quelques rares précédents de très haute renommée.

L'étude diplomatique révèle en parallèle un vocabulaire semblable, témoin de cette volonté d'affirmation princière. Ainsi, à la charnière entre le $\mathrm{XIV}^{\mathrm{e}}$ et le $\mathrm{XV}^{\mathrm{e}}$ siècle, le sire se fait appeler " nostre prince " par plusieurs de ses familiers et de ses officiers ${ }^{27}$, même si l'on peut considérer que cela relève d'un baroud d'honneur puisque dès 1402 est cédée la nue-propriété de la majorité de ses terres. On le voit donc, le "savoir-vivre » 
princier est recherché comme étant le nec plus ultra du mode de vie nobiliaire. Une forme d'imitation graduelle se remarque également dans la course aux prodigalités manifestée dans les clauses testamentaires. Le « savoir-mourir » est en effet une autre facette de ce « savoir-vivre » noble et répond à des critères sociaux. La mort du prince est l'occasion de cérémonies grandioses, selon une organisation codifiée. Mais les nobles eux-mêmes tendent à affirmer leur rang dans la mort et à imiter le chef de la principauté.

En définitive, malgré la diversité du groupe aristocratique savoyard qui puise à différentes sources sa légitimité et sa prééminence sociale, le savoir-être noble demeure un horizon d'attente prégnant dans la Savoie tardo-médiévale. Les documents sont certes le reflet d'un contexte de production bien particulier, mais l'on peut repérer des canaux de diffusion d'un certain idéal nobiliaire, à commencer par les chroniques de cour ; le prince étant par essence un modèle excellent de noblesse. Mais, d'une façon plus détournée et à différents degrés, les sources pragmatiques, à commencer par la comptabilité domaniale, sont les passeurs de cette prééminence sociale qui caractérise la noblesse, malgré sa physionomie bariolée. Par ailleurs, allant de pair avec ce « savoirêtre" noble sanctionné par les formules, un véritable "savoir-vivre" noble se développe. L'architecture se fait l'écho de ce discours autour d'une noblesse revendiquée, fantasmée, héritée ou consolidée. Le "savoir-vivre » noble se diffuse dans plusieurs sphères et se mesure par exemple à l'aune de la gestion de l'hôtel seigneurial, notamment en matière de réception. Or, si la noblesse a des contours parfois mouvants, la société savoyarde demeure hiérarchisée, du moins voulue comme telle par le prince qui en coiffe la structure. C'est tout particulièrement vrai à l'époque d'Amédée VIII. Le premier duc de Savoie développe ainsi un véritable projet de société et la codification de la noblesse participe de cet ordonnancement dont l'une des formulations se trouve dans la promulgation en 1430 des Statuta Sabaudie. Avec notamment l'instauration d'une législation somptuaire touchant en particulier les différents échelons de la noblesse, le prince devient l'artisan de la société. Noble prééminent par excellence, il est un modèle pour les différents lignages aristocratiques qui gravitent autour de lui. Des processus d'imitation princière s'observent ainsi en plusieurs circonstances, notamment dans le cadre des clauses testamentaires, appelant à toujours plus de prodigalité et de magnificence. En somme, le «savoir-mourir » noble constitue un rite de passage et de transmission.

\section{BIBLIOGRAPHIE}

ABALLÉA Sylvie (dir.), Châteaux forts et chevaliers. Genève et la Savoie au XIV siècle, Lausanne, Favre, 2016. 
BILLORÉ Maïté, De gré ou de force. L'aristocratie normande et ses ducs (1150-1259), Rennes, Presses universitaires de Rennes, 2014.

CASTELNUOVo Guido, Ufficiali e gentiluomini. La società politica sabauda nel tardo medioevo, Milan, Franco Angeli (Dipartimento di Storia dell'Università di Torino, 8), 1994.

CASTELnUovo Guido, "Les noblesses et leurs pouvoirs dans les Pays de Savoie au Moyen Âge ", dans MESSIEZ Maurice (dir.), Noblesses en Savoie, L'Histoire en Savoie, 132-133, 1998-1999, p. 9-82.

CASTELNUOvo Guido, «Un idéal nobiliaire dans la Savoie du Xve siècle : la Chronique de la Maison de Challant », Mélanges de l'École française de Rome. Moyen Âge, t. 117, 2, 2005, p. 719-779.

CHAUBET Daniel (éd.), La Chronique de Savoye de Cabaret, Chambéry, Éditions Comp’Act, 2006.

DEMOTZ Bernard, Le comté de Savoie du XI $I^{e}$ au XV siècle. Pouvoir, château et État au Moyen Âge, Genève, Slatkine, 2000.

FOL Michel, « À la table des morts. Repas funéraires, solidarités épulaires et économie du salut en Savoie au temps de la religion flamboyante (vers 1330-vers 1561) » dans FOL Michel, SORREL Christian et VIALLET Hélène (dir.), Chemins d'histoire alpine. Mélanges dédiés à la mémoire de Roger Devos, Annecy, Les Amis de Roger Devos, 1997, p. 59-128.

GUICHENON Samuel, Histoire de Bresse et de Bugey, Lyon, Jean-Antoine HUGUETAN et Marc-Antoine RAVAUD, 1650.

GUILLERÉ Christian et GAULIN Jean-Louis, « Des rouleaux et des hommes. Premières recherches sur les comptes de châtellenies savoyards ", Études savoisiennes, 1, 1992, p. 51-108.

KERSUZAN Alain, Défendre la Bresse et le Bugey. Les châteaux savoyards dans la guerre contre le Dauphiné (1282-1355), Lyon, Presses Universitaires de Lyon (Collection d'histoire et d'archéologie médiévales, 14), 2005.

LE DESCHAULT de MONREDON Térence, Le Décor peint de la maison médiévale. Orner pour signifier en France avant 1350, Paris, Picard, 2015.

LEMONDE Anne, «Les principautés alpines occidentales de la fin du Moyen Âge (Savoie, Dauphiné, Provence). Étude comparée », Histoire des Alpes, 10, 2005, p. 187-202.

RIPART Laurent, « Sociabilité aristocratique et religion princière. L'exemple des ordres princiers de chevalerie savoyards (milieu XIve-milieu Xve siècle) », dans PARAVY Pierrette et TADDEI Ilaria (dir.), Les lieux de sociabilité à la fin du Moyen Âge. Journées d'études des 19-20 avril 2002, Grenoble, CHRIPA (Cahiers du CRHIPA, 9), 2006, p. 75-91.

SIROT Élisabeth, Noble et forte maison. L'habitat seigneurial dans les campagnes médiévales du milieu du $\mathrm{XII}^{e}$ au début du XVI e siècle, Paris, Picard, 2007.

SIROT Élisabeth, « Les modèles princiers et leur imitation dans le milieu seigneurial en territoire genevois et savoyard (XIV $-\mathrm{XV}^{\mathrm{e}}$ siècle) ", dans Aux marches du Palais. Qu'est-ce qu'un palais médiéval ? Données historiques et archéologiques, actes du VII Congrès international d'Archéologie Médiévale (Le Mans-Mayenne 9-11 septembre 1999), Caen, Société d'Archéologie Médiévale, 2001, p. 113-122.

\section{NOTES}

1. Archives départementales de la Savoie (désormais Arch. Dép. de la Savoie ), SA 14184, compte de Humbert de La Porte du 26 février 1358 au 12 mars 1361 (exclu), $1^{\text {ère }}$ peau. 
2. La Chronique de Savoye de Cabaret, éd. D. Chaubet.

3. C. Guilleré et J.-L. Gaulin, « Des rouleaux et des hommes. Premières recherches sur les comptes de châtellenies savoyards ", p. 51-108.

4. B. Demotz, Le comté de Savoie du XI au XVe siècle. Pouvoir, château et État au Moyen Âge, p. 61.

5. Sur la lutte entre Dauphiné et Savoie, voir tout spécialement A. Kersuzan, Défendre la Bresse et le Bugey. Les châteaux savoyards dans la guerre contre le Dauphiné (1282-1355). Sur le Dauphiné, voir les nombreux travaux d'Anne Lemonde qui font autorité et qui ont permis un renouvellement méthodologique et historiographique. Pour une mise en perspective comparatiste stimulante des principautés alpines, voir en tout premier lieu Ead., «Les principautés alpines occidentales de la fin du Moyen Âge (Savoie, Dauphiné, Provence). Étude comparée ", p. 187-202.

6. Dans plusieurs textes dont l'enjeu est agraire, on trouve une opposition entre le planum (le plan, à savoir le fond de vallée) et les montes, à savoir les montagnes au sens ici d'alpage, avec toute la dimension temporaire que cela implique dans les cultures et l'habitat.

7. M. Billoré, De gré ou de force. L'aristocratie normande et ses ducs (1150-1259), p. 33 : « Dans la société médiévale, le noble jouit d'une certaine notoriété, ce qui rappelle la racine latine du mot nobilis: noscere. La noblesse est donc une affaire de prestige et d'identification sociale, ce qui explique que les aristocrates, petits et grands, emploient et paient poètes et jongleurs pour flatter leur réputation ».

8. Guido Castelnuovo mentionne notamment une lettre d'anoblissement de 1439 en faveur d'un certain Humbert Masset, bourgeois de Rossillon, comme étant l'un des premiers exemples: G. Castelnuovo, «Les noblesses et leurs pouvoirs dans les Pays de Savoie au Moyen Âge ", p. 24.

9. Voir entre autres L. Ripart, "Sociabilité aristocratique et religion princière. L'exemple des ordres princiers de chevalerie savoyards (milieu XIV e-milieu Xve siècle) », p. 75-91.

10. Arch. Dép. de la Savoie, SA 182 et SA 185.

11. Nombreux exemples dont celui de Jean Martin junior et de son testament de 1420 dans : M. Fol, «À la table des morts. Repas funéraires, solidarités épulaires et économie $\mathrm{du}$ salut en Savoie au temps de la religion flamboyante (vers 1330-vers 1561)», p. 59-128.

12. Arch. Dép. de la Savoie, SA 12695.

13. Comme on le voit dans un compte de Samoëns de 1355 (Arch. Dép. de la Savoie, SA 14373). Aymon de Challant est parfois qualifié également de "familier du seigneur ", notamment dans un compte de la châtellenie de Montjoie rendu en 1356. Le compte est rendu à Chambéry «presentibus dominis Aymone de Chalant et Guillelmo boni familliaribus domini per Guiffredum Vethone de Chamberiaco clericum domini " (Arch. Dép. de la Savoie, SA 14001). D'autres membres de la famille de Challant exercent de hautes responsabilités à la cour de Savoie ; citons simplement les figures d'Antoine et Boniface de Challant, chancelier et maréchal de Savoie. Sur les trajectoires politiques et administratives des Challant, plusieurs éléments dans: G. Castelnuovo, Ufficiali $e$ gentiluomini. La società politica sabauda nel tardo medioevo. 
14. Cabaret passe notamment sous silence la difficile campagne de soumission du Faucigny en vertu du traité de Paris de 1355.

15. Chronique de Cabaret, p. 280.

16. Ibid., p. 220 notamment.

17. G. Castelnuovo, «Un idéal nobiliaire dans la Savoie du Xve siècle : la Chronique de la Maison de Challant », p. 719-779.

18. Archives départementales de la Côte-d'Or (désormais Arch. Dép. de la Côte-d'Or), B 10458, fol. II $v^{\circ}$ " [...] Isto tempore et anno precedenti fuit comes sabaudie vicarius ecclesie et guerram fecit contra milanenses tamen non obtinuit sed vastavit grandas summas aureas et plures nobiles item istis temporibus Rex Francie expellit omnem potestatem anglicorum a toto regno Francie et Recuperavit totam vasquoniam, equitante capitano pro rege francie quodam valente milite de Britania vocato Bertrando de Claquin [...]».

19. B. Demotz, Ibid., p. 403.

20. Guillaume Martin, domicellus de son état, est ainsi condamné à 8 sous genevois pour une bagarre avec Antoine Dalerii (Arch. Dép. de la Savoie, SA 14185, compte de Humbert de La Porte, châtelain de Sallanches, du 18 mai 1360 inclus au 15 mars 1361 exclu, $4^{\text {ème }}$ peau).

21. C'est particulièrement édifiant dans le cas de la "maison forte» de Sallenove, dominant la confluence des petites et grandes Usses. L'emprise spatiale est importante et l'habitation de ce lignage d'origine chevaleresque revêt «l'allure d'une véritable résidence princière", avec "un ensemble comprenant trois grosses tours quadrangulaires flanquant deux vastes corps de logis » (É. Sirot, Noble et forte maison. L'habitat seigneurial dans les campagnes médiévales du milieu du XII au début $d u \mathrm{XVI}^{e}$ siècle, p. 50-51). Par ailleurs, bien entendu, le statut de la demeure peut être différent de celui du détenteur.

22. Voir la récente somme de T. Le Deschault de Monredon, Le décor peint de la maison médiévale. Orner pour signifier en France avant 1350.

23. Voir en dernier lieu le catalogue de l'exposition tenue à Genève du 7 octobre 2016 au 19 février 2017 qui lui consacre une partie et un fac-similé : S. Aballéa (dir.), Châteaux forts et chevaliers. Genève et la Savoie au XIV siècle; voir notamment les notices de T. Le Deschault de Monredon.

24. S. Guichenon, Histoire de Bresse et de Bugey, continuation $3^{\mathrm{e}}$ partie, p. 231.

25. Arch. Dép. de la Côte-d'Or, B 8240, fol. 177.

26. É. Sirot, «Les modèles princiers et leur imitation dans le milieu seigneurial en territoire genevois et savoyard ( $\mathrm{XIV}^{\mathrm{e}}-\mathrm{XV}^{\mathrm{e}}$ siècle) $), \mathrm{p} .113-122$.

27. La titulature peut osciller mais on trouve parfois même dans les actes en latin cette terminologie princière. Ainsi, en 1405, dans une lettre à Perceval de La Baume, bailli de Bresse et de Montagne, Pierre Liatod, proche conseiller du sire de Thoire-Villars et de son épouse s'intitule « consiliarius magniffici et potentis principis domini humberti domini de thoyre et de villars » (Archives nationales, P 1393², cote 938 quater). Un autre exemple de cette volonté d'affirmation princière est donné par l'incipit du cartulaire du sire déjà cité (Arch. Dép. de la Côte-d'Or, B 10458). Humbert de Thoire-Villars utilise le verbe fort de « régner" pour se placer comme maitre en ses terres (« domino Humberto domino de Thoire et de Vilars Regnante cum domina Maria de Gebenna eius consorte »). 


\section{RÉSUMÉS}

Dans le cadre d'une réflexion sur la noblesse médiévale, ses contours plus ou moins mouvants et ses représentations dans l'arc alpin, il conviendra de s'interroger sur ce que l'on peut appréhender comme étant un véritable « savoir-être noble ». L'étude portera sur les différents éléments de transmission de ce savoir et s'appuiera tout particulièrement sur les archives de la principauté savoyarde suivant une approche plurielle incluant les sources pragmatiques (spécialement la comptabilité domaniale, bien mise en valeur par les travaux de Claude Guilleré et de Jean-Louis Gaulin) et littéraires. L'examen des chroniques comme celle de Cabaret, permet de repérer certains canaux de diffusion d'un véritable idéal nobiliaire. Le "savoir-être " noble s'accompagne alors d'un « savoir-vivre » noble passant par la réalisation de demeures dignes du rang que l'on tient ou que l'on espère tenir ainsi que par la gestion raffinée de l'hôtel seigneurial.

\section{AUTEUR}

\section{FLORENTIN BRIFFAZ}

Doctorant contractuel en Histoire médiévale, Université Lumière - Lyon II, CIHAM - UMR 5648 


\title{
Les Enseignements d'Anne de France à sa fille Suzanne de Bourbon: questions et mises en perspective
}

\author{
Marie-Geneviève Grossel
}

1 Les Enseignements d'Anne de France à sa fille Suzanne de Bourbon ${ }^{1}$ furent offerts comme étrennes, probablement en 1504-1505, à une très jeune fille d'une douzaine d'années. Anne de France, alors veuve de Pierre de Bourbon, s'était éloignée de la cour après y avoir, pendant de longues années, exercé la régence du consentement de son père, Louis XI. En écrivant ce livre, Anne suivait toute une tradition qui nous conduit de Duodha à la Renaissance ${ }^{2}$. Ces ouvrages peuvent prendre des titres différents, speculum, miroir, manuel comme le Manuel pour mon fils ou Livre, comme le Livre des Manières d'Étienne de Fougères ${ }^{3}$, ou encore chastoiements, tous sont mus par une seule visée didactique, ce sont des livres dans lesquels l'écrivain transmet un savoir. Néanmoins, l'œuvre d'Anne ne peut se confondre avec les autres. C'est ce que nous montrerons d'abord par une remise en perspective à l'intérieur de ce registre.

2 Le savoir diffusé peut différer selon que l'enseignement se veut étroitement religieux comme dans le Speculum virginum, qu'il vise une activité spécifique comme pour les regimina principum ou qu'il représente un art de vivre, tel le Chastoiement des dames de Robert de Blois ${ }^{4}$. Déterminer la sorte de transmission visée sera ainsi notre seconde étape. Le plus difficile reste de retrouver un peu de la personne de l'écrivain. Est-ce Anne de France, femme politique éprouvée, qui se dessine à travers son écrit pour transmettre son expérience ou en restons-nous à une typologie étayée d'innombrables références intertextuelles?

\section{Mise en perspective : specula et enseignements}

3 Tout speculum est écrit, le plus souvent en latin, par un clericus, un lettré, qui occupe la position de maître. Ce registre préfère la prose et s'adresse généralement à un interlocuteur ou une classe d'individus masculins. Les specula deviennent de vastes 
encyclopédies, c'est le réel tout entier que l'on cherche à y enfermer. Nous possédons une intéressante liste de manuscrits qui appartenaient à la bibliothèque du Connétable de Bourbon, et de son épouse, Anne, manuscrits en langue romane, mais aussi en latin, italien, espagnol et flamand ; on y relève la présence de plusieurs exemplaires du Miroir Historial de Vincent de Beauvais, ce qui souligne le goût du couple pour l'Histoire, en français et en latin.

On notera aussi la présence de plusieurs «miroir au prince» de Gilles de Rome. Cet intérêt pour la théorie politique n'étonne pas chez ce couple de mécènes éclairés qui appartenaient à la noblesse royale.

d'autres miroirs se trouvaient aussi dans la bibliothèque ducale. On peut ainsi relever un miroer ou l'ame se doit mirer. Ce titre peut renvoyer à cinq miroirs différents 5 . Le premier, destiné à Blanche de Castille, date de la première moitié du XIII ${ }^{\mathrm{e}}$ siècle. Il est caractérisé par son inspiration mystique et se consacre à l'exaltation de la béatitude face aux dangers inscrits dans le monde. Que la destinataire soit une femme est de peu d'importance, mais la couleur particulière qu'y prend la dévotion se retrouve dans d'autres manuscrits de la bibliothèque des Bourbon, tels l'aiguillon d'amour divine, le speculum aureum animce peccatricis ou encore le Livre des révélations de sainte Elisabeth (de Schönau $)^{6}$. Notre Miroer ou l'ame se doit mirer correspond sans doute au petit traité anonyme conservé dans le ms. BnF fr. 996.

De tous ces miroirs ${ }^{7}$, il y en eut un spécialement adressé aux dames et princesses, c'est le Speculum dominarum du franciscain Durand de Champagne qui le dédia à la reine Jeanne de Navarre, l'épouse de Philippe IV le Bel. Le texte latin ne connut la popularité que lorsqu'un franciscain le traduisit en roman. Presque toutes les princesses de la fin du Moyen Âge ont eu ce Miroir des dames dans leur bibliothèque ; s'il n'apparaît pas dans la liste que nous étudions ici, il était déjà dans la librairie de Charles $\mathrm{V}$ et, probablement, dans celle de Louis XI. Il peut avoir influencé Anne de France en certains des conseils qu'elle donne à sa fille. On notera la très haute conscience de son rang :

« En toutes choses [nobles dames] sont et doivent estre le miroer patron et exemple des autres. Ung philosophe dit a ce propoz qu'il n'est sur noble femme point de si petite faulte qui a tous gens de bien ne soit tres desplaisant a veoir. » (p. 65)

7 Or, Durand soulignait les prérogatives accordées aux puissantes dames que concrétisent les appellatifs extrêmement respectueux, cela entraînait l'obligation morale de se montrer à la hauteur de l'idéal impliqué dans les mots 8 . Mais plus profondément significative apparaît la conviction que la dame doit trouver sa sagesse dans l'instruction, ce qui implique de beaucoup lire :

«Vivez en grant craincte et tousjours sur vostre garde que vous n'y soiez deceue et vous gardez d'y estre oyseuse, et par especial d'esperist [...] Et pour mieulx vous sçavoir vivre et conduire en devocion, je vous conseille que lisiez le livret du preudomme de sainct Lis, celui de sainct Pierre de Luxembourg, les sommes le roy, l'orologe de Sapience ${ }^{9}$ ou les aultres livres des Saincts aussi les dictz des philosophes, et anciens saiges, lesquelles doctrines vous doivent estre comme droicte reigle et exemple et c'est tres honneste occupation et plaisant passetemps.» (p. 8-9)

8 De son côté, le franciscain entonne ${ }^{10}$ un vibrant éloge de la lecture, conseillée à la dame, car la sagesse naît de l'instruction et la sagesse est qualité royale: la sagesse est savoureuse, elle apporte au lecteur qui la recherche la paix de l'esprit. Anne de France ajoute que dans la maison d'une noble dame, savants et érudits doivent être accueillis comme un notable honneur ${ }^{11}$. 
9 Pas davantage qu'Anne, Durand ne condamne les atours et parures des puissantes, le luxe est le compagnon obligé du rang à tenir; il faut simplement, préconise le franciscain, ne jamais oublier de se dire que sous la parure, on reste un néant devant Dieu, ce qu'Anne exprime avec autant de vigueur :

«Pensez et recongnoissez en vous qui estes et dont vous venez, a vostre povre et corrompable creation. » (p. 514)

Pourtant si Anne s'inspire du genre des miroirs, le titre qu'elle choisit pour son traité, et qu'elle énonce dans son préambule, est tout autre :

«La parfaicte amour naturelle que j'ay a vous, ma fille [...] recongnoissant la tres briefve subdaine et hastive mort que a toute heure j'attens, nonobstant mon povre, rude et debile engin, me donne couraige et vouloir de vous faire, tandis que je vous suis présente, aucuns petis enseignemens, advertissant vostre ignorance et petite jeunesse, esperant que en aucun temps vous en aurez souvenance et vous pourroient quelque peu profiter. » (p. 1-2)

11 On peut penser que le choix du titre enseignements représente un petit salut aux Enseignements de Saint Louis à son fils ainsi qu'à ceux qu'il avait dédiés à sa fille, Isabelle de Navarre ${ }^{12}$. Pourtant le texte de Saint Louis n'est pas répertorié dans l'inventaire des deux bibliothèques du couple ducal. Le saint roi en restait volontairement à une suite de préceptes religieux; la féminité de la destinataire se marquait dans l'absence de toute référence politique et dans les règles accordées à sa "nature ": les habits, le bavardage, les fréquentations. Les deux « enseignements » sont ainsi assez loin l'un de l'autre, même si Anne recopie certaines recommandations religieuses - que l'on trouve à vrai dire dans la plupart des miroirs. À lire le texte de Saint Louis, on n'imagine pas qu'Isabelle était à la fois princesse royale et reine de Navarre.

D'autres enseignements ont été plus féconds pour guider Anne dans ses recommandations au sujet de la vie dans le monde : elle demande à Suzanne de lire le Livre du chevalier de la Tour Landry pour l'enseignemens de ses filles. La bibliothèque ducale en proposait au moins deux exemplaires. Ce livre ${ }^{13}$ se signale par un grand prosaïsme, avec l'affirmation d'une foi assez rudimentaire, quoique convaincue : les conseils religieux sont avant tout des règles de politesse à respecter quand on va à la messe : ne pas papoter, ne pas s'abandonner à des pensées voluptueuses, prier pour les morts (qui prient aussi pour vous). Les conseils de savoir-vivre sont empreints de ce même gros bon sens : pour les habits, couvrir ce qui doit l'être... pour la paix conjugale, obéir à son mari, surtout devant témoins, ne pas faire la fête la nuit, ne pas manger les bons morceaux quand il est absent... De toute façon, plus le mari est mauvais, meilleure doit être la femme. Certains traits sont même étranges, comme la retenue à garder quand une naissance s'est bien passée, car Dieu, tel une chrétienne Némésis, pourrait en prendre ombrage. Pourtant ce petit noble n'est nullement méprisable : il pense que les filles doivent apprendre à lire, ne redoutant nullement de développer ainsi leur intelligence, et s'il juge superflu qu'on leur enseigne aussi l'écriture, il défend la possibilité du mariage d'amour et non d'un contrat qui peut au mieux permettre au couple une affection sans chaleur et remplie de distance.

13 Anne, qui conseille ce livre à sa fille, ne l'a pas jugé sans intérêt, mais son propos est nettement plus élevé que celui du simple chevalier. Des chastoiements qui édictent un certain nombre de règles de savoir-vivre courtois, Anne ne retient guère davantage. Quand on est du rang de sa fille, on se soucie assez peu de la possible dissymétrie d'un visage ou des soins à apporter à son haleine. Il ne saurait non plus être question de complaisance dans les séductions que la courtoisie suggère. On considérera les jeunes 
filles, les dames mariées, les veuves, non les amantes ni les coquettes. Le propos reste bien celui des miroirs, de haute visée et toujours profondément empreints de religiosité.

\section{Définir le propos et son écriture}

14 Dans la masse des écrits didactiques que le Moyen Âge a destinés aux femmes, l'œuvre d'Anne de France est la seule à avoir été écrite par une laïque s'adressant à sa propre fille en prose romane, pour lui apporter un savoir qui concerne la conduite de sa vie entière, aussi bien dans le monde que pour son salut à venir. Le texte ne vise aucunement à la prose d'art et l'écrivaine ne s'est pas non plus astreinte à la rigueur d'un plan, il y a de nombreuses redites. Le texte évoque une longue réflexion menée un moment d'écriture après l'autre, dans une suite assez lâche des idées, avec un style sobre, aisé et rapide. On peut discerner trois grandes idées directrices qui s'interinfluencent dans cet enseignement à la fois moral et pratique.

15 Le monde où va entrer la jeune Suzanne, Anne de France le connaît parfaitement : c'est une société du regard et de l'omniprésence des autres. Pour y vivre de façon digne, satisfaisante et juste, on doit en posséder à fond les règles et suivre le haut idéal humain que la mère détaille pour sa fille. Un pessimisme affirmé et surmonté en est la clef: il faut se méfier des autres comme de soi-même, car le monde n'est que l'antichambre d'un au-delà où un Dieu des plus exacts vous demandera des comptes.

\section{Une société du regard et de la représentation}

16 Anne part du statut présent de Suzanne, envisage le cas où, sa mère venant à mourir, Suzanne serait un temps demoiselle chez une grande dame ${ }^{14}$; puis vient le mariage, traité longuement, avec le mari et les enfants, enfin le veuvage toujours probable. À chaque temps ses règles et au-dessus, pour tous, une même vision de l'existence.

En entrant dans le monde, la jeune fille expérimente ce qui, sa vie durant, sera l'essentiel : le bruit, c'est-à-dire la renommée ${ }^{15}$. Une renommée se construit, mais une fois détruite, elle l'est à jamais, le regard des autres est impitoyable. Anne énonce alors une longue liste d'interdits, il faut éviter d'être volage et effrenée, coquette, muable. L'habillement est objet de règles précises ${ }^{16}$ : éviter la recherche, respecter la décence, fuir l'excentricité en suivant les coutumes du lieu. Une simple cotte trop serrée peut faire imaginer au prétendant qu'au moment des grossesses, le goût de la dame pour la minceur serait dommageable à l'enfant. Il ne faut pas pour autant s'habiller en dessous de sa condition ${ }^{17}$, la dame sera tout aussi attentive à réprimer les velléités luxueuses de ses suivantes qui doivent rester à leur place ${ }^{18}$.

18 Plus encore que l'habit, le maintien est une ostentation des qualités réelles de la dame pour la rendre à la fois belle et prisée. La gesticulation, les mouvements de la tête sont à bannir :

« Vous gardez [...] de faire nulles lourdes contenances, tant de branler ou virer la teste ça ne la, comme d'avoir les yeulx agus, legiers ne espars. Aussi de beaucop ne trop rire quelque cause qu'il y ait. » (p. 43)

19 Le maintien doit être humble, ce qui veut dire modeste, mais gracieux et courtois, surtout après le mariage, donnant à la dame un abord aisé, agréable, mais aussi ferme, sans

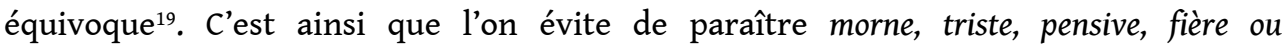




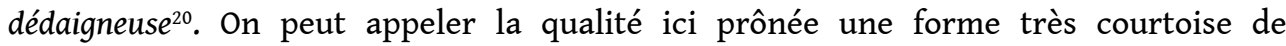
l'affabilité.

Pour qu'il ne s'agisse pas d'une trompeuse apparence, cette affabilité doit reposer sur de rélles habitudes : la coutume de ne jamais agir de soi-même dans les cas importants, mais d'avoir recours au conseil d'amis sûrs ${ }^{21}$, de préférence choisis dans la parentèle d'une part, et, d'autre part le sens très poussé de la discrétion :

«On doit avoir yeulx pour toutes choses regarder, et rien veoir, oreilles pour tout ouyr et rien sçavoir. » (p. 20)

21 On se gardera ainsi des clabaudages intempestifs, de la médisance ou la calomnie qui suscitent la haine vengeresse des autres. Car rien n'est plus dangereux que la langue : $a$ la langue connait on la femme $e^{22}$. S'ensuit un véritable art de la conversation :

"Quant vostre naturelle condicion seroit de peu parler, si vous conviendroit il mettre vostre effort de courtoisement parler et respondre a ceulx desquelz vous seriez en gouvernement. » (p. 72)

On doit tout autant éviter le bavardage qu'être morne et muette, que se montrer maladroite, en n'adaptant pas son langage à la noblesse ou à l'humilité de l'interlocuteur. Il faut faire montre de mesure et discernement, notamment lors de l'arrivée d'hôtes étrangers ${ }^{23}$ : il faut se révéler capable, sans outrance ni contrainte, d'aiguiller la conversation vers leurs centres d'intérêt, repérer les sujets à contourner, bref, mettre à l'aise l'interlocuteur en paraissant soi-même plaisante et aimable, ce qu'Anne appelle estre bien enlangaigie ${ }^{24}$.

23 Cette façon de s'exprimer pleine d'aménité est tout aussi nécessaire lorsque l'on est à l'extérieur, lors de visites des malades ${ }^{25}$. La règle est de ne jamais céder à la diffamation, qui relève de la traitrise, ni à la moquerie, qui est «signe d'un povre entendement ${ }^{26}$. Ainsi se montre-t-on à la fois aimée de Dieu (par la justesse de son action) et du monde (par sa bonne renommée) ${ }^{27}$.

24 Le second des ennemis de Renommée naît de l'oisivetée ${ }^{28}$ qui pousse au péché, car elle distrait l'attention, on peut s'autoriser à se détendre avec des jeux de société et, surtout, la lecture et la prière. Chez les servantes aussi, l'oisiveté est à combattre, il faut donc les tenir dans une assez étroite subjection, en leur permettant de temps en temps, si elles sont jeunes, des divertissements innocents dancer, chanter ${ }^{29} .$. Une maison doit être nette, et cela, « pour vostre honneur et pour vostre profit $»^{30}$.

\section{Un idéal humain de haute valeur}

25 On devine ainsi le train d'un très grand hôtel où l'étiquette fixe l'existence de façon étroite, où la promiscuité réelle implique un nécessaire retrait en soi-même, empreint d'une méfiance sans défaut. Même la vie conjugale n'échappe pas au jugement, obligeant la dame à se montrer «gracieuse, obéissante, douce » dans les gestes adressés à son époux, non plus que le veuvage où un deuil excessif est moqué et laisse les autres incrédules. Ce qui est ici conseillé à la future grande dame est une attitude lisse, sans orgueil, mais assurée, silencieuse, inaccessible et inaltérable :

«Tousjours en port honnorable, en maniere froide et asseuree, humble regard,

basse parolle, constante et ferme, tousjours en ung propoz, sans flechir. » (p. 129)

Cette définition, on le voit, ne nous donne pas seulement la description d'une attitude, mais implique un idéal de vie qui s'exprime tout au long des conseils maternels. L'apparence sur laquelle se fonde la réputation, l'image qui est offerte consciemment 
au regard d'autrui doivent refléter l'être profond de la dame : si, demoiselle, elle était " belle, jeune, chaste, bien morigenee ", c'est toute sa vie qu'elle offrira aux autres :

«Beau port haut et honnorable, doulce maniere bien moriginee et asseuree en toutes choses, [...] compassee en toute raison. » (p. 29)

Anne, qui méprise la beauté, donne à chaque mot sa valeur pleine, raison, assurance, honneur. Aussi une bonne conduite fuira-t-elle le péché contre l'esprit, l'orgueil, car il est menace réelle face à la qualité du sang qui naît nécessairement de la noblesse. Contre l'orgueil, ce sont les vertus qui permettent de triompher, la noblesse doit «s'aourner » de vertus, car son but :

«Est d'avoir bon et honnorable bruit [en étant] vertueuse et prudente.» (p. 58) auxquels elle parle, convaincue que :

"Quant plus vous leur ferez d'honneur et plus accroistrez le vostre [...] c'est vertueux savoir. Or le savoir n'est jamais acquis tout entier ; on apprend jusqu'à la fin. » (p. 122-123)

Prudence est cause de vertu ${ }^{31}$. On rappellera que, au sens médiéval, la prudence est "sagesse qui règle la conduite et fait éviter les fautes ", puis en moyen français le sens glisse vers "savoir-faire». La définition religieuse est "vertu qui associe, dans la conduite de la vie, force d'esprit, faculté de discernement et connaissance de la vérité » Cette notion est l'une des clefs de ce que veut donner à obtenir le livre d'Anne. Les vertus de la dame ne doivent jamais souffrir d'être suspectées, prises en défaut ni par autrui ni par soi-même. Ainsi, à l'égard de ses gens, on doit éviter toute faveur, toute feintise, mais se montrer «leale, constante et veritable » dans le respect du «bon droit » de chacun.

Cela justifie un "art de bien parler ", qui n'est pas seulement inscrit dans le simple respect des règles de politesse, car la parole est un don de Dieu, qui doit être respectée comme telle. Et Dieu est «marry» quand on use mal de la parole ${ }^{32}$. Plus encore que le mariage, le veuvage révèle les qualités profondes d'Anne dont elle désire faire un modèle pour sa fille. Certes, les principales occupations d'une veuve de cette très haute noblesse n'impliquent nullement le retrait du monde. La veuve se gouvernera sagement quant à sa vie privée, mais, désormais retirée des divertissements, elle s'occupera avec diligence et en personne " de ses terres et de ses besognes »; elle en restera la " souveraine » 33 .

Dans cette situation, il lui faut toujours observer avec la plus stricte attention ses gestes, ses mots, ses fréquentations, car le «bruit » de sa vie reste cause première de son efficience. Ainsi la noblesse de la veuve reste intacte dans sa solitude. Noblesse et vertu sont en engendrement réciproque :

« Noblesse ne fut jamais trouvee, si non en cuer humble begnin, courtois.» (p. 119)

Désormais maitresse de son domaine, la veuve se gardera de toute spoliation, elle conservera "sa parolle douce, son chief incliné $»^{34}$ en guise de salut courtois à tous ceux urtant la veuve ici dépeinte - qui emprunte bien de ses traits à la narratrice - reste un objet de convoitise aux yeux masculins, car elle n'est pas si âgée et elle est puissante! Anne se gausse des veuves qui papillonnent : jamais le séducteur ne s'amuse autant que lorsqu'il a triomphé d'une "vieille femme ", ce qu'Anne précise par "l'âge de quarante ans", où l'on commence à voir des fronces sur le visage ${ }^{35}$. Dans les recommandations données à sa fille, on devine des souvenirs qui amusent encore - et tout un art d'éconduire : feindre de ne pas comprendre, servir aux galants un discours convenu $^{36}$ qui explique combien certains tristes sires - au nombre desquels, bien 
entendu, elle affirme ne pas mettre son interlocuteur - sont de pauvres personnages, se montrer imperturbablement «douce et courtoise » au jeu du " on verra bien qui se lassera le premier ", avec en arrière-plan le plaisir subtil de se savoir déjà victorieuse du galant et l'idée non moins délectable qu'il sera doux de se remémorer la défaite du soupirant, avec, enfin, la certitude que l'on ressort bien plus forte de l'assaut ; car, somme toute, on ne connaît la valeur d'une place-forte que lorsqu'elle a résisté à l'attaque ${ }^{37}$. On peut ainsi voir dans cette semi-confidence de femme à femme combien pour finir, dans ses " enseignements ", Anne apprend beaucoup à sa fille sur le monde et sur le bruit que l'on y acquiert sans rien relâcher de la haute vision qu'elle s'est donnée de sa vie de grande dame.

\section{Un pessimisme affirmé et surmonté}

33 Anne ne pensait sans doute pas que sa fille aurait à jouer un rôle politique d'une importance aussi haute que le sien en son temps, néanmoins elle lui recommande des traités de gouvernement, on sait en outre que, bien qu'elle ne les cite pas dans ses conseils de lecteur, Anne possédait dans sa bibliothèque un grand nombre d'œuvres de Christine de Pizan et, d'ailleurs, de nombreuses réminiscences du Livre des Trois Vertus s'échelonnent au fil du texte. Comme Christine, Anne donne à la dame un pouvoir de gouvernance qui apparaît notamment dans le chapitre sur les veuves. Si elle n'a pas les mêmes raisons que la célèbre écrivaine de craindre la souillure de son bruit, elle apparaît au moins aussi méfiante qu'elle sur la capacité de nuisance des hommes dans leur entreprise de séduction ${ }^{38}$, pareillement condamnée par les deux femmes. Les attachements charnels ne durent pas et ne méritent nullement d'être laissés à euxmêmes ${ }^{39}$. Le monde est corrompu, tout va de mal en pis et les hommes sont plus que les femmes touchés par la perversion.

Même dans l'affection entre les époux, les «Enseignements » laissent entendre que les mariages malheureux ne sont pas rares et que la mauvaise conduite de l'homme ne peut qu'être subie sans révolte ${ }^{40}$. Mais ce qui est propre à Anne est le stoïcisme avec lequel elle préconise à sa fille d'endurer cela sans nulle manifestation. S'il faut se cantonner au silence, c'est en l'accompagnant par une relativisation des faits, dans l'idée que toute épreuve vaut pour le salut et qu'en toute souffrance gît son bien. Enfin le sort reste imprévisible:

«Es biens de fortune n'y a rien ferme ny estable.» (p. 120)

Même le bonheur est traversé du sentiment de sa fragilité. Anne évoque avec froideur sa mort prochaine, et les jours où son livre seul perpétuera sa voix près de sa fille. Ce pessimisme marqué est surmonté dans une vision ascétique de la religion ${ }^{41}$. Anne recommande à Suzanne de lire l'Horloge de Sapience de Suso ${ }^{42}$. Au grand mystique rhénan, elle emprunte les moments de contemplation douloureuse de la Passion, mais sa foi inquiète appelle à ne jamais oublier le Jugement dernier; et sa recommandation de réciter systématiquement des prières ${ }^{43}$ pour se protéger, surtout aux heures de la jeunesse, achève de tracer d'elle l'image d'une femme de devoir, sans davantage d'illusions sur elle-même que sur les autres, mais persuadée de l'importance et du rôle de la volonté à chaque instant de l'existence. La tendresse de cette femme austère pour son enfant, qui transparaît à de très rares moments, nous laisse enfin entendre que Suzanne était tout à fait digne de l'ouvrage où sa mère avait mis toute son expérience. 


\section{BIBLIOGRAPHIE}

Anne de France, Les Enseignements d'Anne de France à sa fille Suzanne de Bourbon, texte original d'après le manuscrit unique de Saint-Pétersbourg, par A. M. Chazau, Moulins, 1878 (précédé d'une éd. des Enseignements à Isabelle de Navarre).

Chevalier de la Tour Landry (Le), Livre pour l'enseignement de ses filles, publié par Anatole de Montaiglon, Paris, 1854.

DELISLE Léopold, Durand de Champagne, HLF XXX, Paris, 1888, p. 302-333.

Duodha, Manuel pour mon fils, éd. par Claude MONDÉSERT et Pierre RICHÉ, Paris, Cerf (Sources chrétiennes), 1987.

Enseignements de Saint Louis à son fils, éd. H. François DELABORDE, BEC 73, 1912, p. 337-262.

Enseignements à sa fille Isabelle de Navarre, p. XX-XXVII de l'édition des Enseignements d'Anne de France.

ÉTIENNE DE FOUGÈRES, Livre des Manières, éd. par Jean Thomas, Paris-Louvain (Ktêmata), 2013.

FOX John, Robert de Blois, son œuvre didactique et narrative. Étude linguistique et littéraire suivie d'une édition critique avec commentaire et glossaire de l'Enseignement des princes et du chastoiement des dames, Paris, Nizet, 1950.

DUBY Georges et PERROT Michelle (dir.), Histoire des femmes en Occident, t. 2, Le Moyen Âge, KLAPISCHZUBER Christiane (dir.), Paris, Plon 1992.

HASENOHR Geneviève, Textes de dévotion et lectures spirituelles en langue romane (France, $\mathrm{XII}^{e}$-XVI ${ }^{e}$ siècle), assemblés et revus avec la collaboration de Marie-Clotilde HUBERT, Sylvie LEFÈVRE, Anne-Françoise LEURQUIN, Christine RUBY et Marie-Laure SAVOYE (texte, Codex et contexte XXI), Turnhout, Brepols, 2015.

HENTSCH Alice, De la littérature didactique du Moyen Âge s'adressant spécialement aux femmes, HalleWittenberg, Cahors, 1903, n 95, p. 199-207.

PERRET Noëlle-Laetitia, Les traductions françaises du De regimine principum de Gilles de Rome : parcours, matériel, culturel et intellectuel d'un discours sur l'éducation, Leiden, Brill, 2011.

REGNIER-BOHLER Danielle (dir.), Voix de femmes au Moyen Âge, Paris, éd. Robert Laffont, 2006.

Speculum virginum/Jungfrauen Spiegel, Lateinisch-Deutsch, éd. par Jutta SEYFARTH, Freiburg-NewYork, Herder (Fontes christiani) 2001-2004 (4 vol.).

\section{NOTES}

1. L'œuvre est citée dans l'édition : Les Enseignements d'Anne de France à sa fille Suzanne de Bourbon. J'ai cependant transformé, le cas échéant, la ponctuation de l'éditeur et modernisé l'accentuation de la langue du texte. Chazau a joint à son édition un relevé des livres des bibliothèques que possédait le couple des Bourbon, ce qui nous donne une bonne idée de ce que, de son vivant, Anne pouvait avoir à sa disposition.

2. Duodha, Manuel pour mon fils. Les chastoiement /ensenhamen (en occitan) peuvent être écrits par des clercs pour des laïques ou par des laïques pour des laïques. Ce sont des 
manuels de savoir-vivre et/ou des règles pour vivre courtoisement. Ils traitent de politesse et des relations sociales. Ils sont souvent rédigés en langue vernaculaire. A. Hentsch, De la littérature didactique du Moyen Âge s'adressant spécialement aux femmes, note la triple singularité de l'œuvre d'Anne de France: ce livre a été écrit par une femme pour une femme, par une mère pour sa fille ; par une femme politique le dédiant à une autre femme politique. En ce qui concerne plus spécifiquement la princesse Anne en son temps, voir G. Duby et M. Perrot (dir.), Histoire des femmes en Occident, Ch. Klapisch-Zuber (dir.), t. 2, Le Moyen Âge ; D. Regnier-Bohler (dir.), Voix de femmes au Moyen Âge.

3. É. de Fougères, Livre des Manières.

4. Le Speculum Virginum (composé vers 1140) est destiné à des moniales. Le nombre de ses manuscrits en atteste le succès, Speculum virginum/Jungfrauen Spiegel; les regimina principum sont des miroirs aux princes destinés aux souverains, le plus connu est celui de Gilles de Rome (vers 1269), voir N-L. Perret, De regimine principum de Gilles de Rome : parcours, matériel, culturel et intellectuel d'un discours sur l'éducation ; J. Fox, Robert de Blois, son cuvre didactique et narrative. Étude linguistique et littéraire suivie d'une édition critique avec commentaire et glossaire de l'Enseignement des princes et $d u$ chastoiement des dames.

5. 1) Li mireoirs de l'ame, texte anonyme en prose du XIII ${ }^{\mathrm{e}}$ siècle, écrit pour Blanche de Castille, ms. Mazarine 870 ; 2) Le petit miroer de l'ame devote, anonyme, ms. BnF fr. 1864 ; 3) Li mireoirs de l'ame anonyme en 48 douzains d'octosyllabes, fin XIV siècle, ms. BnF fr 12594 ; 4) Le miroer ou l'ame se doibt mirer, anonyme, copie du Xve siècle (BnF fr 996); 5 ) Le miroir de l'ame écrit par un Chartreux, traduction du Speculum aureum animae peccatricis de Jacob van Gruytrode par Jean Meliot (1451 ?) ; 6) le mirouer de l'ame de Jean Gerson.

6. Charles $\mathrm{V}$ commanda tout spécialement à Jacques Bauchant de Saint-Quentin une traduction des Visions d'Élisabeth (ms. BnF fr. 792). Le manuscrit était certainement resté dans la bibliothèque royale du temps de Louis XI.

7. Respectivement et selon la chronologie : 1) le miroir des dames traduction par un franciscain du Speculum dominarum de Durand de Champagne, avant 1305 ; 2) le mireoir as dames de Watriquet de Couvin de 1324 (1294 octosyllabes) dédié à la reine Jeanne d'Evreux; au $\mathrm{xv}^{\mathrm{e}}$ siècle; 3) le miroir aux dames, version anonyme éd. A. Piaget (136 huitains d'octosyllabes) ; 4) le miroir des dames et des demoiselles de Jean Castel fils ; 5) le mirouer aux dames de Philippe Bouton ; 6) le Miroir des dames, traduction par Isambart de Saint-Léger, qui la dédie à Marguerite de Navarre, d'une partie du Speculum Dominarum. En ce qui concerne le Speculum dominarum et ses traductions, voir L. Delisle, HLF XXX . Pour l'étude de ce registre et l'analyse des œuvres en leur contexte, on se réfèrera à G. Hasenohr, Textes de dévotion et lectures spirituelles en langue romane (France, $\mathrm{XII}^{e}$-XVI ${ }^{e}$ siècle), assemblés et revus avec la collaboration de M.-Cl. Hubert, S. Lefèvre, A.F. Leurquin, C. Ruby et M.-L. Savoye (Texte, Codex et contexte XXI).

8. Ms. BnF fr. 6784, col 33.

9. Sainct Lis est sans doute Saint Louis, L'Orologe de Sapience a été écrite par Henri Suso, le Livre de Pierre de Luxembourg se trouve notamment dans le BnF fr. 457, en compagnie de l'Orologe de Suso.

10. Dans son chapitre 32 .

11. P. 101. 
12. Les Enseignements de Saint Louis à son fils sont édités dans BEC 73, (H. F. Delaborde). Les enseignements à sa fille Isabelle de Navarre sont édités dans l'introduction de l'édition Chazau, p. XX-XXVII.

13. Le Chevalier de la Tour Landry, Livre pour l'enseignement de ses filles, publié par A. de Montaiglon.

14. C'est le chapitre VI.

15. «Toutes femmes de façon qui desirent avoir bon bruit a cause de leurs feminines et doulces condicions ", p. 29

16. Ch. X-XI, ch. XIV.

17. P. 25.

18. P. 91.

19. P. 64.

20. P. 71.

21. P. 79 et 119 .

22. P. 44.

23. P. 69.

24. P. 67.

25. P. 61.

26. P. 88.

27. P. 70.

28. Ch. XXI.

29. P. 93.

30. P. 84.

31. P. 38.

32. P. 71.

33. P. 116.

34. P. 123.

35. P. 108.

36. P. 129.

37. «Car supposé que ung chasteau soit de belle et bonne garde qui jamais ne fut assailly, si n'est il pas a louer » (p. 130).

38. Anne y consacre une bonne partie des ch. XXVI-XXVII.

39. P. 33.

40. P. 73.

41. Le ton est donné dès les premières lignes du traité.

42. Le texte a été très vite traduit en langue française, on en possède de nombreux manuscrits, notamment à la cour de Bourgogne, tel le ms. BnF fr 455, magnifiquement illustré par le Maître de Marguerite d'York. Dès 1493, l'Orloge de Sapience était imprimé à Paris pour Antoine Vérard.

43. P. 26. 


\section{RÉSUMÉS}

Dans un registre bien connu, celui des miroirs et des chastoiements où s'énonce la transmission d'un savoir, Les Enseignements d'Anne de France à sa fille Suzanne de Bourbon se distinguent parce qu'ils sont, de façon originale, le livre laissé par une mère à sa fille, une femme à une femme, une politique à une politique. Ce triple aspect mérite d'être mis en perspective avec les autres traités. Puissante dame, Suzanne devra avoir conscience de son rang et l'appuiera sur sa culture et ses lectures. Vivant dans une société du paraître, la dame doit garder intacte sa renommée, irréprochable dans sa tenue comme dans sa parole qui relève d'un véritable art. Entre lecture et prières, l'oisiveté n'a pas de place. Prudence et discernement sont vertus essentielles. Sa vie durant, de la jeunesse au mariage, au fréquent veuvage, la dame, maîtresse d'elle-même comme de ce qui l'entoure, cultivera un pessimisme surmonté, accordé à une vision stoïque et sans concession de sa religion.

\section{AUTEUR}

\section{MARIE-GENEVIÈVE GROSSEL}

Maître de conférences émérite en philologie et littérature médiévales, Valenciennes, Université Polytechnique des Hauts de France, laboratoire De scripto 


\title{
De la Fleur de lis en medecine à la Fleur de cyrurgie : une stratégie éditoriale?
}

\author{
Adeline Sanchez
}

1 Le $\mathrm{XV}^{\mathrm{e}}$ siècle voit l'essor des traductions de textes scientifiques, notamment en français, traductions d'œuvres intégrales, mais surtout de fragments insérés dans des compilations dont les vocations restent parfois ignorées. Certaines œuvres connaissent un succès particulier par une abondante production de traductions. La multiplication de ces entreprises aboutit au développement de témoins de formes variables dont la portée est parfois faible $d u$ fait d'une circulation en réseaux restreints. Or nous remarquons que ces mêmes œuvres ne connaissent pas toujours un engouement similaire dans leur diffusion imprimée, quand elles font l'objet d'un ou plusieurs projets d'édition, car ce n'est pas toujours le cas. Le Lilium medicinae de Bernard de Gordon est un exemple éclairant de ces pratiques, notamment par des écarts de diffusion dans la production manuscrite en fonction des langues vernaculaires cibles, ainsi qu'une transmission textuelle qui se distingue lors du passage à l'imprimé.

2 Ce Lilium medicinae est une practica, c'est-à-dire une production de type universitaire qui fait la synthèse d'un savoir pratique. Il est composé entre 1303 et 1305 par un maître en médecine de l'université de Montpellier, Bernard de Gordon. Il s'agit d'une composition en latin à visée didactique qui organise la matière médicale en sept livres, contenant eux-mêmes une division en chapitres et sous-chapitres, et suivant un mouvement général du haut vers le bas, soit de la tête aux pieds. Dans ces sept livres, sont inclus un régime de santé au livre $\mathrm{V}$ et un antidotaire au livre VII, auxquels s'ajoute dans les versions françaises, un Secret des dames à la fin du livre VII. Synthèse de la médecine scolastique, le Lilium medicinae s'adresse à des médecins et apprentis, mais trouve très rapidement un lectorat plus large, sortant de l'enceinte des universités et parfois même de la pratique médicale par des professionnels de santé. Nous conservons dans cent deux manuscrits des versions intégrales ou fragmentaires en latin de cette œuvre, ainsi que soixante-deux manuscrits en langue vernaculaire, là encore par des versions intégrales ou fragmentaires. Ces entreprises de traduction apparaissent dès la 
fin $\mathrm{du} \mathrm{XIV}^{\mathrm{e}}$ siècle, avec des traductions en allemand, en catalan et en hébreu, et perdurent jusqu'au début $d u x{ }^{\prime}{ }^{e}{ }^{e}$ siècle pour les traductions en gaélique irlandais. Après une description succincte de notre corpus, nous permettant de poser quelques jalons importants de la transmission manuscrite et imprimée du Lilium medicinae, nous nous intéresserons à la production imprimée en français. Cette focalisation est due à un bouleversement de la production. En 1495, la faculté de médecine de Paris interdit la publication d'œuvre de médecine en français. Or il est imprimé jusqu'en 1509 à une différence près, son titre: la Fleur de lys en medecine devient Fleur de cirurgie. Nous chercherons à interroger ce changement au regard des productions médicales de la fin $\mathrm{du} \mathrm{Xv}^{\mathrm{e}}$ et du début $\mathrm{du} \mathrm{XvI}^{\mathrm{e}}$ siècle, car si l'université n'a pas provoqué la fin de l'impression d'une médecine en français, nous constatons toutefois un arrêt précoce de la production du Lilium medicinae traduit, au regard de l'intérêt porté à l'œuvre en latin et en castillan.

\section{Un large corpus aux variables de transmission importantes}

Comme nous venons de le mentionner, nous conservons cent deux manuscrits comportant une version intégrale ou un fragment en latin du Lilium medicinae, ainsi que plusieurs témoins de traductions en langues vernaculaires, dont trois fragments en français répartis dans trois compilations aux caractères distincts. Ces manuscrits datent $\mathrm{du} \mathrm{Xv}^{\mathrm{e}}$ siècle et appartiennent actuellement au fond français de la Bibliothèque nationale de France, il s'agit des compilations de médecine et de chirurgie, 1288, 1327 et 19989. Notre étude codicologique permet de faire émerger des intérêts différents pour ces trois entreprises. En effet, ne sont pas conservés les mêmes extraits dans ces trois fragments, à l'exception de l'antidotaire présent dans les manuscrits français 1288 et 1327. De plus, ces fragments sont insérés dans des compilations qui font unités au regard de leurs organisations d'ensemble. Ainsi, le manuscrit français 1288 porte des indices d'usage de la médecine absents du français 1327. Ce dernier manuscrit est d'une confection plus riche, mais à ceci en commun avec le français 1288 qu'ils semblent tous deux répondre à une commande ou du moins être destiné à un lectorat précis. Le dernier manuscrit, le français 19989, est une compilation d'usage à vocation personnelle, mais qui conserve comme trait commun avec les deux autres témoins de s'intéresser à la chirurgie. Si dans les français 1288 et 1327 les fragments de textes chirurgicaux sont minoritaires, l'intérêt pour cet art est premier dans le manuscrit français 19989 qui enregistre une traduction de Guy de Chauliac, le Formulaire des aides des appostumes et pustules. Autre particularité, le fragment conservé dans le manuscrit français 19989 correspond à un enrichissement du Lilium medicinae dans les imprimés en français, un Secret des dames dit pseudo-Gordon. Le Lilium medicinae a fait l'objet de plusieurs éditions à travers l'Europe, en latin, en français et en castillan. En France, cinq imprimeurs ont édité cette practica. La plus ancienne a été réalisée par un anonyme à Lyon en 1495, puis quatre éditions ont été réalisées à Paris, en 1504 et 1505 par Durand Guerlier, en 1509 par Durand Guerlier et les frères Marnef, et enfin, en 1509 par Jean Petit. Ces éditions françaises rendent compte d'une immobilité du texte, si ce n'est les variantes de langues qui consistent en une actualisation de celle-ci, notamment au niveau graphique. L'ensemble de cette tradition imprimée française restituerait la traduction faite par un anonyme à Rome en 1377, sous le pontificat de 
Grégoire $\mathrm{I}^{\mathrm{er}}$, selon les colophons présents dès l'édition de 1495. Enfin, le Secret des dames que nous avons mentionné ci-dessous et qui conclut les éditions en français serait une reprise des chapitres du livre VII sur les menstrues. Monica Green parle de cet ajout comme d'un pseudo-Gordon, ce qui est probable ${ }^{1}$. Nous ne rejetons aucune de ces deux hypothèses, car ces procédés d'extraction et de réécriture de la médecine féminine contenue dans le Lilium en un Secret des dames, correspondent à une manipulation des textes lors du processus de traduction qui est courante en français au $\mathrm{xv}^{\mathrm{e}}$ siècle.

Deux choses sont alors frappantes au regard du corpus en langue vernaculaire. Premièrement, le nombre de traductions en langue française est faible, en comparaison des témoins en d'autres langues, comme en hébreu ou en gaélique. Ces efforts de traductions en français sont plus proches des pratiques espagnoles, pour nous ici en catalan et castillan, mais également des besoins de traductions qui apparaissent pour les versions anglaises et allemandes. Nous conservons ainsi, d'après notre dernier relevé, de façon intégrale ou fragmentaire, cinquante-neuf traductions en langue vernaculaire autres que le français, dont une traduction castillane, une catalane, une en moyen anglais et deux allemandes, trente-quatre témoins en hébreu et dix-neuf versions en gaélique irlandais. Pour ce qui est de la réception imprimée en latin, nous avons recensé seize éditions de versions intégrales entre 1480 et $1617^{2}$.

D'après les investigations que nous avons effectuées sur une partie de ces témoins, et au regard des recherches menées sur eux ${ }^{3}$, nous savons actuellement qu'ils s'adressent à des lectorats variés, qu'ils s'agissent des versions latines ou des versions en langue vernaculaire, selon des besoins distincts, même si ces besoins se recoupent parfois. Nous ne pouvons pas exposer ici l'ensemble des cheminements qui conduisent à ces postulats, cependant nous synthétisons les résultats de ces enquêtes sur les besoins et les lectorats de ces témoins.

6 Ainsi premièrement, la diffusion manuscrite du Lilium medicinae se fait par des versions intégrales et de nombreuses versions fragmentaires, en latin comme en langue vernaculaire. Certains de ces manuscrits portent la mention d'acteurs qui sont intervenus dans la confection et/ou transmission de ces objets. Nous relevons alors une majorité de professionnels de santé. Ce sont des médecins, mais également des barbiers-chirurgiens, ce qui n'exclut pas la possession par des apothicaires ou encore d'autres praticiens d'une médecine non réglementée par les corporations ni les universités ${ }^{4}$. Ainsi, la traduction catalane ${ }^{5}$ que nous conservons est une copie de Vicenç de Colunya, barbier-chirurgien installé à Barcelone ${ }^{6}$. L'une des traductions allemandes ${ }^{7}$ serait l'œuvre d'un étudiant en médecine, Jodocus von Prag8. La version en moyen anglais ${ }^{9}$ serait une commande à destination du maître des sépultures d'Henri VI, Robert Broke, qui aurait ensuite circulé parmi des barbiers-chirurgiens à Londres du xvie siècle ${ }^{10}$. Rappelons également que le manuscrit français 1327 fait état de critères qui pourraient indiquer une possession pour le prestige dans une bibliothèque privée. Enfin, cela n'exclut pas une pratique d'automédication, tel que l'indiquent les inventaires de bibliothèques féminines ou encore les inventaires d'après décès de marchands. Si ces inventaires ne mentionnent pas toujours le titre et l'auteur de ces manuels de médecine, l'imprimé castillan de 1495 par Ungut et Polonus à Séville est signé par une certaine Brianva Lincielo ${ }^{11}$. Ainsi, les traductions permettent au Lilium medicinae d'accéder à un nouveau lectorat, un lectorat qui ne connaît pas le latin, mais qui dans sa majorité entretient une pratique de la médecine à partir de ces textes. Les versions fragmentaires sont alors intéressantes, car elles rendent compte d'une 
appropriation du texte qui fait l'objet d'une sélection, d'inclusions ou encore de reformulation, au besoin d'un apprentissage ou d'une pratique. Ces traductions, notamment celles qui sont destinées, ont pour intérêt majeur de montrer l'attention portée par les acteurs de ces objets au lectorat visé, avec une adaptation de la matière, par un travail sur la langue ou sur la forme du texte, dans un but de vulgarisation évident. Le discours de spécialité présent dans le Lilium medicinae évolue et se plie aux contraintes du lectorat, à l'inverse, a priori, de ce qui apparaît dans les imprimés du Lilium medicinae. Nous nous permettons de nuancer car le passage du latin au français étant déjà en soi un premier effort de vulgarisation, un second effort d'adaptation se manifeste dans chacun de ces témoins. Si l'on regarde la tradition imprimée française, nous constatons que la traduction répond encore en partie aux pratiques médiévales et peut témoigner de certaines libertés, même si par les procédés de traduction mis en œuvre il n'est pas élaboré de réécriture aussi marquée que dans le fragment du manuscrit français 1327. Cette impression d'immobilité n'est pas présente, par contre, du côté des imprimés latins qui, eux, sont produits en Italie et en France, avec des variantes plus importantes que celles présentes dans les imprimés français. La diffusion des imprimés français est restreinte, tout comme la castillane pour laquelle nous n'avons recensé que trois productions de 1495 à 1697. Enfin, dernier écart entre les éditions en français, castillan et latin, nous n'avons rencontré aucun cas d'extrait du Lilium medicinae placé au sein de recueil en français ou en castillan, à l'inverse du latin où nous pouvons mentionner au moins quatre exemples ${ }^{12}$.

7 La diffusion du Lilium medicinae est un indice de son succès, dès le XIV siècle par les premiers manuscrits latins, mais également par le nombre important de traductions en langue vernaculaire. Mais nous constatons, notamment quand on s'intéresse aux traductions, que l'imprimé va imposer d'autres modèles de transmission de ce texte, vers une standardisation progressive du texte. Cette production imprimée répond ainsi toujours à un besoin, mais les différences que nous venons d'évoquer, font émerger des contraintes à ces productions qui vont infléchir la transmission du Lilium medicinae, et vont également témoigner d'une évolution du lectorat.

\section{Infléchissement des ambitions du discours médical au service des chirurgiens}

8 La variabilité des titres est un phénomène courant dans la transmission manuscrite, elle l'est moins dans les cas de traditions imprimées telle que celle du Lilium medicinae de Bernard de Gordon. En effet, au regard de la stabilité du texte, malgré les différents imprimeurs et libraires en charge de la production, un changement de titre dès la seconde édition est à étudier, d'autant qu'il fait écho à une traditionnelle opposition présente dans la scolastique, entre médecine et chirurgie.

9 Médecine et chirurgie s'opposent en effet, mais sans que cette frontière soit complètement hermétique ${ }^{13}$. Une partition des actes relevant de médecine et de chirurgie est théorisée. Nous en trouvons des traces évidentes dans les témoins de notre corpus. Le manuscrit français 1288 enregistre ainsi un Argumens de médecine et de cyrurgie qui consiste en la distinction de l'art de chirurgie et de l'art de médecine :

«Il est dit que sirurgie est euvre manuel, laquel nous monstre euvre en corps humains, solvent la continuité et rettourner au premiez estat a la desordonnee et ost les superfluités. Quant sont les instrument de medicine? Je di que.III. Diete, 
pocion, cyrurgie. Quatres sont les entencions. Les.4. entencions de cyrurgie de le myre qui on a asegnir. Je di que trois. La prime a asegnir les congucions des choses separes et.II. a asegnir les departies du corps oultre et de foire nature. La.III. a asegnir atintemant de superfluités. Cestes sont l'especes de cyrurgie. Je di que.II. en chars et en os et ce cy est selon la quantité des membres. ${ }^{14}$ "

Dans le Lilium medicinae également, Bernard de Gordon ponctue son œuvre de recommandations en désignant les limites opératoires du médecin, qui doit alors s'effacer au profit du chirurgien :

«La cure de douleur du chief par percution ou par cheoir ou par tomber en tel cas nous doubtons apostume. Et pour ce, c'est bon de empecher que apostume n'y viengne par medicines evacuatives et discretives et des semblables, car puis que fievre apert et turbacion de pensee, ja commence apostume. Donc tout premier oindés le lieu dolereux d'uille rosat ou mirtine et puis faites saignee. Et se les choses particulieres ne s'acordent en la saignee, si faites cristeres. Et s'elles ne se accordent par cristere, par medicine laxative. Et se signes de apostumes apert, faites emplastres de psidia, balaustia, mirtil et rosa. Et s'il y a plaie, alterez la male complexion aultrement n'y reviendroit point la chair. Et s'il y a trop grant flux de sang, si le restanchez et luy donnés a menger cerveau de plusieurs gelines. Et pour ce que en telle sutures sont diverses playes et concussions et fractures et blessures moult diverses, pour ce je les laisse aux cirurgiens. Touteffois aprés on y mettra choses froides et stiptiques et dissolutives, si comme sont camomille, ordeum, mellilotum, anthos siccados. Il doit bien fuyr toutes choses chauldes et fumeuses, si comme vin et les semblables, et mesmement s'il y fait sirop de siccados et de miel et de eaue qui y vault moult. ${ }^{15}$ "

Dans cet exemple, le médecin prend en charge la pose du diagnostic après observation des signes. Il met alors en place un traitement, selon un ordre prédéfini et évoluant en fonction des réactions du patient. La saignée fait partie des actes qui lui incombent, ainsi que les lavements (clystères), les appositions (emplâtres, baumes, ou encore huiles). Le médecin s'écarte au profit du chirurgien pour s'occuper de certaines plaies et fractures, soit ici, de ce qui relève d'une rupture de matière physique importante (os, chair, tissus). Le médecin peut à nouveau intervenir à la suite des actes du chirurgien pour les soins post-opératoires suivant: la médicamentation et une adaptation de l'hygiène de vie en fonction de l'état du patient, ici des conseils sur la diète à adopter.

12 Mais si nous regardons de plus près, nous constatons que la théorie chirurgicale est nécessaire à la compréhension de la médecine dans une certaine mesure. L'exemple le plus frappant est celui de l'usage de l'anatomie, revendiqué par Bernard de Gordon au livre III dans le cas des maladies ophtalmiques, chapitre I :

«Hanc autem anothomiam possumus breviter multum dicere quantum est possibile ut melius oculorum egritudines videamus quam oculus patitur omnia morborum sicut en morbus consimilis, officilais et communis. ${ }^{16}{ }^{\prime}$

«Ceste anothomie nous l'avons mise briefment ainsi que nous avons peu affin que nous veons mieulx la maladie des yeulx, car l'oeul seuffre toutes manieres de maladies, si comme maladie consimile, officialle et commune. Et pour ce que les maladies de la conjunctive. ${ }^{17}$ "

13 L'anatomie, qui appartient alors au domaine de la chirurgie, est nécessaire au médecin, d'un point de vue théorique et pratique, mais, relevant de chirurgie, Bernard de Gordon en justifie l'usage. Nous comprenons mieux alors la mention suivante, présente dans le prologue du Lilium medicinae en français :

«Donc pour ce que la mémoire de l'omme est foible je n'ay point de vergoigne a dire et a repeter aux humbles aulcunes choses communes de pratique, c'est assavoir de medecine et de cirurgie. ${ }^{18} »$ 
La traduction du prologue en français met en évidence la présence de l'art de chirurgie au côté de celui de médecine, l'un aidant à la pratique de l'autre. Si l'exemple en latin précédent nous indique que cette complémentarité est présente dans le corps du Lilium medicinae en latin, elle n'apparaît pas dans le prologue :

"Quia igitur memoria homnis labilis est, quod communiter dicitur de practica humilibus

repetere non erubesco. ${ }^{19}$ "

15 La coordination des deux substantifs, medecine et cirurgie, est un choix de traduction qui n'est pas vain puisqu'il manifeste le lien nécessaire des deux disciplines à l'exercice de la médecine, lien qui ne serait alors que sous-entendu dans la version latine, par la simple présence du terme practica.

16 Ainsi, c'est pour la diversité du lectorat du Lilium medicinae et sa dimension pratique revendiquant le recours à des connaissances chirurgicales, que l'impression de la traduction française a pu être menée de 1495 à 1509. En 1495, à l'occasion de la sortie du Lilium medicinae en français de la presse lyonnaise d'un anonyme, la faculté de médecine de Paris s'oppose à la diffusion d'une médecine en français, qui porterait atteinte à cette science :

«[La mise en français des autorités médicales et chirurgicales] imprimées à Lyon introduit une perturbation suffisamment grave dans la hiérarchie des savoirs pour qu'à la parution de la Pratique ou Fleur de lys en medecine traduite de Bernard de Gordon en 1495, la Faculté de médecine de Paris tente de s'opposer aux publications médicales en français devenues trop nombreuses à son goût et risquant de divulguer l'art divin à des profanes. Cette préoccupation de mettre à la portée des moins savants les données de la science par le biais de ce nouvel art divin qu'est l'imprimerie, constitue l'un des fondements de la pensée humaniste..$^{20}$ "

Malgré l'influence de l'université de Paris, la Fleur de lis en medecine se fait Fleur de cirurgie en 1504, dans la librairie parisienne de Durand Gerlier, et ce jusqu'en 1509 sous la presse de Jean Petit. À partir de la réédition de l'œuvre en 1504, ce changement de titre sera permanent et ne sera appliqué qu'au titre de l'œuvre, puisque nous trouvons dans les premières lignes des volumes la mention suivante :

«Cy commence la pratique de tresexcellent docteur et maistre en medecine Maistre

Bernard de Gordon qui s'appelle fleur de lys en medecine. ${ }^{21}$ »

18 Ainsi deux hypothèses nous apparaissent. Premièrement, le changement de titre peut être une solution de contournement de l'influence de la Faculté de Paris, puisque le lectorat visé se constitue de barbiers-chirurgiens et de chirurgiens, qui ne sont pas soumis à cette interdiction de divulgation en français de leurs sciences. En effet, si de nombreux ouvrages de chirurgie en latin existent, il ne faut pas oublier qu'il y a une méconnaissance de la langue latine par les barbiers-chirurgiens, et une pratique de la chirurgie en français attestée. La seconde hypothèse est celle d'un changement de lectorat. Il est ainsi possible que les médecins, apprentis ou maîtres, privilégient une lecture des ouvrages de médecine en latin. Seuls les barbiers-chirurgiens, les chirurgiens ou encore des profanes s'intéressant à la chirurgie sont susceptibles d'acheter les éditions du Lilium medicinae en français. En effet, il ne faut pas oublier qu'à la fin $d u \mathrm{Xv}^{\mathrm{e}}$ siècle et au XVI ${ }^{\mathrm{e}}$ siècle, un changement de goûts s'opère dans les milieux profanes s'intéressant aux arts de santé. Les préoccupations de ce lectorat ne sont alors plus tournées vers une littérature médicale curative uniquement, tel que les antidotaires ou les compilations de fragments visant une pratique particulière de la médecine, mais vers une compréhension globale du fonctionnement du corps humain, avec un intérêt nouveau pour l'art de chirurgie et surtout l'anatomie ${ }^{22}$. Nous savons que 
le Lilium medicinae était lu, puisqu'il est toujours imprimé en latin et de façon intégrale de 1480 à 1617 environ, et de façon fragmentaire, au moins jusqu'en 1621. Nous savons qu'il est toujours lu en Espagne en langue vernaculaire, puisque la dernière édition castillane, intitulée Lilio de la medicina, est imprimée à Madrid par Antonio Gonçalez de Reyes avec le concours de Fransceco Sacedón en 1697. Ce changement de titre aurait ainsi plusieurs raisons. Il manifeste le progressif changement de goût du lectorat profane ainsi que le changement d'usage par les professionnels de santé, que sont en premier lieu, les médecins, les chirurgiens et les barbiers-chirurgiens. En tant qu'autorité médicale, Bernard de Gordon suscite toujours l'intérêt des médecins, mais pour une étude de la médecine en latin, privilégiant la production d'œuvres médicales en français dans les cas de compositions récentes. À cet égard, nous mentionnerons l'exemple de l'œuvre de Sébastien Colin imprimé par Enguilbert de Marnef à Poitiers en 1558, L'ordre \& regime qu'on doit garder \& tenir en la cure des fievres. Ainsi, l'arrêt de la production du Lilium medicinae en français serait dû à un changement de statut de cette œuvre. Le choix de langue, soit l'impression en latin ou en vernaculaire, est donc du côté de la vulgarisation, pour toucher un public plus large, mais il est aussi le signe d'un changement de statut des œuvres : le Lilium medicinae en tant qu'autorité médicale est toujours lu et étudié en latin, mais on préfère à sa publication en français, celles de compositions plus récentes.

La transmission du Lilium medicinae de Bernard de Gordon est intéressante à plus d'un titre. Son étude permet de mettre en évidence des réseaux et pratiques de diffusion de l'œuvre, du XIV ${ }^{\mathrm{e}}$ au XVIII ${ }^{\mathrm{e}}$ siècle. En effet, abondamment copié en latin, démembré dans le cas de sa fragmentation et parfois réécrit par le travail des traductions, le succès du Lilium medicinae nous amène à parcourir différentes pratiques de l'œuvre, tant dans sa matérialité (nous entendons là l'objet texte autant que l'objet livre) que dans sa réception. Son étude est aussi intéressante en tant qu'exemple des changements de rapport au livre, changements opérés lors du passage du manuscrit à l'imprimé. Nous avons vu que les pratiques du texte se distinguent alors: les manuscrits montrent une majorité de tradition unique par le travail de transmission dont la traduction, là où l'imprimé va figer l'état du Lilium medicinae, du moins pour les imprimés français. Le changement de titre du Lilium medicinae imprimé en français, soit de la Fleur de lis en medecine à le Fleur de cirurgie, nous apparaît comme une stratégie éditoriale, un choix des imprimeurs-libraires leur permettant de satisfaire une demande, en échappant aux contraintes de la Faculté de médecine de Paris, tout en s'adaptant aux nouveaux besoins et aux nouvelles pratiques de lecture de ce début du Xvi ${ }^{e}$ siècle.

\section{BIBLIOGRAPHIE}

BERRIOT-SALVADORE Evelyne, « La littérature médicale en français de 1500 à 1600 », éd. numérique, Medica, novembre 2010 : [URL : http://www.biusante.parisdescartes.fr/histoire/medica/ litterature-medicale-16e.php] 
COQ Dominique, «Les incunables : textes anciens, textes nouveaux », dans Histoire de l'édition française, t. 1 : Le livre conquérant. Du Moyen Âge au milieu du XVII siècle, CHARTIER Roger et MARTIN Henri-Jean (dir.), en collaboration avec VIVET Jean-Pierre, Paris, Promodis, 1983, p. 189.

CIFUENTES Lluís, La ciència en català a l'Edat Mitjana i el Renaixement, Edicions Universitat de Barcelona, Barcelone, 2006.

CONNELY Erin, " "My Written Books of Surgery in the Englishe Tonge": The London Company of Barber-Surgeons and the Lylye of Medicynes ", Manuscript Studies: A Journal of the Schoenberg Institute for Manuscript Studies, volume II, Number 2, Fall 2017, p. 369-391.

DARRICAU-LUGAT Caroline, « Regards sur la profession médicale en France médiévale ( $\left.\mathrm{XII}^{\mathrm{e}}-\mathrm{XV}^{\mathrm{e}}\right)$ », éd. numérique, Cahiers de recherches médiévales, 6 | 1999 : [URL : http://journals.openedition.org/crm/ 939]

DEMAITRE Luke E., Doctor Bernard de Gordon: professor and practitioner, Toronto, Pontifical Institute of Mediaeval Studies, 1980.

DUMAS Geneviève, Santé et société à Montpellier à la fin du Moyen Âge, Leyde, Brill, 2014.

DUMAS Geneviève, «Traduction et compilation : une coïncidence obligée ? », en collaboration avec Caroline BOUCHER, Early Science and Medicine, 17, 2012, p. 273-308.

GREEN Monica, « From "Diseases of Women" to "Secrets of Women" : The Transformation of Gynecological Literature in the Later Middle Ages ", Journal of Medieval and Early Modern Studies, 30, 2000, p. 5-39.

GREEN Monica, Making Women's Medicine Masculine: The Rise of Male Authority in Pre-Modern, Oxford, Oxford University Press, 2008.

IANCU-AGOU Danièle, «Préoccupations intellectuelles des médecins juifs au Moyen Âge :

inventaires de bibliothèques ", Provence Historique, fasc. 103, 1976, p. 21-44.

JACQUART Danielle, La Médecine médiévale dans le cadre parisien, Paris, Fayard, 1998.

JACQUART Danielle, « De la practica à la pratique médicale effective à la fin du Moyen Âge », dans CHANDELIER Joël, VERNA Catherine et WEILL-PAROT Nicolas (dir.), Science et technique au Moyen Âge (XII $X V^{e}$ siècle), Saint Denis, Presses Universitaires de Vincennes, 2017, p. 293-304.

KEIL Gundolf, « Jodocus von Prag. », Die deutsche Literatur des Mittelalters. Verfasserlexikon 2, Berlin/ New York, De Gruyter, 1983.

WOLFGANG Wegner, "Jodokus von Prag”, Enzyklopädie Medizingeschichte, (éd.) GERABEK Werner E., HAAGE Bernhard D., KEIL Gundolf, WEGNER Wolfgang, Berlin/New York, De Gruyter, 2005.

LE BLÉVEC Daniel, L'Université de Médecine de Montpellier et son rayonnement (XIII-XVe siècles), actes du colloque international de Montpellier (Université Paul-Valéry, Montpellier III), 17-19 mai 2001, coll. De Diversis Artibus, collection de travaux de l'académie internationale d'histoire des sciences, Brepols, 2004.

\section{NOTES}

1. M. Green, «From "Diseases of Women" to "Secrets of Women": The Transformation of Gynecological Literature in the Later Middle Ages », p. 5-39. 
2. Manuscrit Paris, Bibliothèque nationale de France, Français 1288. Manuscrit Paris, Bibliothèque nationale de France, Français 1327. Manuscrit Paris, Bibliothèque nationale de France, Français 19989. Nous n'avons pu travailler que sur les bibliothèques du territoire français, augmentée ponctuellement par la mention de témoins dans certaines bibliothèques étrangères, en particulier au cours de nos recherches, mais sans que ces ajouts ne viennent modifier notre décompte jusqu'à présent. Toutefois, ce travail reste à faire pour les bibliothèques étrangères.

3. Voir notamment les travaux suivants: L. Demaitre, Bernard de Gordon: doctor and Practitioner ; D. Jacquart, La Médecine dans le cadre parisien; G. Dumas, Santé et société à Montpellier à la fin du Moyen Âge.

4. Voir à ce sujet: C. Darricau-Lugat, «Regards sur la profession médicale en France médiévale $\left(\mathrm{xII}^{\mathrm{e}}-\mathrm{XV}^{\mathrm{e}}\right)$ ».

5. Manuscrit 7-4-27, conservé à la Biblioteca Colombina de Séville. La traduction daterait du premier quart du XIV ${ }^{e}$ siècle et la copie du Xv ${ }^{e}$ siècle.

6. L. Cifuentes, La ciència en català a l'Edat Mitjana i el Renaixement, p. 116-120.

7. Codex Vindobonensis Palatinus 2864, conservé à la Österreichische Nationalbibliothek de Vienne, datant du XIV ${ }^{\mathrm{e}}$ siècle.

8. G. Keil, « Jodocus von Prag ».

9. Manuscrit Ashmole 1505, conservé à la Bodleian Library d'Oxford. Le manuscrit daterait du Xvi ${ }^{\mathrm{e}}$ siècle.

10. E. Connely, " "My Written Books of Surgery in the Englishe Tonge": The London Company of Barber-Surgeons and the Lylye of Medicynes ", p. 369-391.

11. Exemplaire conservé à la Bibliothèque nationale de France à Paris, cote: Tolbiac RES TD 2937.

12. Nous avons pu consulter quatre recueils de fragments avec extrait du Lilium medicinae: 1498, Strasbourg, Martin Schott, Artis memorative Matheoli Perusini medicine doctoris praestantissimi... conservé à la Bibliothèque Mazarine à Paris; 1576, Venise, Gaspard Bindoni et Gratiosum Perchacinum, De febribus opus sane aurem... conservé à la Bibliothèque Mazarine à Paris ; 1594, Venise, Medici antiqui Graeci, Latini, atque Arabes qui de febribus scripserunt, par Aecio de Amida, Averroes, Avicena, Bernard de Gordon, ... conservé à la Bibliothèque interuniversitaire de santé de Paris ; 1621, Iéna, Joan-Stephani Strobelbergeri Phil. \& Med. D. Galliae Politicae Medicae Descriptio : De qualitatibus Regni Gallici, ... également conservé à la Bibliothèque interuniversitaire de santé de Paris.

13. Nous nous concentrons ici sur les manifestations de la porosité entre savoir médical et savoir chirurgical présentes dans notre corpus, pour les besoins de concision de l'article. Cette question est en effet plus complexe, notamment si l'on compare les pratiques en Italie et en France.

14. Manuscrit français 1288 conservé à la Bibliothèque nationale de France, f. 232ra.

15. La fleur de cirurgie, traduction du Lilium medicinae de Bernard de Gordon imprimé par Jean Petit en 1509 à Paris. Exemplaire de la Bibliothèque Universitaire de Médecine de Montpellier, cote : J 295, p. 132.

16. Practica seu lilium medicinae, Bernardum Gordonio, Naples, Franciscum de Tuppo, 1480. Exemplaire de la Bibliothèque nationale de France, cote : NUMM-58673, p. 152. 
17. La fleur de cirurgie, traduction du Lilium medicinae de Bernard de Gordon imprimé par Jean Petit en 1509 à Paris. Exemplaire de la Bibliothèque Universitaire de Médecine de Montpellier, cote : J 295, p. 234.

18. Idem, p. 3.

19. Practica seu lilium medicinae, Bernardum Gordonio, Naples, Franciscum de Tuppo, 1480. Exemplaire de la Bibliothèque nationale de France, cote : NUMM-58673, p. 1.

20. D. Coq, « Les incunables : textes anciens, textes nouveaux », p. 189.

21. La fleur de cirurgie, traduction du Lilium medicinae de Bernard de Gordon imprimé par Jean Petit en 1509 à Paris. Exemplaire de la Bibliothèque Universitaire de Médecine de Montpellier, cote : J 295, p. 1.

22. Voir: D. Jacquart, La médecine dans le cadre parisien et E. Berriot-Salvadore, «La littérature médicale en français de 1500 à 1600 ».

\section{RÉSUMÉS}

Fleur de lis en medecine est le titre donné à la traduction du Lilium medicinae de Bernard de Gordon, imprimée en 1495 à Lyon, mais il n'est pas le seul. Alors que le passage du manuscrit à l'imprimé modifie les modalités de transmission de cette œuvre à succès de la medecine médiévale, un changement d'appellation s'opère : la Fleur de lis en medecine se dit Fleur de cirurgie. L'étude des modalités de diffusion et des réseaux de circulation de cette œuvre nous permettra de poser des repères essentiels à la compréhension de sa transmission depuis le XIV siècle. Puis, nous tenterons de saisir les raisons de ce changement, qui relève d'une décision de l'éditeur de cette version française en 1504 , pour répondre aux contraintes de lecteurs aux profils variés.

\section{AUTEUR}

\section{ADELINE SANCHEZ}

Doctorante, Université Paris IV - Paris-Sorbonne, rattachée à l'EA 4509 Sens Texte Informatique Histoire 


\title{
La dynastie des Saugrain : huit générations au service du livre et d'un art
}

\author{
Arnaud Berthonnet
}

\section{Jean Saugrain' (v. 1518-1586), le libraire réformé}

1 Jehan (Jean) Saugrain (1) est né vers 1518 en Normandie dans le pays d'Ouche, à Ferrières-Haut-Clocher, près d'Évreux ${ }^{2}$. Très jeune, il quitte son village pour parcourir l'Europe. Nous sommes à la Renaissance et le jeune homme visite l'Italie et l'Espagne avant de s'installer en Allemagne où il acquiert la connaissance de l'écrit et de son impression. Il se perfectionne à tous les aspects du commerce du livre et profite de ses presque vingt années de voyages et d'apprentissage pour se constituer un réseau professionnel.

2 Durant son séjour en Allemagne, Jean baigne dans l'humanisme et voit progresser à grand pas la Réforme. Acteur de ces grands changements sociaux et religieux, il devient l'un des plus fervents adeptes de la doctrine de Luther. Déterminé à promouvoir les thèses du pasteur allemand, il décide de retourner en France et de s'établir comme libraire-imprimeur à Lyon en 1550. En France, les querelles religieuses font rage depuis plusieurs années ${ }^{3}$.

3 Jean se fait vite reconnaitre comme un des libraires les plus importants de la ville. En 1558, il se marie à Claudine Vallet ([?]-1573). Deux enfants naissent de leur union : Jean (Jehan), sans descendance, et, en 1567, Abraham (2) qui poursuivra l'œuvre du père et implantera les Saugrain à Paris. Il est le fondateur d'une dynastie de huit générations de libraires-imprimeurs, dont l'histoire a été oubliée par les biographes depuis la fin du $\mathrm{XIX}^{\mathrm{e}}$ siècle ${ }^{4}$. Le $\mathrm{XVI}^{\mathrm{e}}$ siècle est l'un des siècles les plus brillants que Lyon ait connu dans son histoire. Avec ses quatre grandes foires annuelles, la capitale des Gaules, trait d'union entre l'Italie et le nord de l'Europe, rayonne en Europe. La ville attire écrivains, 
imprimeurs et artistes de toute l'Europe. Les querelles religieuses n'y sont pas moins extrêmes qu'à Paris mais une tradition de tolérance prédomine.

Après Paris, Lyon est la seconde ville française pour les métiers de l'imprimerie et du commerce de livres. Les imprimeurs-libraires de renom y sont nombreux : Cardon, de Septgranges, Dumergue, Grandjean, Gryphe, Pillehotte, Rigaud, etc. Parmi eux, certains donneront naissance à des dynasties très productives qui travaillent en réseau avec Paris et l'Europe entière. Ils se retrouvent à la grande foire aux livres de Francfort.

5 Qu'est-ce qu'un imprimeur-libraire à partir du xvI siècle ? Avant Gutenberg, c'était un copiste de manuscrits, et le libraire un marchand chargé de vendre les copies de manuscrits originaux, sous la surveillance de l'université devant laquelle il a prêté serment. Après la naissance de l'imprimerie, le libraire-commissionnaire ou libraire d'assortiment est chargé de placer les livres chez les revendeurs; le libraire-éditeur met en vente les livres publiés par ses soins ; le libraire-imprimeur est celui qui cumule les fonctions d'imprimeur et de libraire ; le libraire-juré est celui qui prête un serment rédigé par l'université de Paris qui stipule l'obligation d'observer les règlements.

En 1555, Jean Saugrain s'associe avec son futur oncle par alliance Benoît Rigaud (v. 1525-1597), le premier d'une lignée d'imprimeurs lyonnais ${ }^{5}$. Benoît Rigaud s'est marié avec deux filles d'imprimeurs: Pernette de Septgranges, qui décède sans enfant, puis Claudine Dumergue ([?]-1623), la fille de l'imprimeur Antoine Dumergue ${ }^{6}$. Ce dernier est aussi un parent de Claudine Vallet ${ }^{7}$, la femme de Jean Saugrain.

7 Les deux associés, marchands-libraires, impriment livres et libelles, comme Flores operum de Bernard de Clairvaux (1556). De 1555 à 1558, les auteurs édités sont Clément Marot, François Habert, Guillaume de la Perrière, Léger Bontemps, Guillaume de la Taysonnière, Artus Désiré, Adrien du Hacquet, Gilles de Noyers... ${ }^{8}$. Leur catalogue est presque uniquement constitué de textes parus chez d'autres confrères. Les éditeurs lyonnais publient des textes qui ont eu un certain succès à Paris ou sur d'autres places comme Rouen'.

8 En 1558, Benoît Rigaud, fidèle catholique, se sépare de son neveu par alliance. Les raisons de cette séparation ne sont pas connues. La religion n'y est pas étrangère ${ }^{10}$. La question commerciale participe aussi au divorce. Les deux hommes resteront en bons termes. Jean «le réformé » se spécialise dans la publication d'ouvrages sur la doctrine protestante $^{11}$. La dot de sa femme a permis à Jean de s'installer à son compte. Initialement, le mariage de Jean et Claudine Vallet avait eu pour but de sceller plus fort l'association entre les deux libraires.

9 Jean Saugrain poursuit l'édition de pamphlets et libelles sur la foi catholique. En 1559, il imprime un des "best-sellers» de l'époque, La République d'Utopie du chancelier d'Angleterre Thomas More (1478-1535). L'ouvrage vient d'être traduit du latin en français par Jean Le Blond, précédé d'un préliminaire du poète humaniste Barthélemy Aneau (v. 1505-1561) qui sera tué pour ses idées ${ }^{12}$. Le lynchage de cet «intellectuel » ne modère pas Jean qui poursuit avec ardeur son activité : sa librairie devient le foyer d'où se répandent des libelles anonymes défendant la religion réformée (fig. 1). 
Fig. 1. - La marque de Jean Saugrain $\mathrm{f}^{\mathrm{er}}$.

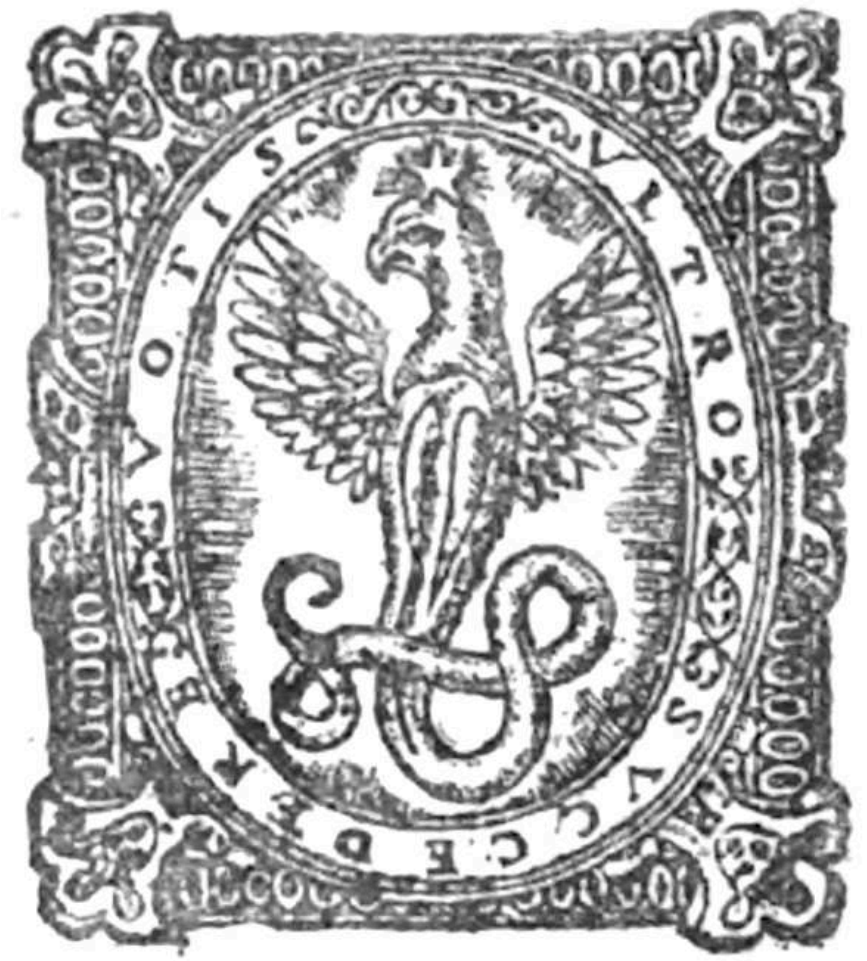

() InSiglo

10 En 1562, Jean publie l'Histoire des vies et faits de trois excellents personnages : Martin Luther, Jean Ecolampade et Huldrik Zuingle. Il est un fervent soutien de l'humaniste et bibliographe lyonnais Antoine du Verdier (1544-1600) qu'il publie. Si Jean fait travailler de nombreux imprimeurs, il s'avère difficile d'attribuer la paternité des livres, libelles et pamphlets : les imprimeurs, en raison du contexte religieux et politique, prennent soin de n'employer aucun signe typographique qui précise leur origine. Certaines années, Jean publiera jusqu’à vingt ouvrages.

11 Au début des années 1560, la Réforme se propage à Lyon. Les éditions défendant les thèses de Luther et de Calvin donnent le sentiment que la ville s'affiche comme la « nouvelle Genève ». À partir de 1563, la production de Jean devient plus polémique : ses publications condamnent directement la papauté. Il édite notamment les textes du réformateur vaudois Pierre Viret, du réformateur genevois Heinrich Bullinger ou encore du théologien Jean de l'Espine (Delespine) ${ }^{13}$. Il délaisse même l'édition d'ouvrages savants. Plus de la moitié de ses éditions concerne des livres de controverses religieuses. Il aurait imprimé entre 1562 et 1566 une quarantaine de titres défendant la nouvelle foi, en majorité des livres de petit format en français, ce qui témoigne de sa volonté de toucher un large lectorat éclairé.

12 Le réformé fait du prosélytisme par le livre, mais son engagement est de plus en plus risqué. Lorsque les catholiques contre-attaquent, les imprimeurs et libraires sont fortement inquiétés : perquisitions, emprisonnements, et les livres hérétiques sont brûlés en place publique. Si Lyon redevient catholique après 1565, Jean ne s'en laisse pas conter et poursuit sa croisade religieuse, avec toutefois moins de véhémence dans sa production. 
13 Nonobstant cette forte activité subversive et sa fervente foi protestante, Charles IX (1550-1560-1574) le désigne premier imprimeur de la ville de Lyon, par lettres patentes du 10 juin 1568 ! Il succède à... Benoît Rigaud entré en disgrâce royale. Jean, le réformé, lui ne semble guère inquiété. Il traverse les affres des guerres de Religion protégé de Jeanne III d'Albret (1528-1572), reine de Navarre et mère du futur Henri IV ${ }^{14}$.

14 Cette femme, figure centrale du protestantisme comme chef du parti des réformés, se déclare haut et fort adepte de Luther et de Calvin. Par l'ordonnance du 19 juin 1561, elle autorise le calvinisme dans son royaume de Navarre. Jeanne III d'Albret se serait convertie au protestantisme en août 1560, sous l'influence de Théodore de Bèze dont les œuvres ont été publiées, on l'a vu, par Jean Saugrain. Après la mort de sa protectrice, le 9 juin 1572, Jean publie un livret en son hommage, en date du 28 juin 1572, soit deux mois avant le massacre de la Saint-Barthélemy, le 24 août 1572. Le libraire lyonnais, certes devenu plus prudent, décide de poursuivre sans répit ses éditions pour défendre sa foi.

15 En 1573, il imprime (avec permission !) Discours et recueil du siège de La Rochelle en l'année 1573 (16 feuillets) (fig. 2). Lyon reste une cité tolérante ; cependant, fin 1572-début 1573, Jean part s'établir à Pau où le futur roi de France Henri IV, tout jeune roi de Navarre, le nomme imprimeur ordinaire de son royaume et libraire de l'académie de Pau. Il découvre la cour de Pau et de Nérac où les arts et la culture sont au firmament. La bibliothèque royale de Navarre possède une quarantaine de précieux manuscrits enluminés; certains viennent de la fameuse bibliothèque de Gaston Phœbus (1331-1391), d'autres ont été acquis et ont une valeur inestimable, comme les Chroniques de Burgos (début Xve siècle). 
Fig. 2. - La première de couverture du Discours et recueil du siège de La Rochelle en l'année 1573, Lyon, 1573, 16 feuillets.

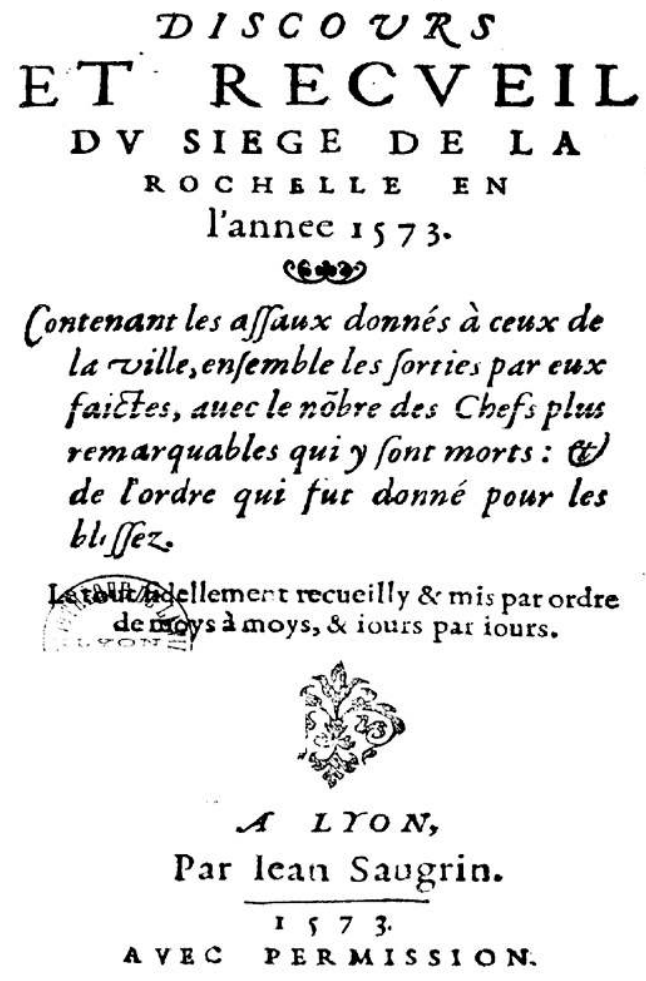

Ce texte sur le siège de La Rochelle est imprimé avec permission royale par Jean Saugrain. (C) InSiglo

Nous disposons de peu d'informations sur la production de Jean, de 1573 à sa mort en 1586. Il publie l'ouvrage Les fictions poétiques (1577) d'Innocent Esgaré et travaille pour les princesses de Navarre ${ }^{15}$. Le 16 février 1580, il s'associe avec Durand-Badel, originaire de Cahors, qui a ouvert une librairie à Pau. Les livres imprimés à Lyon n'entrent pas dans le fonds de la nouvelle société. Le contrat précise qu'à son décès son fils, Abraham, lui succédera dans cette association ${ }^{16}$. Le libraire reçoit des bienfaits du roi Henri de Navarre, qui à son tour choisit Jean par lettres patentes pour être l'imprimeur ordinaire et le libraire de l'académie de $\mathrm{Pau}^{17}$.

Le roi lui fait don d'une maison dépendante de son domaine, située "au-devant du Temple ». Il le fait commensal de sa Maison et lui accorde plusieurs grâces par lettres du 15 mai 1581. Jean décède en 1586 (après le 22 juin) à Pau. Cet humaniste protestant est le père fondateur d'une lignée de libraires et d'imprimeurs sur trois siècles et huit générations.

\section{Sept générations de libraires-imprimeurs parisiens}

Jean Saugrain (v.1566-1622), l'aîné des fils de Jean, s'est établi libraire à Poitiers ${ }^{18}$. Né à Lyon en 1567, Abraham Saugrain (2), le second fils de Jean, a fait son apprentissage à Lyon chez l'imprimeur-libraire Jean II de Tournes (1539-1615) ${ }^{19}$ puis chez le libraire d'origine florentine Barthélemy Honorat (155 ?-1589). À Pau, il a travaillé avec son père, son frère aîné et le libraire Durand-Badel. 
19 Après un passage à Poitiers chez son frère, puis une étape à Orléans où il rencontre sa femme, Espérance Cellier - fille de marchand -, Abraham s'établit à Paris en 1587. Il perfectionne ses connaissances chez Jean Cavellat ([?]-1590) ${ }^{20}$, libraire à «La Salamandre ", rue Saint-Jean-de-Latran. Ce dernier - à la suite de son père Guillaume entretient depuis longtemps des relations avec les libraires lyonnais. Ils sont les représentants de Benoît Rigaud et de Barthélemy Honorat à Paris. C'est au sein de ce cercle fermé et élitiste de maîtres libraires, imprimeurs et papetiers qu'Abraham parfait sa formation initiale. Puis il s'associe au libraire Guillaume Des Rues (librairejuré en 1596), installé rue Neuve-Notre-Dame puis rue Saint-Jean-de-Beauvais.

Vers 1597, Abraham ouvre à 30 ans sa première librairie. Il travaille rue Saint-Jacques «au-dessus de Saint-Benoît » puis déménage à l'Isle du Palais, «du côté du Pont de Bois ». De son mariage, dix enfants naîtront dont Charles I Saugrain (3), le 6 août 1611. Le neuvième de cette postérité perpétuera la tradition du métier de libraire ${ }^{21}$.

La reine de Navarre Catherine l'engage à son service. Par provisions datées du 16 juin 1597, la Royauté lui accorde les titres de « libraire et relieur ordinaire de la Reine ». Le 30 juin 1601, il est reçu libraire-juré à Paris. Il publie des traités historiques et des déclarations du roi mais aucun texte religieux. Il fait imprimer en 1601 la deuxième édition de l'ouvrage de référence d'olivier de Serres (1539-1619) le Théâtre d'agriculture et mesnage des champs. Sept ans plus tard, le libraire édite une mise à jour "pirate » de l'ouvrage, qui ne sera pas du goût de l'auteur ${ }^{22}$.

22 Même si Abraham édite des auteurs protestants comme de Serres, il ne semble pas avoir fait le choix de la foi réformée, ni lui ni aucun de ses descendants. Proche d'Henri IV puis de Louis XIII, Abraham publie à leur gloire des livrets comme Les présages du bonheur du Roi et de la France en 1617. Il décède le 22 avril 1622. Son épouse Claudine poursuit l'activité jusqu'à son décès, le 8 décembre 1640 à Poissy, où les Saugrain ont acquis une demeure.

23 Son fils Charles I Saugrain (1611-1679) représente la troisième génération (3), la moins connue de la dynastie. Il s'unit le 18 juin 1634 à Claude Hourlier (1614-1709). Ils auront treize enfants. Reçu libraire le 3 août 1645, il décède le 13 novembre 1679 à Lyon. Deux de ses fils poursuivent l'activité familiale de libraire à Paris : Charles II et Guillaume I (4).

24 L'aîné, Charles II Saugrain, né le 25 février 1640 à Paris, est reçu maître libraire le 28 juin 1663 . Il se marie le 4 février 1664 à Jeanne Petit qui lui donnera dix enfants, tous décédés très jeunes! Charles meurt le 17 février 1728 à Poissy où il est enterré dans la collégiale Notre-Dame ${ }^{23}$. Il a publié des livres d'administration générale, de liturgie et des guides sur les meilleures adresses de Paris.

25 Mais c'est par Guillaume I, le frère cadet, que la dynastie Saugrain se poursuit à la quatrième génération. Né le 23 mars 1651, il se marie en premières noces à Catherine Vaillant ([?]-1691) avec qui il aura huit enfants dont quatre fils libraires: Charles (1677-1739), Claude-Marin I (1679-1750) (5), Joseph (1685-1724) et Guillaume II (1686-1733). Prenant la suite de son père, l'office de Guillaume, toujours installé quai de Gesvres, près du Pont au Change, à l'enseigne de la "Croix Blanche ", publie des édits royaux et des traités administratifs.

26 Après la mort de sa femme, le 20 juin 1691, Guillaume épouse en secondes noces, le 29 novembre 1692, Françoise Charpentier (v.1653-1734). Trois enfants naissent de leur union dont deux filles qui épousent des libraires: Françoise (1692-1749) le célèbre 
Pierre Prault (1685-1768) et Marie-Henriette (v. 1697-1761) Auguste-Henri Holtz ([?]-1720). Leur troisième enfant, Thomas-Antoine (1695-1724), est également répertorié parmi les libraires en 1710 . Reçu libraire le 10 septembre 1683 et imprimeur en 1686, Guillaume I décède le 30 septembre 1708. Sa veuve lui succède jusqu'à son décès le 21 juin 1734. En 1711, elle s'est associée à son gendre Pierre Prault $(1685-1768)^{24}$.

27 La cinquième génération est certainement celle qui hisse les Saugrain au sommet de leur gloire. Cinq fils perpétuent la profession de libraire-imprimeur et deux filles épousent des libraires de premier plan. Comme les Didot ou les De Bure, les Saugrain forment autour d'eux un réseau de professionnels du livre et d'artistes, qui renforce la puissance économique et artistique de la famille. Charles (1677-1729) est reçu libraire en $1696^{25}$, Claude-Marin I (5) en 1700, Joseph en 1709 et Guillaume II en 1710.

Claude-Marin I (5) est né le 2 juin 1679 à Paris. Il s'unit à Marie-Thérèse Émery (v. 1681-1761), fille et petite-fille de libraire. Elle lui donne quatre enfants dont GuillaumeClaude (6). Reçu maître en 1700 et libraire en 1703, Claude-Marin I est nommé adjoint de la Communauté en 1726. Claude-Marin I, Pierre Prault et sa mère (veuve) publient le fameux Dictionnaire universel de la France ancienne et moderne et de la Nouvelle France (1726).

29 Claude-Marin I s'intéresse à la publication de guides sur Paris qui constitue un marché singulier. Depuis le début du XVIII ${ }^{\mathrm{e}}$ siècle, les guides publiés dans la lignée de ceux de Dechuyes (1654) et de Nicolas de Blégny (1692) font recette chez les librairesimprimeurs. En 1708, Claude-Marin I édite les Adresses de la ville et faux-bourgs de Paris divisez en vingt quartiers ${ }^{26}$. En 1716, il publie ce qui pourrait être l'ancêtre de nos guides touristiques: Les Curiositez de Paris... ${ }^{27}$ (fig. 3). Il a racheté les droits à son beau-père Pierre Émery (v.1652-1730). Le texte de la première édition lui est même attribué. 
Fig. 3. - Les Curiositez de Paris...

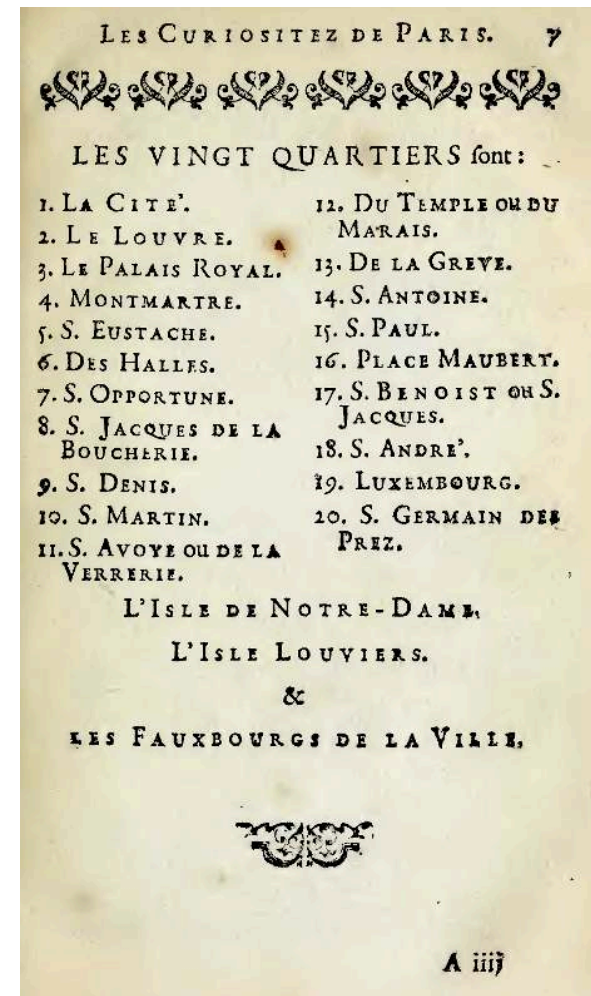

Page de présentation des 24 quartiers présentés dans ce guide.

(c) InSiglo

Claude-Marin I est élu, le 31 janvier 1730, consul des libraires, puis juge-consul et syndic des libraires et imprimeurs de Paris, le 29 janvier 1737. Il est aussi libraire-juré de l'université. Comme syndic des libraires-imprimeurs, il publie en 1744 le code de la librairie et imprimerie de Paris, dit "Code Saugrain", imprimé aux frais de la communauté (fig. 4). Il est l'auteur de cette compilation. Claude-Marin I décède le $1^{\mathrm{er}}$ février 1750, à Paris, rue de Savoie. 
Fig. 4. - En 1744, Claude-Marin I Saugrain (1714-1751) publie le Code de la librairie et imprimerie de Paris.

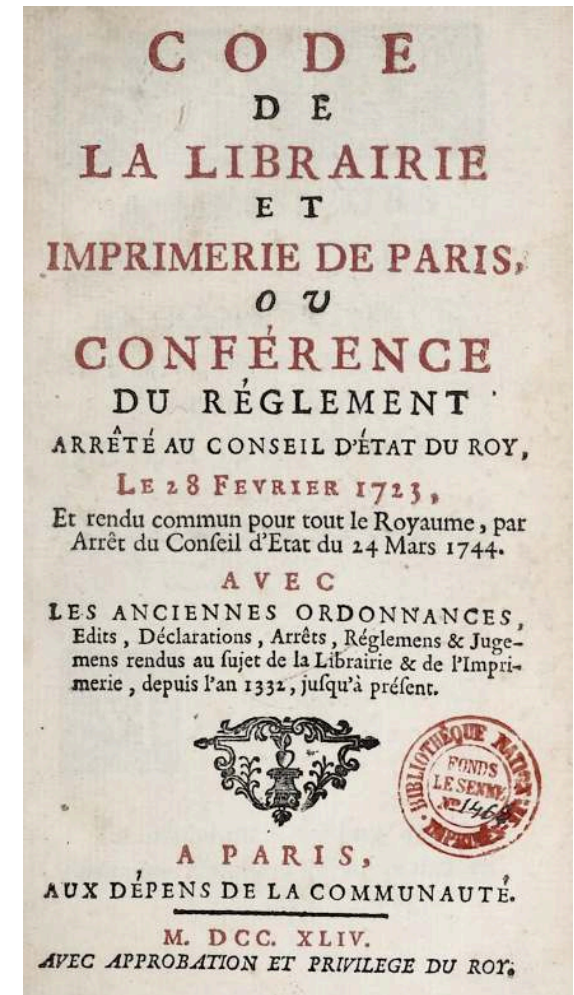

(c) InSiglo

31 Le troisième frère libraire est Joseph I, né le 25 mai 1685 à Paris. Reçu libraire le 14 mai 1709, il se marie, le 18 janvier 1710, avec Jeanne Thoury (1685-1728). De cette union naîtront douze enfants. Libraire quai de Gesvre, il décède le 25 mai 1724 à Paris. C'est leur fils Joseph II (1714-1751), nommé libraire en 1739, qui est l'auteur de la fameuse généalogie Saugrain de 1736 (fig. 5). Ce document de première main pour l'historien du livre est conservé à la Bnf. Il se marie en 1740 à Geneviève, la fille du libraire Claude Prudhomme. 
Fig. 5. - Joseph II Saugrain.

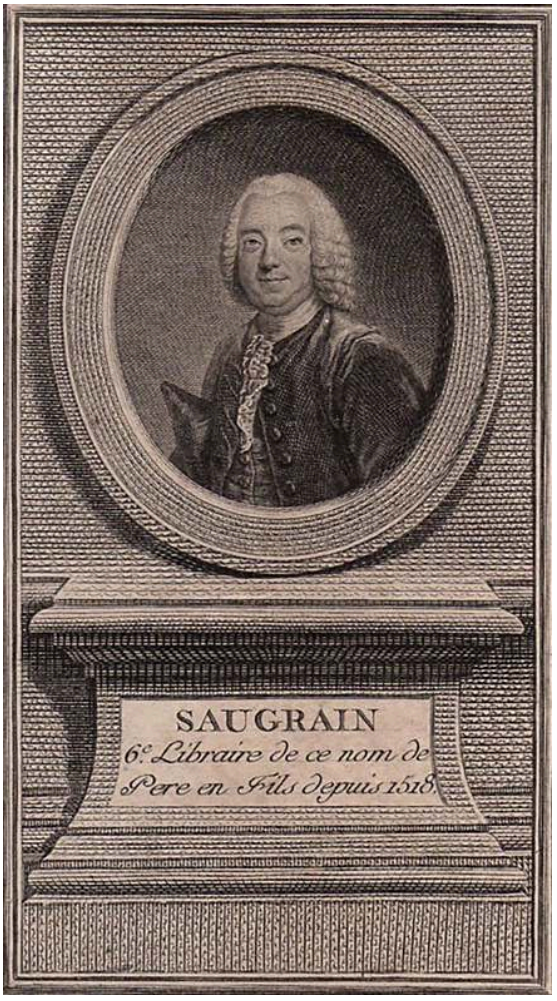

Ce libraire se marie à Geneviève Prudhomme, liée aux Didot par la famille de Bure. On mesure toute l'importance des mariages et des réseaux familiaux dans ces métiers du livre à Paris.

(C) InSiglo

Représentant de la sixième génération, Guillaume-Claude Saugrain (6) est né le 7 juillet 1706 à Paris. Le premier fils de Claude-Marin I est reçu libraire le 26 juin 1724. Il se marie en 1728 avec Anne-Geneviève Prudhomme ([?]-1747), la belle-sœur de son cousin Joseph II. Le père de la mariée est libraire. Guillaume-Claude devient le 5 octobre 1743 adjoint au syndic (son père est alors syndic) et, le 26 avril 1759, syndic des librairesimprimeurs. Sa librairie est installée rue de Savoie. Anne-Geneviève lui donne quatre enfants : Claude-Louise qui décède à la naissance (1729); Antoine-Claude (7), ClaudeMarin et Thérèse-Louise.

- Le premier fils, Antoine-Claude (1730-1796), $7^{\mathrm{e}}$ génération, épouse Marie Brunet (1745-1763), la fille d'une vieille lignée de libraires-imprimeurs parisiens qui exercent leur profession depuis le début du XVII ${ }^{e}$ siècle. Cinq enfants naissent de ce mariage (voir leur biographie ciaprès).

- Le second fils, Claude-Marin II (1735-1805), né le 15 février à Paris, est appelé aussi «le jeune ». Reçu maître le 18 mai 1759, alors que son père est syndic en charge, il est nommé libraire ordinaire de Monsieur le comte d'Artois (futur Charles X) en 1766. Reçu libraire le 9 juin 1781, il cesse son activité dans cette profession vers 1791. Nommé conservateur de la bibliothèque de l'Arsenal, il va tout entreprendre pendant la Révolution pour garder intacte la remarquable collection de livres du comte d'Artois.

- Le dernier enfant de Guillaume-Claude, Thérèse-Louise (1737-1812), née le 18 août, épouse le 21 février 1757 Guillaume-François de Bure (1732-1782), représentant de la quatrième génération de libraires-imprimeurs (sans postérité). 


\section{Les enfants d'Antoine-Claude Saugrain, $7^{\mathrm{e}}$ génération, et de Marie Brunet : des destins exceptionnels}

Antoine-Claude est né le 20 septembre 1730 à Paris. Libraire et imprimeur, il se marie le 20 janvier 1753 avec Marie Brunet. Le couple aura cinq enfants : Marie-Thérèse, MarieLouise (Élise), Claude-Marin III, Thérèse-Angélique et Antoine-François. Les quatre premiers enfants ont connu un chemin de vie des plus singuliers, et le dernier, atypique.

- Marie-Thérèse (1753-1791) épouse le 31 décembre 1779 le libraire et imprimeur Pierre Plassan (v.1751-1810). Avant de devenir le gendre d'Antoine-Claude Saugrain, ce fils de tonnelier bordelais a été son apprenti. Reçu libraire le 14 juin 1785 puis imprimeur, Pierre Plassan commence à exercer vers 1779. Il tient jusqu'en 1791 la «librairie de l'hôtel de Thou » du célèbre écrivain, libraire et éditeur Charles-Joseph Panckoucke (1736-1798). En 1791, il s'établit à son compte imprimeur-libraire.

- La vie de Marie-Louise (Élise) (1755-1832) est l'une des plus originales de la fratrie (fig. 6). Née à Paris le 25 janvier 1755, elle est l'élève du dessinateur, peintre et graveur Moreau le jeune (1741-1814), un cousin par alliance des Saugrain. En effet, Moreau le jeune s'est marié en 1765 à la petite-fille de Pierre Prault, gendre de Guillaume I Saugrain ${ }^{28}$. Marie-Louise épouse, le 14 juillet 1787, le docteur Joseph-Ignace Guillotin (1738-1814), un homme dont la guillotine s'est approprié le nom. La jeune femme se fait une certaine notoriété comme graveur, sous le nom d'artiste d'Élise Saugrain. Elle décède le 17 juin 1832 à Paris, sans postérité. 
Fig. 6. - La peintre Marie-Louise (Élise) Saugrain (1755-1832).

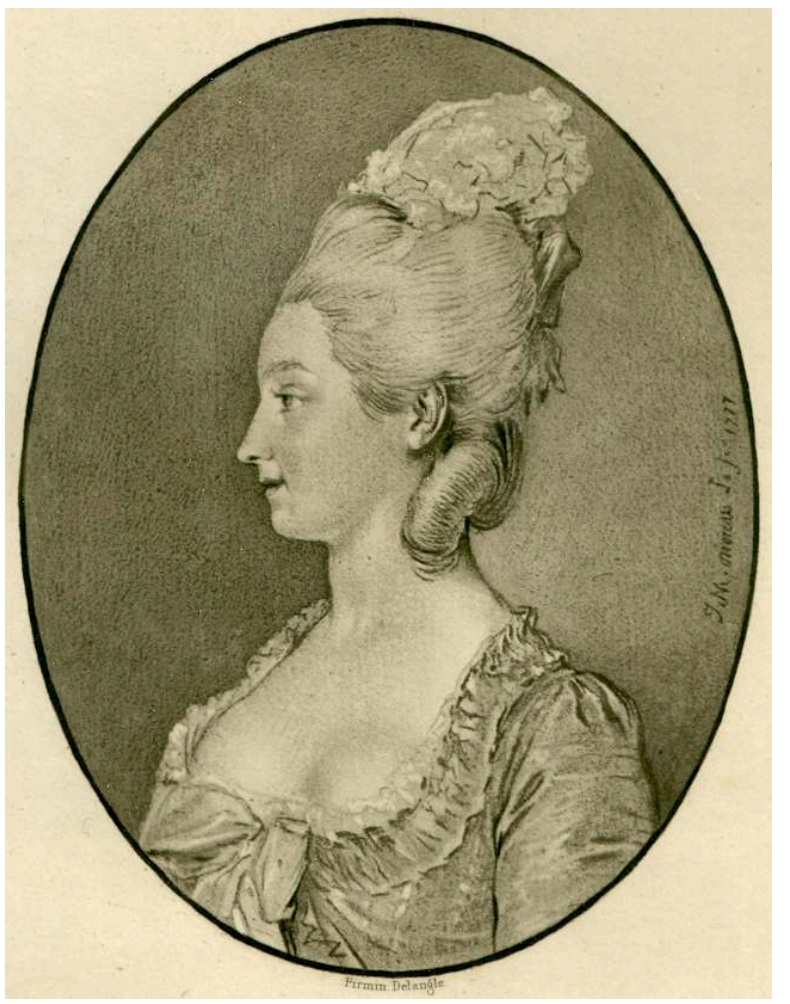

(C) InSiglo

- Claude-Marin III (1756-1821), né le $1^{\mathrm{er}}$ octobre 1756 à Paris, se marie en 1794 à LouiseJosèphe Chalgrin (1777-1826), la fille du célèbre architecte du roi Jean-François Chalgrin (1739-1811), qui est aussi la filleule du roi Louis XVIII. C'est un très beau mariage pour les Saugrain : d'autant plus que la mère de la mariée n'est autre que Marguerite-Émilie Vernet (1760-1794), la fille du peintre Claude-Joseph Vernet (1714-1789 ${ }^{29}$. Le couple aura trois enfants : Émile (1794-1833), maître verrier, Eugénie (1796-1851) et Élise (1798-1814). Ils divorceront le 24 février 1802.

Claude-Marin III est un libraire-éditeur mais surtout un graveur de vignettes. Élève de Charles-Nicolas II Cochin (1715-1790), il entre à l'Académie royale de gravure en 1775. Il publie notamment une version du Nouveau Testament illustré (1793-1798). Son "œuvre », réalisée en collaboration avec Firmin Didot, Pierre Didot et Pierre Plassan entre 1799 et 1809 , est une édition en soixante-douze volumes in-18 de l'Histoire naturelle de Buffon et Lacépède. Au début du XIX ${ }^{\mathrm{e}}$ siècle, la grande histoire des Saugrain par les fils exerçant les métiers de libraires et d'imprimeurs prend fin avec Claude-Marin III.

-Thérèse-Angélique Saugrain (1759-1817) - $8^{\mathrm{e}}$ génération - épouse en 1799 le typographe Henri Didot (1765-1852) - $6^{\text {e }}$ génération de la dynastie Didot $^{30}$.

- Enfin, Antoine-François Saugrain (1763-1820), dit de Vigny, est né le 17 février 1763 à Versailles. Sa vie est la plus épique de la dynastie : un vrai roman d'aventures entre France et Amérique. Son nom reste mentionné dans l'histoire américaine comme le premier scientifique de la vallée du Mississippi ${ }^{31}$.

Après avoir étudié les sciences naturelles à Paris, Antoine-François est envoyé au Nouveau monde en 1783 par le roi Charles II d'Espagne pour étudier les ressources minérales d'Amérique centrale et du sud. En 1786, le scientifique s'intéresse à l'histoire naturelle de la vallée de l'Ohio. En 1788, invité à venir en Amérique du Nord par 
Benjamin Franklin, il s'établit médecin en Louisiane (fig. 7). Lors d'un séjour à Paris en 1782, Benjamin Franklin s'était lié d'amitié avec plusieurs familles de libraires et d'imprimeurs parisiens. Ancien imprimeur à Philadelphie, ce membre assidu de l'Académie des sciences est un passionné des techniques d'imprimerie et des techniques nouvelles. L'illustre Américain qui aurait été fortement impressionné par les prédispositions du jeune Antoine-François lui écrit une lettre de recommandation pour qu'il puisse se déplacer sur le territoire des États-Unis.

Fig. 7. - Le jeune docteur Antoine-François Saugrain (1763-1820).

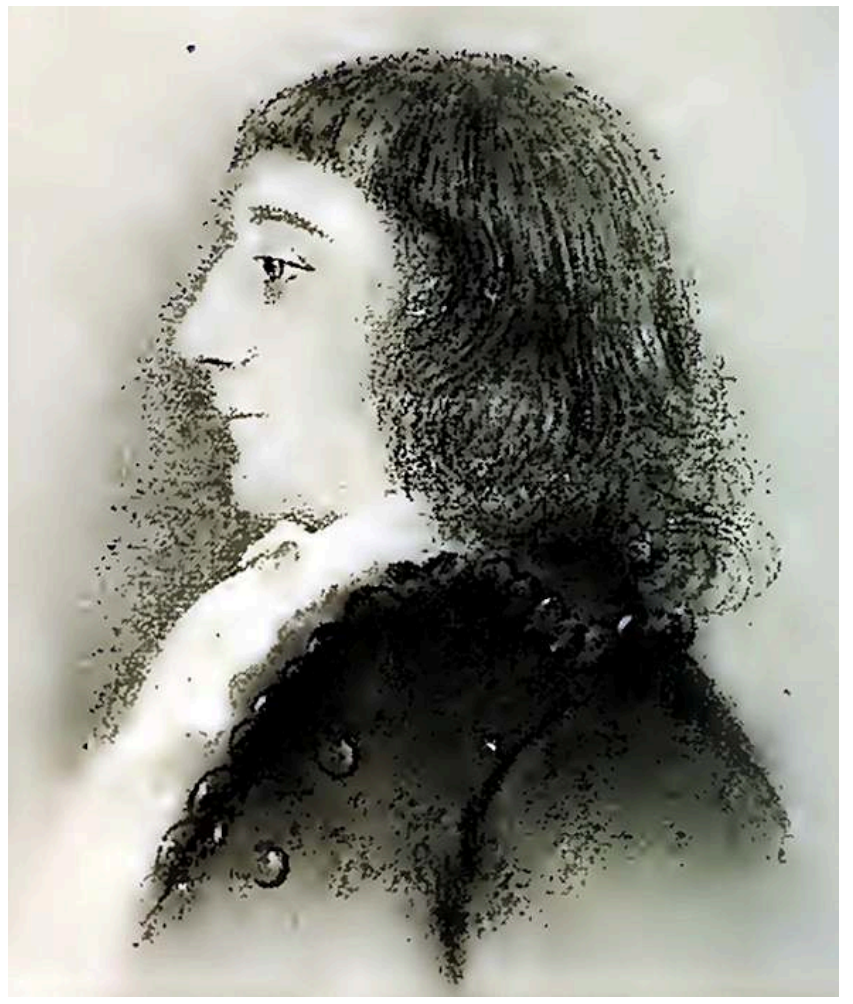

(c) InSiglo

Lors de son voyage en Amérique en 1788, Antoine-François est d'abord capturé par les Indiens, réussit à leur échapper et part à Philadelphie. Après un bref retour à Paris, il repart en Amérique pour participer à l'établissement d'une colonie de peuplement dans l'Ohio. Il vit parmi les colons à Gallipolis où des aristocrates français fuyant la Révolution se sont associés en 1790 pour fonder la compagnie du Scioto ou « compagnie des Vingt-Quatre ». Le 20 mars 1793, le jeune colon se marie à Geneviève Rosalie Michau (1776-1860).

De cette union naissent sept enfants entre 1797 et 1813. Si les deux derniers meurent avant leur premier anniversaire, les cinq ânés grandiront et s'établiront aux États-Unis où certains vivront très âgés: Rosalie Geneviève (1797-1887) épouse Henry Von Phul (1784-1874) ; Élisabeth Maria (1799-1893) se marie à James Kennerly (1792-1840); Alphonse Alfred (1803-1849) à Mary Joséphine Dulcena Linton ; Frédéric (1806-1910) à Marie-Louise Dina Provenchere ; Henriette Thérèse (1808-1837) à Thomas Noël.

La famille Saugrain s'installe à Lexington dans le Kentucky. Le scientifique y étudie le processus d'inoculation destiné à lutter contre des maladies comme la variole. Il multiplie les expériences physiques et chimiques en utilisant notamment des batteries 
électriques. Ses inoculations contre la variole ainsi que ses diverses expériences scientifiques sur les ressources naturelles de la région le rendent célèbre en Amérique.

En 1799, le gouverneur espagnol de la Louisiane le persuade de s'installer à Saint-Louis où il va pratiquer la médecine. Après le transfert du territoire de la Louisiane aux ÉtatsUnis en 1804, il est le seul médecin à exercer à Saint-Louis. En 1806, il est nommé chirurgien à Fort Bellefontaine, au nord de Saint-Louis, sur la rivière Missouri. Le docteur Antoine-François Saugrain décède le 5 mars 1820 dans l'ohio. L'histoire américaine le présente comme le premier scientifique et médecin de la vallée du Mississippi. Ses descendants vivent aujourd'hui en Amérique du Nord.

Comme les dynasties Brunet ou de Bure, les Saugrain cesseront leurs activités au début du XIX ${ }^{e}$ siècle à une période charnière où les techniques d'imprimerie et le commerce de livres se transforment radicalement. Les métiers du livre traversent une vraie révolution technique et commerciale : ils s'industrialisent. En effet, après l'abolition des corporations et la libéralisation du commerce en 1791, la vente de livres passe, au début $\mathrm{du} \mathrm{XIX}_{\mathrm{e}}^{\mathrm{e}}$ siècle, d'une économie de privilège à une économie de marché, ce qui transforme profondément tous les métiers. Et les dés sont de nouveau jetés pour les nouveaux entrants comme l'entreprenant Louis Hachette (1800-1864). À la différence des Didot, famille d'innovateurs et d'industriels du livre, les Saugrain ont privilégié depuis le milieu du XvI ${ }^{\mathrm{e}}$ siècle les métiers de libraire et d'éditeur à ceux d'imprimeur et de fondeur de caractères. Même si l'histoire a occulté cette grande famille, les Saugrain se sont imposés comme une référence dans l'édition en raison de l'importance et la qualité des ouvrages qu'ils ont publiés. C'est la seule famille - avec les Didot $\left(\mathrm{xVII}^{\mathrm{e}} \mathrm{au} \mathrm{XX}^{\mathrm{e}}\right.$ siècle) - à entreprendre sur un temps aussi long: trois siècles et huit générations ( $\mathrm{xvI}^{\mathrm{e}}$ au début XIX ${ }^{\mathrm{e}}$ siècle).

\section{BIBLIOGRAPHIE}

BAUDRIER Henri, Bibliographie lyonnaise. Recherches sur les imprimeurs, libraires, relieurs et fondeurs de lettres de Lyon au XVI ${ }^{e}$ siècle par le Président Baudrier, publiées et continuées par J. Baudrier, Lyon, A. Picard, 1899, volume IV, $423 \mathrm{p}$.

BERTHONNET Arnaud et GÉLIS Bruno, Didot-Saugrain-Gélis. Cinq siècles d'histoire familiale du XVI e siècle au $\mathrm{XXI}$ siècle. Une histoire qui embrasse les métiers du livre, la banque et l'architecture, Rueil-Malmaison, inSiglo, 2018, $240 \mathrm{p}$.

Віот Brigitte, Barthélemy Aneau, régent de la Renaissance lyonnaise, Paris, Champion, 1996, 530 p. BOURALIÈRE de la A., L'Imprimerie et la librairie à Poitiers pendant le XVI ${ }^{e}$ siècle, Paris, Éditions Paul et fils et Guillemin, 1900, 396 p. 
BYARS William Vincent, The first scientist of the Mississippi Valley : a memoir of the life and work of Doctor Antoine François Saugrain, 18 p.

CHARTIER Roger et MARTIN Henri-Jean (dir.), Histoire de l'édition française. Le livre conquérant. Du Moyen Âge au milieu du XVII eiècle, tome I, Paris, Fayard, 1982, 629 p.

CONSTANTIN Léa, Les Enjeux de la controverse religieuse dans l'imprimerie lyonnaise, 1560-1565, diplôme de master, sous la direction de Raphaël Mouren, Université Lumière - Lyon, juin 2011, 170 p.

DANDRIGE M. D., « Antoine-François Saugrain, le premier scientifique de la vallée du Mississippi dans l'histoire de l'Ohio ", The Scholarly Journal of the Ohio Historical Society, volume 15, 1906.

FOURE SELTER Hélène, L'Odyssée américaine d'une famille française : le docteur Antoine Saugrain. Étude suivie de manuscrits inédits et de la correspondance de Sophie Michau Robinson, Institut français de Washington (D.C.) Baltimore, The Johns Hopkins Press, 1936, 123 p.

Généalogie de la famille des Saugrain, libraires depuis 1518 jusqu'à présent (janvier 1736), mise en ordre, imprimée et présentée par Joseph II Saugrain, le $1^{\mathrm{er}}$ janvier 1736, imprimerie Pierre Prault.

LACAZE Louis, Les Imprimeurs et les libraires en Béarn (1552-1883), Chez Léon Ribaut, Pau, 1884, 322 p.

PLANTEY Damien, Les Bibliothèques des princesses de Navarre au XVI ${ }^{e}$ siècle : livres, objets, mobilier, décor, espaces et usages, Paris, Presses de l'ENSSIB, 2016, 247 p.

SAUGRAIN Claude-Marin, Les Adresses de la ville et faux-bourgs de Paris divisez en vingt quartiers, Paris, Chez Saugrain, 1708, $202 \mathrm{p}$.

SIRDEY Jérôme, Réforme, Contre-Réforme. La production comparée de deux libraires lyonnais de la seconde moitié du XVI siècle: Michel Jouve et Jean Saugrain, Mémoire d'étude DCB, Lyon, Enssib, 2010, 170 p.

VIDAL Bernard, « Les démêlés d'Olivier de Serres avec son imprimeur, à propos d'un contrat d'impression du Théâtre d'agriculture et d'une édition pirate ", Histoires et sociétés rurales, 2013/1, volume 39, p. 43-69.

WERDET Edmond, Histoire du livre en France depuis les origines les plus reculées jusqu'en 1789, Paris, Éditions Dentu, tome I, 1861, 372 p.

\section{NOTES}

1. Le patronyme « Saugrain » dériverait du mot « salgranan » " grain de sel ».

2. H. Baudrier, Bibliographie lyonnaise [...].

3. Par exemple, Étienne Dolet (1509-1546) a été brûlé le 3 août 1546 à Paris pour ses prises de position en faveur de la religion réformée. Cet ami de Marot et de Rabelais, imprimeur, écrivain et libre penseur, défendait la nouvelle foi protestante.

4. Depuis le livre de Baudrier (1899), les Saugrain n'ont plus été étudiés par les historiens.

5. Ses descendants occuperont jusqu'au XVIII ${ }^{\mathrm{e}}$ siècle une place majeure dans la librairie lyonnaise. Benoît Rigaud édite des ouvrages historiques et poétiques et des romans de chevalerie (un Lancelot du Lac en 1591). Il promeut le livre à bon marché qui néglige souvent la qualité du papier. Imprimeur pour le Gouvernement de la ville (1561-1568), il édite les publications officielles, édits et ordonnances royaux. 
6. Antoine Dumergue a épousé Madeleine Chastaing, la tante de Pernette de Septgranges. Madeleine Chastaing est la fille du célèbre imprimeur lyonnais Pierre Chastaing (1562-1595), dit « Pierre Dauphin ».

7. La mère de Claudine Vallet, née Dumergue, est la sœur de Claudine Dumergue, fille d'Antoine et de Madeleine Chastaing et deuxième épouse de Benoît Rigaud.

8. L. Amazan, Remettre en lumière le catalogue d'un libraire à ses débuts: Benoît Rigaud, 1555-1570, de l'état au virtuel.

9. Idem, p. 82-86. Sur la période 1555-1558, le mémoire de recherche de Louise Amazan recense 57 œuvres éditées en collaboration entre le neveu et l'oncle par alliance.

10. L. Constantin, Les enjeux de la controverse religieuse dans l'imprimerie lyonnaise, 1560-1565 ; J. Sirdey, Réforme, Contre-Réforme. La production comparée de deux libraires lyonnais de la seconde moitié du XVI siècle: Michel Jouve et Jean Saugrain.

11. J. Sirdey, « Deux éditeurs lyonnais aux avant-postes du combat religieux : Michel Jouve et Jean Saugrain ».

12. Le professeur de rhétorique Barthélemy Aneau, figure de la Renaissance lyonnaise avec Rabelais, Dolet et Marot, est massacré en juin 1561 par des catholiques, sans aucune preuve qu'il n'ait été un réformé. Il se voulait un trait d'union entre catholiques et protestants dans une ville où se rencontrent humanistes, hommes de loi, poètes, artistes, imprimeurs, libraires. B. Biot, Barthélemy Aneau, régent de la Renaissance lyonnaise. Ce livre est tiré d'une thèse soutenue en 1992 à l'université de Lyon II, sous la direction de Gabriel Pérouse.

13. R. Chartier et H.-J. Martin (dir.), Histoire de l'édition française. Le livre conquérant. Du Moyen Âge au milieu du XVII siècle.

14. Nièce du roi de France François $I^{\mathrm{er}}$, élevée sous son autorité à la cour de France, Jeanne d'Albret est la fille d'Henri II d'Albret, roi de Navarre, et de Marguerite d'Angoulême. Elle épouse Antoine de Bourbon (1518-1562), premier prince du sang. Elle est la mère du roi Henri IV (1553-1610) et de Catherine de Bourbon (1559-1604).

15. D. Plantey, Les bibliothèques des princesses de Navarre au $\mathrm{XVI}^{e}$ siècle: livres, objets, mobilier, décor, espaces et usages (publié à partir d'une thèse soutenue en 2011).

16. L. Lacaze, Les imprimeurs et les libraires en Béarn (1552-1883).

17. Généalogie de la famille des Saugrain, libraires depuis 1518 jusqu'à présent (janvier 1736), mise en ordre, imprimée et présentée par Joseph II Saugrain, le $1^{\text {er }}$ janvier 1736 , imprimerie Pierre Prault.

18. A. de La Bouralière, L'imprimerie et la librairie à Poitiers pendant le XVI siècle.

19. Fils de Jean I de Tournes (1504-1564), le fondateur de la dynastie, Jean II est l'imprimeur officiel du roi à Lyon. Après plusieurs emprisonnements, ce protestant doit quitter Lyon en octobre 1585 après avoir vendu son matériel à Antoine Gryphe. Il s'installe à Genève où les Tournes fondent une dynastie d'imprimeurs, active jusqu'à la fin du XVIII siècle.

20. Libraire en 1578, Jean Cavellat a débuté en tant que négociant en livres. Ses deux frères sont également de la profession. Le beau-père de Jean Cavellat n'est autre que le célèbre libraire, papetier-juré et fondeur de caractères Guillaume Le Bé I (1524-1598).

21. Généalogie de la famille des Saugrain, libraires depuis 1518 jusqu'à présent (janvier 1736), mise en ordre, imprimée et présentée par Joseph II Saugrain, le $1^{\text {er }}$ janvier 1736 , imprimerie Pierre Prault. 
22. B. Vidal, «Les démêlés d'Olivier de Serres avec son imprimeur, à propos d'un contrat d'impression du Théâtre d'agriculture et d'une édition pirate ", Histoires et sociétés rurales.

23. Dans la collégiale Notre-Dame de Poissy a été posée une dalle funéraire en mémoire de Claude Hourlier, Charles Saugrain et Clémence Bégulle, tous trois éditeurs parisiens. Elle a été érigée par Antoine Saugrain (1657-1745), quatorzième et dernier enfant de Charles, devenu chanoine chevecier de l'église royale de Notre-Dame de Poissy, en l'honneur de sa mère et de son frère Charles, libraire à Paris décédé à Poissy le 17 février 1728.

24. Né en 1685 à Bourges, apprenti chez l'imprimeur-libraire parisien Urbain Coustelier, Pierre Prault est reçu libraire le 22 septembre 1711, en qualité de gendre du défunt Guillaume I Saugrain, et imprimeur le 10 septembre 1723.

25. Il prend l'habit aux Carmes en juin 1697 sous le nom de Père Marin de Saint-JeanBaptiste.

26. Claude-Marin Saugrain, Les Adresses de la ville et faux-bourgs de Paris divisez en vingt quartiers.

27. Les curiositez de Paris, de Versailles, de Marly, de Vincennes, de Saint-Cloud et des environs. Tout en mêlant descriptions littéraires et images de la ville (Notre-Dame, la place Dauphine, le Vieux-Louvre, le palais des Tuileries, place Louis XV, etc.), l'ouvrage fournit des informations sur les activités de Paris et de sa proche région. Réédité à six reprises $(1719,1723,1733,1742,1771,1778)$, il reste le modèle des guides parisiens du $\mathrm{xVIII}^{\mathrm{e}}$ siècle, le grand ancêtre des guides touristiques Baedeker, Piesse ou, plus tard, Michelin.

28. Dessinateur, peintre et graveur, Jean-Michel Moreau dit le jeune (1741-1814) est le dessinateur du Cabinet du roi. Membre de l'Académie royale de peinture et de sculpture, il est le frère du peintre et graveur à l'eau-forte, Louis-Gabriel Moreau (1740-1806), dit l'aîné.

29. Recherches généalogiques sur Horace Vernet, Paul Delaroche et leur famille par Horace Delaroche-Vernet.

30. A. Berthonnet et B. Gélis, Didot-Saugrain-Gélis. Cinq siècles d'histoire familiale du XVI siècle au XXI siècle. Une histoire qui embrasse les métiers du livre, la banque et l'architecture.

31. Sur le docteur Antoine-François Saugrain, voir M. D. Dandrige, «Antoine-François Saugrain, le premier scientifique de la vallée du Mississippi dans l'histoire de l'Ohio ", W. V. Byars, The first scientist of the Mississippi Valley [...], H. Foure Selter, L'Odyssée américaine d'une famille française[...].

\section{RÉSUMÉS}

À l'époque où, vers 1530-1540, le livre imprimé acquiert ses caractéristiques propres, le fondateur de la dynastie des Saugrain, Jean, se forme aux métiers du livre en Allemagne, berceau de l'imprimerie moderne. Cet esprit humaniste, converti au protestantisme, fonde en 1550 une 
librairie à Lyon et devient imprimeur. Sept générations de libraires-imprimeurs lui succéderont, non à Lyon mais à Paris, capitale de la librairie et de l'édition française. Les Saugrain traverseront trois siècles d'histoire du livre, dont le «Grand Siècle ", puis les Lumières, où ils seront au sommet de leur art.

\section{AUTEUR}

\section{ARNAUD BERTHONNET}

Docteur en histoire, Université Paris IV - Paris-Sorbonne, historien d'entreprise et éditeur, chargé de cours, Université Paris IX - Paris-Dauphine et au CNAM Paris et Bordeaux 


\title{
Les maîtres écrivains : acteurs méconnus de la transmission des savoirs
}

\author{
Célia Cabane
}

1 Qui sont les maitres écrivains, et tout particulièrement, comme ce sera le cas tout au long de cette intervention, les maîtres écrivains jurés? Il s'agit d'une corporation parisienne, créée en 1570 suite à une affaire judiciaire encore peu éclaircie. En effet, le 7 mars 1569, Pierre Hamon, secrétaire de la chambre du roi et habile calligraphe, est pendu et brûlé place de Grève à Paris avec l'ensemble de ses livres et papiers, ainsi que les papiers du procès. Le procès de Pierre Hamon est une énigme en soi, puisque plusieurs chefs d'inculpation ont été avancés par les différentes sources qui nous racontent l'événement : faux en écritures et imitation de la signature royale ${ }^{1}$, procès pour cause de religion ${ }^{2}$, rédaction de libelles diffamatoires contre le parlement de Paris ${ }^{3}$. Ces trois chefs d'accusation, qui ont probablement été couplés lors du procès, permettent d'expliquer la rapidité de la procédure et surtout la sanction appliquée, notamment pour la contrefaçon de la signature royale, acte de haute trahison.

2 Toujours est-il qu'à la sortie de ce procès, une délégation de neuf maîtres écrivains exerçant tous à Paris mais dans des juridictions différentes, adresse au roi une requête pour se constituer en corporation ${ }^{4}$. Ces neuf écrivains sont ceux qui ont procédé à la vérification des pièces suspectées de faux lors du procès de Pierre Hamon et qui ont conclu à la contrefaçon. Cette requête en forme de statuts, qui présente 5 articles organisant la profession, est alors soumise à une commission du prévôt de Paris, qui doit vérifier que les prérogatives demandées par les maîtres écrivains n'empiètent pas sur des prérogatives accordées à des corporations parisiennes déjà instituées. Le prévôt de Paris ne voit rien à redire à la demande des maîtres écrivains et le roi accorde ainsi des lettres patentes à la nouvelle communauté afin qu'elle soit enregistrée par le Châtelet, dont elle dépendra juridiquement, ainsi que par le parlement de Paris ${ }^{5}$. Par souci de commodité, j'emploierai tout au long de ce texte comme des synonymes «maître écrivain », « écrivain juré » et « maître écrivain juré », bien qu’un chapitre de 
ma thèse pour le diplôme d'archiviste paléographe, sur lequel je n'ai pas le temps de m'arrêter ici, soit consacré à la désignation dans les actes des écrivains jurés ${ }^{6}$.

Qu'y a-t-il dans ces 5 articles, qui définissent la profession de maître écrivain juré ? Essentiellement les deux privilèges professionnels qu'entendent exercer les maîtres écrivains jurés : la vérification des écritures suspectées de faux dans les tribunaux et l'enseignement de l'écriture.

4 Avant d'entrer dans les détails concernant les maîtres écrivains, un petit arrêt sur la bibliographie disponible. On trouve mention de la corporation dans les ouvrages consacrés aux corporations parisiennes, que sont par exemple L'organisation corporative de la France d'Ancien Régime de François Olivier-Martin, publié en $1938^{7}$ ou Histoire des corporations de métiers depuis leur origine jusqu'à leur suppression en 1791 d'Étienne Martin Saint-Léon, publié en $1941^{8}$. Les ouvrages d'histoire de l'éducation comme ceux de Chantal Grell ${ }^{9}$ ou de Louis-Henri Parias ${ }^{10}$ les évoquent à peine, et presque toujours d'une façon négative, les accusant de déréguler l'enseignement de l'écriture à Paris en entraînant les maîtres des petites écoles dans des procédures judiciaires sans fin. Néanmoins, une mince bibliographie plus spécifiquement consacrée aux écrivains jurés existe. Elle commence au XIX ${ }^{\mathrm{e}}$ siècle, avec le livre de Jacques Bonzon, La Corporation des maîtres-écrivains et l'expertise en écritures sous l'Ancien Régime, publié en $1899^{11}$, empreint du contexte de l'affaire Dreyfus. Plus récemment, Christine Métayer a produit un travail de mémoire non publié, La corporation des maitres écrivains jurés de Paris sous l'Ancien Régime, soutenu en $1986^{12}$, accompagné de deux articles dans différentes revues. Jean Hébrard a également commis un article, plus particulièrement tourné vers les manuels des maîtres écrivains, "Des écritures exemplaires : l'art du maître écrivain en France entre $\mathrm{XVI}^{\mathrm{e}}$ et $\mathrm{XVIII}{ }^{\mathrm{e}}$ siècle" publié en $1995^{13}$. Pour le XXI ${ }^{\mathrm{e}}$ siècle, on trouve notamment le livre d'Isabelle de Conihout et Frédéric Gabriel, Poésie \& calligraphie imprimée à Paris au XVII siècle: autour de la "Chartreuse" de Pierre Perrin, poème imprimé par Pierre Moreau en 1647 , publié en $2004^{14}$, qui s'intéresse à un maître écrivain en particulier, ainsi que l'Histoire de la calligraphie française de Claude Mediavilla, publié en $2006^{15}$, un bel ouvrage de prestige qui s'attache à mettre en valeur la calligraphie française depuis l'époque gauloise jusqu'au $\mathrm{xx}^{\mathrm{e}}$ siècle, mais qui manque de notes indiquant les sources utilisées. On le voit, la bibliographie est courte pour un sujet courant sur trois siècles. Pourquoi personne ne parle-t-il des maîtres écrivains? Qui sont-ils?

\section{La corporation des maîtres écrivains : des praticiens entre deux monopoles}

\section{La vérification des écritures}

5 Après cette rapide introduction plutôt historique sur la corporation, il s'agit à présent de se pencher sur les hommes qui peuplaient cette communauté d'arts et métiers et d'essayer de comprendre comment ces articles des statuts se transposent dans la réalité du Paris de l'Ancien Régime. Mon propos portera principalement sur le $\mathrm{XVII}^{\mathrm{e}}$ siècle, objet de ma thèse de l'École des chartes soutenue en juin 2017 sous la direction de Marc Smith, professeur de paléographie à l'École des chartes et à l'École pratique des hautes études, et de Reynald Abad, professeur d'histoire moderne à l'ancienne université Paris-Sorbonne devenue Sorbonne Université ${ }^{16}$. 
6 Le premier privilège revendiqué par les maitres écrivains est donc celui de l'expertise des écritures suspectées de faux lors des procès dans les tribunaux parisiens ${ }^{17}$. Ce besoin émane directement du procès de Pierre Hamon, convaincu d'avoir imité la signature du roi, mais les maîtres écrivains peuvent être appelés dans des affaires de vérification des écritures bien moins prestigieuses. Les écrivains jurés produisent lors de ces expertises des rapports séparés que les juges croisent afin de prouver ou non la fausseté de l'écriture. Il existe donc dans les sources judiciaires de nombreux tribunaux des rapports qu'ils ont rédigés et qui font partie des documents qui auraient pu attirer l'attention des historiens sur cette corporation ${ }^{18}$.

7 Comme toutes les expertises en justice sous l'Ancien Régime, ce monopole de l'expertise en écritures s'appuie sur la pratique d'un métier qui permet à un auxiliaire de justice comme le maître écrivain d'apporter de l'aide aux juges grâce à sa connaissance particulière du domaine ${ }^{19}$. C'est dans cette optique que les maitres écrivains demandent et se voient accorder une deuxième prérogative, l'enseignement de l'écriture. Cette profession était en réalité celle qu'exerçaient, avant l'érection du métier juré, les neufs écrivains qui ont adressé la requête au roi ${ }^{20}$. Le changement majeur n'est donc pas la création d'une nouvelle activité d'enseignement de l'écriture, mais la réglementation de cette activité auparavant exercée par divers maîtres dans Paris.

\section{L'enseignement de l'écriture}

8 L'enseignement de l'écriture peut prendre trois formes chez les maîtres écrivains jurés : la tenue de classes publiques d'écriture, le préceptorat et l'apprentissage pour devenir maître écrivain. Tout d'abord, ce qui est leur véritable monopole ${ }^{21}$, la tenue de classes d'écriture (et d'écriture seule). Ils sont en effet les seuls à pouvoir tenir de réelles classes d'écriture, les autres enseignants tenant une classe devant proposer au moins deux enseignements (écriture et lecture) ou seulement lecture en fonction du public visé. Cette tenue de classe n'est pas visible à travers des contrats, puisque les parents ne passent pas devant un notaire pour mettre leurs enfants à l'école.

9 En revanche, on peut la voir dans les archives notariales à travers les inventaires après décès, qui nous décrivent les habitations des maîtres et leurs meubles, parmi lesquels on trouve des meubles réservés à une classe d'écriture. Au XvII e siècle, il s'agit toujours d'une pièce, souvent une chambre, aménagée pour la tenue de la classe. Les maîtres écrivains n'utilisent en effet pas les espaces traditionnellement réservés aux boutiques d'artisans, ce que l'on peut remarquer par la fréquence des contrats de location par les maitres de ces boutiques à d'autres artisans. François Gautrain par exemple loue « une bouticque, salle [et] portion de cave qui est celle qui a soupiral sur rue " à Pierre Domicirre, maître cordonnier, le 14 juillet $1636^{22}$ (fig. 1). On trouve en revanche dans l'inventaire après décès de Guillaume Lefevre, maître écrivain, en 1697, la description des biens contenus "dans une grande salle servant de classe au 1er etage ${ }^{23}$ (fig. 2). Cette pièce contient « quatorze tables sur leur treteaux, vingt banchelles de bois, prisé le tout ensemble tel quel trente livres ${ }^{24}$. Comme autre ameublement de la pièce, "deux tableaux peints sur toille, l'un representant un St Pierre et l'autre une Magdeleine aus clous, bordurés de bois doré », surveillent maître et élèves pendant leurs cours ${ }^{25}$. 
Fig. 1. - Bail de location par François Gautrain, maître écrivain, d'une boutique à Pierre Domicirre, maître cordonnier.

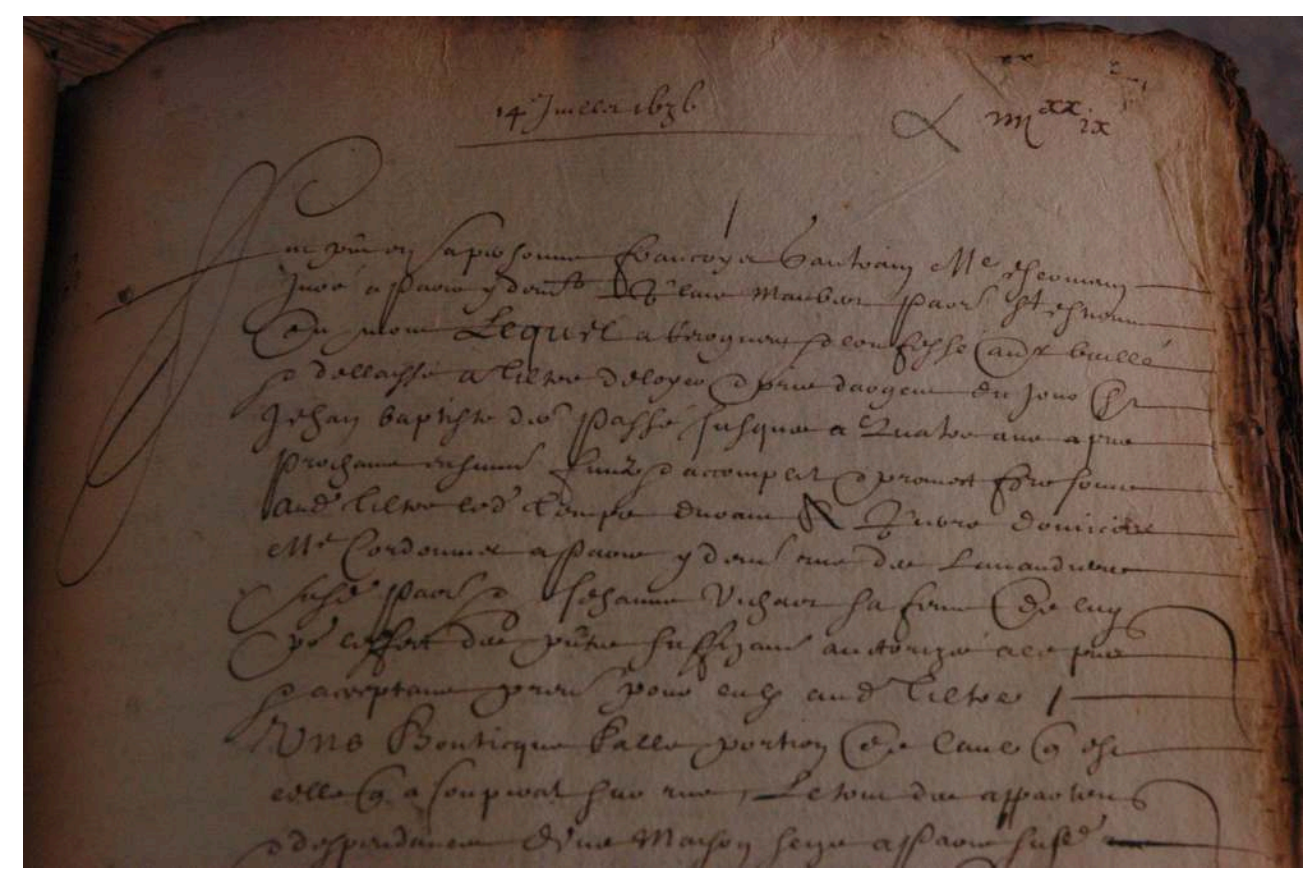

Archives nationales, Minutier central des notaires parisiens, étude XVIII, liasse 249, 14 juillet 1636.

Fig. 2. - Inventaire après décès de Guillaume Lefevre, maître écrivain, dans lequel est fait mention d'une chambre dédiée à la classe d'écriture.

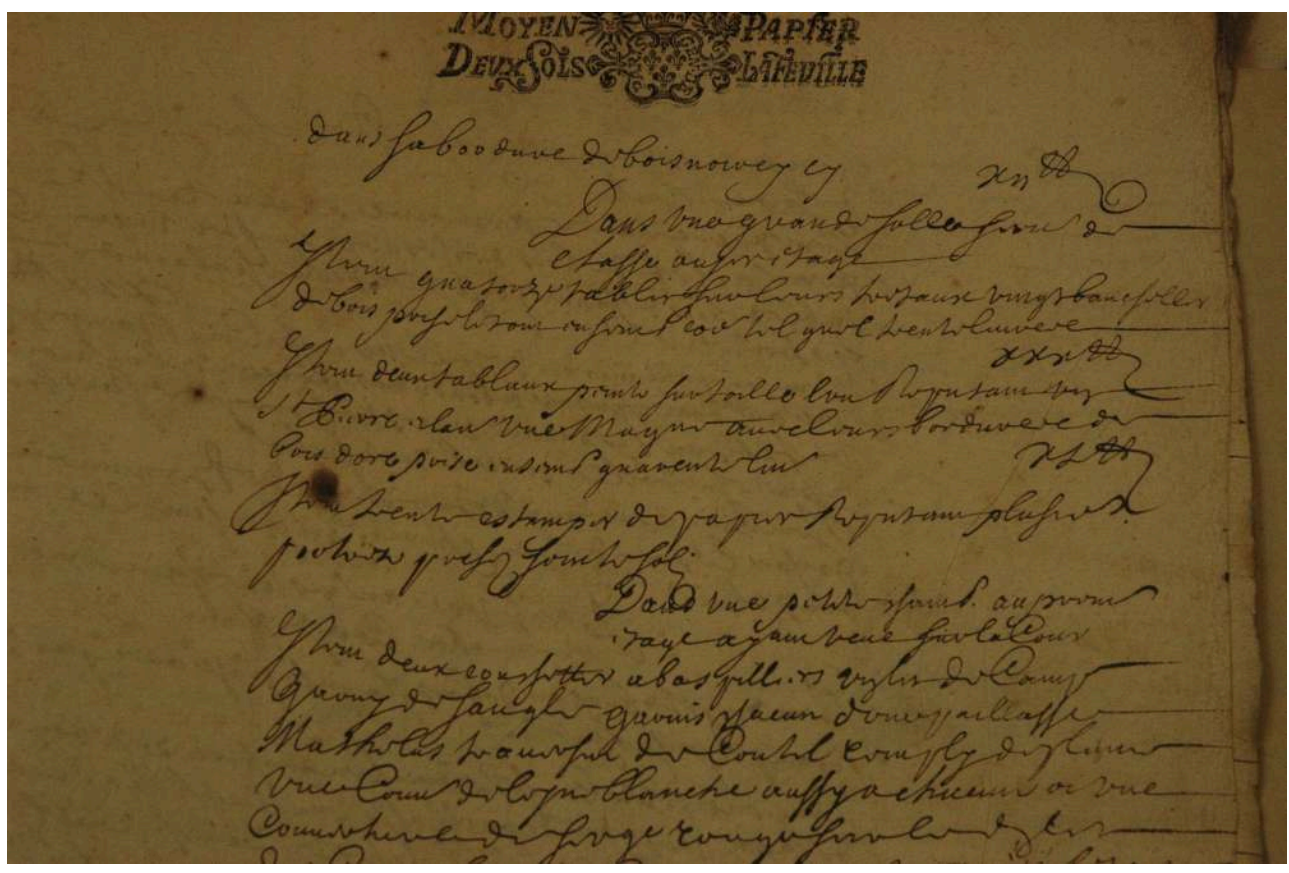

Archives nationales, Minutier central des notaires parisiens, étude CXIX, liasse 69, 13 juillet 1697.

10 Outre la tenue de classes d'écritures, les maîtres écrivains pouvaient également dispenser leur art sous la forme du préceptorat, qu'il s'agisse de cours pour maîtriser l'écriture ou de véritables pensions afin d'amener un élève jusqu'à la maitrise de la communauté. Ces cours sont visibles dans les archives notariales également, à travers 
des contrats d'enseignement de l'écriture. Il s'agit d'élèves, enfants et adultes, qui cherchent à perfectionner leur écriture et ce notamment pour les familles aisées qui ne mettent pas leurs enfants dans les classes publiques. On voit par exemple au bas de ce contrat d'enseignement datant du 20 avril 1684 et liant Louis Mary, maître écrivain, et Macé Larcher que la signature de Larcher, adulte, traduit une connaissance des bases de l'écriture, et que ce dernier cherche à se perfectionner ${ }^{26}$ (fig. 3).

Fig. 3. - Signatures du contrat d'apprentissage de l'écriture par Macé Larcher auprès de Louis Mary, maître écrivain.

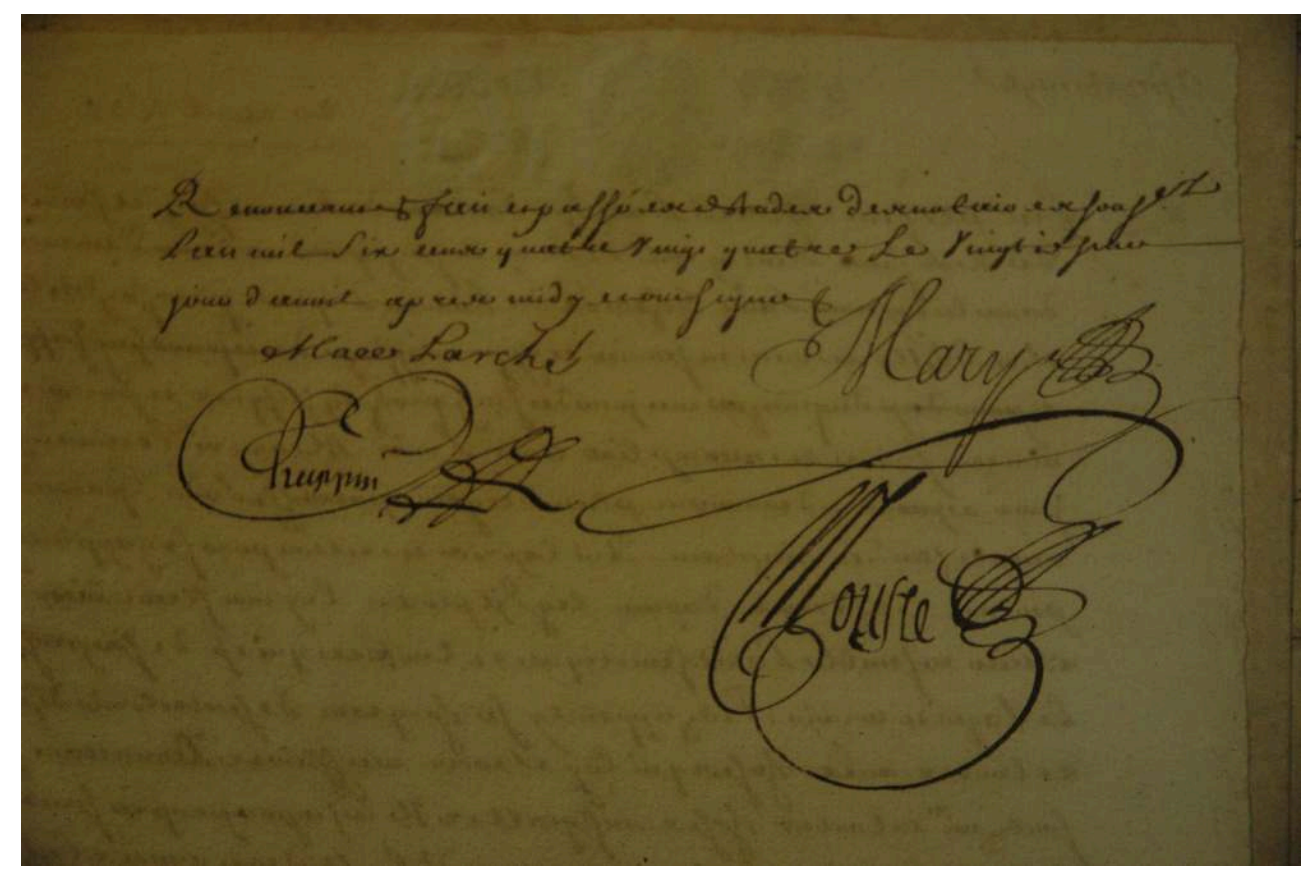

Archives nationales, Minutier central des notaires parisiens, étude XCVI, liasse 133, 20 avril 1684

\section{Manuels et méthodes d'écriture}

11 Les maîtres écrivains ne se contentent pas tous de donner des cours d'écriture: certains produisent également des manuels d'écriture, qui sont ensuite vendus. Ces manuels sont des ensembles de texte imprimé et de planches gravées qui donnent des méthodes et des exemples à suivre pour apprendre à bien écrire. Il existe une grande variété de manuels de maîtres écrivains, dont Marc Smith recense actuellement tous les exemplaires conservés afin de mettre au point une bibliographie de la production des maitres écrivains parisiens, sinon français, $d u X V I I^{e}$ au XVIII ${ }^{e}$ siècle.

On peut distinguer trois temps différents dans les publications de manuels de maîtres écrivains au XVII ${ }^{\mathrm{e}}$ siècle $^{27}$. Le premier, avant la réforme de l'écriture de 1633, est un temps de virtuosité calligraphique, pendant lequel les manuels sont majoritairement composés de planches gravées, jusqu'à la page de titre. L'exemple le plus frappant de cette période est le Tivoly ou jardin d'escriture de Robert Vignon, publié au tout début du $\mathrm{XVII}^{\mathrm{e}}$ siècle $^{28}$ (fig. 4). La grande virtuosité des planches et leur caractère artistique laissent penser que l'enseignement de l'écriture n'était pas la seule utilisation qui en était faite. Il est probable que ce genre de pièces ait également attiré des 
collectionneurs, notamment ceux qui étaient déjà séduits par les arts graphiques et les estampes.

Fig. 4. - Page de titre.

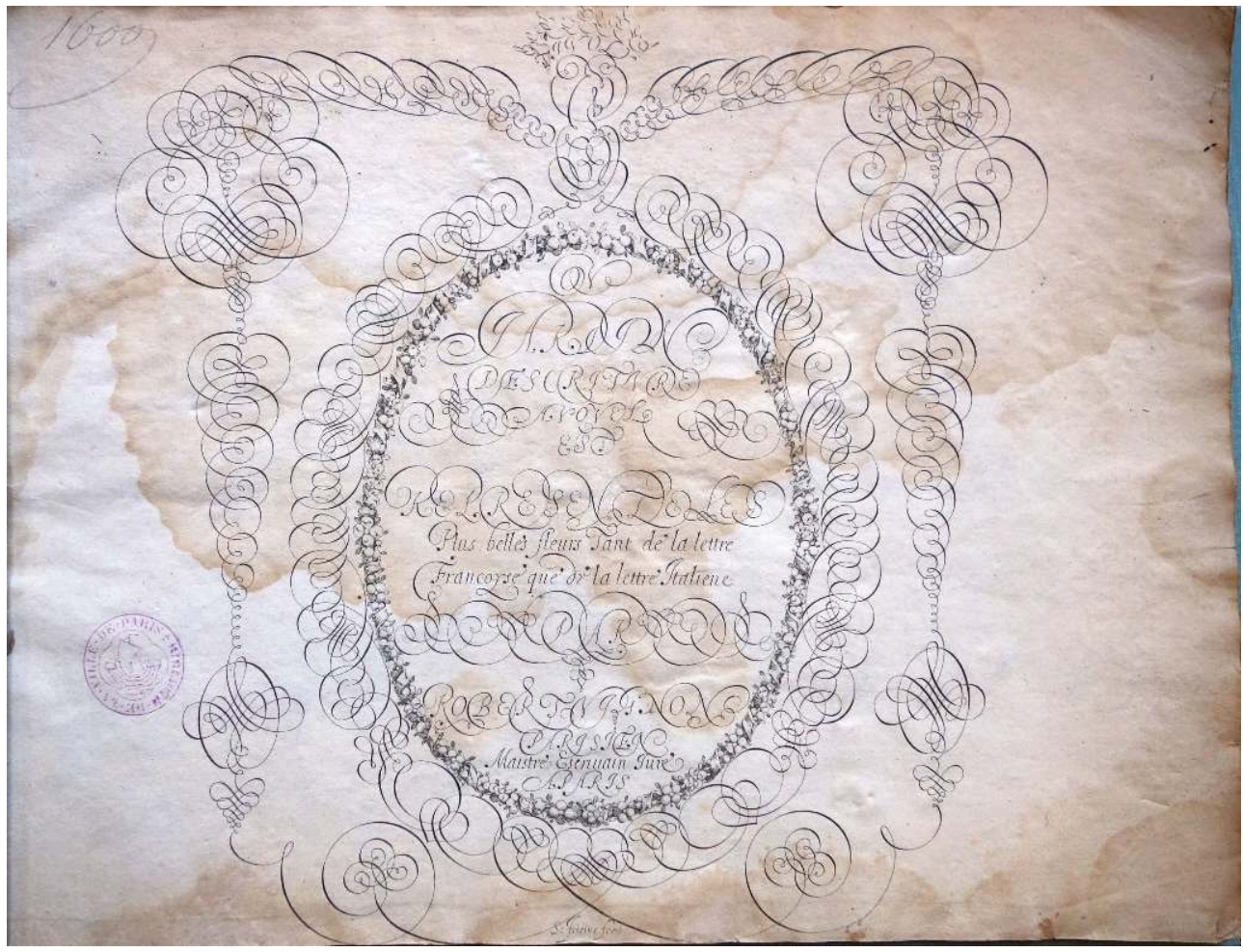

Robert Vignon, Tivoly ou jardin d'escriture, auquel est representé les plus belles fleurs tant de la lettre françoyse que de la lettre italiene, Paris, 1600.

BHVP, Réserve 104805.

13 Le deuxième temps dans la production des manuels d'écriture est celui qui suit la réforme de l'écriture de 1633. Cette année-là, le parlement de Paris charge la communauté des maîtres écrivains de réformer les modèles d'écriture afin de rendre à nouveau lisible l'écriture des greffiers, notamment ceux du Parlement lui-même ${ }^{29}$. Suite à cette décision et à la réalisation de nouveaux modèles par les maîtres écrivains, les manuels d'écriture vont connaître une certaine rigidité, afin de diffuser ces nouveaux modèles. Un exemple emblématique de cette série de manuels est le Traité de l'art d'escriture, publié par Jean Petré en $1647^{30}$. Ce traité comporte 18 pages de texte imprimé et 35 pages de planches gravées. Le texte imprimé est une méthode pédagogique pour apprendre à former les écritures ronde et italienne bâtarde. Le corps des planches gravées, qui est représentatif de la production des écrivains jurés après la réforme, est composé de six pages d'alphabets des deux écritures, minuscules et majuscules, ainsi que de vingt-deux pages d'exemples d'écriture, de deux à quatre lignes chacune. Ces exemples d'écriture sont classées par ordre alphabétique de leur première lettre et composées de maximes ou de début de formulaire d'actes de la pratique (fig. 5). Elles permettent ainsi aux élèves de copier des exemples courts mais qui contiennent néanmoins toutes les lettres et notamment tous les tracés des lettres majuscules de l'alphabet, afin de savoir comment les lier au reste de la ligne. 
Fig. 5. - Exemple commençant par la lettre « $\mathrm{H} »$.

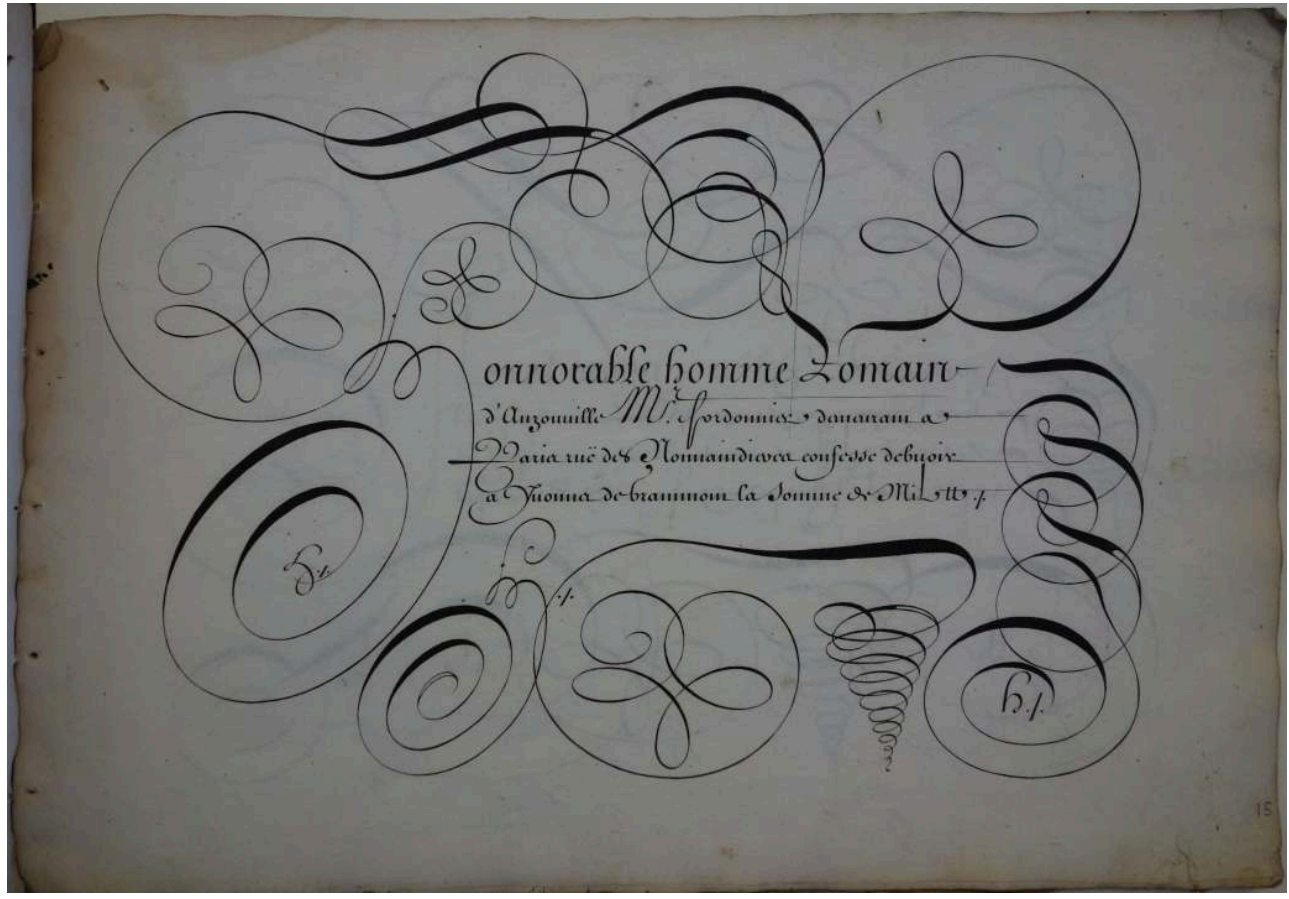

Jean Petré, Traité de l'art d'escriture, avec les exemples de tous les differents caracteres, qui se pratiquent en ce royaume, Paris, 1647, f. 41.

Houghton Library, Harvard, TypW 615.47.684.

Le troisième temps dans la production des manuels de maîtres écrivains est un retour à plus de fantaisie autour voire dans les exemples d'écriture. Il correspond également au développement d'une nouvelle méthode d'apprentissage, qui sera ensuite reprise tout au long du XvIII ${ }^{\mathrm{e}}$ siècle. Pour la partie plus créative, on peut voir les nombreux ouvrages de Louis Senault, comme les Curieuses et nouvelles recherches des escritures ${ }^{31}$ (fig. 6). L'autre maître écrivain actif à la fin du XVII ${ }^{\mathrm{e}}$ siècle est Jean-Baptiste Alais, qui dans L'art d'ecrire innove : une seconde page de titre, gravée, suit le texte imprimé, accompagnée de planches détaillant sa méthode d'apprentissage de l'écriture en vingt-cinq pages ${ }^{32}$ (fig. 7). Il s'agit de planches pédagogiques pour apprendre à tracer les différents traits composant les lettres et d'observations sur la tenue de la plume. Les deux dernières planches sont des alphabets, mais ce livre ne pousse pas plus loin l'apprentissage de l'écriture, et ne propose notamment pas d'exemples d'écriture de plusieurs lignes comme le faisaient les autres manuels. 
Fig. 6. - Louis Senault, Curieuses et nouvelles recherches des escritures financieres et italiennes bastardes suivant l'usage le plus nouveau et le plus usité dans ce royaume, Paris, après 1674, f.10.

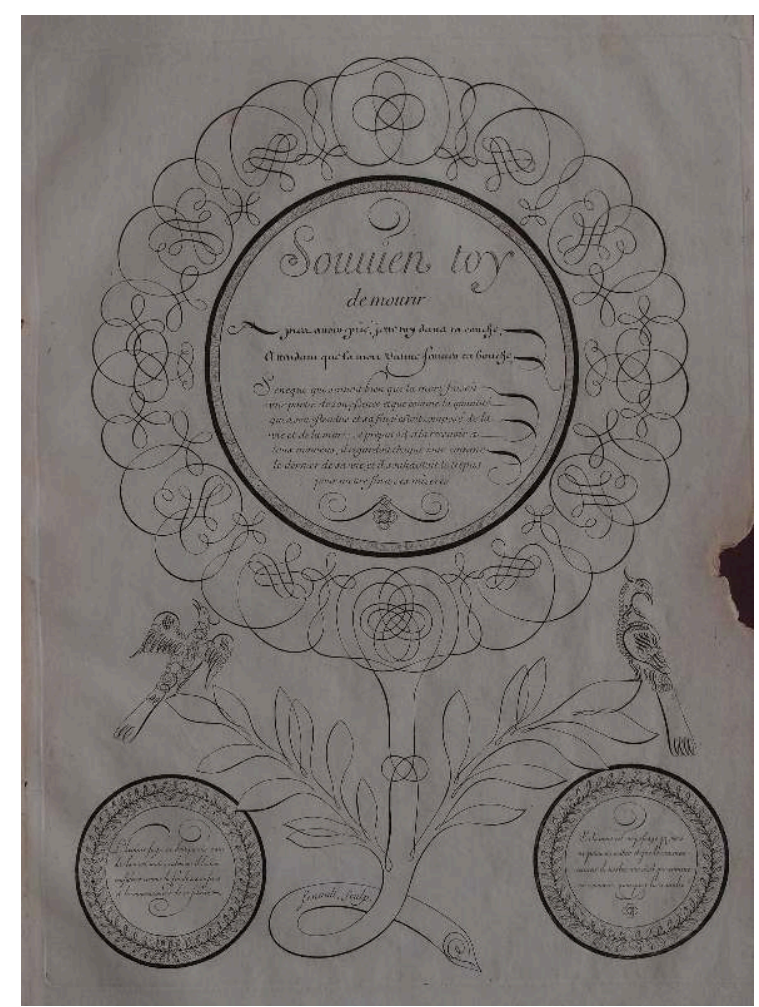

Musée National de l'Éducation, Rouen, 1979.34012. 
Fig. 7. - Planche traitant des effets de plume.

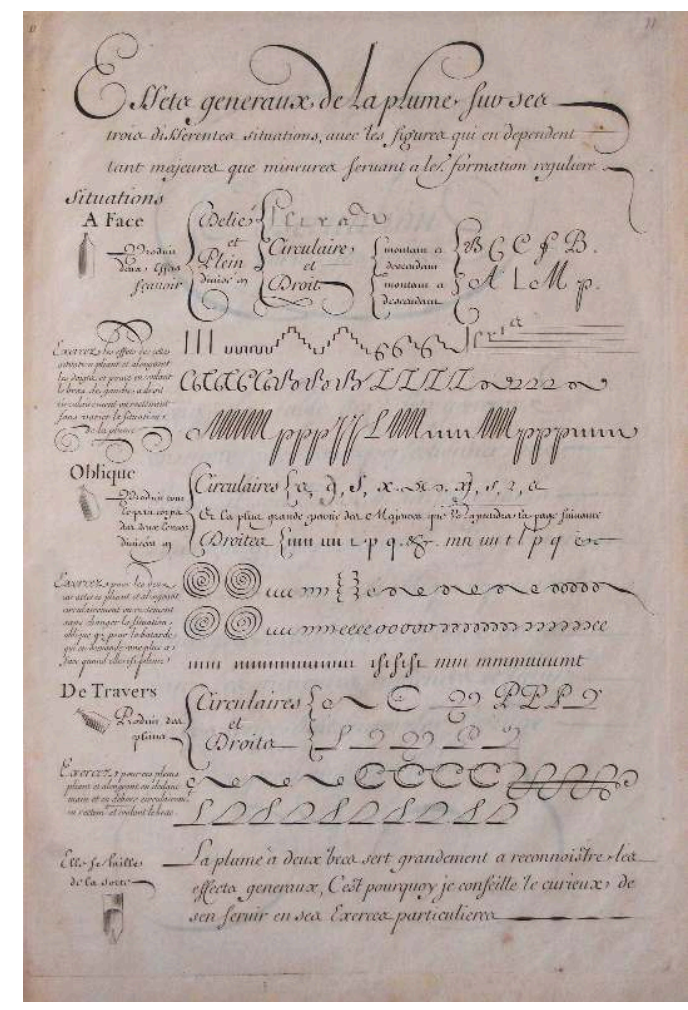

Jean-Baptiste Alais, L'art d'écrire, Paris, 1680, f.10.

Newberry Library, Chicago, Wing fZW 639. A315.

\section{Quelles sources pour faire l'histoire des maîtres écrivains?}

\section{Les actes notariés}

Voilà un rapide aperçu de qui sont les maîtres écrivains et de comment s'organise leur profession d'enseignants de l'écriture. Il y a donc des traces de leur enseignement, qu'il s'agisse des contrats d'apprentissage, d'enseignement ou de la présence de meubles destinés à la tenue de classes dans leurs inventaires après décès. À ces documents s'ajoutent les manuels produits par les écrivains jurés, qui sont autant de sources pour l'histoire du livre mais également pour celle des maîtres en particulier. Ce n'est donc pas vraiment un problème de documentation sur eux qui a pu empêcher les historiens de faire leur histoire.

\section{Les sources judiciaires}

Outre ces sources, les maîtres écrivains ont également laissé des traces de leur existence à travers les conflits qu'ils ont eus avec d'autres acteurs de l'écriture à Paris. C'est le cas notamment du conflit multiséculaire qui les a opposés aux maitres des petites écoles, les premiers concernés par la réorganisation de l'enseignement de l'écriture qui a lieu lors de la création de la corporation des maîtres écrivains. Les deux communautés se retrouvent régulièrement devant les tribunaux pour contester 
l'empiètement de l'un sur les affaires de l'autre, et après un grand nombre de jugements à la fois de l'officialité et du Châtelet de Paris, règlent leurs différends au parlement de Paris, juridiction d'appel pour les deux communautés ${ }^{33}$. Les écrivains jurés se rendent également devant le Parlement pour faire évoluer leurs statuts, par exemple en 1630 , pour apporter des précisions sur les examens d'accession à la maitrise ${ }^{34}$.

17 Peut-être faut-il se tourner vers la date tardive de leur création pour expliquer l'absence d'études sur eux ? En effet, l'enseignement de l'écriture dans les rues de Paris n’a pas commencé à l'érection de la communauté des maitres écrivains, puisque les maîtres des petites écoles, mais également les maîtres des écoles capitulaires, des fondations religieuses et aussi de nombreux précepteurs se partageaient déjà l'enseignement de l'écriture. Leur création en 1570 oblige l'ensemble de ces professions à se réorganiser, puisqu'il n'est plus question pour eux de tenir des classes d'écriture publiques, qui deviennent le privilège des seuls écrivains jurés. L'institution de cette prérogative peut sembler redondante à la fois pour les contemporains de l'époque moderne, et aussi pour les historiens puisqu'ils viennent perturber une organisation qui avait assuré un maillage serré des quartiers de Paris, et ainsi expliquer le manque d'intérêt pour cette corporation.

En sus de cette impression de redondance, il faut s'attarder maintenant sur le statut de la profession, qu'il n'est pas aisé de déterminer.

\section{Être maître écrivain, est-ce être enseignant ou artisan?}

\section{Des maîtres qui enseignent}

19 Les maîtres écrivains sont ainsi pris entre deux statuts qui semblent s'opposer sous l'Ancien Régime. Ils sont des enseignants, car l'écriture, art qu'ils enseignent, est un art libéral ${ }^{35}$. Elle seconde l'apprentissage de la grammaire, l'un des sept arts libéraux avec la rhétorique, la poésie, la peinture, la sculpture, l'architecture et la musique. Ils revendiquent ainsi le même statut que les autres enseignants de la ville que peuvent être les maitres des petites écoles ou les nombreux répétiteurs dans les collèges.

Ces revendications liées à l'exercice de leur métier se retrouvent également dans les actes notariés qu'ils contractent, qui sont des lieux de revendications sociales complexes $^{36}$. On peut notamment y voir les maîtres écrivains revendiquer un statut supérieur à celui de nombreux artisans, ce qu'ils justifient à la fois par leur statut de maître mais également par leur maîtrise de l'écriture, qu'ils mettent en valeur par la réalisation de grandes et belles signatures destinées à montrer leur importance dans la société parisienne. Sur ce contrat de location, Pierre Dubrueil effectue une grande signature bien plus imposante que celle de son bailleur, Claude Michelet, qui est marchand de Paris, donc probablement socialement plus élevé que Dubrueili3 (fig. 8). Cela permet à l'écrivain juré de montrer qu'il n'est pas un simple artisan qui louerait une boutique, mais bien un enseignant. 
Fig. 8. - Signatures du bail de location par Claude Michelet d'un étage de maison à Pierre Dubrueil.

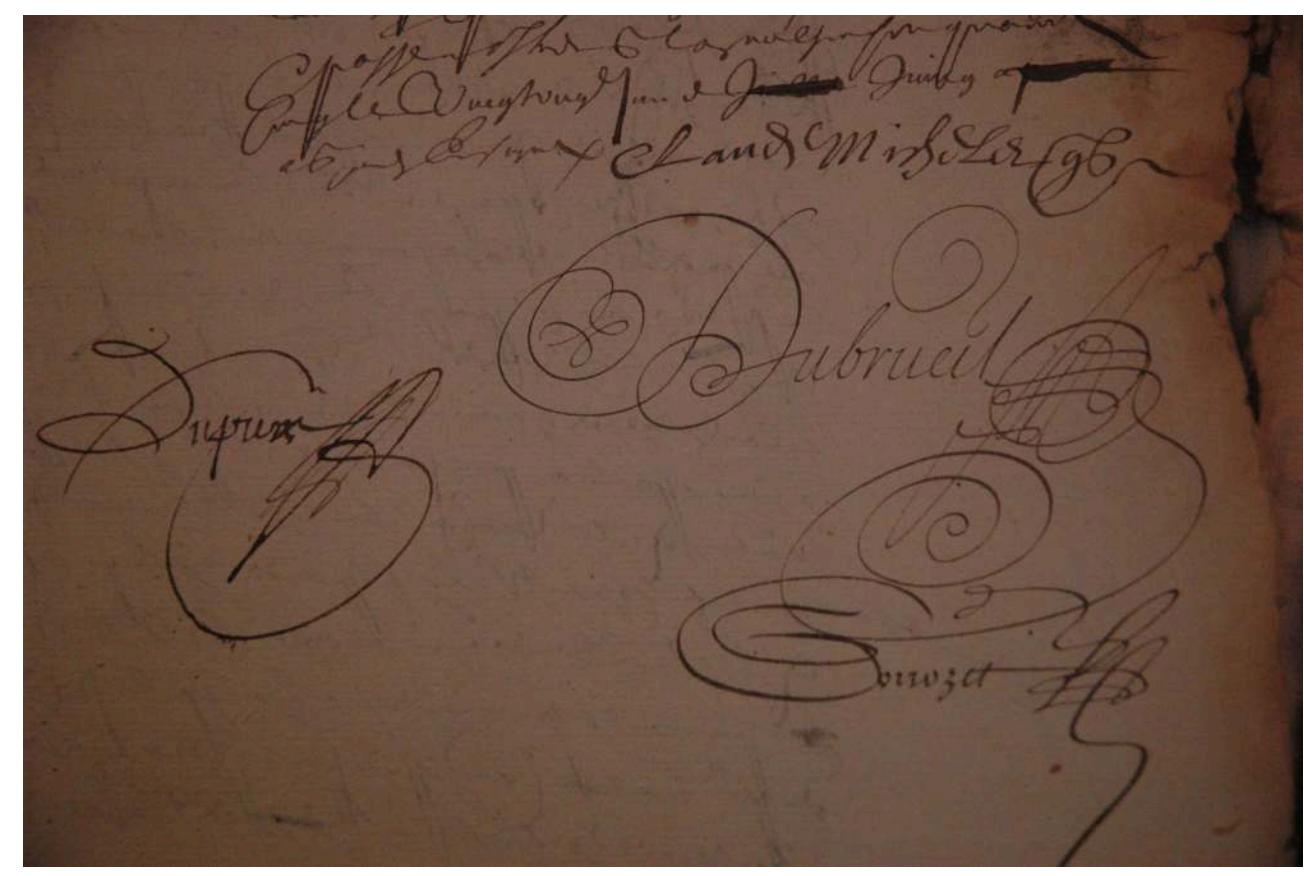

Archives nationales, Minutier central des notaires parisiens, étude XXIX, liasse 182, 21 juin 1645.

\section{Des maîtres qui font partie d'une communauté d'arts et métiers}

Mais les maîtres écrivains sont juridiquement dépendants du Châtelet et forment une communauté d'arts et métiers. À ce titre, ils sont des artisans, au même titre que les bouchers, les boulangers ou les orfèvres. Ils ont d'ailleurs une organisation semblable à celle des autres communautés, notamment par la réalisation de chef-d'œuvre pour accéder à la maîtrise ${ }^{38}$.

De plus, leur poids dans la société, s'il est supérieur à celui des artisans moyens, est tout de même plutôt égal à celui des maîtres des autres corporations parisiennes, sans aller jusqu'aux Six-Corps de Paris ${ }^{39}$. Ils font ainsi jeu égal avec les maîtres papetiers, les imprimeurs libraires et même, pour les plus fortunés d'entre eux, avec certains marchands, que ce soit en termes de richesse ou d'honneur ${ }^{40}$.

Les maîtres écrivains ont ainsi un statut intermédiaire, entre artisans et enseignants, selon qu'on les considère sous le prisme de leur statut juridique ou sous celui de l'exercice de leur métier et de l'art qu'ils enseignent. Ce statut mouvant, difficile à ranger dans une seule catégorie, explique aussi probablement l'absence d'études qui leur sont consacrées. Comme ils forment une corporation mais d'art libéral, les historiens des communautés ne s'en sont pas occupés, les historiens de l'enseignement et de l'éducation les reléguant à quelques mentions à cause de ce statut d'artisans imposé par leur rattachement au Châtelet.

N'ayons plus peur des maitres écrivains! Cette corporation parisienne a laissé des traces permettant son étude, qu'il s'agisse d'étudier les destins particuliers de ses membres à travers les actes notariés, l'organisation de la communauté et la défense de 
ses prérogatives face aux autres acteurs de l'enseignement de l'écriture et de la vérification des faux en justice en utilisant les différentes archives judiciaires, ou encore l'évolution de l'écriture manuscrite et de ses modèles à travers les différents manuels que les écrivains jurés ont publiés.

\section{BIBLIOGRAPHIE}

BONZON Jacques, La Corporation des maîtres-écrivains et l'expertise en écritures sous l'Ancien Régime, Paris, V. Giard et E. Brière, 1899.

CABANE Célia, « "Aux plumes d'or". Les maîtres écrivains à Paris, calligraphes au XVII siècle », thèse pour le diplôme d'archiviste paléographe, Paris, École nationale des chartes, 2017, (2 vol.). CONIHOUT Isabelle (de), GABRIEL Frédéric (éd.), Poésie \& calligraphie imprimée à Paris au XVII siècle : autour de la «Chartreuse » de Pierre Perrin, poème imprimé par Pierre Moreau en 1647, Paris, 2004. COSANDEY Fanny (éd.), Dire et vivre l'ordre social en France sous l'Ancien Régime, Paris, Éditions de l'École des hautes études en sciences sociales, 2005.

CRESPIN Jean, Histoire des martyrs persecutez et mis à mort pour la vérité de l'Évangile, Toulouse, éd. de la Société des livres religieux de Toulouse, 1889, (3 vol.).

DOLAN Claire (dir.), Entre justice et justiciables. Les auxiliaires de la justice du Moyen Âge au XX siècle, Québec, Université Laval, 2005.

GRELL Chantal, Histoire intellectuelle et culturelle de la France du Grand Siècle : 1654-1715, Paris, Nathan, 2000.

HÉBRARD Jean, « Des écritures exemplaires : l'art du maître écrivain en France entre XVI ${ }^{\mathrm{e}}$ et XVIII ${ }^{\mathrm{e}}$ siècle », Mélanges de l'École française de Rome. Italie et Méditerranée, t. 107, 1995, p. 473-523.

MARTIN SAINT-LÉON Étienne, Histoire des corporations de métiers depuis leur origine jusqu'à leur suppression en 1791, 4e édition, Paris, 1941.

MEDIAVILLA Claude, Histoire de la calligraphie française, Paris, Albin Michel, 2006.

MÉTAYER Christine, « La corporation des maîtres écrivains jurés de Paris sous l'Ancien Régime », mémoire de maîtrise, Québec, Université Laval, 1986.

OLIVIER-MARTIN François, L'Organisation corporative de la France d'Ancien Régime, Paris, Sirey, 1938. PAILLASSON Charles, Notice historique sur les hommes de toutes les nations de l'Europe, qui, depuis la renaissance des sciences et des arts, se sont distingués dans la configuration des caractères qui composent les diverses écritures et qui ont donné au public des principes et pièces sur cet art, Paris, circa 1760.

PARIAS Louis-Henri (dir.), Histoire générale de l'enseignement et de l'éducation en France, Paris, G.-V. Labat, 1981, 4 (vol.).

VÉNARD Marc (éd.), Les « mémoires » d'un curé de Paris (1557-1590) au temps des guerres de religion, Paris, Droz, 2004. 


\section{NOTES}

1. On trouve cette cause du procès et de la mort de Pierre Hamon dans la Notice historique sur les hommes de toutes les nations de l'Europe, qui, depuis la renaissance des sciences et des arts, se sont distingués dans la configuration des caractères qui composent les diverses écritures et qui ont donné au public des principes et pièces sur cet art, rédigée par Charles Paillasson, maître écrivain et rédacteur de l'entrée Maîtres écrivains dans l'Encyclopédie. Cette Notice historique a été conservée à la Bibliothèque nationale de France dans le Dictionnaire de chiffres et de lettres ornées, à l'usage de tous les artistes, contenant les vingt-quatre lettres de l'alphabet... de Jean-Henri-Prosper Pouget, aux pages XLIX à CXIV. La mention sur Pierre Hamon s'y trouve à la page LX.

2. L'hypothèse du procès pour religion se trouve à la fois dans la Notice historique de Charles Paillasson, page LX, et dans l'Histoire des martyrs persecutez et mis à mort pour la verité de l'Evangile, de Jean Crespin, éditée par la Société des livres religieux de Toulouse en 1889, tome III, p. 654-655.

3. Cette accusation est avancée dans le journal de Jean de La Fosse, édité par Marc Vénard sous le titre Les «mémoires » d'un curé de Paris (1557-1590): au temps des guerres de religion, p. 82-83.

4. Cette requête nous est parvenue dans un manuscrit de Nicolas de La Mare, préparatoire à son Traité de la Police, manuscrit dans lequel il a copié un grand nombre de lettres patentes accordées aux corporations parisiennes. Il est conservé à la Bibliothèque nationale de France, ms. fr. 21747, f. 138-143.

5. L'enregistrement de ces lettres patentes prend plus de temps que prévu au Parlement, probablement parce qu'il est la juridiction d'appel des maîtres des petites écoles, rivaux des maîtres écrivains, contrairement au Châtelet.

6. C. Cabane, " "Aux plumes d'or". Les maîtres écrivains à Paris, calligraphes au XVII siècle ", p. 151-165.

7. F. Olivier-Martin, L'organisation corporative de la France d'Ancien Régime.

8. E. Martin Saint-Léon, Histoire des corporations de métiers depuis leur origine jusqu'à leur suppression en 1791.

9. C. Grell, Histoire intellectuelle et culturelle de la France du Grand Siècle : 1654-1715.

10. L.-H. Parias (dir.), Histoire générale de l'enseignement et de l'éducation en France.

11. J. Bonzon, La Corporation des maîtres-écrivains et l'expertise en écritures sous l'Ancien Régime.

12. C. Métayer, «La corporation des maîtres écrivains jurés de Paris sous l'Ancien Régime ».

13. J. Hébrard, «Des écritures exemplaires : l'art du maitre écrivain en France entre $\mathrm{XVI}^{\mathrm{e}}$ et XVIII ${ }^{\mathrm{e}}$ siècle ».

14. I. de Conihout, F. Gabriel, Poésie \& calligraphie imprimée à Paris au XVII siècle : autour de la «Chartreuse » de Pierre Perrin, poème imprimé par Pierre Moreau en 1647.

15. C. Mediavilla, Histoire de la calligraphie française.

16. C. Cabane, « "Aux plumes d'or". Les maîtres écrivains à Paris, calligraphes au XVII siècle ».

17. On le trouve dans la requête adressée au roi en 1570 : «Seront lesdits $\mathrm{M}^{\text {es }}$ écrivains et non autres appellez à la visitation des actes, contrats, cédules et autres 
enseignemens maintenus de faux quand l'occasion se présentera, et deffenses à toutes autres personnes soy entremettre et juger ", conservée à la Bibliothèque nationale de France, ms. fr. 21747, f. 140.

18. Hors de Paris, on peut notamment citer un document conservé aux Archives Départementales et Métropolitaines de Lyon, BP 2483, qui est un rapport d'experts daté de 1662 et rédigé notamment par un maître écrivain de Paris, Pierre Dubrueil.

19. Pour aller plus loin sur la question, consulter C. Dolan (dir.), Entre justice et justiciables. Les auxiliaires de la justice du Moyen Âge au $\mathrm{Xx}^{e}$ siècle.

20. Il s'agit de "Adam Charles, notre ecrivain ordinaire, Antoine Perier et Jacques Fustel, maitres ecrivains jurez en notre université de Paris, et Thomas Danet, Mathieu Bietry Christofle Barbier, Jacques Barbier, Antoine le Grand et Martin Fustel, aussi maitres ecrivains et tenans escoles d'ecriture en ladite ville ", dont les métiers sont précisés dans la copie de la requête adressée au roi, conservée à la Bibliothèque nationale de France, ms. fr. 21747, f. 140.

21. «Premièrement, que tant les supplians que tous autres $\mathrm{M}^{\text {es }}$ écrivains en cette ville de Paris faisant estat de tenir écoles publiques d'écriture pour enseigner les enfans tant à l'écriture que au get et calcul seront tenus faire le serment pardevant le prévost de Paris ou son lieutenant en la chambre civile, et en sera fait registre auquel chacun écrira son seing et parafe, a quoy faire ils seront receus, après que ledit lieutenant aura sommairement informé de la vie et mœurs de chacun d'eux, et de leur suffisance.» dans la copie de la requête adressée au roi, conservée à la Bibliothèque nationale de France, ms. fr. 21747, f. 139.

22. Archives nationales, Minutier central des notaires parisiens, étude XVIII, liasse 249, 14 juillet 1636, «Location par François Gautrain d'une boutique à Pierre Domicirre ».

23. Archives nationales, Minutier central des notaires parisiens, étude CXIX, liasse 69, 13 juillet 1697, «Inventaire après décès de Guillaume Lefevre ».

24. Ibid.

25. Ibid.

26. Archives nationales, Minutier central des notaires parisiens, étude XCVI, liasse 133, 20 avril 1684, «Contrat d'apprentissage de l'écriture par Macé Larcher auprès de Louis Mary ».

27. Pour en savoir plus sur les différents manuels de maîtres écrivains publiés au XVII ${ }^{\mathrm{e}}$ siècle, voir C. Cabane, " "Aux plumes d'or". Les maîtres écrivains à Paris, calligraphes au XVII ${ }^{e}$ siècle ", p. 293-325.

28. R. Vignon, Tivoly ou jardin d'escriture auquel est representé les plus belles fleurs tant de la lettre françoyse que de la lettre italienne.

29. Les maîtres écrivains sont ainsi convoqués devant le parlement de Paris le 14 juillet 1632, comme en témoigne l'arrêt du Parlement de cette date conservé aux Archives nationales, série $\mathrm{X}^{1 \mathrm{~A}}$, article 2054.

30. J. Petré, Traité de l'art d'escriture avec les exemples de tous les différents caracteres, qui se pratiquent en ce royaume.

31. L. Senault, Curieuses et nouvelles recherches des escritures financieres et italiennes bastardes suivant l'usage le plus nouveau et le plus usité dans ce royaume.

32. J.-B. Alais, L'art d'ecrire. 
33. On peut prendre pour exemple l'arrêt pris par le parlement de Paris le 2 juillet 1661 pour régler un contentieux entre maîtres écrivains et maîtres des petites écoles qui durait depuis le précédent arrêt du Parlement de 1600. On peut trouver cet arrêt du 2 juillet 1661 dans un recueil d'arrêts du parlement de Paris conservé à la Bibliothèque nationale de France, F-23669 (735).

34. La Bibliothèque nationale de France conserve de nombreuses impressions d'arrêts de règlement $d u$ Parlement de Paris, très utiles à l'histoire des corporations parisiennes. On trouve notamment un arrêt de règlement précisant les réceptions des nouveaux maîtres écrivains dans le ms. fr. 21739, fol. 146-149.

35. Les maîtres écrivains comme leurs détracteurs s'accordent pour dire que « ainsi ne peut cet art estre dit des mecaniques, ains tenu entre les arts liberaux, estant les principaux exercices d'iceux tirez de l'esprit plutost que des actions du corps ", ici dans un recueil de lettres patentes royales conservé à la Bibliothèque nationale de France, F-23610 (532).

36. Sur ces questions, voir entre autres F. Cosandey (éd.), Dire et vivre l'ordre social en France sous l'Ancien Régime.

37. Archives nationales, Minutier central des notaires parisiens, étude XXIX, liasse 182, 21 juin 1645, «Location par Claude Michelet d'un étage de maison à Pierre Dubrueil ».

38. On lit par exemple dans un manuscrit conservé à la Bibliothèque Historique de la Ville de Paris, CP3784, fol. 17 : l'aspirant à la maitrise doit réaliser «trente pièces de présentation pour messieurs les anciens et puis vingt cinq pièces de chef-d'œuvre ».

39. Les « Six-Corps de Paris » est l'appellation qui regroupe les six corporations les plus puissantes de Paris, à savoir les apothicaires-épiciers, les bonnetiers, les drapiers, les merciers, les orfèvres et les pelletiers.

40. Pour en savoir plus sur ce sujet, consulter C. Cabane, " Aux plumes d'or". Les maîtres écrivains à Paris, calligraphes au XVII ${ }^{\mathrm{e}}$ siècle », p. 189-208.

\section{RÉSUMÉS}

Sous l'Ancien Régime, l'enseignement primaire est pris en charge par les curés, les maîtres des petites écoles laïcs, les instituteurs des congrégations... Les historiens de l'éducation ont cependant accordé moins d'attention à un autre groupe professionnel, celui des maîtres écrivains. Également négligés par les historiens des corporations, qui ne les font que rarement figurer dans leurs synthèses, les maîtres écrivains, dont la première communauté a été créée en 1570 à Paris, ont pourtant laissé des traces de leur enseignement, dans les archives notariales comme dans la production imprimée de l'époque ou les archives judiciaires. Ces traces éclairant leur activité sont au cœur de cette communication, qui se concentre sur le XVII siècle, afin de comprendre leur rôle dans le maillage éducatif parisien et le silence historiographique qui les entoure. Ils sont à la fois artisans, enseignants ou artistes : ce statut hybride n'expliquerait-il pas l'absence d'études les concernant? 
AUTEUR

CÉLIA CABANE

Conservatrice des bibliothèques, Bibliothèque nationale de France $(\mathrm{BnF})$ 


\title{
Les livres d'ingénieurs au XVIII siècle : le cas emblématique de Bélidor
}

\author{
Bernard Delaunay
}

1 Les ingénieurs ont-ils besoin de livres spécifiques ? Se poser la question et y répondre positivement, c'est reconnaitre que leurs savoirs et leurs savoir-faire se placent dans le monde de la technique, avec un statut particulier, celui, comme le nomme Hélène Vérin, des « sciences pratiques" :

«Ces "sciences pratiques" [...] qui se tiennent dans un lieu qui n'est pas celui du vrai mais celui du meilleur possible définissent le domaine dans lequel la technique moderne est apparue. ${ }^{1}$ "

Mais alors, il importe de définir ce qu'est un «livre d'ingénieur », et nous pourrions commencer par une tautologie, un livre d'ingénieur est un livre écrit pour les ingénieurs, le plus souvent par des ingénieurs. Passée cette "fausse évidence ", il convient de chercher plus avant ce qui fait la spécificité d'un livre que l'on pourrait qualifier, plus généralement, de livre technique. Il est possible de retourner la question en cherchant à savoir, au moins grossièrement, ce que n'est pas un "livre d'ingénieur ». Ce n'est pas un livre scientifique, exposant un savoir scientifique constitué, à des fins d'enseignement scientifique et de publication de résultats de recherche, sans visée pratique, c'est un livre constitué autour de la résolution de problèmes techniques, dans un champ donné. Ce n'est pas non plus un «manuel technique » destiné à un exécutant, même qualifié mais non concepteur. Il se situe en quelque sorte dans un entre-deux de la technique, ni scientifique producteur de savoir, ni pratique, au plus près de l'action donc, mais qui se caractérise par des savoirs et des savoir-faire spécifiques.

Nous nous proposons de questionner très partiellement l'historicité de ces livres, en particulier dans la forme qu'ils prennent au début du XvIII ${ }^{e}$ siècle. Dans la présentation concrète de quelques livres contemporains, anachronisme assumé, nous voulons dans une première partie, sorte de continuation de l'introduction, mettre en lumière quelques caractéristiques de ce type d'ouvrage et en faire ressortir une finalité, la 
formation, initiale ou continue, des ingénieurs. À partir d'un personnage emblématique, Bélidor, et de ses livres, son Cours de mathématiques ou plus encore, L'Architecture hydraulique, nous dégagerons quelques caractères propres de ses ouvrages en tentant de souligner leur nouveauté par rapport aux livres techniques précédents, comme les réductions en art ou les théâtres de machines. Enfin, dépassant cette première moitié du siècle des Lumières, nous chercherons à présenter l'existence d'un marché de l'édition du livre d'ingénieur destiné à une profession qui se constitue alors autour d'une technique «scientifisée ».

\section{Un anachronisme assumé}

4 Attention, il ne s'agit pas de comparer tout et n'importe quoi, de dire que tout procède de tout et réciproquement, mais de repérer des permanences incontournables. Le concepteur d'une machine hydraulique du XvIII ${ }^{e}$ siècle et l'équipe de conception d'un système radar font face à la difficulté de réaliser un objet technique complexe et pour cela utilisent des ressources intellectuelles, des connaissances et des expériences partagées, qui leurs sont fournies par des livres qui traitent de leur sujet. Pour oser, tout de même, un violent anachronisme, un ingénieur contemporain peut plus facilement entrer dans les livres de Bélidor que dans celui de Ramelli.

Pour faire comprendre plus directement ces caractéristiques en partant d'une expérience personnelle, nous commencerons par un exemple contemporain, le manuel de référence ${ }^{2}$ des ingénieurs radaristes des années 1960-1980, le "Skolnik ${ }^{3}$ ». Cet ouvrage qui est tout autant destiné à l'enseignement qu'à la pratique, contient l'essentiel des connaissances indispensables au métier des ingénieurs spécialistes de ce domaine, connaissances "enseignées » mais qui nécessitent évidemment une mise en pratique dans des équipes techniques. Ces connaissances sont à la fois théoriques, appuyées sur les mathématiques et la physique, partant des équations de Maxwell, le juste nécessaire pour démontrer les résultats pratiques et utilisant des résultats expérimentaux rationalisés, chaque fois que les phénomènes concernés ne sont ni modélisables ni mathématisables. La transmission des connaissances, après les indispensables présentations scientifiques et les développements mathématiques, se fait en partant des réalisations existantes ou des exemples pratiques. L'auteur précise bien que les connaissances mathématiques approfondies ne sont pas indispensables ou bien, si tel est le cas les rappelle brièvement :

«Altough mathematics is a valuable tool of the system engineer, no special mathematical background is assumed here. Where mathematics is necessary, it is reviewed briefly in the text. ${ }^{4}$ "

6 Nous pouvons également citer un autre ouvrage "de référence »: Théorie et calcul des asservissements linéaires ${ }^{5}$. Cet ouvrage est nettement plus théorique puisqu'il se propose de fournir aux ingénieurs chargés de concevoir des systèmes mécaniques automatiques, les règles et les méthodes de calcul des circuits électroniques commandant ces automatismes. C'est dans cet ouvrage que l'on trouve en exergue la phrase suivante :

« Nichts ist praktischer als eine gute Theorie. ${ }^{6}$ "

7 Ces deux exemples montrent qu'aujourd'hui encore, un livre d'ingénieur est à la fois un support d'enseignement et un outil d'aide à la résolution de problèmes pratiques se posant à un ingénieur travaillant dans un domaine technique donné. 


\section{Un personnage emblématique : Bélidor}

Fig. 1. - Portait de Bernard Forest de Bélidor.

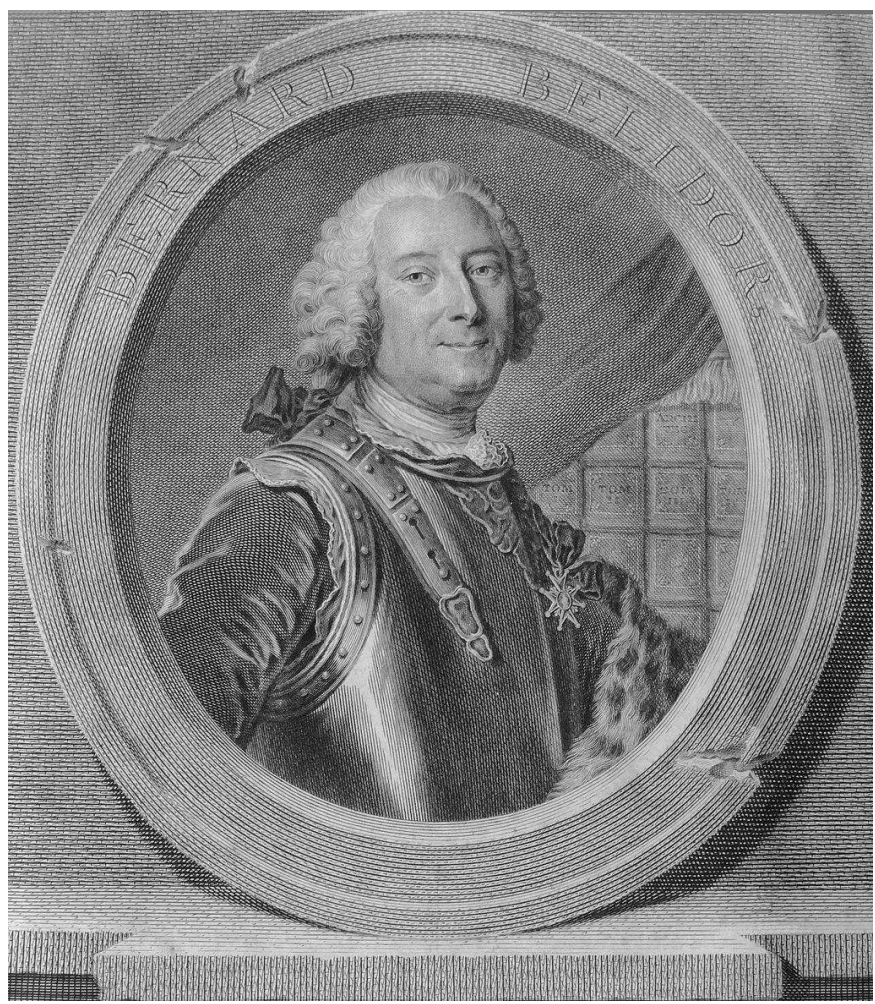

Frontispice de la seconde partie de l'Architecture hydraulique (1750).

Wikipédia : Architecture hydraulique - Seconde partie - Tome premier - 1750 @ Domaine public

Une remarque préliminaire : si Bélidor est très bien connu au XVIII ${ }^{\mathrm{e}}$ siècle et au début du XIX ${ }^{e}$ siècle (il fut réédité et commenté par des ingénieurs savants comme Coriolis ou Navier), il n'existe, à notre connaissance, aucun ouvrage qui en parle de façon détaillée, sauf un livre d'un ancien ingénieur hydraulicien du début du $\mathrm{xx}^{\mathrm{e}}$ siècle, qui se borne essentiellement à vérifier les calculs de Bélidor et ne donne qu'une biographie succincte, correspondant à l'éloge funèbre de Bélidor à l'Académie royale des sciences publié en 1763. Cet éloge, rédigé par Jean-Paul Grandjean de Fouchy, secrétaire perpétuel de l'Académie royale des sciences de 1743 à 1776, semble bien être la seule source biographique disponible ${ }^{7}$. Un ouvrage de synthèse publié à la fin du XVIII ${ }^{e}$ siècle reprend en abrégé l'éloge académique, sans ajouter d'information. Nous devons donc nous fonder sur cet éloge académique pour retracer la biographie de notre personnage.

Si on voulait le caractériser synthétiquement, nous pourrions dire qu'il commence une carrière d'ingénieur militaire, au sens du XvIII ${ }^{e}$ siècle, c'est-à-dire un spécialiste des fortifications, de l'attaque et de la défense des places. Il est ensuite enseignant dans des écoles techniques et rédacteur de "livres d'ingénieur». Après un retour à la vie militaire, il reprend une carrière administrative, tout en continuant une production d'ouvrages techniques et en renforçant ses liens avec le monde savant. Les guerres de la première moitié du siècle rythment sa carrière, en particulier la guerre de Succession d'Autriche. 

Fossébourg, officier d'artillerie, puis par la veuve de celui-ci, qui le confie à son frère, M. Cayot de Blanzy, ingénieur en chef auprès duquel il commence des études de mathématiques. Il l'accompagne aux sièges de Bouchain et du Quesnoy en 1712 (il a alors 14 ou 15 ans), où il acquiert une première expérience pratique. Touché par la "grâce mathématique ", lieu commun des éloges académiques du siècle, il se doit d'être touché ensuite par la "grâce académique » puisqu'il travaille à la prolongation de la méridienne, avec Cassini et de la Hire. Ceux-ci le détournent de la vocation religieuse, autre lieu commun, et le présentent au Régent qui le nomme professeur de mathématiques à l'école d'artillerie de La Fère (actuellement dans l'Oise, au nord-ouest de Laon) en 1720 (mais la date n'est pas certaine). Il faut toujours se souvenir qu'au xvIII siècle, des études de "mathématiques", un livre de "mathématiques", recouvrent aussi des "mathématiques pratiques", c'est-à-dire des éléments de physique.

11 À partir de sa nomination à l'école d'artillerie, il commence une carrière d'enseignant et fait paraître trois livres destinés aux élèves officiers des "Armes savantes ». Le premier ouvrage paru en 1725 , le Nouveau cours de mathématiques à l'usage de l'Artillerie et du Génie, remporte un grand succès dans le milieu des écoles d'artillerie. Bélidor devient alors commissaire d'Artillerie. Il publie en 1729, La Science des ingénieurs dans la conduite des travaux de fortifications et d'architecture civile. Suit en 1731 Le Bombardier français. Son ouvrage le plus connu, Architecture hydraulique, paraît entre 1737 et 1753 (avec une interruption au cours de la guerre de Succession d'Autriche). convaincre : son rédacteur, Jean-Paul Grandjean de Fouchy, secrétaire perpétuel de l'Académie, rend compte en détail des livres sans diminuer ses mérites militaires mais en les plaçant en toile de fond justificative. On peut dire que Bélidor fait "carrière " comme auteur de livres techniques. Une progression se dessine dans la suite de ses livres, avec d'abord un livre (Cours de mathématique à l'usage de l'Artillerie et du Génie) visant un public précis, les élèves de l'école d'artillerie de La Fère et les ingénieurs militaires, écrit dès le début de sa prise de fonction de professeur, puis un livre plus approfondi, destiné plus spécialement aux ingénieurs, au sens de l'époque, les officiers en charge de la réalisation des places fortes, de leur attaque et de leur défense ( $L a$ Science des ingénieurs), ainsi qu'un livre également plus approfondi sur le tir d'artillerie (Le Bombardier français). Enfin, l'Architecture hydraulique se dégage des seules préoccupations militaires pour s'étendre à tous les problèmes civils, tant de construction que d'aménagement et de construction de machines.

\section{Quels livres ? quelle nouveauté ?}

Les livres de Bélidor constituent, dans cette première année du siècle, une nouvelle approche de la technique. Le Cours de mathématiques, paru en 1725, ne se limite pas aux mathématiques, c'est un manuel d'ingénieur, en ce sens qu'il donne aux utilisateurs les moyens nécessaires à une exécution raisonnée et savante de leur métier. Ce n'est pas un manuel de règles standard, chaque proposition ou chaque théorème sont démontrés. Partout où cela est possible les démonstrations sont mathématiques, Bélidor cherche à asseoir une pratique savante des techniques des ingénieurs et des artilleurs sur des principes scientifiques. Dans cet ouvrage, Bélidor propose déjà le 
calcul par «fractions décimales», pour contourner la difficulté due aux unités du temps.

La Science des ingénieurs ${ }^{8}$, publié en 1729, est clairement une continuation du livre précédent: il l'avait annoncé dans la préface de celui-ci. Cette fois il n'y a plus, ou presque, de mathématiques, elles sont supposées connues par le cours précédent (Bélidor précise dans la préface que la mention en marge «V. le C. art. etc.» renvoie au cours de mathématiques, article etc.). Bélidor a pris de l'assurance, il est commissaire de l'artillerie en plus de son poste de professeur. Le livre est édité chez Jombert, qui va devenir libraire pour l'Artillerie et le Génie (ce n'est pas mentionné pour La Science des ingénieurs de 1729, mais apparaît sur le premier tome de l'Architecture hydraulique de 1737). Le contenu est plus nettement «technique », d'un niveau supérieur, comme s'il s'adressait à des ingénieurs plus confirmés ayant à assurer des responsabilités effectives de constructions d'ouvrages de fortification. Dans la préface, Bélidor expose l'objectif pédagogique du livre, qui est de rationaliser la formation des ingénieurs par des principes, par la théorie qui ne s'oppose pas à la pratique mais qui structure et rationalise l'apprentissage par l'expérience :

«Mais si l'on fait réflexion qu'on s'instruit fort lentement quand on apprend les choses qu'à mesure qu'elles se présentent et qu'il arrive rarement qu'un jeune ingénieur puisse voir dans une même province toutes les différentes espèces de travaux qui dépendent des fortifications, l'on conviendra que rien ne serait plus utile qu'un bon livre dans lequel il pût acquérir une connaissance générale de toutes les parties de son métier, afin que venant à passer d'une place à une autre, il ne se présente rien dont il ne puisse avoir la conduite dès qu'il joindra la théorie à ce que la pratique peut lui apprendre. ${ }^{9}$ "

Quoique ce livre soit encore plus, si l'on ose dire, un livre d'ingénieur, nous n'entrerons pas plus avant dans l'analyse détaillée des matières traitées; si l'on se reporte à la préface que donne Bélidor, le contenu y est résumé :

«Livre premier: Où l'on enseigne la manière de se servir des principes de la mécanique pour donner les dimensions qui conviennent aux revêtements des ouvrages de fortification, pour être en équilibre avec la poussée des terres qu'ils ont à soutenir.

Livre second: Qui traite de la mécanique des voûtes, pour montrer comme s'en fait la poussée et la manière de déterminer l'épaisseur de leurs pieds-droits.

Livre troisième : Qui comprend la connaissance des matériaux, leur propriété, leur détail et la manière de s'en servir.

Livre quatrième : Qui traite de la construction des édifices militaires et civils.

Livre cinquième : Où l'on enseigne tout ce qui peut appartenir à la décoration des édifices.

Livre sixième : Qui comprend la manière de faire les devis pour la construction des fortifications et celle des bâtiments civils. ${ }^{10}$ »

Cet ouvrage a été réédité en 1830 , cent après sa première édition, avec des notes et des commentaires d'Henri Navier, polytechnicien, ingénieur des Ponts et Chaussées ${ }^{11}$, preuve de l'intérêt persistant du travail de Bélidor, même si Navier reprend les calculs ou les raisonnements de Bélidor pour les corriger à partir des connaissances du début du XIX siècle.

17 La caractéristique que l'on peut souligner, est que Bélidor s'attache à démontrer, par le calcul ou par le raisonnement tous les résultats qu'il présente, les règles de construction et de dimensionnement des constructions, tant civiles que militaires. Le livre sixième, intitulé «Qui comprend la manière de faire les devis pour la construction des fortifications et celle des bâtiments civils " mérite d'être lu pour pénétrer une 
pensée d'ingénieur dans son aspect économique, un ordonnateur des travaux, combinant ce que nous distinguons aujourd'hui, maitrise d'ouvrage et maitrise d'œuvre, même s'il recommande d'avoir à traiter avec un seul entrepreneur, un maître d'œuvre donc, à chaque fois que cela est possible. Dans son Dictionnaire portatif, Bélidor donne la définition suivante du mot devis :

«DEVIS. Est un mémoire général des quantités, qualités et façons des matériaux, des ouvrages faits sur des desseins cotés et expliqués en détail, avec des prix à la fin de chaque espèce d'ouvrage, par toisé ou par tâche, que l'on remet aux entrepreneurs pour s'y conformer après l'adjudication; et lorsque les ouvrages sont achevés, on les examine tout de nouveau pour voir s'ils sont conformes au Devis, avant que de satisfaire au paiement parfait. ${ }^{12}$ "

Cette définition peut nous apparaître très contemporaine, très compréhensible aujourd'hui. Bélidor formalise une pratique existante puisque l'on connaît des devis de Vauban $^{13}$ mais cette partie est une véritable instruction méthodologique sur l'établissement des devis. Citons enfin ce passage connu de la Science des ingénieurs:

«On peut donc dire qu'un Devis doit être regardé comme le chef-d'œuvre de l'ingénieur et que c'est de là que dépend absolument l'exécution bonne ou mauvaise du dessein que l'on a en vue. Combien de fois n'est-il pas arrivé que de grands ouvrages ont échoué faute d'avoir été précédés d'un bon Devis. ${ }^{14}$ »

Le mot devis porte une signification plus large que celle que nous lui attribuons aujourd'hui, il s'agit d'un cahier des charges détaillé, où le problème technique est entièrement résolu par l'ingénieur qui n'attend des entrepreneurs que le chiffrage des lots de travaux correspondant aux différentes parties de la fortification à réaliser. Une fois l'adjudication faite, le devis de l'ingénieur devient un document contractuel qui sert ensuite à réceptionner les travaux et à déclencher les paiements.

Le Bombardier français, paru en 1731, est un ouvrage très spécifique au tir d'artillerie, contenant toutes les instructions nécessaires à l'emploi des mortiers pour tirer des bombes sur une place forte, avec des tables de réglages du tir analogues à ce que l'on nommerait aujourd'hui des « tables de tir ». 
Fig. 2. - Frontispice du Bombardier français.

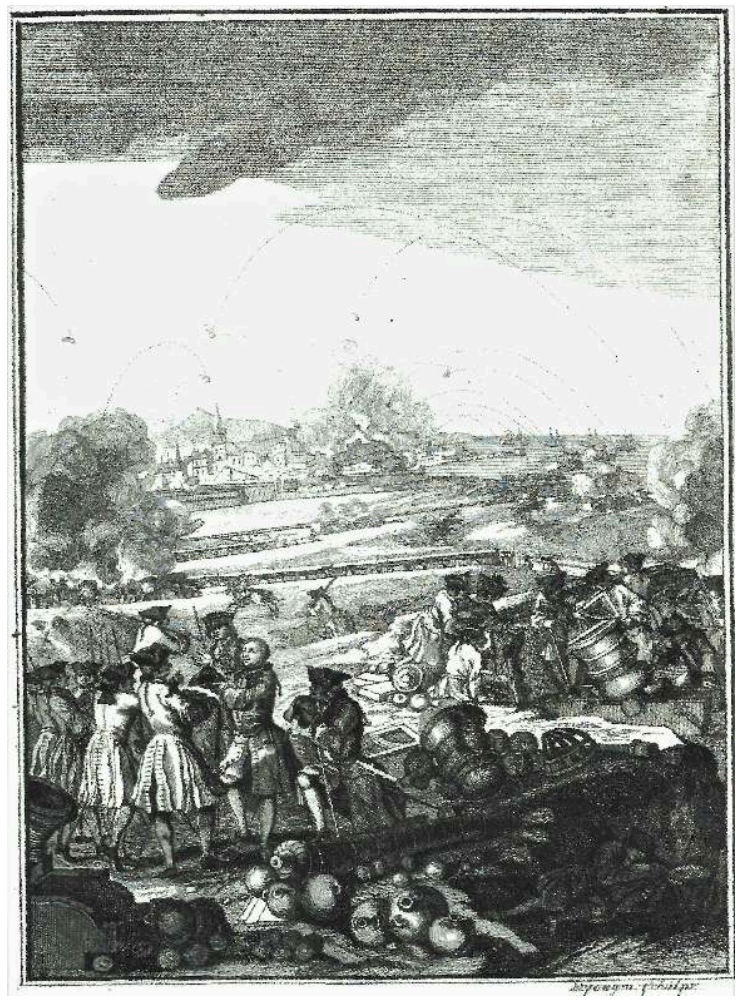

Source : Google Books.

21 Dans la guerre de siège de l'époque moderne, le tir au canon avec des boulets pleins n'a que peu d'effet sur les fortifications bastionnées, type Vauban et les canons ne tirent pas de projectiles explosifs. Ceux-ci sont tirés avec des mortiers. En observant le frontispice, on peut voir les mortiers qui tirent les bombes, les trajectoires courbes des bombes et les officiers réglant l'angle de tir du mortier. 
Fig. 3. - Extrait du Bombardier français, p. 25.

\begin{tabular}{|c|c|c|c|c|c|c|c|}
\hline \multicolumn{2}{|c|}{ Eprewves } & \multicolumn{2}{|c|}{ de. 122,6} & \multicolumn{4}{|c|}{ de I24 toijes, à Is. } \\
\hline 21.4 & $3 x \cdot 32$ & $.8 z$ & 1.9 .49 & 1,2 & $197 \cdot 47$ & & 127.55 \\
\hline 416 & $3 z$. & 84 & 10. 4 & 144 & 18. 5 & 204 & 28. 21 \\
\hline 218 & 32. $3^{8}$ & 86 & 10. 19 & 146 & 18. 22 & 206 & 28. 47 \\
\hline 220 & 33.13 & 88 & 10. 34 & 148 & 18. 40 & 208 & 29. 14 \\
\hline 222 & 33. 50 & 90 & 10. 49 & 150 & 18. 57 & 210 & 29. $4 \pi$ \\
\hline 224 & 34.99 & 92. & II. 4 & 152. & 19. 15 & 212 & 30. 9 \\
\hline 226 & 3.5. ro & 94 & IX. 20 & 154 & 19. 34 & $2 \pi 4$ & 30. $3^{8}$ \\
\hline 228 & 35.54 & -6 & 1.1. 35 & 156 & 19.52 & 216 & 31. 8 \\
\hline 230 & $3^{6 .} \cdot 4^{2}$ & 98 & 11. 50 & 158 & 20.10 & $2 \times 8$ & 3I. $3^{8}$ \\
\hline 232 & $37 \cdot 35$ & 100 & 12. 6 & 160 & 20. 29 & 220 & 32. 10 \\
\hline 2340 & 38.35 & 102 & 12.2 21 & 162 & 20. 48 & 222 & 32.44 \\
\hline 236 & 39. 42 & 104 & 12. 37 & 164 & $2 \pi \cdot 7$ & 224 & 33. 18 \\
\hline 238 & $41, \quad 18$ & 106 & 12. 52 & 166 & 21.26 & 226 & 33.55 \\
\hline 240 & 45.0 & 108 & 13. 8 & 168. & $2 \mathrm{I} \cdot 45$ & 228 & 34.33 \\
\hline $22^{t}$ & 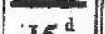 & IIo & 13.24 & 170 & 22. 4 & 230 & 35. 14 \\
\hline $22^{2}$ & $150^{\circ}$ & 11.2 & 13. 39 & 172 & 22. 24 & 232. & 35. $5^{8}$ \\
\hline$\cdot 56$ & 6. $3^{8}$ & $\begin{array}{l}114 \\
116\end{array}$ & $\begin{array}{r}13.55 \\
14.11\end{array}$ & $\begin{array}{l}174 \\
176\end{array}$ & $\begin{array}{l}22.44 \\
22.4\end{array}$ & $\begin{array}{l}234 \\
236\end{array}$ & $\begin{array}{l}36.45 \\
37.27\end{array}$ \\
\hline $5^{8}$ & 6. .2 & 318 & $14 \cdot 27$ & 178 & 23.25 & 238 & 38.36 \\
\hline 60 & 7. 7 & 120 & 14,43 & 180 & 23.46 & 240 & 39. 42 \\
\hline 62 & 7.21 & 2.22 & Is. & 182 & 24. & 242 & 41. is \\
\hline 64 & $7 \cdot 3^{6}$ & 124 & 15.16 & 184 & $24 \cdot 28$ & 244 & 45. 0 \\
\hline 66 & $7 \cdot 51$ & 126 & 15.32 & 186 & 2450 & & \\
\hline 68 & 8. 5 & 128 & 15.49 & 188. & 2.5 .71 & $124^{\circ}$ & $15 .^{d}$ \\
\hline 70 & 8. 20 & 130 & 166.5 & 190 & $25 \cdot 34$ & & \\
\hline 72 & 8. 35 & 132 & 16.22 & 192 & $25 \cdot 5^{6}$ & 56 & 6. $3 \mathrm{I}$ \\
\hline 74 & 8. 49 & 134 & 16. 39 & 194 & 26. 19 & $5^{8}$ & 6. 45 \\
\hline 76 & 9. 4 & 136 & 16.96 & 196 & 26.43 & 60 & 7. 0 \\
\hline 78 & 9. 19 & 138 & 17.13 & 198 & 27.6 & $6_{2}$ & 7. 14 \\
\hline & 9. 34 & 140 & $17.3^{\circ}$ & 20 & 27.31 & 64 & \\
\hline
\end{tabular}

Source : Google Books.

22 La méthode utilisée est la suivante : en premier lieu l'artilleur doit tirer un coup d'essai (tir d'épreuve) avec le mortier à pointer, la poudre dont il dispose, les conditions atmosphériques, en général ce qui est spécifique de la situation et toujours à un angle de tir de $15^{\circ}$. Par exemple sur la table ci-dessus, le tir à $15^{\circ}$ a lancé la bombe à 122 toises (environ 240 mètres) si l'objectif visé se trouve à 200 toises il faudra pointer le mortier à $27^{\circ} 31^{\prime}$. Ce livre est destiné aux officiers d'artillerie et fait très certainement partie de leur formation à l'école d'artillerie de La Fère, elle permet de régler le tir très rapidement.

23 L'Architecture hydraulique est sans doute l'ouvrage de Bélidor qui est le plus connu, le premier volume paraît en 1737, Bélidor l'avait annoncé dans la Science des ingénieurs. En 1737, Bélidor est professeur à l'école de La Fère depuis 17 ans, il est connu et reconnu pour ses ouvrages précédents, correspondant de l'Académie royale des sciences. L' Architecture hydraulique fait l'objet d'un examen officiel par l'Académie, deux commissaires ont été désignés, Nicole et Pitot, ils ont rendu un avis très favorable :

«Nous avons lu un livre intitulé Architecture Hydraulique par Mr. Bélidor, correspondant de l'Académie et nous croyons que cet ouvrage qui contient la description et la théorie de quantité de machines qui ont été exécutées avec succès sera très utile au public. ${ }^{15}$ "

24 Mais encore, et cela est très rare, un commentaire plus détaillé, plus élogieux, figure dans la première partie de l'Histoire de l'Académie pour 1737'16. L'Académie remarque le caractère très spécifique de l'ouvrage, à la fois rassemblement et mise en ordre de connaissances existantes complétées par de nouvelles connaissances, qui en fait un ouvrage de référence : 
«Il y en a deux sortes [d'ouvrages] à qui ce titre [très utile] peut appartenir en matière de Sciences, ceux qui donnent des vues nouvelles et solides et ceux qui, rassemblant ces vues répandues en un grand nombre d'ouvrages différents, non seulement empêchent qu'elles échappent aux savants même, comme elles pourraient le faire quelquefois, mais encore les fortifient par l'ordre et par l'union. Si de plus, de nouvelles vues s'y joignent, il n'y a rien de plus à désirer pour l'utilité et elle y est même plus grande que celle des ouvrages purement originaux. Telle est l'Architecture Hydraulique de M. Bélidor. C'est un grand corps de science, où tout est établi par ses premiers principes et suivi dans toutes ses conséquences et ses applications. ${ }^{17}$ "

Les trois premiers livres écrits par Bélidor étaient essentiellement des livres support de son enseignement à La Fère, cette fois le public visé est plus large, il ne s'agit pas seulement des ingénieurs militaires spécialistes des fortifications ou des officiers d'artillerie, il s'agit de toucher un public «civil», des «aménageurs ${ }^{18}$ ", des mécaniciens qui ne portent pas nécessairement le nom et, encore moins le titre d'ingénieur. L'Architecture Hydraulique devient le " livre de chevet » des ingénieurs des Ponts et Chaussées, et restera d'un usage courant jusque dans les années 1820-183019.

Fig. 4. - Frontispice de l'Architecture hydraulique.

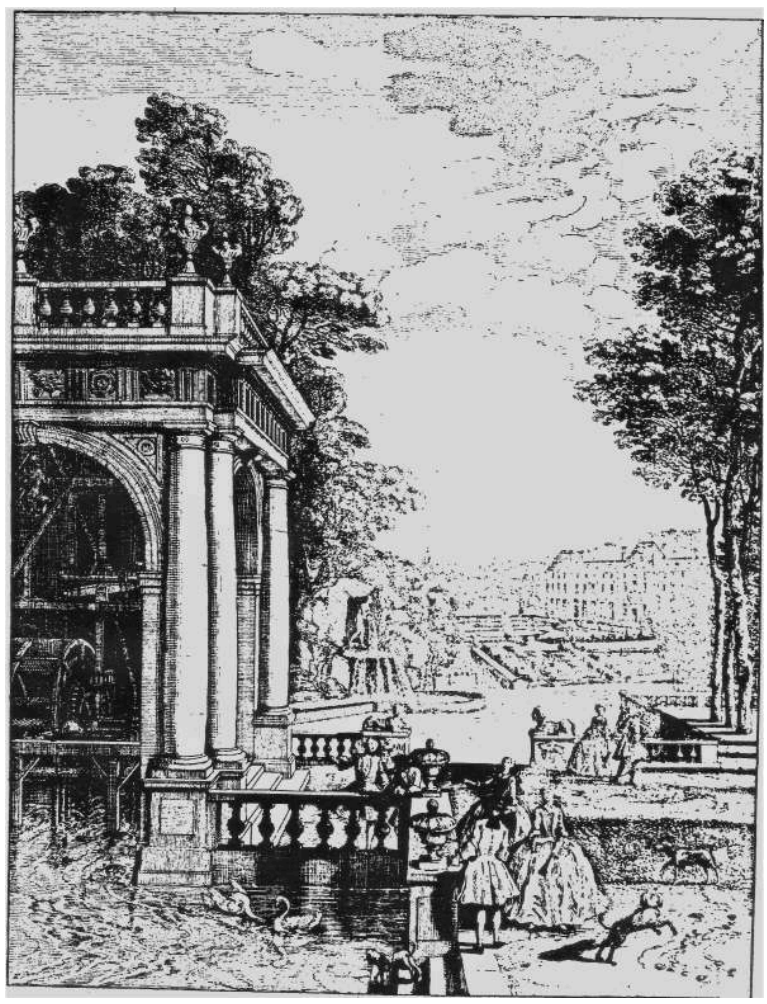

Source : Google Books.

Les matières traitées dans les deux ouvrages diffèrent alors très sensiblement. Le frontispice du premier volume illustre tout à fait ce passage du militaire au civil. Sur la partie gauche de ce frontispice, on peut observer une roue hydraulique entraînant par un jeu d'engrenage une pompe destinée aux fontaines du jardin, de plus les personnages ne sont plus des militaires mais des civils. Dans la Science des ingénieurs, il s'agit de construire des fortifications et leurs aménagements et, accessoirement, tous les édifices civils qui peuvent y être construits. Dans l'Architecture hydraulique, il s'agit 
de guider les constructeurs de bâtiments civils, de moulins hydrauliques, seuls " moteurs » utilisés au XVIII ${ }^{\mathrm{e}}$ siècle ${ }^{20}$, dans les aménagements hydrauliques. Le premier tome, après un exposé, dans le livre premier, des principes de la mécanique, traite des divers moulins. Dans le chapitre I du livre second, traitant des moulins à blé, Bélidor expose les principes généraux applicables à la réalisation des roues hydrauliques destinées à entraîner les moulins. Les chapitres suivants de ce livre traitent des moulins à scier (bois, pierre), à poudre, et à entraîner des pompes à chapelet pour épuiser les eaux. Nous ne nous intéresserons dans cet article au tome premier qui, de plus, contient une dédicace à l'Académie et une assez longue préface où Bélidor expose sa démarche. Passons sur la dédicace, morceau de bravoure de flagornerie, Bélidor cherche à l'évidence une reconnaissance académique plus éclatante que l'approbation, certes louangeuse, qu'il fait figurer au début de son livre, reconnaissance pouvant aller jusqu'à le faire passer de l'état de correspondant à celui d'associé libre, puisque, ne résidant pas à Paris, il ne peut être admis à aucun autre état. Mais cette consécration académique n'interviendra que bien plus tard, il échoue une première fois en 1746 contre d'Alembert pour être finalement élu en 1756 associé surnuméraire puis libre, en fin de carrière donc. On peut se demander si l'Académie n'a pas été réticente à accorder sa reconnaissance à un homme de la technique qui se voulait un ingénieur savant, mais ne semblait pas suffisamment savant aux yeux de l'institution.

Dès la préface, le ton est donné, le but de ce traité est de donner les principes, la théorie de «l'architecture hydraulique » opposée à l'architecture civile par sa complexité. Ce qui est en cause pour Bélidor, c'est la justification de la nécessité des mathématiques, de la théorie, et la volonté de sortir d'une opposition stérile entre théorie et pratique sans en mépriser aucune mais en montrant que la priorité de la théorie sur la pratique était indispensable à une bonne formation, théorie qu'il a, semble-t-il, des difficultés à faire admettre à ses élèves. $\mathrm{Si}$, en effet on peut admettre que les praticiens expérimentés arrivent à maîtriser leur pratique uniquement par l'expérience acquise, il n'est pas admissible que les « jeunes gens » se détournent de la théorie :

«Tout le monde conviendra que pour rendre un ouvrage accompli, il faut qu'il soit construit solidement, qu'il réponde bien à son objet et que la dépense soit tellement ménagée, qu'elle paraisse répandue que sur ce qui est indispensablement nécessaire. Ces conditions sont si naturelles qu'on en serait porté à croire que les gens du métier s'en écartent jamais si l'événement ne prouvait quelquefois le contraire [...] ils méritent bien plus d'excuse que de blâme d'être parvenus à faire les choses aussi passables qu'elles le sont sans autre secours que celui qu'ils ont tiré des réflexions qu'une longue expérience leur a suggérées, [...] cette manière de penser est une vraie théorie, à laquelle on doit le succès qui en est la suite ; alors sans le savoir on imite les Géomètres, on en a l'esprit et les vues puisqu'on cherche à parvenir au même but. [...]. Si l'on était en droit d'accuser d'un peu de négligence ceux qui ont la conduite des ouvrages qui intéressent l'État, ce reproche devrait principalement regarder les jeunes gens qui [...] affectent d'exalter la pratique au mépris de la théorie, espérant par là autoriser leur peu de goût pour l'étude, mais connaissent-ils cette pratique à laquelle ils veulent se borner ? ${ }^{21}$ ”

L'originalité de la démarche de Bélidor, rappelons qu'il assure une fonction d'enseignant pour des ingénieurs militaires chargés de construire des places fortes, est de se tourner vers les machines. Après avoir justifié l'emploi des mathématiques, en particulier de l'algèbre, l'importance de la théorie ${ }^{22}$ dans tout ce qui regarde la construction, alors qu'il enseigne depuis 10 ans, il prend conscience de la difficulté de la conception d'une machine : 
«[...] lorsque voulant faire le projet d'une machine pour élever l'eau, je fus fort surpris de ne savoir comment m'y prendre pour en déterminer exactement toutes les parties de manière à satisfaire un bon esprit qui m'aurait demandé compte de la disposition de chaque pièce, la raison de leur dimension, celle du degré de vitesse $[\ldots]^{23} »$

\section{Il conçoit alors une prolongation de son
mettant en ordre des écrits disparates :}

«[...] personne n'ayant écrit sur les Machines dans le goût que je viens d'insinuer [...] ainsi je ne songeai plus qu'à m'instruire pour me mettre en état d'instruire les autres $[\ldots]^{24}$ »

Il justifie ainsi le plan qu'il donne à son premier tome dont nous pouvons donner quelques éléments. En effet, le livre I qu'il nomme introduction, contient au chapitre I un rappel de mécanique générale qui traite de la statique et de l'équilibre des forces, des machines simples, de la mécanique élémentaire (mouvements uniformes et accélérés, chute des corps, plan incliné). Le chapitre II traite des frottements en s'appuyant sur les premiers résultats des académiciens Amontons et Parent (proportionnalité à la force appliquée, invariance en fonction de la vitesse pour le frottement sec). Le chapitre III aborde l'hydraulique, d'abord l'hydrostatique puis l'hydrodynamique, en particulier l'action de l'eau en mouvement sur les surfaces dans le but de rendre compte de l'action de l'eau sur les aubes de moulins et les écoulements. Dans la section XI, partant comme Parent de l'hypothèse de Mariotte sur l'action de l'eau sur une aube, il redémontre la formule de Parent, à savoir l'optimum de réglage du moulin hydraulique lorsque la vitesse tangentielle de l'aube est le tiers de la vitesse du courant. Il reprend d'ailleurs, mot pour mot, le début du mémoire de Parent de $1704^{25}$ stigmatisant les approximations « à l'aveugle » des machinistes, même les «plus habiles » et il en fait un vibrant éloge. Son apport essentiel est alors de détailler les conséquences pratiques des calculs de Parent, pour bien faire comprendre que des conclusions intuitives peuvent être totalement erronées, comme de considérer qu'une roue hydraulique entrainant une pompe, comme celle de la Samaritaine à Paris, donne d'autant plus d'eau qu'elle tourne vite :

« Si je me suis un peu étendu sur un sujet qui pouvait être expliqué en moins d'une page, c'est que mon dessein est d'écrire pour tout le monde et que je me suis aperçu qu'il n'était point aisé de faire entendre à bien des gens et même à ceux qui s'imagine savoir beaucoup, que c'était une erreur de conclure que plus une roue avait de vitesse et plus l'effet de la machine était grand..$^{26}$ "

31 Afin de faciliter l'utilisation des résultats théoriques, Bélidor prend soin de donner des tables où l'on peut trouver les vitesses de courant, les hauteurs de chutes donnant cette vitesse, le « choc » (la force) exercée sur un pied carré.

Bélidor reprend également le tube de Pitot, dispositif destiné à mesurer la vitesse d'un courant d'eau (ou réciproquement la vitesse d'un navire par rapport à l'eau). Cette première partie (livre I) se termine par la flottabilité, le théorème d'Archimède. Cette longue introduction théorique occupe 276 pages sur 388 pages de texte, hors planches non paginées, préface et tables des matières, $71 \%$ donc de ce premier volume. Le livre II expose très en détail les différents usages que l'on peut faire de ces «moteurs hydrauliques » avec les particularités diverses d'installation, les différents types de roues, l'application des résultats théoriques de la première partie. On y trouve les moulins à blés, les machines à scier, les moulins à poudre, les moulins à chapelets, les machines à épuiser les eaux. Le discours se fait plus applicatif et Bélidor prend soin 
d'asseoir ses recommandations et ses calculs sur des exemples existants. Ainsi, on trouve la description d'un moulin exécuté à Mont-Royal avec les proportions des pièces, le calcul de toutes les parties ou bien la description des moulins du Basacle à Toulouse ou bien encore la description d'un moulin utilisant la force marémotrice à Dunkerque. Le propos pédagogique est clair : après les principes généraux de calcul, les exemples calculés illustrent la méthode, la justifient et servent à convaincre le lecteur de l'utilité de ces calculs et de ces formules.

Nous nous limiterons ici à l'examen détaillé de ce premier tome de l'Architecture hydraulique, et nous ne dirons rien d'autre sur les autres tomes que leur contenu général. Le deuxième tome traite des propriétés de l'air, la pression atmosphérique en particulier, des moulins à vent, des pompes, des machines actionnant les pompes, de la machine hydraulique du Pont Notre-Dame et des améliorations projetées par Bélidor pour le compte de la Ville, de la distribution de l'eau et des écoulements. Un chapitre est consacré aux machines à vapeur ${ }^{27}$, ensuite Bélidor traite des aqueducs et autres dispositifs de distribution dans une ville ou dans les jardins d'agrément. Le troisième tome parait 11 ans après les deux premiers et traite des travaux d'aménagements hydraulique et non plus de machines, il contient :

"L'art de construire les écluses pour diriger les eaux de la mer et des rivières, à

l'avantage de la défense des places, du commerce et de l'agriculture. ${ }^{28}$ "

Le quatrième tome parait peu de temps après le troisième et c'est une continuation des aménagements hydrauliques, le sous-titre est donc le même que celui du troisième tome, la numérotation des livres se fait en continuité avec celle du troisième. Ce dernier tome contient comme le premier un frontispice très représentatif du projet de Bélidor.

\section{Pour conclure}

La diffusion des ouvrages de Bélidor est bien attestée, par leur longévité d'abord. Nous l'avons cité, c'est le "livre de chevet » des ingénieurs des Ponts et Chaussées. Autre indice d'une diffusion au-delà des cercles immédiats des "ingénieurs savant", l'utilisation de ses ouvrages comme "livre du maitre " à l'école de mathématiques pratique de Reims ${ }^{29}$. Cette école sert de classe préparatoire aux écoles du Génie et de l'Artillerie où l'on retrouve l'importance de Bélidor ${ }^{30}$.

Les livres publiés chez Jombert portent la mention «Jombert, libraire du Roi pour le génie et l'artillerie »: on peut considérer que cet éditeur, ou plutôt cette maison d'édition, tient une place centrale dans la diffusion de ces «livres d'ingénieur». Le catalogue est considérable, il comprend plus de 200 titres, on y retrouve beaucoup d'auteurs connus, Vauban, Pitot, Bouguer, Deidier, Wolff, etc. Les prix sont significatifs : les 4 volumes de Bélidor coûtent 100 livres en 1771 (quelque chose comme 100 journées de manœuvre à 20 sols la journée); c'est donc cher, mais apparaître au catalogue de Jombert signifie une réputation assurée. Cependant, en explorant plusieurs catalogues de vente de bibliothèques, nous n'avons pas trouvé de livres de Bélidor, alors que les Histoires de l'Académie royale des sciences ou l'Encyclopédie y sont très souvent présents, pour ne citer que ces ouvrages connus. Tout se passe comme si Bélidor était connu et reconnu parmi les ingénieurs ou les savants, mais que sa renommée se limitait à ce cercle plus étroit quoique très significatif. 
Nous voudrions terminer cette présentation des ouvrages de Bélidor en soulignant la nouveauté qu'ils apportent aux ouvrages techniques, tels que les "Réduction en art » ou les "Théâtres de machines" des $\mathrm{XVI}^{\mathrm{e}}$ et XVII ${ }^{\mathrm{e}}$ siècles. C'est une nouvelle approche : non plus partir de la pratique pour rassembler des pratiques dispersées, encore que cette volonté de synthèse ne soit pas absente, nous l'avons vu, mais partir de la théorie pour passer à la pratique à partir d'exemples analysés, calculés, « exemplifiés ", d'où la structure différente des traités de réduction en art et des livres comme ceux de Bélidor. Dans ceux-ci, des démonstrations, des descriptions à partir desquelles on " réduit », on rédige, des principes généraux des formules ou des tables qui sont destinés à aider le concepteur et non à le guider étroitement. Naturellement nous durcissons cette opposition pour montrer l'évolution de la réduction en Art vers un autre type de littérature technique. L'opposition n'est pas aussi caricaturale, Bélidor rassemble des savoirs dispersés dans l'Architecture hydraulique; force est tout de même de bien constater que le modèle s'impose et se retrouve au siècle suivant, on peut le voir dans le Traité élémentaire de mécanique industrielle de Stéphane Flachat, jusqu'aux exemples contemporains qui ont été cités en introduction. Autre exemple, cette fois contemporain de Bélidor, l'ouvrage de Pitot, La théorie de la manœuvre des vaisseaux réduite en pratique, dont le titre est très explicite. Il s'agit non plus de "réduire en art ", mais partir de la théorie pour la « réduire en pratique » : c'est-à-dire rédiger la pratique à partir de la théorie et non mettre en ordre et rédiger l'art.

Il semble raisonnable de dater l'apparition des livres d'ingénieur, dans leur acception actuelle du début du XvIII ${ }^{\mathrm{e}}$ siècle. C'est aussi contemporain, voire un peu antérieur de « la naissance de l'ingénieur moderne » (A. Picon) et des écoles d'ingénieurs. Ces livres sont à la fois des livres d'enseignement et des guides pratiques de conception pour les ingénieurs. On y observe un glissement progressif de la pensée opératoire vers le régime de la technologie par l'instauration d'une nouvelle relation entre théorie et pratique et la mobilisation des savoirs scientifiques et des mathématiques « au service » de la technique. Avec Bélidor nous découvrons un acteur essentiel, assez peu connu en fait, représentant caractéristique de ce glissement ${ }^{31}$.

\section{BIBLIOGRAPHIE}

DELAUNAY Bernard, Penser la technique à l'Académie Royale des sciences, Paris, Honoré Champion, 2018.

DELAUNAY Bernard, « Newcomen à l'Académie », e-Phaistos, VI-1 2017-2018.

FLACHAT Stéphane, Traité élémentaire de mécanique industrielle, Paris, Tenré et Dupuy, 1835.

FOREST DE BÉLIDOR Bernard, Nouveau cours de Mathématique à l'usage de l'Artillerie et du Génie, Paris, Nyon, 1725. 
FOREST DE BÉLIDOR Bernard, La Science des ingénieurs dans la conduite des travaux de fortifications et d'architecture civile, Paris, Jombert, 1729.

FOREST DE BÉLIDOR Bernard, Le Bombardier français, [Paris, 1731], Amsterdam, (?), 1734.

FOREST DE BÉLIDOR Bernard, Architecture hydraulique, Paris, Jombert, 1737, 1739, 1750, 1753, (4 vol.).

FOREST DE BÉLIDOR Bernard, Dictionnaire portatif de l’ingénieur, Paris, Jombert, 1755.

FOREST DE BÉLIDOR Bernard, La Science des ingénieurs dans la conduite des travaux de fortifications et d'architecture civile, réédition par Navier, Paris, Firmin Didot, 1830.

GARÇON Anne-Françoise, L'Imaginaire et la pensée technique, Paris, Garnier, 2012.

GILLE Jean-Charles, DECAULNE Paul et PÈLERIN Marc, Théorie et calcul des asservissements linéaires,

Paris, Dunod, 1970.

$\left.{ }^{(* *}\right)$, Histoire de l'Académie royale des sciences avec les mémoires de mathématiques et de physique tirés des registres de cette Académie, année MDCCLXI, Paris, Imprimerie royale, 1763.

PICON Antoine, « Les ingénieurs et la mathématisation. L'exemple du génie civil et de la

construction ", dans Revue d'histoire des sciences, t. 42, $\mathrm{n}^{\circ}$ 1-2, 1989.

PICON Antoine, L'Invention de l'ingénieur moderne : l'École des Ponts et Chaussées (1747-1851), Paris,

Presses de l'École nationale des Ponts et Chaussées, 1992.

РІтот Henri, La Théorie de la manœuvre des vaisseaux réduite en pratique, Paris, Jombert, 1731.

PON-WILLEMSEN Charlotte, « L'enquête de Vauban en 1681 », dans Groupement d'études rétaises, Cahiers de la Mémoire, ${ }^{\circ}$ 22, hiver 1985.

SKOLNIK Merrill I., Introduction to radar systems, International student edition, Mc Graw Hill, New York, 1962.

VÉRIN Hélène, La Gloire des ingénieurs, Paris, Albin Michel, 1993.

\section{NOTES}

1. H. Vérin, La Gloire des ingénieurs, p. 10.

2. De la même manière, Antoine Picon qualifie l'Architecture hydraulique de Bélidor d'ouvrage de référence des ingénieurs des Ponts et Chaussées jusqu'aux premières décennies du XIX ${ }^{\mathrm{e}}$ siècle, voir infra.

3. M. I. Skolnik, Introduction to radar systems.

4. «Bien que les mathématiques soient un outil utile pour l'ingénieur système, aucunes connaissances mathématiques préalables ne sont supposées dans cet ouvrage. Là où les mathématiques sont nécessaires, elles sont revues brièvement dans le texte". M. I. Skolnik, Introduction to radar systems, p. v.

5. J.-Ch. Gille, P. Decaulne et M. Pèlerin, Théorie et calcul des asservissements linéaires. La technique des asservissements est au fondement de tous les automatismes mécaniques.

6. La traduction est évidente, l'auteur est mentionné : A. Leonhard, un auteur allemand dont nous n'avons pu retrouver l'ouvrage d'où elle tirée.

7. $(* * *)$ : Histoire de l'Académie royale des sciences (...), année MDCCLXI. p. 167-181 (en abrégé HARS 1761). 
8. Le titre est très explicite, le métier d'ingénieur doit avoir des fondements scientifiques et pas seulement pratiques.

9. Bélidor, La science des ingénieurs, Préface, np. C'est nous qui soulignons.

10. Ibid. p. np.

11. La science des ingénieurs dans la conduite des travaux de fortifications et d'architecture civile, réédition par Navier.

12. Dictionnaire portatif, p. 96.

13. Voir C. Pon-Willemsen, «L'enquête de Vauban en 1681 ».

14. La Science des ingénieurs, Livre VI, p. 2. (pagination par livre). Il est intéressant de rapprocher ce mot français de l'anglais to devise qui signifie «imaginer, inventer, concevoir ", remplacé par to design, les deux mots n'ayant pas de connotation financière, le devis financier se traduisant par « quotation ».

15. Archives de l'Académie des sciences, registre de séance du 30 juillet 1737 (en abrégé AADS, R 30 juillet 1737).

16. HARS 1737, p. 105.

17. Ibid., p. 105.

18. On voudra bien pardonner ce néologisme, mais il semble assez approprié, compte tenu de la place que va prendre l'Architecture hydraulique dans le bagage des ingénieurs des Ponts et Chaussées.

19. A. Picon, «Les ingénieurs et la mathématisation. L'exemple du génie civil et de la construction » dans Revue d'histoire des sciences, note 3 p. 157.

20. Les moulins à vent sont également traités mais leur importance est nettement moindre que celle des moulins hydrauliques.

21. Architecture hydraulique, np.

22. Les calculs des murs en fonction de la poussée des terres, la résistance des voûtes, le calcul des voûtes, etc.

23. Ibid., np.

24. Ibid., np.

25. AADS, R 26 novembre 1704.

26. Architecture hydraulique, p. 251.

27. Machines de Savery et de Newcomen. (Voir B. Delaunay "Newcomen à l'Académie », e-Phaistos, VI-1 2017-2018).

28. Bélidor, Architecture hydraulique, tome 3, p. 1.

29. Voir B. Delaunay, Penser la technique à l'Académie Royale des sciences, p. 300-302.

30. Ibid. p. 322-323.

31. Au sens que donne A.-F. Garçon dans L'Imaginaire et la pensée technique. 


\section{RÉSUMÉS}

Précédant la création des premières écoles d'ingénieurs au milieu du XVIII siècle, un nouveau type d'ouvrage technique apparaît et contribue fortement à la diffusion d'une nouvelle pensée technique. Bélidor, professeur à l'école d'Artillerie de La Fère est un exemple de ces ingénieurs qui écrivent des livres pour les ingénieurs, pour les former, pour leur transmettre des connaissances techniques d'une façon nouvelle. À travers ses ouvrages, comme la Science des ingénieurs, le Bombardier français et L'Architecture hydraulique, cet article se propose d'analyser l'apparition de ce nouveau mode de transmission de la technique et les caractères propres de ce type de livres appelés à un grand développement. Ces ouvrages permettent également un renouvellement de l'enseignement « technique » destiné en particulier aux futurs ingénieurs. Ces ouvrages caractérisent alors l'évolution de la pensée opératoire qui entre dans le régime de la technologie.

\section{AUTEUR}

\section{BERNARD DELAUNAY}

Docteur en histoire, chercheur associé à l'Institut d'histoire moderne et contemporaine, Université Paris 1 - Panthéon-Sorbonne 


\title{
Le projet épigraphique de Jean- François Séguier : fondements, réalisation, portée (1703-1784)
}

\author{
Michel Christol
}

1 Le projet scientifique de Jean-François Séguier, membre important de la « République des Lettres » comme le montre l'intérêt qui lui fut porté par D. Roche ${ }^{1}$, et comme le renouvelle un projet de publication de sa correspondance, conduit depuis Aix-enProvence par Emmanuelle Chapron, avec le concours très actif à Nîmes de François Pugnière $^{2}$, est pour notre propos exemplaire. Il est au cœur de la question de la transmission d'un savoir à l'époque de l'Encyclopédie, car en même temps qu'il envisage la réalisation de cet objectif, il l'associe à la constitution de ce savoir luimême. On peut rapidement illustrer ces deux propositions qu'il fit sienne tout au long de sa vie, et plus particulièrement quand il revint à Nîmes, sa ville natale, en 1755 : un savoir ne doit pas rester isolé et replié sur lui-même, il doit rayonner ; inversement, un savoir qui se diffuse doit être un savoir rigoureusement constitué : à quoi servirait-il s'il était incertain ou incomplet? Combien dérisoire et même fallacieuse serait la diffusion d'un savoir insuffisant ou altéré.

2 Jean-François Séguier a sa place dans la constitution de la science épigraphique. Mais il suffit de revenir sur le déroulement de sa vie scientifique et d'en analyser les contenus. En son temps, son rayonnement vint établir sa position et sa réputation; à présent, la redécouverte de son quotidien scientifique le confirme, et toutes les recherches sur les «archives" qu'il a laissées (correspondance, notes de travail, bibliothèque, et même une demeure faite pour accueillir les visiteurs et présenter ses collections) sont là pour faire surgir l'« existentiel » d'un homme de savoir. Le carnet dans lequel il signala, à partir de 1773, les personnes de toute l'Europe qui venaient le rencontrer à Nîmes, visiter ensemble les monuments de la ville et aborder des sujets scientifiques, en constitue un témoignage exceptionnel ${ }^{3}$. En matière d'épigraphie latine sa réputation avait été confortée par la restitution de l'inscription apposée sur la façade de la Maison Carrée à Nîmes, car elle avait fait grand bruit en 1758 et en 1759 , d'abord par sa divulgation à l'Académie des Inscriptions où les découvertes archéologiques au site de 
la fontaine avaient déjà impressionné, puis par la publication qui en 1759 en avait plus largement fait connaître son contenu $u^{4}$. Mais il était aussi très connu dans le monde des naturalistes, et ses connaissances en numismatique étaient tout aussi remarquables.

Ce n'est pas la renommée parmi les élites qui accomplirent le "Grand Tour » en passant par Nîmes qu'il importe d'examiner dans le cadre retenu pour le congrès. C'est l'attachement durable à la réalisation d'une œuvre qui, à la différence des travaux de botanique ou d'histoire naturelle, resta inédite. Cette œuvre fut engagée à l'initiative du marquis Scipione Maffei, grand personnage de la «République des Lettres », qu'il accompagna dans tous les lieux marquants de l'Europe, puis en Italie. Peut-être même cette œuvre aurait-elle été oubliée - en tout cas minorée -, si le projet nécessaire, mais grandiose et ambitieux - trop grandiose et trop ambitieux peut-être - qu'avait conçu cet Italien si original de l'Europe des Lumières, avait pu être réalisé. Car l'activité scientifique de Jean-François Séguier, déclarée et assumée de manière forte, se réalisa et s'exprima plutôt en deçà des intentions initiales énoncées à l'initiative de Scipione Maffei dans le Prospectus de la Nouvelle académie de Vérone (1732) qui s'adressait aux savants de toute l'Europe : réaliser un recueil complet des inscriptions de l'Antiquité, et l'accompagner d'une sorte de guide scientifique, l'Ars critica epigraphica. L'aboutissement de l'effort dans un immense recueil, bien ordonné, ne se produira qu'un peu plus d'un siècle après, et dans une approche différente en ce qui concerne la réalisation formelle, la classification : c'est le corpus de Berlin, réalisé sous l'autorité de l'Académie de Prusse et de Théodore Mommsen, assisté en premier par W. Henzen et par G. B. de Rossi. Quant à l'ouvrage sur l'Ars critica epigraphica, il sera publié par Sebastiano Donati en 1765, à Lucques, avec un titre qui montre tout l'apport de Scipione Maffei, mais qui montre aussi les conditions de l'achèvement: Clarissimi viri Scipionis Maffei marchionis Artis criticae lapidariae quae extant, ex ejusdem Autographo ab Eruditissimo viro Ioh. Francesco Séguiero Nemausensi fideliter excripta, et a Sebastiano Donato Presbytero Lucensi Edita, variisque observationibus inlustrata, et aucta. J.-Fr. Séguier avait confié à ce savant italien tout ce qui avait été préparé par son maître et il l'avait transcrit de sa belle écriture pour faciliter le travail de l'auteur.

4 Mais, tout autant que le travail actif d'interprétation et d'exploitation, qui s'exprime à la fois dans la publication de la restitution de l'inscription de la Maison Carrée et dans la correspondance qui comporte très souvent une part d'érudition, il faut tenir compte d'un ensemble de manuscrits de nature très diverse, mais tournés vers la même finalité. Ce sont les manuscrits de la BnF cotés de 16929 à 16935. Ils appartenaient aux divers fonds légués par Séguier à l'académie de Nîmes, à sa mort en 1784. Ils étaient devenus biens de la ville après la suppression de cette institution. Ils furent prélevés et transférés à Paris en 1805 par Chardon de La Rochette, ce qui a laissé un souvenir amer dans la mémoire locale.

5 Ils contiennent une histoire de l'épigraphie latine, plus narrative et bibliographique qu'explicative, des inventaires mettant en évidence la quête bibliographique, dont on trouve un pendant dans de nombreuses lettres où percent les soucis d'acquisition d'ouvrages ou, plus généralement, d'informations, un recueil de copies d'inscriptions italiennes, vues ou relevées par d'autres. Ici, Séguier est dans la continuité du Prospectus de 1732. Mais ce qui émerge plus nettement, ce sont les deux ouvrages dits de l'index absolutissimus (BnF 16934 et 16935) $)^{5}$. Ils ont retenu l'attention des spécialistes qui connaissaient l'œuvre de Séguier, et ils correspondent bien à l'entreprise qui, dans 
l'esprit de Séguier lui-même au sein du vaste projet de Scipione Maffei, représentait l'objectif à viser de façon nécessaire et le possible à réaliser dans une vie de savant.

Jean-François Séguier paraît avoir poursuivi consciencieusement la réalisation de son ouvrage jusqu'à la fin de sa vie, même si l'on peut constater que des informations obtenues sur des inscriptions signalées par ses correspondants n'avaient pas encore trouvé place dans les listes qu'il avait confectionnées. Il s'explique sur son entreprise dans quelques feuillets, formant un petit cahier qui a été rattaché au premier volume de la série, le manuscrit BnF 16929. Il est intitulé Fragments de traduction des prolégomènes du grand ouvrage de M. Séguier. Le titre est d'une autre main que la sienne, mais les pages qui furent rédigées sont de l'écriture du savant ${ }^{6}$. Se suivent deux textes d'à peu près une égale longueur, mais le second a été biffé et annulé, quoique conservé : il est placé à la suite, mais c'est la première version. Son contenu fut remanié, mais la rédaction initiale fut conservée, comme une archive. On dispose ainsi de deux étapes d'une réflexion. Il y eut donc de la part du rédacteur le souci d'améliorer, par des reprises et par des modifications, l'expression de sa pensée. En reprenant le fil de ces rédactions, qui se placent à un certain intervalle l'une de l'autre, on parvient à saisir un aboutissement de la réflexion sur le déroulement d'une œuvre, en isolant les points repris ou les passages fermement remaniés. C'est une réflexion, mûrie par la distance de l'abandon, de la reprise et de la réécriture, sur l'activité destinée à constituer un horizon scientifique. Le second texte comporte ainsi de profonds remaniements du plan et parfois du contenu, il y a des suppressions, compensées par quelques amplifications et par des adjonctions.

7 À l'instar du projet défini par le Prospectus, lancé par l'académie de Vérone à l'instigation du Marquis Scipione Maffei, le travail de Séguier part d'un ensemble de constats. L'utilité des inscriptions antiques comme source documentaire avait été reconnue depuis longtemps. L'utilité des inscriptions latines attirait l'attention sur l'Italie, sur Rome et sur les diverses cités de la péninsule, mais aussi sur les régions européennes auxquelles s'était imposée la domination romaine. L'utilité des inscriptions grecques avait été mise en évidence dans le courant du XviII ${ }^{e}$ siècle par de nouvelles découvertes et par la divulgation de nouveaux documents, dans laquelle les savants britanniques se mettaient en valeur. C'était, comme Maffei l'avait écrit dans le Prospectus, un moyen de saisir l'ensemble de l'Antiquité.

8 Mais sur tous les recueils, soit particuliers, c'est-à-dire se rapportant à une ville ou une région, soit généraux, c'est-à-dire permettant d'embrasser de plus amples problèmes que ceux d'histoire locale, pesaient des suspicions que déploraient les érudits mais qu'ils étaient impuissants à faire disparaître. Ils se retrouvaient devant les mêmes difficultés que Mabillon et ses disciples mauristes, devant le foisonnement de textes hagiographiques de valeur inégale, parfois corrompus, parfois fabriqués. Il fallait séparer le vrai du faux dans un champ documentaire bien délimité. Séguier met en évidence les trois défauts qui portent ainsi atteinte au "vrai » : les « copies infidèles ", les «corrections arbitraires», les «monuments suspects de fausseté ». Il fallait de surcroît ajouter aux documents déjà connus ceux que le hasard, les prospections ou les recherches faisaient apparaître un peu partout. La circulation des inédits, leur communication d'érudit à érudit faisait en effet partie des usages de la correspondante savante. Toutes les archives du savant, la correspondance, les notes volantes qui subsistèrent en portent largement témoignage. 
9 L'ouvrage de référence était le recueil de Jan Gruter (Anvers, 1560 - Heidelberg, 1627), intitulé Inscriptiones antiquae totius orbis Romani in corpus absolutissimum redactae, publié à Heidelberg en 1601, puis réédité en 1707 à Amsterdam avec les compléments qu'avait apportés J. G. Graevius (1632-1703), alors en quatre volumes, mais sans que l'on puisse envisager que la facture de l'œuvre avait été améliorée. Gruter avait été aidé pour la confection des index par J. J. Scaliger (1540-1609), grand érudit français qui termina sa vie comme professeur à Leyde. Toutefois l'ouvrage souffrait d'être de plus en plus incomplet, mais aussi de comporter des erreurs et d'avoir accueilli des faux ${ }^{7}$. Le Novus thesaurus veterum inscriptionum de L. A. Muratori (1672-1750), archiviste et bibliothécaire du duc d'Este à Modène, en quatre volumes, parus en 1739-1742, plutôt que de combler un vide avait ravivé les polémiques dans le milieu érudit, suscitant des déclarations enflammées et le dénigrement des plus modérés des savants ${ }^{8}$, car les imperfections étaient encore plus flagrantes. La question du travail sur la documentation, tâche d'érudition, devenait essentielle, si l'on souhaitait séparer le vrai du faux.

10 C'est cet objectif qui, lorsqu'il devient primordial afin d'assurer les fondements de l'édifice à construire, imposa un détour méthodologique et une révision des objectifs. Il imposa l'effacement de l'impératif qui avait conduit - en particulier J. J. Scaliger lorsqu'il composa les «tables » qui suivaient le corpus de Gruter (corpus absolutissimum) - à la confection des index en fin d'ouvrage, afin de mieux parcourir ce qui avait été ordonné et constitué en documentation pour le savoir, c'est-à-dire une intervention réalisée a posteriori. En remplacement, on accordait tous les soins à un outil destiné à préparer cette documentation, en réglant en premier lieu la question du vrai et du faux, c'est-à-dire en se donnant les moyens de séparer les inscriptions authentiques et les inscriptions fabriquées ou bien imparfaitement établies. On s'imposait un préalable qui reculait l'aboutissement du travail en le soumettant à un a priori. Le travail de Séguier est, d'une manière consciente, un nécessaire travail préparatoire destiné à protéger les savants des insuffisances ou des erreurs qui existaient dans la documentation accessible, et qu'il devenait insupportable d'accepter si l'on voulait préserver l'intégrité du savoir, celui du savant lui-même et celui des membres de la même communauté savante avec l'aide de qui il pouvait constituer ou faire apparaître un savoir plus accompli. Il se plaçait dans la perspective du projet de Maffei, qui composait en parallèle une ars critica epigraphica, mais il le façonnait à sa propre manière, en étalant dans le temps sa réalisation et en faisant précéder la collectio universalis ou le corpus que voulait réaliser le bouillant marquis, d'un répertoire préalable, nécessaire scientifiquement, un index.

11 On peut alors s'interroger, comme le fait Séguier, sur les critères d'organisation du répertoire général, en partant du constat de l'impossibilité de contrôler de visu toutes les inscriptions. Il faut substituer à l'inspection directe du monument, qui reste exceptionnelle, une connaissance livresque mais qui doit être éminemment critique pour échapper aux défauts reprochés aux prédécesseurs.

«J'ai souvent réfléchi sur toutes ces difficultés, sur le moyen qu'il conviendrait de prendre pour ne renvoyer la connoissance de l'inscription qu'on cherche, qu'à la page du livre où elle est rapportée en entier, ou de ceux qui l'ont répétée, afin d'en pouvoir faire la collation. J'avois observé que $\mathrm{Gr}<\mathrm{a}>\mathrm{evius}$ dans la dernière édition de Gruter, pour faciliter le moyen de connoître les inscriptions en vers qui se trouvent dans ce recueil, ajouta à celles de Scaliger une $25^{\mathrm{e}}$ table, où il rapporta selon l'ordre alphabétique le premier vers de chaque épigramme, ce qui en facilita la 
connoissance aussi prompte qu'on pouvoit la désirer. Il me parut donc qu'en suivant l'exemple qu'on avoit donné pour les inscriptions en vers, je pouvois l'appliquer à celles qui étoient en prose. J'essayai cette méthode et, à mesure que ma table se formoit sous ma main, j'y trouvai une facilité qui surpassa mon espérance [...] L'ordre alphabétique m'a paru le plus convenable et presque le seul qu'il y avoit à suivre [...]»

12 Il en découle deux exigences. L'une concerne la bibliographie épigraphique, et l'on comprend pourquoi dans l'ensemble des volumes apportés à Paris par Chardon La Rochette, il y avait une liste des ouvrages utilisés et, si l'on peut dire, dépouillés de leur contenu épigraphique. On trouve ici le fondement qui préfigure le "lemme génétique ", c'est-à-dire de la mise en ordre, chronologiquement construite, des références : celles qui impliquent le contrôle personnel («autoptique ») du document, et celles qui venant après ou s'intercalant, dérivent de seconde main d'une lecture originale. On retrouve cette bibliographie dans toutes les pages de l'index absolutissimus, à partir d'un niveau de base ou d'un état qu'assuraient les meilleurs recueils antérieurs. Il n'y a pas de rupture entre Séguier et l'entreprise postérieure dirigée par Mommsen.

13 L'autre concerne l'accès à la documentation, son utilisation. En rendre aisée l'utilisation est aussi une tâche de l'érudition, dont les exigences deviennent plus accessibles. Ici Séguier recourt à l'expérience aboutie de la codicologie, qui classe les documents par les premiers et les derniers mots : incipit et explicit, le premier toujours, le dernier quand c'est nécessaire, si l'inscription a été mutilée au début.

On comprend mieux pourquoi, un demi-siècle après sa disparition, lorsque le projet d'un recueil général des inscriptions latines prit forme en France, on redécouvrit l'intérêt du travail de J.-Fr. Séguier et l'on décida de le faire «mettre au propre » en le recopiant $^{9}$. Il conservait amplement son utilité, comme l'indiquent les appréciations qui accompagnent la liste des « auctores » cités en tête de plusieurs volumes du corpus de Berlin ${ }^{10}$. On avait même envisagé de publier la partie bibliographique des manuscrits de la Bibliothèque nationale ${ }^{11}$.

Mais en même temps, le travail entrepris montrait ses limites, inhérentes aux moyens dont disposaient les savants. Initialement, la compilation des données s'était faite sur la base des grands recueils existant à l'époque : elle était un état de la documentation. Les pages des deux volumes étaient partagées en deux grandes colonnes. Une, à gauche, avait été réservée aux inscriptions connues: Séguier avait aussi systématiquement indiqué quelle était la source, souvent Gruter, mais pas toujours. On relève ainsi l'usage des travaux des grands épigraphistes qu'il utilisa. À droite une colonne laissée en blanc permettait d'ajouter, ou d'insérer, soit de nouvelles références soit de nouvelles inscriptions. Mais c'était, au total, un espace fini, qui interdisait d'accroître indéfiniment la collecte documentaire. Même si l'écriture de Séguier se rétracte avec le temps, les nouvelles données remplissent peu à peu le champ qui avait été laissé libre et viennent le saturer.

Ce n'était donc qu'un état de la question à un moment donné. Le même problème se posa lorsque le nouveau projet, patronné par l'Académie de Prusse, vit le jour. Il fallut pour les nouveautés ou pour les compléments, créer une collection intitulée Ephemeris Epigraphica. C'était la solution d'attente, précédant les suppléments donnés à tel ou tel volume de la collection. Tel qu'il est livré aux utilisateurs, et tel qu'il est éclairé par les deux versions des Prolégomènes, l'effort qui conduisit à la rédaction de l'Index absolutissimus, entrant dans une production scientifique plus ample, vient signaler les conditions mises à la constitution d'un savoir. En premier et avant tout, les préalables 
d'érudition destinés à mettre de l'ordre dans la documentation accessible, à en jauger la valeur, à la débarrasser des scories ou des impuretés. Ces préalables s'accompagnaient d'exigences d'esprit critique, c'est-à-dire fait de contrôle, de rigueur et de précision. Le souci d'exhaustivité (le corpus absolutissimum) ne devait pas faire renoncer à la conception la plus rationnelle de l'effort scientifique : c'est ce qui différencie le travail de J.-Fr. Séguier de celui de Muratori par exemple. C'était aussi afficher qu'il s'agissait d'un travail spécialisé et exigeant, en invoquant dans les Prolégomènes deux mots-clefs de la démarche scientifique, « ordre " et " méthode ». C'est ce qui le conduisit, lorsqu'il était encore sous la tutelle de Scipione Maffei, à remplacer l'objectif tracé par le Prospectus de 1732 par un projet tout aussi ambitieux qu'il réalisa en préalable. Les fondements étaient posés dès 1749. L'œuvre se poursuivit jusqu'à sa mort en 1784. Il s'y était consacré avec acharnement, mais sans renoncer à ses travaux de botanique ou d'histoire naturelle. S'il ne parvint pas à un plein aboutissement, il laissa suffisamment de témoignages sur ses intentions et sur leur réalisation, éclairant les détails de sa démarche et justifiant son bien-fondé.

\section{BIBLIOGRAPHIE}

CHAPRON Emmanuelle, L'Europe à Nîmes : les carnets de Jean-François Séguier (1732-1783), Avignon, A. Barthélemy, 2008.

CHAUSSINAND-NOGARET Guy, Marmontel (1720-1799). Le philosophe qui chantait Cythère, Paris, L'Harmattan, 2017.

CHRISTOL Michel, « Jean-François Séguier et l'épigraphie », Bulletin de l'École antique de Nîmes, 26, 2003-2006, p. 3-16.

CHRISTOL Michel, Dissertation sur l'inscription de la Maison Carrée de Nîmes par Jean-François Séguier. Présentation et commentaire, Aix-en-Provence, Edisud, 2005.

CHRISTOL Michel, «Jean-François Séguier et l'épigraphie : l'aboutissement d'une réflexion », dans CHAPRON Emmanuelle, PUGNIÈRE François (dir.), Écriture épistolaire et production des savoirs au XVIII siècle. Les réseaux de Jean-François Séguier, Paris, 2019, p. 127-142 (avec le texte des Prolégomènes : annexe II, p. 273-285).

La BLANCHÈRE René de, Histoire de l'épigraphie romaine, depuis les origines jusqu'à la publication du "Corpus », Paris, Ernest Leroux, 1887.

NICOLET Claude (avec la collaboration de Sylvie AUBENAS et Pierre COSME), « Le véritable projet de Jean-François Séguier », dans « Alla Signorina ». Mélanges offerts à Noëlle de La BLANCHARDIÈRE, Rome, École française de Rome, 1995, p. 311-328.

ROCHE Daniel, « Correspondants et visiteurs de Jean-François Séguier », dans E. MOSELE, Un accademico dei Lumi fra due città : Verona e Nîmes. Scritti in onore di Jean-François Séguier nel secondo centenario della morte, Verona, 1987, p. 33-50.

ROCHE Daniel, Les Républicains des lettres : gens de culture et Lumières au XVIII siècle, Paris, Fayard, 1988. 
SCHEID John, « Le projet français d'un recueil général des inscriptions latines », dans Bartolomeo Borghesi, Scienza e libertà. Colloquio internazionale AIEGL (Bologna, 1981), Faenza, Fratelli Lega, 1982, p. 337-353.

WALTZING Jean-Paul, Le recueil général des inscriptions latines (Corpus inscriptionum latinarum) et l'épigraphie latine depuis 50 ans, Louvain, Peeters, 1892.

\section{NOTES}

1. D. Roche, Les Républicains des lettres : gens de culture et Lumières au XVIII èècle.

2. UMR Telemme (Maison méditerranéenne des sciences de l'Homme, Aix-enProvence), Université d'Aix-Marseille.

3. Bibl. mun. Nîmes, ms 284 (1) et (2) ; D. Roche, "Correspondants et visiteurs de JeanFrançois Séguier", dans E. Mosele, Un accademico dei Lumi fra due città : Verona e Nîmes. Scritti in onore di Jean-François Séguier nel secondo centenario della morte, p.33-50. Les Républicains des Lettres, p. 263-285; E. Chapron, L'Europe à Nîmes: les carnets de JeanFrançois Séguier (1732-1783). Mais il y a vraisemblablement une "préhistoire» de ce carnet dans un contexte qui n'inclut pas encore la demeure qu'il se fit construire dans les faubourgs de la ville et qui était en cours d'installation en 1772 : on en trouve trace dans des récits ou mémoires de gens qui firent le «Grand Tour » ou qui parcoururent les provinces du royaume. Tel Marmontel en 1760 : G. Chaussinand-Nogaret, Marmontel (1720-1799). Le philosophe qui chantait Cythère, p. 90.

4. Il s'agit de l'opuscule intitulé Dissertation sur l'inscription de la Maison Carrée de Nîmes: M. Christol, Dissertation sur l'inscription de la Maison Carrée de Nîmes par Jean-François Séguier. Présentation et commentaire, 2005.

5. Le titre complet est le suivant: Inscriptionum antiquarum index absolutissimus, In quo Graecarum Latinarumque Inscriptionum omnium, Que in editis libris reperiri potuerunt prima verba describuntur. Operumque in quibus referuntur Loca indicantur. Etruscarum et Exoticarum Indice ad calcem adjecto Opera Joan. Francisci Seguierii anno 1749.

6. S. Aubenas dans C. Nicolet (avec la collaboration de S. Aubenas et P.Cosme), «Le véritable projet de Jean-François Séguier», dans "Alla Signorina». Mélanges offerts à Noëlle de La Blanchardière, p. 316. Une analyse par M. Christol, « Jean-François Séguier et l'épigraphie : l'aboutissement d'une réflexion ».

7. R. de La Blanchère, Histoire de l'épigraphie romaine, depuis les origines jusqu'à la publication $\mathrm{du}$ «Corpus », p. 25-27, p. 31-32.

8. R. de La Blanchère, Histoire de l'épigraphie romaine, p. 33 ; J.-P. Waltzing, Le recueil général des inscriptions latines (Corpus inscriptionum latinarum) et l'épigraphie latine depuis 50 ans, p. 23 ; sur les polémiques, M. Christol, «Jean-François Séguier et l'épigraphie », p. 10 avec n. 30 .

9. R. de La Blanchère, Histoire de l'épigraphie romaine, p. 59.

10. On renverra à l'éloge de Wilhelm Henzen, CIL, VI, 1, p. LXI et aux pages d'Otto Hirschfeld, CIL, XII, p. 387-388. C'est ce dernier savant, à qui Mommsen avait confié la préparation des volumes sur les Gaules, qui procéda à Paris à l'examen des manuscrits de Séguier qui se trouvaient à la Bibliothèque Nationale et qui en exploita le contenu (CIL, V, 2, p. XXIII). 
11. J. Scheid, "Le projet français d'un recueil général des inscriptions latines", p. 339-341.

\section{RÉSUMÉS}

Le projet épigraphique de Jean-François Séguier a pour finalité la constitution d'un corpus documentaire général, appelé index absolutissimus. Il vise à réunir l'information sur l'ensemble des inscriptions connues (latines surtout, mais aussi grecques, étrusques, etc.) avec l'intention de recueillir des textes authentiques, effort d'érudition pour écarter les documents faux ou corrompus. Outre l'index lui-même, qui montre comment le projet fut réalisé, et la correspondance qui accompagne cet effort de longue durée, il existe les réflexions de l'auteur luimême, analysant sa pratique scientifique. On peut apprécier les limites de l'entreprise, inhérentes à sa conception et aux moyens techniques qui accompagnaient sa réalisation, son inaboutissement par la non-publication.

\section{AUTEUR}

\section{MICHEL CHRISTOL}

Professeur émérite à l'Université de Paris I - Panthéon-Sorbonne 


\title{
Un savoir régional : le Dictionnaire de la Provence du docteur Claude- François Achard (1785-1788)
}

\author{
Régis Bertrand
}

1 À la fin de l'Ancien Régime, la Provence et ses confins ont fait l'objet d'une tentative d'encyclopédie régionale en six volumes in-quarto parus entre 1785 et 1788 , le Dictionnaire de la Provence et du Comté Venaissin dédié à Monseigneur le maréchal prince de Beauvau par une société de gens de lettres, travail collectif dont l'initiative et la conception générale reviennent, ainsi sans doute qu'une large partie de la rédaction, au docteur Claude-François Achard (1751-1809). C'est la conception de l'ouvrage et la façon dont il a été réalisé en un temps très bref qui retiendront avant tout mon attention ${ }^{1}$.

2 Il est constitué de trois parties. La langue d'abord, avec le premier dictionnaire de thème occitan qui ait été publié, le Tome I. Contenant le vocabulaire françois-provençal (732 p.), et le dictionnaire de version, le Tome II. Contenant le vocabulaire provençal-françois (654 p.), tous deux imprimés à Marseille par Jean Mossy en 1785. Le Vocabulaire provençal-françois est le deuxième paru pour le provençal, après celui du Père Pellas en 1723. Pour l'ensemble des dialectes occitans, il occupe la troisième place chronologique après celui de Pellas et le Dictionnaire languedocien-français de l'abbé Boissier de Sauvage (Nîmes, 1756). Vient ensuite le dictionnaire biographique, le premier de cette ampleur à être publié pour la Provence: Tomes III-IV. Contenant l'histoire des hommes illustres de la Provence (535 et 523 p.), imprimés à Marseille par Jean Mossy en 1786 et en 1787.

3 Enfin la Description Historique, Géographique et Topographique des Villes, Bourgs, Villages \& Hameaux de la Provence ancienne \& moderne, du Comté-Venaissin, de la Principauté d'Orange, du Comté de Nice, \& c, pour servir de suite au Dictionnaire de la Provence. Par M. Achard, Médecin de Marseille, membre de plusieurs Académies. Précédée d'un Discours sur l'état actuel de la Provence par M. Bouche, Avocat au parlement d'Aix, associé à l'académie de Marseille, de celle des Arcades de Rome, \& c. (650 et 576 p.), imprimé à Aix par Pierre-Joseph Calmen en 1787-1788. Il s'agit d'un dictionnaire topographique fournissant des notices de nature encyclopédique sur chaque lieu habité, là aussi sans équivalent provençal jusqu'alors et assez peu encore dans l'espace français. 
Le changement de titre et d'imprimeur indique d'emblée les difficultés de l'édition, que l'on peut suivre à travers la précieuse correspondance échangée entre Achard et son maître de l'université d'Avignon, Esprit Calvet (1728-1810), premier professeur de médecine à la facultée .

5 Achard a conçu la Provence comme une entité historique et humaine débordant les frontières strictes du comté et de ses terres adjacentes pour inclure les terres qui furent provençales ou dépendirent des comtes de Provence au Moyen Âge, soit au moment de la formation de la langue d'oc : les États pontificaux et le comté de Nice, qui appartenaient alors à des souverains étrangers, la principauté d'Orange, qui lors de son annexion par Louis XIV avait été rattachée au Dauphiné. Il s'agit donc d'une Provence définie comme aire culturelle. La volonté de commencer cette encyclopédie du monde provençal par un dictionnaire de langue n'en est que plus remarquable. Dans sa conception initiale, l'ouvrage se présentait comme la découverte progressive d'une identité régionale à travers trois de ses éléments essentiels.

«La connoissance de la langue provençale - écrit Achard dans la préface générale qui ouvre le tome premier -, précède l'histoire topographique de la Provence et celle-ci est suivie de la vie des Hommes illustres dont les noms ainsi que les actions méritent d'être transmis à la postérité. ${ }^{3}$ "

6 L'ordre théorique doit donc être, selon Achard lui-même, rétabli de la façon suivante. D'abord les deux volumes d'un dictionnaire de langue, le Vocabulaire françois-provençal et le Vocabulaire provençal-francois, qui furent les premiers à paraître. Aurait dû venir ensuite la Description, que son faux-titre désignera comme une Géographie, faite de notices des espaces habités et de leur population, perçue en particulier à travers ses usages et ses fêtes. Enfin L'Histoire des hommes illustres de la Provence, faite des habitants qui s'illustrèrent et méritèrent de survivre dans la mémoire, au moins régionale. Des "raisons particulières », sans doute le retard pris dans la rédaction de la Description, imposèrent une inversion de l'ordre de parution au profit des Hommes illustres. Achard l'annonce dans l'avertissement du tome II, le Vocabulaire provençal-français ${ }^{4}$.

\section{Un médecin aux curiosités encyclopédiques}

7 Claude-François Achard est né à Marseille le 23 mai 1751. Fils de Joseph Achard, marchand-fabricant de papier, et de Catherine-Rose Chaulan ${ }^{5}$, il est envoyé à l'âge de sept ans auprès de son oncle paternel qui était curé du Pègue, petit village du Dauphiné situé dans le sud de la Drôme actuelle. C'est là qu'il achève son enfance et passe son adolescence, étudiant d'abord avec son oncle puis au séminaire de Viviers, sans doute à partir de 1762 et jusqu'aux années scolaires 1767 et 1768, dates où il doit y être élève de philosophie (cette classe terminale dure deux ans alors). Il ne persévère pas cependant dans la voie de la cléricature. En avril 1769, Achard prend sa première inscription trimestrielle à la faculté de médecine d'Avignon dans le cours du professeur Esprit Calvet, dont il sera un des élèves les plus chers. Le 19 octobre 1771, Achard est reçu bachelier en médecine. Il peut dès lors obtenir la licence, trois mois plus tard, ce qu'il fait le 20 janvier 1772. Enfin, un dernier examen sans délai imposé, d'une durée de cinq heures, conférait alors le doctorat. Dès le surlendemain, 22 janvier, Achard soutenait sa thèse doctorale.

8 Ses études faites, muni de son bonnet de docteur remis par Calvet en personne, C.F. Achard revient dans sa ville natale ou plutôt à proximité. Marseille était dotée d'un 
collège de médecine, institution corporative existant dans les villes importantes du royaume qui ne possédaient pas d'université. Les jeunes docteurs ne pouvaient être agrégés au collège des médecins marseillais, et donc y exercer, que s'ils justifiaient de trois années de pratique hors de la ville. Achard s'installe donc à Aubagne. De 1772 à 1775 , il y est chargé de l'hôpital et eut «quelques malades en ville ». Il s'y marie. En 1775, Achard présente sa candidature au collège de médecine et est admis au second essai. Il va s'y faire une clientèle et laissera le souvenir d'un médecin charitable. Il est à partir de 1779 du nombre des médecins que l'hôpital de la Grande-Miséricorde salarie de façon modeste -, pour visiter les " pauvres malades ».

9 Claude-François Achard est nommé en janvier 1781 membre correspondant de la Société royale de médecine de Paris. Grâce à Félix Vicq d'Azyr (1748-1794), son secrétaire perpétuel, cette société entretenait un réseau d'une centaine de correspondants élus à travers toute la France et à l'étranger. Un tel titre fait d'Achard l'une des notabilités médicales de Marseille. Il sera tour à tour secrétaire puis syndic du collège de médecine de la ville.

\section{Les quatre premiers volumes}

10 C'est dans une lettre à E. Calvet datée du 28 avril 1783 qu'Achard semble faire pour la première fois mention, de façon très allusive, d'un projet de Dictionnaire ${ }^{6}$. Il lui écrit le 27 décembre 1784: "Le premier volume du Dictionnaire est imprimé ». Puis le 16 septembre 1785, il annonce à Calvet l'envoi du second volume ${ }^{7}$. Le 30 décembre 1785, Achard écrit à Calvet :

«[...] J'ai entrepris seul le grand ouvrage dont le $3^{\mathrm{e}}$ volume a paru, dont on imprime le $4^{e}$ et dont je mets au net le $5^{\mathrm{e}}$ ou la Géographie. J'avais des associés, ils m'ont quitté dès qu'il a fallu financer. ${ }^{8}$ "

11 On sait que les volumes III et IV sont respectivement datés de 1786 et 1787. La parution de ces premiers volumes vaut à Achard d'être élu membre de l'Académie des lettres, sciences et arts de Marseille le 14 août 1786 et d'y être reçu lors de la séance publique du 6 décembre $1786^{9}$.

Comment Achard a-t-il pu réaliser cette œuvre en un temps aussi bref ? Il apporte des éléments de réponse pour les deux volumes de langue dans l'Avertissement du tome I en indiquant ses sources écrites ${ }^{10}$. Nous indiquons entre crochets l'identification des ouvrages qu'il cite :

«Le Dictionnaire du P. Pellas, Minime, nous a fourni des termes peu connus, que nous avons placés en indiquant cet Auteur. [Sauveur-André Pellas, 1667-1727, Dictionnaire provençal et françois..., Avignon, F.-S. Offray, 1723, 324 p.]. Un petit ouvrage du P. Merindol de l'Oratoire, nous a donné l'étymologie de quelques mots Provençaux tirés du Grec. [Mitre Mérindol, Dilucida et compendiosa graecorum accentum praxis..., Aix, 1651]. Nous avons également consulté le savant Dictionnaire de feu M. de Montvallon, si connu dans le Bareau \& si regretté dans la République des Lettres ; M. son fils, Doyen de MM. les Conseillers au Parlement de Provence, \& M. son petit-fils, Officier au Régiment du Roi, nous ont cédé ce Manuscrit précieux sans réserve, \& avec cette honnêteté qui leur est naturelle. [André de Barrigue de Montvallon, 1678-1769, B. Méjanes, ms 1664, 262 p.]. Les héritiers de M. Germain, ancien Chancelier de France à Alger, nous avoient déjà communiqué le Dictionnaire Provençal-François manuscrit de ce Poëte Marseillois ; ouvrage volumineux, \& qui avoit acquis une certaine perfection. [Jean-Baptiste Germain, 1701-1781, manuscrit non localisé]. Le Dictionnaire Provençal du P. Puget, Minime, manuscrit, conservé 
dans la Bibliothèque des Religieux de cet Ordre, à Aix, nous a fourni des étymologies latines \& grecques. [Pierre Puget, 1671-1747, B. Méjanes, ms 158, XIII-849 p.]. Nous avons aussi profité des connoissances que nous ont procurés les Savans de cette Province, qui ont fait une étude particulière de notre langue. » également un ouvrage du xvII siècle qui avançait des étymologies grecques pour des termes provençaux et surtout trois dictionnaires manuscrits, ceux de Barrigue de Montvallon et de Puget, entrés depuis en collections publiques, et celui de Germain, peut-être sa source principale, qui n'est pas localisé aujourd'hui. Il est cependant très réducteur de considérer ses deux volumes comme une pure compilation ${ }^{11}$. Achard a aussi dépouillé des textes littéraires en provençal des XVII et $\mathrm{XVIII}^{\mathrm{e}}$ siècles. Dans sa correspondance, il demande à Calvet de lui prêter ceux de ces ouvrages qu'il ne parvient pas à trouver à Marseille ${ }^{12}$.

Il a également bénéficié des apports d'informateurs. Achard avait une intéressante expérience du provençal et de certains de ses dialectes puisqu'il était né et vivait à Marseille, avait grandi auprès de son oncle, curé d'une paroisse rurale du Dauphiné et avait fait ses études médicales à Avignon, ville où le Père Pellas avait vécu et rédigé son dictionnaire. Sa principale lacune était la langue de la partie septentrionale de la Haute-Provence, l'occitan alpin. Il la reconnaît et annonce un supplément, qui ne paraîtra pas, qui :

«Contiendra beaucoup de termes usités dans la montagne, c'est-à-dire dans la Haute-Provence : un manuscrit qui est arrivé à la fin de l'impression de ce volume nous les a transmis et nous en devons l'hommage au public pour la perfection de cet ouvrage. ${ }^{13}$ »

La notice des « auteurs vivants » du tome IV permet de préciser qu'il s'agit du travail de «Bois Joseph-Marc, curé de Noyers sa patrie, né en 1727, [qui] a fourni le supplément au Vocabulaire provençal pour les mots usités dans la Haute-Provence ${ }^{14} »$.

Achard dit «avoir adopté de préférence le langage de Marseille [...] qui [lui] est le plus familier » et non celui d'Aix, qu'apparemment des habitants de cette ville considéraient comme «le vrai provençal ${ }^{15}$ ». Il est intéressant d'observer que son dictionnaire renferme des mots qui entrent pour la première fois dans la lexicographie imprimée. Pour en citer deux que l'on a souvent cru dater du xix siècle, la notice «Bouilhir » est pour l'essentiel consacrée à la bouillabaisse :

«Bouilhe-Baisso, terme de pêcheur, sorte de ragout qui consiste à faire bouillir du poisson dans l'eau de la mer. L'on dit bouilhe-baisso, parce que dès que le pot bout, on le tire du feu, on l'abaisse. ${ }^{16}$ »

La notice « Santoun, ono » donne deux dérivés, dont :

«On le dit aussi pour figurer des saints en plâtre que l'on vend pour amuser les enfants. »

Le santon de crèche en argile n'existe pas encore, il apparaîtra à la fin de la Révolution : on a ici le premier sens du terme, plus large, qui explique son étymologie de petit saint $^{17}$.

\section{Les volumes biographiques}

19 Dans son discours préliminaire, Achard s'inscrit directement dans la vision des hommes dignes de mémoire que développent les Lumières : 
«Il manquoit à l'histoire littéraire de notre province un ouvrage destiné à transmettre à la postérité, le nom des artistes, des savans et des héros qui l'ont illustrée. »

Il précise aussi :

«Le mérite des hommes illustres dépend de leurs actions [...] Les généalogies des familles n'entrent aucunement dans notre plan..$^{18}$ "

Il ne s'agit plus, comme dans les histoires de Provence des générations précédentes, de faire la généalogie des familles illustres par leur noblesse, leur ancienneté. Achard prend certes en compte la naissance noble mais c'est à travers la détention des hautes charges, la trace laissée dans l'histoire. Il étudie avant tout les «talents " (hommes de lettres, de sciences, artistes, savants, en particulier médecins) ${ }^{19}$. Achard a su trouver, non sans difficultés et déboires, une équipe de rédacteurs. Il les énumère dans son « Discours préliminaire de l'Histoire des hommes illustres » et fournit même le moyen d'identifier les auteurs de certaines notices.

«Les articles désignent leur Auteur par une des indications suivantes. (C. B.) Ces lettres désignent M. l'Abbé de Capris de Beauvezer, Prêtre à Cuers [...]. Ce Savant nous a communiqué avec le désintéressement le plus rare, dix cahiers Mss. contenant la vie des Illustres Provençaux par ordre chronologique [...] [JeanBaptiste Capris de Beauvezer, 1729- ?].

(V.P.) C'est ici l'indication de l'Auteur du Vocabulaire Provençal-François, \& FrançoisProvençal [Claude-François Achard]. (P. C.) Les articles terminés par ces Lettres, ont été fournis par un Savant Religieux, connu avantageusement dans la République des Lettres par des ouvrages qui font honneur à son amour pour la Patrie [...] [P. Calixte de Brignoles, Jean-Baptiste Roland, capucin]. (P.N.) Les articles qui ont cette indication, appartiennent à un Religieux Minime, connu à Marseille [P. LouisThomas Nuiratte, 1724-1792]. (E-H.) M. Bouche, Avocat au Parlement de Provence [Charles-François Bouche, 1737-1795]. (B. O.) Le P. Bicaïs de l'Oratoire, aussì éclairé que modeste, nous a fourni des articles curieux \& des anecdotes presque oubliées. Le Mss. du P. Zacharie Artaud de l'Oratoire, intitulé : Athenœum Massilliensis, nous a été d'un grand secours. Cet Auteur avoit fait des découvertes qui lui font un honneur infini, \& qui rendent notre Dictionnaire très-intéressant. M. l'Abbé Paul, ancien Professeur d'éloquence au Collège d'Arles, \& M. Gombert, ancien Curé des Pennes, auprès de Marseille, avoient chacun un Mss. sur les Grands-Hommes de la Provence: ils n'attendoient l'un \& l'autre qu'une circonstance favorable pour les livrer à l'impression. Nous avons acquis le fruit de leurs travaux [...]. Les articles qui nous ont été fournis par d'autres Savans, portent le nom de leurs Auteurs, à moins que leur modestie ne nous ait empêché de les faire connoître : de ce nombre sont quelques Membres de l'académie de Marseille. ${ }^{20}$ »

À noter qu'Achard reconnaît que certains auteurs avaient eu, avant lui, l'idée de réaliser un dictionnaire biographique, en particulier l'abbé Amant-Laurent Paul (1740-1809), ancien jésuite et un autre ecclésiastique, l'abbé Antoine Gombert (1717- ?). Charles-François Bouche était l'auteur d'un Essai sur l'histoire de Provence, suivi d'une notice des Provençaux célèbres en deux volumes, qui venait de paraitre ${ }^{21}$. Certaines des notices publiées dans l'Histoire des hommes illustres de la Provence ont été reprises par Bouche de cet ouvrage, au prix de quelques modifications : elles sont signées, on l'a noté, EH, abréviation des premiers mots de son titre. Enfin, Achard avait eu un prédécesseur évident, l'oratorien Joseph Bougerel (1680-1758), dont le Projet d'une histoire des hommes illustres de Provence, avancé en 1718, n'avait connu qu'un début de publication, peu avant sa mort, avec un recueil de quelques notices. Achard semble avoir obtenu de consulter le manuscrit de Bougerel auprès de son héritier ${ }^{22}$. 

quasiment rien de certains personnages sans les notices d'Achard. Ainsi celle de Laurent Durand (1629-1708), auteur d'un succès de librairie, Les Cantiques de l'âme dévote, dits Cantiques de Marseille, qui ont connu de nombreuses éditions entre 1680 et 1950. Il n'a été possible de retrouver en archives qu'une seule trace de son existence, son acte de décès ${ }^{23}$. Autre exemple, la notice sur Françoise Duparc (1726-1778), artiste-peintre ${ }^{24}$. Les quatre tableaux signalés à la fin la notice, qui sont des chefs-d'œuvre de l'art du XVIII ${ }^{\mathrm{e}}$ siècle, sont aujourd'hui au Musée des Beaux-Arts de Marseille. $80 \%$ de nos connaissances sur leur auteur viennent de la notice publiée par Achard. Le 30 décembre 1785, il indique à Calvet que Marin lui a suggéré d'ajouter un développement consacré aux auteurs vivants :

«M. Marin, censeur de mon Dictionnaire, m'a conseillé de mettre au bas de mon second volume des hommes illustres les noms des auteurs vivans et les titres de leurs ouvrages. Je vous prie, Monsieur de vouloir m'indiquer ceux que vous connaissez. J'avais aussi pensé d'inviter les auteurs à fournir eux-mêmes cette notice. Le Courrier d'Avignon pourrait-il annoncer cela? Je l'ai déjà fait insérer dans les Affiches de Marseille. ${ }^{25}$ "

Cette exigence a certainement dû retarder la parution du volume. Le "Catalogue des auteurs vivans avec le titre de leurs Ouvrages. On y a joint les Provençaux qui se sont fait un nom dans les arts " se trouve placé à la fin de l'ouvrage aux p. 497-523, après les "Supplément et additions» (p. 402-470), la «Table chronologique» (p. 471-475) et la «Table chorographique qui indique le nombre des grands Hommes que chaque Ville a produits » (p. 496).

Enfin Achard a pris part à la grande redécouverte des troubadours qui marque la seconde moitié du xvIII siècle. Achard consacre aux troubadours une "Dissertation " de 51 pages $^{26}$. Il avait indiqué dans le « Discours préliminaire » de l'ouvrage :

«Il semble qu'après les vies de ces poètes données depuis peu par M. l'abbé Millot d'après les recherches de $M$. de Sainte-Palaye, la matière doit être entièrement épuisée ; nous avons cependant trouvé des anecdotes curieuses et peu connues dans les manuscrits anciens qu'on a bien voulu nous communiquer. ${ }^{27}$ »

Cette remarque avait intrigué autrefois Camille Chabaneau, qui a relevé les quelques notations qui ne paraissaient pas provenir de ses prédécesseurs, Nostredame, Millot ou Papon - Achard indique ordinairement les sources de ses notices. Chabaneau en a conclu qu'Achard avait eu connaissance « d'au moins deux chansonniers provençaux autres que ceux que nous possédons aujourd'hui ${ }^{28} »$.

\section{La Description de la Provence (ou Géographie)}

Dans une lettre non datée reçue par Calvet, Achard espère sa parution "avant la Toussaint [1787]». Le 23 novembre 1787, Achard annonce à Calvet que «le premier volume paraîtra dans les premiers jours de décembre ${ }^{29}$ ». Achard présente «le premier volume de la description topographique de la Provence " à ses confrères de l'académie de Marseille lors de la séance du 16 janvier $1788^{30}$. Au cours de l'année 1788 , le second volume commence à paraître, par fascicules. Achard écrit à Calvet le 16 janvier 1789 :

«Mon dernier volume aurait déjà paru sans l'absence de M. Marin, mon censeur. Je suis obligé de lui envoyer mes manuscrits à Paris. Cela occasionne des retards extraordinaires et je crains trop qu'ils ne s'égarent. ${ }^{31}$ » 
le 20 février 1790, Achard signale à Calvet qu'il espère pouvoir publier la fin du volume « dans le mois d'avril au plus tard, si la constitution a fixé les départements de la Provence ${ }^{32}$ ». La Description de la Provence est en fait restée inachevée. Le texte s'arrête brusquement au début d'une phase à l'article «Velaux ». Les derniers fascicules n'ont pas été publiés mais l'on possède des copies de leur manuscrit. Achard avait d'abord espéré que la petite équipe de collaborateurs qu'il avait rassemblée lui permettrait de couvrir l'espace provençal, ce qu'il indique dans l'Avertissement du premier volume :

«La Géographie de la Provence est composée des articles fournis par les Gens de Lettres qui coopèrent à cet Ouvrage. Nous nous ferons un devoir de nommer ceux qui voudront nous le permettre. Nous indiquerons les autres par une ou deux lettres capitales, qui, sans faire connoître l'Auteur, indiqueront les articles appartenans à une même personne. ${ }^{33}$ "

Il dut suivre une autre méthode ; il s'efforça de constituer un réseau de correspondants parmi les notables locaux, susceptibles de lui fournir des notices. Ces dernières ne sont pas signées. Il est possible d'entrevoir ses échanges par la lettre qu'il adressa à EspritJoseph Pellicot, avocat et co-seigneur de Seillans (Var) :

«Monsieur, vous m'avez promis si obligeamment l'article de Seillans pour mon dictionnaire géographique, que je me crois autorisé à vous rappeler votre promesse. Les imprimeurs, comme vous le savez très bien, n'aiment pas à se reposer au milieu d'un ouvrage et le mien est assez avancé pour que je doive désirer que vous me rendiez au plus tôt le service que j'ai droit d'attendre de vos bontés. Je me flatte que vous allez vous occuper de moi et acquérir de nouveaux droits à ma reconnaissance. J'ai l'honneur d'être, etc. $»^{34}$

Il a été possible de reconstituer ici, grâce aux notices les plus développées, une grille de questions qu'Achard a pu envoyer à ses correspondants, à moins qu'il n'ait redistribué leurs réponses en fonction de ces rubriques, dans le but d'unifier très relativement les notices de l'ouvrage. Son souci d'envisager tous les aspects d'un lieu de vie est particulièrement remarquable par le regard ethnographique qu'il porte sur la vie collective et en particulier les usages traditionnels et les fêtes :

- nom latin (en général repris d'Expilly), nom provençal,

- localisation : diocèse, viguerie,

- distance des principales villes (empruntée à Expilly),

- nombre de feux fiscaux, population (d'après le dénombrement de 1765, mais non systématique),

- site, état seigneurial,

- historique,

- titulaire de la paroisse, nomination et statut des clercs qui la desservent, dîmes, parfois reliques,

- autres bénéfices, couvents, parfois chapelles de confréries (essentiellement celles de pénitents),

- fêtes et leurs particularités ; parfois coutumes locales,

- climat, fréquence des maladies,

- nature du sol, productions agricoles,

- richesses minérales,

- cours d'eau, sources et fontaines,

- écarts, hameaux, fiefs séparés,

- remarques historiques diverses (parfois armoiries),

- bureau de poste pour le courrier. 
Cependant, lorsqu'il n'a pu bénéficier d'une notice originale ou pour certains renseignements, Achard s'est servi du Dictionnaire [...] des Gaules et de la France de JeanJoseph Expilly (1719-1793), chanoine de Tarascon, dont les notices constituent alors le tissu conjonctif des siennes ${ }^{35}$. Au fur et à mesure que l'ouvrage avançait, Achard a eu tendance à reprendre de plus en plus les notices telles qu'elles étaient envoyées. Il est possible de le vérifier avec la notice Valensole: un érudit de la génération suivante, François Aubert, a pu recopier le texte du correspondant d'Achard, l'abbé Aubanel, qui sert de substance à la notice imprimée ${ }^{36}$.

Ce grand travail sera cependant sans achèvement ni suite, la vie d'Achard ayant pris un cours nouveau avec la Révolution. Dès 1790, Achard commence à constituer la bibliothèque publique de Marseille, dont il est nommé bibliothécaire en 1793. Il devient le premier fonctionnaire culturel qu'aient eu les Bouches-du-Rhône. Le 6 novembre 1794, il met en place la Commission temporaire des arts, qui s'efforce de préserver des éléments du patrimoine et amorce les collections du musée de Marseille, et il sera en 1801-1802 conservateur du Musée des Arts. Le classement et l'inventaire de la bibliothèque l'occupent dès lors, ainsi que la rédaction d'un Cours élémentaire de bibliographie, paru en trois volumes en 1806-1807 ${ }^{37}$.

Achard eut également un rôle de premier plan dès avril 1799, dans la création du Lycée des sciences et des arts, qui devint le 15 mai 1802 l'Académie des sciences, belles-lettres et arts de Marseille. Achard en fut alors élu secrétaire perpétuel de la classe des lettres alors qu'il avait été élu en 1786 à un fauteuil de la classe des sciences. Le fait est révélateur de la reconversion qu'il avait accomplie durant la Révolution. Ajoutons qu'il avait été vénérable avant la Révolution de la loge maçonnique La Triple union, fondée à Marseille en 1782 et affiliée en 1785 à l'ordre écossais rectifié. Il réveilla la loge dès 1801 et échangea à cette occasion une précieuse correspondance avec le Lyonnais JeanBaptiste Willermoz (1730-1824), qui a été récemment éditée ${ }^{38}$. Mais à partir de 1808 , sa santé semble se détériorer et il meurt le 29 septembre 1809.

\section{Postérité du Dictionnaire de la Provence}

L'œuvre d'Achard a été souvent jugée sévèrement au XIX ${ }^{\mathrm{e}}$ siècle. Il a été alors de bon ton de souligner ses insuffisances et ses erreurs. L'homme et son œuvre ont longtemps souffert des jugements catégoriques du principal érudit marseillais du Second Empire, le juge de paix Augustin Fabre (1797-1870), dont on citera ici une anthologie :

«C.-F. Achard, docteur en médecine, mit sa vie laborieuse au service de son pays avec un zèle ardent qui ne fut pas toujours selon le goût et la science. Il composa plusieurs ouvrages sur des sujets très bien choisis, mais fort mal exécutés [...]. Le Dictionnaire géographique de la Provence par Achard est fait avec la même précipitation et ne mérite aucun éloge [...]. Son Histoire des hommes illustres de la même province est plus utile et sera toujours consultée. Mais que de défauts on y remarque ! [...]. Achard, peu difficile dans ses goûts littéraires et ne possédant pas la moindre notion de critique, prit des articles de toutes mains [...]. Achard a mis au jour d'autres ouvrages moins connus, où l'on trouve les mêmes imperfections, l'absence de tout art, l'affranchissement de toute méthode, l'incorrection d'un style froid, diffus, insipide, incolore. L'auteur, tout à la fois bon homme et faiseur d'embarras, eut le tort de négliger l'exercice de la médecine pour se jeter dans des compositions au-dessus de la portée de son esprit. ${ }^{39}$ » 

détail de la Description, dans la seconde moitié $\mathrm{du} \mathrm{xx}^{\mathrm{e}}$ siècle, l'appréciation en a été au contraire de plus en plus positive. Elle a en particulier servi de banque de données quantifiables et cartographiables pour des études universitaires. Citons avant tout les travaux de Michel Vovelle, qui a décerné à Achard le titre de "primitif de l'ethnographie provençale ${ }^{43}$ ». La Description est une des sources principales de son étude sur les fêtes ${ }^{44}$ et de bien d'autres recherches. Ainsi Michel Vovelle a reconstitué à travers la désignation des lieux dans les articles de la Description la hiérarchie du réseau urbain et villageois de l'ancienne Provence, telle qu'elle était perçue par l'élite du temps ${ }^{45}$. Marie-Hélène Froeschlé-Chopard l'a également beaucoup étudiée et en a proposé une réédition partielle pour la Provence orientale ${ }^{46}$. Très récemment, un ouvrage collectif sur les fêtes à bravade a republié le texte de la totalité des mentions de ces fêtes fournies par Achard ${ }^{47}$.

Le Dictionnaire de la Provence est une source fort riche à condition de se reporter toujours aux erratas et compléments et pour la Description, à une des copies manuscrites 
de la fin de l'ouvrage, qui renferment également de nombreuses rectifications et ajouts aux articles. Par-delà d'inévitables erreurs ou approximations, il faut savoir gré à cet homme des Lumières d'avoir rassemblé et organisé un ensemble de connaissances qui sans lui seraient restées éparpillées, inédites ou même n'auraient pas été consignées par écrit.

\section{BIBLIOGRAPHIE}

[ACHARD Claude-François], Dictionnaire de la Provence et du comté Venaissin, dédié à Monseigneur le maréchal prince de Beauvau, par une Société de gens de lettres. Tome I. Contenant le vocabulaire françoisprovençal. Tome II. Contenant le vocabulaire provençal-françois Marseille, Impr. de Jean Mossy, 1785, 732 et 654 p. Tomes III-IV. Contenant l'histoire des hommes illustres de la Provence, id., 1786-1787, 535 et 523 p., 4 vol. in $-4^{\circ}$.

ACHARD Claude-François, Description Historique, Géographique et Topographique des Villes, Bourgs, Villages \& Hameaux de la Provence ancienne \& moderne, du Comté-Venaissin, de la Principauté d'Orange, du Comté de Nice, \& c, pour servir de suite au Dictionnaire de la Provence. Par M. Achard, Médecin de Marseille, membre de plusieurs Académies. Précédée d'un Discours sur l'état actuel de la Provence par M. Bouche, Avocat au parlement d'Aix, associé à l'académie de Marseille, de celle des Arcades de Rome, \& c., Aix, Pierre-Joseph Calmen impr., 1787-1788, 650 et 576 p.

BERTRAND Régis, Crèches et santons de Provence, Avignon, éd. A. Barthélemy, 1992.

BERTRAND Régis, «Claude-François Achard, l'homme qui aimait les livres », dans Marseille, $\mathrm{n}^{\circ}$ 168, 1993, p. 16-19.

BERTRAND Régis, «Les Cantiques de l'âme dévote de Laurent Durand (dits Cantiques de Marseille), ou le long succès d'un auteur », dans QUÉNIART Jean (dir.), Le Chant, acteur de l'histoire, Rennes, Presses de l'Université de Rennes, 1999, p. 51-64.

BERTRAND Régis, «La génération érudite provençale des années 1770-1780 et les troubadours », dans COUROUAU Jean-François et LUCIANI Isabelle (dir.), La Réception des troubadours en Languedoc et en France, $\mathrm{XVI}^{e}$-XVIII ${ }^{e}$ siècle, Paris, Classiques Garnier (Études et textes occitans 3), 2018, p. 263-281

BILLIOUD Joseph, « Une peinture de types populaires, Françoise Duparc de Marseille (1726-1778) », dans la Gazette des Beaux-Arts, octobre 1938, p. 173-184.

BONNET Jean-Claude, Naissance du Panthéon : essai sur le culte des grands hommes, Paris, Fayard, 1998. BOUCHE Charles-François, Essai sur l'histoire de Provence, suivi d'une notice des Provençaux célèbres en deux volumes, Marseille, Jean Mossy père et fils, 1785, (2 vol.).

BOUVIER Jean-Claude, « Préface » à Mistral Frédéric, Lou Tresor dóu Felibrige. Dictionnaire provençalfrançais, Aix-en-Provence, Édisud, 1979, p. 5-47.

BROCKLISS Laurence W. B., Calvet's Web : enlightenment and the Republic of Letters in eighteenth-century France, Oxford, Oxford University press, 2002.

CHABANEAU Camille, Notes sur quelques manuscrits provençaux perdus ou égarés (...), Paris, Maisonneuve frères et $C$. Leclerc, 1886. 
CROZE-MAGNAN [Simon-Célestin], « Éloge de M. Achard », Mémoires publiés par l'Académie de Marseille t. IX, Marseille, impr. de J.-F. Achard, 1812, p. 53-68.

EXPILLY Jean-Joseph, Dictionnaire géographique, historique et politique des Gaules et de la France, Paris, Desaint et Saillant, 1762-1770, (6 vol.).

FABIÉ David, « L'essor des études lexicographiques et grammaticographiques », dans coUROUAU Jean-François (dir.), La langue partagée. Écrits et paroles d'oc, 1700-1789, Genève, Lib. Droz, (Bibliothèque des Lumières), 2015, p. 307-392.

FABRE Augustin, Les rues de Marseille, Marseille, Lebon, 1868, t. IV, p. 76-80.

FOURNIER Laurent-Sébastien et HAMEAU Philippe (dir.), Les Fêtes à bravade, Forcalquier, éd. C'est-àdire, 2018.

FROESCHLÉ-CHOPARD Marie-Hélène et GUÉRIN Simon (éd.), Images de l'ancienne Provence : « Description historique, géographique et topographique des villes, bourgs, villages et hameaux de la Provence... " par M. Achard, Nice, Serre, 2010.

FROESCHLÉ-CHOPARD Marie-Hélène, « La fête au village dans l'ancienne Provence selon ClaudeFrançois Achard », dans RÉGIS Bertrand et FOURNIER Laurent-Sébastien (dir.), Les Fêtes en Provence, autrefois et aujourd'hui, Aix-en-Provence, Presses universitaires de Provence, 2014, p. 51-66.

FUKASAWA Katsumi, « Claude-François Achard dans sa jeunesse : médecin, académicien et francmaçon marseillais à la fin du XVIII ${ }^{\mathrm{e}}$ siècle ", Provence historique, t. LXII, fasc. 247, 2012, p. 11-24.

GARCIN Étienne, Dictionnaire historique et topographique de la Provence ancienne et moderne, Draguignan, l'auteur, 1835, (2 vol.).

MASSON Paul, Les Bouches-du-Rhône, Encyclopédie départementale, vol. IV-2, Dictionnaire biographique des origines à la Révolution, Paris-Marseille, H. Champion-Archives départementales, 1931, p. VIII.

MERLE René, « Le chemin d'Honnorat », Amiras/Repères occitans, nº 13, 1986, p. 85-98.

MERLE René, «C.-F. Achard et le bilinguisme provençal de la fin des Lumières », Provence historique, t. XXXVIII, fasc. 153,1988 , p. 303-322.

MERLE René, L'Écriture du provençal de 1775 à 1840 : inventaire du texte occitan, publié ou manuscrit, dans la zone culturelle provençale et ses franges, Lille, Atelier national reproduction des thèses-Bézier, Centre international de documentation occitane, 1990.

MINOIS Georges, Le Culte des grands hommes, des héros homériques au star system, Paris, Audibert, 2005 ,

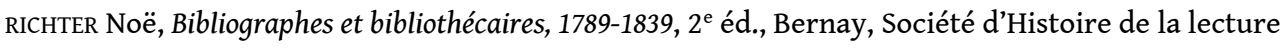
(Matériaux pour l'histoire de la lecture et de ses institutions, $\left.\mathrm{n}^{\circ} 21\right), 2008$.

RONDAT Jacques, La Correspondance maçonnique échangée par Jean-Baptiste Willermoz et Claude-François Achard, Marseille, éd. de la Tarente (Fragments maçonniques), 2017, t. I, Un cours de maçonnerie rectifié, t. II, Transcription de la correspondance.

STEFANINI Jean, Un provençaliste marseillais, l'abbé Féraud, 1725-1807, Aix-en-Provence, PUP, 1969.

TEISSIER Octave, Histoire d'une ancienne famille de Provence, Toulon, impr. d'E. Aurel, 1862.

VOVELlE Michel, Les Métamorphoses de la fête en Provence de 1750 à 1820, Paris, Aubier-Flammarion, 1976. 
VOVELLE Michel, De la cave au grenier, un itinéraire en Provence de l'histoire sociale à l'histoire des mentalités, Québec, Serge Fleury, 1980.

\section{NOTES}

1. Le dédicataire est Charles-Juste de Beauvau-Craon (1720-1793), gouverneur de Provence de 1782 à 1790.

2. Bibl. mun. d'Avignon, ms 2368 (lettres d'Achard à Calvet de 1770 à 1806). Sur le réseau de correspondants de Calvet: L. Brockliss, Calvet's Web : enlightenment and the Republic of Letters in eighteenth-century France.

3. C.-F. Achard, Dictionnaire de la Provence et du Comté Venaissin, t. I, Vocabulaire françoisprovençal, p. VII.

4. C.-F. Achard, Dictionnaire de la Provence et du Comté Venaissin, t. II, Vocabulaire provençal-françois, p. VI.

5. Données biographiques extraites de S.-C. Croze-Magnan, «Éloge de M. Achard » et

R. Bertrand, «Claude-François Achard, l'homme qui aimait les livres ».

6. Bibl. mun. d'Avignon, ms 2368, p. 148.

7. Bibl. mun. d'Avignon, ms 2368, p. 169 et 174.

8. Bibl. mun. d'Avignon, ms 2368, p. 182-183.

9. Académie des sciences, lettres et arts de Marseille. Registre de p.v. des séances $n^{\circ} 8$, p. 88. Discours de remerciement d'Achard, Recueil de l'Académie des Belles-Lettres, sciences et arts de Marseille pour l'année 1786, Marseille, J. Mossy, 1787, p. 113-123.

10. C.-F. Achard, Dictionnaire de la Provence et du Comté Venaissin, t. I, Vocabulaire françoisprovençal, p. VII.

11. Ce que tend à faire D. Fabié, "L'essor des études lexicographiques et grammaticographiques », p.325. Voir auparavant les analyses de J.Stefanini, Un Provençaliste marseillais, l'abbé Féraud, 1725-1807, p. 274-278 et surtout de R. Merle, «C.F. Achard et le bilinguisme provençal de la fin des Lumières » et R. Merle, L'Écriture $d u$ provençal de 1775 à 1840, p. 163-212.

12. Bibl. mun. d'Avignon, ms 2368, p. 163, lettre du 21 juillet 1784 et p. 164 , lettre du 5 août 1784.

13. C.-F. Achard, Dictionnaire de la Provence et du Comté Venaissin, t. II, Vocabulaire provençal-françois, p. V.

14. C.-F. Achard, Dictionnaire de la Provence et du Comté Venaissin, t. IV, Histoire des hommes illustres de la Provence, 1787, p. 500.

15. C.-F. Achard, Dictionnaire de la Provence et du Comté Venaissin, t. II, Vocabulaire provençal-françois, p. V.

16. C.-F. Achard, Dictionnaire de la Provence et du Comté Venaissin, t. II, Vocabulaire provençal-françois, p. 109.

17. C.-F. Achard, Dictionnaire de la Provence et du Comté Venaissin, t. II, Vocabulaire provençal-françois, p. 572. R. Bertrand, Crèches et santons de Provence, p. 43-61.

18. C.-F. Achard, Dictionnaire de la Provence et du comté Venaissin, t. III, Histoire des hommes illustres de la Provence, p. IX et XI. 
19. J.-C. Bonnet, Naissance du panthéon. G. Minois, Le Culte des grands hommes, des héros homériques au star system, p. 228-266.

20. C.-F. Achard, Dictionnaire de la Provence et du comté Venaissin, t. III, Histoire des hommes illustres de la Provence, p. XI-XIV.

21. C.-F. Bouche, Essai sur l'histoire de Provence, suivi d'une notice des Provençaux célèbres, t. II, p. 273-446.

22. Ce manuscrit est au Musée-bibliothèque Paul Arbaud de l'Académie des sciences, agriculture, arts et belles-lettres d'Aix-en-Provence (non coté).

23. C.-F. Achard, Dictionnaire de la Provence et du Comté Venaissin, t. III, Histoire des hommes illustres de la Provence, 1786, p. 250 (notice par Achard). Voir R. Bertrand, «Les Cantiques de l'âme dévote de Laurent Durand... ".

24. C.-F. Achard, Dictionnaire de la Provence et du Comté Venaissin, t. III, Histoire des hommes illustres de la Provence, 1786, p. 583-584 (notice anonyme). J. Billioud, "Un peintre de types populaires, Françoise Duparc de Marseille ».

25. Bibl. mun. d'Avignon, ms 2368, p. 182-183.

26. C.-F. Achard, Dictionnaire de la Provence et du Comté Venaissin, t. IV, Histoire des hommes illustres de la Provence, 1787, p. 350-401.

27. C.-F. Achard, Dictionnaire de la Provence et du Comté Venaissin, t. I, Vocabulaire françoisprovençal, p. 178.

28. C. Chabaneau, Notes sur quelques manuscrits provençaux perdus ou égarés, p. 38-41. Voir R. Bertrand, «La génération érudite provençale des années 1770-1780 et les troubadours », p. 271-272.

29. Bibl. mun. d'Avignon, ms 2368, p. 207 et p. 197.

30. Archives de l'Académie des sciences, lettres et arts de Marseille, Registre de p.v. des séances $\mathrm{n}^{\circ}$ 8, p. 125.

31. Bibl. mun. d'Avignon, ms 2368, p. 223.

32. Bibl. mun. d'Avignon, ms 2368, p. 253.

33. C.-F. Achard, Dictionnaire de la Provence et du Comté Venaissin, t. I, Vocabulaire françoisprovençal, p. VIII.

34. O. Teissier, Histoire d'une ancienne famille de Provence, p. 215 et aussi p. 158-160.

35. J.-J. Expilly, Dictionnaire géographique, historique et politique des Gaules et de la France.

36. C.-F. Achard, Description [...] de la Provence ancienne et moderne, t. II, p. 548-552. Copie du mémoire de l'abbé Aubanel, Aix-en-Provence, Musée-bibliothèque Paul ArbaudAcadémie de sciences, agriculture, arts et belles-lettres d'Aix-en-Provence, ms. MD 10.

37. N. Richter, Bibliographes et bibliothécaires, 1789-1839.

38. K. Fukasawa, "Claude-François Achard dans sa jeunesse ». J. Rondat, La Correspondance maçonnique échangée par Jean-Baptiste Willermoz et Claude-François Achard.

39. A. Fabre, Les Rues de Marseille, t. IV, p. 76-80.

40. R. Merle, «Le chemin d'Honnorat ». J.-Cl. Bouvier, «Préface » à Frédéric Mistral, Lou Tresor dóu Felibrige. Dictionnaire provençal-français, p. 9-13.

41. P. Masson, Les Bouches-du-Rhône, Encyclopédie départementale, vol. IV-2, Dictionnaire biographique des origines à la Révolution, p. VIII. 
42. É. Garcin, Dictionnaire historique et topographique de la Provence ancienne et moderne, p. 4.

43. M. Vovelle, De la cave au grenier, un itinéraire en Provence de l'histoire sociale à l'histoire des mentalités, p. 407-435.

44. M. Vovelle, Les Métamorphoses de la fête en Provence de 1750 à 1820, p. 13-101.

45. M. Vovelle, De la cave au grenier, un itinéraire en Provence de l'histoire sociale à l'histoire des mentalités, p. 19-38.

46. M.-H. Froeschlé-Chopard et S.Guérin éd., Images de l'ancienne Provence. M.H. Froeschlé-Chopard, «La fête au village dans l'ancienne Provence selon ClaudeFrançois Achard».

47. L.-S. Fournier et Ph. Hameau (dir.), Les fêtes à bravade, p. 179-186.

\section{RÉSUMÉS}

Le Dictionnaire de la Provence et du Comté Venaissin (six volumes parus entre 1785 et 1788) de Claude-François Achard (1751-1809) est constitué de trois parties. La langue, avec le premier dictionnaire français-provençal publié et le Vocabulaire provençal-françois, l'Histoire des hommes illustres de la Provence, enfin la Description historique, géographique et topographique des villes, bourgs, villages et hameaux. Achard a utilisé et publié la substance de travaux antérieurs manuscrits, dont certains ne nous sont pas parvenus. Il a bénéficié d'un réseau de collaborateurs et de correspondants locaux. Il a rassemblé et organisé un ensemble de connaissances qui sans lui seraient restées éparpillées, inédites ou même n'auraient pas été consignées par écrit. Le Vocabulaire a d'emblée suscité des émules. Il est à l'origine de la grande entreprise d'Honnorat. Certaines de ses notices biographiques ont été sans cesse reprises depuis Michaud, car elles fournissent les seules données connues sur des auteurs ou des peintres. La Description a été réutilisée et imitée. Elle a servi de source informative pour nombre de travaux d'histoire locale et aussi de banque de données quantifiables et cartographiables pour des études très variées.

\section{AUTEUR}

\section{RÉGIS BERTRAND}

Professeur émérite, Aix-Marseille Université, CNRS, TELEMME, Aix-en-Provence, France, membre émérite du CTHS, section Histoire du monde moderne, de la Révolution française et des révolutions 


\title{
Du Magasin pittoresque à la Bibliothèque des Merveilles : les défis encyclopédiques d'Édouard Charton
}

\author{
Annie Lagarde-Fouquet
}

1 Au cours de la session consacrée aux bibliothèques populaires, une congressiste s'interrogeait sur la présence des «Chartons » dans ces bibliothèques. L'utilisation de ce terme générique, et la question de leur présence dans les bibliothèques populaires, valide la notoriété, au moins auprès des spécialistes, des publications qu'Édouard Charton a dirigées, à savoir, les revues Le Magasin pittoresque et Le Tour du Monde, et les livres de la collection la Bibliothèque des Merveilles. Pendant près de soixante ans, de 1833 à 1890, Édouard Charton a contribué, par ces publications, à la diffusion des connaissances et à la transmission des savoirs. Laissant de côté la revue Le Tour du Monde, spécialisée dans les récits de voyages, nous ne retenons dans cette étude que les deux autres publications, en raison de leur caractère généraliste, pour ne pas dire encyclopédique. Leur contenu a déjà été étudié dans le livre consacré aux activités éditoriales d'Édouard Charton $^{1}$, et dans sa biographie ${ }^{2}$, aussi avons-nous choisi d'aborder la question par l'étude des « acteurs ", c'est-à-dire les rédacteurs, qui en ont assuré la qualité et le succès sur la période 1833-1890.

\section{Rappels biographiques}

2 Édouard Charton est né en 1807, à Sens. En 1824, il vient à Paris pour préparer son baccalauréat ès lettres et étudier le droit. Sa chambre d'étudiant est située dans un immeuble du quartier Latin, au 12 rue Taranne (disparue lors du percement du Boulevard Saint-Germain), où sont installées plusieurs sociétés savantes et philanthropiques. Parmi celles-ci, la Société pour l'Instruction Élémentaire, fondée en 1815, et son émanation, la Société pour l'enseignement Mutuel, ainsi que la Société pour la Morale Chrétienne, fondée en 1821. Logé en échange de divers travaux, le jeune étudiant a été introduit auprès de ces sociétés par Eugène Cassin, un cousin de son père. Plusieurs années avant d'en devenir membre, Édouard Charton se forme et s'imprègne de leurs 
idées progressistes. Il participe à leurs actions, contribue à leurs réflexions et collabore à leurs publications. Elles sont le creuset dans lequel se forgent les convictions qu'il défendra aussi bien dans le cadre de ses activités éditoriales, qu'au cours de sa carrière d'homme politique républicain.

Pour situer les orientations de la Société pour la Morale Chrétienne, voici quelques sujets abordés au sein de ses comités : la traite négrière, les prisons, la peine de mort, la paix. Elle organise des concours pour recueillir les meilleures idées sur ces sujets. En 1830, la société a lancé, à l'initiative de Charles de Lasteyrie, une pétition contre la peine de mort. Charton signe ce document corédigé par son ami Hippolyte Carnot. Les membres fondateurs de la Société française pour l'Abolition de l'Esclavage, créée en 1834, sont pour beaucoup issus de cette société. Dès 1825, dans la rubrique «Analyse et extraits » du Journal de la Société pour la Morale Chrétienne, il signe des résumés et analyses d'ouvrages et publie ses premiers articles en 1828. En 1829, déjà membre rémunéré du conseil de rédaction de cette publication, il est élu rédacteur en chef du Bulletin de la Société pour l'instruction élémentaire. Cette même année, le saint-simonisme vient le cueillir à domicile, à l'occasion d'une réunion organisée rue Taranne par Armand Bazard. Il s'installe dans la maison commune, là où demeurent les dirigeants saint-simoniens et leurs familles, au 6 rue de Monsigny. Il rejoint, après les journées révolutionnaires de 1830, Michel Chevalier à la rédaction du journal Le Globe, qui vient d'être cédé, par Pierre Leroux, aux saint-simoniens. En 1831, il accède au rang de prédicateur ; il part en Bretagne et en Saintonge. De retour à Paris, à la fin de l'année, après avoir tout abandonné à la cause saint-simonienne, il retrouve un groupe en crise. La rupture entre Enfantin et Bazard provoque, en novembre 1831, le départ d'adeptes qui s'écartent de Prosper Enfantin.

4 Charton fait partie de ces dissidents. Cette parenthèse l'a brouillé avec les philanthropes. Il a perdu son poste de rédacteur à la Société pour l'instruction élémentaire. Il réussit cependant à renouer, en compagnie d'Hippolyte Carnot, qui comme lui, était parti en 1831.

\section{Le rêve encyclopédique au service du plus grand nombre}

5 Philanthropes et saint-simoniens partagent la conviction qu'il faut diffuser largement les connaissances et transmettre les savoirs au plus grand nombre. Ils veulent ouvrir à tous, tous les champs de la connaissance, aussi n'est-il pas surprenant qu'ils s'investissent dans des projets à caractère encyclopédique. Ils ambitionnent d'accompagner un progrès qui ne doit pas se cantonner aux domaines scientifiques et techniques, mais s'élargir aux sciences humaines, aux mœurs, et à la société dans sa globalité. Il faut évidemment replacer leurs tentatives dans le contexte plus général du foisonnement des publications de ce type, au XIx ${ }^{e}$ siècle.

6 Quatre projets ont été retenus en raison de la proximité de leurs fondateurs avec Édouard Charton et de l'intérêt qu'ils ont suscité chez lui. Si le progrès est bien au centre de ces entreprises, chacune revendique une approche différente, assez bien identifiée par les titres choisis.

7 L'encyclopédie thématique ou le dictionnaire encyclopédique sont des outils lourds, difficiles à mettre à jour, coûteux, et mal adaptés à une large diffusion. Pour y remédier, 
François Guizot, membre des sociétés philanthropiques de la rue Taranne, lance en 1826 une Encyclopédie progressive, sans plan préétabli. Dans le prospectus d'introduction au premier et unique volume de cet ouvrage, Guizot expose sa conception de la diffusion des connaissances au plus grand nombre :

"C'est qu'il en est aujourd'hui des richesses intellectuelles comme de toutes les autres, leur distribution plus étendue, plus égale, et leur rapide circulation sont un besoin impérieux pour la société. De là vient le succès invincible des encyclopédies; c'est l'état actuel de la civilisation qui les rend indispensables et les fait triompher de toutes les objections. Ce qui importe aujourd'hui, ce n'est pas de discuter la convenance ou la possibilité des Encyclopédies, mais de leur donner tout de suite le mérite et toute l'utilité dont elles sont susceptibles. ${ }^{3}$ »

L'historien Guizot accorde une place de choix à sa discipline, comme en témoigne le titre choisi : Encyclopédie progressive, ou Collection de traités sur l'histoire, l'état actuel et les progrès des connaissances humaines. Ce projet ambitieux d'encyclopédie à deux vitesses prévoyait de publier un dictionnaire encyclopédique (encyclopédie élémentaire), complété par des articles plus approfondis constituant une encyclopédie savante. Il ne dépassa pas le stade de la première livraison. On trouve dans la liste des rédacteurs engagés sur ce projet plusieurs membres de la Société pour la Morale chrétienne, et il est probable que le jeune Charton, qui était, à cette époque, actif au sein de la société, en ait eu connaissance.

9 À trente ans d'intervalle, des saint-simoniens ont tenté de publier une encyclopédie, celle de Leroux et Reynaud est partiellement imprimée, celle de Pereire est restée à l'état de projet. En 1834, Jean Reynaud, saint-simonien dissident, lance l'Encyclopédie Nouvelle avec Pierre Leroux. Leurs critiques de l'encyclopédie rejoignent celles de Guizot, mais leur approche est différente car ils ne visent ni l'exhaustivité, ni la progressivité, mais la cohérence autour d'une doctrine, « la doctrine du progrès et de la perfectibilité, doctrine de vie et de salut, non seulement pour l'espèce mais pour l'individu $»^{4}$. Les auteurs revendiquent une nouvelle conception. Leur encyclopédie est :

«Un livre qui, au moyen d'une doctrine générale, embrasse le cercle entier des connaissances humaines, sans se perdre et s'absorber dans les détails, laissant aux monographies et aux traités spéciaux leur rôle et leur utilité. [Il en résulte que c'est plus] un Dictionnaire philosophique qu'un recueil de faits et de renseignements. Une multitude de faits y sont recueillis, sans doute, mais recueillis dans un but d'édifier une philosophie qui domine, explique et résume tous ces faits. ${ }^{5}$ »

Il s'agit d'une encyclopédie orientée, et c'est ce qui explique qu'elle soit restée inachevée, victime de désaccords entre Leroux et Reynaud; le huitième et dernier volume parait en 1841, mais les tomes V et VII sont incomplets et le volume VI n'a jamais été publié. Sans surprise, le titre évoque en premier la philosophie : Encyclopédie Nouvelle, dictionnaire philosophique, littéraire et industriel, offrant le tableau des connaissances humaines au dix-neuvième siècle. Charton y a contribué en rédigeant quelques articles. L' Encyclopédie Pereire a été lancée vers 1861 par des saint-simoniens ralliés à l'Empire, Émile et Isaac Pereire avec Michel Chevalier. Le projet est piloté par Charles Duveyrier chez qui se tiennent les réunions de travail thématiques, rassemblant anciens saintsimoniens et personnalités du monde économique, scientifique et littéraire. Charton est le seul saint-simonien opposant à l'Empire qui participe à ces réunions. Jamais publiée, cette encyclopédie est connue par les archives du comité préparatoire qui s'est réuni pendant un peu plus de deux ans. Charles Duveyrier, secrétaire de l'encyclopédie, rédige un avant-propos. Pour Philippe Régnier : 
«Il s'agit, selon une démarche analogue à celle de ces expositions universelles du Second Empire dont Arlès-Dufour et Chevalier sont les maîtres d'œuvre, de passer en revue tous les domaines du savoir pour y mettre en lumière les facteurs susceptibles de contribuer au " progrès » - le maître-mot absolu du texte..$^{6}$ »

11 Dans le titre, les sciences précèdent les autres disciplines: Encyclopédie, Exposition universelle des progrès des sciences, des arts et des lettres au XIX siècle. Édouard Charton a participé ou suivi ces deux projets. Il a aussi collaboré à la Revue Encyclopédique après sa reprise par Hippolyte Carnot avec Pierre Leroux. Jean Reynaud participe à cette tentative de sauvetage de la revue fondée en 1819 par Marc-Antoine Jullien. Hippolyte Carnot réaffirme les objectifs fixés par son fondateur et le caractère encyclopédique de cette revue dont le titre complet était: Revue encyclopédique ou Analyse raisonnée des productions les plus remarquables dans la littérature, les sciences et les arts. Ils voulaient aussi faire de cette revue, reconnue par la communauté scientifique et intellectuelle, une tribune pour les saint-simoniens dissidents, privés des colonnes du Globe.

L'expérience est de courte durée. En dépit des efforts fournis en particulier par Leroux et Reynaud, la difficile situation de la revue ne s'améliore pas ; la nouvelle direction ne peut tenir ses engagements de publication trimestrielle. Elle cesse de paraître avec le numéro d'octobre-décembre 1833, livré avec plusieurs mois de retard, en 1834. C'est à cette époque que Leroux et Reynaud prolongent l'aventure en lançant une Encyclopédie pittoresque à deux sous, rachetée, après sa faillite, l'année suivante, par le libraire Gosselin et transformée en Encyclopédie Nouvelle. Austère et élitiste, dépourvue d'illustrations, la Revue Encyclopédique peut cependant, par la nature des sujets abordés et par la participation de nombre de ses rédacteurs au Magasin pittoresque, être considérée comme un précurseur de cette revue populaire, qui paraît l'année de sa disparition.

\section{Le Magasin pittoresque}

13 En 1833, Alexandre Lachevardière, imprimeur, fondateur avec Pierre Leroux du journal Le Globe, revient d'Angleterre avec le projet de lancer une publication inspirée du Penny magazine, un journal illustré, bon marché, publié à Londres pour la diffusion des connaissances parmi les classes populaires. Il en propose la direction à Édouard Charton, qui, inscrit au tableau de l'ordre des avocats depuis 1831, mais peu attiré par la profession, accepte. Alexandre Lachevardière est le premier imprimeur qui utilise des presses mécaniques à vapeur permettant des tirages importants. Pour mêler textes et dessins en utilisant les procédés de gravure sur bois, et la stéréotypie, Charton œuvre à la constitution d'un atelier de gravure associé, dont les propriétaires prendront finalement le contrôle de la revue, après le départ de son fondateur.

14 Le Magasin pittoresque naît de cette rencontre de l'esprit d'entreprise, de la modernité, et de la volonté de produire une revue de qualité, illustrée, et accessible au plus grand nombre. Il s'agit d'intéresser, d'instruire ceux qui n'ont ni les moyens financiers, ni les loisirs de le faire, tout en les distrayant. Quelques mois seulement après son lancement le journal est tiré à 40000 exemplaires. Au bout d'un an, il a 60000 abonnés. En 1835, l'atelier équipé de deux presses produit 100000 exemplaires hebdomadaires. Seul le Journal des Connaissances utiles (1831-1836) de Girardin connaît de tels tirages à son apogée vers 1832, avant de décliner en 1834 puis disparaître en 1836. Le Magasin 
pittoresque, contrairement à son modèle anglais, rapidement disparu, paraîtra jusqu'en 1916.

15 Édouard Charton, persuadé de l'importance des images, porte autant d'attention aux illustrations qu'aux textes, aux dessinateurs et graveurs qu'aux auteurs. Ces circonstances expliquent, avec l'implication d'un réseau de rédacteurs de qualité, non seulement le succès immédiat, mais aussi la pérennité de la publication. Les articles ne sont pas signés, mais Charton prend la peine, dès 1837, d'en citer les principaux auteurs. Dans ce premier cercle où figurent quarante-cinq noms, un tiers appartient à la mouvance saint-simonienne; ils sont favorables à cette nouvelle littérature, profitable à une société basée sur les sciences, les industries et les arts. Vingt-neuf, soit plus de la moitié, ont collaboré à la Revue Encyclopédique.

Le Magasin pittoresque ne s'affiche pas comme un projet encyclopédique, il le devient. Le titre, qui parle plus à l'imagination qu'à la raison, le confirme. Car Charton réussit l'exploit de mobiliser, au-delà de ses relations de jeunesse, sur deux, voire trois générations, tout un réseau de scientifiques, d'historiens, d'ingénieurs ou d'érudits dont il supervise et coordonne les travaux, pour constituer comme il le confie à son gendre Paul Laffitte, une "encyclopédie en désordre ». Huit pages hebdomadaires, à deux sous, accessibles au plus grand nombre.

17 La fréquence de la publication (hebdomadaire, puis mensuelle) évolue dans le temps au gré des lois régissant la presse, mais le format ( $20 \times 29)$ reste le même avec 408 pages, soit environ 500 articles par an, car, à côté d'articles occupant une à deux ou trois pages, sur deux colonnes, on trouve de courtes informations sur une colonne ou une demi-colonne. Bien que courts, ces articles ne sont pas anodins, c'est par exemple la lecture de l'un d'eux qui a donné à Jules Verne l'idée du tour du monde en quatrevingts jours. Jusqu'en 1882, les articles ne sont pas signés : à la liste de 1837 viennent s'ajouter périodiquement des listes de rédacteurs. Dessinateurs et graveurs sont aussi à l'honneur, ils ont parfois été à l'origine d'articles rédigés autour de dessins commandés par Charton. Bien que notre étude reste limitée aux seuls rédacteurs, les illustrateurs ont largement contribué à l'attrait de la publication et à la transmission des savoirs.

À partir de ces documents on a établi une liste révisée couvrant la période 1833-1888, date à laquelle Charton quitte la direction du Magasin pittoresque. Les noms correspondants à de simples citations en ont été extraits, lorsqu'ils ont été détectés, car il s'agit de collaborations involontaires. L'identité des auteurs sous pseudonyme a été rétablie. Les listes sont cumulatives et il arrive qu'un nom disparaisse d'une liste postérieure ; faute d'explication, nous avons choisi de maintenir ces « disparus ». Elle comporte trois cent quatre-vingt-quinze noms, mais il y a peut-être des absents. Par exemple, George Sand, auteure d'un article sur la Creuse, qui ne figure dans aucune liste, a été ajoutée. Il est question dans leur correspondance de cet article illustré par Grandsire, publié en $1858^{7}$. S'agit-il d'un oubli, d'une omission volontaire de Charton, ou d'un souhait de George Sand? Y a-t-il d'autres auteurs incognito? Un seul Reclus figure dans cette liste, il s'agit de Paul, le médecin. Il est surprenant que Charton n'ait pas sollicité et obtenu d'article de son frère, Élisée, pour lequel il était intervenu après son arrestation en 1871, et avec qui il correspondait pendant son exil en Suisse. L'absence de Pierre Leroux est moins surprenante, sur fond de querelle avec Jean Reynaud, mais celle-ci n'intervient qu'en 1841.

19 Pour trois cent cinquante auteurs, on peut rassembler des renseignements biographiques complets et précis permettant de renseigner avec certitude leurs états 
civils, leurs formations, leurs fonctions et éventuellement les institutions auxquelles ils ont appartenu. Une trentaine d'auteurs ont été partiellement identifiés, et pourraient vraisemblablement être mieux connus en effectuant des recherches complémentaires. Pour quinze rédacteurs, aucune information biographique ou de carrière n'a pu être trouvée avec certitude, parfois en raison d'homonymies. Signalons la présence de vingt-quatre femmes, soit un peu plus de $6 \%$ du total, ce qui compte tenu de l'époque est remarquable.

Il n'est généralement pas possible de déterminer, sauf exceptions, s'il s'agit d'un rédacteur occasionnel ou d'un collaborateur régulier. L'exemple de l'astronomie a été étudié par M-L. Aurenche ${ }^{8}$ et par G. Adam sur la période $1833-1870^{9}$. Nous savons que les articles de la première année sont dus à Abel Transon et Jean Reynaud, polytechniciens, saint-simoniens, et que Reynaud tient par la suite une rubrique régulière. Nous savons aussi qu'il a été remplacé par Flammarion en 1863. Arago qui n'apparaît dans aucune liste officielle aurait aussi collaboré, indirectement, mais peutêtre aussi directement :

« Mais le MP, à la fin de la période étudiée n'hésite pas à faire appel à de prestigieux professionnels. Arago, le premier des vulgarisateurs modernes est présent. Avec des citations de son astronomie populaire (MP 1855, p. 104, 1857, p. 392), mais aussi avec des textes généraux, d'une sensibilité très moderne, traitant des superstitions liées au ciel (MP 1839, p. 57, p. 94). ${ }^{10}$ »

Jacques Babinet cité par ces auteurs figure bien dans les listes. Il est très actif autour des années 1863 et contribue à grossir le nombre d'articles consacrés à l'astronomie. Preuve de la réactivité de Charton, Babinet a été sollicité en 1858, pour rédiger une notice illustrée à l'occasion de l'éclipse du 15 mars, après avoir signalé dans le Journal des Débats, l'importance du dessin pour la compréhension des phénomènes astronomiques. Nous ne pouvons disposer de ces informations qu'en les recherchant dans d'autres publications, dans ce cas, un texte de Babinet publié dans le Bulletin scientifique du Journal des Débats :

«Les éditeurs du Magasin pittoresque [...] étaient venus me demander à la minute une notice illustrée qui en quelques jours et presque en quelques heures, fut imprimée, dessinée, gravée et tirée à vingt mille exemplaires, dont plus de quinze mille mis en circulation dans le public. ${ }^{11}$ ”

En dépit de toutes ces insuffisances, la liste établie, permet d'avoir une vue d'ensemble des rédacteurs et d'expliquer en partie la variété et la bonne tenue des articles proposés. Charton était bien conscient que le succès de sa revue dépendait de la qualité de ses rédacteurs, charge à lui d'en assurer le renouvellement et de veiller à l'équilibre entre les sujets traités. Le graphique des plages d'années de naissance montre que, si beaucoup d'entre eux, nés entre 1800 et 1819, appartient à la génération de Charton, celui-ci a su mobiliser les générations suivantes sur son projet (tab. 1).

Tab. 1. - Répartition générationnelle des rédacteurs du Magasin pittoresque.

\begin{tabular}{|l|l|}
\hline Année de naissance & Nombre \\
\hline Avant 1760 & 3 \\
\hline $1760-1769$ & 3 \\
\hline $1770-1779$ & 10 \\
\hline $1780-1789$ & 5 \\
\hline
\end{tabular}




\begin{tabular}{|l|l|}
\hline $1790-1799$ & 24 \\
\hline $1800-1809$ & 81 \\
\hline $1810-1819$ & 86 \\
\hline $1820-1829$ & 52 \\
\hline $1830-1839$ & 34 \\
\hline $1840-1849$ & 29 \\
\hline $1850-1859$ & 16 \\
\hline Après 1860 & 7 \\
\hline
\end{tabular}

(c) Annie Lagarde-Fouquet. engagements politiques et les institutions auxquelles ils appartiennent. Vingt et un (5\%) sont d'anciens élèves de Polytechnique, ils sont majoritairement saint-simoniens ou fouriéristes, et de la génération de Charton. Plusieurs donnent des cours du soir dans le cadre de l'Association polytechnique. Ils font partie du groupe de rédacteurs pour lesquels transmettre les connaissances constitue un engagement nécessaire pour asseoir la société qu'ils rêvent d'instaurer. Vingt-quatre ingénieurs: quelques ingénieurs des Mines et dix anciens de l'École centrale des Arts et Manufactures, dont Henry de Dion, un des soixante-douze savants dont le nom a été inscrit sur la Tour Eiffel. Sept normaliens, dont un saint-simonien et un homme politique républicain, des agrégés, des diplômés de l'université. Quinze (3,5\%) sont d'anciens élèves de l'École des chartes, sept sont nés avant 1820, huit après. Dans ce groupe, on rencontre des érudits soucieux de partager leurs connaissances, sans objectif idéologique. Un seul, Paul Lacombe, ami de Gambetta a eu des engagements politiques.

Il y a bien sûr des naturalistes, (Albert Geoffroy-Saint Hilaire), des architectes (Léon Vaudoyer) des archéologues (Jules Quicherat, directeur de l'École des chartes), des agronomes (Euryale Cazeaux), des historiens (Henri Martin), des orientalistes (Jean Gabriel Deveria), des géographes (Charles Maunoir), des géologues (Armand Landrin), des voyageurs, des diplomates. Les juristes, avocats, magistrats sont moins nombreux, et interviennent généralement en dehors de leur spécialité. Écrivains, hommes et femmes de lettres, littérateurs, poètes, sont plus de cinquante, mais cela ne correspond toujours qu'à $12 \%$ de l'ensemble. Le nombre d'artistes, peintres, dessinateurs, sculpteurs, musiciens est du même ordre. Par exemple, Eugène Delacroix a été identifié comme auteur d'un dessin accompagné d'un texte, souvenir de son séjour au Maroc ${ }^{12}$. Les professeurs, quarante-cinq (11\%), qui se répartissent pour moitié entre disciplines littéraires et scientifiques, sont bien représentés. Plusieurs sont des auteurs de manuels scolaires (Pierre Foncin). Édouard Charton, décrit par ses amis toujours aux aguets pour trouver des sujets et solliciter des articles auprès de son entourage, a réussi à enrôler cinq professeurs, scientifiques et littéraires, du lycée de Versailles, sa ville de résidence, dont il a aussi été conseiller municipal. Un seul appartient à sa génération, les quatre autres, nés entre 1832 et 1834, appartiennent à la deuxième génération de rédacteurs. Les conservateurs de bibliothèques ou de musées, sont aussi bien représentés : trentetrois, essentiellement parisiens. Ces derniers sont particulièrement intéressants pour Charton, toujours à l'affût de documents iconographiques authentiques. Le lecteur 
provincial découvre les trésors des bibliothèques et des musées parisiens auxquels il n'aurait jamais eu accès. Citons l'amiral Pâris, conservateur des collections de Marine, ancêtre du Musée de la Marine, au Louvre, ou Alexandre Bertrand, directeur du Musée des Antiquités de Saint-Germain en Laye. Quelques officiers, sept, mais seulement un théologien protestant de Genève et quatre ecclésiastiques. L'un est grammairien, deux autres sont archéologues (l'abbé Cochet est conservateur des antiquités au musée de Rouen), le quatrième est un voyageur, membre des Missions évangéliques de Paris.

Les femmes sont souvent femmes de lettres, traductrices, institutrices. Les premières, Pauline Roland et Adélaïde de Montgolfier, viennent de la mouvance saint-simonienne, elles ont aussi collaboré à l'Encyclopédie Nouvelle. Plus tard, elles se recrutent parmi les écrivains pour la jeunesse, parfois un peu moralisatrices. Parmi les personnalités marquantes, citons George Sand, l'agronome Cora Millet-Robinet, première femme titulaire du Mérite agricole. Elles sont parfois parentes d'un rédacteur, comme Charlotte Deveria, femme du diplomate Gabriel Deveria. Musicienne, compositrice, elle a publié, au retour de son séjour en Chine, un article très remarqué sur la musique et les instruments chinois ${ }^{13}$.

Eugène Lesbazeilles, gendre $\mathrm{du}$ saint-simonien Émile Souvestre, par ailleurs bibliothécaire, met sa plume au service d'Édouard Charton sur des sujets divers, mais il y a peu de polygraphes. Édouard Charton considérait que le journalisme n'était pas une profession:

"On n'est journaliste que quand on écrit dans un journal ; on le devient et on cesse

de l'être du jour au lendemain. ${ }^{14}{ }$ ”

On en a identifié une vingtaine, littérateurs ou scientifiques, dont moins de dix collaborent à de grands titres. Par exemple, Mme Marie-Thérèse Blanc, née en 1840, traductrice, une des rares femmes titulaires de la Légion d'honneur, est journaliste à la Revue des deux Mondes.

Dans le Magasin pittoresque, on suit le passage de la vulgarisation scientifique engagée, avec par exemple les fouriéristes Victor Meunier, fondateur en 1855 de l'Ami des Sciences, et Frédéric Zurcher, officier de marine, ancien élève de Polytechnique, à la vulgarisation genre littéraire. Mais s'il accueille de jeunes vulgarisateurs, Charton refuse d'introduire la science-fiction dans sa revue. La nouvelle génération est représentée par l'astronome Camille Flammarion ${ }^{15}$ et Gaston Tissandier ${ }^{16}$. Flammarion, présenté à Charton par Henri Martin, a repris la chronique astronomique en 1863, après le décès de Jean Reynaud. Tissandier, ingénieur chimiste, aéronaute, qui ne cache pas son admiration pour Charton, lance la revue de vulgarisation scientifique La Nature en 1873. Il espère en faire un Magasin pittoresque dédié aux sciences et aux techniques.

Les institutions les plus prestigieuses sont représentées : au total dix-neuf membres des diverses académies parisiennes (Académie française, Beaux-Arts, Sciences, Médecine), des membres de l'Institut, du Museum, quelques professeurs au Collège de France. Bien sûr, tel académicien ou membre de l'Institut ne l'est peut-être pas encore quand il collabore au Magasin Pittoresque, mais cela nous donne une indication de la qualité et de l'implication de ces spécialistes (ou « hommes spéciaux» comme on disait à l'époque). Dans ses index, Charton n'hésite pas à préciser les titres de ses auteurs, règle qu'il s'applique en rappelant qu'il fut conseiller d'État.

30 Ce survol des rédacteurs qui ont participé, d'abord anonymement de 1833 à 1882, puis en signant leurs articles de 1883 à 1888, au rayonnement du Magasin pittoresque, permet de comprendre comment Édouard Charton a réussi, avec leurs contributions, 
volontaires ou sollicitées, illustrées et organisées, à transformer cette modeste revue en une petite encyclopédie. Dirigée par lui pendant plus de cinquante années, elle a évolué sous l'influence des événements extérieurs. Certains thèmes, comme la statistique qui ouvrait le champ à des réflexions sur la société, sont abandonnés sous l'Empire.

La revue vieillit avec son directeur. Dans les années 1880, elle s'essouffle, le recrutement des rédacteurs est moins actif, mais Édouard Charton a réussi à maintenir son cap : instruire en distrayant, mettre à la portée du plus grand nombre, par des articles courts et illustrés, rédigés par des auteurs compétents, les connaissances dans les domaines artistique, géographique, historique, industriel, littéraire, scientifique, technologique, c'est-à-dire, donner à lire au plus grand nombre tout ce que promettaient les lanceurs d'encyclopédies qu'il avait côtoyés.

\section{La Bibliothèque des Merveilles}

En 1832, les membres de la Société de la Morale chrétienne s'inquiètent de la prolifération d'une littérature de mauvaise qualité, largement diffusée en raison du prix modique de ces petits livres. Une commission est créée pour trouver des palliatifs à ce phénomène. Édouard Charton et Hippolyte Carnot en font partie ; Charton en est le rapporteur ${ }^{17}$. Ils proposent l'organisation d'un concours pour la réalisation de petits ouvrages (100 pages maximum, in $18^{\circ}$ ), afin que l'éditeur avec lequel la Société aura pris :

"Les arrangements nécessaires pour leur publication, soit tenu de ne vendre jamais chaque exemplaire plus de cinq à six sous, même avec des gravures ou vignettes..$^{18}$ "

En 1837, Charton crée La Bibliothèque du Magasin pittoresque; complétant la revue, elle devait être constituée d'une série d'ouvrages abordant les sujets d'une façon "plus suivie et plus abondante ». Il ne s'agit pas, comme précédemment de substituer de bonnes lectures aux mauvaises, mais de mettre à la portée de tout le monde " toutes les sciences, toutes les études, toutes les idées ${ }^{19}$. Ce projet, sans le dire, se présente comme un projet de nature encyclopédique, mais il rejoint rapidement la série des encyclopédies inachevées, puisque seuls quatre livres seront publiés en 1838. On peut en partie attribuer cet échec à l'inadéquation des sujets par rapport à l'attente des lecteurs du Magasin pittoresque, et au manque de soutien de l'éditeur.

À partir de 1850, Édouard Charton est en relation avec Louis Hachette sur plusieurs projets. Cette collaboration se concrétise en 1860 avec le lancement de la revue de voyage, le Tour $d u$ monde, elle est suivie en 1865, d'une collection d'ouvrages de vulgarisation, la Bibliothèque des Merveilles. La publication de ces petits volumes illustrés, à deux francs, répond à la politique de collections de l'éditeur Hachette et à l'idéal philanthropique d'Édouard Charton.

35 Le contrat signé avec l'éditeur lui donne l'occasion de publier enfin de bons livres populaires, ceux auxquels il pense depuis son passage à la Société pour l'Instruction élémentaire, là où il avait eu connaissance des tentatives (mise au concours d'ouvrages) pour « encourager la composition d'ouvrages élémentaires destinés aux lectures du peuple ${ }^{20} »$.

36 Toute sa vie, Charton poursuit cette quête de bons livres. Membre actif de la Société Franklin, dont l'objectif est de créer des bibliothèques populaires, il interroge George Sand, en juin 1862, au sujet des livres à proposer en milieu rural.

"Chère Sand, vous qui aimez, connaissez, comprenez si bien les habitants de la campagne, dites-moi, je vous prie de quels livres devrait se composer une 
bibliothèque communale ? Faudrait-il se contenter de réimprimer des classiques, en les abrégeant ? ${ }^{21} »$ longue expérience dans ce domaine. Si au Magasin pittoresque, la consigne était d'instruire en distrayant, les auteurs de la Bibliothèque des Merveilles doivent susciter l'intérêt de leurs lecteurs. Pour le premier volume, Édouard Charton s'adresse à Camille Flammarion. Il ne pouvait pas faire meilleur choix, Les Merveilles célestes lance véritablement la collection et feront l'objet de nombreuses rééditions (25 000 en 1875, 60000 en 1895) avant d'être repris, toujours chez Hachette, dans une autre collection, La Bibliothèque des écoles et des familles. Flammarion le raconte dans ses mémoires :

«M. Édouard Charton me parla de son projet de fonder à la Librairie Hachette une Bibliothèque des Merveilles qui serait formée d'une série de petits volumes populaires à deux francs, consacrés à faire connaître les Merveilles de la Nature. Il désirait commencer par Les Merveilles célestes et me proposa d'écrire le premier volume, pour lancer la collection. ${ }^{26}$ " rédigé pour être vendu séparément. Cent trente-six volumes séparés, d'environ trois 
cents pages, sont publiés de 1865 à 1890 . Certains auteurs ont traité du même sujet en plusieurs volumes, comme les deux tomes d'Amédée Guillemin sur les chemins de fer, mais chacun étant indépendant, nous les avons comptés séparément. Ils ont été rédigés par quatre-vingt-un auteurs, dont trente-cinq ont collaboré aux autres publications dirigées par Charton: seize ont commencé au Magasin pittoresque, deux au Tour du Monde, avant de travailler pour la nouvelle collection; réciproquement, dix-sept auteurs de la Bibliothèque des Merveilles poursuivront leur collaboration dans l'une ou l'autre de ces revues. En cette seconde moitié du XIX siècle, certains commencent à faire profession de vulgarisateur: Flammarion rédige, en 1866 et 1867, sous le pseudonyme de Fulgence Marion - sans doute parce qu'il sort de son domaine - trois autres livres pour la collection. Gaston Tissandier rédige cinq volumes, de 1867 à 1886 . Parmi les autres écrivains vulgarisateurs, on découvre: Frédéric Zurcher et Élie Margollé (7 volumes), Wilfried de Fonvielle (5 volumes), Amédée Guillemin (4 volumes), Maxime Vuillaume (pseudo: Maxime Helene 3 volumes), Raoul Marquis (pseudo: Graffigny 2 volumes), Victor Meunier (2 volumes).

Comme au Magasin pittoresque, on trouve à côté de ces rédacteurs qui collaborent à d'autres publications, et dont certains sont très spécialisés, des ingénieurs, des chartistes, des normaliens, des universitaires, des artistes, des écrivains et... une femme. Épouse du géologue Stanislas Meunier, belle-fille de Victor Meunier, Léonie publie deux livres : L'Écorce terrestre en 1882 et Les Sources en 1886. Théodore du Moncel, avec Le Téléphone, le microphone et le phonographe (1878), et l'agronome Ernest Menault, avec L'Intelligence des animaux (1868) et L'Amour maternel chez les animaux (1874) comptent parmi les auteurs à succès, dont les ouvrages sont réédités jusqu'au début du $\mathrm{Xx}^{\mathrm{e}}$ siècle.

44 Édouard Charton recherche systématiquement de jeunes "savants» auxquels il suggère des sujets : le naturaliste Guillaume Capus ${ }^{27}$ répond, en rédigeant L' $\mathbb{E}$ uf chez les plantes et les animaux (publié en 1885), à une demande formulée par Charton à JeanLouis Quatrefages de Bréau, professeur au Muséum d'Histoire Naturelle. Ces débutants côtoient les rédacteurs les plus éminents comme Charles Lévêque, professeur de philosophie au Collège de France, membre de l'Institut, auteur de nombreux ouvrages consacrés à l'esthétique et à l'art. La dédicace de son livre Les Harmonies providentielles nous informe des instructions reçues du directeur de publication: démontrer la providence divine en la rendant accessible à tous les esprits, c'est-à-dire à un ouvrier de 16 ans, ayant reçu une bonne instruction primaire. La première édition de cet ouvrage, que l'on peut classer dans la catégorie philosophie des sciences (1872) a été rapidement épuisée et a fait l'objet d'au moins trois rééditions. Citons aussi Jules Roy, professeur à l'École des chartes qui publie L'An mille; formation de la légende de l'an mille, état de la France, de l'an 950 à l'an 1050 en 1885. Charton, amateur de théatre demande au peintre Jean-Pierre Moynet, illustrateur du Tour $d u$ Monde, mais aussi décorateur, un ouvrage sur les décors de théâtre, L'Envers du Théâtre, machines et décorations (1874). Les arts décoratifs (orfèvrerie, tapisserie, céramique) sont aussi à l'honneur.

Avec cette collection, Édouard Charton a réalisé le complément dont il avait rêvé pour Le Magasin pittoresque. Indépendante de tout esprit de système, l'accumulation des petits volumes de la collection qui célèbrent le progrès technologique sans négliger ni la nature, ni l'histoire et l'archéologie, ni les arts et l'architecture, constituait déjà à sa mort, en 1890, un apport majeur pour la diffusion des connaissances. La collection a survécu à son fondateur jusqu'en 1954, mais avec un rythme de publication bien moins 
soutenu, seulement dix-neuf titres entre 1891 et 1934, dont certains déjà initiés par Charton, et après une longue interruption, sept volumes de 1950 à 1954.

De 1833 à 1890, Édouard Charton, directeur du Magasin pittoresque et de la Bibliothèque des Merveilles a travaillé avec près de quatre cent quarante rédacteurs de qualité, dont l'apport a été plus ou moins important, souvent ponctuel, parfois régulier. Il a su mobiliser au moins deux générations de collaborateurs, dont les motivations évoluaient au fil du temps, et assurer un certain équilibre entre des disciplines diversifiées pour relever le défi de construire, avec pragmatisme et sans esprit de système, une œuvre marquée par la volonté de combattre l'ignorance et l'idéal encyclopédique.

\section{BIBLIOGRAPHIE}

ADAM Gilles, « La valeur scientifique des articles d'astronomie publiés dans le Magasin pittoresque de 1833 à 1870 », dans ANDRIÈs Lise (dir.), Le partage des savoirs XVIII ${ }^{e}$-XIX ${ }^{e}$ siècles, Lyon, Presses Universitaires de Lyon, 2003, p. 269-290.

AURENCHE Marie-Laure, « La diffusion du savoir dans le Magasin pittoresque (1833-1870) :

l'astronomie, une science pour tous ", dans ANDRIÈs Lise (dir.), Le partage des savoirs XVIII ${ }^{e}-\mathrm{XIX}{ }^{e}$ siècles, Lyon, Presses Universitaires de Lyon, 2003, p. 243-268.

AURENCHE Marie-Laure, Édouard Charton et l'invention du Magasin pittoresque, (1833-1870), Paris, Honoré Champion, Collection Romantisme et Modernités, n 57, 2002.

BABINET Jacques, « Bulletin scientifique », Journal des Débats politiques et littéraires, samedi 3 avril 1858, n p.

CHARTON Édouard, « Livres de lecture du peuple », Journal de la Société de la Morale Chrétienne, t. VI, 1832, p. 234-239.

CHARTON Édouard (attribué à), en tête de volume, Le Magasin pittoresque, 1837.

CHARTON Édouard, Correspondance générale (1824-1890), rassemblée et annotée par M-L. AURENCHE, Paris, Honoré Champion, 2002, 2 vol.

DELACROIX Eugène, « Une noce juive dans le Maroc », Le Magasin pittoresque, 1842, p. 28-30.

DÉVERIA Charlotte, « Essai nouveau sur la musique chez les Chinois », Le Magasin Pittoresque, Paris, 1885, p. 234-238, 287-288, 327-328, 390-392.

FLAMmaRion Camille, Mémoires, Paris, Éd. Flammarion, 1912.

GUIZOT François, Encyclopédie progressive, ou Collection de traités sur l'histoire, l'état actuel et les progrès des connaissances humaines. Encyclopédie, article servant de discours préliminaire, Paris, Bureau de l'Encyclopédie progressive, 1826, $46 \mathrm{p}$. 
LAGARDE-FOUQUET Annie, LAGARDE Christian, Édouard Charton (1807-1890) et le combat contre l'ignorance, Rennes, Presses Universitaires de Rennes, Collection Carnot, 2006.

LEROUX Pierre, REYNAUD Jean (dir.), Encyclopédie Nouvelle, dictionnaire philosophique, littéraire et industriel, offrant le tableau des connaissances humaines au XIX ${ }^{e}$ siècle; par une société de savants et de littérateurs, Prospectus publié dans P. LEROUX, Réfutation de l'éclectisme où se trouve exposée la vraie définition de la philosophie, et où l'on explique le sens, la suite, et l'enchaînement des divers philosophes depuis Descartes, Paris, Gosselin, 1839, 12 pages.

RÉGNIER Philippe, « Du Saint-Simonisme comme science et des Saint-Simoniens comme scientifiques : généralités, panorama et repères », Bulletin de la Sabix, Éd. numérique, 44 | 2009, consulté le 2 avril 2018. [URL : http://journals.openedition.org/sabix/626]

RENOUARD Charles, « Rapport de M. Ch. Renouard sur la proposition de M. le baron Gérando », Journal d'éducation, décembre 1854, p. 50.

SAND George (attribué à), «Les bords de la Creuse », Le Magasin pittoresque, 1858, p. 67-70 et p. 252-254

\section{NOTES}

1. M-L. Aurenche, Édouard Charton et l'invention du Magasin pittoresque, (1833-1870), p. 456-457.

2. A. Lagarde-Fouquet, Ch. Lagarde, Édouard Charton (1807-1890) et le combat contre l'ignorance, p. 87-99.

3. F. Guizot, Encyclopédie progressive, ou Collection de traités sur l'histoire, l'état actuel et les progrès des connaissances humaines. Encyclopédie, article servant de discours préliminaire, p. 1.

4. Prospectus, Encyclopédie Nouvelle, dictionnaire philosophique, littéraire et industriel, offrant le tableau des connaissances humaines au dix-neuvième siècle; par une société de savants et de littérateurs, dans P. Leroux, Réfutation de l'éclectisme où se trouve exposée la vraie définition de la philosophie, et où l'on explique le sens, la suite, et l'enchaînement des divers philosophes depuis Descartes, n.p.

5. Ibid.

6. Ph. Régnier, «Du Saint-Simonisme comme science et des Saint-Simoniens comme scientifiques : généralités, panorama et repères ", alinéa 28.

7. G. Sand (attribué à), « Les bords de la Creuse », p. 67-70, p. 252-254.

8. M-L. Aurenche, «La diffusion du savoir dans le Magasin pittoresque (1833-1870): l'astronomie, une science pour tous », p. 243-268.

9. G. Adam, « La valeur scientifique des articles d'astronomie publiés dans le Magasin pittoresque de 1833 à 1870 », p. 269-290.

10. Ibid, p. 283.

11. J. Babinet, «Bulletin scientifique », n. p.

12. E. Delacroix, «Une noce juive dans le Maroc ».

13. C. Déveria, «Essai nouveau sur la musique chez les Chinois », p. 234-238, 287-288, 327-328 et 390-392. 
14. Éd. Charton (dir.), Dictionnaire des professions ou guide pour le choix d'un état, p. 305.

15. Camille Flammarion, né en 1842.

16. Gaston Tissandier, né en 1843.

17. Éd. Charton, «Livres de lecture du peuple », Journal de la Morale chrétienne, t. VI, 1832, p. 234-239.

18. Journal de la Morale chrétienne, t. VII, 1833, p. 254.

19. Le Magasin pittoresque, 1837, en tête de volume.

20. Ch. Renouard «Rapport de M. Ch. Renouard sur la proposition de M. le baron Gérando ", Journal d'éducation, décembre 1854, p.50.

21. Éd. Charton, « lettre à George Sand, datée du 8 juin 1862 », dans Édouard Charton, Correspondance générale (1824-1890), p. 1140-1141.

22. G. Sand, «lettre à Édouard Charton, datée du 16 juin 1862 », dans Édouard Charton, Correspondance générale (1824-1890), p. 1144-1145.

23. IMEC, Archives Hachette, HCT, Bibliothèque des Merveilles, t. II, fo 322.

24. Ibid.

25. « Notice sur la librairie de MM. Hachette et Cie. », p. 37.

26. C. Flammarion, Mémoires, p. 303.

27. Guillaume Capus, né en 1857.

\section{RÉSUMÉS}

En acceptant de prendre la direction du Magasin pittoresque en 1833, le jeune saint-simonien Édouard Charton y voit une opportunité pour combattre l'ignorance. Cette date marque pour lui le début d'une longue carrière au service de l'édition. Il dirige cette " encyclopédie en désordre ", comme il la qualifiait lui-même, jusqu'en 1888. En 1860, la Librairie Hachette lui confie la direction de la revue de voyages Le Tour $d u$ Monde, et en 1864, celle d'une nouvelle collection encyclopédique, La Bibliothèque des Merveilles. Après un rappel rapide de la biographie d'Édouard Charton, des spécificités du Magasin pittoresque et de la Bibliothèque des Merveilles, nous nous intéresserons aux rédacteurs, plus de quatre cents, représentant toutes les branches du savoir, qu'il a su intéresser et mobiliser, pour construire une œuvre encyclopédique, caractérisée par le pragmatisme et l'absence d'esprit de système.

\section{AUTEUR}

\section{ANNIE LAGARDE-FOUQUET}

Ingénieur en retraite, membre de la Société de géographie et de Centrale Histoire 


\title{
Littérature de jeunesse et métier des armes : la formation de l'esprit militaire chez Alexandre de Saillet, maître de pension et pédagogue (1812-1866)
}

\author{
Louis Bergès
}

1 «La rage d'écrire a gagné même la classe militaire qu'une carrière d'action semblait devoir préserver de cette fièvre [...] Si nos épées sommeillent, nos plumes ne chôment guère $^{1} "$, peut-on lire en réponse à une publication sur l'armée française du généralécrivain Joachim Ambert en 1840. En pleine campagne d'Algérie, l'armée royale s'interroge sur son renouvellement, l'instruction des hommes, l'éducation morale de ses cadres, la qualité du commandement. Après la révolution de Juillet, un immense champ de réflexion s'ouvre à tous ceux qui détiennent les clés de l'éducation intellectuelle et morale des jeunes esprits dans tous les domaines. S'agissant de la «formation » (le mot n'existe pas encore à cette période) de tous ces enfants du siècle au métier des armes, nous sommes en présence d'un sujet fondamentalement littéraire dans une France des notables du XIXe siècle bercée par la légende napoléonienne : des auteurs majeurs s'y intéressent, c'est le cas d'Alfred de Vigny, Servitudes et grandeurs militaires (1836) mais aussi de Stendhal avec Lucien Leuwen, et surtout de Paul de Molènes, l'écrivain-soldat, auteur à la mode de romans et de nouvelles militaires²

2 J'ai choisi de présenter ici un écrivain pédagogue dont le nom, aujourd'hui oublié, est celui d'un auteur relativement célèbre à l'époque de l'éclosion de la littérature de jeunesse, un homme dont l'univers mental est largement tourné vers l'avenir du métier des armes : il s'agit d'Alexandre de Saillet dont la carrière démarre lors de la sortie des nouvelles qui apportent à Vigny sa célébrité et s'achève vers 1862, au moment où sont créées les bibliothèques scolaires par le ministre Rouland ${ }^{3}$.

3 Il sera intéressant de voir comment l'auteur traite les questions d'éducation du jeune soldat qu'il développe dans ses écrits destinés à la jeunesse. Trois niveaux sont à 
distinguer dans cet apprentissage, la culture générale (connaissances scolaires), l'éducation militaire (transmission des valeurs du commandement et de la discipline) et l'instruction militaire (formation technique). Saillet, comme maître de pension s'adressant à de jeunes adolescents, s'intéresse dans son œuvre au second niveau d'enseignement, l'éducation militaire. Mais l'homme prend parti dans le débat sur l'instruction scolaire des militaires, ce qui le place en cette période en première ligne de l'attention des familles notables et du gouvernement. Le sujet est d'autant plus capital jusqu'à la fin du siècle qu'en raison de la persistance de préjugés bien ancrés dans l'armée envers l'instruction scolaire puis universitaire, jugée peu utile pour le combat, l'insuccès des écoles régimentaires créées à partir de 1835 oblige les autorités militaires à se pencher sur le problème, sans toutefois parvenir à dépasser la difficulté, comme en témoignera beaucoup plus tard Dutreuil de Rhins en 1882 :

«Formez une armée de professeurs agrégés, mettez en face une armée d'Auvergnats et de Savoyards illettrés, ordonnez l'attaque et si, au bout de vingt minutes, il reste un seul savant debout, nous portons de nos mains la Sorbonne au Panthéon. ${ }^{4}$ "

4 Le métier des armes n'est pas la seule carrière à laquelle s'intéresse Saillet: le pédagogue parcourt dans son œuvre l'ensemble des débouchés auxquels peut se destiner une élite juvénile appartenant à la France des notables. La recherche que j'ai entreprise porte sur la majeure partie de la production littéraire de Saillet, hormis quelques titres qu'il n'a pas été possible de trouver ou de consulter, s'agissant d'œuvres posthumes. Il s'agit d'une trajectoire littéraire qui se situe entre 1840 et 1860 comprenant un ensemble de 27 ouvrages publiés chez plusieurs éditeurs comme Barbou, Mame ou Lehuby, parmi lesquels se dégage naturellement un titre qui a fait son succès, Les Enfants peints par eux-mêmes décliné en deux volumes, considéré comme l'un des premiers spécimens de la littérature panoramique, qualifié d'« ouvrage qui a fondé un genre en librairie ${ }^{5}$ ", et dont la diffusion atteindra dès 1842 l'Europe et l'Amérique espagnole $^{6}$ et fera même l'objet d'une représentation théâtrale sous forme de vaudeville ${ }^{7}$.

\section{Un homme de tradition militaire marginal}

5 Le portrait de Saillet ${ }^{8}$ nous révèle un physique à la Stendhal au même âge : relativement grand et épais, l'homme, âgé d'une trentaine d'années, est représenté à l'époque de son succès d'écrivain. Il est issu d'une famille d'officiers nobles d'Ancien Régime ayant servi dans divers régiments royaux d'infanterie. Dernier rejeton d'une petite lignée de quatre générations d'officiers originaires, en Lorraine, de la seigneurie de Souhesme-laPetite ${ }^{9}$, Alexandre appartient à une noblesse rurale peu fortunée, qui va réussir à s'allier grâce aux relations établies pendant l'émigration, à une famille beaucoup plus importante, celle des comtes de Croix de Drumez, seigneurs de Wasquehal en Flandre, dont la généalogie remonte aux premières croisades. L'homme célèbre de cette famille est Charles-Joseph, comte de Clerfayt, lieutenant-gouverneur et capitaine général des Pays-Bas autrichiens, Feldmarschall du Saint Empire, son oncle par alliance, l'un des vaincus de la campagne de Valmy ${ }^{10}$.

6 François, le père d'Alexandre, jeune officier sans fortune, parti en émigration en juillet 1792, engagé dans les troupes de la Contre-Révolution pendant la campagne d'Argonne (Valmy), retrouve le château de famille après le décès de son père en l'an VII à la faveur 
d'une amnistie. Il se marie avec une cousine éloignée du général autrichien, MarieLouise, elle-même fille d'officier appartenant à une branche de la famille restée sur place, favorable à la Révolution, à laquelle les Saillet sont déjà liés par des alliances dans les générations précédentes. Alexandre connaîtra peu son père, décédé quatre ans après sa naissance ${ }^{11}$. Il est élevé par sa mère à Paris avec ses quatre autres frères et sœurs, vivants grâce au soutien des Croix de Drumez. Sa mère, devenue veuve, rentre au couvent des Carmélites de Paris après la Révolution de 1830. Âgé de 18 ans pendant la révolution parisienne de juillet, il passe son baccalauréat de lettres en 1831 et décide dans un premier temps de se lancer dans l'enseignement en ouvrant un cours privé à partir de 1834, tandis que son frère plus âgé, Charles, s'installe difficilement comme artiste-peintre et lithographe. Ni l'un ni l'autre n'ont songé à la carrière militaire comme les quatre générations de Saillet qui les ont précédées. En 1838, il fait un premier mariage avec Eulalie de Raveton, fille d'un garde du corps du comte d'Artois, appartenant à une famille normande légitimiste ${ }^{12}$. Installé à Paris, en créant son cours privé, il accole à son patronyme, le titre de vicomte de Croix, du nom de sa mère.

\section{Une œuvre pédagogique originale}

7 La formation intellectuelle de Saillet vient de sa famille maternelle: légitimisme, catholicisme, attachement aux institutions royales, adhésion aux valeurs de l'aristocratie d'Ancien Régime. L'homme qui construit son avenir personnel autour du métier de pédagogue puis d'homme de lettres, qui dispose du niveau minimum requis pour l'enseignement privé primaire et secondaire, fait le choix de s'orienter dans un premier temps vers les ouvrages techniques d'enseignement. Mais devenu essayiste, historien, romancier, poète à ses heures ${ }^{13}$, il fait en sorte qu'aucune discipline n'échappe à son intérêt. Sa première publication est un Traité d'analyse grammaticale suivi par une Géographie de l'Europe et de la France, tous publiés en 1840.

8 Pendant la même période, le maître de pensions à Paris, bachelier ès lettres puis diplômé de l'université met quelques années à ouvrir un cours privé : ne disposant d'aucun élément biographique à son sujet pendant les premières années qui suivent la Révolution de juillet, on est réduit à supposer qu'il a pris du temps pour se former auprès des pensions existantes. Ce n'est qu'à partir de 1834 qu'il commence son activité pédagogique : l'almanach royal de 1835 mentionne pour la première fois une pension Saillet de Croix au 27 rue Saint Dominique; en 1838, l'adresse se transporte au 15 rue des Martyrs ${ }^{14}$; en 1841 il est installé au 29 rue Goquenard ${ }^{15}$. Dans les années 1850-1851, son local situé au 7 rue Bleue, est signalé comme « un ex-hôtel particulier, il y a encore de l'or au plafond d'une des classes». La même source indique que «le berceau véritable de son établissement a été rue du Bac, $36^{16} »$. Le cours de Saillet prépare à la fois l'honnête homme et le futur serviteur de l'État à travers un cursus de préparation aux écoles du gouvernement accessibles par concours depuis $1832^{17}$ dont les cinq grandes militaires, le Génie à Metz, Polytechnique, Saint-Cyr et l'État-Major à Paris, Navale à Brest. La pension Saillet permet de recevoir des élèves à la fois pour les classes ordinaires et pour l'enseignement préparatoire (rédaction française, enseignement spécifique par répétition particulière à des concours oraux de mathématiques spéciales, puis histoire-géographie après 1850).

Le contexte est favorable et le système vit son âge d'or au cours de la décennie 1840 : les pensions privées de l'enseignement secondaire sont en pleine expansion à Paris depuis 
1830 (au nombre de 72 en 1835), placées à l'époque sous la tutelle de l'Université parisienne ; elles sont au départ en concurrence avec les internats publics des collèges et lycées pour l'instruction générale mais aussi pour la préparation aux concours, avec les établissements publics assurant les cours magistraux et les pensions privées, le logement, l'encadrement et l'entraînement aux épreuves ${ }^{18}$. Avec les fonctions d'hébergement et de répétition destinées aux meilleurs élèves, les cours privés sont toutefois très dépendants de leur réputation et des aléas de la situation économique.

10 À partir de 1850, on assiste à un déclin de ces établissements privés, notamment ceux préparant aux grandes écoles de l'État ; la raison en est le grand mouvement de reprise en main voulue par le nouveau régime dans le cadre de l'enseignement secondaire : la réforme du ministre Fortoul par décret-loi du 9 mars 1852 impose le baccalauréat à tous les candidats aux grandes écoles militaires, tout en rendant plus performante la filière préparatoire publique aux dépens des classes des pensions privées; dans le même temps, l'enseignement confessionnel dirigé par les congrégations se développe sous la protection de la loi Falloux du 15 mars $1850^{19}$. Saillet va maintenir sa pension privée à Paris, semble-t-il, jusqu'en 1865, année au cours de laquelle il souhaite transporter son activité à Provins, mais il n'a pas le temps d'organiser la nouvelle pension car il décède l'année suivante ${ }^{20}$.

11 Pendant deux décennies, Saillet mène ainsi de front les trois activités d'enseignant, de journaliste et d'écrivain pour la jeunesse : faisant usage à l'occasion de pseudonymes ${ }^{21}$, il publie la plus grande partie de son œuvre entre 1840 et 1848 , soit 18 ouvrages sur 27 titres (dont un de géographie et un autre de grammaire) édités entre 1840 et 1862, auquel il faut ajouter un magazine bimensuel pour la jeunesse, édité de 1844 à 1845, Le Monde des enfants, dont le succès sera éphémère ${ }^{22}$.

12 L'œuvre de Saillet s'adresse à un public scolaire, enfant et adolescent, du niveau du lycée et dans certains cas aux parents d'élèves. Le pédagogue s'implique largement dans la nouvelle littérature panoramique qui s'adresse particulièrement à ce que la société libérale issue de 1830 considère comme une véritable classe sociale, la jeunesse estudiantine. Il publie en 1842 deux Physiologies (la poupée, le grand-papa et la grandmaman), la série des Enfants, publiée de 1841 à 1848 (garçons et filles peints par euxmêmes, les enfants chez tous les peuples, les enfants en famille, les jeunes Français de toutes les époques). Saillet est le premier écrivain pédagogue à faire usage de ce nouveau type de publication à des fins éducatives. Le reste de son œuvre est assez homogène dans le but poursuivi : les enfants continuent à représenter son lectorat privilégié à travers des galeries de portraits (Galerie de l'enfance), des présentations de loisirs utiles (Une journée au jardin des plantes), des contes (La Fille du chat botté) et des romans historiques (Les Fils du Gaulois).

\section{Une vision ouverte à la modernité}

13 Même si ses origines et ses opinions ne l'y poussaient pas naturellement, Saillet a participé au vaste mouvement intellectuel qui est né à la faveur de la Révolution de Juillet 1830 et de l'arrivée aux affaires d'hommes d'État comme Guizot et Thiers qui souhaitaient engager un plan d'éducation ambitieux pour la jeunesse.

S'agissant de l'éducation exclusive de la future élite militaire, à l'exception du soldat de base enrégimenté et formé dans les écoles régimentaires, Saillet tend à mettre en scène tous les types sociaux et fait appel à toutes les dispositions juridiques qui encadrent la 
société. Au départ, il reprend néanmoins à son compte le lieu commun contemporain des classes bourgeoises, à savoir que la jeunesse, pour s'élever socialement doit passer les concours d'État: le spectre du déclassement social, très présent dans la littérature romantique, doit servir de stimulant pour étudier et réussir les différents concours et examens de passage. Il s'agit désormais d'une carrière entièrement au service de l'État, ce qui exclut le mercenariat ou l'aventure individuelle: cet assujettissement au gouvernement est nouveau dans l'esprit des élites et ne manque pas d'être regretté par certains écrivains qui ont la faveur du public comme Balzac ${ }^{23}$. Le style de Saillet est nouveau : susciter la sensibilité, offrir avec le regard d'adulte un univers irréel présenté avec une visée morale, didactique et divertissante qui donne de la guerre et de la vie militaire une impression à la fois favorable et exigeante. Le rapport à la violence est assez semblable à la vision vignéenne : le soldat doit user de la violence non parce qu'il est un envoyé de Dieu mais parce qu'il en reçoit l'ordre et qu'il doit obéir à ses chefs.

On peut retrouver dans chacune des grandes œuvres de Saillet les leçons que le pédagogue veut développer en matière d'esprit militaire. Dans l'ouvrage qui l'a fait connaître et a connu une diffusion internationale, Les Enfants peints par eux-mêmes, il présente sous forme de sujet de composition le portrait de l'enfant de troupe, fils adoptif d'un grognard de l'Empire, sur lequel retentit le prestige de l'uniforme, notamment celui du tambour-major lors du défilé, mais aussi le courage et l'intrépidité du soldat, l'attachement à la famille même adoptive, la fidélité au souverain; la fascination pour les combats de la période impériale est très présente, comme le modèle d'organisation napoléonien des pupilles de la garde. Saillet fait une brève allusion aux campagnes d'Afrique de la période contemporaine ${ }^{24}$.

Dans les Mémoires d'un centenaire (1842), il traite du rapport entre les générations au regard de l'éducation reçue : à travers la carrière du marquis de Penhoët, entré à l'École militaire à 13 ans, où « les idées sur l'honneur, la noblesse, le courage... allaient jusqu'à la plus vive exaltation et dépassaient souvent les limites de la raison ${ }^{25}$ ", il retrace le modèle de l'officier royal qui recueille, suite à une première campagne (celle de Hanovre en 1760), « les plus beaux grades de l'armée ${ }^{26}$ ». Les épreuves de la Révolution (prison, fuite et exil) vont changer l'homme : c'est le retour en France en catimini dans des conditions difficiles, l'opinion nouvelle d'un vieil officier royal face à Napoléon avec qui « la France avait repris l'attitude noble et fière qu'elle avait toujours eue parmi les nation ${ }^{27}$ ", et surtout le sort d'un petit-fils, entré dans la carrière militaire en passant par le lycée impérial en 1808 et qui espère désormais, par l'épreuve du feu, devenir colonel ou général des armées napoléoniennes. À la fin de la période, le vieux marquis se laisse enfin convaincre qu'il ne peut «nier et repousser les progrès incontestables qui se sont opérés dans les arts, l'industrie, les lettres ${ }^{28} »$, dont le militaire doit tenir compte.

17 La fidélité familiale reste l'une des valeurs universelles du soldat: dans Les Enfants chez tous les peuples (1843), Saillet passe en revue le caractère et la personnalité de divers peuples européens en relevant certaines qualités utiles à la guerre notamment dans le cas de combats de résistance acharnée comme celui des carlistes en Espagne où il signale la fidélité à toute épreuve du fils par rapport au père ${ }^{29}$, puis de la même manière celui des fils de Souliotes pendant la guerre d'indépendance de Grèce ${ }^{30}$.

Dans les Écoles royales de France (1843) dédié au dauphin d'Orléans, Philippe comte de Paris, alors âgé de cinq ans, Saillet s'attaque à la formation de l'officier au sein des six écoles militaires auxquelles chaque Français peut désormais accéder depuis 1832 par 
concours d'entrée ou en fonction du rang de sortie, à savoir, Polytechnique, Saint-Cyr, l'École d'application de l'état-major, l'École de cavalerie de Saumur, l'École navale de Brest, l'École d'application du génie et de l'artillerie de Metz. Saillet insiste sur le fait que le métier ne procure aucun avenir en termes financiers, qu'il est fait de dévouement et d'abnégation, bien éloigné des préoccupations bourgeoises d'établissement dans la société. Il n'hésite pas à parler de la monotonie de la vie quotidienne des écoles, comme celle de Metz, de la rude condition de vie du cavalier, de la brutalité des mœurs des élèves à Saint-Cyr, de la difficulté des études à Polytechnique qui laissent de nombreux "fruits secs ${ }^{31}$ sur le chemin. Parmi les grandes écoles militaires étudiées, il fait une différence entre la guerre et l'administration de la guerre, insistant pour la seconde filière, sur le fait :

[qu'] «un jeune homme... n'aura que rarement l'occasion de déployer son intelligence et de grands talents, les fonctions qui lui seront départies ne demandant d'ordinaire que de l'aptitude et de l'assiduité, les esprits les moins énergiques peuvent y arriver très haut et les capacités les plus actives végéter longtemps dans les rangs inférieurs. ${ }^{32}$ ”

On serait tenté de voir chez Saillet une certaine hostilité aux écoles militaires du gouvernement qui résonne comme une mise en cause d'un processus de fonctionnarisation de l'armée frappant l'ancienne aristocratie : passage du concours ou de l'examen d'entrée, importance du salaire et de son évolution, éloignement de Paris, comparaison permanente avec les autres grandes écoles civiles (carrière d'ingénieur plus rémunératrice que celle de militaire). Le regard négatif de Saillet sur les écoles militaires pourrait aussi s'expliquer par la période peu guerrière de la monarchie de Juillet qui ne mobilise pas des contingents importants, qui laisse la conscription en sommeil et n'ouvre comme perspective aux militaires de carrière que les campagnes africaines. Pour Saillet, il s'agit désormais de prendre en compte une situation nouvelle comme l'arrivée des jeunes bourgeois politisés dans l'armée rejetant le modèle ancien de la virilité militaire et le service de l'État ${ }^{33}$.

Dans Les Jeunes Français de toutes les époques (1846), Saillet dresse le portrait du page et d'écuyers : il y célèbre cette fois-ci « les mille nuances du savoir qui se résument en seul mot, le tact » des courtois chevaliers ${ }^{34}$. À la fin de l'ouvrage, la présentation du cas exemplaire de Jacques Sibière est significative : il s'agit d'un fort en thème, roturier originaire d'une famille pauvre, qui fait une brillante carrière militaire en Algérie grâce à une bourse royale.

21 Dans les Confessions d'un écolier (1848), on découvre le profil d'un jeune homme destiné à la carrière militaire par les soins de son oncle général et qui passe par tous les malheurs de l'école et de la pension en raison de son caractère turbulent et indiscipliné ; la mère du garçon justifie les actions du fils en raison de son tempérament de lion impétueux qui a permis à un jeune officier de gagner les batailles d'Arcole et de Lodi, mais le général lui apprend que la principale vertu du soldat comme de l'officier est la discipline ${ }^{35}$.

Le tableau ne serait pas complet si Saillet n'avait pas fini par célébrer les traditions militaires aristocratiques dans l'Histoire des duels célèbres (1857) où l'auteur rappelle que fierté, honneur et courage restent des valeurs indispensables pour le jeune soldat au combat. Nous nous situons bien dans le cadre d'une reconstruction de la fierté française mise à mal par la défaite de Waterloo. Saillet privilégie-t-il la carrière militaire parmi les débouchés qui s'ouvrent aux jeunes étudiants dont il assure la formation par ses livres? De façon générale, la haute protection grâce au réseau familial lui apparaît 
encore comme importante pour tout avancement dans une carrière civile ou militaire et donc peu adaptée aux idéaux anciens d'héroïsme (amour du danger, exaltation de la patrie, obéissance aux ordres donnés) qu'il continue pourtant à véhiculer. Le métier des armes n'est plus pour lui le métier à préférer par les élites, il est désormais en concurrence avec ceux d'ingénieurs ou de savants.

On peut se demander à qui Saillet souhaite finalement s'adresser : quelle classe sociale veut-il privilégier pour le métier des armes ? La proportion des nobles dans l'armée est en chute constante après 1830 à cause du concours d'accès obligatoire dans les écoles d'officiers ${ }^{36}$; dans la mesure où l'idéal nobiliaire du chevalier médiéval garde toute sa vigueur et qu'il s'adresse désormais aussi aux nouvelles élites bourgeoises, on comprendra que Saillet souhaite contribuer à " aristocratiser » l'image du soldat.

En passant en revue l'œuvre, on s'apercevra pourtant que de nombreux aspects de la vie militaire ne sont pas traités par Saillet : il ne fait par exemple aucune allusion à la préséance dans les cérémonies qui font pourtant l'objet en 1845 d'un nouveau code ${ }^{37}$, ni au déploiement du soldat sur le champ de bataille; il n'analyse pas non plus le temps militaire, celui de l'attente, celui du repos et celui du combat ${ }^{38}$ et ne s'appesantit guère sur les savoirs nécessaires à la formation du soldat, ceux hérités des siècles passés et ceux qui sont en construction, sur la place de l'éducation intellectuelle dans la construction des savoirs militaires. En revanche, il sait mettre en avant des valeurs militaires, promues comme essentielles: honneur, courage, patriotisme, discipline, abnégation, solidarité dans l'adversité. La question de la fidélité au pouvoir politique est éludée : le sujet est peu évoqué si ce n'est dans les Mémoires d'un centenaire dans le cadre de la légende napoléonienne, très présente dans l'histoire qu'il raconte. Saillet considère que le soldat employé par l'État doit se montrer loyal envers le régime en place, montrant en cela son hostilité à toute forme de contre société militaire aux origines du bonapartisme politique en cours de développement à l'époque où il écrit.

L'œuvre de Saillet est singulière parce qu'elle se situe à la charnière du grand bouleversement dans l'éducation des élites au XIXe siècle : même s'il s'agit de divertir la jeunesse tout en l'instruisant, l'auteur veut, sans paraître subordonné à des instructions officielles, donner une matérialité littéraire et iconographique à une certaine vision morale dans laquelle la carrière des armes, c'est-à-dire celle de la défense des intérêts de la nation, tient une place importante sans être privilégiée.

Cette place particulière de Saillet dans le panorama des écrivains de la littérature enfantine se retrouve dans le jugement de ses premiers ouvrages porté par la censure officielle qui fait état "d'intentions excellentes de l'auteur et du but scientifique et moral qu'il poursuit ». Cependant, il est ajouté que Saillet « n'appuie pas assez sur les principes du christianisme, sur les fondements de la vraie morale... ${ }^{39}$ ». Il serait intéressant d'analyser l'influence de Vigny ou de Paul de Molènes sur Saillet : peut-on parler dans ses récits militaires de préférence pour la domination de l'esprit aux dépens de la force brutale? Saillet refuse-t-il à ses jeunes lecteurs le miroir de l'aventure et l'épopée loin des frontières? Les allusions à la campagne d'Algérie sont présentes mais on ne peut parler d'une attirance affirmée pour l'exotisme et l'épreuve des «lointains" avec le début des conquêtes coloniales ${ }^{40}$. Saillet se lance-t-il subrepticement dans la redéfinition d'un héroïsme de nature philosophique? Ses 
modèles d'héroïsme et de courage sont largement à puiser parmi les ancêtres gaulois et francs, les chevaliers médiévaux en quête de la belle mort. Saillet veut-il transmettre aux jeunes générations une nouvelle sagesse ? En réalité, l'humanisation de la figure du soldat est peu présente chez lui. Sur tous ces points, il semble qu'il n'aille pas aussi loin que Vigny. Enfin, le prestige de l'uniforme est réaffirmé mais l'avenir en termes d'avantages de toute nature reste incertain comme d'ailleurs toutes les carrières de fonctionnaires proposées par les écoles du gouvernement.

Il est un des aspects traditionnels que Saillet défend : la spécificité du métier militaire. Il s'agit de puissance de la hiérarchie (sens du rang), de respect des traditions, de virilité affirmée, de patriotisme intégral et sans réserve, des modèles retenus de la noblesse d'épée ("l'épée anoblit») avec le goût du paraitre et une conception pointilleuse de l'honneur. La formation par de solides connaissances commence à devenir l'avenir de la réussite individuelle, même si elle ne remplace pas encore la naissance. En tout état de cause, le processus d'élévation et de reproduction sociale passe de plus en plus par la qualité de la formation et son adéquation aux aptitudes innées du sujet. En même temps, le modèle aristocratique s'étend à toute la condition militaire : désormais le métier de militaire anoblit, ce qui correspond bien au modèle qu'a voulu diffuser Saillet auprès de toutes les familles de notables.

\section{BIBLIOGRAPHIE}

BALZAC Honoré de, Le Curé de village : scène de la vie de campagne, Paris, 1841, 2 tomes.

BELHOSTE Bruno, «La préparation aux grandes écoles scientifiques au XIX siècle : établissements publics et institutions privées ", Histoire de l'éducation, nº 90, 2001, p. 101-130.

BOTREL Jean-François, « La Presse et les transferts culturels en Espagne au xIX ${ }^{\mathrm{e}}$ siècle (1833-1914) », dans THERENTY Marie-Ève, VAILLANT Alain (dir.), Nations et mondialisation au XIX ${ }^{e}$ siècle, Éditions Nouveau Monde, 2010, p. 55-74.

BRUTER Annie, «Les autorisations d'ouverture de cours publics dans les départements français (1808-1875) », éd. numérique, Lyon, LAHRA, UMR CNRS 5190, 2009, [URL : http://rhe.ishlyon.cnrs.fr/?q=courspub-list\&discipline=All\&page=204]

Bulletin de censure : index français, tables mensuelles et raisonnées de tous les produits de la librairie française..., $1^{\text {ère }}$ année, $n^{\circ} 1,1843$, p. 48.

CARON Jean-Claude, «Jeunes élites et processus de politisation : le rôle des étudiants dans la France des notables ", dans ATTAL Frédéric, GARRIGUES Jean, KOUAMÉ Thierry et VITTU Jean-Pierre (dir.), Les universités en Europe du XIII siècle à nos jours : espaces, modèles et fonctions, actes du colloque international d'Orléans 16 au 17 octobre 2003, Paris, Publications de la Sorbonne, 2005, p. 63-76.

DUTREUIL DE RHINS Jules-Léon, La Bohême militaire ou de l'avenir des sous-officiers dans l'armée, Paris, $1882,295 \mathrm{p}$. 
FORCADE Olivier, Le temps militaire à l'époque contemporaine : pratiques et représentations, Bibliothèque de l'École des Chartes, 1999, tome 157-2, p. 479-491.

HUGUET Françoise, «Les pensions et institutions privées secondaires pour garçons dans la région parisienne ", Histoire de l'éducation, 90, 2001-2, p. 205-221.

LATZARUS Marie-Thérèse, La littérature enfantine dans la seconde moitié du XIX ${ }^{e}$ siècle, Paris, PUF, 1923, $310 \mathrm{p}$.

LEFEUVE Charles, Histoire du lycée Bonaparte (collège Bourbon), Paris, 1852, 334 p.

MARLY Mathieu et LEMBRÉ Stéphane, «À l'école du régiment : instruction, culture scolaire et promotion dans les rangs de l'armée française au XIX siècle ", Revue d'histoire du XIX $x^{e}$ siècle, $\mathrm{n}^{\circ} 48$, 2014-1, p. 145-161.

MASUREL Hervé, « Héroïsme et exotisme : le militaire à l'épreuve des lointains (1820-1914) », Romantisme, 2013-3, $\mathrm{n}^{\circ}$ 261, p. 35-44.

OMARI Nejma, « En mo(n)de mineur : l'“anthroporama" de l'enfance d'Alexandre de Saillet ", mémoire de master II, Université Paul Valéry - Montpellier III, 2017.

SERMAN William, «La noblesse dans l'armée française au XIX siècle (1814-1890) », dans Les noblesses européennes au XIX ${ }^{e}$ siècle, actes du colloque de Rome, 1985, publications École française de Rome, 107, 1988, p. 551-558.

TOUSSAINT G., Code de préséance et des honneurs civils, militaires, ecclésiastiques, maritimes et funèbres, Paris, $1845,390 \mathrm{p}$.

\section{NOTES}

1. Voir l'article du capitaine Cury dans Le Spectateur militaire, mai 1840, vol. 30, sur les Essais en faveur de l'armée de M. Ambert, p. 330.

2. Paul Gaschon de Molènes (1821-1862) se fait connaître par Valperi, mémoires d'un gentilhomme du siècle dernier (1845) puis par ses Caractères et récits du temps: La garde mobile. Les souffrances d'un houzard. Etc. (1853) tout en servant comme officier dans les chasseurs lors des campagnes de Crimée et d'Italie.

3. Le ministre de l'instruction publique et des cultes, Gustave Rouland, a pris l'arrêté de création le $1^{\mathrm{er}}$ juin 1862.

4. Voir J-L. Dutreuil de Rhins, La Bohême militaire ou de l'avenir des sous-officiers dans l'armée, p. 56. Cité par Mathieu Marly et Stéphane Lembré, «À l'école du régiment: instruction, culture scolaire et promotion dans les rangs de l'armée française au XIX siècle ", Revue d'histoire du XIX $X^{e}$ siècle, $\mathrm{n}^{\circ}$ 48, 2014-1, p. 145.

5. Voir C. Lefeuve, Histoire du lycée Bonaparte (collège Bourbon), p. 301.

6. Voir J.-F. Botrel, La Presse et les transferts culturels en Espagne, p. 58 et sq. Évoquant la rédaction de l'ouvrage de Saillet, l'auteur suppose que ce sont les élèves de son cours les plus doués qui ont rédigé les 21 compositions qui constituent le texte.

7. Les Enfants peints par eux-mêmes, revue-vaudeville en un acte, d'après l'ouvrage d'Alexandre de Saillet, par MM. A-A. de Berruyer et A. Guénée, 15 p.

8. Le seul portrait connu est celui qui est publié sous forme de lithographie en 1848 dans l'édition des Confessions d'un écolier. 
9. Actuelle commune de Souhesmes-Rampont, département de la Meuse, près de Verdun.

10. Le Feldmarschall (1733-1798), wallon d'origine, qui commande les troupes autrichiennes en 1792 sous l'autorité du duc de Brunswick, organise la retraite après les défaites autrichiennes de Valmy et Jemmapes. Il gagne la bataille de Neerwinden face à Dumouriez (18 mars 1793) et réussit à forcer le blocus de Mayence en octobre 1795 contre Kléber, Marceau, Dessaix et Bernadotte.

11. Alexandre naît à Paris le 10 mars 1812, son père y décède le 23 avril 1816.

12. Suite au décès de cette première épouse en 1851 , il se remarie à Joséphine Primois en 1852, qui décède à son tour en 1859. Remarié en 1860 à Claudine d'Utruy de Brosse, âgée de 20 ans, ils ont une fille, Alexandrine, qui naît à Provins en 1863.

13. Voir la Revue des deux mondes, vol. 3 , nouvelle série, $n^{\circ} 1$, juillet 1843 , «Poetae minores " par Charles Labitte, p. 123. Son poème Ciel et terres est étrillé : « la poésie maussade de M. de Saillet est de celles qui n'ont aucune physionomie et dont on ne se souvient plus avant même d'avoir fermé le livre, qu'on a hâte d'ailleurs de quitter. »

14. Journal général de l'instruction publique, vol. 7, $\mathrm{n}^{\circ}$ 150, 22 décembre 1838.

15. Almanach royal pour l'année 1841, p. 925.

16. Voir Ch. Lefeuve, ibid.

17. Ordonnance dite de Soult ( $\mathrm{du}$ nom du ministre de la guerre) en date du 20 septembre 1832.

18. Voir F. Huguet, «Les pensions et institutions privées secondaires pour garçons dans la région parisienne ", Histoire de l'éducation, $\mathrm{n}^{\circ}$ 90, 2001, p. 212-214.

19. Voir B. Belhoste, «La préparation aux grandes écoles scientifiques au $\mathrm{XIX}^{\mathrm{e}}$ siècle : établissements publics et institutions privées », p. 101-130.

20. Arch. nat. F 17 6702. Demande d'ouverture d'un cours privé à Meaux le 14 décembre 1865 ; laissé sans suite par décision du 29 janvier 1866. Saillet est décédé à Provins le 26 décembre de la même année. Consulter aussi la base créée par Annie Bruter sur les autorisations d'ouverture de cours publics dans les départements français (1808-1875).

21. Les pseudonymes utilisés par Saillet alternent entre celui du bourgeois, Joseph Hérin, et celui de l'aristocrate d'Ancien Régime, le vicomte de Bourbon-Ginestous.

22. Sur l'ensemble de l'œuvre, voir N. Omari.

23. L'auteur de la Comédie humaine dénonce en 1838 dans Le Curé de village à propos de l'École polytechnique, «je pense à l'effroyable conscription de cerveaux livrés chaque année à l'État par l'ambition des familles... ", voir le tome 2, p. 163.

24. Alexandre de Saillet, Les Français peints par eux-mêmes..., t. 1, p. 19 et sq. L'ouvrage paraît dans une collection de bibliothèque chrétienne et morale, approuvée par l'évêque de Limoges, lieu de l'édition.

25. Alexandre de Saillet, Mémoires d'un centenaire..., p. 59.

26. Ibid., p. 80.

27. Ibid., p. 180-181.

28. Ibid., p. 285.

29. Alexandre de Saillet, Les Enfants chez tous les peuples, p. 379-380.

30. Ibid., p. 406. 
31. Alexandre de Saillet, Les Écoles royales en France, p. 65. On trouve les mêmes termes chez Balzac dans Le Curé de village..., p. 163.

32. Ibid., p. 402.

33. Voir J.-C. Caron, "Jeunes élites et processus de politisation : le rôle des étudiants dans la France des notables », p. 64-5.

34. Alexandre de Saillet, Les Jeunes Français de toutes les époques, p. 280.

35. Alexandre de Saillet, Confessions d'un écolier, p. 312-313.

36. Voir W. Serman, «La noblesse dans l'armée française au xix ${ }^{e}$ siècle (1814-1890) », dans Les noblesses européennes au XIX ${ }^{e}$ siècle, p. 554 et suivantes.

37. Voir G. Toussaint, Code de préséances et des honneurs.

38. Étudié par O. Forcade, «Le temps militaire à l'époque contemporaine : pratiques et représentations ", p. 479 et suivantes.

39. Voir Bulletin de censure..., p. 48.

40. H. Masurel, "Héroïsme et exotisme: le militaire à l'épreuve des lointains (1820-1914)», p. 41 sq.

\section{RÉSUMÉS}

La place de la guerre dans l'instruction publique de l'époque romantique jusqu'aux débuts du vaste mouvement de scolarisation massive instauré par III ${ }^{\mathrm{e}}$ République constitue l'un des grands défis nationaux qui s'inscrit dans le cadre chronologique des deux grandes défaites militaires françaises de Waterloo et de Sedan. Dans l'immense champ d'étude de la formation des jeunes esprits au début $\mathrm{du} \mathrm{XIX}^{\mathrm{e}}$ siècle, la place des concepteurs de livres pour enfants, dans une période de paix relative revêt un intérêt particulier : celui de mesurer les enjeux politiques et sociaux de la construction du militaire à l'époque de la conscription et du remplacement. Alexandre de Saillet (1812-1866), pédagogue et aventurier de la littérature de jeunesse, est l'auteur d'une production littéraire relativement abondante dans laquelle il sera pertinent de scruter l'adéquation avec les instructions officielles ainsi que le rapport du métier des armes avec la religion. La présentation des écoles militaires, la problématique de la transmission des hauts faits d'armes, le développement de l'activité physique appartiendront aussi à notre champ d'investigation dans une œuvre aujourd'hui oubliée.

\section{AUTEUR}

\section{LOUIS BERGÈS}

Conservateur général du patrimoine, membre du CTHS, section Histoire du monde moderne, de la Révolution française et des révolutions 


\title{
Les missionnaires traducteurs et la transmission des savoirs occidentaux en Chine au XIX ${ }^{\mathrm{e}}$ siècle : étude du cas de Timothy Richard
}

\author{
Yi Zhang
}

Dans l'histoire chinoise, il existe deux vagues de transmission des connaissances occidentales vers la Chine. La première vague se situe au tournant des dynasties des Ming et des Qing - marquée par la présence jésuite en 1583, année pendant laquelle Michele Ruggieri (1543-1607) et Matteo Ricci (1552-1610) ont obtenu l'autorisation de s'installer en Chine - jusqu'au décès du dernier père jésuite Joseph-Marie Amiot (1719-1793) ${ }^{1}$. L'avènement des Qing marque un tournant majeur dans l'histoire de la Chine: les Jésuites n'eurent guère à souffrir du changement de dynastie, leur implantation fut même consolidée au début des Qing. Les jésuites profitèrent de l'intérêt général des Chinois pour les sciences et les techniques de l'Europe appelées « xixue 西學》 pour s'intégrer à l'appareil mandarinal ${ }^{2}$. Ils se livrèrent à des enseignements et à des travaux scientifiques. Ils ont opté pour la stratégie de pénétration par le biais des sciences profanes qui constituaient l'une des raisons importantes de l'adhésion des lettrés à la doctrine du Maître du ciel ${ }^{3}$. Toutefois, les activités des missionnaires furent interrompues pendant presque un siècle, suite à l'édit de l'empereur Yongzheng interdisant la prédication du christianisme en $1724^{4}$, et à la politique de la porte fermée.

2 Ce n'est qu'au début du xix siècle que les missionnaires occidentaux sont de retour dans l'Empire du Milieu. L'année 1807, au cours de laquelle le premier missionnaire protestant Robert Morrison (馬禮遜, 1782-1834) arrive en Chine, marque le début des activités des missionnaires au XIX ${ }^{e}$ siècle. Les missions d'évangélisation ont repris dans un contexte complètement différent par rapport à la période précédente. Depuis la seconde moitié du XIX ${ }^{e}$ siècle, à cause des activités militaires des pays occidentaux en particulier, le pays est pris malgré lui dans un processus d'ouverture et de modernisation. En effet, les missionnaires occidentaux sont rentrés en Chine grâce aux 
traités signés à la suite de la défaite chinoise au cours de la première guerre de l'opium (1840-1842). À ce titre, John K. Fairbank signale le statut ambivalent des missionnaires dans le contexte historique du XIXe siècle ${ }^{5}$.

3 À cette époque, l'échange de connaissances entre l'Occident et la Chine s'avère plus manifeste. C'est par la pratique de traduction que les missionnaires participent à la diffusion des connaissances occidentales en Chine. Le processus est réalisé principalement à travers quatre types de ressources ${ }^{6}$. Les traductions furent alors réalisées essentiellement par des dispositifs institutionnels et des maisons d'édition privées, dans lesquels les missionnaires jouèrent un rôle de premier plan ${ }^{7}$. Tout d'abord, sous le choc des deux guerres de l'opium et de l'insurrection des Taiping, les dirigeants des Qing se virent obligés d'entreprendre le chemin de la modernisation afin de consolider leurs propres pouvoirs. Dans ce contexte, les mandarins disposant d'un pouvoir réel des Qing ont opté pour l'apprentissage et la mise en application des connaissances occidentales dans le cadre du Mouvement d'occidentalisation (洋務運動, yangwu yundong) entre les années 1860 et 1890 . Certains missionnaires furent recrutés par les centres de publication et de traduction établis par le gouvernement des Qing pour des missions de traduction et d'enseignement des langues étrangères aux étudiants chinois. Ensuite, il existe également des maisons d'édition établies par les sociétés missionnaires telles que Mohai shuguan (墨海書館, The London Missionary Society Press), Meihua shuguan (美華書館, The Presbyterian Mission Press) et Guangxue hui (廣學會, The Christian Literature Society of China). À la suite de l'échec de la prédication directe, elles se tournent progressivement vers la traduction et l'introduction des connaissances occidentales afin de pallier l'ethnocentrisme culturel des Chinois. Enfin, le gouvernement des Qing et les missionnaires ont fondé beaucoup d'écoles modernes. La plupart de ces écoles ont élaboré des cours de langues étrangères ou de traduction. Nombre d'ouvrages occidentaux ont été traduits par les missionnaires en collaboration avec leurs élèves. De plus, ces écoles avaient un grand besoin de manuels scolaires. En 1877, les missionnaires ont mis en place à Shanghai Yizhi shuhui (益智書會, The School and Textbook Series Committee) qui éditait les traductions des manuels scolaires. Enfin, les hôpitaux et les organisations de formation de la médecine occidentale établis par les missionnaires traduisirent de nombreux ouvrages portant sur la médecine occidentale, dont certains furent traduits par la suite en japonais.

Les activités de traduction, au début provisoires et visant à propager la foi chrétienne, devinrent régulières à mesure que les missionnaires intervenaient de plus en plus dans les changements sociaux à la fin des Qing. À travers leurs traductions, nous assistons à une volonté palpable de réinterprétation des savoirs occidentaux afin de faciliter les changements sociaux et de participer à la reconstruction de la culture moderne chinoise.

\section{Une étude de cas : Timothy Richard}

5 Cette recherche sera centrée sur l'étude du cas de Timothy Richard (李提摩太, 1845-1919), l'un des missionnaires les plus importants dans l'histoire des échanges entre l'Occident et la Chine. Missionnaire baptiste écossais, Timothy Richard a profondément marqué la modernisation de la Chine et l'avènement de la République de Chine, en agissant durant sa mission en tant que missionnaire, érudit et homme politique. Il convient de considérer sa pratique de la traduction comme un volet 
essentiel de sa politique apostolique ${ }^{8}$. En effet, contrairement aux protestants " piétistes » dont la mission est centrée sur l'annonce du salut en Jésus-Christ, Timothy Richard est « libéral » et met l'accent sur le développement de la société chinoise, le renouveau de sa culture traditionnelle tout en ménageant l'accès des Chinois à une connaissance plénière de l'Évangile?

6 Vers la fin de ses études théologiques au Collègue théologique d'Haverfordwest ${ }^{10}$, il décide de rejoindre une mission en Chine. Il soumet une demande à la Mission à l'intérieur de la Chine demandant à être envoyé au nord de la Chine pour annoncer l'Évangile. Plus tard, il explique les raisons de sa décision dans ses Mémoires:

«[...] as the Chinese were the most civilized of non-Christian nations, they would, when converted, help to carry the gospel to less advanced nations, and that by working in the north temperate zone Europeans could stand the climate, while the natives of North China, after becoming Christians, could convert their fellow countrymen all over the Empire. ${ }^{11}$ "

7 Il arrive en Chine en 1870. Durant quarante-cinq ans, il ne cesse de chercher les méthodes apostoliques les plus efficaces, en fonction de la réalité de la société chinoise pour évangéliser le pays. Il écrit dans ses Mémoires :

«[...] in all my after missionary life I endeavoured to seek the methods most productive of results, rather than adhere to old ones not adjusted to the changing needs of the times. ${ }^{12}$ "

Il fut l'un des missionnaires du xIX siècle qui a su poursuivre la méthode initiée par Matteo Ricci ${ }^{13}$. Cette méthode se caractérise par une vision des missionnaires de l'organisation sociale chinoise strictement hiérarchisée, couronnée par l'institution impériale ${ }^{14}$, ce qui les conduit à privilégier l'objectif d'attirer l'élite érudite. Timothy Richard a précisé dans ses Mémoires :

« [...] I must fit myself more fully for influencing the leaders of China. ${ }^{15}$ "

Le projet conçu par Timothy Richard consiste à influencer les membres de la haute société chinoise tels que les mandarins, les leaders religieux et l'élite éduquée pour les intéresser, voire les convertir au christianisme. En effet, il les considère comme la classe intermédiaire reliant la personne impériale aux gens ordinaires. Ce faisant, Timothy Richard vise à convaincre les gens ordinaires, voire toute la Chine. Pour cela, il juge nécessaire d'obtenir le soutien des mandarins chinois, ceux qui détiennent le pouvoir politique, afin de s'assurer leur protection dans son approche de prédication verticale. Il profite de ses amitiés personnelles avec les mandarins tels que Li Hongzhang 李鴻章, Zhang Zhidong 張之洞 et Zuo Zongtang 左宗棠 pour leur proposer de protéger la liberté de croire en Dieu. Il développe alors une autre méthode de prédication qui consiste à les influencer par la diffusion des savoirs occidentaux. Timothy Richard adopte cette approche pour deux raisons. D'une part, au cours de l'évangélisation, il a découvert qu'une des principales difficultés pour convertir les Chinois était leurs superstitions :

"Among the religious problems I had to contend with was the superstition of fengshui. No one dared build a house, or put up a fence, or dig a well, without having first consulted the teachers of feng-shui. It occurred to me that the best way to remove this superstition was to teach the natural sciences, such as astronomy, physics, chemistry. ${ }^{16}$ "

10 D'autre part, lorsqu'il participe aux efforts de secours en faveur des sinistrés du Shandong et du Shanxi, touchés par la sécheresse entre 1876 et 1879, il a acquis une meilleure connaissance de la structure de la société chinoise. Il a compris qu'il était 
essentiel de commencer l'évangélisation par les élites éduquées pour que le christianisme se diffuse davantage. Par ailleurs, Timothy Richard estimait que la raison pour laquelle la Chine avait échoué dans ses efforts de secours et dans ses guerres contre les pays occidentaux était l'ignorance systématique des lois de la nature pour utiliser les forces de Dieu ${ }^{17}$.

11 Il a profité du support des médias publics pour diffuser les savoirs occidentaux parmi tous ceux qui savaient lire et qui cherchaient à se libérer des entraves du système de la fin des Qing. Il était l'un des traducteurs clés de l'association Guangxue hui et devint son secrétaire général en octobre 1891. Plus tard, sous sa direction, Guangxue hui, un imprimeur éditant initialement des brochures visant à répandre la religion chrétienne, devint l'une des plus grandes maisons d'édition à la fin des Qing. Elle publiait une dizaine de magazines tels que Wanguo gongbao (《万国公报》, The Review of the Times) et plus de 2000 sortes d'ouvrages dans les domaines littéraire, historique, géographique, politique et économique, etc. ${ }^{18}$ Parmi les lecteurs, nous trouvons non seulement les lettrés, mais aussi les mandarins et l'empereur Guangxu (1871-1908). Timothy Richard resta en fonction pendant 25 ans.

\section{Traduire l'histoire du monde}

\section{Présentation du corpus}

La base de notre étude est constituée de la traduction la plus importante de Timothy Richard: Taixi xinshi lanyao 泰西新史撫要 (L'Essentiel de l'histoire récente des pays occidentaux), traduit de l'ouvrage historique The Nineteenth Century: A History, par l'historien britannique Robert Mackenzie. Cet ouvrage retrace les révolutions et les réformes qui ont eu lieu au XIX siècle dans les pays occidentaux. Il met l'accent sur les progrès sociaux et la succession des régimes politiques que les réformes entraînent. Il ne s'agit pas d'une histoire centrée sur les élites, ni une histoire portant sur la société dans son état statique ${ }^{19}$. L'auteur compare notamment les réformes réussies de la France, des États-Unis etc. à l'immobilisme de l'Autriche, de la Turquie ainsi que du Vatican $^{20}$. Toutefois, cet ouvrage paraît peu connu des lecteurs avertis. Nous pouvons en déduire que cet ouvrage ne devait pas attirer les spécialistes de l'histoire. En effet, nous trouvons seulement une brève présentation de l'ouvrage dans The Cambridge History of China : Late Ch'ing 1800-1911:

«[...] the most widely circulated of all missionary translations of secular works, Mackenzie, was a vulgar hymn to the conquests of science and the dogma of progress, described by R. G. Collingwood as being 'among the most unsavoury relics of third-rate historical work. ${ }^{21}$ »

\section{Motivations de la traduction}

13 Timothy Richard commence à traduire cet ouvrage en mars $1893^{22}$. Au départ, la version intitulée La chronique des événements des pays occidentaux durant les cent dernières années 泰西近百年來大事記 (Taixi jin bainian lai dashi ji) fut publiée dans Wanguo gongbao de mars à septembre en $1894 .{ }^{23}$ Elle fut renommée Taixi xinshi lanyao et publiée en un seul volume par Guangxue hui en 1895. La traduction joue un rôle dans sa vision de la politique et de la société chinoises : il vise par là à promouvoir la modernité politique. ${ }^{24} \mathrm{Il}$ convient de signaler que Wanguo gongbao dans lequel la traduction a 
d'abord été publiée par parties successives adoptait une position ouvertement réformiste. D'une part, les principaux promoteurs de la Réforme des Cent Jours 百日維 新 dont Kang Youwei 康有為 et Liang Qichao 梁啟超 étaient des lecteurs fidèles. D'autre part, les traductions publiées dans le journal deviennent des actes politiques, car les réformateurs s'inspirent des principes politiques et sociaux qu'il défend en vue de la conceptualisation de la démocratie en Chine ${ }^{25}$.

Dans ses Mémoires, Timothy Richard parle brièvement des deux raisons qui l'ont conduit à traduire cet ouvrage d'histoire : en premier lieu, il avait l'intention de fournir aux mandarins chinois des informations sur les progrès que le monde avait connus dans un passé proche; en second lieu, il voulait montrer que les Chinois pouvaient sauver leur pays s'ils mettaient en place des réformes, à l'instar des pays occidentaux ${ }^{26}$. Ces deux intentions s'expriment également dans la préface de la traduction. Timothy Richard commence par affirmer la grande valeur de cette traduction :

此書為暗室之孤燈, 迷津之片筏, 詳而譯之, 質而言之, 又實救民之良藥, 保國 之堅壁, 療䆩之寶玉, 而中華新世界之初桄也, 非精兵億萬、戰艦什佰所可比而 擬也。

«Cet ouvrage est la lumière solitaire d'une salle sombre et le seul radeau qu'on trouve lorsqu'on se perd. J'ai effectué une traduction minutieuse de cet ouvrage. En réalité, il représente un remède efficace pour sauver le peuple, un rempart solide pour défendre le pays, un jade précieux pour guérir la pauvreté et une introduction au nouveau monde chinois. Des centaines de millions de soldats d'élite ou mille navires de guerre ne sont pas comparables à cet ouvrage. ${ }^{27}$ »

De plus, il a voulu présenter les expériences des réformes des pays occidentaux par le truchement de cette traduction. Il remarque dans la préface qu'il existe des Chinois qui souhaitent promouvoir les réformes, mais ils manquent de méthodes :

且即有蓄意言之, 設法改之者, 亦以未諳各國整頓之道, 往往無從下手。

«Même s'il y a des gens qui osent préconiser des réformes et s'efforcent de les entreprendre, ils ne connaissent pas les méthodes des pays étrangers pour la mise en place de ces réformes et ne savent pas comment s'y prendre. ${ }^{28}$ "

En expliquant les raisons de son choix du texte de départ, il met aussi en évidence les motivations de sa traduction. Il estime que l'ouvrage original contient les clés des savoirs occidentaux permettant aux Chinois de connaître les raisons de la prospérité des pays occidentaux ainsi que les avantages et les désavantages des réformes conduites dans ces pays, ce qui leur permettrait de mettre à profit ces expériences :

及讀英國馬懇西先生所著《十九周大事記》 [...], 則誠新史而兼明鏡之資也。中 國服官之䍙、讀書之士，其於中國之古訓，自己爛熟於肮中，若欲博考西學振興 中土, 得此入門之秘錀, 於以知西國之所以興, 與夫利整之所在, 以華事相印 證，若者宜法，若者宜戒，則於治國讀書之道思過半矣。

"Quand j'ai lu Shijiuzhou dashi ji (Note de l'auteure: The Nineteenth Century: A History) écrit par le britannique Mackenzie [...], j'ai pensé que cet ouvrage portait sur l'histoire récente et pouvait servir de "miroir" permettant aux Chinois de tirer des enseignements de l'histoire. Pour les anciens préceptes, les mandarins et les lettrés chinois les connaissent par cœur. Pour ceux qui veulent avoir accès aux connaissances occidentales pour revitaliser la Chine, s'ils obtiennent cet ouvrage qui est la clé, ils connaîtront les raisons pour lesquelles les pays occidentaux sont prospères et les avantages ainsi que les désavantages des réformes de ces pays. Ils peuvent les comparer avec la Chine. Certaines choses sont à suivre, d'autres sont à éviter. Comme cela, ils pourront avoir recours à plus de la moitié des méthodes pour gouverner le pays et pour faire leurs études..$^{29}$ " 


\section{Réinterprétation des savoirs}

En examinant le texte de départ et la traduction, nous remarquons quelques tentatives de réinterprétation des savoirs. Cette volonté révèle, de la part du traducteur, une volonté de contrôler son texte et l'interprétation qui en émane. En effet, Timothy Richard fait de la traduction un moyen d'expression et un instrument de transformation sociale ${ }^{30}$. Il traite les passages sur la Révolution française avec beaucoup de prudence. Dans la version traduite, au lieu de traduire le mot « révolution » comme 《革命》 (geming), Timothy Richard le traduit comme 《民變》 (minbian, insurrection), 《民叛》 (minpan, révolte du peuple), 《亂》 (luan, chaos) ou 《整頓》 (zhengdun, mise en ordre).

«But in the middle of the night a courtier entered the King's chamber and told him that Paris was in arms and the Bastille taken. The dismayed monarch sat long in silence. "Why, this is a revolt ! he said at length. No Sire, replied the courtier, It is a revolution! !31"»

[La traduction de Timothy Richard]

至夜, 諜報百姓盡挾兵刃, 巴士的獄已破, 王始悚然, 而無言可達。既而問

日：“我民竟盡反乎?”某官侍側, 對日：“民叛事小, 恐非民叛, 直欲為國家整

頓，事正大也。”

[Notre traduction en français]

Au milieu de la nuit, un messager dit au roi que le peuple armé avait pris la Bastille. Le roi fut effrayé et incapable de lui répondre. Puis, le roi demanda : «Mon peuple s'est révolté contre moi? ». Un courtisan qui était à côté de lui répondit: «La révolte a peu d'importance. Je crains qu'il ne s'agisse pas d'une révolte mais que le peuple veuille mettre en ordre le pays. Ça, c'est grave..$^{32}$ ”

Timothy Richard utilise plusieurs phrases pour expliquer ce que signifie la « révolution ». En fait, dans sa traduction, Timothy Richard s'efforce de distinguer la « révolution» et la "révolte». En traduisant, Timothy Richard ajoute sa propre conception de la « révolution » qui est la mise en ordre d'un pays voulue par le peuple. Plus tard, il assimile la « révolution » à l'« insurrection » du peuple :

« Napoleon's own inclination destined him for a military career, and while a child of eleven, he began his training in the school of Brienne. When the revolution broke out he was found on the popular side. $\|^{33}$

[Traduction de Timothy Richard] 拿破崙幼而好武, 年十一歲入武備學堂肄業, 越數年值法國民變, 拿破崙躍躍欲 動, 即因民心之推戴 [...]

[Notre traduction en français]

Lorsqu'il était enfant, Napoléon était passionné par les affaires militaires. À l'âge de onze ans, il est entré dans une école militaire. Quelques années plus tard, l'insurrection du peuple français éclata. Il brûlait d'envie de s'y engager. Il était populaire parmi le peuple $[. . .]^{34}$ »

Par ces deux exemples, nous constatons que, d'une part, Timothy Richard évite d'évoquer le renversement du pouvoir royal français par la violence populaire. Cela s'explique par deux raisons. Premièrement, il adapte sa traduction aux lecteurs cibles composés principalement de mandarins et de lettrés chinois désireux de remédier à la crise de la Chine par les réformes. Deuxièmement, il a un point de vue négatif sur la Révolution française. Dans la traduction, Timothy Richard fait les ajouts délibérés afin d'émettre ses propres points de vue très négatifs sur la Révolution française :

法國整頓國制之時有絕大之弊焉,倚於君主之國之人與倚於民主之國之人分為兩 黨。[...] 法國八十年中君主、民主兩班分毫不肯相讓, 甚至不通慶吊, 幾如不共 戴天，識者從旁窅之，幾何不為之菌冷哉？ 
«La mise en ordre de la France donna lieu à de nombreux abus. Deux partis se formèrent: l'un en faveur de la monarchie, l'autre de la démocratie [...] Pendant 80 ans, les deux partis ne firent jamais de compromis l'un envers l'autre. Ils ne s'entendent pas. Ils semblent être des ennemis mortels. Ceux qui les observent ne se moquent-ils pas d'eux ? ${ }^{35}$ "

En 1903, face aux idéaux erronés de certains Chinois sur la violence de la révolution, Timothy Richard s'est engagé dans les débats parmi les intellectuels chinois sur l'essence de la «nouvelle méthode occidentale». Il a publié un article dans Wanguo gongbao dans lequel il a cité les absurdités de la Révolution française pour réfuter ce que prétendaient certains journaux chinois. Selon lui, «jusqu'à aujourd'hui, les Européens deviennent encore nerveux lorsqu'ils parlent de la Révolution française $»^{36}$, car les révolutionnaires voulaient "tout détruire», ce qui montre que «la liberté et l'égalité obtenues par la violence entraînent des conséquences néfastes sans fin pour la quête d'un nouvel ordre social ${ }^{37}$ ».

21 Par cette étude, nous espérons avoir apporté un éclairage sur la fonction des missionnaires traducteurs dans la transmission de connaissances occidentales en Chine au XIX ${ }^{\mathrm{e}}$ siècle à travers le cas de Timothy Richard. Si nous ne pouvons pas sous-estimer l'orientation religieuse de ses traductions, il ne dissimule pas un désir de promouvoir la modernité politique par la transmission et la réinterprétation des savoirs occidentaux. De plus, il fait face à un public de lettrés qu'il est nécessaire de convaincre. Il fait de la traduction un moyen d'expression visant à inciter les Chinois à repenser leur modèle social à un moment crucial marquant la transition de la Chine du régime impérial au régime républicain.

\section{BIBLIOGRAPHIE}

CHARBONNIER Jean, Histoire des Chrétiens de Chine, Paris, Les Indes savantes, 2002.

FAIRBANK John King, “Introduction : The Many Faces of Protestant Missions in China and the United States", dans The Missionary Enterprise in China and America, edited by John K. Fairbank, Cambridge (Massachusetts), Harvard University Press, 1974.

FAIRBANK John King (dir.), The Cambridge History of China, vol. 10 : Late Ch'ing 1800-1911 (Part 1), eds. by John K. Fairbank. New York, Cambridge University Press, 1978.

FENG Qiufang 馮秋芳, «Chuanjiaoshi yu jindai zhongguo de shuji chuban : yi Guangxue hui de shuji chuban weili 傳教士與近代中國的書籍出版一以廣學會的書籍出版為例 [Missionaries and the Book Publishing in Modern China - Take the Publishing Activities of "The Christian Literature Society for China" as an Example] », mémoire de master en Histoire, Université d'Anhui, 2008. GERNET Jacques, Chine et christianisme : la première confrontation, édition revue et corrigée, Paris, Éditions Gallimard, 1982. 
HE Shaobin何紹斌, «Yuejie yu xiangxiang : wanqing chuanjiaoshi yijie huodong yanjiu 越界與想 像一晚清新教傳教士譯介活動研究 [Transgression et imagination : une étude sur les activités de traduction des missionnaires protestants à la fin des Qing] », thèse de doctorat, Université de Fudan, 2006.

LANDRY-DERON Isabelle, La Preuve par la Chine : la « Description » de J.-B. Du Halde, jésuite, 1735, Paris, Éditions de l'École des hautes études en sciences sociales, 2002.

Liu Yajun 劉雅軍, “Litimotai yu Taixi xinshi lanyao de yijie 李提摩太與《泰西新史攬要》的譯介 [Timothy Richard, la traduction et l'introduction de Taixi xinshi lanyao en Chine]", Hebei shifan daxue xuebao (zhexue shehui kexue ban) 河北師範大學學報（哲學社會科學版） 2014 (11), vol. 27, $\mathrm{n}^{\circ}$ 6, p. 119-124.

MACKENZIE Robert, The Nineteenth Century : A History, Londres, Thomas Nelson and Sons, 1882.

MACKENZIE Robert, Taixi xinshi lanyao 泰西新史㨘要. [Traduit par Timothy Richard et Cai Erkang] 蔡爾康. Shanghai : Shanghai shudian chubanshe, 2002.

RICHARD Timothy, Forty-five Years in China : Reminiscences by Timothy Richard, New York, Frederick A. Stokes Company Publishers, 1916.

RICHARD Timothy, “Yiben xu 譯本序 [La Préface de la traduction]” in Taixi xinshi lanyao 泰西新史 攬要, translated by тімотну Richard et CAI Erkang 蔡爾康. Shanghai, Shanghai shudian chubanshe, 2002, p. 1-4.

XIONG Yuezhi 熊月之. Xixue dongjian yu wanqing shehui 西學東漸與晚清社會 [La Diffusion des savoirs occidentaux en Orient et la société de la fin des Qing], Shanghai, Shanghai renmin chubanshe, 1994.

wU Huiyi « Traduire la Chine au XVIII ${ }^{\mathrm{e}}$ siècle : les jésuites français traducteurs de textes chinois et la reconfiguration des connaissances européennes sur la Chine (1687-CA.1740) », thèse de doctorat en Histoire, Université Paris Diderot, 2013.

ZHANG Yi, «La traduction et la modernité chinoise de la fin des Qing : le cas de Timothy Richard », dans Europeana/ 《欧洲评论》, collection KUBABA, série Europe \& Asie, $n^{\circ} 10$ : « L'Europe et la construction de la modernité chinoise », Paris, L'Harmattan, 2017, p. 45-70.

\section{NOTES}

1. $\mathrm{H}$. Wu, « Traduire la Chine au Xviıe siècle : les jésuites français traducteurs de textes chinois et la reconfiguration des connaissances européennes sur la Chine (1687-CA. 1740)», p. 8.

2. Y. Zhang, «La traduction et la modernité chinoise de la fin des Qing: le cas de Timothy Richard », p. 51.

3. J. Gernet, Chine et christianisme : la première confrontation, p. 82.

4. I. Landry-Deron, La Preuve par la Chine : la « Description» de J.-B. Du Halde, jésuite, 1735, p. 75.

5. J-K. Fairbank, "Introduction: The Many Faces of Protestant Missions in China and the United States", p. 2.

6. Voir, pour les canaux principaux de la diffusion des savoirs occidentaux en Chine de l'époque, S. He 何紹斌, «Yuejie yu xiangxiang: wanqing chuanjiaoshi yijie huodong yanjiu 
越界与想象一晚清新教传教士译介活动研究 [Transgression et imagination : une étude sur les activités de traduction des missionnaires protestants à la fin des Qing] », p. 4-5.

7. Y. Zhang. «La traduction et la modernité chinoise de la fin des Qing: le cas de Timothy Richard », p. 47.

8. Ibid, p. 48.

9. J. Charbonnier, Histoire des Chrétiens de Chine, p. 233.

10. Il s'agit de l'une des trois écoles théologiques mises en place par l'Église baptiste dans le pays de Galles durant cette époque. Les deux autres écoles étaient respectivement le Collège de Pontypool et le Collège de Llangollen.

11. T. Richard. Forty-five Years in China: Reminiscences by Timothy Richard, p. 29.

12. Ibid., p. 26.

13. Voir Y. Zhang. «La traduction et la modernité chinoise de la fin des Qing: le cas de Timothy Richard », p. 48-53.

14. I. Landry-Deron. La preuve par la Chine : la « Description» de J.-B. Du Halde, jésuite, 1735, p. 74.

15. T. Richard. Forty-five Years in China: Reminiscences by Timothy Richard, p. 48.

16. Ibid., p. 123.

17. Ibid., p. 158.

18. H. Jiang 江漢文. “Guang xue hui shi zen yang yi ge ji gou 《廣學會》是怎樣一個機構 (Guangxue hui, quel type d'organisation s'agit-il?)", dans Chuban shiliao出版史料, 1990(4), p. 37. Quoted in Q. Feng 馮秋芳, “Chuan jiao shi yu jin dai zhong guo de shu ji chu ban - yi Guang xue hui de shu ji chu ban wei li 傅教士與近代中國的書籍出版一以廣學會的 書籍出版為例 Missionaries and the Book Publishing in Modern China - Take the Publishing Activities of 'The Christian Literature Society for China' as an Example", p. 12.

19. Y. Liu 劉雅軍. “Litimotai yu Taixi xinshi lanyao de yijie 李提摩太與《泰西新史撫要》 的譯介 [Timothy Richard, la traduction et l'introduction de Taixi xinshi lanyao en Chine]", p. 120.

20. Ibid.

21. J.-K. Fairbank (dir.), The Cambridge History of China, vol. 10 : Late Ch'ing 1800-1911 (Part 1), p. 587.

22. Y. Xiong熊月之. Xixue dongjian yu wanqing shehui 西學東漸與晚清社會 [La Diffusion des savoirs occidentaux en Orient et la société de la fin des Qing], p. 601.

23. Ibid.

24. Y. Zhang. «La traduction et la modernité chinoise de la fin des Qing: le cas de Timothy Richard », p. 60.

25. Ibid.

26. T. Richard. Forty-five Years in China: Reminiscences by Timothy Richard, p. 230-231.

27. R. Mackenzie. Taixi xinshi lanyao 泰西新史撫要 traduit par Timothy Richard et Cai Erkang 蔡爾康, p. 1.

28. T. Richard. “Yiben $x u$ 譯本序 [La Préface de la traduction]", dans Tai xi xin shi lan yao 泰西新史锶要 traduit par Timothy Richard et Cai Erkang 蔡爾康, p. 3.

29. Ibid., p. 3. 
30. Y. Zhang. «La traduction et la modernité chinoise de la fin des Qing: le cas de Timothy Richard », p. 60.

31. R. Mackenzie, The Nineteenth Century: A History, p. 21.

32. Id., Taixi xinshi lanyao 泰西新史鲵要 traduit par Timothy Richard et Cai Erkang 蔡爾 康, p. 11.

33. Id., The Nineteenth Century: A History, p. 31.

34. Id., Taixi xinshi lanyao 泰西新史㩖要 traduit par Timothy Richard et Cai Erkang 蔡爾 康, p. 19.

35. R. Mackenzie. Taixi xinshi lanyao 泰西新史撫要 traduit par Timothy Richard et Cai Erkang 蔡爾康, p. 276.

36. 歐洲人直至於今, 尚皆談虎色變. T. Richard. “Qiang ya zhao bian qiang shen zhao ba fa wei 強壓召變強伸召霸發微 [Sur l'essence et les valeurs de la liberté]” dans Wan guo gong bao wen xuan 萬國公報文選 [๔uvres choisies de Wanguo gongbao] compilées et révisées par Li Tiangang 李天綱, Pékin: Sanlian shudian, 1998. Cité dans Y.Liu. “ Litimotai yu Taixi xinshi lanyao de yijie 李提摩太與《泰西新史䉥要》的譯介 [Timothy Richard, la traduction et l'introduction de Taixi xinshi lanyao en Chine]", p. 122.

37. 此則強自由平等為求新之遺禍無窮也[...] I bid.

\section{RÉSUMÉS}

Nous tenterons d'explorer le rôle des missionnaires traducteurs dans la transmission de connaissances de l'Occident vers la Chine au XIX siècle en articulant les méthodes historique et traductologique. Tout au long $\mathrm{du} \mathrm{xIX}^{\mathrm{e}}$ siècle, les missionnaires occidentaux, présents en Chine depuis 1807 , ont été le vecteur principal des connaissances occidentales. Cette recherche, par le biais d'une étude du cas de Timothy Richard, étudie les manières dont les missionnaires réinterprètent les éléments des savoirs occidentaux au cours du processus de la traduction pour faciliter les changements sociaux en Chine. Par la pratique de la traduction, le missionnaire qui représente l'agent de transfert des savoirs occidentaux favorise la modernité politique en Chine à la fin de la dynastie des Qing.

\section{AUTEUR}

\section{YI ZHANG}

Doctorante en traductologie, Institut national des langues orientales (INALCO), membre de l'Institut français de recherche sur l'Asie de l'Est (IFRAE) (INALCO - Université Paris VII - ParisDiderot - CNRS) 


\title{
Les « chroniques » dans les revues archéologiques : exploration d'un espace de diffusion des savoirs de 1873 à 1914
}

\author{
Sandra Péré-Noguès
}

1 De la création du Journal des Savants en 1665 aux revues numériques, le périodique s'est imposé comme l'un des vecteurs les plus efficaces de diffusion des informations scientifiques. Avec le développement au $\mathrm{XIX}^{\mathrm{e}}$ siècle des périodiques spécialisés, notamment dans le champ de l'archéologie préhistorique et classique, ce rôle s'est renforcé par l'usage fréquent de rubriques qui offraient à beaucoup de savants un accès rapide et fiable aux actualités archéologiques. Qu'elles soient désignées sous les termes de «notes », de « chroniques » ou de " correspondances », toutes ces rubriques sont le résultat d'un travail de veille assez exceptionnel, d'autant qu'il était souvent accompli par une poignée de rédacteurs. À la lecture de tout ce qui pouvait être imprimé, ceux-ci ajoutaient les informations diffusées par les innombrables courriers que pouvaient s'échanger les archéologues de toutes les régions de France. À partir de quelques exemples choisis dans des revues de grande diffusion, telles que la Revue archéologique, les Matériaux pour l'histoire primitive et naturelle de l'homme, L'Anthropologie, ou encore la Revue des études anciennes, il s'agira de comprendre dans quelles conditions ces rubriques sont apparues et comment elles étaient fabriquées. L'objectif sera aussi de poser le problème de leur statut dans des périodiques dont la vocation principale était de donner à lire des articles de fond. Enfin, il s'agira de s'interroger sur la valeur qu'il faut leur accorder par rapport à d'autres archives liées à ce que les savants de l'époque nommaient le « mouvement scientifique».

\section{Le corpus étudié}

2 Une brève présentation des revues examinées ici ${ }^{1}$ est tout d'abord nécessaire puisqu'elles ont été créées à des moments différents du XIXe siècle et n'ont parfois pas 
eu un parcours linéaire. Fondée en 1844 et publiée à Paris, la Revue archéologique figure parmi les périodiques les plus anciens dans le domaine de l'archéologie ${ }^{2}$. À l'origine de sa création se trouvent un éditeur A. Leleux, qui en a assuré la direction jusqu'en 1859, et tout un groupe de savants, au premier chef desquels Jean-Antoine Letronne qui se serait inspiré de la revue allemande Archäologische Zeitung créée en 1843 à Berlin par Eduard Gerhard. Si comme le souligne Ève Gran-Aymerich, la première livraison de la Revue archéologique " parachève l'organisation de l'archéologie française avant $1848 »^{3}$, c'est entre 1860 et 1932 que la Revue construit sa réputation grâce au travail de collaboration étroite de trois de ses directeurs: Alexandre Bertrand (1883-1902), Georges Perrot (1883-1914) et Salomon Reinach (1903-1932)

Deux décennies après la Revue archéologique, le préhistorien Gabriel de Mortillet créa les Matériaux pour l'histoire primitive et philosophique de l'homme, revue qui fut rachetée en 1868 par Émile Cartailhac pour la somme de 2000 francs, et dont le nom évolua: Matériaux pour l'histoire primitive et naturelle de l'homme et l'étude du sol, de la faune et de la flore qui s'y rattachent (1869-1872) puis Matériaux pour l'histoire primitive et naturelle de l'homme (1873-1888)5. Si la direction en était assurée par Cartailhac depuis Toulouse, elle comptait également un nombre important de collaborateurs ${ }^{6}$. Cependant, malgré tous les efforts que le préhistorien toulousain avait consentis sur le plan financier notamment, la revue dut finalement fusionner avec deux autres périodiques, la Revue d'Anthropologie et la Revue d'Ethnographie, pour devenir L'Anthropologie en 18907. Enfin, c'est la scission de revues qui étaient soutenues par les universités de Bordeaux, Toulouse, Montpellier et Aix-en-Provence qui permit la création de la Revue des études anciennes $^{8}$ par Georges Radet en 1899.

\section{La fabrication d'une rubrique nouvelle}

Dès l'origine, la direction de la Revue Archéologique a, dans chaque livraison, accordé une place à une rubrique d'abord appelée "Découvertes et nouvelles", puis « Nouvelles archéologiques et correspondances", ce qui devait répondre à la vocation de la revue : être "un organe d'informations et de liaison ", jouer en somme le rôle d'un journal avec une périodicité régulière et une diffusion large. Plus lente fut la mise en place d'une telle rubrique dans les Matériaux dirigés par Cartailhac: ce n'est qu'en 1883 qu'apparaît une rubrique clairement identifiée comme "Nouvelles et correspondances ", régulièrement alimentée chaque mois. Ce décalage s'explique sans doute par le fait que la revue conserva pendant des années la structure qu'en avait établie de Mortillet. Quant à la Revue des études anciennes, on note les mêmes tâtonnements dans la mesure où une « Chronique gallo-romaine » ne fut véritablement formalisée qu'à partir de 1905/1906.

5 Toutes ces rubriques couvraient des périmètres précis : l'archéologie classique pour la Revue archéologique, la préhistoire pour les Matériaux et L'Anthropologie; enfin tout ce qui relevait du celtique (voire du préhistorique régional) et du gallo-romain pour la Revue des études anciennes. Cette nécessité de définir un périmètre le plus précis possible était liée à la relative concurrence que ces rubriques pouvaient instaurer entre revues. Ainsi faut-il interpréter la vive réaction de Salomon Reinach face à la création en 1891 d'une rubrique " Nouvelles et Correspondance $»^{10}$ dans le Bulletin de Correspondance hellénique :

«À la lecture des Nouvelles et Correspondances insérées dans le Bulletin de Correspondance Hellénique, jusqu'à présent si avare de renseignements de ce genre, je 
me suis demandé si je ne ferais pas bien de suspendre la publication de mes Chroniques, en laissant au journal de l'École d'Athènes le soin de les continuer. Réflexions faites, j'ai repris la plume. Le Bulletin est l'organe d'un établissement gouvernemental : son directeur exerce des fonctions qui lui imposent autant de réserve dans le langage que d'initiative sur le terrain. Il n'a pas, il ne peut pas avoir dans la critique l'indépendance d'un humble attaché du Musée de Saint-Germain. Je continue donc la série de mes Chroniques, et je la continue dans le même esprit que par le passé, heureux de pouvoir dire ce que je pense comme je le pense, d'appeler un chat un chat et les fabricants de certains prétendus chefs-d'œuvre des faussaires. ${ }^{11}$ »

6 Il est vrai que cette nouvelle chronique pouvait faire de l'ombre au travail de Reinach, notamment pour tout ce qui concernait le monde grec et oriental. Dans son commentaire, le directeur utilise aussi un argument plus politique, en invoquant «l'indépendance » de la revue puisqu'elle n'était affiliée à aucun établissement public. Cette volonté sera réaffirmée quelques années plus tard, en 1902, au moment de la disparition de Bertrand, l'ancien directeur :

«La Revue n'a jamais été inféodée à aucune école et elle s'est toujours montrée

hospitalière à l'expression de toutes les idées réfléchies. ${ }^{12}{ }$ '

En réalité, toute nouvelle revue s'évertuait à proposer de telles rubriques. En 1904, le premier numéro du Bulletin de la Société préhistorique de France paraissait et comportait une rubrique nommée "Renseignements préhistoriques». Une note en précisait l'organisation :

«Pour la rédaction de ces rubriques qui, dans notre pensée, doivent trouver leur place dans chaque bulletin, il est fait appel à la bienveillante collaboration de tous les membres de la Société. Le Secrétaire général centralisera tous les renseignements et en donnera connaissance en séance. ${ }^{13}$ »

\section{Une forme originale}

Dans la forme, ce type de rubrique était pensé comme le compte-rendu d'une séance prononcée dans les académies ou les sociétés savantes, les informations se succédant les unes aux autres sans ordre déterminé. Il ne semble pas non plus qu'il y ait eu des règles de rédaction, ni des spécificités typographiques clairement définies : les notices mentionnent en général un titre et les initiales du rédacteur. Quant à la nature des informations, elle est extrêmement hétérogène: il peut s'agir de reproductions in extenso de lettres, d'articles de journaux, de décrets, de discours restitués, et même de bêtisiers rédigés à partir de la lecture de journaux et livres ${ }^{14}$. Dans le cinquième numéro de l'année 1906 de L'Anthropologie figurent ainsi deux notes de Cartailhac relatives à des courriers qu'il a reçus. Dans le premier cas, le rédacteur restitue intégralement l'extrait d'une lettre de l'abbé Breuil concernant son étude des cavernes de la province de Santander, lettre que l'auteur lui-même souhaitait qu'elle fût destinée aux lecteurs de la revue (fig. 1) ${ }^{15}$. Dans le second cas, Cartailhac rend indirectement compte d'une carte postale envoyée par Clarence Bicknell à propos d'une nouvelle campagne de reconnaissance de roches sculptées dans la vallée des Merveilles (fig. 2) ${ }^{16}$. Le mode d'énonciation différait donc au gré de la nature du courrier reçu, des intentions de l'informateur et du choix du rédacteur. Quand des informations sont directement transmises par un correspondant de la revue (souvent un abonné), son nom apparaît dans la chronique : c'est notamment le cas de Joseph Déchelette qui, en qualité de 
"Vice Président de la Société éduenne », informe la Revue archéologique de l'héritage par la Société de la collection du docteur Loydreau ${ }^{17}$ (fig. 3).

Fig. 1. - Extrait de L'Anthropologie, 1906, 17, p. 625.

\section{Cavernes espagnoles peintes et gravées.}

Nous extrayons d'une lettre de notre savant collaborateur, M. l'abbé Breuil, les passages suivants :

Je ne veux pas laisser attendre trop longtemps aux lecteurs de L'Anthropologie des nouvelles de mon voyage de cet été aux cavernes nouvelles de la province de Santander. Grâce à l'aimable accueil et à la conduite de MM. Alcade del Rio et du Père Sierra, leurs inventeurs, j'ai pu, dans les meilleures conditions possibles, réaliser une exploration des plus fructueuses.

Je me suis occupé d'abord d'Altamira, où j'ai passé deux journées, partiellement à revoir ce que je connaissais bien déjà - puisque c'est le troisième séjour que j'y faisais -, partiellement à étudier quelques gravures nouvelles découvertes par M. Alcade. J'avoue qu'il n'a pu me convertir à considérer zomme des dessins d'oiseaux certains assemblages de traits; l'un de ceux qui, ¿ première vue, lui aurait donné raison, s'est trouvé, après un examen approondi, devenir les pieds d'une de ces étranges figures anthropomorphes que lous avions, M. Cartailhac et moi, précédemment signalées ; M. Alcalde l'a d'aileurs reconnu avec moi. Pour plusieurs autres dessins nouveaux, j'ai reconnu e bien fondé de ses observations.

J'ai examiné sous sa conduite le gisement, et ai pu aussi dessiner les princirales pièces de la remarquable collection recuejllie au cours de ses fouille: lous reparlerons ici-même du mobilier archéologique qu'elle renferme.

Le principal but de mon voyage était d'explorer avec M. A. del Rio, en faisant le nouveaux relevés aussi exacts que possible, les cavernes qu'il avait récemaent signalées dans un livre dont j'ai ici-même donné l'analyse. Avec beaucoup e courtoisie et de désintéressement, M. A. del R. m'a secondé dans ce travail,

L'ANTHRopologte. - T. XVII. - 1906.

40

Fig. 2. - Extrait de L'Anthropologie, 1906, 17, p. 627.

Les rochers sculptés au dessus du col de Tende.

Une carte postale de M. C. Brecknell, partie du Val Casterino de Tende, nous informe que notre confrère a fait cette année une très heureuse campagne dans les hautes régions alpines dont les rochers sont couverts d'images gravées. Il a pu trouver de telles inscriptions en grand nombre et toujours de nouvelles figures, sur les rochers auprès des Haghi hunghi, avant d'arriver à la région maintenant célèbre du lac des Merveilles.

E. C. 
Fig. 3. - Extrait de Revue archéologique, 1906, 4e série, VIII, p. 323.

\section{La collection Loydreau.}

La Société Ėduenne vient d'hériter de l'importante collection néolithique du Dr Loydreau, décédé à Neuilly-lès-Arnay (Côte-d'Or), dans sa $86^{\ominus}$ année, au mois de décembre 1905.

- On sait que cette collection avait été formée par les trouvailles du camp de Chassey (Saône-et-Loire), exploré par le $D^{r}$ Loydreau. Elle est déjà installée et classée dans une salle spéciale du musée de la Société Éduenne, à Autun, hôtel Robin.

Nous nous proposons, avec l'aide et sous le patronage de la Société Éduenne, de publier sur cette riche station la monographie illustrée, en vue de laquelle le $D^{*}$ Loydreau avait préparé une nombreuse série de clichés photographiques. Joseph DÉchelette, Vice Président de la Société Éduenne.

9 La même diversité se lit dans les contenus de chaque chronique: découvertes archéologiques, exploration de terrain, achats de collections, dépenses des musées nationaux et même dépouillement de journaux ou de revues en langue française ou étrangère ${ }^{18}$. Dans ce dernier cas, Salomon Reinach en traduisait scrupuleusement tous les titres d'articles ${ }^{19}$. Cette variété donne aussi une idée de l'ampleur du travail de veille éditoriale que pouvaient réaliser les rédacteurs. Le plus souvent, les principaux contributeurs étaient les responsables de chaque revue: Perrot et Reinach pour la Revue archéologique, Jullian pour la Revue des études anciennes pour ne citer que ces exemples. Ils savaient cependant requérir l'aide de collaborateurs qui pouvaient témoigner plus directement des informations transmises ${ }^{20}$ : comme pour la note de Déchelette à propos de la collection Loydreau, c'est une notice qui est publiée dans la Revue archéologique par Raymond Lizop ${ }^{21}$, secrétaire de la Commission des fouilles de Saint-Bertrand-de-Comminges, qui rend compte des fouilles exécutées dans la basilique paléochrétienne.

\section{La circulation des informations}

Malgré la concurrence progressive qui pouvait s'instaurer entre certaines revues, les rubriques ont eu pour vertu d'engager les préhistoriens et les archéologues classiques dans un dialogue réciproque dont la finalité espérée était une forme de partage des savoirs. C'est ce qui ressort d'une note signée par Marcellin Boule dans L'Anthropologie :

« En se lançant courageusement dans la préhistoire, M. Salomon Reinach a rendu à nos études un service signalé, par sa contribution personnelle d'abord, par l'exemple donné ensuite. Grâce à lui nous sommes moins ignorés qu'autrefois du monde des archéologues classiques et des historiens. Mais voici que l'exemple est suivi. Nous voyions naguère l'éminent directeur de l'Enseignement supérieur, M. Bayet, enthousiasmé à la vue des fac-similés des peintures d'Altamira et nous l'avons entendu, à la séance de clôture du Congrès de Monaco, rendre un hommage précieux aux résultats acquis par les Préhistoriens. Une autre recrue, qui nous fait le plus grand honneur, est M. le Professeur Jullian du Collège de France, dont les chroniques gallo-romaines de la Revue des études anciennes, comprises dans un esprit des plus larges, embrassent tous les temps préhistoriques. Notre Revue y est toujours dépouillée avec soin ; son rôle a été apprécié par M. Jullian dans des termes trop élogieux pour que je puisse les reproduire ici. Mais que notre éminent confrère ne croie pas que c'est pour lui rendre sa politesse que je recommande à nos amis la lecture de ses Chroniques gallo-romaines si substantielles et si nettes. Je veux leur 
indiquer un des autres coins de France "où l'on travaille le mieux, sans bavardage et

avec profit continu". ${ }^{22}$ ”

11 Même si les deux savants se connaissaient - Boule avait fait visiter les Eyzies à Jullian quelque temps auparavant - il est clair que l'objectif était de décloisonner les périodes archéologiques à l'instar de ce qu'Alexandre Bertrand ${ }^{23}$ avait pu faire lorsqu'il dirigeait la Revue archéologique. Bertrand et Jullian à sa suite étaient sans doute les mieux placés pour engager ce processus tant leurs études portaient sur une période qui n'était pas encore bien identifiée, la protohistoire. Mais par-delà les motivations scientifiques, le rapprochement entre certaines revues s'inscrivait aussi dans une forme de réaction et de critique à l'égard des concurrentes. On peut ainsi penser que la citation anonyme qu'utilise Boule est une critique à peine voilée du nouveau Bulletin de la Société préhistorique de France.

Si la circulation des informations fut une priorité, il n'en reste pas moins qu'elle fut soumise à quelques limites. Deux exemples sont assez instructifs des choix qui pouvaient être faits. Le premier exemple concerne la découverte de silex égyptiens sur l'île de Riou près de Marseille en 1905. Alors que les premiers résultats en sont exposés devant les membres de l'Académie des Inscriptions et Belles-Lettres par Louis Capitan, la meilleure publicité en est assurée par Jullian qui note dans ses chroniques :

« Tout le monde savant connaît cette extraordinaire découverte de silex égyptiens dans le misérable îlot de Riou près de Marseille. Le relevé de la fouille et la description des objets viennent de paraître (Revue de l'École d'anthropologie de Paris, 1905 ; Capitan et Arnaud d'Agnel). J'ai vu, chez M. le docteur Capitan ${ }^{24}$, dont la savante bonne grâce est à l'épreuve de toutes les importunités, les silex de Riou : leur analogie, leur identité avec ceux du Fayoum est indiscutable. ${ }^{25}$ "

13 La publicité fut moindre, semble-t-il, dans les autres revues: Reinach signale la découverte dans le «Bulletin mensuel de l'Académie des Inscriptions et BellesLettres ", une autre rubrique de la Revue archéologique qui faisait état des séances de l'Académie ${ }^{26}$; quant à Boule il fait simplement référence dans la rubrique intitulée « le mouvement scientifique » à l'article de Capitan et Arnaud d'Agnel, tout en notant cependant :

«Devant un fait aussi curieux et aussi gros de conséquences, pour me servir de l'expression même des auteurs, de nouvelles études devront être faites à Riou avec le concours d'un géologue expérimenté, car bien des points sont encore à éclaircir dans cette affaire. ${ }^{27}$ "

14 Il faut dire que les présomptions d'une supercherie se manifestèrent bien vite. Même Jullian se lança dans une enquête secrète auprès de J. Déchelette pour avoir son avis ${ }^{28}$. Quelques mois plus tard, Louis Capitan dut reconnaître son erreur, acte qui eut là encore peu d'écho dans les revues ${ }^{29}$.

En cette même année 1906 disparaissait aussi une figure éminente de l'archéologie préhistorique : Édouard Piette. Si les trois revues rendent un hommage unanime, les notices nécrologiques ne jettent pas le même éclairage sur la carrière du savant. Ainsi dans la Revue archéologique, c'est Reinach qui fit la nécrologie du défunt en citant le discours qu'il avait lui-même prononcé lors des obsèques ${ }^{30}$. Dans L'Anthropologie, Boule assure la rédaction de la notice nécrologique tout comme il dresse un inventaire des publications du préhistorien ${ }^{31}$. Enfin, pour la Revue des études anciennes, Jullian confie cette tâche à Cartailhac: non seulement ce dernier avait bien connu Piette, mais il appartenait aussi à la même communauté préhistorienne ${ }^{32}$. Dans ce type d'exercice se 
posait donc la question de la légitimité des auteurs par rapport au savant disparu, et des relations de ce dernier avec la revue et ses collaborateurs.

Ces deux exemples révèlent à notre sens les limites que ces chroniques imposent à toute étude historique. Certes, elles donnent à voir la vie d'une discipline au travers des découvertes, des publications, des nominations, des disparitions, parfois des scandales, que celle-ci put connaître. Mais elles sont aussi au cœur de choix consciemment opérés par les rédacteurs eux-mêmes, et ce en fonction de critères différents. Tout d'abord la nécessité de respecter le périmètre de la chronique et celui de la revue : malgré les efforts d'un Jullian qui ouvre ses chroniques gallo-romaines à la préhistoire, celles-ci restent le plus souvent dans le domaine régional et antique. Espace de discussions et de débats, elles le furent aussi comme en témoignent des droits de réponse ou des commentaires parfois ajoutés aux nouvelles transmises par des tiers. Par ailleurs, il reste difficile de cerner les attentes du lectorat de chacune d'entre elles, sachant que leur audience est aussi compliquée à délimiter. Même si le prix au numéro avoisinait le plus souvent une vingtaine de francs, cela devait aussi limiter leur achat régulier pour nombre d'archéologues amateurs.

Un autre critère était aussi celui des relations que les archéologues pouvaient entretenir avec ces revues au titre de collaborateurs réguliers ou occasionnels, ou bien au titre de simples lecteurs. Il faut souligner le fait qu'aucune de ces revues n'était totalement sans relation avec des institutions savantes. Si une revue comme la Revue archéologique défendait farouchement son indépendance, d'autres revues comme la Revue des études anciennes restaient affiliées à des universités. Dans d'autres cas, les lecteurs pouvaient être membres d'une société dont la revue était un important support éditorial à l'instar du Bulletin de la Société préhistorique de France. Il est donc nécessaire de prendre en compte de telles relations, car elles ont pu influer sur la teneur des volumes. Chaque information était donc soumise à des filtres plus ou moins explicites, ce qui oblige à en relativiser non seulement l'exhaustivité mais aussi l'influence dans le mouvement scientifique.

Que faire aujourd'hui d'une telle documentation? Plusieurs perspectives sont possibles allant de l'étude de la vie scientifique de l'archéologie française, surtout à une époque où les découvertes abondaient et où certaines disciplines commençaient (ou achevaient) de s'institutionnaliser, jusqu'à l'analyse des réseaux qui pouvaient graviter autour de ces publications. Bien que mal identifiées sur le plan académique, ces rubriques offrent surtout l'image d'une discipline, l'archéologie, en plein dynamisme et en constante mutation. Sur le plan historiographique, enfin, elles sont des témoignages complémentaires et utiles aux études de fonds d'archives, tout particulièrement aux correspondances.

\section{BIBLIOGRAPHIE}

BOULE Marcellin 1906, «Édouard Piette », L'Anthropologie, XVII, p. 214-224. 
BOULE Marcellin 1906, « Mouvement scientifique », L'Anthropologie, XVII, p. 427.

BouLE Marcellin 1906, « La Préhistoire chez les classiques », L'Anthropologie, XVII, p. 500-501.

CAPITAN Louis 1907, «Silex égyptiens de Riou », Comptes rendus des séances de l'Académie des Inscriptions et Belles-Lettres, 51-5, p. 227-228.

CARTAILHAC Émile 1906, « Cavernes espagnoles peintes et gravées », L'Anthropologie, XVII, p. 625.

CARTAILHAC Émile 1906, « Les roches sculptées au-dessus du col de Tende », L'Anthropologie, XVII, p. 627.

CARTAILHAC Émile 1906, «Édouard Piette », Revue des Études anciennes, VIII-3, p. 274-276.

DÉCHELETTE Joseph 1906, « La collection Loydreau », Revue archéologique, 4e série, VIII, p. 323.

DUBOIS Sébastien 2011, Émergence et développement de l'archéologie préhistorique en Midi toulousain entre $\mathrm{XIX}^{e}$ et $\mathrm{XX} \mathrm{X}^{e}$ siècle, thèse de doctorat en Préhistoire, Université Toulouse II-Le Mirail.

GRAN-AYMERICH Ève 2007, Les chercheurs de passé 1798-1945 : naissance de l'archéologie moderne, Paris, Éditions du CNRS.

HOMOLLE Théophile 1891, « Nouvelles et correspondance », Bulletin de Correspondance hellénique, 15, p. 441.

JULLiAn Camille 1906, «Les silex égyptiens de Riou », Revue des études anciennes, 8-1, p. 67.

LANTIER Raymond 1945, « Autour d'un centenaire », Revue archéologique, 6e série, XXIII, p. 5-26.

LE ROY Christian 1994, «Cent cinquante ans de littérature archéologique à travers la RA et ses lecteurs. Essai de bilan », Revue archéologique, Nouvelle série, 2, p. 229-242.

LINTON Jimmy, AFFOLTER Jehanne et SESTIER Claude 2008, « Des lames en silex rubané tertiaire de la collection des fouilles anciennes du camp de Chassey (Saône-et-Loire) », Revue archéologique de l'Est, 57, p. 5-20.

LIzop Raymond 1914, « Nouvelles découvertes à Saint-Bertrand de Comminges », Revue archéologique, $4^{\mathrm{e}}$ série, XXIII, p. 11-112.

PÉRÉ-NOGUÈS Sandra (dir.) 2014, Joseph Déchelette, un précurseur de l'archéologie européenne, Paris, Éditions Errance.

RAYMOND Paul 1904, «Renseignements préhistoriques », Bulletin de la Société préhistorique de France, I, 1, p. 41-44.

REINACH Salomon 1892, «Chronique d'Orient », Revue archéologique, $3^{\mathrm{e}}$ série, XIX, p. 65.

REINACH Salomon 1902, « La Revue des études anciennes en 1901 », Revue archéologique, $3^{\mathrm{e}}$ série, XLI, p. 426-429.

REINACH Salomon 1903, « Alexandre Bertrand », Revue archéologique, 4 série, I, p. 53-60.

REINACH Salomon 1906, « Bulletin mensuel de l'Académie des Inscriptions », Revue archéologique, $4^{\mathrm{e}}$ série, VII, p. 205.

REINACH Salomon 1906, « Édouard Piette », Revue archéologique, 4e série, VIII, p. 151-153.

REINACH Salomon 1911, « Nouvelles archéologiques et correspondance », Revue archéologique, 4 e série, XVII, p. 178. 


\section{NOTES}

1. Le choix de ces revues est tout à fait arbitraire et il mériterait d'être étendu à d'autres périodiques. Il a été déterminé par le fait que nous avons retrouvé ces revues citées dans plusieurs archives dont nous faisons (ou avons fait) l'analyse.

2. Le titre originel de la revue est le suivant: Recueil de documents et de mémoires relatifs à l'étude des monuments et à la philologie de l'Antiquité et du Moyen Âge publiés par les principaux archéologues français et étrangers. Sa périodicité était d'abord mensuelle, puis à partir de 1883 elle devint bimestrielle. À partir de 1884, elle fut également publiée par les éditions E. Leroux à Paris. Sur l'histoire de la revue : Lantier 1945, p. 5-26; Le Roy 1994, p. 229-242.

3. Gran-Aymerich 2007, p. 136.

4. La direction était bicéphale avec un représentant de l'archéologie classique : Lantier 1945, p. 21. Il est à noter qu'il existait une forme d'intégration confraternelle, puisque Bertrand y fut accueilli par Alfred Maury, et y invita Salomon Reinach.

5. Sur ce rachat et l'histoire des Matériaux, voir Dubois 2011, p. 183-207. La revue était mensuelle et l'éditeur C. Reinwald de Paris en assurait la diffusion.

6. En 1872 était également créée la Revue d'Anthropologie par Paul Broca, revue qui était directement concurrente des Matériaux. Cette année-là, Cartailhac requit l'aide de deux proches : le géologue Paul Cazalis de Fondouce et l'anthropologue Ernest Chantre. Leurs noms figurent sur les couvertures au titre de rédacteur et/ou directeur : Dubois 2011, p. 194-195.

7. Éditée par l'éditeur Masson à Paris, la revue était aussi bimestrielle.

8. La revue était trimestrielle et éditée à Bordeaux par la maison Fréret et fils. Elle est restée affiliée aux universités de Bordeaux et du Midi jusqu'en 1936.

9. Lantier 1945, p. 7.

10. Il est instructif de lire le texte de présentation de cette nouvelle rubrique telle qu'il fut rédigé par Théodore Homolle, ancien condisciple de Reinach à l'École française d'Athènes : « Les Nouvelles n'ont jusqu'ici tenu dans le Bulletin qu'une très petite place ; notre désir est de leur en faire une beaucoup plus large et nous voudrions, s'il est possible, présenter chaque mois un tableau complet des découvertes qui se font en Orient. Celui que nous donnons aujourd'hui, et qui porte sur le premier semestre de l'année 1891, n'est qu'un essai. Le service des correspondances, le dépouillement des journaux n'ont pu encore être organisés; nous espérons que l'on voudra bien nous aider et nous permettre de rendre nos informations aussi rapides, exactes et complètes qu'il est nécessaire pour le bien de la science. Nous accueillerons surtout avec reconnaissance les communications qui nous seront faites directement par les auteurs ou les témoins des découvertes, que nous ne pouvons toutes suivre nous-mêmes.» (Homolle 1891, p. 441).

11. Le texte de Reinach est publié dans la «Chronique d'Orient » : Reinach 1892, p. 65.

12. Reinach 1903, p. 53.

13. Raymond, 1904, p. 41 n. 2.

14. Salomon Reinach a ainsi introduit dans quelques numéros des «Opinions téméraires » dont voici un exemple amusant : «Que d'hérésies sont commises tous les jours par des savants, des archéologues de profession! J'en pourrais citer de moi-même 
qui sont énormes. Mais je préfère terminer en notant cette opinion téméraire de M. Forrer, de crainte qu'elle ne fasse son chemin sous le couvert d'un nom aussi estimé : «La bataille d'Agen nous montre que l'armée des Cimbres et des Tigurins s'était écartée vers l'ouest de la ligne du Rhône. Étaient-ce les bons vins de BordeauxBurdigala, étaient-ce les trésors de cette ville commerçante qui les avaient attirés vers l'Occident? » (Keltische Numismatik der Rhein- und Donaulande, Strasbourg, 1908, p. 336). Les vins de Bordeaux du temps de Marius ? Déjà ! (Reinach 1911, p. 178).

15. Cartailhac 1906, p. 625.

16. Cartailhac 1906, p. 627.

17. Déchelette 1906, p. 323. La collection Loydreau rassemble plusieurs milliers de silex issus des fouilles réalisées entre 1860 et 1880 par le docteur Loydreau dans le camp de Chassey, site d'époque néolithique de Saône-et-Loire. Elle est aujourd'hui encore conservée au musée Rolin d'Autun : Linton et alii 2008, p. 5.

18. Voir Reinach 1902, p. 426-429.

19. Sur le problème des langues étrangères dans la diffusion des savoirs archéologiques, voir Péré-Noguès 2014, p. 235.

20. Déchelette fut ainsi un collaborateur régulier de la Revue archéologique et de la Revue des études anciennes : Péré-Noguès 2014, p. 215 et 219.

21. Lizop 1914, p. 111-112.

22. Boule 1906, p. 500-501.

23. Sur ce point: Lantier 1945, p. 22. L'auteur explique que la revue est devenue « en quelque sorte l'organe de Commission de Topographie des Gaules» du fait qu'elle a contribué à en divulguer beaucoup des travaux. Des essais de classification sont aussi publiés comme ceux de Joseph Déchelette sur la chronologie préhistorique de la Péninsule ibérique.

24. Louis Capitan (1854-1929) : médecin, anthropologue et préhistorien. Capitan fit une présentation de cette découverte dans une séance de l'Académie des Inscriptions et Belles Lettres le 11 août 1905.

25. Jullian 1906, p. 67.

26. Reinach 1906, p. 205.

27. Boule 1906, p.427. Il recommande du reste le «fin stratigraphe Vasseur» aux inventeurs!

28. "Cette découverte est vraiment curieuse mais il me semble que les deux auteurs vont beaucoup trop vite en parlant de relations directes avec l'Égypte. Le seul type caractéristique des silex est le couteau à soie. Au surplus, je voudrais être bien sûr que les silex ont été tous récoltés par les inventeurs eux-mêmes et que nulle supercherie d'ouvriers ne soit à craindre. » Lettre de J. Déchelette à C. Jullian, 6 janvier 1906 (Musée des Beaux-Arts et Archéologie Joseph Déchelette, Roanne).

29. Capitan 1907, p. 227-228. Lors de la séance du 3 mai 1907, Capitan expliquait qu'il s'agissait d'une supercherie, réalisée par « un vieillard, aujourd'hui très malade » qui avait avoué à M. Clerc avoir voulu tromper l'abbé Arnaud d'Agnel.

30. Reinach 1906, p. 151-153.

31. Boule 1906, p. 214-224.

32. Cartailhac 1906, p. 274-276. 


\section{RÉSUMÉS}

C'est au cours du XIX ${ }^{\mathrm{e}}$ siècle que des périodiques spécialisés, notamment dans le champ de l'archéologie préhistorique et classique apparaissent, donnant un accès rapide et fiable aux actualités nationales et étrangères. Leur rôle fut aussi renforcé par l'usage fréquent de chroniques, résultat d'un véritable travail de veille éditoriale puisqu'il supposait non seulement la lecture de tout ce qui était imprimé, mais aussi des liens épistolaires suffisamment étendus pour alimenter chaque livraison. À partir de quelques exemples choisis dans des revues telles que les Matériaux pour l'histoire primitive et naturelle de l'homme, l'Anthropologie, la Revue des études anciennes ou encore la Revue archéologique, il s'agira de comprendre dans quelles conditions ces chroniques furent fabriquées, de s'interroger sur leur mise en forme souvent originale et la place qui leur était accordée dans les revues. Enfin, c'est la question de leur influence dans la diffusion des savoirs mais aussi la question de leur utilité historiographique qui seront posées.

\section{AUTEUR}

\section{SANDRA PÉRÉ-NOGUÈS}

Maître de conférences en histoire à l'université de Toulouse - Jean-Jaurès, membre du laboratoire Travaux et recherches archéologiques sur les cultures, les espaces et les sociétés (TRACES, UMR 5608, CNRS) 


\title{
Savoir-vivre et savoir être dans les romans de T. Trilby : éléments d'une stratégie éducative
}

\author{
Mathilde Hallot-Charmasson
}

1 Marie-Thérèse de Marnyphac est née en 1875 à Louveciennes. Troisième et dernière fille d'une grande famille aristocratique, elle reçoit une éducation catholique rigide et suit des études d'infirmière ${ }^{1}$. Le 10 janvier 1899, elle épouse Louis Delhaye, un industriel fortuné, à qui elle donne un fils, Jacques. Pendant la Première Guerre mondiale, elle devient infirmière militaire. Elle exerce à l'hôpital auxiliaire $n^{\circ} 95$ à Paris, tenu par la Croix-Rouge française ${ }^{2}$. Elle reçoit la croix de guerre, est nommée chevalier de la Légion d'honneur ${ }^{3}$ et est remarquée par le maréchal Pétain qui la cite à l'ordre du jour du régiment en $1919^{4}$.

2 Après la guerre, elle est active à l'hôpital des réformés de Neuilly. Elle est par ailleurs qualifiée de membre fondateur de la Société de secours aux blessés militaires (SSBM), l'une des trois sociétés à l'origine de la Croix-Rouge française. Il s'agit d'un titre honorifique, car la société a été fondée par Henri Dunant (1828-1910) en 1864. Elle ne devient membre du comité local de la SSBM à Neuilly qu'entre 1926 et $1931^{5}$. Elle devient secrétaire de ce comité entre 1931 et 1935. Elle figure également parmi les membres statutaires des comités d'Athis-Mons (Essonne), des $5^{\mathrm{e}}$, $6^{\mathrm{e}}$ et $17^{\mathrm{e}}$ arrondissements de Paris. Après la Seconde Guerre mondiale, la SSBM ayant fusionné avec deux autres organisations regroupées sous le nom de Croix-Rouge, elle devient vice-présidente de la section de Neuilly. Le comité local gérait alors dans ses bâtiments un jardin d'enfants, sans qu'il soit possible de déterminer le rôle que Marie-Thérèse de Marnyphac y jouait exactement ${ }^{6}$. Karine-Marie Voyer, auteur de la seule étude disponible sur Trilby et qui a eu accès à des archives familiales, affirme qu'en 1935, elle crée avec ses amies infirmières un dispensaire pour les forains, installé dans une roulotte, où elle soigne gratuitement les gitans ${ }^{7}$. Veuve à l'âge de soixante ans, elle s'éteint le 18 novembre 1962 à La Rochelle, à quatre-vingt-sept ans.

3 Cette riche dame d'œuvres, aujourd'hui très oubliée, est aussi l'auteur d'une œuvre littéraire prolifique comptant plusieurs centaines de romans publiés à partir de 1900 
dans divers journaux tels L'Écho de Paris, Le Petit Écho de la mode, Le Journal rose ou encore Les Veillées des chaumières et dans la collection «Stella» sous le pseudonyme de Trilby8. À partir de 1936 et jusqu'à sa mort, elle publie également sous le même nom une soixantaine de romans pour la jeunesse, pour la plupart illustrés par Manon Iessel et publiés dans la collection "Pour les jeunes» de Flammarion. Mettant en scène de jeunes héros et héroïnes de sept à seize ans confrontés aux épreuves du déclassement social, de la maladie et de leur propre faiblesse morale, ces romans ont, pour plusieurs générations, fait partie des lectures incontournables de la pré-adolescence, conseillées par les adultes et plébiscitées par les enfants.

4 Ce sont les éléments d'une sociologie - celle de la bourgeoisie conservatrice et catholique dont elle est issue - mais aussi d'une théologie - celle de la religion catholique - que visent à communiquer les récits de Trilby, conduisant ainsi l'auteur à la remise en cause de la forme romanesque au profit de traditions largement attestées dans la littérature éducative, exempla, catéchismes ou paraphrases des Évangiles. Ces lectures occupent, dans la formation des enfants, une place à la fois complémentaire et décalée par rapport à l'école, complétant d'une éducation morale l'instruction scolaire. Ce faisant, elles s'insèrent dans une stratégie éducative plus large des familles, s'intégrant dans les processus de transmission informelle de savoir-vivre et de savoir être propres à une classe sociale.

\section{Les formes traditionnelles de la littérature éducative pour modèles}

5 L'écriture de Trilby est paradoxalement marquée par le refus du romanesque. Ses œuvres sont à lire en relation avec des modèles de littérature éducative et morale, vies de saints ou de héros, contes ou encore paraphrases d'Évangile. Tout au long de son œuvre, l'écrivain fait référence, plus ou moins explicitement, à ces modèles et à ces genres littéraires. Elle y fait usage, comme les écrivains antiques et les prédicateurs médiévaux, de l'exemplum dans son double sens rhétorique et homilétique.

\section{Une galerie de grands hommes, de héros et de saints : de l' exemplum à l'hagiographie}

Trilby présente en effet à ses jeunes lecteurs une galerie de héros, de grands hommes et de saints. L'auteur propose à leur imitation des personnages aussi variés que Pasteur, Christophe Colomb, saint Louis, Bayard, Lyautey, saint Vincent de Paul, Mansart, Le Nôtre, Marie-Antoinette ou encore Jeanne d'Arc. Les figures de grands hommes sont aussi bien de grands scientifiques, des explorateurs, des « chevaliers sans peur et sans reproche " que des saints. Le Panthéon de Trilby mêle Ancien Régime et République, saints et héros laïcs dans un souci de faire de l'histoire un recueil d'exemples inspirants. Comme les moralistes antiques, elle "fait appel à la mémoire de la nation » et exhorte ses jeunes lecteurs à « être digne de leurs ancêtres ${ }^{9}$ ».

7 Cette galerie de héros est complétée par les pères, les mères et, d'une façon générale, les adultes qui entourent les enfants dans ces récits. Ce sont tous des «figures qui tendent à la perfection dans l'amour de Dieu et des autres ${ }^{10}$ ». 
8 Ainsi dans Paris-Londres, roman qui met en scène M. Poitou, inventeur d'une «autobateau », en manque chronique d'argent, jusqu'à mettre en difficulté sa famille. Son fils Patrick affirme pourtant à sa sœur :

«Si tu voyais papa quand il se rend compte que ses calculs sont justes, il y a sur son visage une telle joie qu'elle rayonne. On dirait par moments qu'autour de sa tête il y a une auréole. Ce n'est pas étonnant, Martine, papa est presque un saint, il ne vit que pour son invention. ${ }^{11}$ "

9 Au-delà de ces exemples internes aux récits, ce sont les jeunes héros et héroïnes euxmêmes qui constituent des exemples pour les jeunes lecteurs, invités à transposer leur trajectoire morale dans leur vie quotidienne. Comme les prédicateurs médiévaux, Trilby utilise ainsi l'exemplum pour transmettre un message moral.

\section{Paraphrases et réécritures contemporaines des Évangiles}

Pour reprendre les mots de Jacques de Voragine dans La Légende dorée :

« Fondamentalement, tout exemplum est la représentation de la Vérité : le Christ est comme un livre exemplaire, à l'exemple duquel nous devons mener toute notre vie, et la corriger. ${ }^{12}$ "

11 Fidèle en cela à la tradition des exempla, Trilby écrit, explicitement ou implicitement, pour inspirer à ses lecteurs le désir de devenir meilleur chrétien, c'est-à-dire de devenir de nouveaux Christ dans le contexte contemporain.

12 Ses jeunes héros vivent des expériences qui sont autant de paraboles contemporaines venant commenter et actualiser celles du canon des Écritures. Ainsi dans Une sainte, des démons et Kiki, trois jeunes frères et sœurs sont recueillis par Éléonore, une jeune femme célibataire, à la suite de la disparition de leur père, explorateur, et de la mort de l'amie qui en avait la garde. Lors d'un séjour à la campagne le plus âgé des trois, Jacques, qui n'a jamais accepté d'être recueilli par Éléonore, vole un bateau pour s'enfuir, manque se noyer et tombe gravement malade avant de se rendre compte de la bonté de la jeune femme qui a accepté sa garde. Au terme de sa maladie, soigné avec dévouement par Éléonore, il lui dit : « L'histoire du fils prodigue, n'est-ce pas un peu la mienne $^{13}$ ? », amenant ainsi le lecteur à une relecture de ses aventures à la lumière de la parabole évangélique et consacrant le glissement d'Éléonore vers un rôle explicitement maternel, déterminant pour la suite de l'intrigue. Comme Une sainte, des démons et Kiki, chaque roman de Trilby peut donc être perçu comme une paraphrase des Évangiles.

\section{Des romans organisés selon le schéma narratif du conte}

13 S'il est vrai, comme le souligne Nicolas Louis dans ses travaux sur l'exemplum, que l'équivalent littéraire de cet outil du rhéteur et du prédicateur est le conte, qui en est une forme développée, il n'est pas étonnant de constater que les romans de Trilby peuvent être lus comme autant de réécritures des contes traditionnels. Reprenant le schéma traditionnel de l'initiation enfantine, certains passages font même directement allusion à ce fonds de culture commune ${ }^{14}$.

14 C'est par exemple le cas dans Titi la carotte et sa princesse où Emmanuel, dit Titi, fils d'un sergent de ville et d'une concierge, se retrouve voisin d'une jeune princesse exilée par la guerre d'Espagne et alitée par une jambe cassée, Manuela. Il devient son ami, et au 
bout de quelques visites la malade, désormais guérie, lui demande de l'accompagner en promenade :

« Titi est stupéfait, il ne s'attendait pas à cette demande, peut-il se promener avec une princesse dans le bois ? Et voici que tous les contes merveilleux de son enfance encombrent son cerveau. Est-il bien réveillé, cette petite princesse blonde n'est-elle pas la Belle au Bois dormant qui a dormi cent ans; et cette dame blanche, à l'air sévère, n'est-elle pas celle qui, avec un fuseau, l'a piquée ? Est-il le prince charmant ou Riquet à la Houppe, il ne sait pas [... $]^{15}$ »

15 Tour à tour contes, réécritures de l'Évangile ou hagiographies, les romans de Trilby sont des exempla aux différents sens qu'a pu prendre ce mot dans l'histoire littéraire. Ils forment un ensemble dans lequel la dimension narrative est mise au service de la fonction didactique qu'ils peuvent remplir. On peut y voir autant de «livres de sagesse ", de catéchismes romancés ou de manuels de théologie pratique et morale répondant à la question: comment vivre l'Évangile dans le contexte particulier du passage à l'âge adulte et dans un monde qui connaît des transformations tant économiques que sociales? C'est ainsi une conception de la littérature enfantine comme élément d'une éducation morale qui se dessine dans ces romans où l'intrigue est celle d'une initiation spirituelle des jeunes héros.

\section{La littérature, élément d'une éducation morale}

\section{Un rapport ambivalent avec l'institution scolaire}

16 S'inscrivant dans l'atmosphère de suspicion entretenue par les sphères conservatrices dans la première moitié $\mathrm{du} \mathrm{xx}^{\mathrm{e}}$ siècle, colorée dans les milieux catholiques d'une nette méfiance à l'égard de l'école républicaine, l'« école sans Dieu ", l'œuvre de Trilby entretient des rapports ambivalents avec l'institution scolaire ${ }^{16}$. L'auteur y affirme ainsi à de multiples reprises qu'il est important de bien travailler à l'école, pour préparer son avenir et parce que cela fait partie du «devoir d'état » d'un enfant. Mais ses romans sont aussi parsemés de plaintes récurrentes sur la difficulté des compositions et la charge de travail trop importante que constituent les devoirs.

17 à l'appui de cette conception, l'auteur crée l'archétype du bon élève brillant mais égoïste. Pointant les insuffisances d'un système scolaire qui instruit sans éduquer, ce personnage que l'on retrouve de roman en roman s'oppose à celui, non moins récurrent, du cancre ou de l'élève moyen, mais doté d'un grand cœur. Ainsi Reine s'oppose à sa cadette Yvette dans Cordon, s'il vous plaît. Le récit, publié en 1955, met en scène la famille Sarlac, comptant un fils et deux filles. Militaire de carrière, le père a disparu en Indochine, la mère est donc contrainte de prendre une loge de concierge pour survivre. Reine, 13 ans, est présentée comme « égoïste, personnelle, n'aimant que ses études et ne s'occupant guère de sa famille ${ }^{17}$ ». Sa sœur, Yvette, 12 ans, est quant à elle une « bonne petite fille [...], très gaie, très impulsive, et adorant cette maman qui, elle s'en rend bien compte, se donne beaucoup de mal pour élever ses trois enfants ${ }^{18}$. Mais « la si tendre Yvette " " ne travail[e] pas toujours très bien à cause de fantaisies qui [viennent] dans sa tête elle ne [sait] pourquoi. $\star^{19}$

Dans cette opposition se donne à voir l'ambiguïté de Trilby par rapport à l'école. À à ses yeux, cette dernière ne remplit pas son rôle, si elle instruit sans éduquer. L'auteur s'attache à faire comprendre au fil de ses romans et des personnages qu'elle y présente qu'un cœur grand ouvert vaut mieux qu'une tête bien pleine. Les romans de Trilby se 
proposent donc d'offrir à leurs lecteurs une éducation morale en complément de l'instruction scolaire. Ce faisant, ils s'intègrent dans un " arsenal » éducatif pensé dans ce même but.

\section{La stratégie éducative d'une classe sociale}

19 À partir des années 30, une véritable galaxie d'éditeurs, Bayard, J. de Gigord, Desclée de Brouwer ou encore Mame, diffuse des romans pour enfants approuvés par les autorités ecclésiastiques et servant ouvertement des buts d'éducation spirituelle et morale. La création de la collection « Signe de piste », avec la parution en 1937 du premier volume de la saga des aventures du Prince Éric, par Serge Dalens, Le Bracelet de vermeil, est à cet égard significative ${ }^{20}$. Le succès de cette entreprise littéraire ouvertement catholique est emblématique de la création d'un univers de romans catholiques dont Trilby est l'un des auteurs les plus prolifiques et, du moins à l'époque, l'un des plus connus.

Dans cette constellation, la collection «Pour les jeunes» de la maison Flammarion, dans laquelle paraissent d'emblée la plupart des romans pour enfants de Trilby, occupe une place relativement marginale dans la mesure où elle est publiée par une maison d'édition dont l'offre n'est pas uniquement ni explicitement catholique ${ }^{21}$. Elle présente cependant un contenu assez homogène. Publiant des auteurs comme Johnny (1907-199 ? 22 ou Magdeleine Du Genestoux (1873-1942), sa couverture verte et son format caractéristiques permettent au jeune lecteur de Trilby, mais surtout à ses parents et à ceux qui sont chargés de son éducation, d'identifier immédiatement son appartenance à la mouvance catholique. Par sa remarquable fidélité à la maison Flammarion et à la collection « Pour les jeunes ", Trilby s'intègre ainsi pour ses lecteurs dans un monde cohérent.

21 Cette cohérence est renforcée par la collaboration avec Manon Iessel (1909-1985). Participant à La Semaine de Suzette, périodique crée par Henri Gautier en 1905, dont elle dessine notamment les publicités pour les vêtements de la "Poupée Bleuette », insérées toutes les semaines dans le magazine, Manon Iessel collabore aussi avec la plupart des auteurs de la collection « Pour les jeunes » et illustre les vies de saints publiées dans la collection «Belles histoires, Belles vies» des éditions Fleurus. Son trait franc et classique aux lignes épurées, l'attention qu'elle porte aux vêtements des personnages et les forts contrastes entre les visages et les attitudes austères des héros, par opposition aux lignes sinueuses et aux mouvements désordonnés des personnages négatifs, permettent ainsi au lecteur naviguant dans les différentes collections, publications et médias de la « Bonne presse » de se sentir en terrain familier dans ces supports divers ${ }^{23}$. Ainsi donc, les romans de Trilby ne sont pas les seuls de leur genre : ils s'insèrent dans une offre plus large de romans similaires. Ils constituent les éléments de la bibliothèque idéale du lecteur - et sans doute surtout de la lectrice - de La Semaine de Suzette ou de L'é toile noëliste et participent à la construction d'un environnement cohérent qui suivra le jeune homme, et plus encore la jeune fille, dans son développement.

Comme sa contemporaine Berthe Bernage (1886-1972), Trilby a en effet consacré une partie de sa carrière littéraire à publier des romans pour jeunes filles en feuilleton dans des journaux bien-pensants comme Le Petit Écho de la mode ou Les Veillées des chaumières. Ces romans aux titres évocateurs, L'Impossible Rédemption, Aimer c'est pardonner, Tout par amour ou encore à tout péché miséricorde, pour n'en citer que quelques-uns, sont ensuite 
repris dans la collection «Stella ». Publiée par les éditions du Petit Écho de la mode, cette collection est présentée au moment de sa création en 1919 en ces termes :

« La collection "Stella" est une garantie de qualité morale et de qualité littéraire. ${ }^{24}$ »

La production pour jeunes filles de Trilby s'intègre ainsi parfaitement dans l'univers romanesque de la galaxie éditoriale catholique, prolongeant son travail pour les enfants. Ce qui lie les œuvres pour adultes et les œuvres pour enfants de Trilby, c'est en effet la conviction que la fonction première de la littérature est de transmettre des valeurs morales, identiques pour l'âge adulte et pour les enfants. L'intrigue principale de ses romans réside donc dans la façon dont le héros ou l'héroïne refuse le mal pour s'élever vers Dieu, avec une coloration particulière dans chacun des univers ainsi créés.

Pour l'auteur du Droit d'aimer, de Lulu, le petit roi des forains et de Casse-Cou ou la miraculeuse aventure, transmettre des connaissances ne suffit pas, la littérature doit transmettre des valeurs. Dans son esprit, la raison d'être de ses romans est de suppléer aux lacunes de l'école et de compléter les efforts de la famille, entrant ainsi dans les stratégies informelles de transmission des savoir-vivre et des savoir être propres à une classe sociale, celle de son lectorat de destination, la bourgeoisie catholique. Deux domaines sont particulièrement concernés : les comportements sociaux et les attitudes de genre.

\title{
La transmission des savoir vivre et savoir être de la bourgeoisie catholique conservatrice
}

\begin{abstract}
«Dieu a créé les hommes, créateurs d'eux-mêmes, et pendant leur passage sur la terre ils ont trois missions [...]. La première, ta mission personnelle : veux avant tout être un honnête homme, vivant avec un idéal. La seconde, ta mission familiale, aimer et respecter tes parents, les entourer, les soutenir quand ils seront vieux, aimer ta femme, tes enfants, que tu devras diriger avec l'expérience que tu auras acquise; et la dernière, très importante, ta mission sociale : faire du bien à tous ceux qui vivront autour de toi et leur montrer le bon chemin..$^{25}$ "
\end{abstract}

L'intrigue principale des romans de Trilby est, ce discours du Père Marie, missionnaire en Afrique, au jeune Kounto et à ses amis en témoigne, centrée autour du passage à l'âge adulte des jeunes héros qu'elle met en scène. Refusant la tentation du mal, cette « maladie morale » infantile ${ }^{26}$, ils s'intègrent dans leur classe sociale et dans leur genre. Les romans de Trilby, à l'image des romans d'initiation du début du siècle, sont en ce sens autant des romans de conformation que des romans de formation, pour reprendre les mots de Denis Pernot ${ }^{27}$. Pour devenir adulte, les jeunes héros de Trilby doivent en premier lieu assumer la place qui est la leur dans la société.

\section{La richesse est une responsabilité : les pratiques charitables}

Le corpus des romans pour enfants de Trilby est ainsi émaillé de descriptions vivantes de réalités sociales contemporaines de sa période d'écriture, s'étendant des années 30 aux années 60 , la crise économique, qui entraîne le déclassement de la famille de Moineau, la petite libraire, le mal-logement, qui est au cœur de l'intrigue de plusieurs romans, comme Risque-tout, président du Conseil ou encore les patronages de quartiers populaires comme celui fondé à Montmartre par Madame Durnal, bienfaitrice du jeune Casse-Cou (Casse-Cou ou la miraculeuse aventure). 

l'État dans le fonctionnement de la société et en particulier dans le domaine de l'aide
aux plus pauvres, Trilby promeut dans ses romans le schéma qui a gouverné les
engagements de sa vie de dame d'œuvres. Elle donne clairement, au fil de ses romans à la charité et aux solidarités familiales contre l'assistance sociale, ainsi qu'aux pratiques paternalistes contre les syndicats et la lutte politique. Elle s'attache donc, tout au long de ses romans, à transmettre à ses jeunes lecteurs, faisant a priori partie d'une classe sociale aisée, l'idée que la richesse a pour conséquence naturelle le devoir de faire attention aux plus pauvres, à condition bien sûr qu'ils soient "méritants ». Il s'agit d'ancrer en eux la conviction de la nécessité des pratiques charitables de la classe dont ils sont issus, malgré le développement, aux lendemains de la crise des années 30 , de l'État-providence.

\section{Devenir un homme, devenir une femme : normes et attitudes de genre}

Devenir adulte c'est non seulement assumer ses responsabilités sociales mais devenir un homme ou une femme, en acceptant les rôles que ces derniers doivent assumer dans la société. La description, dont le rôle est prescriptif, de la répartition des rôles entre les genres, est présente en filigrane dans chacun des romans de Trilby, mais particulièrement sensible dans un récit comme Totor et cie, mettant en scène deux amis, Totor et Pierrot, ainsi que la sœur de ce dernier, Nénette. Les relations entre Nénette et Totor leur font assumer des rôles traditionnellement dévolus aux adultes jusqu'à l'apothéose d'un projet de mariage. Ainsi le soir où la grand-mère de Totor, qui l'élève, est emmenée à l'hôpital, Totor est accueilli par Nénette en rentrant chez lui :

« Nénette a revêtu la tenue de cuisinière de mère-grand. [...]. D’une voix douce que Totor ne lui connaît pas, elle dit :

- Ton dîner est prêt, si tu veux venir le manger, ça me fera bien plaisir, et, timide, cette nouvelle cuisinière attend la réponse de son invité.

- Mon dîner, répète Totor, ne comprenant pas.

- Mais oui, mère-grand m'a recommandé de m'occuper de toi, alors je m'en occupe.

J'ai trouvé des provisions, je les ai accommodées. [...]

Pendant que mère-grand est à l'hôpital, il faut que je m'occupe de ton ménage ; je serai ta ménagère jusqu'à son retour, si tu le veux?

[...] Nénette est toute prête à comprendre que le rôle des petites filles est pareil à celui des mamans : être la servante des gens qu'on aime..$^{29}$ "

31 Quand Nénette tombe malade après avoir mangé trop de chocolats volés dans une pâtisserie à Noël, Totor prend soin d'elle et il le justifie ainsi :

«- Ne t'occupe pas de moi ; je suis là pour te soigner, pour te protéger.

- Pourquoi ? demande-t-elle d'une voix faible

- Parce que je suis un homme et qu'un homme, M. l'abbé nous le dit toujours, doit protéger les plus faibles. ${ }^{30} »$ 
Apprivoisant leur identité masculine et féminine en adoptant l'un vis-à-vis de l'autre les comportements de genre prescrits par leur entourage, Nénette et Totor deviennent ensemble. Cette dynamique relationnelle initiatrice trouve sa conclusion dans un projet de mariage formée par Nénette mais auquel Totor souscrit, tout autant par désir de contribuer à l'amélioration morale de l'insupportable Nénette que par volonté de devenir le frère de son ami Pierrot. Ainsi Nénette explique-t-elle à Totor :

«On se mariera et je te promets de ne te faire enrager qu'une fois par semaine; si

j'étais toujours gentille, tu t'ennuierais. ${ }^{31}$ "

33 Le rapport qu'entretient Trilby avec les stéréotypes, qu'ils soient sociaux ou genrés, est pourtant plus complexe qu'il n'y paraît à première vue. Ainsi, dans l'exemple que nous venons d'exposer, c'est Nénette qui est à l'initiative de l'idée du mariage et sa personnalité remuante de jeune cancre au grand cœur fait d'elle une jeune fille loin de la passivité que certains lieux communs attribuent aux femmes.

\section{Un rapport complexe avec les stéréotypes}

En effet, ce qu'entend prôner Trilby dans ses romans, c'est avant tout le développement de la personne et de ses possibilités, au nom de l'universalisme évangélique. Ces valeurs universelles sont communes aux jeunes héros et aux jeunes héroïnes. Ainsi la conclusion de Cordon s'il vous plait sur les projets d'avenir des enfants Sarlac ne fait aucune différence entre Thibaud et ses sœurs :

«Thibaud entrerait dans l'armée. Reine voulait être médecin pour s'en aller dans les pays où il n'y en avait pas, campagne ou colonies. Et Yvette était toute fière de dire qu'elle aussi avait choisi sa carrière. Infirmière, n'était-ce pas le plus beau métier du monde? Et ces projets, le colonel les avait approuvés, heureux de constater que ses enfants n'avaient pas attendu son arrivée pour comprendre que toute vie doit être utile et qu'il faut choisir jeune la route qu'on veut prendre, et la suivre avec un cœur vibrant d'enthousiasme et d'espérance. ${ }^{32}$ ”

Dans le domaine social, cet universalisme évangélique peut conduire l'auteur à des prises de position assez inattendues, notamment sur la question du colonialisme : elle rejette l'exploitation des peuples colonisés car, enfants de Dieu comme les Occidentaux, ils devraient avoir les mêmes droits qu'eux. Le dialogue entre la jeune Éléonore Mancel et les dames de la paroisse Saint-Sulpice où elle participe activement aux activités de l'ouvroir est à cet égard emblématique :

«- Ma concierge n'aime pas les visages de couleur.

- Et vous, vous les aimez?

- Ce sont des chrétiens, comme nous.

- Comme nous! Entendez-vous cela, Mesdames? La plupart sont des infidèles, des hérétiques qu'on ne devrait pas recevoir en France.

- Pourquoi ? Nous avons été créés par le même Créateur, répond Éléonore avec le plus grand calme. ${ }^{33}$ "

Toutefois, l'activité d'écrivain de Trilby s'étend sur plus de soixante ans, trente si l'on ne prend en compte que sa production de littérature enfantine. Elle y défend toujours les mêmes principes et sa vision de la société ne change pas, alors même que celle-ci se trouve dans cette période aux prises avec d'importantes transformations économiques et sociales. Au début de sa carrière, elle prend des positions qui peuvent alors apparaître comme relativement novatrices, ainsi son attitude envers les pauvres, au moment de la diffusion de la doctrine sociale de l'Église et des balbutiements de la mise en place de l'aide étatique pour les classes populaires ${ }^{34}$. Pourtant elle ignore la 
formation de l'État-providence et présente encore, au milieu des Trente Glorieuses, un modèle de société fondé sur les solidarités organiques et familiales où la lutte sociale apparaît comme un blasphème. D'un progressisme mesuré au début de sa carrière, ses prises de position sociales, inchangées à la fin de sa vie, deviennent alors non seulement traditionnelles, mais traditionalistes.

Ainsi en va-t-il également du rôle des femmes dans la société. La mise en scène de femmes fortes qui prennent des responsabilités traditionnellement considérées comme masculines, récurrente dans le corpus de ses romans pour enfants, est la trace de l'embryon d'une émancipation féminine pensée sur le modèle de la Première Guerre mondiale. Les femmes ne sortent de leur foyer que pour pallier l'absence des hommes et aspirent à se démettre desdites responsabilités dans les mains d'un mari. Correspondant à la réalité vécue dans une société privée d'une grande partie de ses hommes jeunes par la Grande Guerre, le modèle apparaît anachronique et conservateur dans les derniers romans de l'auteur comme Marion la vedette ou Leurs Excellences Zoupi et Zoupinette, publiés dans les années 1960.

C'est ainsi une femme formée par les idéaux du XIX siècle et marquée par les contradictions de l'époque de sa propre formation intellectuelle et morale qui écrit tout au long de sa vie pour transmettre les valeurs qui sont les siennes. T. Trilby s'inscrit alors dans les stratégies éducatives de sa classe sociale, mais ne peut être réduite au rôle de porte-parole cynique d'une classe dominante avide de perpétuer son pouvoir. Elle porte aussi l'idéal d'une société chrétienne et la volonté d'une éducation morale à l'Évangile pour chacun de ses lecteurs, malgré les paradoxes qui marquent ce projet pédagogique.

\section{Lire et relire Trilby}

Les romans de Trilby ont rencontré un immense succès, tant public que critique. Moineau, la petite libraire, publié pour la première fois en 1936, est réédité cinq fois jusqu'en 1982 et Dadou, gosse de Paris, initialement publié la même année, connaît quatre rééditions jusqu'en 1982. Aujourd'hui encore, certaines de ses œuvres emblématiques sont rééditées par les éditions du Triomphe.

On peut toutefois émettre l'hypothèse que le succès de ces romans ne vient pas tant du but que se donnait l'auteur, c'est-à-dire transmettre des valeurs morales et contribuer à l'éducation spirituelle de ses jeunes lecteurs, que de la subversion de ce but par les lecteurs en question. Pour ces enfants, l'expérience narrative prime sans doute sur l'expérience morale ${ }^{35}$. Les romans de Trilby constituent alors un monde fictionnel doté d'une géographie et de personnages familiers. Comme les contes de fées, ces œuvres répondent ainsi au besoin psychique profond de compréhension du réel ${ }^{36}$. Leur réception par les lecteurs serait doncla plus nuancée que celle prévue par l'auteur : ils constitueraient certes des boussoles axiologiques, mais aussi les éléments d'un imaginaire familier de l'enfance. 


\section{BIBLIOGRAPHIE}

BETTELHeim Bruno, Psychanalyse des contes de fées, Paris, Robert Laffont (collection Pocket), 1999.

CONSTANS Ellen, Ouvrières des lettres, Limoges, PULIM, 2007.

LouIs Nicolas, « Exemplum ad usum et abusum : définition d'usages d'un récit qui n'en a que la forme », dans DUCHÉ Véronique et JEAY Madeleine (dir.), Le Récit exemplaire (1200-1800), Paris, Garnier, 2011, p. 17-36.

ORY Pascal, « "Signe de Piste" : le pays perdu de la chevalerie », La Revue des livres pour enfants, n 134-135, automne 1990, p. 72-81.

PARMEGIANI Claude-Anne, Les Petits Français illustrés, 1860-1940 : l'illustration pour enfants en France de 1860 à 1940, les modes de représentation, les grands illustrateurs, les formes éditoriales, Paris, éditions du Cercle de la librairie (collection Bibliothèques), 1989.

PERNOT Denis, Le Roman de socialisation en France (1889-1914), Paris, PUF, 1998.

PROPP Vladimir, Morphologie du conte, traduit par Claude LIGNY, Paris, Gallimard, 1970.

RENONCIAT Annie (dir.), Livre, mon ami. Lectures enfantines, 1914-1954, exposition présentée à la Bibliothèque Forney du 10 septembre au 19 octobre 1991, et à la mairie du Ve arrondissement $d u$ 19 novembre au 22 décembre 1991, Paris, Agence culturelle de Paris, 1991.

RENONCIAT Annie, « Catholic Criticism of Children's Literature at the Beginning of the 20th Century in France », dans DE MAEYER Jan, EWERS Hans-Heino, GHESQUIÈRE Rita, MANSON Michel, PINSENT Pat et QUAGHEBEUR Patricia (éd.), Religion, Children's Literature and Modernity in Western Europe. 1750-2000, Louvain, Presses universitaires de Louvain, 2005, p. 349-363.

T. TRILBY, Lulu, le petit roi des forains, Paris, Flammarion (collection Pour les jeunes), 1935.

T. TRILBY, Titi la carotte et sa princesse, Paris, Flammarion (collection. Pour les jeunes), 1938.

T. TRILBY, Une sainte, des démons et Kiki, Paris, Flammarion (collection Pour les jeunes), 1938.

T. TRILBY, D'un palais rose à une mansarde, Paris, Flammarion (collection Pour les jeunes), 1939.

T. TRILBY, Totor et Cie, Paris, Flammarion (collection Pour les jeunes), 1945.

T. TRILBY, La Grande Découverte, Paris, Flammarion (collection Pour les jeunes), 1946.

T. TRILBY, Le Petit Monsieur Vincent, Paris, Flammarion (collection Pour les jeunes), 1951.

T. TRILBY, Cordon, s'il-vous-plaît, Paris, Flammarion (collection Pour les jeunes), 1955.

T. TRILBY, Kounto et ses amis, Paris, Flammarion (collection Pour les jeunes), 1956.

T. TRILBY, Paris-Londres, Paris, Flammarion (collection Pour les jeunes), 1956.

VOYER Karine-Marie, Trilby, un auteur à succès pour la jeunesse, 1875-1962 : sa vie, son cuvre, Paris, éditions du Triomphe, 1997. 


\section{NOTES}

1. La biographie de l'auteur reste assez difficile à établir. Les notices qui lui sont consacrées dans les différents dictionnaires d'auteurs de littérature enfantine donnent des renseignements contradictoires. Karine-Marie Voyer, dans Trilby, un auteur à succès pour la jeunesse, ayant eu accès à des archives familiales toujours en main privée, donne une biographie plus complète, mais il n'a pas toujours été possible de vérifier les informations qui y figurent. La responsable du blog «Au bon vieux temps de la Semaine de Suzette " a accepté de nous fournir certains des documents dont elle s'est servie pour rédiger la notice biographique de l'auteur sur son site (http:// nouvellesuzette.canalblog.com/archives/auteur_ttrilby/index.html [consulté le 25 août 2018]). Nous avons également consulté le dossier de Légion d'honneur de l'auteur (Archives nationales, base Léonore, dossier 19800035/1483/72347, disponible en ligne http://www2.culture.gouv.fr/public/mistral/leonore_fr [consulté le 25 août 2018]), son dossier d'auteur de la Société des gens de lettres, dont les archives sont déposées aux Archives nationales (Archives nationales 454 AP 561) ainsi que des documents la concernant dans les archives de la Croix-Rouge, mis à disposition par Mme Virginie Alauzet, chef de la mission archives et documentation de la Croix-Rouge.

2. http://gallica.bnf.fr/ark:/12148/bpt6k65748700/f127.item.r=trilby

3. (http://www.culture.gouv.fr/LH/LH350/PG/FRDAFAN84_019800035v2830667.htm )

4. Ordre $\mathrm{n}^{\circ}$ 23.187D, 19 octobre 1919 : «Madame Delhaye, infirmière major, a rendu les plus éminents services de 1916 à 1919, comme directrice de l'hôpital chirurgical des réformés $\mathrm{n}^{\circ} 1$. S'est distinguée par son dévouement et son sang-froid, notamment pendant la période d'opérations du printemps 1918, où elle est restée à son poste nuit et jour, descendant elle-même les mutilés à la cave pendant les bombardements ", K.M. Voyer, Trilby, un auteur à succès pour la jeunesse, annexe 2, p. 91.

5. http://gallica.bnf.fr/ark:/12148/bpt6k9687711v/f21.item.r=trilby

6. Archives Croix-Rouge française: Fonds Procès-verbaux des élections départementales et locales (1940-2008) (en cours de cotation), communiqué par Madame Virginie Alauzet.

7. K.-M. Voyer, Trilby, un auteur à succès pour la jeunesse, p. 13. Nous n'avons pas pu vérifier cette information.

8. L'auteur ne s'est jamais expliqué sur le choix de son pseudonyme qu'elle utilise également pour ses activités charitables. Karine-Marie Voyer formule plusieurs hypothèses sur l'origine de ce nom de plume, sans qu'aucune paraisse plus probable qu'une autre.

9. N. Louis, «Exemplum ad usum et abusum : définition d'usages d'un récit qui n'en a que la forme », p. 17-36.

10. K.-M. Voyer, Trilby. Un auteur à succès pour la jeunesse, p. 67.

11. T. Trilby, Paris-Londres, p. 68.

12. Cité par N. Louis, «Exemplum ad usum et abusum : définition d'usages d'un récit qui n'en a que la forme », p. 25.

13. T. Trilby, Une sainte, des démons et Kiki, p. 123.

14. V. Propp, Morphologie du conte, trad. par Claude Ligny.

15. T. Trilby, Titi la carotte et sa princesse, p. 34. 
16. Sur cette question et son influence sur les écrivains de romans de formation, voir entre autres D. Pernot, Le Roman de socialisation 1889-1914.

17. T. Trilby, Cordon, s'il vous plaît, p. 19.

18. Ibid., p. 17-18.

19. Id.

20. P. ory, " "Signe de Piste" : le pays perdu de la chevalerie », p. 72-81.

21. A. Renonciat (dir.), Livre, mon ami. Lectures enfantines, 1914-1954, exposition, présentée à la bibliothèque Forney du 10 septembre au 19 octobre 1991, et à la mairie du Ve arrondissement du 19 novembre au 22 décembre 1991.

22. Pseudonyme de Germaine de Bournazel.

23. C.-A. Parmegiani, Les Petits Français illustrés, 1860-1940: l'illustration pour enfants en France de 1860 à 1940, les modes de représentation, les grands illustrateurs, les formes éditoriales.

24. Cité par E. Constans, Ouvrières des lettres, p. 121. Remarquons que le discours, dans la droite ligne de l'abbé Bethléem et des discours critiques catholiques, met en premier lieu en avant la qualité morale des œuvres, avant leur qualité littéraire qui apparaitt secondaire. Sur cette question, voir A. Renonciat, "Catholic Criticism of Children's Literature at the Beginning of the $20^{\text {th }}$ Century in France », p. 355.

25. T. Trilby, Kounto et ses amis, le P. Marie à Kounto, p. 46.

26. L'assimilation du mal à une maladie est constante dans l'œuvre de Trilby: voir par exemple D'un palais rose à une mansarde, Le Petit Monsieur Vincent ou encore La Grande découverte.

27. D. Pernot, Le Roman de socialisation, p. 81.

28. D'un palais rose à une mansarde, p. 70, 111, 131-132.

29. T. Trilby, Totor et Cie, p. 74-77.

30. Ibid., p. 95.

31. Ibid., p. 164.

32. T. Trilby, Cordon, s'il vous plaît, p. 168.

33. T. Trilby, Une sainte, des démons et Kiki, p. 6-7.

34. L'encyclique Rerum Novarum de Léon XIII (15 mai 1891) est reprise par ses successeurs Pie X (1903-1914), Benoît XV (1914-1922), mais surtout Pie XI (1922-1939) et Pie XII (1939-1958).

35. G. Pozzi, «De l'expérience narrative à l'expérience morale: quel rôle pour la littérature pour la jeunesse? ", Raison publique.fr, 30 octobre 2010, disponible en ligne : http://www.raison-publique.fr/article371.html [consulté le 11 septembre 2018].

36. B. Bettelheim, Psychanalyse des contes de fées. 


\section{RÉSUMÉS}

L'œuvre de T. Trilby (1875-1962), auteur de romans pour la jeunesse publiés principalement dans la collection « Pour les jeunes » de Flammarion entre 1935 et 1961, dessine au fil des publications un monde cohérent à l'usage des enfants, destiné à transmettre des savoir-vivre et des savoir être plutôt que des savoirs scolaires. Ces romans initiatiques, qui ont connu un grand succès, sont représentatifs d'une conception normative de la littérature pour la jeunesse. Leur trame narrative reprend ainsi les éléments traditionnels d'une littérature éducative autoritaire, recueils d'exempla, catéchismes ou paraphrases des Évangiles. Ces livres destinés aux enfants s'insèrent donc dans une stratégie éducative plus large des familles de la bourgeoisie conservatrice et catholique, s'intégrant dans les processus familiaux de transmission informelle de savoirs, savoir-vivre et savoir être propres à une classe sociale. Ce faisant, ces lectures occupent, dans la formation des enfants, une place à la fois complémentaire et décalée par rapport à l'école, complétant d'une éducation morale l'instruction scolaire.

\section{AUTEUR}

\section{MATHILDE HALLOT-CHARMASSON}

Conservateur des bibliothèques, responsable des manuscrits au département des Arts $\mathrm{du}$ spectacle de la Bibliothèque nationale de France 


\title{
Les Instructions du CTHS pour la
} Recherche des antiquités dans le nord de l'Afrique (1890) et l'histoire de l'archéologie du Maghreb

\author{
Roger Hanoune
}

Cet article est consacré à un livre qui a été le manuel, et le seul, d'archéologie de l'Afrique du Nord pour plusieurs générations de chercheurs, les Instructions adressées par le Comité des Travaux historiques et scientifiques aux correspondants du Ministère de l'Instruction publique. Recherche des antiquités dans le nord de l'Afrique. Conseil aux archéologues et aux voyageurs (Paris, Leroux, 1890) (fig. 1). Petit par son format (12,5x18,5 cm), il comprend 252 pages, avec de nombreuses illustrations (au trait le plus souvent et déjà quelques photos), et une carte dépliante de l'Afrique. Il a été publié de façon sinon anonyme (les paragraphes ou chapitres sont signés), du moins collective par le CTHS en 1890; il n'est pas rare: les bibliothèques classiques en ont souvent plusieurs exemplaires (le mien provient d'un "désherbage " de la bibliothèque de l'École française de Rome dans les années soixante-dix et il a dû servir à de nombreux Farnésiens). Il a été édité en deux formats, grand (in $8^{\circ}$ ) pour bibliothèques et petit (in $12^{\circ}$ ) pour emporter sur le terrain, comme l'a expliqué dès sa sortie un compte-rendu un peu publicitaire paru dans la Revue archéologique de 1891 et dû peut-être à un des auteurs, Salomon Reinach ${ }^{1}$. 
Fig. 1. - Page de titre.

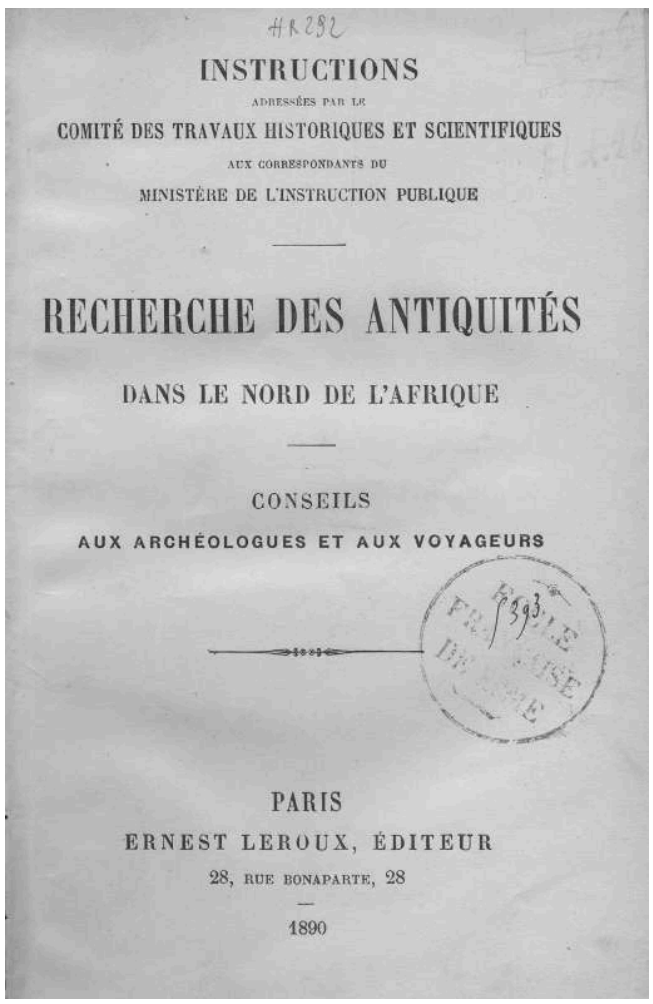

D’après Instructions adressées par le Comité des Travaux historiques et scientifiques...

2 Sur ces Instructions, J.-P. Laporte a déjà presque tout dit sur le site « Tabbourt » (http:// www.tabbourt.com/) :

«Ces Instructions ont été le livre de chevet (voire le manuel sur le terrain) de beaucoup d'archéologues de la fin du XIX ${ }^{e}$ siècle et du début du xxe. Bien qu'il soit aujourd'hui totalement dépassé, il est intéressant de savoir qu'il a été rédigé par les plus importantes autorités scientifiques de la fin du XIX siècle, et de comprendre la manière dont nos prédécesseurs appréhendaient le terrain. »

On l'abordera ici de quatre façons : comme une production du CTHS, comme un livre de science pratique, comme le témoin d'une tradition de littérature scientifique assez curieuse, et enfin comme un moment dans l'histoire de l'archéologie de l'Afrique du Nord.

\section{Une réalisation du CTHS}

4 C'est ce qui est le plus évident. Une des missions fondamentales du CTHS depuis sa création sous la Monarchie de Juillet (1834), à l'époque de la conquête de l'Algérie, et encore plus à partir de l'établissement du protectorat en Tunisie (1881), est de s'occuper d'archéologie africaine, ce qui va être pendant longtemps une sorte de chasse gardée scientifique de la France coloniale.

5 Pour nous rapprocher de la date de nos Instructions, citons le programme du congrès du CTHS de 1885 à la Sorbonne (II Section -Archéologie- § 6) qui se trouve dans la circulaire préparatoire du 24 août 1884 : 
"Signaler les édifices antiques de l'Afrique, tels que arcs de triomphe, temples, théâtres, cirques, portes de ville, tombeaux monumentaux, aqueducs, ponts, etc. et dresser le plan des ruines romaines les plus intéressantes. ${ }^{2}$ »

6 On peut considérer que les Instructions sont l'outil pratique pour réaliser ce programme et il est dû à une institution interne du CTHS, une « commission » qui se met en place à cette époque.

7 Sous l'influence de Charles Tissot, cette institution est créée par un arrêté du 18 décembre 1884, et rattachée à la Section d'archéologie. Sous la présidence d'Ernest Renan, elle est chargée de « recevoir les communications relatives à l'archéologie de la Tunisie ", puis de recueillir aussi l'archéologie de l'Algérie. Tout de suite Salomon Reinach, son secrétaire, est chargé de rédiger des instructions ${ }^{3}$. En novembre 1888, le Ministre de l'Instruction publique fait savoir que « le moment paraît venu de faire de la Commission l'instigatrice et le centre des recherches archéologiques dans toute l'Afrique du Nord», et la commission charge l'orientaliste Philippe Berger, l'épigraphiste René Cagnat et l'archéologue universel Salomon Reinach de rédiger les instructions destinées aux personnes intéressées: ce sont les membres des sociétés savantes (il y en a en Algérie depuis la «Société archéologique du Département de Constantine » en 1852), les officiers (surtout membres des brigades topographiques), les voyageurs et amateurs, et même des religieux comme le P. Delattre en Tunisie (mais son cas suscite quelque discussion).

Enfin, la Commission devient, en janvier 1889, le comité ou la commission «de publication des documents archéologiques en Tunisie et en Algérie ». C'est ce qu'on a appelé « la commission de l'Afrique du Nord», sur laquelle le point a été fait de façon limpide dans un article fondamental de M. Desanges en $1996^{4}$. C'est cette préhistoire de la commission qui correspond à la période de rédaction de nos Instructions ${ }^{5}$. Mais il faut noter que, du côté tunisien, le Service des antiquités avait déjà été institué, avec une loi de gestion et protection du patrimoine, et qu'en février 1885 son directeur, de La Blanchère, avait publié des Instructions pour la recherche des antiquités et les travaux de géographie comparée en Tunisie, adressées spécifiquement à Messieurs les Officiers de la division d'occupation (Imprimerie nationale, 18 p.).

\section{Les auteurs et leurs textes}

Que trouve-t-on dans les Instructions de 1890? Des textes dus à des auteurs qui connaissent bien l'Afrique, des savants confirmés, mais qui sont souvent encore jeunes. Salomon Reinach a 32 ans, Ernest Babelon 36, René Cagnat 38, l'architecte Henri Saladin 39, l'orientaliste Philippe Berger 44 ; seul le géographe Henri Duveyrier a déjà 50 ans. Deux auteurs qui sont un peu à part donnent des textes très spécialisés, le général Victor Derrécagaix (1933-1915) sur la topographie et Ernest Babelon (1854-1924) sur la numismatique de toute période ${ }^{6}$. On a l'impression que le maitre d'œuvre du livre est René Cagnat, mais c'est peut-être une illusion (ce serait plutôt Reinach, secrétaire de la Commission), illusion due à l'importance de ses travaux africains à venir ; en tout cas ce n'est pas le plus important des auteurs, au moins en nombre de pages ; c'est Saladin qui, traitant d'architecture de toutes époques, a écrit 80 pages ; Duveyrier, Cagnat et Berger ont rédigé respectivement 24,26 et 31 pages, Reinach seulement 16 ; le général Derrécagaix a donné 6 pages sur la topographie ; le cas de Babelon est particulier car, à ses 22 pages de numismatique, s'ajoutent autant de planches de dessins de monnaies. 
10 L'introduction définit le public visé : «l'officier qui traverse un pays, soit pour y faire des relevés topographiques, soit pour s'occuper des affaires indigènes, le forestier en tournée, l'ingénieur des ponts et des mines, l'agent du service des domaines, l'administrateur de communes mixtes » et « les voyageurs amateurs » (nous dirions les touristes cultivés) qui sont déjà capables de faire des photographies. Elle explique ensuite la vocation de l'ouvrage qui est d'envoyer des documents nouveaux au CTHS et de fournir à la science des pièces utilisables grâce à la photographie et à l'estampage pour les inscriptions, dont les techniques sont expliquées, et au relevé de terrain (le matériel nécessaire est bien indiqué et impressionnant) (fig. 2 et 3). L'introduction fournit aussi un abrégé d'histoire ancienne et d'archéologie, qui est un simple rappel pour des lecteurs qui semblent avoir un bon fonds de culture classique traditionnelle.

Fig. 2. - Le relevé : instruments et principes.

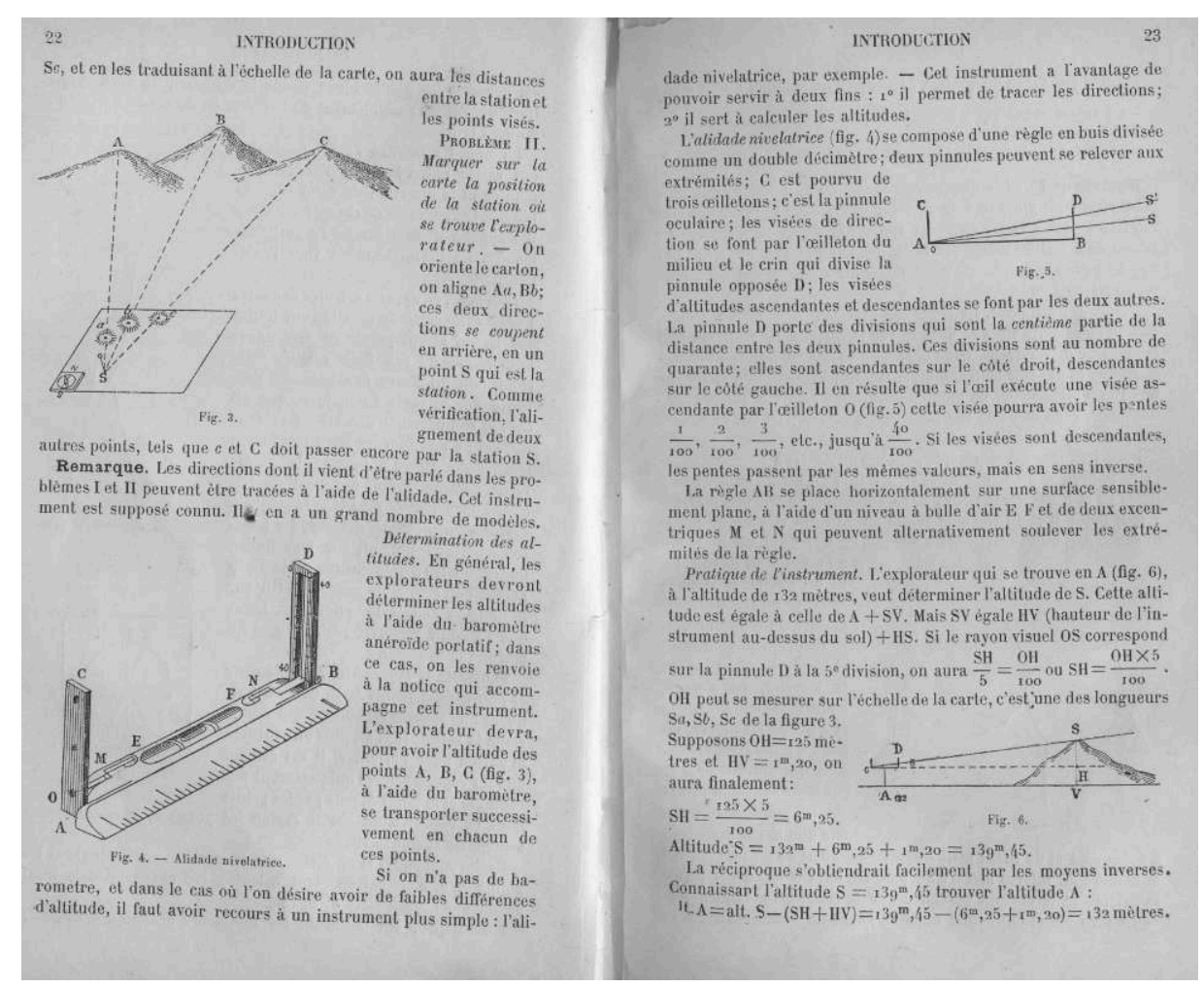

D'après Instructions adressées par le Comité des Travaux historiques et scientifiques... 
Fig. 3. - Le relevé coté.

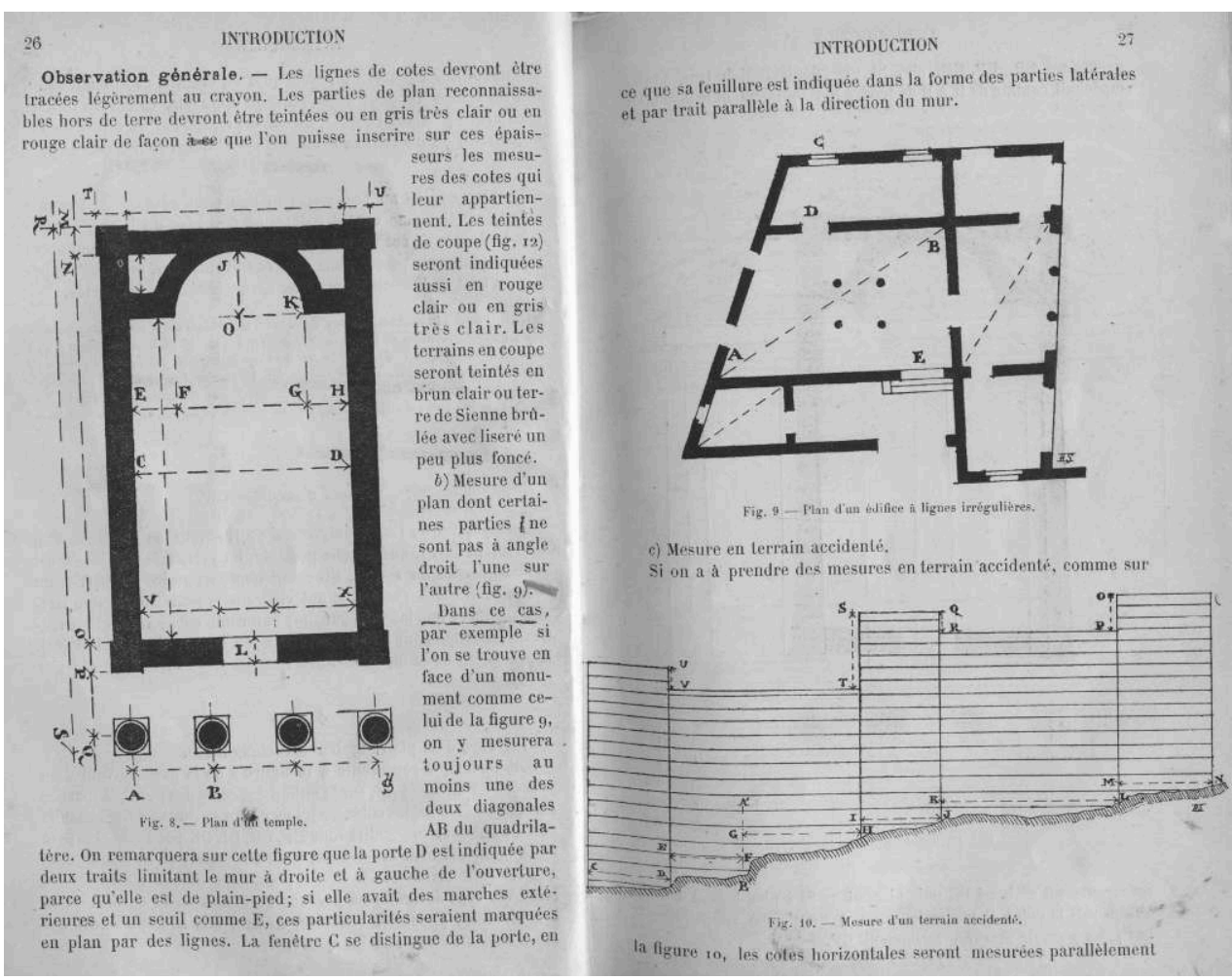

D’après Instructions adressées par le Comité des Travaux historiques et scientifiques...

11 Le livre est divisé en deux parties très différentes: la première, la plus copieuse (p. 35-215), fournit des connaissances scientifiques, plus ou moins poussées, sur les grandes périodes historiques, et des dessins souvent devenus classiques, (la troisième partie consacrée à l'époque romaine est de beaucoup la plus importante avec ses 50 pages). La première section sur la préhistoire est due à $\mathrm{S}$. Reinach et présente les vestiges mégalithiques avec beaucoup de comparaisons européennes. À partir de la suivante, les sections sont organisées sur le même plan: d'abord les inscriptions, ensuite les monuments. Dans la deuxième section, c'est d'abord Duveyrier, l'explorateur du Sahara qui va mourir en 1892 peu après la parution des Instructions, qui décrit les inscriptions libyques en grand détail et ce qu'on sait des Berbères, de l'Égypte aux Canaries ; c'est ensuite Philippe Berger et Henri Saladin qui exposent les textes et les monuments de l'époque punique et néo-punique (fig. 4 et 5). La troisième section (l'Afrique romaine, vandale et byzantine) est surtout due à Cagnat et Saladin : c'est la plus classique, c'est aussi la plus utile pour une région où les vestiges du Haut et du Bas Empire abondent, et les auteurs fournissent des explications assez détaillées sur ce qu'il est possible de voir, surtout des constructions publiques (il n'y a pas encore vraiment de maisons fouillées à cette date) (fig. 6, 7, 8). La dernière section chronologique («IV Hébreu et Arabe ») est très brève et assez curieuse : Berger y présente une inscription funéraire juive d'Alger de 1792 un peu incongrue ici, Duveyrier et Saladin traitent en quelques pages des inscriptions et des monuments arabes : ce n'est visiblement pas ici le sujet des Instructions et c'est ce qui explique que, dans la réédition des Instructions en 1929, il y aura un complément dû à William Marçais pour les vestiges d'époque musulmane. La $\mathrm{V}^{\mathrm{e}}$ et dernière section est consacrée à la numismatique de toutes époques, y compris arabe, et se présente de façon très pratique, avec beaucoup de 
dessins qui permettent d'interpréter les trouvailles (sur mon exemplaire les pages consacrées aux pièces romaines et à leurs légendes ont visiblement été bien utilisées).

Fig. 4. - L'épigraphie libyque.

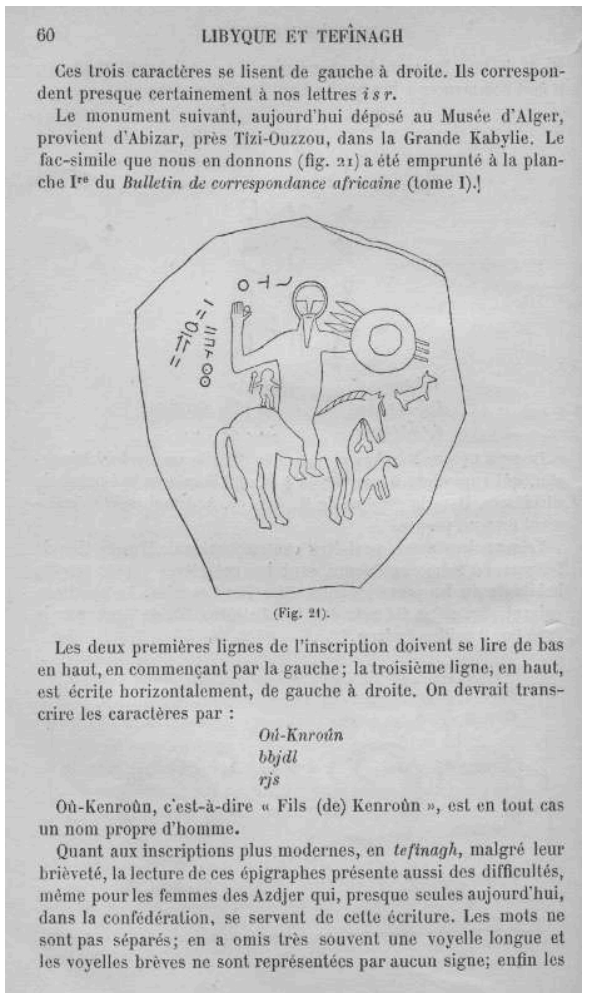

D’après Instructions adressées par le Comité des Travaux historiques et scientifiques... 


\section{Fig. 5. - L'épigraphie romaine.}

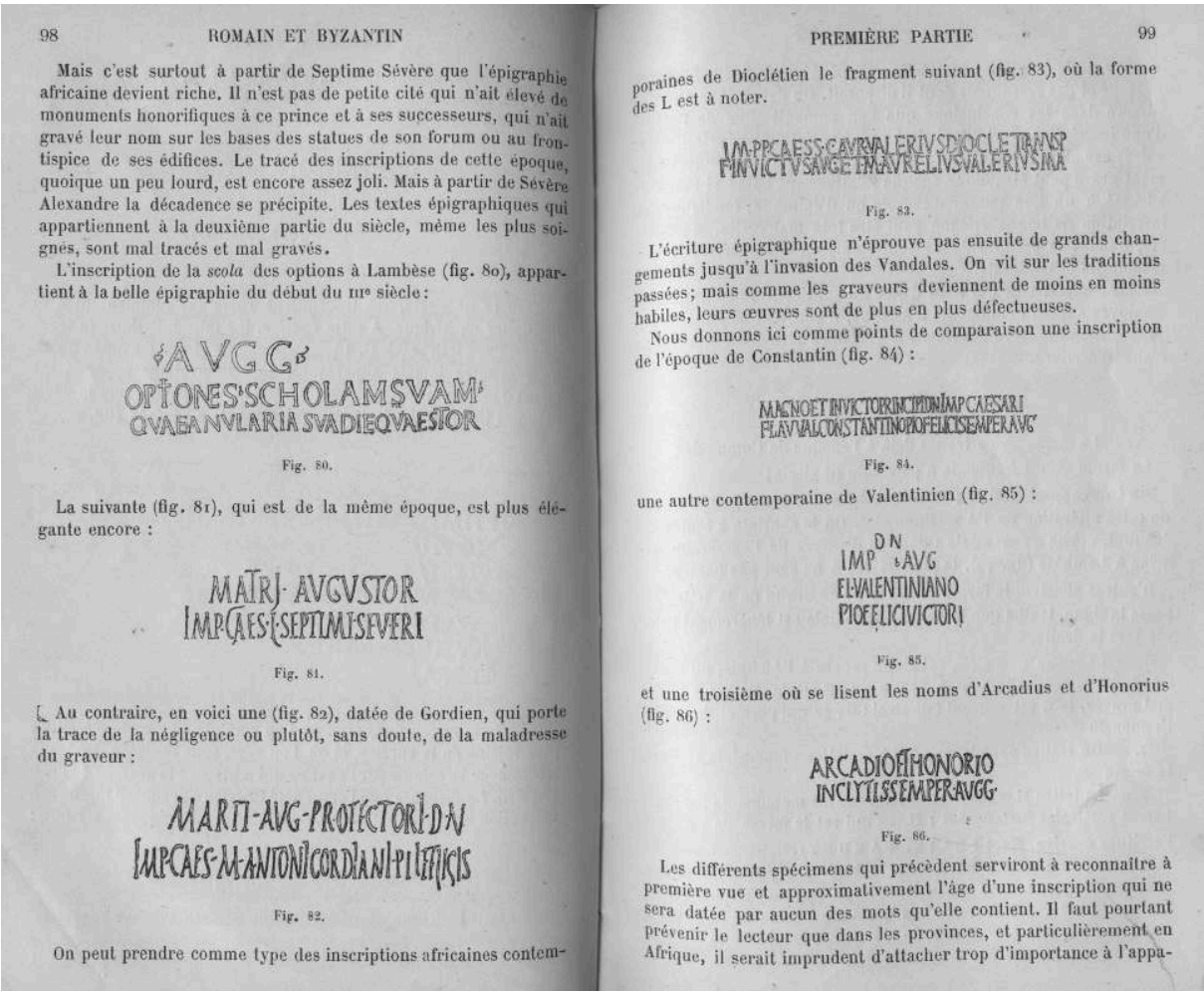

D’après Instructions adressées par le Comité des Travaux historiques et scientifiques...

Fig. 6. - L'architecture : le mausolée de Dougga avant reconstruction.

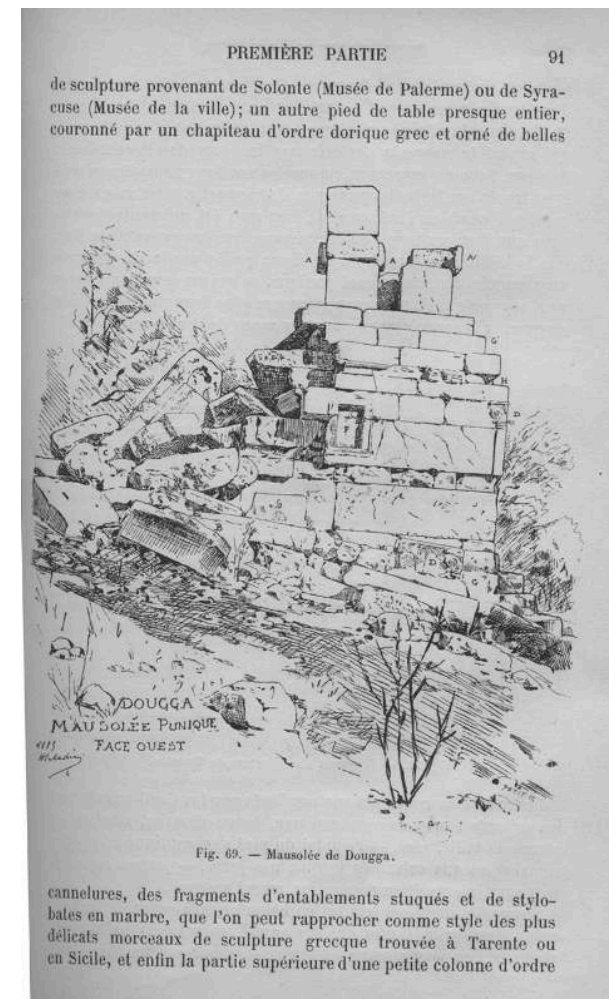

D’après Instructions adressées par le Comité des Travaux historiques et scientifiques... 
Fig. 7. - L'architecture : huileries.

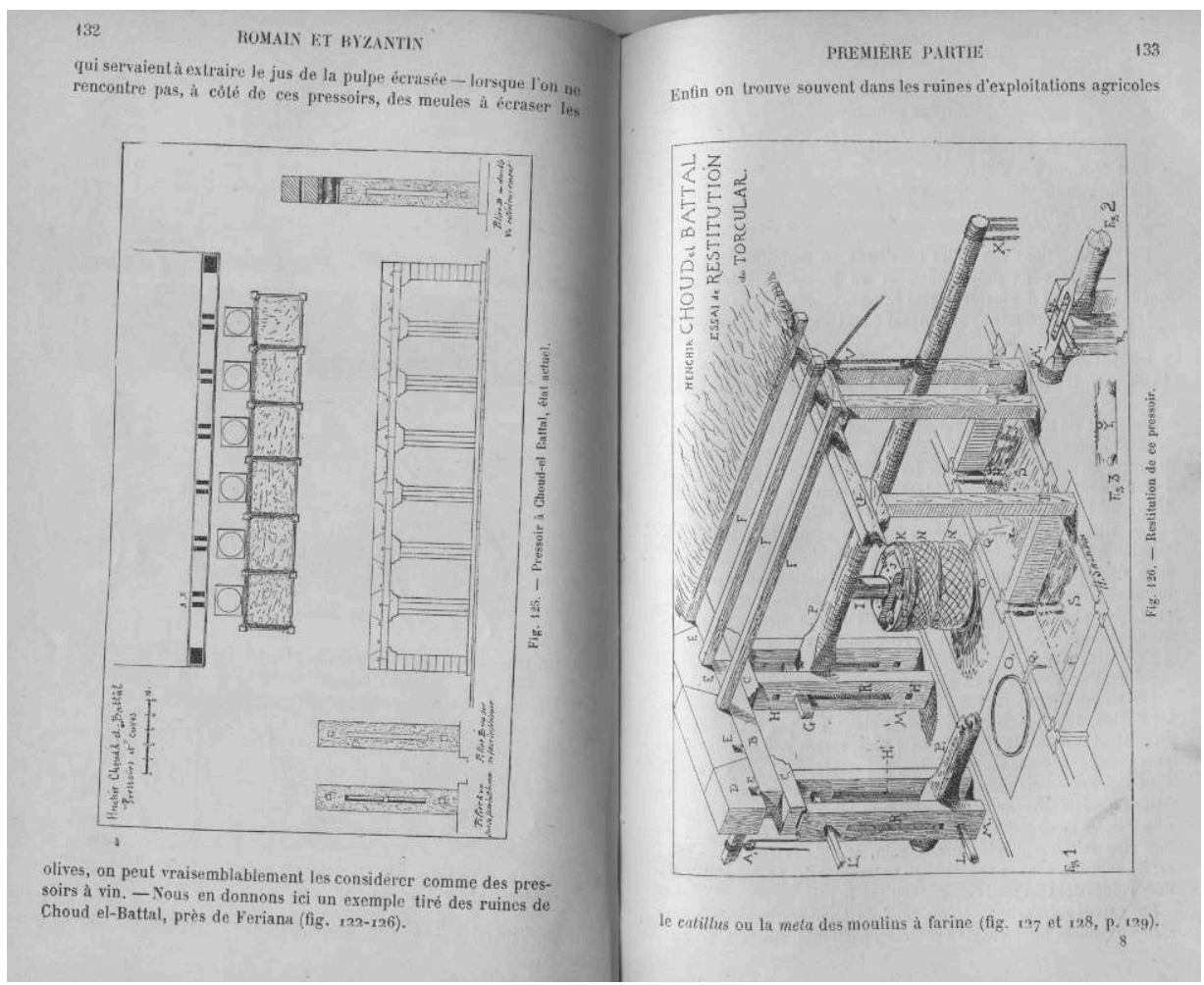

D’après Instructions adressées par le Comité des Travaux historiques et scientifiques...

Fig. 8. - L'architecture : tombes en cupules.

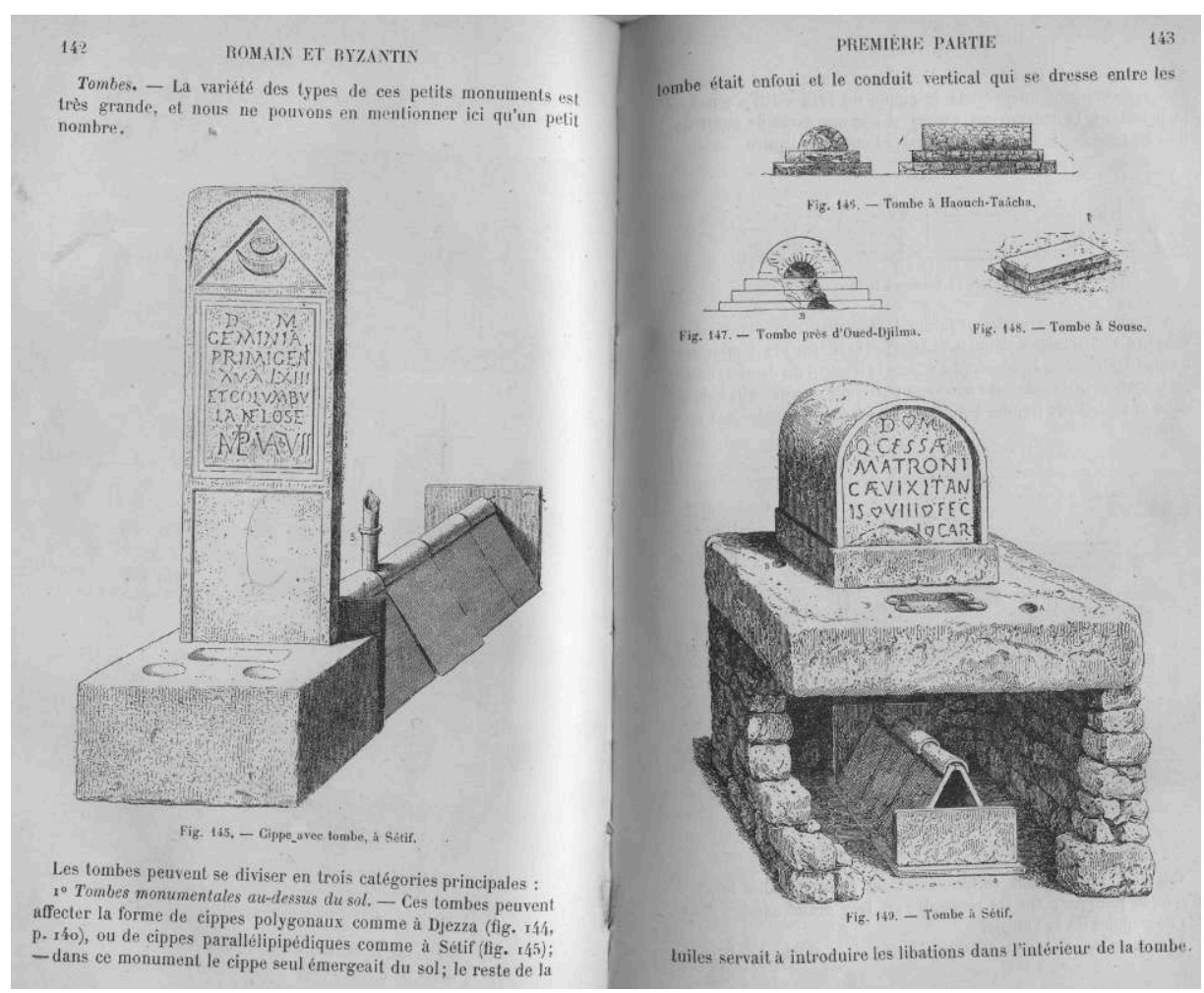

D’après Instructions adressées par le Comité des Travaux historiques et scientifiques... 
12 La seconde partie de l'ouvrage est très réduite (p. 217-231) et elle comporte des renseignements qui n'ont plus d'intérêt pour nous (les dépôts, collections et musées à visiter, les livres à consulter et à emporter, les bibliothèques locales à visiter). Mais les premières (p. 217-223) sont encore instructives et donnent beaucoup de conseils : que faire sur le terrain, par exemple dans des ruines antiques (henchir)? Ce qu'on peut demander aux « indigènes », comment on a pu préparer sa visite et ne pas perdre son temps à relever ce qui est déjà connu, comment passer du connu à l'inconnu (par exemple par un supplément de fouille), comment on peut rechercher des vestiges antiques dans les maisons ou cimetières arabes, comment il est nécessaire de procéder avec discrétion et délicatesse, etc. Tout à la fin, deux textes fondamentaux pour la topographie historique, la Table de Peutinger et l' Itinéraire d'Antonin, mettent directement le lecteur en contact avec la documentation antique (toponymes et distances).

\section{Une tradition de littérature pratique}

13 Les Instructions ne sont ni un grand ouvrage scientifique (comme Cagnat en a par la suite rédigé ou dirigé, dans les champs de l'épigraphie ou de l'histoire, de l'archéologie ou de la topographie), ni un guide touristique : Cagnat avait déjà publié ses missions en Tunisie de 1881 à 1883, dans son rapport de 1885 (son compagnon de voyage, l'architecte Saladin, l'avait fait dans son rapport de 1887) ; puis il avait repris ce texte dans leur feuilleton du Tour du Monde de 1884 à 1893, et enfin dans le volume du Voyage en Tunisie de $1894^{7}$; vers la même date, il a aussi donné un Lambèse dans une série de Guides en Algérie à l'usage des touristes et des archéologues chez le même éditeur Leroux (Paris, $1893 ; 72$ pages).

14 C'est donc un document censé être normatif, comme des instructions données au chargé d'une mission; en réalité on reste plutôt dans le registre des conseils pratiques ou des informations scientifiques utiles à la compréhension d'un domaine ${ }^{8}$. Il faut se dire qu'il a été rédigé dans une époque d'organisation de la recherche (en 1885 déjà en Tunisie, bien avant la France) qui sera réalisée sur place par les chargés de mission et surtout par les correspondants des institutions centrales, et qu'il y a donc eu, au CTHS et en général dans l'administration française, une tradition de ces textes utilitaires et programmatiques. Un modèle en est le volume de 1858, les Instructions du Comité historique des arts et monuments. Architecture gallo-romaine et architecture du Moyen Âge, dues à Mérimée inspecteur général des Monuments Historiques jusqu'en 1860, et à Lenoir, Leprévost et Lenormant, suivies par les Instructions sur la Musique, dues à Bottée de Toulmon (Paris, Imprimerie Impériale, 244 p., ill., 7 pl.) : le programme du ministre de l'Instruction publique est clair: «il s'agit de dresser la carte monumentale de la France» dans les 37200 communes de l'époque, en dirigeant une armée de correspondants locaux pour qu'ils travaillent de façon coordonnée avec le même vocabulaire pour éviter toute ambiguïté).

15 Nos Instructions de 1890 sur l'archéologie du Maghreb s'inscrivent donc dans une collection de textes qui les ont précédées ou suivies. Auparavant, il y avait eu par exemple les publications de Léon Rénier, "Instructions pour la recherche des Antiquités en Algérie », (16 p., publiées dans la Revue algérienne et coloniale, nov. 1859), ou du Général Faidherbe et de Topinard, "Instructions sur l'anthropologie de l'Algérie»(parues dans les Matériaux pour l'histoire primitive de l'Homme, t.9, 1873, 
p. 473-478). Après 1890, on notera surtout la notice de P. Pallary, Instructions pour les recherches préhistoriques dans le nord-ouest de l'Afrique, Alger 1909, souvent citée par les spécialistes, ou l'opuscule de Stéphane Gsell (mais publié sans nom d'auteur), Instructions pour la conduite des fouilles archéologiques en Algérie, Alger, Jourdan, 1901 (publié par le Gouvernement général de l'Algérie, Service des Monuments historiques) : ce dernier texte du au grand historien de l'Afrique antique commence à s'écarter de l'esprit des Instructions du CTHS en s'intéressant beaucoup plus à la pratique de l'archéologie de terrain et à la conduite des fouilles, avec nombre de conseils encore très utiles sur la rigueur de l'enregistrement ou sur l'intérêt historique de toute trouvaille (qui ne doit pas devenir un "bibelot d'étagère »), et même une certaine préfiguration de la stratigraphie et des «étages chronologiques » (qui n'empêche pas le désastreux conseil de fouiller en suivant les murs). Gsell n'oublie pas à la fin (p. 14-15) de recommander aux "personnes qui désireront acquérir les notions nécessaires pour faire des études archéologiques en Algérie» de se procurer la petite édition des Instructions du CTHS.

Le genre des Instructions se poursuit jusqu'à peu avant la Seconde Guerre mondiale: citons par exemple les Instructions sommaires pour la collecte d'objets ethnographiques, Paris, Palais du Trocadéro, 1931 (d'après les cours de l'Institut de l'Institut d'ethnologie par Paul Rivet, Marcel Mauss, M. Lévy-Bruhl), ou les Instructions d'enquête linguistique: instructions pour les voyageurs, établies par Marcel Cohen, Paris, Institut d'ethnologie de l'Université de Paris $1928^{\circ}$. D'une certaine façon, les Instructions pour Recherche des antiquités dans le nord de l'Afrique ont aussi eu une vocation militaire particulière: on a vu que dès l'origine elles s'adressaient aux officiers qui parcouraient le terrain en Algérie et en Tunisie; Mme Dondin-Payre a aussi repéré son adaptation encore en 1925 au $\operatorname{Maroc}^{10}$. Dans le milieu militaire, ce genre d'informations se diffuse encore sous forme de notices culturelles jusqu'à la guerre d'Algérie (voir par exemple une petite Notice à l'usage des militaires affectés Tunisie, Tunis, s.d.).

\section{L'intérêt des Instructions}

Quel est l'intérêt de ces Instructions de 1890 ? Entre l'attendrissement pour cette époque ancienne où la photographie est encore une grande nouveauté et où la mosaïque ne fait qu'une toute petite apparition (p. 222 : il faut la réenterrer), et l'exaspération devant le colonialisme naïf du temps, ou, du point de vue scientifique, devant cette archéologie où la stratigraphie est le plus souvent encore à découvrir et où on peut faire des trous où l'on veut, où la céramique n'a d'intérêt que pour ses estampilles (p. 107), et où le mérite ou même le but de l'archéologie est surtout de procurer des inscriptions, on pourrait penser qu'il n'y a plus rien à en tirer, et que leur valeur n'est qu'historiographique.

D'abord, ces Instructions ont encore un intérêt scientifique : on peut mettre au défi un spécialiste actuel d'archéologie africaine de ne pas faire dans ce texte au moins une découverte qui l'intéressera. Pour mon compte, j'ai admiré que Reinach donne à la fig. 15 une représentation de stratigraphie (avec des réflexions sur sa nécessité p. 37), ou qu'il montre p. 41 que "mégalithique » n'est pas synonyme de " préhistorique » (il y a des dolmens africains d'époque classique), que Berger montre que des inscriptions funéraires donnent bizarrement des durées de vie multiples de 5 et explique qu'on comptait aussi par lustres de 5 ans (p. 74), qu'il soit recommandé de ne pas ramener des 
stèles puniques (il y en a déjà tellement au Louvre et au musée Alaoui), que les pages de Cagnat sur la graphie romaine des inscriptions (p. 96 sq) soient encore si utiles (elles mériteraient toujours de se retrouver dans un Manuel d'épigraphie romaine comme celui de J.-M. Lassère ( $2^{e}$ éd. 2007), ou en architecture que les tubes à voûtes soient si bien décrits p. 122 (et signalés comme toujours utilisés), etc.

Ensuite, on admirera la qualité des contributions, et l'exigence des auteurs envers leurs futurs collaborateurs qui ne se promèneront pas mais travailleront sans préjugés; il leur faudra apprendre à faire un petit relevé de maison ou de moulure architecturale, à déchiffrer une inscription libyque, punique ou arabe, ou une monnaie byzantine; l'ouverture d'esprit demandée au visiteur ou au chercheur qui ne doit pas être seulement classicisant est tout à fait remarquable et tranche avec la spécialisation d'une époque plus récente. Au nom de cet amour de la science, on pardonnera le cocorico (le seul de tout le livre) de la dernière ligne de la p. 231, en l'honneur de ceux qui ont travaillé «pour le plus grand bien de la science française et de l'Afrique française! ».

Évidemment ces Instructions sont datées, et ne se comprennent que dans cette période de mise en place des institutions culturelles et patrimoniales, entre le second Empire et la Première Guerre mondiale (services des antiquités, musées, législation) et dans le cadre bien connu de l'archéologie de l'époque coloniale, pour l'histoire de laquelle on peut désormais renvoyer à de nombreuses études ${ }^{11}$.

21 Est-ce que le succès de ce livre n'a pas finalement eu des conséquences négatives pour la recherche archéologique africaine de la première moitié du XIX siècle ? Alors que la France avait le Manuel d'archéologie préhistorique, celtique et gallo-romaine de Déchelette et Grenier (1904-1960), il n'y avait rien de tel pour l'Afrique (avant le vol. III, X, VII de l' Enciclopedia Classica: la Topogragrafia e archeologia dell'Africa Romana de Romanelli de 1970). Ce serait injuste de le lui reprocher : si on n'a pas eu l'ouvrage unique, l'essentiel de la matière africaine est passé dans le Manuel d'archéologie romaine de Cagnat et Chapot, 1917-1920), et dans les Monuments antiques de l'Algérie de Gsell (1901). Mais aucun n'a l'ampleur thématique des Instructions. On penserait plutôt à mettre dans leur filiation certes très lointaine les Programmations de l'archéologie au Ministère de la Culture qui visent à organiser la recherche depuis 1985 (texte de C. Goudineau dans La recherche archéologique en France 1985-1889, Ministère de la culture, 1990, p. 5-7).

Il y a eu en 1929 une réédition des Instructions sous le même titre, chez le même éditeur Leroux), une "édition complétée par des additions ", dont surtout un complément sur les antiquités islamiques par Georges Marçais; mais le nombre de pages est resté le même (250), et le tirage assez confidentiel (un seul exemplaire à la BnF 16-V-19745). À la veille du centenaire de la conquête de l'Algérie, à une époque de professionnalisation de l'archéologie (enseignement universitaire de l'histoire ancienne, mise en place de services, de débats sur le cadre juridique de ce qu'on n'appelle pas encore le patrimoine, et de réflexions qui dans 10 ans mèneront à la loi Carcopino, le moment était passé. Une curiosité : en 2013 un éditeur algérien a sorti un petit volume intitulé Tifinagh et autres inscriptions, vestiges et antiquités en Afrique du Nord, avec cinq auteurs qui sont toujours Reinach, Duveyrier, Berger, Saladin et Cagnat (Alger, Belles Lettres- 
Études, 2013) : c'est encore un extrait clairement indiqué de nos Instructions, désormais complétement dépassées.

\section{BIBLIOGRAPHIE}

Coll., Instructions adressées par le Comité des Travaux historiques et scientifiques aux correspondants du Ministère de l'Instruction publique. Recherche des antiquités dans le nord de l'Afrique. Conseil aux archéologues et aux voyageurs. Paris, Leroux, 1890, 252 p., une carte dépliante (deuxième édition, Paris, Leroux, 1929).

CAGNAT René, SALAdIN Henri, Voyage en Tunisie (1894), Éd. François Baratte, Paris, CTHS, 2005. CHARMES Xavier, Le Comité des travaux historiques et scientifiques (histoire et documents). T. II, actes officiels relatifs au CTHS, Paris, 1886.

DESANGES Jehan, « La Commission dite "de l'Afrique du Nord” au sein du CTHS : origine, évolution, perspectives ", dans LANCEL Serge (éd.), Numismatique, langues, écritures et arts du livre, spécificité des arts figurés, (actes du VII Colloque international « Histoire et archéologie de l'Afrique du Nord » réunis dans le cadre du $121^{e}$ Congrès des Sociétés historiques et scientifiques, Nice, oct. 1996), Paris, CTHS, 1999, p. 11-24.

DRIDI Hédi, Mezzolani Andreose Antonella (éd.), Under Western Eyes, Approches occidentales de l'archéologie nord-africaine (XIXe-XXe siècle), Bologne 2016.

FÉVRIER Paul-Albert, Approches du Maghreb romain, Aix-en-Provence, Edisud, 1989, vol. I, chap. I

(Les étapes de la recherche. Colonisation et connaissance).

GRAN-AYMERICH Ève, Naissance de l'archéologie moderne 1798-1945, Paris, CNRS, 1998, (p. 146-8 ; en général chap. 4-6).

GRAN-AYMERICH Ève, Dictionnaire biographique d'archéologie (1798-1945), Paris, CNRS, 2001.

GUTRON Clémentine, L’Archéologie en Tunisie, Paris, Karthala, 2010.

LANDES Christian, «À propos d'un rapport “confidentiel” sur le musée de Carthage rédigé en juillet 1903 par Paul GAUCKLER, directeur des Antiquités et Arts de la Régence de Tunis, conservé aux archives du musée d'Archéologie nationale », Antiquités nationales, 40, 2009, p. 227-248, 22 fig. OULEBSIR Nabila, Les usages du patrimoine : monuments, musées et politique coloniale en Algérie (1830-1930), Paris, Éd. de la Maison des sciences de l'Homme, 2004.

REY Sarah, Écrire l'histoire ancienne à l'École française de Rome (1873-1940), Rome, 2012 (Coll. EFR 462).

\section{NOTES}

1. Je remercie pour leur aide Jean-Pierre Laporte (http://www.tabbourt.com/ et communication du 27 août 2006) et Monique Dondin-Payre (communication du 27 avril 2005). 
2. Charmes II, 1886, p. 342.

3. Landes 2009, p. 230.

4. Desanges 1996, p. 11-24 (en particulier p. 12-15).

5. Sur ce texte, Gran-Aymerich 2001, p. 128-129 (notice : René Cagnat, 1852-1937).

6. J.-P. Laporte signale un manuscrit aux Archives nationales avec des corrections de Renan, président de la Commission (communication 27 août 2006 : "J'ai trouvé aux Archives nationales, dossier F.17.237, des "Instructions sur la recherche des antiquités et des travaux de géographie comparée par les officiers du corps d'occupation", en 1884, un manuscrit rédigé par Cagnat et des épreuves corrigées de la main de Renan. J'ai repéré mais pas encore vu en F.80.1733 (3) des instructions pour la "Recherche des antiquités" rédigées par Rénier et approuvées par le Prince Napoléon). »

7. Voir l'édition du Voyage en Tunisie donnée au CTHS par F. Baratte, 2005, p. 9-20.

8. On penserait aujourd'hui à un volume comme une Archéologie du Maghreb antique pour les Nuls. On imagine bien Bouvard et Pécuchet (chap. 3, fin) en train de consulter les Instructions comme ils font pour le Guide de Géologie de Bonté.

9. Disponible à l'adresse suivante: http://halley.ens.fr/search S25*frf?/ tInstructions+d\%27enqu\%7bu00EA\%7dte+linguistique+

$\% 3 \mathrm{~A}+$ instructions+pour+les+voyageurs/

tinstructions+denquete+linguistique+instructions+pour+les+voyageurs/-3,-1,0,B/browse

10. M. Dondin-Payre, communication du 27 avril 2005, sur l'adaptation des Instructions « à l'intention des officiers servant au Maroc par un chargé de mission au Service des antiquités de Rabat, J. Colin, qui le présentait au cours des Affaires indigènes de Rabat, sous le titre Instructions pour la recherche des antiquités au Maroc, adressées aux officiers du Service géographique de l'Armée et aux officiers de Renseignements. L'occupation romaine au Maroc ».

11. Par exemple Février 1989 (vol. I, chap. I : Les étapes de la recherche. Colonisation et connaissance) et Gran-Aymerich 1998 (p. 146-8 et en général chap. 4-6) ; et les diverses études de Oulebsir 2004, Gutron 2010, Rey 2012 et Dridi, Mazzolani 2015.

\section{RÉSUMÉS}

Le Comité des travaux historiques et scientifiques a publié au XIX siècle des guides de recherche très spéciaux, presque touristiques (mais sans itinéraires), en réalité très savants, mais aussi très pratiques, pour honnêtes gens et pour professionnels, par exemple les Instructions du Comité historique des arts et monuments (Architecture gallo-romaine. Architecture du Moyen-Âge [par Mérimée]. Musique), 1857. Cette littérature d'une formule originale, technique et culturelle, mérite qu'on s'y intéresse, en particulier les Instructions du CTHS : recherche des antiquités dans le nord de l'Afrique. Conseils aux archéologues et aux voyageurs, 1890 (sans nom d'auteur, en réalité œuvre de René Cagnat). Après avoir présenté l'ouvrage et les disciplines qu'il aborde (initiations à l'histoire et à l'archéologie du Maghreb, fouille, épigraphie, numismatique, religions, etc.), on étudiera son rôle 
dans la création d'une archéologie africaine à l'époque coloniale. On se demandera enfin si ce genre a eu une postérité dans les guides « culturels » actuels.

\section{AUTEUR}

\section{ROGER HANOUNE}

Maître de conférences honoraire en archéologie romaine, Université de Lille - UMR HALMA,

CNRS 8164, membre du CTHS, section Histoire et archéologie des civilisations antiques 


\title{
La presse écrite généraliste contemporaine française : vecteur de transmission de savoirs nouveaux et pas encore fixés?
}

\author{
Annick Batard
}

1 En 1998, dans le magazine d'actualité hebdomadaire Le Point, Jean Guisnel explique à propos du cédérom ludo-éducatif Adi, du nom du personnage éponyme qui est censé aider les enfants dans leur scolarité :

«Après avoir créé leur propre personnage, ils vont se déplacer à partir d'une chambre d'enfant dans cet univers devenu très professionnel, mais aussi se connecter au Web, rejoindre des classes virtuelles pour discuter avec d'autres enfants. Bref, apprendre intelligemment. À voir absolument. ${ }^{1}$ "

Dans la perspective des sciences de l'information et de la communication, nous interrogerons ici la presse écrite généraliste contemporaine française comme vecteur de transmission de savoirs, instrument ayant certes une dimension d'accompagnement, de pédagogie, voire de vulgarisation, néanmoins de transmission de savoirs pas encore fixés ou en cours de construction. Outre la dimension journalistique d'information par rapport à de nouveaux produits culturels multimédias comme nous l'avons montré dans notre thèse ${ }^{2}$, la presse généraliste française accompagne de manière pédagogique les nouveaux termes qui se forgent, et les nouveaux usages qui se développent, afin d'aider les lecteurs à comprendre le nouveau périmètre de la culture et des savoirs, pris dans un sens large, allant de la culture aux loisirs ou aux divertissements en passant par les industries créatives. Poursuivant nos interrogations, nous montrerons que la presse généraliste accompagne l'usage des cédéroms culturels ou éducatifs (musées, écrivains ou artistes, dictionnaires, etc.) sous une forme d'édition numérique éditée, au passage à une forme entièrement en ligne. Précisons que les innovations techniques sont fortement liées aux discours qui les accompagnent. Ces nouveautés technologiques entraînent également la création de nouveaux mots et de nouvelles pratiques. Nous aborderons donc ces trois dimensions, la technique, les discours et la langue, et enfin, 
les nouveaux usages liés à ces innovations, de manière séparée pour l'analyse, mais en précisant qu'ils sont le plus souvent imbriqués.

\section{Des innovations techniques auxquelles la presse fait un large écho}

3 La presse généraliste française contemporaine a pour but d'informer en matière d'informations générales et politiques mais aussi culturelles. C'est ce qu'elle fera en abordant le domaine des cédéroms et des jeux vidéo. En effet, lors de notre thèse ${ }^{3}$, nous avons eu l'occasion d'interroger la légitimation des cédéroms et des jeux vidéo par la presse écrite généraliste, comme nouveaux objets culturels, ce qui n'était pas forcément évident au début. En effet, les cédéroms "culturels", ou plutôt " ludo-éducopratico-culturels ", ou encore " para-culturels», outils de stockage, auraient pu rester de simples objets informatiques. Ce ne sera pas le cas. Durant plusieurs années, au milieu des années quatre-vingt-dix, ils deviendront de nouveaux produits culturels multimédias, entrant dans la catégorie des "produits reproductibles supposant l'activité d'artistes $»^{4}$. En effet, la mise en place d'une critique des cédéroms et des jeux vidéo, certes éphémère, a pu légitimer de nouveaux produits culturels multimédias, et même au-delà, a accompagné la diffusion des savoirs techniques, des pratiques culturelles et médiatiques, dans un univers nouveau. La mise en place d'une critique culturelle éphémère à but en partie éducatif pour la diffusion de nouveaux outils comportant des contenus se fait donc et remplit son rôle de pédagogue face au grand public.

4 Précisons que les cédéroms comportent des contenus multimédias culturels ou éducatifs dans une dimension non académique. En effet, il s'agit, comme les appelle Pierre Mœglin, de "produits pour l'éducation non formelle ${ }^{5}$ " par rapport à des outils strictement éducatifs comme les manuels ou les outils et plateformes numériques développées spécifiquement pour l'éducation. En ce qui nous concerne, nous parlons de cédéroms à destination du grand public, proposant des programmes plus ou moins culturels (allant du plus savant au plus simple), des contenus plus ou moins éducatifs, d'autres plus ou moins ludiques, en passant par les jeux vidéo, avec également un certain nombre de contenus pratiques. Cela va du jeu dans lequel il s'agit de tuer tous ses adversaires à des titres portant sur de nombreux musées, notamment Le Louvre, ou diverses encyclopédies. Le fait que les industries proposent des programmes culturels contribue à les inscrire dans l'univers des nouveaux produits culturels multimédias. La régularité de la critique journalistique de l'époque permet de présenter de nombreux titres multimédias et présente un gage de " pédagogie ». Le lecteur sait alors qu'il peut compter sur ses journaux pour l'aider à découvrir des nouveaux outils et des nouveaux usages, en lien avec la culture.

\section{La critique journalistique des cédéroms et des jeux vidéo}

Retournons au milieu des années quatre-vingt-dix et lisons un extrait de critique journalistique du cédérom consacré au Louvre, entre autres, en soulignant que le musée du Louvre contribue largement au développement de la popularité des cédéroms. L'article de Carl Méeus du Figaro en 1994, présente plusieurs cédéroms et 
notamment celui du Louvre. D'ailleurs, le journaliste raconte son expérience personnelle face au logiciel. Le chapeau de l'article est explicite, voire enthousiaste :

«Mettez un littéraire devant plusieurs CD-ROM et laissez-le mijoter pendant quelques heures. Résultat : il devient passionné d'informatique. Expérience vécue. ${ }^{6}$

»

6 Le corps de la critique ne l'est pas moins :

«Fini le temps où je devais empiler sur mon bureau les volumes des encyclopédies pour trouver des informations complètes d'abord sur Le Louvre, puis sur les tableaux du musée. Avec le nouveau CD-ROM sur Le Louvre, peinture et palais (coproduction de la Réunion des Musées Nationaux et de Montparnasse Multimédia), je peux aisément obtenir la majeure partie des informations que je désire. Pas toutes malheureusement [...] j'ai pour moi tout seul la Joconde à domicile. Sans la cohue des Japonais, ni la vitre blindée qui la protège. En plus, je peux l'observer à satiété sans être dérangé et suivre les explications sur son élaboration [...] Fini la lecture linéaire qui imposait des passages obligés : avec les CD-ROM, je brûle les étapes, reviens en arrière ou passe sur des événements moins importants. Lorsque j'entre dans une rubrique, comme le système des poupées russes, je peux instantanément accéder à d'autres informations en cascade. ${ }^{7}$ »

7 Remarquons l'idéologie de l'apprentissage rendu facile grâce aux nouvelles technologies et à l'idée d'accroissement du savoir et de la culture, ce qui peut se résumer ironiquement par le "musée en pantoufles». La lecture de la presse de l'époque permet donc de constater un véritable engouement pour le domaine de la culture liée au multimédia. Comme l'écrit Daniel Ichbiah, journaliste qui s'intéresse aux nouvelles technologies et écrit sur les jeux vidéo :

«Le CD-Rom arrive à point nommé pour rendre la découverte des connaissances plus amusante, plus excitante. Aucun support n'est mieux approprié à la présentation d'un sujet culturel [...] Mais le CD-Rom est encore jeune et les éditeurs n'en ont pas, à ce jour, exploré toutes les possibilités. À la vue de certains titres, on a parfois l'impression d'assister aux débuts du cinéma. Toutefois, plusieurs œuvres remarquables ont déjà vu le jour, telles qu'Encarta ou Ainsi vient la vie. Voix, enregistrements musicaux, photographies et séquences filmées sont judicieusement mis à contribution pour instruire et captiver. ${ }^{8}$ "

Le quotidien Le Monde n'est pas en reste et revendique la synesthésie chère à Baudelaire et aux autres artistes de cette période en parlant d'un cédérom :

«La technologie du CD-ROM permet d'approcher chaque artiste à travers ses œuvres [...] C'est dans le mélange, les résonances, les renvois d'une œuvre à l'autre que gît la saveur de la découverte - celle qui vous attire vers l'écran pour ne le lâcher qu'à regret. "Les inventions d'inconnu réclament des formes nouvelles" disait Mallarmé de Verlaine [...] Quelques lenteurs, des parcours imposés, l'impossibilité d'imprimer directement les textes, ne font figure que de minimes désagréments face à la réussite d'ensemble de ce titre. On attend impatiemment le deuxième consacré à Matisse, Prokofiev et Aragon..$^{9}$ "

9 De nombreux cédéroms font donc l'objet d'une critique dans la presse généraliste, concernant des musées, des expositions, des artistes ou des auteurs ${ }^{10}$. Des expositions ou remises de prix existent également pour informer et familiariser le grand public de la publication de ces nouveaux produits culturels multimédias. D'ailleurs, en 1995, le journaliste de Télérama fait remarquer que les titres de cédéroms sont très divers et variés (plus de 5000 titres dans le monde), et concernent aussi beaucoup les domaines culturels :

«Une véritable porte ouverte à tout, et parfois à n'importe quoi. Dans un disque, par exemple, on visite à l'envi le musée du Louvre (instructif); dans un autre, on se 
promène à travers les œuvres de Nicolas Poussin (complet et magnifique). On apprend tout sur Prince ou Bob Dylan (en jouant). ${ }^{11}$ "

10 et ses connaissances grâce aux titres multimédias, avec une dimension ludique C'est oublier qu'il faut une volonté de la part du public et aussi des moyens financiers, dans la mesure où les cédéroms et jeux vidéo proposés sont coûteux.

11 Victor Scardigli ${ }^{12}$, en parlant de " l'imaginaire des technologies de l'information et de la communication » établit un tableau des sept enjeux de progrès, avec comme corollaire les espérances et miracles attendus ou les catastrophes redoutées. Il parle de sept enjeux, qui recouvrent le pouvoir sur les contraintes, le savoir, la mort, la justice sociale, la prospérité économique et la solidarité planétaire ${ }^{13}$. Les extraits de critiques de cédéroms montrent clairement que ce sont les thèmes liés au pouvoir sur les contraintes, au savoir et à ce qui concerne le lien social, qui sont les plus fréquents. La plupart des critiques de cédéroms insistent, surtout au début de l'exercice, sur les effets de «liberté » procurés par la navigation, sur le fait qu'on peut visiter un musée sans être dérangé..., sur l'accroissement du savoir, sur les possibilités d'« apprendre de la même façon » (thème de la justice sociale). Le thème du lien social intervient dans les aspects de réconciliation des familles autour du savoir.

\section{De nouveaux supports et outils multimédias}

12 S'intéresser à la transmission des savoirs, et notamment aux formes, canaux et instruments de la transmission, c'est s'intéresser aux outils (du moins à certains) qui accompagnent la diffusion de ces savoirs. Jean-Paul Lafrance ${ }^{14}$ qui interroge les bouleversements suscités par ce qu'il nomme « les nouveaux médias » observe que :

«L'ordinateur a donc modifié en profondeur les cinq fonctions essentielles du travail livresque : la lecture, le livre, comme support matériel, l'encyclopédie, le statut de l'auteur et le cadre juridique de sa rémunération (le droit d'auteur), le rôle de l'éditeur et du libraire. Ironie du sort avec Internet [...] on revient mille ans en arrière, on revient au rouleau de parchemin, au volumen, en faisant défiler le texte sur l'écran. C'est l'individu qui fait ses choix ; c'est le lecteur qui fait œuvre. ${ }^{15}$ »

En ce qui nous concerne ici, nous retiendrons particulièrement les points deux et trois, à savoir le livre comme support matériel et l'encyclopédie, dans la mesure où nous nous intéressons à la médiation journalistique dans la pédagogie des nouveaux savoirs. Nous garderons également à l'esprit ce qu'indique Lafrance quant à l'importance donnée au lecteur et à ses choix, principe qui guide - du moins en partie - les choix possibles proposés dans les arborescences multimédias.

Nous avons vu qu'il existait des nouveaux supports multimédias de contenus paraculturels comme les cédéroms. Ajoutons que de nombreuses innovations techniques sont apparues et la presse généraliste française en rend compte régulièrement. Appuyons-nous notamment sur le lancement de l'iPad en 2010, que nous avons analysé précédemment ${ }^{16}$. En effet, l'iPad est un outil technique qui permet d'accéder à de nombreuses informations, que ce soit via Internet ou pour des applications permettant de visionner des images et entendre des sons, fixes ou animés. L'iPad, qui est un objet permettant une certaine transmission des savoirs, est soutenu dès son lancement de manière enthousiaste par la presse écrite. Dans cet article, nous indiquions la filiation de l'iPad à la confluence des ordinateurs, des liseuses et des téléphones dit intelligents (smartphones). Nous insistions sur le relais enthousiaste des différents journaux de la 
presse généraliste française qui ont d'ailleurs un certain intérêt dans l'affaire, dans la mesure où ces journaux disposent de leurs éditions en ligne. En analysant la temporalité conjointe de la démarche marketing et commerciale de la firme Apple et la publication de différents articles, nous précisions aussi un élément à prendre en compte, à savoir que l'iPad est un outil qui permet d'accéder à des contenus, multiples, et donc a fortiori permettant d'accroître ses connaissances, si toutefois l'usager le souhaite et le peut. La question des contenus est en effet importante en matière de transmission des savoirs. Si les cédéroms et les jeux vidéo représentent en quelque sorte des contenus édités avec de la technologie pour les lire, l'iPad quant à lui permet d'accéder à de multiples fonctions. Nous notions d'ailleurs à l'époque que l'iPad était fortement utilisé pour les jeux de toutes sortes et le visionnage de la télévision mais nous proposions de rester prudent quant à l'avenir de la lecture sur iPad, que ce soit en matière de livres ou de presse.

Revenons à la question des contenus proposés sur des supports multimédias pour observer que nous interrogions, lors d'une recherche précédente ${ }^{17}$, la possibilité de considérer certaines œuvres disposées sur un cédérom comme celui de Machines à écrire participant à «ces hybridations actuelles possibles entre le monde littéraire et artistique, ainsi qu'entre la tradition lettrée et le monde numérique ${ }^{18}$ ».

Précisons enfin que les cédéroms et les jeux vidéo ne sont pas les seuls titres de contenus multimédias à être expliqués et légitimés, du moins en partie, par la presse écrite. Ainsi, les DVD vidéo le sont-ils aussi. Comme nous l'avons montré dans un article précédent ${ }^{19}$, la continuité de la critique des cédéroms et des jeux vidéo s'effectue, là encore de manière éphémère, par la critique des DVD vidéo. Dans ce cas de figure, la presse aide le grand public à faire connaitre des œuvres oubliées, ou encore des œuvres récentes, que le public n'a pas pu aller voir au cinéma. Cette critique insiste sur la dimension de patrimonialisation - certes individuelle - des œuvres cinématographiques et sur la question des bonus, qui, éventuellement, accompagnent et enrichissent le DVD.

\section{Le vocabulaire et la langue}

La critique journalistique qui accompagne les nouveaux produits culturels multimédias (cédéroms et jeux vidéo) familiarise les lecteurs avec un nouveau vocabulaire. Roland Barthes, dans "Les éléments de sémiologie " a indiqué que des éléments de langage, fixés par "décision", voient le jour lors de "besoins nouveaux, consécutifs au développement de la société ${ }^{20} »$ notamment.

La critique journalistique permet donc de présenter différents titres multimédias, et d'habituer ainsi les lecteurs à ce nouveau vocabulaire. Les termes naviguer ou surfer s'imposeront, ce qui là encore, n'était pas acquis au départ. Il aurait pu s'agir de circuler, voyager, comme nous le verrons plus loin. Un ensemble de termes nécessaires à la pratique du multimédia voit ainsi le jour. Si aujourd'hui ils nous sont familiers, rappelons qu'en 1994, ils ne le sont pas du tout. Gardons à l'esprit que menu, loupe, etc., ne renvoyaient pas aux mêmes objets avant le multimédia. 
19 Avant de donner quelques exemples de termes forgés pour le multimédia et recouvrant une réalité complexe, précisons que lors de notre thèse, nous avons mis à jour quatre grandes normes multimédias prises en compte par les journalistes ${ }^{21}$ :

- $1^{\circ}$ ) le rapport homme-machine (configuration, commande, interface),

- $2^{\circ}$ ) le déplacement et le choix (parcours, arborescence, hypertexte, navigation, choix de cheminement possible),

- $3^{\circ}$ ) la représentation ou l'écriture (mise en scène, graphisme, décor,...),

- $4^{\circ}$ ) les liens et la mise en relation (liens hypertextes, liens avec le réseau Internet, interactivité).

Prenons quelques exemples de termes nouveaux liés au multimédia expliqués par la presse et induisant de nouveaux usages. Le terme de navigation est utilisé par la journaliste Françoise Dargent dans Le Figaro dès 1996 à propos d'un cédérom consacré à la ville de Paris, autour de la dimension culturelle :

« Premier avantage de ce $\mathrm{CD}$-Rom, un système de navigation très convivial. La visite s'organise autour d'un sommaire général; l'épine dorsale du disque [...] le plus charmant est sans doute le chemin des poètes : Péguy et Pablo Neruda sont lus par une voix off. Séduisante également, la version des photographes qui ont immortalisé Paris dans la première moitié du siècle, comme Eugène Atget..$^{22}$ "

21 L'interactivité est un autre concept important, expliqué et apprécié par les journalistes. Citons tout d'abord un exemple de Jacques Drillon du Nouvel Observateur, qui dans un article didactique, détaillé et illustré sur trois pleines pages, intitulé « Tous les chemins mènent au CD-Rom ", explique l'interactivité de manière simple :

«Les CD-Rom ont d'autres avantages. Ils peuvent être "interactifs". Le mot est lâché. Cela signifie que vous décidez de la manière de prendre connaissance du contenu du disque. Le logiciel vous offre des possibilités, et vous choisissez. ${ }^{23}$ "

L'un des trois encadrés de l'article, intitulé "Le règne de pouvoir » souligne avec pertinence et ironie l'idéologie véhiculée par le multimédia, à savoir le fait de pouvoir accéder à la culture et au savoir. Encore faut-il en avoir envie. Lisons une autre critique journalistique sur ce sujet, en l'occurrence de Pierre Allais de La Croix :

«Parmi les risques qui guettent le spectateur d'un CD-ROM, l'ennui n'est pas le moins fréquent. Et l'on serait curieux de savoir combien de ces ouvrages ont été explorés de A à Z. Non qu'ils soient tous d'une richesse telle que l'on n'ait pas le temps d'en venir à bout; simplement l'interactivité qui fait tout leur intérêt par rapport à un livre ou à un film est encore loin d'être toujours bien au point. Souvent les auteurs, tout heureux d'avoir trouvé un schéma pour dérouler leur scénario se contentent de le répéter à l'infini, obligeant ainsi le spectateur à refaire sans cesse les mêmes gestes, ce qui devient rapidement lassant. Des titres comme Le Trésor de San Diego évitent cet écueil en multipliant les approches $[. . .]^{24}$ »

Voyons également le concept d'interface qui, rappelons-le, n'est pas très connu du grand public à l'époque, c'est pourquoi les journalistes de la presse généraliste l'expliquent dans leurs articles. Lisons deux exemples: lors de la mise en place d'une critique régulière consacrée aux cédéroms et aux jeux vidéo, Libération précise :

«Les interfaces, cet ensemble de flèches et boutons qui permettent d'avancer dans la découverte du CD-Rom, sont plus fonctionnelles et plus discrètes. Le temps est révolu de ces toiles de maitres "mangées" par une prolifération d'instruments de navigation. ${ }^{25}$ "

24 En 2000, Gérard Pangon explique lui aussi dans Télérama ce qu'est une interface à l'aide d'une métaphore : 
«Pour traduire cette étrange relation entre l'acte et son effet sur l'écran, on pourrait reprendre une expression de gamin: “j’ai fait ça et ça a fait ça!” Et naturellement, l'essentiel pour que ça fasse ça, c'est le ça intermédiaire, autrement dit l'interface. Depuis toujours elle préoccupe les inventeurs sur écran, créateurs de logiciels, d'installations interactives, de CD-Rom ou de sites Internet: que faire apparaître sur la machine pour inciter l'utilisateur à s'en aller ici ou là, à déclencher tel mouvement ou tel son ? ${ }^{26}$ "

Durant plus de cinq ans, les journalistes de la presse généralistes française détaillent, expliquent les nouveaux mots et les nouvelles actions liées à la lecture des titres multimédias. Ajoutons un dernier concept, celui d'archives numérisées. En effet, dès le milieu des années quatre-vingt-dix, les musées numérisent activement leurs œuvres et leurs archives afin de disposer leurs contenus de manière numérique. Les débuts de cette numérisation se font via les cédéroms, comme le remarquent les journalistes. Depuis lors, les musées disposent de leurs propres sites internet et de leur propre numérisation d'œuvres et d'archives. Mais les débuts de la critique journalistique des cédéroms et des jeux vidéo permettent de familiariser le public à cette dimension. Lisons un exemple d'un cédérom concernant les œuvres de Michel-Ange sous la plume de Colette Mainguy :

«Michel Ange en CD-Rom. Scala, le plus grand éditeur d'art disposant d'archives numérisées en Europe, et Emme ont obtenu du Vatican l'autorisation d'utiliser les somptueuses images inédites du "Jugement dernier", la fresque restaurée qui emplafonne la chapelle Sixtine. Cette partie est à s'en repaître jusqu'à l'oubli de tout. Le CD, hélas un peu confus dans son arborescence, retrace minutieusement l'œuvre du génie renaissant par une description docte et détaillée de ses peintures, croquis et sculptures. ${ }^{27}$ »

Relevons d'ailleurs que la journaliste apprécie plutôt l'accessibilité des œuvres picturales du patrimoine culturel que les possibilités offertes par la technique. Cette critique des cédéroms et des jeux vidéo permet ainsi d'aborder des questions plus larges, ainsi que nous l'avons indiqué par les quatre grands types de normes. Les critiques, outre le vocabulaire, habituent donc leurs lecteurs à de nouveaux concepts et de nouveaux usages, liées au développement du monde numérique. également, la lecture des critiques permet d'aborder des questions relatives aux musées, aux encyclopédies, aux livres numériques, aux jeux vidéo même si elles sont abordées de manière embryonnaire par la critique des cédéroms et des jeux vidéo. Cela montre bien que la presse généraliste accomplit son rôle de pédagogie, à la fois dans les termes et dans les usages, concernant ces nouvelles technologies.

\section{De nouvelles pratiques et leurs termes entrés dans les usages}

27 S'intéresser à la transmission des savoirs nouveaux concernant le multimédia présenté par la presse écrite pose quelques questions. En effet, la lecture des critiques de cédéroms et de jeux vidéo de l'époque permet de constater un fort intérêt des journalistes pour les musées, les expositions, les différents artistes ou écrivains, comme vu précédemment, mais aussi les encyclopédies et dictionnaires. 


\section{La question des encyclopédies : d'Encarta à Wikipédia} technophile au tout début de la mise en place d'une critique régulière portant sur les cédéroms encyclopédiques au milieu des années quatre-vingt-dix :

«Encarta est remarquablement belle, bien finie, d'un maniement simple. Une encyclopédie multimédia propose d'abord le plaisir de la navigation : on prend un sujet, on rebondit sur un article connexe, on s'attarde sur une voie de traverse, on revient au tronc principal. Tout ce vagabondage n'est peut-être pas très efficace, pas très utilitaire, mais bien agréable. C'est là le véritable terrain sur lequel il faut juger ces programmes, pas celui de l'utilité, mais celui du plaisir. Et qui sait, peutêtre nous restera-t-il ensuite quelques copeaux de connaissances arrachées au cours de ces pérégrinations? Mais le charme d'une encyclopédie multimédia, ce sont aussi les petits gadgets, les hymnes musicaux de chaque pays qui renouvellement le plaisir enfantin de la page "drapeaux" des dictionnaires, les animations des planètes qui bougent autour du soleil, et cerise sur le gâteau, les animations vidéo. ${ }^{28}$ "

Alain Le Diberder utilise plus volontiers la métaphore végétale, mais, comme nous l'avons souligné précédemment, c'est la métaphore nautique de la navigation et du surf qui l'emporte. Lisons également une critique concernant une encyclopédie au tournant des années 2000. La critique de Patrick Longuet publié dans Le Monde concernant l'encyclopédie Encarta 2000 est globalement positive, mais elle souligne toutefois les insuffisances et le manque de précision de la démarche :

«Encarta 2000 propose bien entendu des clips vidéo, des diaporamas, des extraits d'enregistrements [...] ainsi que des "interactivités". Ce terme désigne en général des tableaux où quelques éléments sont à déplacer, par exemple un insecte à reconstituer morceau par morceau (et comme il s'envole à la fin, on ignorera son nom) ou la découverte du moteur à explosion circuit par circuit comme des calques posés les uns sur les autres. ${ }^{29}$ »

L'enthousiasme concernant les encyclopédies multimédias hors-ligne ne concerne pas seulement les journalistes de la presse quotidienne. Les journalistes de la presse magazine s'en emparent aussi. Ainsi, L'Express s'adjoint-il au début l'aide de la revue spécialisée en informatique grand public L'Ordinateur individuel et écrit-il :

« Votre encyclopédie prend la poussière sur une étagère. Vous êtes épuisé rien qu’à l'idée de la compulser pour trouver la moindre information? Goûter sa version électronique! Tapez le mot "astronomie" sur le clavier, et, aussitôt, la liste des articles concernés s'affiche. Vous choisissez celui sur la lune : immédiatement, il apparaît à l'écran. Bien sûr, il est possible de l'imprimer ou même de l'insérer dans un texte que vous êtes en train de saisir sur votre ordinateur [...] Instrument de travail idéal pour les élèves du secondaire et de l'enseignement supérieur, le CDROM est aussi une fenêtre ouverte sur le monde pour tous les curieux... "

31 Le passage des encyclopédies éditées sur papier au multimédia n'est qu'une étape dans l'évolution des encyclopédies. Depuis lors, nombre d'encyclopédies ou de dictionnaires sont édités en ligne, participant ainsi à la question des savoirs. Encyclopédies multimédias hors ligne ou bien en ligne, la question se pose aussi concernant la coexistence des encyclopédies traditionnelles aux encyclopédies collaboratives. Ainsi, Wikipédia, crée en 2001, représente un élément incontournable dans l'univers des encyclopédies en ligne. à ce propos, Rivka Dvira écrit :

«L'encyclopédie virtuelle Wikipédia est devenue de nos jours une nouvelle "bible laïque", comme l'était en son temps et l'est encore pour certains, le dictionnaire traditionnel. Nul ne peut nier la contribution de ce projet gratuit et collectif au 
monde de l'éducation, ni le fait qu'elle constitue aujourd'hui l'une des références essentielles de l'accès au savoir et de sa diffusion dans le monde informatisé. »

journaliste pose la question de la multiplication des écrans, même au sein des instances académiques, et celle de l'utilisation des jeux vidéo, longtemps jugés illégitimes en matière de savoirs, par des enseignants. L'article explique ensuite : est une des spécificités de la neutralité wikipédienne [...] Alors que l'encyclopédie classique propose un éthos d'expertise et de finitude, Wikipédia par contre propose un éthos de souplesse infinie, puisque toujours ouverte au changement. Le savoir se construit par discussion participative et jamais terminée, ad infinitum. Le fait n'est pas absolu et dépend de l'accord entre les contributeurs. Pour Wikipédia, il s'agit donc d'une aspiration permanente à la neutralité plutôt que de l'affirmation péremptoire de pouvoir être neutre. ${ }^{31}$ "

Yves Jeanneret dans ses analyses de la trivialité précise lui aussi à propos de Wikipédia :

«On peut penser [...] que si une conception active de la trivialité, et plus généralement $\mathrm{du}$ politique, s'exprime dans les règles de Wikipédia, c'est principalement par le partage entre ce qui doit être strictement déterminé sur un tel site et ce qui au contraire n'est pas pris au sérieux. ${ }^{32}$ »

Il ajoute :

«Le dispositif repose donc sur une représentation de la communication qui n'a pas forcément besoin d'être explicitée pour être puissante - qui est d'autant plus puissante qu'elle n'est pas explicitée - et qui déborde largement ce que les règles des concepteurs ont formulé : une théorie peu élaborée mais agissante de ce qui fait la trivialité des êtres culturels, en l'occurrence la recherche de consensus sur un savoir acquis et cumulatifs. ${ }^{33}$ "

De profonds changements en matière d'accès aux savoirs encyclopédiques et culturels ont donc eu lieu. Que ce soit en matière d'accès, de pratiques ou de philosophies, les savoirs et leurs accès font cohabiter les méthodes anciennes et les nouvelles possibilités liées à l'univers numérique. Certes, la presse écrite généraliste contribue à vulgariser les savoirs, mais la lecture des deux derniers auteurs souligne pourtant la différence entre questionnement académique et journalistique. Néanmoins, la presse écrite généraliste contemporaine française, même si c'est de manière modeste, contribue à informer ses lecteurs et développe une forme de vulgarisation pédagogique pour leur permettre de se former aux nouveaux outils techniques et culturels et discriminer les bons et moins bons titres destinés au grand public.

\section{Les jeux vidéo et la dimension pédagogique}

Revenons à l'accompagnement journalistique en matière de nouveaux savoirs liés aux nouvelles technologies. Un dossier de Télérama publié en 2018 interroge les nouveaux outils pour l'enseignement de l'histoire. Le dossier intitulé de manière provocante «Jeux vidéo, Youtube... Auront-ils la peau des profs d'histoire? » en Une de Télérama précise en accroche du dossier :

«Costume d'époque, décors, atmosphère [...] on s'y croirait! Le jeu vidéo Assassin's Creed aligne tant d'atouts que même les historiens le plébiscitent. Fera-t-il bientôt son entrée dans les écoles? Comme la vidéo, qui ouvre de nouvelles perspectives à la recherche historique, sur toutes sortes d'écrans. ${ }^{34}$ »

Au-delà de la dimension journalistique de Une qui cherche à susciter la vente, le matiere de savoirs, par des enseignants. L'article explique ensuite: 
« Installé au Québec depuis près de vingt ans, le directeur créatif d'Assassin's Creed a toutes les raisons d'être satisfait. Discovery Tour, une version remaniée du dernier volet de cette saga vidéoludique qui met aux prises Templiers et Assassins, sera bientôt disponible. Expurgée de toute intrigue, de violence et de combats, centrée exclusivement sur l'exploration et la connaissance, ce "cocktail sans alcool" exauce un de ses vieux rêves. S'appuyant sur un colossal travail de documentation et des équipes d'historiens de tout poil, Assassins's Creed est devenu une référence en matière de reconstitution historique. Créée en 2007, adaptée au cinéma, la saga, dont chaque épisode se déroule à des moments charnières de l'Histoire - les croisades, Florence au temps des Borgia, la guerre d'Indépendance américaine, la Révolution française, etc. - a durablement marqué les esprits. Couramment utilisés comme supports visuels dans de nombreuses universités nord-américaines, ces jeux souvent présents dans les boutiques des musées des villes qui leur servent de théâtre, ont transmis le virus de l'histoire à plusieurs générations..$^{35}$ " multimédias grand public de manière académique, ce qui n'est pas forcément le cas de la France pour le moment.

à l'issue de ce parcours, nous avons montré combien la presse écrite participait à la pédagogie face à ces nouveaux produits culturels multimédias et même au-delà, aux bouleversements dans les différents univers de la culture et des médias et à leur accès. La presse parle des nouveaux produits culturels que sont les cédéroms et les jeux vidéo, elle aide le public à mieux en maîtriser les outils, à se familiariser à ces nouvelles pratiques, aux nouvelles manières de pouvoir accéder à la culture, dans sa dimension numérique. Elle le fait d'une manière protéiforme en vulgarisant, à côté des savoirs plus académiques. La presse écrite généraliste française montre bien ainsi sa participation, même modeste, à la transmission des savoirs nouveaux et pas encore fixés.

\section{BIBLIOGRAPHIE}

BARTHES Roland, L'Aventure sémiologique, Paris, Seuil, Points-Essais, 1985.

BATARD Annick, « La critique journalistique des cédéroms “culturels”, entre promotion commerciale et invention d'un genre ", thèse de doctorat sous la direction des professeurs Pierre MCEGLIN et feu Roger DELBARRE, Université Paris 13, reprographiée et microfichée, 2 tomes, 2003.

BATARD Annick, « La critique des DVD vidéo, une deuxième chance pour la critique cinématographique?", dans Mutations des industries de la culture, de l'information et de la communication, colloque international OMIC, 25-27/09/2006, Maison des Sciences de l'Homme Paris Nord.

BATARD Annick, «Le lancement de l'iPad par Apple : la presse généraliste française, un relais intéressé de l'événement médiatique et culturel ? », dans BALLARDINI E., PEDERZOLI R., REBOUL-TOURÉ 
S., TRÉQUER-FELTEN G. (éd.), Les facettes de l'événement : des formes aux signes, mediAzioni 15, 2013, http://mediazioni.sitlec.unibo.it

BATARD Annick, « Le cédérom Machines à écrire, hybride entre le livre d'art en papier et le livre numérique? ", dans CHOL Isabelle et KHALFA Jean (éd.), Les Espaces du livre. Supports et acteurs de la création texte/image (XX-XXI ${ }^{e}$ siècles), Berne, Éditions Peter Lang, 2015, p. 151-166.

DVIRA Rivka, «L'éthique du discours dans Wikipédia : la question de la neutralité dans une encyclopédie participative ", Argumentation et analyse du discours, éd. numérique, [URL : http:// journals.openedition.org/aad/2286]

JEANNERET Yves, Critique de la trivialité. Les médiations de la communication, enjeu de pouvoir, Paris, Éditions Non Standard, 2014.

LAFRANCE Jean-Paul, La Civilisation du CLIC. La vie moderne sous l'emprise des nouveaux médias, Paris, L'Harmattan, 2013.

MIÈGE Bernard, Les Industries du contenu face à l'ordre informationnel, Grenoble, Presses Universitaires de Grenoble, 2000.

MÆGLIN Pierre, Les Industries éducatives, Paris, Presses Universitaires de France, coll. Que sais-je ?, 2010.

SCARDIGLI Victor, Les Sens de la technique, Paris, Presses Universitaires de France, 1992.

\section{NOTES}

1. J. Guisnel et alii, « “Cyberesp@ce”. Adi entre en sixième ", Le Point, 02/05/1998.

2. A. Batard, «La critique journalistique des cédéroms "culturels", entre promotion commerciale et invention d'un genre ». Lorsque nous citons des passages de la presse généraliste de l'époque, ceux-ci sont extraits de notre thèse.

3. Idem.

4. B. Miège, Les industries du contenu face à l'ordre informationnel, p. 19.

5. P. Mœglin, Les industries éducatives, p. 91.

6. C. Méeus, « Tous les chemins mènent au CD-ROM », Le Figaro, 28/11/1994.

7. Idem.

8. D. Ichbiah, «Évasion et émotion à domicile », Le Nouvel Observateur-PCDirect-PCExpert, 24/11/1994.

9. M. Colonna d'Istria, « Doux révolutionnaires des sens », Le Monde, 6-7-11/1994.

10. Pour avoir une idée de la profusion de titres critiqués dans la presse généraliste française, voir le catalogue établi lors de notre thèse. A. Batard, «La critique journalistique des cédéroms "culturels"... »

11. V. Le Leurch, « Faut-il céder aux CD-Rom? », Télérama, 26/04/1995.

12. V. Scardigli, Les sens de la technique, p. 50-51.

13. Idem.

14. J.-P. Lafrance, La civilisation du CLIC. La vie moderne sous l'emprise des nouveaux médias, p. 28-29.

15. Idem. 
16. A. Batard, «Le lancement de l'iPad par Apple: la presse généraliste française, un relais intéressé de l'événement médiatique et culturel ?».

17. A. Batard, «Le cédérom Machines à écrire, hybride entre le livre d'art en papier et le livre numérique? ».

18. Ibid., p. 152.

19. A. Batard, «La critique des DVD vidéo, une deuxième chance pour la critique cinématographique?».

20. R. Barthes, L'aventure sémiologique, p. 34.

21. A. Batard, « La critique journalistique des cédéroms "culturels",...».

22. F. Dargent, « Paris sur CD-Rom », Le Figaro, 04/01/1996.

23. J. Drillon, "Tous les chemins mènent au CD-Rom», Le Nouvel Observateur, 11-17/05/1995.

24. P. Allais, « Le trésor du San Diego : un naufrage passionnant », La Croix, 5-6/11/1995.

25. R.-P. Lagrange, « La guerre des Cézanne », Libération, 22/09/1995.

26. G. Pangon, « Magiciens de l'interface », Télérama, 27/09/2000.

27. C. Mainguy, « Multimédias », Le Nouvel Observateur, 23/03/1995.

28. A. Le Diberder, « Interactifs », Libération, 19-20/11/1994.

29. P. Longuet (Canal +), « Encarta 2000 étale ses connaissances », Le Monde, 20/10/1999.

30. « Le savoir en son et lumière », L'Express - L'Ordinateur individuel, 22/09/1994.

31. R. Dvira, «L'éthique du discours dans Wikipédia : la question de la neutralité dans une encyclopédie participative ».

32. Y. Jeanneret, Critique de la trivialité. Les médiations de la communication, enjeu de pouvoir, p. 42.

33. Ibid., p. 43.

34. S. Jarno, «Quand l'histoire prend du relief. L'histoire sur tous les écrans ", Télérama, $21 / 02 / 2018$.

35. Idem.

\section{RÉSUMÉS}

L'article interroge la contribution de la presse généraliste contemporaine française dans la transmission des nouveaux savoirs pas encore fixés, notamment concernant les produits culturels multimédias que sont les cédéroms et les jeux vidéo. En effet, la presse, à côté des instances et outils strictement académiques, explique et vulgarise un ensemble de produits culturels multimédias, ainsi que le vocabulaire et les pratiques qui les accompagnent. Après l'examen des discours journalistiques sur les cédéroms et les jeux vidéo et sur les nouveaux supports dédiés aux pratiques culturelles et médiatiques, ainsi que le constat de la création de nouvelles normes et de nouveaux termes liés au multimédia, l'article rappelle les débuts des encyclopédies éditées sur des cédéroms et les nouvelles questions qui se posent après plus de 
trente ans de pratique, notamment concernant la coexistence d'encyclopédies traditionnelles et de pratiques collaboratives, ainsi que la dimension historique conférée aux jeux vidéo.

\section{AUTEUR}

\section{ANNICK BATARD}

Maître de conférences en Sciences de l'information et de la communication, Université

Paris XIII - Paris-Nord, LabSic (Laboratoire des Sciences de l'information et de la communication, EA 1803) 